\title{
ESPACIOS DE PRODUCCIÓN Y USO DE LOS ÚTILES \\ DE PIEDRA TALLADA DEL NEOLÍTTCO
}

\author{
TESIS DOCTORAL PRESENTADO POR \\ MARGARITA SANCHEZ ROMERO
}

\begin{abstract}
BAJO LA DIRECCIÓN DEL DOCTOR: GABRIEL MARTÍNEZ FERNÁNDEZ
\end{abstract}

DEPARTAMENTO DE PREHISTORIA Y ARQUEOLOGIA UNIVERSIDAD DE GRANADA ENERI 1999

Volumen 1 
ESPACIOS DE PRODUCCIÓN Y USODE LOS ÚTILES DE PIEDRA TALLADA DEL NEOLÍTICO

UNIVERSIDAD DE GRANADA

12 -NE. 1999

COMISION OE DOCTORADO

TESIS DOCTORAL PRESENTADA POR

MARGARITA SÁNCHEZ ROMERO

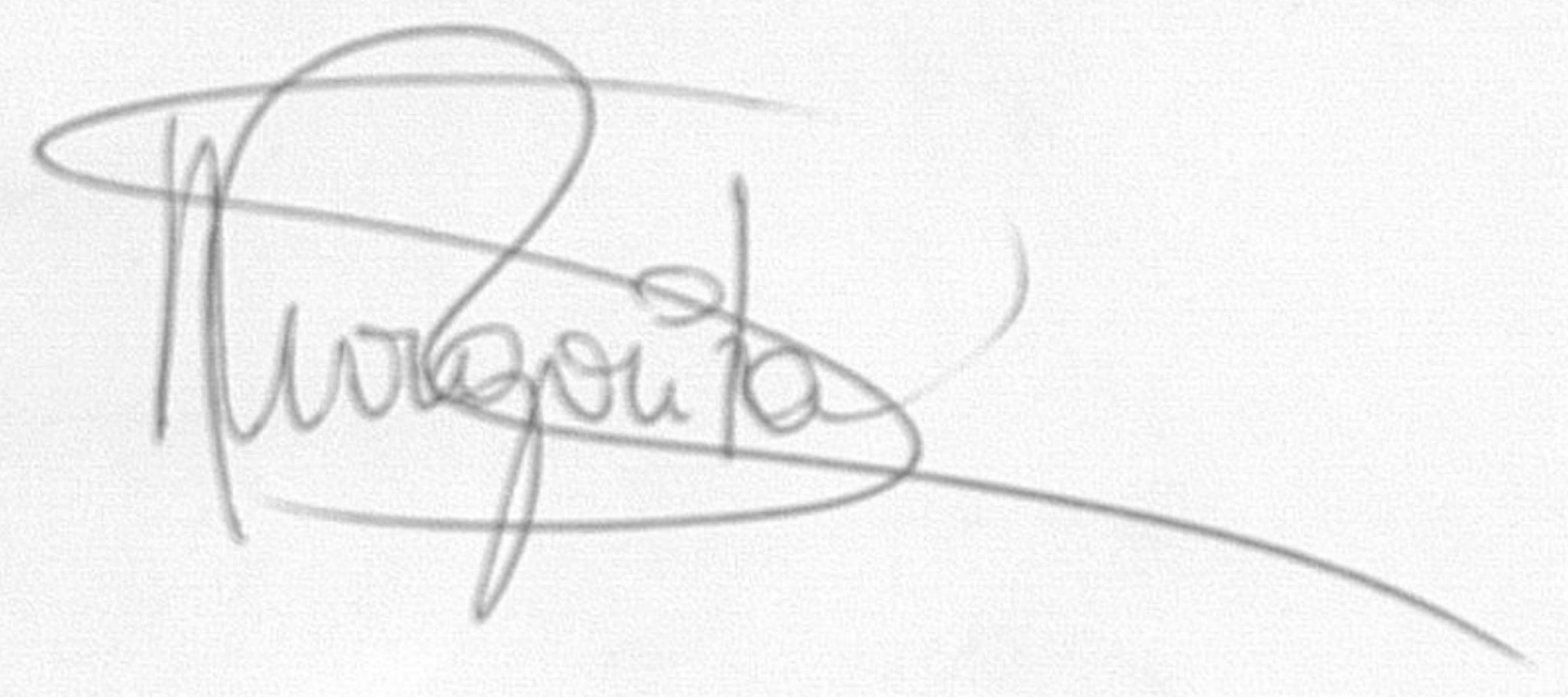

BAJO LA DIRECCIÓN DEL DOCTOR:

GABRIEL MARTIINEZ FERNÁNDEZ

BIBLIOTECA UNIVERSITARIA

GRANADA

No Documentob18725447

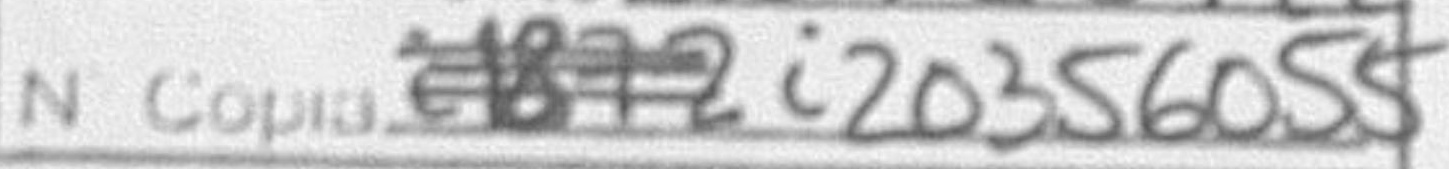

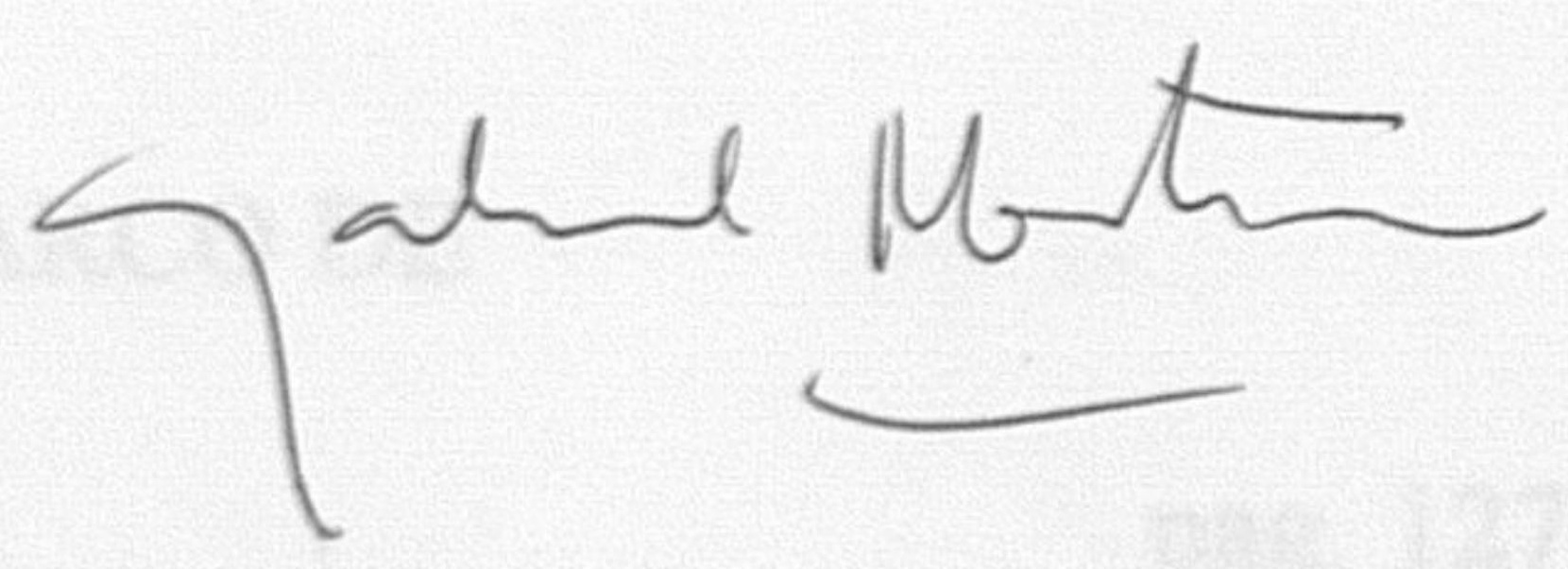

DEPARTAMENTO DE PREHISTORIA Y ARQUEOLOGÍA

UNIVERSIDAD DE GRANADA

ENERO 1999 


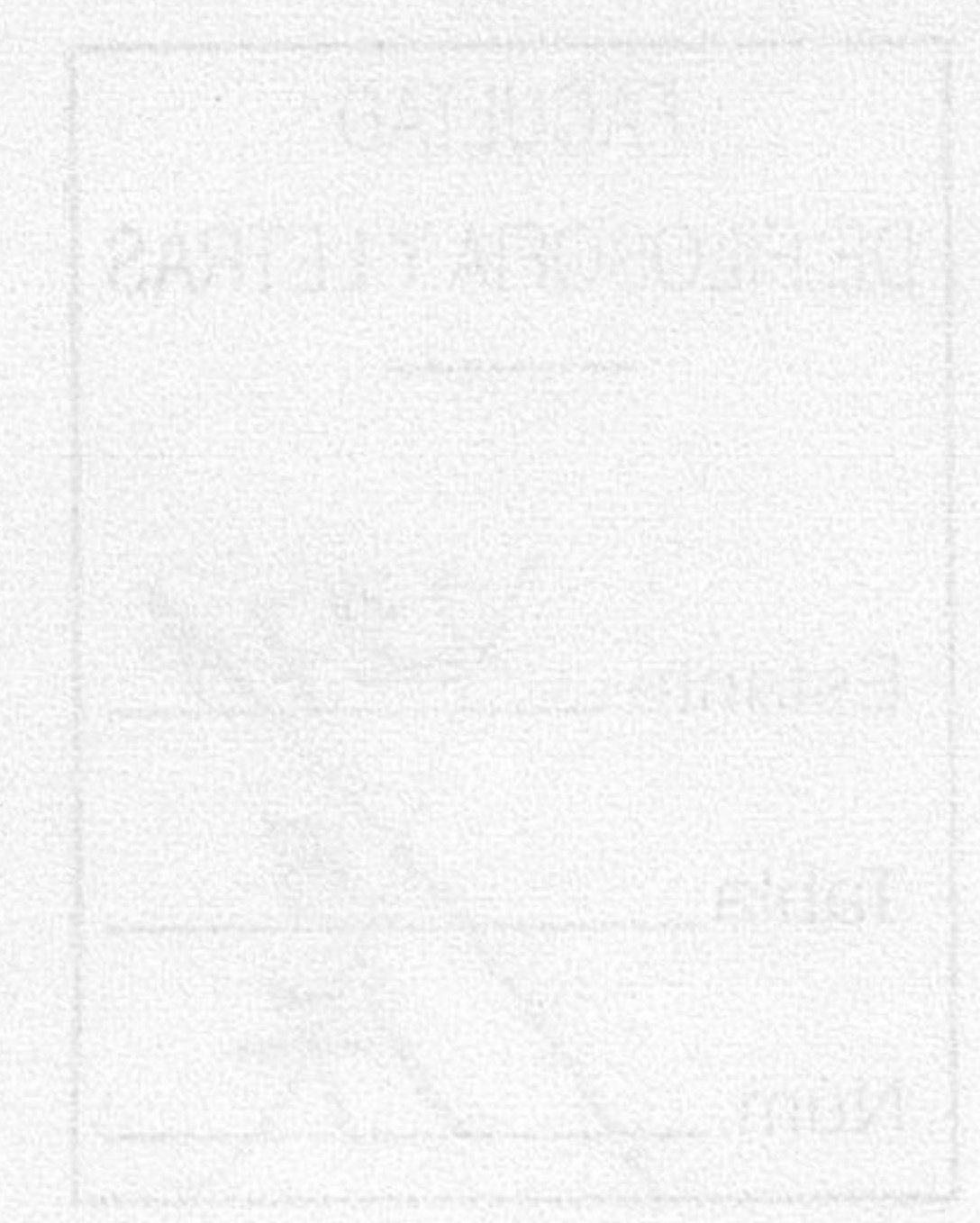

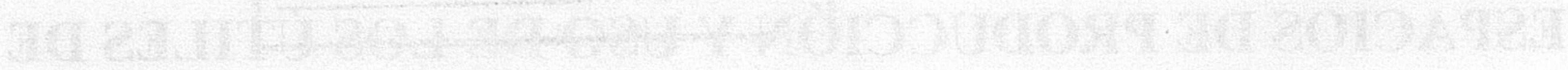

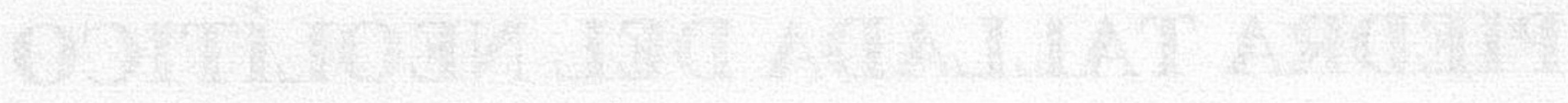
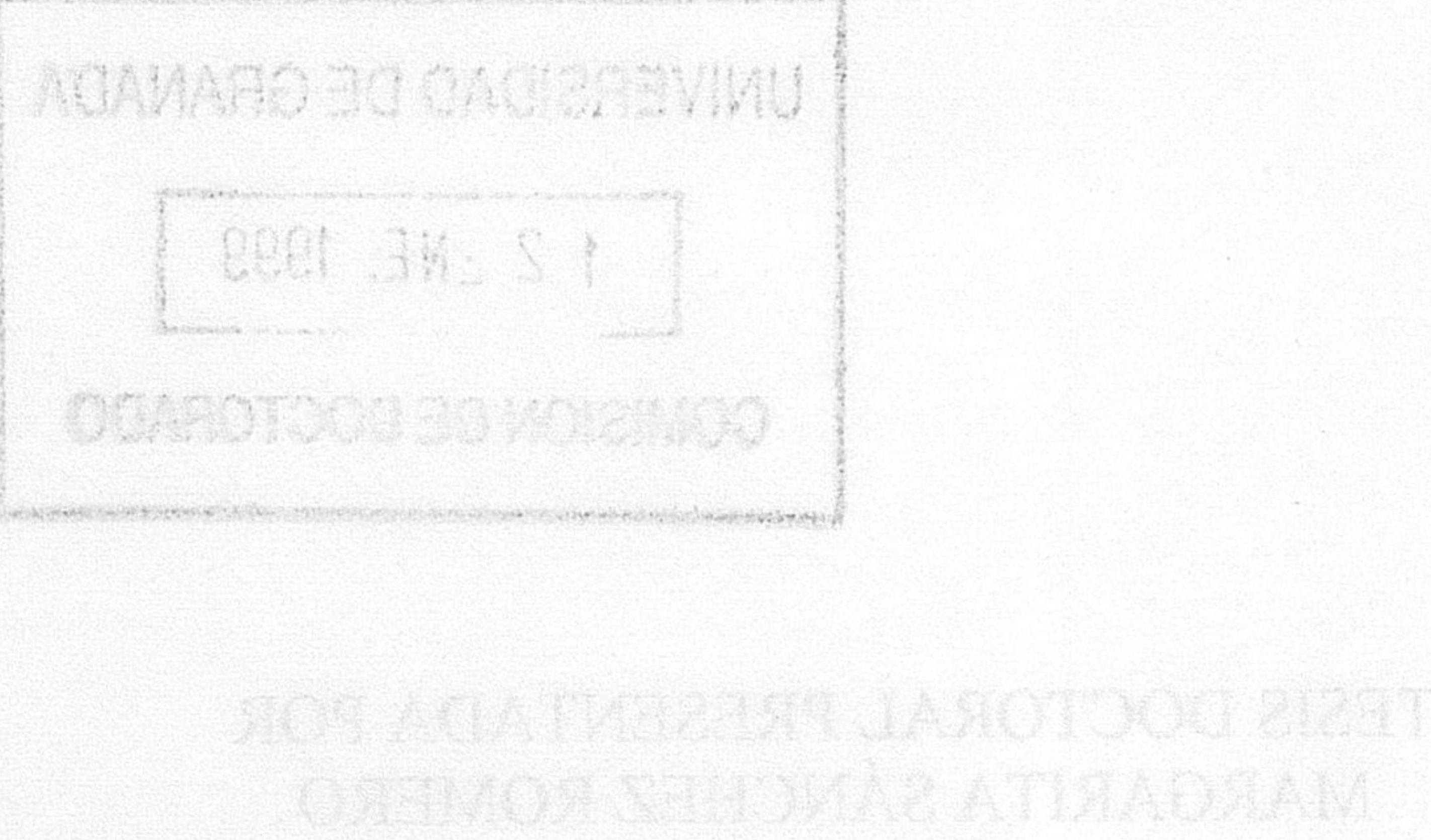

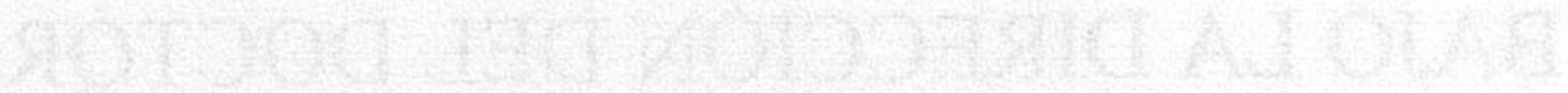

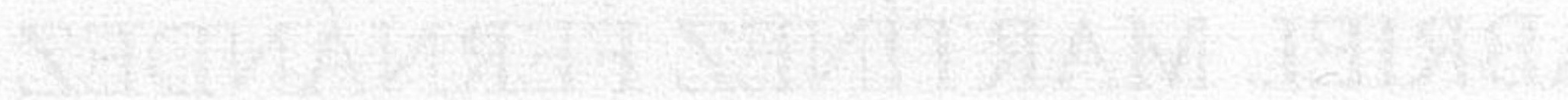

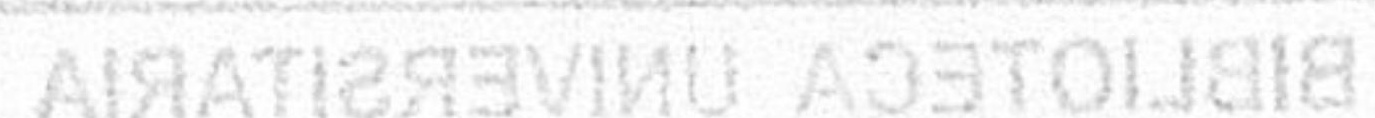

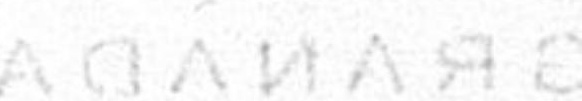


ESPACIOS DE PRODUCCIÓN Y USO DE LOS ÚTILES DE PIEDRA TALLADA DEL NEOLÍTICO

II. LA INDUSTRIA LÍTICA COMO ARGUMENTO. BREVE HISTORIA DE LAS IDEAS.

II.1. La industria lítica como fósil director pag. 15

II.2. Teconología y útiles: la perspectiva funcionalista pag. 22

II.3 Hacia la redefinición de la industria lítica como producto pag. 36

III. LA DIMENSIÓN CONTEXTUAL DEL REGISTRO ARQUEOLÓGICO pag. 47

IV. PROCESOS DE TRANSFORMACIÓN DEL REGISTRO ARQUEOLÓGICO pag. 55

IV.1. Procesos deposicionales pag. 59

IV.2. Procesos postdeposicionales pag. 65

V. METODOLOGÍA pag. 69

V.1. Análisis tecnotipológico de los útiles de piedra tallada pag. 71

V.2. Análisis espacial de los contextos arqueológicos: aplicaciones estadísticas pag. 81

VI. EL POBLADO DE “LOS CASTILLEJOS” EN EL MARCO DE LAS INVESTIGACIONES ARQUEOLÓGICAS EN EL SURESTE Y LA ALTA ANDALUCÍA.

VI.2. Correlación estratigráfica entre las distintas campañas de excavación del yacimiento de Los Castillejos. 
VII.1. Estudio descriptivo del material lítico

pag. 149

VII.2. Descripción de los complejos estructurales

pag. 176

VII.3. Aplicación estadística. Metodología y resultados

pag. 185

VIII. CONCLUSIONES: PROPUESTAS PARA AVANZAR EN EL ÁMBITO DE LA METODOLOGÍA Y EN EL CONOCIMIENTO DE LA ORGANIZACIÓN DE LAS SOCIEDADES PREHISTÓRICAS pag. 187

BIBLIOGRAFÍA pag. 203

GRÁFICOS pag. 224

TABLAS pag. 497

FIGURAS pag. 797 
I. INTRODUCCIÓN 
Cuando realizamos una investigación arqueológica concreta son variados los problemas con los que debemos enfrentarnos. Desde nuestra perspectiva teórica, uno de los más importantes handicap estaría relacionado con el objetivo último que debe cumplir cualquier investigación arqueológica, a saber, la interpretación en términos sociales del proceso histórico. Entendemos que en los últimos años del desarrollo teórico-metodológico de nuestra disciplina se han introducido toda una serie de posicionamientos teóricos que han puesto el acento en la necesidad de un salto cualitativo que nos permitiera abordar los procesos sociales desde nuevas perspectivas.

Un buen ejemplo sería el conjunto de teorías que han tratado de explicar el proceso de creciente complejidad social documentado en la Prehistoria Reciente del Sudeste. No obstante, estas nuevas perspectivas se han apoyado en un conjunto de datos obtenidos bajo perspectivas teóricas diferentes, y por tanto, para dar respuesta a problemas de conocimiento concretos que distan de las nuevas necesidades creadas.

Evidentemente este hecho supone un importante desajuste entre los objetivos de investigación que actualmente nos planteamos y el conocimiento acumulado a lo largo de la historia de las investigaciones arqueológicas. Esta nueva situación está provocando el desarrollo de toda una serie de hipótesis y de construcciones teóricas que necesariamente hay que contrastar, o lo que es lo mismo, crear líneas de investigación capaces de generar la suficiente información que de cobertura a la nuevas necesidades de investigación.

Con este planteamiento en ningún caso desestimamos la información actualmente disponible, simplemente matizamos su alcance. Advirtiendo del peligro que supone el desajuste, que entendemos existe entre el desarrollo de teorías concretas y la información arqueológica disponible, y que nos puede conducir a incidir de forma desigual en el aspecto teórico, que aunque indispensable, tan sólo forma una parte del proceso de investigación.

El principio epistemológico que nos posibilita realizar el anterior planteamiento parte de una visión de carácter materialista según la cual la realidad objetiva es la materia cuya existencia 
es independiente de nuestra conciencia, presentando unas características que le son propias y que podemos llegar a conocer mediante la articulación de procedimientos lógicos.

Esta perspectiva nos permite entender cómo la documentación obtenida desde cualquier posicionamiento teórico es perfectamente asumible desde otra concepción, siempre y cuando esa documentación responda a las características objetivas de la realidad y puedan ser contrastadas. No obstante, como ya hemos indicado, las posibilidades inferenciales quedan, obviamente, condicionadas por la documentación disponible, obtenida para cubrir unos objetivos puntuales.

Veamos a continuación algunas de las etapas más importantes de la estructura general del proceso de investigación que nos van a servir de nos van a servir de elemento de referencia para comprender y justificar el contenido del trabajo de tesis doctoral que presentamos.

De forma general, el movimiento de proceso del investigación va desde los datos hacia la teoría. Para ello, el investigador se enfrenta a la obtención y manipulación de datos, situación en la cual se genera la información empírica de la cual arranca toda una serie de procedimientos inferenciales que deberá conducir a la explicación de los procesos estudiados. Sim embargo, esta secuencia de procedimientos necesita ser programada. El método de investigación consiste precisamente en planificación lógica de los procedimientos prácticos e inferenciales, lo que implica necesariamente un movimiento desde la teoría de la realidad hacia los datos como punto de partida indispensable (Bate 1998:141).

Por tanto, la investigación de cualquier proceso histórico comienza con el desarrollo de toda una serie de hipótesis sobre la realidad que se pretende investigar. Estas hipótesis que deben partir de un cuerpo teórico-metodológico explícito y del conjunto de información empírica disponible. Esta primera fase de cualquier proyecto es básica e imprescindible. La asunción de una determinada teoría y el conocimiento de sus categorías de análisis, ya sea de forma consciente o inconsciente, se convierte en un elemento de primera magnitud que condiciona el desarrollo de cualquier investigación.

Además, la sistematización de procedimientos lógicos adecuados debe apoyarse en lo que hasta ese momento se conoce sobre la realidad que se desea investigar (Lull 1988: 74-75). No es 
posible plantearse cómo conocer si no se posee ninguna noción sobre qué es lo que se busca conocer, o sea, sobre las características del objeto de conocimiento. Intentar documentar toda la información que nos pueda ofrecer un determinado contexto arqueológico sería una tarea, además de imposible, absurda.

El proceso de investigación continúa con la contrastación del conjunto de hipótesis planteadas. Precisamente, la objetividad científica implica la correspondencia del conocimiento con la realidad existente fuera de la conciencia humana. De aquí se desprende que validez y verdad no son sinónimos, un conocimiento válido es el resultado de la correcta aplicación de los principios y procedimientos lógicos, pero como se trata de procedimientos subjetivos, el resultado puede ser verdadero o falso. Un conocimiento verdadero es el que corresponde a determinadas propiedades de la realidad objetiva y debe poderse formular con validez lógica (Bate 1982: 13).

En este sentido sólo existe un criterio de contrastación, la práctica como criterio de verdad. Sólo mediante la praxis podremos discriminar aquellas concepciones que no se ajusten a las características de la realidad que deseamos conocer, siendo esta la única forma de enfrentar contradictoriamente nuestras concepciones con la realidad. Con la práctica se resuelve el problema de la relación entre el sujeto y el objeto descubriéndose, de esta forma, la auténtica fuente de conocimiento (Pretel 1994: 143).

Ahora bien, cómo se trasladan estos conceptos generales a la especificidad de la arqueología. En nuestra disciplina la teoría que se encarga de analizar la singular naturaleza de nuestro objeto de estudio ha sido denominada como teoría de la observación (Gándara 1987; Argelés y otros 1995), teoría de la reconstrucción (Ruiz Zapatero 1991) o teorías mediadoras (Bate 1998:106). Su cometido, es por tanto, explicar las conexiones entre las propiedades de los fenómenos empíricamente observables y las regularidades que rigen la causalidad y estructura de los procesos estudiados. Frente a la teoría sustantiva es la que interpreta los procesos que constituyen el objetivo último de la investigación. 
La explicación de los nexos entre los información empírica actual y las características de la sociedad que estudiamos es la formula para poder evaluar las inferencias que realizamos sobre un pasado con el cual no coexistimos, y por tanto, no tenemos relación directa.

Se trataría de analizar cómo los grupos humanos transforman materialmente la naturaleza, desarrollando actividades concretas y orgánicamente vinculadas, que poseen y confieren formas culturales tanto a los objetos producidos como al entorno transformado. Para ello, la particular teoría de la historia de los contextos arqueológicos que integran una cultura arqueológica es la que posibilita el conocimiento del conjunto de actividades realizadas por un grupo social a partir de la evidencia empírica, generalmente afectada por procesos de transformación tanto naturales como sociales (Bate 1998:36).

El desarrollo de la teoría de la observación es un elemento básico para validar lógicamente las inferencias de orden social que realizamos sobre la evidencia arqueológica.

La teoría de la observación posee como una de sus características más importantes su relativa independencia, ya que, al margen de cómo se interprete la realidad desde una determinada teoría sustantiva, lo importante sería definir como claridad qué es lo que se intenta explicar, aceptando que la realidad es una y que presenta unos atributos que pueden ser reconocidos y caracterizados desde posicionamientos teóricos diferentes.

La aceptación de diferentes significados contextuales de los atributos potencialmente observables es el principio en el que se basa la relativa independencia de la teoría de la observación. Aunque es inevitable la selección de determinados atributos relacionados con los contenidos de la posición teórica asumida, este hecho no confiere un único y posible significado a los elementos documentados (Bate 1998:199).

Un determinado elemento o conjunto de elementos posee simultáneamente diversos significados en función de su posición relativa en los distintos niveles de integridad de los cuales participa. Este planteamiento hace posible que el conjunto de elementos que nosotros hayamos seleccionado puedan formar parte de otras concepciones teóricas (Bate 1998:119). 
Nos hemos detenido en esta fase del proceso general de investigación arqueológica, ya que nuestras investigaciones se enmarcan dentro de la denominada como teoría de la observación. Como hemos indicado entendemos que el conocimiento acumulado sobre las sociedades neolíticas aún no es suficiente como para iniciar valoraciones mínimamente consistentes sobre las relaciones sociales de las comunidades neolíticas.

Ante este panorama la investigación que hemos desarrollado no tiene por objeto principal interpretar el proceso histórico protagonizado por las sociedades neolíticas desde una perspectiva global, y por tanto, no ofrecemos una explicación de la historia concreta de las sociedades analizadas, aunque evidentemente realicemos referencias puntuales a diversas hipótesis que se hayan planteado o podamos plantear. No obstante, sí debemos indicar que es trabajo de investigación se basa, como anteriormente se ha indicado en el conocimiento acumulado, y particularmente en los estudios sobre industria lítica.

El objetivo es utilizar la información proporcionada por las campañas de excavación realizadas en el poblado de Las Peñas de los Gitanos (Montefrío, Granada), para intentar definir, en la medida de nuestra posibilidades y con las limitaciones que a lo largo del trabajo apuntaremos, unidades de análisis de carácter espacial tanto a nivel diacrónico como en su evolución temporal. De tal forma, que podamos contribuir a definir el conjunto de actividades desarrolladas por una determinada sociedad. Se trata de caracterizar las diversas actividades humanas que inciden en la naturaleza generando objetos y condiciones ambientales, para a partir de ellas poder analizar el conjunto de relaciones sociales que las hace posibles, y por tanto, poder interpretar el proceso histórico en su conjunto (Bate1998: 109). Con esta última parte, consistente la inferencia del conjunto de regularidades que rigen un proceso cultural concreto y que utilizamos para su explicación se cierra el desarrollo de un proyecto de investigación abriendose nuevas perspectivas de conocimiento.

Por tanto, la problemática que abordamos se basa en cómo podemos definir una determinada unidad de análisis que nos permita entender la conexión entre las propiedades de los contextos arqueológicos y la historia de la sociedad que constituye el objeto último de nuestra investigación; ya que, entendemos que la única posibilidad de interpretar un determinado proceso 
histórico basado en la cultura arqueológica es a través de, por una parte, demostrar que los contextos arqueológicos que nosotros recuperamos son el resultado de determinadas actividades humanas que podemos caracteriza a pesar de los procesos que han intervenido en el aspecto que esos contextos presentan a la observación. Por otra parte, sólo a partir de la caracterización del conjunto de actividades desarrolladas por una determinada sociedad estaremos en disposición de inferir los sistemas producción, reproducción social, consumo, intercambio, distribución..., que son en definitiva los elementos para intentar definir las relaciones sociales que hacen comprensible el proceso social estudiado. El objeto del presente trabajo se basa en la primera parte del planteamiento que acabamos de realizar.

En este sentido, hemos utilizado la documentación de la excavación desarrollada en el poblado de las Peñas de los Gitanos durante las campañas de 1991 a 1994. Aunque este excavación no fue realizada para cubrir los objetivos aquí señalados, si posee unas características suficientes para realizar una primera aproximación. Así mismo, vamos a utilizar a la industria lítica en el intento de caracterización de unidades de análisis espaciales que nos permitan el estudio de la actividad/es realizadas en el espacio analizado. 
II. LA INDUSTRIA LÍTICA COMO ARGUMENTO. BREVE HISTORIA DE LAS IDEAS. 


\section{II.1. La industria lítica como fósil director}

El estudio de la industria lítica durante sus inicios estuvo basado en la consideración de los objetos de piedra tallada como la única muestra conservada del Paleolítico. Boucher de Perthes consideraba que desde el momento en que fuese posible conocer los útiles, éstos nos llevarían a descifrar tanto el trabajo que realizaban como el resultado del mismo, lo que permitiría el conocimiento del desarrollo intelectual de los pueblos (BREZILLON 1977).

La utilización del fósil director como principio básico dentro de la estrategia de investigación arqueológica, estuvo desde un principio motivada por dos circunstancias fundamentales, por un lado la influencia de las ciencias naturales y sus métodos de ordenación y, por otro, una perspectiva "museológica" por la que los útiles eran valorados principalmente en términos de calidad estética. De esta manera, los prehistoriadores intentaron definir y ordenar la estructuración del tiempo prehistórico en términos de fósiles directores, es decir formas de útiles cualitativamente diagnóstico, cuyas distribuciones estratigráficas restringidas se pensaba que delineaban los principales bloques culturales y sus principales subdivisiones evolutivas (SACKETT 1968; MARTÍNEZ FERNÁNDEZ 1995-96:20).

A. Leroi-Gourhan definió la Prehistoria como una historia de las técnicas (LEROIGOURHAN 1962:525) en la que los objetos eran considerados como testigos accesorios de los hechos. Es por esto que afirmaba que la Prehistoria podría pasar por una ciencia natural reclamante de una sistemática de los objetos como existe una sistemática de rocas o de seres vivos, para dirigir la interpretación sincrónica y diacrónica de los testigos (LEROI-GOURHAN 1964:527)

Así, parecía lógico que la única manera de conocer e interpretar de manera coherente estos útiles era incluirlos dentro de una clasificación. El inicio de la Prehistoria como ciencia, íntimamente ligada a otras ciencias naturales como la geología o la biología, hizo aún más patente la necesidad de un organigrama en el que estuvieran presentes todos los elementos que hicieran 
posible su universalización y comunicación y, por lo tanto, su avance a lo largo de la historia (BREZILLON 1977).

Hasta el siglo XVI los animales, vegetales y minerales se encontraban organizados únicamente en función de una observación muy somera que en la mayoría de los casos sólo expresaba la relación que el hombre mantenía con los mismos. Sin embargo, el avance del conocimiento hizo que la multiplicación de tipos llevase a un intento de clasificaciones mucho más sistemáticas. Las primeras en aparecer fueron las clasificaciones botánicas, entre las que cabe destacar la del italiano A. Cesalpin (1519-1603), que propone la clasificación de las plantas según la duración de la vida, el número de granos y la forma de las raíces (BREZILLON 1977).

Ya en el siglo XVII se forma la noción de género con el impulso del naturalista inglés J. Ray (1628-1705) y del francés J. Pitton de Tournefort (1628-1708) que distinguió los caracteres propios del género entre los que no servían para distinguir a nivel de la especie (BREZILLON 1977).

Con Ch. Linneo (1707-1778) aparece la nomenclatura binaria, todavía en uso en las ciencias naturales y que aporta un perfeccionamiento decisivo en el plano de la nomenclatura, esto es, el uso del binomio latino, asociando al nombre de género el epíteto específico. Adoptado internacionalmente, fue clave a la hora de producir el intercambio entre los investigadores. Al mismo tiempo A.L. de Jussieu (1748-1836) propone la clasificación natural por la que se tiene en cuenta el mayor número posible de caracteres y en la que unos están subordinados a otros de rango más elevado, lo que supone que un pequeño carácter puede permitir la separación en el interior de un grupo (BREZILLON 1977).

J.B. Lamarck (1744-1829) intentó combinar ambas clasificaciones, la de Linneo y la de Jussieu, mediante las claves dicotómicas, las cuales, a través de una serie de dobles cuestiones orientan progresivamente al lector y le llevan finalmente a la especie descrita en la serie natural, en unas tablas que permiten la búsqueda simple y rápida del nombre de cada planta. G. Cuvier (1789-1832) aplica al reino animal la clasificación de Lamarck. Pero es P.C. de Candolle (17781841) quien pone las primeras bases de las reglas indispensables de la nomenclatura, así surgen 
el Código internacional de la nomenclatura botánica y las Reglas internacionales de la nomenclatura zoológica. A partir de entonces, los seres vivos son entidades abstractas clasificadas como taxones, y se clasifican jerárquicamente a partir del taxón fundamental: la especie (BREZILLON 1977).

Es lógico que en este ambiente de afán clasificador en el desarrollo de las ciencias, los prehistoriadores intentaran a su vez la clasificación de los materiales de los que disponían para hacer más fácil su estudio. Sin embargo, es claro que los problemas a los que tenían que hacer frente los prehistoriadores no eran los mismos que los que resolvían botánicos o geólogos, aunque sí existían algunos en común. Por un lado, las categorías a las que representaban los diversos nombres no eran fijas, sino que fluctuaban a la vez que avanzaba el conocimiento y esto hacía que el mismo progreso quedara limitado por la dificultad que existía, y existe, en sustituir un término por otro y romper con el orden previo de categorías establecidas. Igualmente, la palabra que designa a un objeto, lleva en sí misma un límite preciso, tajante y absoluto que no existe jamás en la naturaleza (ROYER 1876:758) por lo que nunca se podrá designar a un objeto en particular sino que se hará sobre una idea-tipo, la media entre los distintos tipos individuales (BREZILLON 1977)

En un principio, el objetivo era definir el tiempo prehistórico usando como indicadores formas animales extintas. Al fracasar en el intento, el interés se centró en un simil de los fósiles biológicos, los artefactos de piedra tallada. La asunción básica al proceder así era la aceptación de la existencia del progreso tanto en las formas de los seres vivos como en las técnicas humanas representadas por sus artefactos.

Los prehistoriadores intentaron establecer una tipología de los artefactos arqueológicos, es decir, adscribir cada elemento dentro de una clase ilustrada por un tipo. El término tipo fue rápidamente aceptado por los arqueólogos para designar los instrumentos característicos de un nivel, los primeros fósiles directores aislados fueron denominados simplemente por el lugar donde fueron reconocidos por primera vez. Así el término tipo vendría definido por el modelo ideal, que reúne un alto grado de trazas esenciales de todos los objetos de la misma naturaleza. 
En un principio, los objetos líticos sometidos a la tipología eran objeto de una primera selección, es decir, que como condición de partida mostrasen trazas de intervención humana. De esta manera, los objetos llamados de piedra tallada eran aquellos que presentaban alguna superficie de lascado en la que aparecieran las trazas de la fractura concoidea de algunas rocas vinculada a la percusión intencionada o por la existencia del bulbo de percusión frecuentemente acompañado en la proximidad del punto de impacto. A medida que se reafirmaba la noción de fósil director, las preocupaciones de los prehistoriadores se orientaban más hacia el establecimiento de un dispositivo cronológico que hacia el desarrollo de una tecnología prehistórica. (BREZILLON 1977). Desde los trabajos pioneros de G. de Mortillet hasta la Segunda Guerra Mundial la estrategia de investigación estuvo fuertemente influenciada por la noción del fósil-director (SACKETT 1968).

Las principales consecuencias de la asunción de esta posición metodológica fueron la adopción de un modelo orgánico de la cultura (SACKETT 1968) que llevó en múltiples ocasiones a la confusión entre biología y cultura.

Indudablemente, la utilización de este sistema espacio-temporal, retardó el desarrollo de la reconstrucción cultural y su interpretación. Primero, porque la manera similar en que fueron concebidos los fósiles paleontológicos y arqueológicos favoreció inevitablemente la asunción de que la historia cultural se desarrollaba dentro de un modelo de evolución orgánica $\mathrm{o}$, al menos, natural. Además cuando los patrones de la dinámica cultural reflejados en estos esquemas no podían ser explicados se atribuían a diferencial biológicas entre las diferentes comunidades humanas (SACKETT 1968).

Una segunda e igualmente desafortunada consecuencia de la utilización del fósil irector fue que, asumiendo una correlación de uno a uno entre cultura y estratigrafia natural, se impidió a los prehistoriadores estimar la complejidad del registro arqueológico. La unidad mínima de excavación reconocida no fue nunca menor a un estrato arqueológico, con lo cual, los conjuntos artefactuales individualizados eran el resultado de la mezcla de diversos niveles de ocupación. Este principio teórico provocó el desarrollo de líneas metodológicas cuya finalidad era recoger únicamente los datos utilizables para obtener una secuencia ordenada de horizontes 
arqueológicos. Así, los conjuntos de artefactos fueron recogidos sin tener en cuenta la distribución vertical y horizontal de los útiles. Además, se desarrolló una fuerte tendencia a obviar todos aquellos artefactos sin valor cronocultural, enfatizando, por tanto, la búsqueda de los fósiles directores, de forma que se consiguiera el objetivo último de la investigación, a saber, el encuadre cronocultural con connotaciones étnicas. El desarrollo del concepto de fósil director dio paso a la creación de tipologías donde encajar estos útiles tipo (SACKETT 1968).

El concepto de fósil director utilizado desde una perspectiva cualitativa tal y como acabamos de analizar, dejó de utilizarse debido al fracaso de su papel de indicador cronológico preciso, una vez que el refinamiento de las técnicas de excavación lo puso en evidencia, al mismo tiempo dio paso a un nueva concepción en donde el desarrollo evolutivo era entendido en función de la aparición de determinadas frecuencias de útiles, es decir, se pasa de una perspectiva cualitativa a otra cuantitativa (SACKETT 1981).

En ésta última se estudian conjuntos no seleccionados, con el objetivo fundamental de descubrir la proporción en que aparecen los diferentes tipos en relación con el total industrial, para aislar culturas y facies dentro de ellas, en función de las variaciones porcentuales observadas en una lista-tipo definida previamente (SACKETT 1981). Es entonces cuando los arqueólogos se enfrentan a la necesidad de definir el concepto de tipo.

Para Smith el tipo es una forma que se encuentra de modo no fortuito y es significativa en el tiempo, en el espacio, o en ambos en relación con el problema estudiado (SMITH 1966:29).

J. Fortea opina que es la formalización individual de una serie de caracteres primarios y secundarios y al integrarla con la definición anterior propone que tipo es la formalización individual de caracteres primarios y secundarios que se encuentra de modo no fortuito y es significativa temporal y espacialmente en relación con un problema (FORTEA 1973:47).

Para J.M. Merino debería ser el esquema mental creado por el hombre prehistórico, con un sentido utilitario evidente a cuya semejanza fabricó series de útiles. Pero en realidad nunca 
podemos conocer la mentalidad de tal hombre, y ni siquiera podemos dar por cierto que existieran tales esquemas mentales, cuanto más cuales fueron, el tipo pasa a ser una abstracción nuestra, actual que se crea como común denominador de una serie de objetos que tienen entre si unas semejanza formal, técnica o presumiblemente utilitaria (MERINO 1980:68).

Desde una perspectiva completamente diferente a las anteriores A.C. Spaulding entiende que tipo es la asociación de dos o más atributos ligados entre sí por un vínculo no aleatorio (SPAULDING 1953).

El cambio de un sistema a otro comienza en la década de los años 40 y se fija a comienzos de la década de los 50, cuando el método estadístico se estableció de una forma definitiva por dos autores: F. Bordes observó que el estudio de la industria lítica dentro de términos cuantitativos no implicaba únicamente una simple manera de contar, sino que permitía la introducción de nuevos elementos dentro de una metodología sistemática, argumentando que la tipología de los artefactos, es decir el significado formal del conjunto, y la definición de su filiación genética, es decir, su significación cronocultural, constituían procedimientos y objetivos distintos (SACKETT 1981; MARTÍNEZ FERNÁNDEZ 1995-96:27-28).

G. Laplace, aún dentro de la misma corriente, desarrollará la Tipología Analítica o Estructural, una metodología que se caracteriza por estar basada en el método dialéctico, por la explicitación de los criterios sobre los que se fundamenta y de sus objetivos además de por la realización de una crítica acertada de otras metodologías. Se parte del concepto de estructura que se define como el modo de organización de un conjunto industrial. El estudio de esta estructura revela que tiene una articulación interna. Ciertos elementos parecen poseer una función determinada, observándose por tanto la constitución de estructuras de segundo orden. A partir de estas premisas, Laplace creó la noción de complejo industrial. Denominando así a los grupos de conjuntos industriales que presentan los mismos fenómenos estructurales (MARTÍNEZ FERNÁNDEZ 1995-96).

Sin embargo, el método o métodos estadísticos en tipología prehistórica de la piedra tallada no están muy alejados en sus planteamientos ni en sus objetivos del método del fósil- 
director, puesto que el fósil o fósiles directores característicos que servían para definir un horizonte cronocultural son ahora sustituidos por los porcentajes representativos de una serie de tipos (los incluidos en la Lista tipo). Por eso ha sido objeto de las críticas de la Nueva Arqueología por la arbitrariedad de sus planteamientos, por la subjetividad de sus definiciones y por la inconsistencia de sus resultados al equiparar los conjuntos industriales redefinidos con culturas, siendo el caso más característico el del Musteriense (MARTÍNEZ FERNÁNDEZ 199596).

Estos planteamientos nuevos al enlazar con otra línea de investigación que comenzó a desarrollarse antes incluso que los métodos estadísticos, han dado lugar al surgimiento del enfoque que podemos denominar conductual. Con la aparición de esta corriente podemos decir que hacia mediados de los 70 se inaugura una nueva etapa en el estudio del utillaje prehistórico que nos permitirá una nueva aproximación al conocimiento de las sociedades prehistóricas, aunque ello no ha supuesto el abandono de los planteamientos tipológico, sino su integración en una perspectiva más amplia y compleja: la conductual (MARTÍNEZ FERNÁNDEZ 1995-96).

Recientemente, G. Martínez ha desarrollado un enfoque holístico para el estudio de los artefactos prehistóricos de piedra tallada, por el que la industria lítica habría que entenderla como reflejo de los procesos socieconómicos de las diferentes culturas y no como simples trazas culturales. Esta perspectiva fue expuesta en la tesis doctoral de J.A. Marrero y se ha ido desarrollando más ampliamente con posterioridad por ambos autores (MARTíNEZ y AFONSO 1995); en el apartado II.3.- La industria lítica como producto analizaremos más detalladamente esta perspectiva. 


\section{II.2. Tecnología y útiles. La perspectiva funcionalista}

A continuación vamos a tratar de desarrollar y analizar las nuevas perspectivas que, para abordar el estudio de los artefactos de piedra tallada en el marco de nueva concepción teóricometodológica, comienzan a desarrollarse a partir de finales de los años 60 en las universidades americanas y que, rápidamente, van a tener una importante repercusión en el discurso arqueológico internacional ${ }^{1}$; nos referimos obviamente a la Nueva Arqueología (BINFORD 1968; 1972).

Comencemos presentando una breve caracterización de los principios teóricos y metodológicos de la Nueva Arqueología para, posteriormente, valorar el nuevo significado de la cultura material en general, y de la industria lítica en particular, que desde entonces, de acuerdo con las nuevas coordenadas teóricas se va a insertar en una nueva matriz teórico-metodológica en donde prima una concepción de la cultura concebida desde una perspectiva funcionalista.

La arqueología se considera como una ciencia social, siendo su objetivo desarrollar modelos explicativos de los procesos sociales. Para conseguir una arqueología explícitamente cientifica (WATSON et al. 1974) la nueva arqueología va a asumir el modelo hempeliano de explicación, consistente en la aplicación del método científico llamado hipotético-deductivo. Ello implicó el surgimiento del interés por adoptar estrategias de investigación en las que las hipótesis son el punto de partida y su contrastación el objetivo de la investigación, a diferencia de lo que

${ }^{1}$ En lo referente al discurso arqueológico peninsular la incorporación de este nuevo desarrollo teórico se produce tarde, básicamente a partir de los años 80 , y sin que realmente se genere un verdadero debate, simplemente se asume una nueva terminología y toda un serie de nuevos desarrollos metodológicos que van a ser aplicados, en la mayoría de los casos, sin una mínima revisión crítica. Nos referimos a los análisis espaciales como el Site Cachement Analysis, teoría del lugar central, polígonos de Thyssen, análisis macroespaciales, microespaciales, introducción de técnicas informáticas y estadística para el análisis de los datos, la recuperación del contexto medioambiental mediante el desarrollo de técnicas aplicadas a la reconstrucción paleoambiental, etc. 
ocurría en la arqueología tradicional en donde, supuestamente, la interpretación ${ }^{2}$ era el resultado final. Por tanto, se adoptó un patrón de investigación más adecuado al de las ciencias experimentales.

Por otra parte, la arqueología es concebida como parte de la antropología (BINFORD 1962), por lo que compartiría con ella el mismo objetivo específico, a saber, la explicación de la variabilidad cultural, entendiendo por cultura el contexto extrasomático de adaptación de una sociedad a su ambiente físico y social (BINFORD 1965).

Frente a la concepción normativista de la cultura White, y por extensión la Nueva Arqueología, utiliza el concepto de la simbolización como elemento de referencia en la articulación de su nueva concepción de la cultura Cuando cosas y acontecimientos que dependen del simbolizar se consideran e interpretan en términos de relación con los organismos humanos, es decir, en un contexto somático, entonces propiamente pueden denominarse conducta humana y la ciencia correspondiente: psicología. Cuando estas mismas cosas y acontecimientos que dependen del simbolizar son considerados e interpretados en términos de contextos extrasomático, es decir, en términos de su mutua relación más bien que de su relación con organismos humanos, podemos entonces llamarlos cultura y la ciencia correspondiente culturología. Esta definición rescata a la antropología cultural de las abstracciones intangibles, imperceptibles y ontológicamente irreales a las que se había encadenado y le proporcionaba su objeto real, sustancial y observable. (WHITE 1974:139-140).

Desde esta perspectiva se supera por tanto, la concepción normativista de la cultura introducida en antropología por E. Tylor, según la cual la cultura debe ser entendida como un todo complejo que incluye el conocimiento, las creencias, el arte, la moral, el derecho, las costumbres y cualesquiera otras capacidades o hábitos adquiridos por el hombre (COLLINS 1986).

${ }^{2}$ En realidad desde una perspectiva tradicional la arqueología quedaba reducida a la descripción de la historia cultural, ya que, la explicación de los procesos históricos tenían como elemento último de referencia el conjunto de normas mentales de los sujetos históricos del pasado, que consideraban inaccesibles al investigador. 
Para poder contrastar en el registro arqueológico nuestras hipótesis sobre los procesos históricos, es necesario justificar cómo la cultura material puede informarnos sobre sociedades pasadas. Esta justificación se realiza afirmando la naturaleza sistémica de la cultura en la que diferentes subsistemas tienen articulaciones regulares. Desde esta perspectiva cualquier subsistema, al estar relacionado con el resto de los subsistemas, nos debe informar las características del sistema cultural global. Por tanto, los materiales arqueológicos deben reflejar, en mayor o menor medida, la operación de los diferentes subsistemas (BINFORD 1965).

En realidad el concepto sistémico de la cultura es igualmente asumido de la obra de White. Dentro de la concepción sistémica White distingue tres subsistemas El sistema tecnológico se compone de instrumentos materiales, mecánicos, físicos y químicos, junto a las técnicas de su uso, por medio de las cuales el hombre, como especie animal, es articulado en su hábitat natural. (...) El sistema sociológico está formado de relaciones interpersonales expresadas en modelos de comportamiento, tanto colectivas como individuales. En esta categoría encontramos sistemas sociales, de parentesco, económicos, éticos, políticos, militares etc. El sistema ideológico está compuesto de ideas, creencias, conocimientos, expresados en lenguaje articulado u otra forma simbólica (WHITE 1992:349-350). Estos tres subsistemas estarían integrados, pero su interacción no sería igual. El sistema tecnológico representa el papel principal: toda cultura y vida humanas descansan y dependen de él (WHITE 1992:350).

Binford asume estos principios planteando la organización sistémica de la cultura, y su articulación en tres subsistemas: ideológico, económico y tecnológico, afirmando que sería necesario señalar aquellos artefactos relevantes dentro del conjunto total de artefactos, que hayan tenido su contexto de funcionamiento primario en los subsistemas social, tecnológico e ideológico del sistema cultural total. No debemos equiparar "cultura material" con tecnología (...). Estamos de acuerdo en que no podemos excavar una terminología de parentesco o una filosofia, pero podemos, y de hecho lo hacemos, excavar los objetos materiales que funcionaron junto con estos atributos más conductuales dentro de los subsistemas culturales apropiados. La estructura formal de los conjuntos de artefactos junto con sus relaciones contextuales deberian $y$ de hecho lo hacen, presentar una imagen sistemática y comprensible del sistema total cultural extinto. (BINFORD 1962:21). 
Por tanto Binford, al igual que plantea White, se decanta por el carácter determinante del subsistema tecnológico y, en última instancia, el elemento de referencia para el análisis y estudio del resto de subsistemas que integrarían el sistema cultural total.

Por otra parte, y frente a la concepción tradicional de la cultura, desde una perspectiva sistémica la cultura sería un fenómeno diferencialmente compartido en función de la distinta integración de individuos en actividades y segmentos sociales diversos.

A partir de esta premisa se desarrolla una fuerte crítica de las tipologías como metodología, planteando que la agrupación de materiales con características similares, valorados en términos de homogeneidad cultural, afiliación étnica y la mismo tiempo posición cronológica, encubre las posibles diferencias culturales que otro tipo de análisis revelaría, planteamiantos que resultan evidentes en la polémica mantenida entre Bordes y Binford en torno al significado del Musteriense, y que posteriormente analizaremos con más detalle.

En relación con las tipología Binford plantea lo siguiente este énfasis sobre rasgos compartidos en nuestros sistemas de clasificación resulta en el enmascaramiento de las diferencias, y en el amontonamiento de fenómenos que resultarian discretos bajo otro método taxonómico. La cultura no es un fenómeno univariado (...), sino multivariado, y su operación debe ser entendida en términos de muchas variables causalmente relevantes que pueden funcionar independientemente o en combinaciones variadas. Es nuestra tarea el detectar estos factores causativos y buscar relaciones estables, regulares y predecibles entre ellas. (BINFORD 1965:199).

Esta búsqueda de los factores causales y de las relaciones estables y predecibles se realiza a partir del concepto de estructura arqueológica, es decir, la organización del registro arqueológico que puede demostrarse con la distribución y asociación no aleatoria de los elementos arqueológicos. Un sistema cultural es un conjunto de articulaciones constantes o cíclicamente repetitivas entre los medios adaptativos extrasomáticos social, tecnológico e ideológico, asequibles a las poblaciones humanas. (WHITE, en GÁNDARA 1982:75). 
La articulación sistemática de yacimiento, organización del espacio y útiles con tareas especificas desarrolladas por segmentos sociales resulta un conjunto estructurado de relaciones espacioformales en el registro arqueológico. La gente no coopera exactamente en la misma manera cuando realiza tareas distintas. En forma similar, tareas diferentes no son realizadas uniformemente en los mismos espacios, y así como varían los grupos de cooperación, varían los útiles e instalaciones necesarios para la realización de estas tareas. La perdida, ruptura y abandono de instrumentos y estructuras en diferentes lugares, donde grupos de organización variable realizaron tareas diferentes, deja un registro fósil de la operación real de una sociedad extinta. Este registro fósil puede ser leído a través de las agrupaciones espaciales cuantitativamente variable de clases de artefactos. (BINFORD 1964:136).

Por tanto, para Binford, dada la naturaleza extrasomática y adaptativa de la cultural, la realización de actividades por parte de los grupos sociales tiene, por una parte, un carácter organizado, y por otra, variable, es decir, los lugares donde se realizan las actividades, así como la composición de los grupos que intervienen y las herramientas utilizadas, varían en función de la naturaleza de la actividad desarrollada.

Existen tres clases básicas de datos arqueológicos :

-Artefactos: entidades cuyas características formales resultan total o parcialmente de la actividad humana, son objetos naturales modificados por y para el uso humano, o nuevos objetos formados completamente por las acción humana. Las características formales de los artefactos no se modifican ni alteran de las condiciones en que se encuentran, conservan su apariencia después de que los arqueólogos las extraigan. Por tanto, un artefacto es cualquier elemento portable que es modificado o totalmente creado por la actividad humana (SHARER y ASHMORE 1979:70-72).

-Estructuras: artefactos no transportables, la posición y la organización son los aspectos claves de las estructuras; por esta razón no pueden ser extraídos de la matriz en la que se encuentran después de su descubrimiento sin alterar o destrozar su forma original. Sin embargo, pueden ser reconstruidas en el museo a posteriori. Algunos ejemplos de 
estructuras arqueológicas son hogares, enterramientos, fosas de almacenamiento... Se suele distinguir entre estructuras simples, como las anteriores, y estructuras compuestas como restos de edificios. Las estructuras (casas, almacenes, templos, palacios...)pueden ser revelados arqueológicamente tanto por los patrones de distribución del suelo, hoyos de poste, muros y entradas como por la asociación de estructuras simples como hogares, fosas, etc. (ibid.)

-Ecofactos: son restos materiales no artefactuales que tienen relevancia cultural y aunque no han sido directamente creados por el hombre (actividad humana) proporcionan una importante información sobre la conducta humana. Así, los ecofactos incluyen restos de animales domésticos y salvajes y especies de plantas, que nos indicarían condiciones medioambientales, tipos de alimentos... (ibid.)

Una vez establecido el modelo de la relación estructurada entre comportamiento humano y la distribución espacial de la evidencia arqueológica ... podemos recuperar a partir tanto de la naturaleza de las poblaciones de artefactos como de sus asociaciones espaciales, la estructura fosilizada del sistema cultural total. La estructura arqueológica de una cultura debería, y en mi opinión lo hace, reflejar todas las otras estructuras, por ejemplo, la de parentesco, la económica y la politica. Todas son abstraídas a partir de eventos que tuvieron lugar como parte del funcionamiento normal de un sistema cultural. La estructura arqueológica resulta de esos mismos eventos (BINFORD 1964:136).

Desde esta perspectiva se introducen las técnicas de muestreo y análisis estadístico como elemento de referencia. Se parte del supuesto de que el material arqueológico no es autoevidente, por lo que los procedimientos tradicionales como la tipología deben ser evaluados para demostrar que miden los parámetros de interés.

Las inferencias deberán estar sometidas a prueba según establece el ya citado método hipotético-deductivo. Las analogías con información etnográfica pueden tomarse como punto de partida en la formulación de hipótesis, aunque deben ser contrastadas (BINFORD 1968). 
El razonamiento por analogía se funda en la premisa que si dos clases de fenómenos son semejantes en un aspecto, pueden ser semejantes en otros aspectos también. Como forma de inferencia la analogía puede ser definida como la transferencia de información de un objeto a otro sobre la base de alguna relación de comparabilidad entre ellos (HODDER 1982). Se puede hacer una distinción entre analogía formal y relacional. Respecto a la analogía formal se sugiere que si dos objetos o situaciones tienen propiedades comunes, probablemente tendrán otras similaridades. Tal analogía tiene su punto débil en que la asociación observada de las características de los objetos y situaciones puede ser fortuita o accidental. La otra clase de analogía, la relacional, busca determinar algún vínculo cultural o natural entre los diferentes aspectos (HODDER 1982).

En Arqueología, la analogía se usa para inferir la identidad de relaciones entre datos arqueológicos sobre la base de la comparación con fenómenos similares documentados en sociedades humanas vivas. Este razonamiento puede ser directo cuando estemos tratando aspectos o atributos particulares, pero a la hora de elaborar modelos generales o interpretaciones detalladas deben tenerse en cuenta tres condiciones fundamentales: continuidad cultural, igualdad en el medio ambiente y similitud de la forma cultural (SHARER y ASHMORE 1979), lo que reduce drásticamente su efectividad. Para evitar este problema es necesario poner el énfasis en examinar todos los aspectos diferentes del contexto que puedan modificar características particulares de la cultura material.

La contribución de la etnografia podría ser dividida en tres componentes: (1) Los estudios comparativos ayudan a establecer los términos de referencia para una investigación arqueológica, es decir, pueden formularse hipótesis específicas para probarlas. (2) Los datos etnográficos ofrecen a menudo inspiración para la interpretación de la evidencia arqueológica, cuya significación podría ser de otra manera oscura. (3) La aplicación de métodos arqueológicos al material etnográfico puede probar la validez y limitaciones de las inferencias arqueológicas (ISAAC 1968:254).

Una vez planteados de forma general los principios teóricos y metodológicos que caracterizan a la Nueva Arqueología o arqueología funcionalista, vamos a tratar de analizar cómo el nuevo enfoque transforma las líneas de investigación relacionadas con los estudios prehistóricos 
en general y de la industria lítica en particular, de tal forma que ésta es concebida desde una perspectiva funcional y por tanto como uno de los medios utilizados en la interrelación hombremedio.

Para ello, como ya hemos mencionado, vamos a plantear uno de los debates más interesantes que enfrenta la visión tradicional de la arqueología con la nueva arqueología, concretamente hacemos referencia a la polémica en torno al Musteriense. La controversia surge a raíz de la interpretación de las variaciones que se suceden en la industria de piedra tallada del Paleolítico Medio. F. Bordes afirmaba que estas diferencias de utillaje eran debidas al transfondo cultural (BORDES 1961; BORDES y BOURGON 1951; BORDES y SONNEVILLE-BORDES 1970; SONNEVILLE-BORDES 1974-75) mientras S. y L. Binford consideraban que era la funcionalidad el elemento diferenciador de las distintas facies del Musteriense (BINFORD y BINFORD 1966; 1975; BINFORD 1973; 1988; MONTES RAMIREZ 1988).

F. Bordes, dentro de una concepción tradicional de la arqueología, había desarrollado un sistema para clasificar los instrumentos de piedra tallada y unas técnicas dedicadas a describir y caracterizar cuantitativamente los conjuntos. Para él, las técnicas empleadas en la fabricación de instrumentos deberían ser analizadas con total independencia, ya que eran elementos derivados de dos situaciones distintas: por un lado la técnica empleada estaba condicionada por las diferentes materias primas utilizadas, y por tanto no era importante a la hora de reconstruir la historia cultural; por otro lado, las formas de los útiles derivaban de otras circunstancias como las formas de los retoques posteriores o la orientación de las lascas sobre las que estaban realizadas (BINFORD 1988).

Realmente, el denominado método Bordes, no es estrictamente una tipología ya que tiene en cuenta también la tecnología. Bordes basa su tipología en una idea básica: la constatación de que muy pocas formas artefactuales son realmente características de un sólo periodo y de que determinados útiles que habían sido considerados de una determinada época aparecían en momentos anteriores o posteriores. Para el autor, los utensilios de piedra podían ser clasificados según una serie de atributos morfológicos y técnicos de fabricación que se agruparían en conjuntos susceptibles de ser comparados (BINFORD y BINFORD 1966). Así, la tipología no 
se debía hacer sobre los artefactos típicos, sino sobre los conjuntos y los porcentajes de elementos en cada uno de ellos (BORDES 1984).

De esta manera se pasa del enfoque del fósil-director anterior, a un nuevo método estadístico denominado método Bordes. El método se basa en (SONNEVILLE-BORDES 197475):

-El establecimiento de una tipología que reconoce, define y describe tipos por el análisis técnico y morfológico y los clasifica eventualmente en grupos.

-La elección de una lista-tipo, en la que quedarían incluidos el total de útiles de un nivel de ocupación único, bien delimitado estratigráficamente, y del que quedaría excluido el material no retocado, que sería analizado posteriormente.

-La utilización de gráficos acumulativos que permitieran la representación del desarrollo o la tendencia de la serie.

-La definición y uso de una serie de índices y grupos característicos, reuniendo uno o varios grupos técnica, tipológica o culturalmente significativos que eventualmente son aislados y figurados por bloques diagramas.

Con este método Bordes distinguió cuatro grupos básicos en la industria Musteriense (BINFORD 1988):

-Musteriense de tradición achelense:reconocido por la presencia de hachas de mano, una gran cantidad de denticulados y muescas y un número considerable de cuchillos de dorso rebajado. Los raspadores laterales aparecen en escasa cantidad.

-Musteriense típico: disminuyen los porcentajes de cuchillos de dorso rebajado y casi desaparecen las hachas de mano. 
-Musteriense con denticulados: continúan bajando los porcentajes de hachas de mano y cuchillos de dorso rebajado, al igual que el de los raspadores. Abundan las muescas y los denticulados.

-Grupo charetiense: en este grupo dominan los raspadores, continua la escasez de hachas de mano y cuchillos de dorso rebajado y disminuye considerablemente el número de muescas y denticulados. Dentro de este grupo, Bordes distingue el subtipo Quina, en el que los raspadores son transversales y casi no aparece la técnica Levallois, y el subtipo Ferrassie, en el que aparecen frecuentemente la técnica Levallois.

Sin embargo, la aplicación del método Bordes, requiere de una serie de condiciones. Por un lado, y como el propio Bordes reconoció, sólo es fiable con un número considerable de piezas (a partir de las 200); además no se puede aplicar más que a recogidas totales de objetos, con lo que resulta imposible estudiar conjuntos de excavaciones antiguas. Por otro lado, no tiene en cuenta el aspecto cualitativo de la muestra (SONNEVILLE-BORDES 1974-75).

La crítica más intensa viene dada por la visión del pasado que ofrecía la utilización de este método, el resultado era la existencia de una serie de líneas culturales que venían desde muy antiguo, denominadas phila, que se mantenían con muy pocas variaciones a lo largo del tiempo y que no admitían mezclas con otras líneas. Este es el punto de vista orgánico del pasado (SACKETT 1968), por el cual los distintos conjuntos de material o especies culturales avanzaban, retrocedían y reaparecían dentro de un mismo espacio geográfico ${ }^{8}$.

Con el desarrollo de la Nueva Arqueología este punto de vista orgánico va a chocar frontalmente con el punto de vista cultural, defendido por los funcionalistas y, según el cual, se intentaba establecer una estrecha relación entre las formas culturales extintas y los diferentes tipos de medio ambiente, basándose en la distribución espacial de los rasgos y complejos existentes en los grupos étnicos y sociales conocidos, es decir, mediante la etnología.

\footnotetext{
${ }^{8}$ En este sentido es interesante observar cómo los cuatro grupos musteriense se articulan y diferencian en función de la aparición y aumento o desaparición y disminución de los distintos elementos: muescas, denticulados, raspadores, cuchillos de dorso y bifaces. En la secuencia de Combe Grenal, además, existe la alternancia de los distintos grupos a lo largo de toda la secuencia estratigráfica (BINFORD 1983:99, fig.38).
} 
Mientras que en el método Bordes el único elemento de referencia era el análisis tecnotipológico de las industrias líticas, con el objetivo de ordenar el material cronoespacialmente, Binford propuso la división de los conjuntos de útiles según reflejaran distintas actividades; así la variación dentro de la composición de un conjunto estaría directamente relacionada con la forma, naturaleza y ordenación espacial de las distintas actividades realizadas (BINFORD y BINFORD 1966).

Combinando dos aspectos predominantes dentro de la arqueología funcionalista, el contexto y las técnicas analíticas, se pretendía llegar a un conocimiento más exacto de los acontecimientos sucedidos. El razonamiento de Binford era que diferentes tipos de actividad producían diferentes asociaciones de restos materiales, siempre los mismos, así, si se aislaban estas asociaciones podrían reconocerse igualmente las actividades desarrolladas y sus áreas dentro del yacimiento (BINFORD 1988).

Estas actividades, a su vez, vendrían determinadas por una serie de variables como los fenómenos estacionales, la composición del grupo, el tamaño y la estructura social, y causas igualmente importantes serían la situación de un grupo determinado frente a los recursos: suministro de materias primas para la fabricación de útiles, abrigos, alimentos...(BINFORD y BINFORD 1966).

Sin embargo, Binford se encontró con la barrera de la documentación de las excavaciones, debido a que no era homogénea a la hora de sistematizar los distintos materiales: piedra tallada, cerámica, huesos de animal... con lo que las asociaciones eran prácticamente imposible. De esta manera llegó a la conclusión de que la única manera de desarrollar métodos arqueológicos de inferencia era a través del estudio de pueblos primitivos contemporáneos o del análisis de yacimientos arqueológicos históricos de los que se tuviese información complementaria (escrita). Paralelamente se desarrolló en gran manera la denominada arqueología experimental (BINFORD 1988).

Bordes respondió a las críticas de Binford en un artículo en el que revisaba el complejo Musteriense, en él afirmaba que la mayor parte de la variabilidad observada en este periodo era 
Espacios de producción y uso de los útiles de piedra tallada del Neolítico

de origen cultural y no el resultado de actividades especializadas. Bordes considera los distintos tipos de Musteriense como haces coherentes (BORDES 1983:262) que no corresponden a áreas de diferentes actividades, sino a tradiciones culturales distintas; critica, por tanto, la identificación entre útiles y actividades propuesta por Binford ya que implicaría que cuando no aparecen determinados útiles en un yacimiento es que no se realizan ciertos tipos de actividad?

En realidad la polémica supone un callejón sin salida, ya que, se parte desde dos posiciones epistemológicas, y por extensión ontológicas, completamente diferentes, es más, ambos desarrollos teóricos corresponden a dos realidades sociopolíticas concretas. Frente a la visión evolucionista-idealista del método Bordes, se contrapone una visión aparentemente materialista de la realidad. Por tanto, las categorías de análisis, las hipótesis de partida y las estrategias metodológicas responden a concepciones irreconciliables a las diferentes instancias.

Desde nuestra perspectiva una de las aportaciones más importantes de la arqueología funcionalista sería la incorporación del contexto espacial a las explicaciones arqueológicas, y por tanto, de todas las líneas metodológicas desarrolladas en esta dirección. De hecho, en la actualidad e independientemente del marco teórico que defina nuestra investigación, el análisis de los patrones de organización de la evidencia arqueológica, en nuestro caso las interrelaciones entre los diversos artefactos líticos y su relación con el resto de elementos contextuales, se ha convertido en un elemento de referencia básico.

En esta misma línea de interés por las relaciones contextuales, también es destacable la preocupación continua por los proceso de formación de los depósitos arqueológicos y sus posibles alteraciones. En definitiva, junto al aspecto temporal definido y desarrollado desde la arqueología tradicional aparece ahora la connotación espacial que, como hemos indicado, no solo posee, como posibilidad interpretativa, la connotación funcionalista desarrollada desde la llamada arqueología explícitamente científica.

${ }^{9}$ Señala, por ejemplo, la ausencia de bifaces en Provenza frente a la presencia de los mismos en el Perigod. 
Sin embargo existen varias proposiciones en las que se ha centrado la crítica a las propuestas de la Nueva Arqueología; uno de los puntos centrales del debate está referido a la adopción del modelo hempeliano hipotético-deductivo con el objetivo de obtener leyes generales o cobertoras que puedan ser aplicadas en numerosos casos, y que son demasiado limitadoras (TRIGGER 1978). Según Flannery, en realidad lo único que se consigue son leyes triviales e irrelevantes, denominadas por el autor leyes de Mickey Mouse (FLANERY 1973), que debido a su laxitud pueden explicar cualquier cosa (GÁNDARA 1982), y que no prestan atención a los aspectos ideológicos y simbólicos de las sociedades. Por otra parte, en las leyes cobertoras, los significados culturales son impuestos previamente y desde la perspectiva occidental (HODDER 1987).

Por otro lado, la Nueva Arqueología enfatiza los aspectos adaptativos de la cultura obviando el conflicto como causa del proceso histórico; Carandini se manifiesta así al respecto: Incluso reconociendo la gran importancia del "materialismo cultural" (...) no podemos dejar de ponernos en guardia contra el materialismo abstracto y mecánico, el determinismo tecnológicoambiental que está expresado por una ideología que parece tener fundamentalmente miedo de sacar a la luz los aspectos politicos y sociales de la producción (las relaciones del hombre con el hombre siempre han sido vistas por las clases dominantes y por sus intelectuales como bastante más peligrosas que las del hombre con la naturaleza). Esta observación sirve también con respecto a la Nueva Arqueología (...), que parece arraigada a esta tradición cultural (CARANDINI 1984:76). O como señala Gilman la nueva arqueología explica la variabilidad arqueológica en términos ecológicos (una forma de materialismo que consigue evitar las complicaciones políticas, acudiendo más hacia Darwin que hacia Marx como fuente) (GILMAN 1988:51).

Por otra parte la Nueva Arqueología basa gran parte de su aparato metodológico: análisis estadísticos, análisis paleoecológicos, análisis espaciales... en la pretensión, totalmente imposible, de un conocimiento neutral que legitime al profesional teórico (HODDER 1984).

Uniendo estos dos conceptos la Nueva Arqueología muestra una imagen del hombre como un animal pasivo y controlado por leyes que no pueden ser cambiadas; y en las que las sociedades 
Espacios de producción y uso de los útiles de piedra tallada del Neolítico

pueden ser descritas y clasificadas en términos de su control tecnológico sobre la naturaleza (HODDER 1984). Las tesis más influyentes basadas en la interacción hombre-medio pueden remontarse a principios de siglo en el que se había manifestado un interés creciente por las sociedades humanas y su relación con su localización medioambiental, estimulando la visión funcional de uno de los aspectos primordiales del comportamiento humano, es decir, los análisis de los paleoambientes y las adaptaciones ecológicas de las culturas. Desde esta perspectiva se suponía que el ambiente natural, más que determinar la naturaleza específica de la respuesta, fijaba los límites de las diferentes clases de adaptaciones posibles (TRIGGER 1992).

En los años 30, estas propuestas se vieron reafirmadas por autores como G. Childe (1975) que explicó algunos de los cambios socioeconómicos del Neolítico como respuestas a estímulos medioambientales y al logro de un mayor control sobre la naturaleza, poniendo un énfasis especial en el desarrollo de las innovaciones tecnológicas (TRIGGER 1992); o G. Clark (1980) que, desde una perspectiva distinta, adoptó el enfoque funcionalista en el que se definía la arqueología como el estudio de cómo se vivía en el pasado; para lograr este objetivo los hallazgos arqueológicos tendrían que ser explicados desde un punto de vista funcional. La función de la cultura, o modo de vida, era asegurar la supervivencia de la sociedad, considerándola como un sistema adaptativo, todos los aspectos de la cultura están influidos en mayor o menor grado por los condicionantes ecológicos ${ }^{10}$.

\footnotetext{
${ }^{10} \mathrm{Ambas}$ ediciones son de los años 30 la obra de G. Childe fue editada en 1936 y la primera edición de la obra de G. Clark es de 1939.
} 


\section{II.3. La industria lítica como producto}

En los apartados anteriores hemos analizado las diferentes concepciones teóricometodológicas que han caracterizado el estudio de la Prehistoria en general y de la industria lítica en particular. Desde esta perspectiva, hemos abordado las transformaciones que ha sufrido el concepto de objeto arqueológico a lo largo de la historiografia para, a continuación, proponer un análisis de la industria lítica entendida como producto, es decir, como el resultado de un determinado proceso de trabajo, entendiendo por trabajo el necesario proceso mediante el cual el hombre transforma la naturaleza por medio de la aplicación de unas determinadas fuerzas corporales e intelectuales, de tal forma, que gracias a este proceso y en función su diferente articulación, define su propia realidad sociocultural.

En el proceso laboral en abstracto, o sea, sin incluir la relaciones sociales de producción y reproducción, que en última instancia definen cualquier desarrollo sociocultural y cuya caracterización y análisis se convierte en el objetivo básico de nuestras investigaciones, intervienen diversos elementos que, de forma sintética, serían los siguientes: la fuerza de trabajo, la materia prima y los medios de producción

(CARANDINI 1984).

Desde esta perspectiva, el análisis de cualquier proceso de producción implica la caracterización de un complejo conjunto de procesos entre los que destacamos: sistemas de aprovisionamiento de materia prima, procesos técnicos de manufactura, procesos de uso, reparación o reciclado y procesos de abandono (SCHIFFER 1983; 1987).

Tal y como hemos indicado, del proceso laboral se deriva un producto, un valor de uso, es decir, una materia natural adaptada a las necesidades humanas gracias a una serie de transformaciones realizadas por el hombre de forma intencionada. Evidentemente el resultado de un determinado trabajo puede convertirse en un nuevo medio de producción, de hecho, el carácter de materia prima o medio de trabajo no esta unido a un valor de uso sino a su posición en el 
proceso laboral y simbólico. Por tanto, el intercambio material entre hombre y naturaleza y su resultado en forma de productos es una necesidad de la vida humana común a todas las formas sociales (CARANDINI 1984).

No obstante, este necesario proceso de intercambio, cuando forma parte de un determinado desarrollo sociocultural, sólo es comprensible dentro de unas relaciones sociales de producción y reproducción. Precisamente son las condiciones sociales de la producción las que articulan de una forma concreta el proceso de trabajo. Ello explica la razón por la cual los medios de producción no sólo sirven para medir los diversos desarrollos de las fuerzas productivas, sino que también son el reflejo de unas relaciones sociales.

La tecnología revela el comportamiento activo del hombre con respecto a la naturaleza, el inmediato proceso de producción de su vida, y con él también el inmediato proceso de producción de sus relaciones sociales vitales y de las ideas del intelecto que se derivan (MARX en: CARANDINI 1984:66).

Desde esta perspectiva sólo mediante el análisis de los procesos de producción y distribución y por tanto, de las relaciones sociales que los sustentan, entendemos que debemos caracterizar a cualquier desarrollo cultural, así como, plantear modelos explicativos de la variabilidad cultural.

No obstante, la conceptualización del producto como el resultado de un determinado proceso laboral adquiere, tal y como hemos indicado, una nueva dimensión en relación con un determinado contexto social, según el propio Marx los restos de antiguos medio de trabajo tienen, para el estudio de las formas económicas de las sociedades desaparecidas, la misma importancia que tiene la estructura de los fósiles para el conocimiento de la organización de las razas extinguidas. Lo que distingue a una época económica de otra es menos lo que se fabrica que la manera de fabricarlo ${ }^{11}$, los medios de trabajo con los que se fabrica. Los medios de trabajo

\footnotetext{
${ }^{11}$ Énfasis nuestro.
} 
son los barómetros del desarrollo del trabajador y los exponentes de las relaciones sociales en las que trabaja (MARX en: BALIBAR 1979:230-231).

En esta reflexión Marx nos revela cómo el contexto de cualquier proceso laboral se convierte en un elemento básico en el análisis de cualquier sociedad, es decir, lo importante es cómo se fabrica, cómo se organiza socialmente la producción, lo que desde una perspectiva de análisis arqueológico se traduce en el estudio de los patrones de distribución/asociación de los elementos arqueológicos que conforman el registro de un determinado desarrollo cultural. De esta forma, los análisis contextuales se convierten en una pieza básica en la caracterización de las sociedades prehistóricas.

Obviamente el concepto de contexto que aquí presentamos difiere del analizado anteriormente dentro de la concepción funcionalista de la arqueología, basado en el análisis de los patrones observables en el registro arqueológico, para desde una visión funcional de los mismos, apoyar modelos explicativos de carácter adaptativo. El modelo analítico que nosotros presentamos está basado igualmente en el estudio contextual de los diversos elementos arqueológicos, aunque el objetivo es el análisis de los procesos de producción y redistribución, para a través de ellos caracterizar las relaciones sociales que los han generado y desde esta perspectiva contribuir al desarrollo de modelos explicativos sobre el cambio cultural.

En los estudios existentes sobre procesos de producción lítica habría que destacar, como uno de los elementos más característicos, la falta de análisis sobre las implicaciones sociales de un determinado proceso productivo, es decir, básicamente los trabajos realizados han sido dirigidos a la investigación de la secuencia de actos necesarios para la obtención de un resultado premeditado. En este sentido, ha sido creado el concepto de cadena operativa o conjunto de operaciones llevadas a cabo con el fin de transformar la materia prima en producto. Las líneas de investigación desarrollas desde esta concepción se han basado en la experimentación arqueológica, el remontaje y la antropología comparada (AFONSO 1993; MARTÍNEZ y AFONSO 1994). 
En ningún caso estas investigaciones han aportado resultados sobre las condiciones sociales de la producción que en última instancia determinan, tal y como ya hemos indicado, el propio proceso laboral, con lo cual las posibilidades de caracterizar las relaciones sociales de producción y reproducción, así como los conflictos derivados de la propia estructura social, son nulas.

En esta línea estaríamos de acuerdo con la redefinición del concepto de técnica en el sentido de que se pueden distinguir dos aspectos, por una parte, la técnica estaría en relación con el conocimiento adquirido por la práctica y transmitido en el marco de las relaciones sociales de producción y reproducción, y por otro, con la secuencia de transformación de la materia, en definitiva con el proceso laboral. En el caso del proceso de producción lítica la secuencia de transformación implica siempre el recurso a toda una serie de estrategias reductivas que poseen dos limitaciones, por un lado, la mecánica de fractura de la materia prima, y por otro, las necesidades socioeconómicas de la comunidad (MARTÍNEZ y AFONSO 1994).

Entendemos la producción lítica como la articulación de procesos sucesivos y/o paralelos y/o acumulativos, implicados en la transformación de la materia prima en productos y articulados como una red estructurada con mutuas interrelaciones, condicionadas tanto por las características fisicas de la materia como por las necesidades socioeconómicas de las formaciones sociales. Estos procesos comprenderían a los sistemas de aprovisionamiento de la materia prima, los procesos técnicos de manufactura, mantenimiento y reciclado, y procesos de uso culminando con el abandono (Martínez y Afonso 1995:14).

Estos procesos están compuestos por un conjunto de etapas y actividades, se entiende por etapa cada uno de los estados en que puede encontrarse la materia prima en el transcurso de la secuencia y por actividad, cada uno de los procesos técnicos necesarios para transformar la materia prima de un estado a otro (Martínez y Afonso 1995:16). Así etapas y actividades se articulan de la siguiente forma (Fig. 1):

I etapa (materia prima)

$I^{e r}$ conjunto de actividades (modificación primaria) 
II etapa (soporte, núcleo)

$2^{a}$ conjunto de actividades (modificación secundaria) $o$

$3^{\text {er }}$ conjunto de actividades (uso)

III etapa (implemento)

$3^{\text {er }}$ conjunto de actividades (uso)

IV etapa (útil embotado)

$4^{o}$ conjunto de actividades (desecho, depósito, abandono, pérdida) o

$5^{\circ}$ conjunto de actividades (mantenimiento)

III etapa (útil reavivado)

$3^{\text {er }}$ conjunto de actividades (uso)

$4^{\circ}$ conjunto de actividades (desecho, depósito, abandono, pérdida)

$6^{\circ}$ conjunto de actividades (reciclado) iniciación de un nuevo proceso a partir de las etapas

I, II o III y las diferentes etapas implicadas.

Pasamos ahora a resumir algunas de las principales aportaciones que sobre estos temas se han realizado recientemente.

Durante mucho tiempo, el estudio de las materias primas líticas ha sido considerado como un elemento anecdótico en el que se ha primado la descripción de las misma o del proceso de obtención más que su significado dentro de un marco socioeconómico determinado (Terradas 1996:2).

Sin embargo, el concepto de materia prima no responde a una condición natural (Andrefsky 1994:386a), sino que está determinado por su reconocimiento social y por su integración en el proceso productivo global de una sociedad, convirtiéndose en un elemento más dentro de las fuerzas productivas. Su valoración como tal materia prima por parte de una sociedad se relaciona con el conocimiento que esa sociedad posee sobre las condiciones naturales objetivas del medio ambiente en el que operan y de sus recursos minerales, con la 
capacidad tecnológica que posea esa sociedad para explotar las materias primas (Andrefsky 1994:21b) y con el grado de importancia social que tendrán los diversos objetos producidos por esas materias primas, siendo esta última premisa la condición más esencial (Terradas 1996:130-131).

La obtención de materias primas, junto con la transformación de estas en instrumentos líticos, constituyen los procesos de trabajo que configuran el proceso de producción lítica (Martínez y Afonso 1995:14); este proceso productivo tiene como finalidad la manufactura de útiles líticos, en función de los cuales una comunidad organiza diferentes estrategias de acuerdo con lo que necesita en cada momento para asegurar su mantenimiento y reproducción y con lo que está en disposición de obtener y/o producir (Terradas 1996:8).

Por tanto, entendemos por estrategias de obtención, los procesos que las distintas sociedades ponen a punto para abastecerse de las materias primas necesarias para la producción de sus útiles de trabajo, bienes de consumo y demás medios de subsistencia; distinguimos dos formas básicas:

1. -el acceso directo, mediante el que se explotan directamente los recursos minerales de un territorio por parte de una población. En este caso es imprescindible no sólo el conocimiento de su existencia, sino también la valoración de las posibilidades de explotación teniendo en cuenta la cantidad de materia prima, la capacidad de esta para poder ser transformada en útiles o su dificultad de extracción. (Terradas 1996:133).

2. -acceso indirecto, cuyo mecanismo más frecuente es el intercambio (con sus diferentes modalidades), por el que las materias primas se obtienen mediante los contactos con otras poblaciones

Independientemente, y ante la dificultad que representa documentar a través del registro arqueológico estos procesos, nosotros identificamos dos estrategias de obtención, son dos comportamientos que podemos aislar y que responden a situaciones diferentes. Están definidas 
desde un punto de vista técnico y a efectos del análisis arqueológico son más interesantes y directas (el aprovisionamiento y el suministro) (Martínez y otros, e. p.).

- La primera (aprovisionamiento) comprendería aquel conjunto de estrategias según las cuales la modificación primaria, la secundaria y el uso se producen en el mismo lugar.

La segunda (suministro), incluiría aquellas en las que la modificación primaria se realiza en un lugar diferente de la secundaria y el uso.

A primera vista, esta clasificación de las estrategias de obtención de materias primas puede confundirse con la distinción entre acceso directo e intercambio, pero hay que tener en cuenta que en la que proponemos no se toma en consideración la intervención o no de terceros en el proceso de obtención de materias primas; las estrategias, son deducidas del registro arqueológico y la determinación de la existencia de una u otra dependerá exclusivamente de los datos contenidos en el mismo, es decir, que es la estructura y organización de los conjuntos líticos recuperados la que nos permitirá caracterizar la producción lítica como de un tipo u otro (Beck y Jones 1990:284; Martínez y otros, e.p.).

La modificación primaria está formada por un conjunto de procesos que tienden a la obtención de soportes técnicos idóneos parala realización de los útiles. Estos procesos pueden intergrarse en dos fases, la fase de preparación y la fase de explotación (García Barba y otros, e.p.) (Fig.2).

La fase de preparación comienza con actuaciones sobre la materia prima, denominada acondicionamiento inicial, como la fracturación del soporte natural y/o el descortazado. Los productos así obtenidos pueden derivarse hacia la modificación secundaria o el uso, o iniciar la fase de preparación propiamente dicha, si se desea obtener productos con características especiales como, por ejemplo, las hojas prismáticas. En algunas ocasiones los productos/soportes de núcleo han de tratarse térmicamente dependiendo de la técnica de talla aplicada (García Barba y otros, e.p.). 
En la fase de preparación se pretende dar a los productos obtenidos en el acondicionamiento inicial la morfología idónea que garantice el máximo control sobre la producción en la fase de explotación, para lo que se articulan varios procesos tendentes a definir el futuro plano de percusión y el futuro frente de extracción. La definición de plano consiste en la elección de una superficie natural, o de un negativo, que posea las características necesarias para el desarrollo de la explotación, o bien su creación por medio de uno o más levantamientos.

La definición de frente supone la demarcación de un área a la que se van a restringir las extracciones, con el fin de limitar la posibilidad de que se produzcan errores en el transcurso de las mismas, esto se consigue mediante uno o varios levantamientos que limitan la anchura del futuro frente (preparación lateral). La preparación do fondo, que puede ser opcional, tiene como resultado la predeterminación de la longitud máxima de las hojas y, al mismo tiempo, persigue garantizar la morfología prismática de los soportes al eliminar la materia prima sobrante que podría provocar o el reflejado o el sobrepasado de las extracciones. El proceso se completa con la elección de una arista que sirva de guía en la primera extracción o su creación por medio de levantamientos sin dirección preferente o mediante una preparación (unifacial o bifacial) por talla y/o retoque, siendo la primera extracción una hoja de cresta Ambos conjuntos de procedimientos técnicos están estrechamente relacionados, sucediándose uno a otro sin prioridad de inicio en ninguno de ellos (García Barba y otros, e.p.).

El resultado de la combinación de todos o de algunos de estos procesos es la configuración de un prenúcleo. Del correcto desarrollo de esta fase depende que el prenúcleo pase a ser explotado o que, por el contrario, sea desechado o reciclado para otros uso (García Barba y otros, e.p.).

Posteriormente, en la fase de explotación del núcleo se obtendrían una serie de productos que son usados directamente o utilizados como soportes de otros útiles. Este proceso se denomina extracción y en él pueden emplearse diversas técnicas. En el desarrollo de dicho proceso la articulación ortogonal de frente y plano, así como la definición de frente, pueden modificarse si la continuación de la talla no resulta posible o el control sobre los 
productos que se quieren obtener se redujera por debajo del umbral considerado aceptable. Llegados a este punto se abren varias posibilidades: el mantenimiento del núcleo, el reciclado o el desecho (García Barba y otros, e.p.).

Por otra parte, la modificación secundaria comprende la transformación de un producto o conjunto de productos en implementos mediante el retocado, es decir, la talla por percusión o presión de sus filos y/o de sus superficies, y/o mediante la fracturación, es decir, la eliminación por fractura técnica de las partes que dificultan el uso o el acondicionamiento para el mismo (Martínez y Afonso 1995:19).

El siguiente grupo de actividades está representado por el retocado de los filos y/o de las superficies de los útiles que a fuerza de ser usados han perdido se efectividad funcional (mantenimiento) o que han sido recuperados de contextos de desecho, pérdida o abandono (reciclado), produciendose su reentrada en el contexto sistémico, bien a través de un nuevo uso, o bien mediante su empleo como soporte para nucleo u otro implemento (Martínez y Afonso 1995:19).

Por otra parte, el producto en su contexto socioeconómico participa en una serie de relaciones que se definen a través de una superficie, de un espacio, concretamente hacemos referencia a la problemática de la estructura arqueológica y por extensión de la unidades espaciales de análisis. La práctica de las relaciones de producción en tanto que proceso de trabajo y, en consecuencia, de desarrollo de una actividad que articula la relación hombre/naturaleza en la realización de una proceso de transformación de una determinada materia, implica la deposición de una serie de elementos (medios de trabajo, útiles, deshechos...) cuya disposición en el registro arqueológico nos permite reconstruir el proceso en sentido inverso ${ }^{12}$, con lo cual podemos aislar aéreas de producción, de consumo, de

\footnotetext{
${ }^{12}$ Evidentemente las posibilidades de análisis contextual de una determinada actividad van a estar en relación directa con las características deposicionales y postdeposicionales de la fenomenología arqueológica, en este sentido, la excavación de un yacimiento puede ofrecer una gradación amplia de hallazgos contextualizados, desde aquellos que serían el resultado de un abandono precipitado hasta el lento proceso de destrucción de un sitio tras una marcha planificada, con la consiguiente selección de lo transportable. Por otra parte, el proceso de destrucción de un yacimiento puede haber modificado la deposición de los artefactos desde el momento de abandono. Desde esta perspectiva, es necesario distinguir entre la situación exacta del objeto en la coyuntura de abandono y su
} 
descanso, de intercambio, rituales... Desde esta perspectiva entendemos que las áreas de actividad o unidades espaciales menores en donde se desarrollan actividades específicas constituyen el primer paso para el análisis del producto, por cuanto delimita la constatación real de su valor de uso (RUIZ et al. 1986b).

En relación con el concepto de estructura arqueológica entendemos interesante retomar la posición planteada desde la arqueología funcionalista. En este sentido, compartimos que el registro arqueológico presenta una distribución y asociación no aleatoria de los diversos elementos que contiene. De la articulación en el espacio de tareas específicas desarrolladas por segmentos sociales resulta un conjunto estructurado de relaciones espacio-formales. La gente no coopera exactamente en la misma manera cuando realiza tareas distintas. En este sentido, tareas diferentes no son realizadas uniformemente en los mismos espacios, y así como varían los grupos de cooperación, varían los útiles e instalaciones necesarios para la realización de estas tareas. La pérdida, ruptura y abandono de instrumentos y estructuras en diferentes lugares, donde grupos de estructura variable realizaron tareas diferentes, deja un registro fósil de la operación real de una sociedad extinta (BINFORD 1964:136).

Evidentemente este concepto de estructura arqueológica que entendemos como válido quedaría inscrito dentro de la concepción teórica anteriomente expuesta, en donde la estructura arqueológica es entendida como el resultado de los procesos de producción y reproducción social.

Desde esta perspectiva teórica hemos abordado el estudio de la industria lítica recuperada en la última campaña de excavaciones realizada en el poblado de Los Castillejos de las Peñas de los Gitanos (Montefrío, Granada) (RAMOS et al. 1994; AFONSO et al. 1995), para ello hemos elegido dentro de los diferentes periodos culturales analizados varias fases de ocupación cuya relación entre la coyuntura de deposición, es decir, entre el proceso social que

posición en la coyuntura del hallazgo, que ha podido variar en función de los procesos de alteración causados por agentes físicos y/o humanos (RUIZ et al. 1986), en esta misma línea recientemente han sido propuestas las categorías de análisis de unidad de origen, es decir, el patrón conductual que ha generado un determinado contexto, y la unidad de procedencia o patrón deposicional que explicaría una determinada articulación de los materiales arqueológicos (MARTíNEZ y AFONSO 1994). 
ha generado un determinado patrón deposicional, y las características del depósito arqueológico en el momento de su excavación, haya variado lo mínimo posible.

A partir de esta elección hemos desarrollado un análisis contextual de la producción lítica documentada, al objeto de caracterizar los contextos etnográficos y, por extensión, las relaciones sociales de producción y reproducción tanto de un momento cultural concreto como de su evolución en el tiempo. 
III. LA DIMENSIÓN CONTEXTUAL DEL REGISTRO ARQUEOLÓGICO 


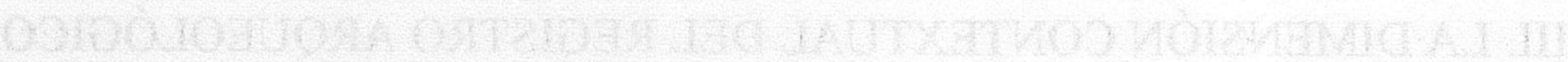


La investigación arqueológica ha pasado, como hemos analizado, por diversos cambios a medida que se ha desarrollado la teoría arqueológica, pero se ha centrado fundamentalmente en el análisis tecnotipológico de los artefactos independientemente del material en que estaban realizados; así, las tipologías de cerámica o piedra tallada han sido, en múltiples ocasiones, la finalidad de las investigaciones arqueológicas.

El análisis de los depósitos arqueológicos empezó a ser crucial cuando la orientación ecológica comenzó a eclipsar la interpretación de la historia cultural, esta nueva perspectiva se centró en la reconstrucción del paisaje, la fauna y la flora lo que requería una nueva conciencia de las asociaciones contextuales de las partículas sedimentarias dentro de los yacimientos. Los arqueólogos empezaron a considerar entonces el contexto arqueológico como un fenómeno contemporáneo con una complicada historia (Stein 1987:338). El paso de un interés por el aspecto estratigráfico o diacrónico de los yacimientos a otro de carácter horizontal o sincrónico, abrió las puertas para una nueva perspectiva de los análisis del registro arqueológico (Carbonell et al. 1986).

Precisamente han sido los Binford quien ha destacado una de las principales características del los contextos arqueológicos, concretamente, la actualidad de los datos arqueológicos (Binford, 1988:108). El dato empírico del que el arqueólogo dispone para su observación es necesariamente contemporáneo al observador, de otro modo sería imposible establecer una relación de conocimiento.

El registro arqueológico es contemporáneo; existe en la actualidady cualquier observación que realice a cerca de él es una observación del presente (BINFORD, 1988: 108).

A la hora de caracterizar el concepto de contexto arqueológico, entendido como unidad de análisis básica, hay que considerar, por tanto, las relaciones que hay entre el dato arqueológico actual que obtiene el investigador y las características de dichos datos culturales en su contexto social original, es decir, como manifestaciones de una sociedad viva. 
Cuando los objetos y transformaciones materiales que generó una sociedad determinada dejan de pertenecer a ella como sistema, dichos efectos materiales de la actividad humana pasan a participar de nuevas y complejas interacciones causales. La posibilidad de considerar el dato cultural como información empírica que permita realizar inferencias sobre la historia de la sociedad en estudio está condicionada por el conocimiento de la cadena de causalidades en que participó originalmente la acción del hombre como creador de cultura y dichos datos transformados en lo que conocemos como contexto arqueológico (Bate 1982:18).

Por tanto tan sólo explicando la conexión existente entre el dato arqueológico actual y las sociedades que estudiamos es posible validar la inferencias a cerca de la historia que se pretende explicar a partir de la información empírica (Bate 1998:107).

Diversos autores ha señalado la necesidad de conocer las relaciones entre los datos actuales y la historia de las sociedades del pasado. No obstante, el principal problema viene definido por la conceptualización del registro arqueológico como estático.

"Este es el problema básico y fundamental, no exclusivo del periodo musteriense, sino endémico de la arqueología: ¿Cómo podemos realizar inferencias dinámicas a partir de datos estáticos? (...) Pero sin embargo, lo que nos interesa como arqueólogos es el pasado. Todo ello me sugiere que los arqueólogos nos encontramos entre los seres más optimistas del mundo. Excepto en el caso de que conozcamos las articulaciones necesarias y determinantes que se dan entre causas dinámicas y consecuencias estáticas, ¿cómo podemos justificar una inferencia realizada de unas a otras? El aspecto dinámico del pasado hace tiempo que desapareció" (Binford 1988:108).

Es evidente que el aspecto dinámico desapareció y tan sólo poseemos el contexto arqueológico como objeto de observación. No obstante, esto no significa que los contextos arqueológicos sean estáticos. Simplemente los elementos que componen esos contextos se han incorporado a una nueva dinámica que necesariamente hay que conocer y explicar, ya que sólo de esta forma podemos conocer las características del conjunto de actividades desarrollas por las sociedades que estudiamos. 
Calificar de estáticos a los contextos arqueológicos supone considerar la teoría de las transformaciones de los contextos arqueológicos como carente de importancia (Bate 1998:108).

La posibilidad de conocer la historia de los contextos arqueológicos se funda en algunas premisas. La primera sería la existencia de diferencias y relaciones objetivas entre la evidencia arqueológica que poseemos y las sociedades del pasado que investigamos, las relaciones vendrían marcadas por el conjunto de conexiones causales que se dieron necesariamente, mientras que las diferencias procederían de la influencia de los factores de formación y transformación del registro arqueológico. En segundo lugar, hay que tener en cuenta que existe una correspondencia determinada entre el contexto arqueológico y las actividades de la sociedad que lo generó, teniendo en cuenta las particularidades de cada sociedad y la combinación de los factores causales de la transformación de los contextos (Bate 1998:107-108).

Veamos a continuación algunos intentos de definición de la categoría de análisis contexto arqueológico.

Uno de los autores básicos a la hora de analizar los procesos de formación del registro arqueológico ha sido Schiffer, quien ha desarrollado una importante labor investigadora que ha desembocado en una corriente teórico-metodológica conocida como arqueología conductual. El objetivo de esta nueva tendencia nacida en los años 70 es definido como sigue: "Consideramos que la arqueología consiste principalmente en las actividades de investigación sobre las relaciones entre la conducta humana y los artefactos, en todo lugar y en toda época" (Schiffer 1991:32).

El principio básico del que parte Schiffer es el de que todos los contextos están sujetos a cambios. Establece una distinción contexto sistémico y contexto arqueológico (Schiffer 1972, 1987:4).

El contexto sistémico definido por Schiffer $(1972,1987: 4)$, también denominado contexto conductual (Carr 1984:114) o contexto momento (Bate 1998:109) se refiere a la condición de un elemento que está participando en un sistema conductual, mientras que el contexto arqueológico 
describe el material que ha pasado a través de un sistema cultural y que ahora es objeto de investigación para los arqueólogos.

El contexto sistémico o contexto-momento viene definido por la actividad humana. Por tanto, su naturaleza se caracteriza por la organización espacio-temporal de sus componentes, siendo el comportamiento social el principal factor causal de su movimiento.

En cada contexto-momento se pueden distinguir dos aspectos: por una parte la forma cultural de las actividades y componentes involucrados, y por otra, su contenido social referido a los tipos de actividades y funcionalidad de sus elementos (Bate 1998:109). El objetivo de la teoría estrictamente arqueológica sería definir los contextos sistémicos a partir de los contextos arqueológicos.

Así, la estructura actual del contexto arqueológico es un reflejo distorsionado del sistema conductual pasado, que resulta de la operación a lo largo del tiempo de procesos culturales y naturales. Al desligarse de la actividad humana los diferentes elementos que forman parte de un determinado contexto sistémico, la conducta social deja de ser un factor causal en del movimiento de sus componentes originando lo que ha sido definido como contexto arqueológico. Aunque, en el momento de su formación las relaciones espaciales que guardan los componentes de un determinado contexto arqueológico son efecto, principalmente, de las actividades humanas que los generaron.

El contexto arqueológico vendría, por tanto, definido por los restos materiales que pueden ser observadas directamente en el presente desligados de la actividad humana que los produjo. Estaría compuesto por dos entidades: los conjuntos deposicionales y las áreas deposicionales; los primeros serían el correspondiente contemporáneo de los conjuntos de actividades, y las áreas deposicionales serían aquellas donde aparecen reunidos los componentes de los conjuntos deposicionales (Carr 1984:114).

Es el contexto arqueológico el que nos da el cuerpo necesario para inferir el contexto sistémico mediante dos aspectos observables: las propiedades de sus componentes y la 
distribución espacial de los mismos, es decir, el estudio de las áreas y los conjuntos deposicionales nos dotará de elementos para comprender los conjuntos y las áreas de actividad del pasado.

La distinción entre los conjuntos de actividad y conjuntos deposicionales y áreas de actividad y áreas deposicionales es necesaria debido a que aunque pudieran parecer fenómenos análogos en los contextos sistémico y arqueológico, en realidad pueden diferenciarse tanto internamente, en sus componentes y su organización, como externamente, en las relaciones con entidades de la misma o diferente clase y en su significado conductual. Esta diferenciación viene provocada, como veremos, por los diferentes procesos deposicionales y postdeposicionales, que no sólo transformarán los materiales cuantitativamente, sino que también tendrán un efecto de transformación espacial.

Bajo esta nueva perspectiva los componentes materiales de un determinado contexto arqueológico deben ser contemplados, en primer lugar, como puntos materiales que son producto de unos determinados fenómenos deposicionales y posteriormente como partículas sedimentarias que se van a ver sometidas a los distintos procesos postdeposicionales. Los eventos deposicionales nos interesan ya que corresponden a una conducta propia del sistema cultural desaparecido. Mientras que los postdeposicionales son fundamentales a la hora de conocer y reconocer las transformaciones que puede sufrir el registro arqueológico durante el enorme periodo de tiempo que va desde su deposición hasta su redescubrimiento (Ramos 1986:83).

Los contextos arqueológicos presentan diversas propiedades entre las que podemos destacar:

a) La composición, es decir la organización espacial de los componentes de un determinado contexto. En segundo lugar, la composición implica considerar las propiedades de los componentes que permiten definir su funcionalidad. Esto es lo que permite la identificación de áreas de actividad (Bate 1998:126). 
b) La amplitud, supone el espacio continuo en donde se documentan evidencias arqueológicas. Sus límites son establecidos por el investigador como unidad de análisis (Bate 1998:126).

c) La densidad, implica la diversidad o reiteración de actividades realizadas en la amplitud de un contexto (Bate 1998:126).

En el ámbito conductual, los dos últimos conceptos nos llevan a considerar que los conjuntos de actividad pueden ser monotéticos, si se efectúa una sola actividad o varias actividades en las que se use el mismo tipo de componentes o politéticos, si se realizan varias actividades en las que no predomina ningún componente. Igualmente varias áreas de actividad podrán ser superpuestas o no superpuestas en cuanto a su disposición física, (Carr 1984:120) ya sea por que se han realizado simultánea o sucesivamente. En la mayoría de las ocasiones las áreas de actividad tienden a ser politéticas y superpuestas.

Pretendemos analizar los contextos arqueológicos pertenecientes a las diferentes fases de ocupación neolíticas identificadas en el poblado de Los Castillejos de las Peñas de los Gitanos (Montefrío, Granada) a través de los dos aspectos fundamentales que forma el contexto arqueológico: las propiedades de sus componentes y la distribución espacial relativa de los mismos.

El objetivo sería a través del análisis de estos dos elementos descubrir la existencia de patrones de distribución y asociación relacionados con actividades o palinseptos mediante las recurrencias en cada una de las áreas. Analizando, igualmente, los posibles procesos de formación y transformación que han conducido a un determinado registro arqueológico actual aunque este no es el objetivo principal de la presente tesis doctoral. 
IV. PROCESOS DE TRANSFORMACIÓN DEL REGISTRO ARQUEOLÓGICO 
(2)

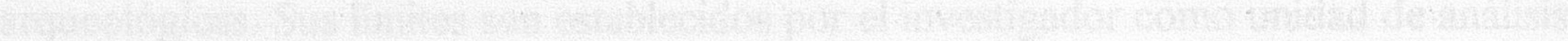

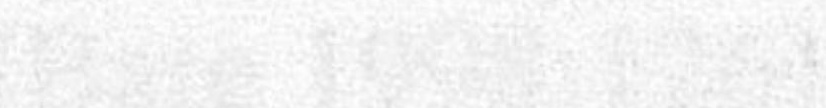

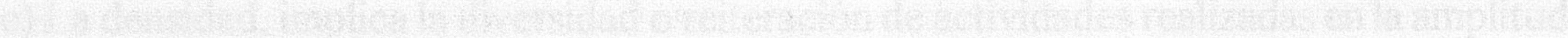

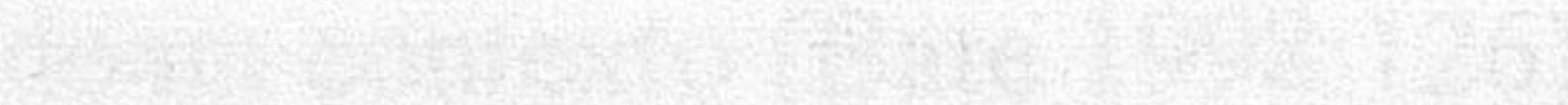

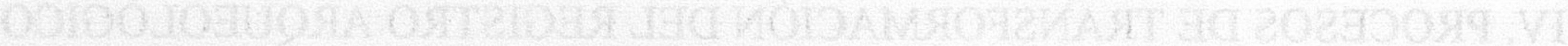

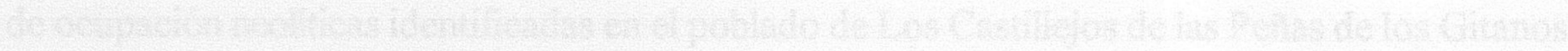

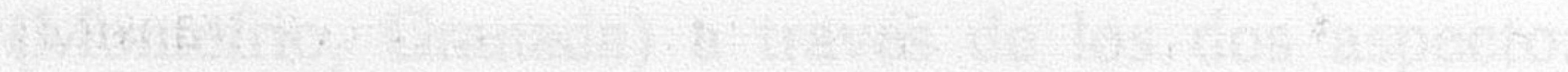

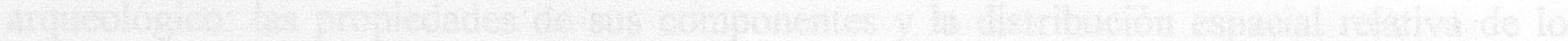
(20)

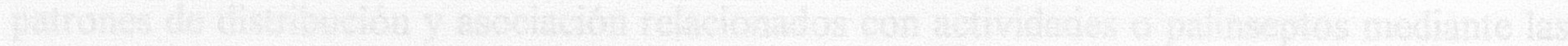

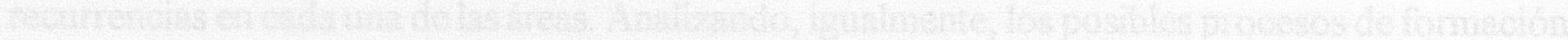

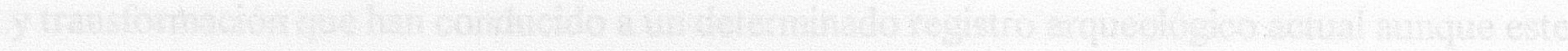

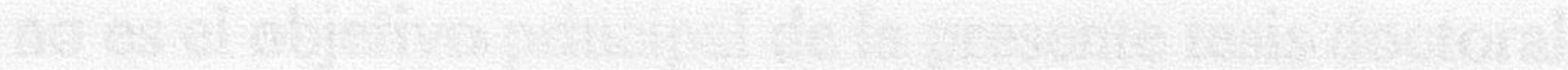


Como ya hemos visto, uno de los primeros ejercicios que debemos realizar es distinguir las entidades del pasado de las del presente arqueológico (Carr 1984:114), la idea de la relación entre los materiales arqueológicos depositados y la actividad del hombre que en principio se creyó unívoca, (Zjaruk 1976:4-5, cit. en Bate 1992:52, ) se ha ido transformando con el tiempo y con el conocimiento de una serie de fenómenos etiquetados como procesos de formación (y transformación añadiríamos nosotros) del registro arqueológico (Adanez 1986:9) ya que, tan importantes como los propios items son las relaciones entre ellos y con las estructuras en las que quedan situados (Adanez,1986:14). Por tanto, para inferir la conducta humana en el pasado, debemos comprender los procesos que los han influido creando un contexto arqueológico determinado (Schiffer 1991:39).

Una de las premisas fundamentales que debemos considerar es que los contextos arqueológicos y los materiales que lo componen no son estáticos, como se ha reiterado en diversas ocasiones (Binford 1988:108), si no que, al desligarse de la actividad humana, adquieren una nueva dinámica sufriendo transformaciones que alteran algunas de sus propiedades (Bate 1992:52).

La progresión de los procesos que son los responsables de la formación y transformación del registro arqueológico podrían alinearse en varios pasos:

- El primero lo constituirían los procesos sistémicos de organización de la vida, la movilidad, el programa de trabajo, la tecnología y la subsistencia y otras acciones que afectan al emplazamiento de las actividades humanas.

- Los eventos de agregación de los materiales naturales, su modificación y su desecho, pérdida o abandono que estructuran las consecuencias de las actividades creando el registro arqueológico.

- La interacción de sucesos conductuales y deposicionales separados por el tiempo, que resultan de la superposición de múltiples eventos de desecho dentro de unidades deposicionales únicas. 
- Los procesos postdeposicionales naturales y culturales que afectan a la preservación, la integridad y visibilidad del registro arqueológico

- La metodología arqueológica, es decir la forma de descubrir, medir y analizar nuestros datos y las desviaciones que estos métodos introducen en nuestras interpretaciones de su significado (Ebert 1992:21).

Además de las actividades sociales que nos interesan definir es necesario considerar los procesos de formación que contribuyen a la variabilidad que se observa en el registro arqueológico. Los procesos de formación se definen como todos los eventos, actividades y procesos que afectan a los artefactos después de su uso inicial en un tipo particular de actividad , y estos procesos pueden ser tanto culturales como naturales (Schiffer, 1991:40).

La actividad humana es un sistema continuo de movimientos, organizados bajo las relaciones sociales, que al ir desplazándose sus agentes, ocupan distintos segmentos del espacio vivido de una sociedad; son habituales en la vida cotidiana los procesos de reintegración de elementos del contexto arqueológico de nuevo al contexto sistémico, lo que implica que no existe un momento deposicional único. Por tanto, no existe una demarcación única entre procesos deposicionales y postdeposicionales, sino que se integran en una secuencia e la que se intercalan sucesivamente ambos tipos de eventos (Bate 1992:64). 


\section{IV.1. Procesos deposicionales}

Los C-Transform o procesos de formación cultural permiten al investigador especificar de qué manera un sistema cultural da salida al material que eventualmente puede ser observado arqueológicamente.

\section{IV.1.1. La deposición cultural}

El primer tipo de proceso de formación cultural es el de la deposición cultural, cuando los materiales pasan del contexto sistémico al contexto arqueológico. Si sobre un objeto, que ya no pueda realizar la función para la que había sido creado, no se produce el reuso, normalmente pasa al registro arqueológico. Este proceso, que puede implicar varios pasos de almacenamiento y transporte se denomina rechazo.

Para los arqueólogos, la localización del rechazo dentro de un asentamiento es de gran importancia. Si los artefactos están abandonados en sus localizaciones de uso, al área se la denomina contexto de rechazo primario. Estos mismo artefactos situados en cualquier otra parte se denominan rechazo secundario. En muchas ocasiones se asume que los suelos de ocupación son contextos de rechazo primario cuando, en realidad, esto ocurre en muy escasas circunstancias (Schiffer 1987:59).

Es claro que lo que guía al acto del desecho es el deseo de depositar el rechazo fuera de las áreas de actividad usadas con frecuencia, de manera que no moleste en futuras tareas, ya que la acumulación de desechos de útiles podría molestar o impedir su realización, y de hacerlo con el menor esfuerzo posible (Hayden y Cannon 1983:119).

Mientras que algunos yacimientos como canteras, cazaderos...producen en su mayor parte áreas de rechazo primario, los asentamientos estables producen normalmente contextos de rechazo secundario en los que los más tardíos podrían ser relacionados con áreas de trabajo o cabañas. Una característica primordial de estos conjuntos de rechazo secundario es que están 
juntos ya que la gente tiende a depositar el desecho donde ya se ha hecho previamente. Sin embargo, los útiles y esquirlas más pequeñas podrán permanecer en el rechazo primario dependiendo de la naturaleza del área de actividad, de su uso y de los patrones de mantenimiento, un esfuerzo que dependería de la cantidad de rechazo generada por una actividad, de la variedad de actividades realizadas o de la frecuencia en la que se realizan las actividades (Schiffer 1987:6065).

Por tanto, para la conducta que conlleva la deposición definitiva del rechazo podemos plantear unas hipótesis iniciales (Hayden y Cannon1983:119)

- Diferentes tipos de rechazo deberían ser tratados de diferente forma de acuerdo a su relativa utilidad o potencial de estorbo

- La disposición del rechazo en un determinado lugar debería estar afectada por el número, tipo, extensión e intensidad de las actividades que se realizan en ese lugar

- El tamaño del lugar de rechazo deberá ser un factor importante para determinar el nivel de estorbo creado por una acumulación de rechazos.

- La proximidad de los basureros, ya sean naturales o culturales, sería un factor principal en las decisiones que conciernen al lugar donde el rechazo se deposita fuera de la zona de residencia.

Sin embargo, como ya hemos indicado, esta deposición puede implicar transporte y varios pasos en la secuencia de deposición. Cada una de estas circunstancias dará lugar a distintos y reconocibles cambios en la frecuencia, diversidad de tipos y patrones espaciales.

El estado de preabandono en términos conductuales, implica el uso y deposición de materiales dentro del contexto sistémico. La deposición puede ser intencionada o no y es probable que muchos de esos materiales vuelven al uso mientras dura el almacenamiento. Puede estar afectada por el ciclo de utilización de las estructuras e incluye: 
Espacios de producción y uso de los útiles de piedra tallada del Neolítico

- rechazo provisional: es el almacenamiento intencionado de items dañados o fragmentados para su futura deposición o reuso, durante esta fase transitoria, el rechazo puede ser transformado por la actuación de varios procesos que incluyen, roturas accidentales, inclemencias de tiempo, el comportamiento de los niños jugando, los efectos de las actividades de los animales... estos factores a menudo influyen en el desplazamiento y conservación de los items. Suelen depositarse dentro de las casas o en las zonas exteriores cercanas a las mismas (Hayden y Cannon 1983:131-132)

- rechazo por mantenimiento: se produce por la limpieza de estructuras y refleja la intención de mantener activas y en disposición de trabajar las áreas de actividad.

- la pérdida: es la inesperada disociación de un objeto de su dueño o usuario. Posee dos componentes independientes, la probabilidad de que un artefacto se pierda y la probabilidad de que el objeto no sea encontrado por su dueño. Las principales variables que pueden influir en la pérdida de un objeto son: el tamaño del artefacto, la naturaleza del sustrato donde es usado, las propiedades formales del artefacto o el esfueszo empleado en buscarlo (Schiffer 1987:76-77).

Podríamos considerar por tanto, que muchos de los artefactos que forman parte del conjunto deposicional de un yacimiento arqueológico representarían este estadio de desecho provisional en el contexto sistémico. Esto debe ser tenido en cuenta para no interpretar automáticamente ese patrón espacial en términos de áreas de actividad sino como representantes primarios de espacios muertos entre las estructuras (Hayden y Cannon 1983:159)

El abandono es el proceso mediante el cual un lugar, un área de actividad, una estructura o un asentamiento completo pasan al contexto arqueológico, puede ser gradual o rápido, este último es denominado rechazo de facto y se produce cuando los útiles, facilidades y estructuras son abandonados cuando todavía son aprovechables. La naturaleza del rechazo está relacionada el potencial de estorbo que representa, por el número tipo e intensidad de las actividades de las que formaban parte, con su capacidad para el transporte, con la distancia al área de actividad más cercana ocupada...(Hayden y Cannon 1983:120). 
Este mismo proceso puede observarse en las estructuras, durante la ocupación de una unidad doméstica dada hay un ciclo continuo de reutilización y renovación de las estructuras, las estructuras separadas pueden cambiar de función como nuevas estructuras o pueden retener su función original a través de toda o gran parte de la historia del yacimiento simplemente renovándolas o construyéndolas; este ciclo termina para cada estructura cuando se abandona completamente, se usa para deposición del rechazo, se desmantela para reciclar los materiales o se destruye para situar otros elementos.

La formación del contexto arqueológico tiene su germen en la deposición de los materiales en el contexto sistémico, que da lugar a áreas diferenciadas:

Áreas de rechazo primario único: áreas en las que se realiza una sola actividad

Áreas de rechazo primario múltiple, áreas polifuncionales en las que se realiza más de una actividad.

- Áreas de rechazo secundario único. Varios conjuntos de actividad también pueden generar un sólo depósito de rechazo secundario. Esta situación se crea cuando todo el rechazo al que da salida una comunidad es arrojado y depositado en otra localización. Los subsistemas de movimiento de lo rechazado, almacenaje, transporte y desecho determinan una compleja asociación de artefactos que puede aparecer en el área de rechazo secundario.

- Áreas de rechazo secundario múltiple. Cuando varias áreas de actividad generan varios e independientes depósitos de rechazo secundario. La composición artefactual de las áreas de rechazo nos da información directa sobre los elementos de los conjuntos de actividad, es decir sobre las distintas actividades que se han podido realizar en un lugar, aunque no están situados en sus áreas de actividad originales (Schiffer 1976:67-69). 


\section{IV.1.2. Procesos de reclamación}

Los materiales, una vez depositados, no siempre permanecen en el registro arqueológico pueden volver al contexto sistémico mediante otra serie de procesos los denominados procesos de reclamación. En ocasiones los items pueden volver a entrar en el contexto sistémico, por ejemplo, si se reocupa un asentamiento abandonado. Igualmente todos los procesos de preabandono mencionados anteriormente, entrarían en esta categoría si se prolongara su estado durante largos periodos de tiempo.

\section{IV.1.3. El reuso}

La forma en que las distintas sociedades retienen los artefactos en el contexto sistémico a través del reuso son muy diferentes y determina muchas de las características del registro arqueológico. Cuando un objeto se rompe, se gasta o por otra razones pierde sus funciones utilitarias o simbólicas, es probable que se produzca este fenómeno (Schiffer 1987:28).

El reuso puede ser definido por un cambio en el uso, en los usuarios o en la forma de un artefacto. Existen varias alternativas:

1. el ciclo lateral, que implica sólo un cambio en el usuario del artefacto; la transferencia de individuo a individuo y de unidad social a unidad social constituye un ciclo lateral siempre que la forma y el uso del artefcato no se hayan alterado. En las bandas de cazadoresrecolectores, donde los derechos de propiedad individual están muy a menudo ausentes, los artefactos cambian de mano constantemente. Este proceso, desde el punto de vista arqueológico, puede crear problemas de identificación, ya que no hay cambios en la dimensión formal que puedan ser atribuidos a un cambio de usuario, y sin embargo, es probable que altere la frecuencia, la relación y la dimensión espacial de los artefactos

2. el reciclado, Darnay y Frankin definen el reciclado como un proceso mediante el cual un material secundario es introducido como materia prima en el proceso industrial en el que se transforma en un nuevo producto, de manera que pierda su identidad anterior (Darnay 
y Frankin 1972:2), es decir, el retorno de un artefacto después de algún tiempo al proceso de manufactura.

3. el uso secundario, es una variante definida por Schiffer sobre el reciclado, y se produce cuando los objetos toman nuevos usos sin necesidad de extensas modificaciones, algunas veces, sin embargo, las huellas de uso, las roturas y fracturas motivadas por el mantenimiento alteran algo la forma del artefacto. La habilidad para inferir este tipo de reuso depende de la aparición de huellas de uso diferentes en su clase o emplazamiento a las producidas por su uso inicial. Si el uso secundario de un objeto es primordialmente simbólico, puede presentar huellas poco visibles e incluso no tenerlas; para obtener o inferir el uso secundario, se deben examinar otras dimensiones de variabilidad, la espacial y la relacional (Schiffer 1987:30).

\section{IV.1.4. La deposición no cultural}

Los procesos de formación no culturales pueden agruparse de acuerdo a la escala de sus efectos en tres grupos principales, deterioro de artefactos, alteración de sitios y procesos regionales. El deterioro incluye la interacción entre artefactos individuales y el medio ambiente (en contextos arqueológicos y sistémicos), algunos ejemplos comunes son la descomposición de materiales orgánicos y la corrosión de los metales. Los procesos de alteración de sitos van desde la actividad de las lombrices hasta la alteración producida por los ciclos congelacióndescongelación. Los procesos regionales tales como el crecimiento de la vegetación o los aluviones provocan en algunas ocasiones modificaciones drásticas que no solo alteran los yacimientos sino también nuestra capacidad para detestarlos (Schiffer, 1991:40).

A pesar de que los procesos de formación se combinan de manera compleja cada proceso opera conforme a leyes generales de la conducta humana o según procesos naturales. Debido a que la mayoría de los procesos de formación operan en la actualidad o pueden ser simulados es posible obtener nuevas leyes de procesos de formación mediante la experimentación o a través de la etnoarqueología (Schiffer, 1991:41). 


\section{IV.2 Procesos postdeposicionales}

Son los procesos que provocan la alteración de los componentes arqueológicos sin que estos entren en el contexto sistémico.

Butzer clasifica estos procesos según el grado de alteración con el que actúan sobre el yacimiento. Así distingue:

1.-Dispersión pre-sepultamiento de los restos materiales por la acción del agua en movimiento, la gravedad, la congelación, las pisadas animales, raíces de plantas, etc.

2.-Alteración post-deposicional por diversos agentes: animales (consumo y transporte de restos orgánicos, madrigueras), plantas, alteración bioquímica, congelación del suelo, dilatación y contracción de arcillas pueden igualmente desvirtuar la disposición original.

3.-Destrucción del yacimiento y dispersión de los restos materiales por diferentes fuerzas o agentes naturales (erosión, corrientes de agua, terremotos, lluvias, la acción de los cambios de temperatura).

Son los que Schiffer denomina N-Transform o los procesos de formación no cultural, causan cambios postdeposicionales en el yacimiento y en los artefactos mediante la acción de agentes no culturales. Estos procesos pueden ser exclusivos de los artefactos o afectar a todo el yacimiento determinan tanto la formación como la conservación del registro arqueológico e, igualmente, producen un registro de su propia operación consistente en los ecofactos que proporcionan evidencias para la reconstrucción paleoambiental (SCHIFFER 1976; 1988).

\section{IV.2.1. Pedoturbación}

La pedoturbación o mezcla de suelos, es la remoción de un suelo por causas biológicas, químicas y fisicas, creando alteraciones horizontales o provocando discontinuidades estratigráficas (Erlanoson y Rockwell 1987: 60), F. D. Hole (1961, cit. Wood y Johnson 1974:317) reconoció nueve procesos, de los que algunos, obviamente, son más comunes en ciertas regiones. 
1 Alteraciones por la fauna: las mezclas de suelo producidas por la fauna pueden ser de varios tipos: madrigueras de mamíferos (ratones, topos, conejos e incluso zorros) o alteraciones producidas por insectos tales como hormigas, terminas $\mathrm{u}$ otros animales pequeños como gusanos (Wood y Johnson 1974:318-327), en estos casos de animales pequeños, la intensidad de su acción no siempre va acompañada de la visibilidad del daño producido (Nash y Petraglia 1987:191).

2 Alteración por la vegetación o mezcla mecánica del suelo por las plantas en el transcurso del crecimiento de las raíces o el arrastre de tierra en la caida de un árbol (Wood y Johnson 1974:328).

3 Crioturbación: es la alteración por la acción del hielo-deshielo, los objetos pueden ser movidos por el peso del hielo o las grietas producidas en la roca por la contracción termal (Wood y Johnson 1974:333-342).

4 Graviturbación: esencialmente es la mezcla del suelo durante la degradación de la roca (Wood y Johnson 1974:346)

5 Deslizamiento del suelo: puede ser provocado por distintos fenómenos aparte del hielo, como la nieve (Savelle 1987: 30-31), la humedad, el agua (Schick 1987:86), la sequía, la erosión (Banessz et al. 1995) o la actividad biológica (Wood y Johnson 1974:349).

6 La subsidencia:es el desplazamiento hacia abajo de los materiales de superficie sin que se aprecie desplazamiento horizontal (Wood y Johnson 1974:352).

7 Argiliturbación: es la alteración producida por la contracción y expansión de las arcillas (Wood y Johnson 1974:354)

8 Aeroturbación: alteración producida por el gas del suelo o el viento (Wood y Johnson 1974:358) 
9 Alteración por terremotos, entre sus consecuencias están las grietas, normalmente acompañadas de remoción de tierra hacia arriba o hacia abajo y rellenadas con otros materiales (Wood y Johnson 1974:366).

\section{IV.2.2. Pisoteo}

Además, existen toda una serie de factores culturales que pueden afectar postdeposicionalmente a los yacimientos y a sus componentes, es lo que se denomina alteración cultural, el saqueo de sepulturas, las actividades de los excavadores, las labores agrícolas, construcciones, canalizaciones, o incluso la excavación selectiva distorsionan gravemente el estado original de sedimetación geoarqueológica (BUTZER 1989:95-96).

En el curso del desarrollo de las actividades, especialmente al andar, se alteran los artefactos previamente depositados sobre o cerca de la superficie del suelo produciendo un deterioro parecido al retoque o la fractura técnica. El efecto del pisoteo depende de la intensidad, de la naturaleza del sustrato y de las características de los materiales depositados siendo el sustrato el que juega un papel predominante ya que los artefactos pisoteados sobre un suelo más duro se dañan más (McBrearty y otros 1998: 122).

\section{IV.2.3 Arado}

Gran parte del registro arqueológico ha estado o es sometido en la actualidad a diversas formas de manipulación agrícola, entre las más utilizadas está el arado. Los arqueólogos conceden a este tipo de manipulación una acción bipolar, por un lado informa sobre el material que puede haber bajo la superficie, mientras que por otro altera el registro cambiando su forma tamaño y localización (Dunnell y Simek 1995:305). Sin embargo el énfasis desarrollado en el estudio de los procesos deposicionales y postdeposicionales y la consciencia de que la mayor parte del registro arqueológico en superficie ha estado sometido a una gran variedad de procesos naturales y culturales que trasladan los objetos tanto vertical como horizontalmente ha hecho que el estudio de las zonas aradas se realice con más confianza y una mayor garantía de éxito.

Su efecto depende del tamaño del artefacto, generalmente los objetos más grandes es más probable que se muevan hacia la superficie que los más pequeños y son además los que se 
desplazan más en horizontal (Schiffer 1987:131).

La primera indicación del transporte es el deterioro que exhiben algunas piezas, en la mayoría localizado en ambas caras, lo que es más consistente con el hecho de que su deterioro resulta del movimiento de corrientes que del pisoteo o de otros que puedan producirse "in situ" (Dibble y otros 1997:634-635).

\section{IV.2.4. Construcción y minería}

Las edificaciones tanto de las sociedades preindustriales como las actuales dejan su rastro en el contexto arqueológico, esto es un hecho comprobable en la arqueología urbana, la minería tiene efectos importante en los yacimientos arqueológicos (Schiffer 1987:133-134)

Aunque todos estos procesos mencionados se combinan de múltiples maneras, cada uno de ellos por separado actúa conforme a leyes generales de la conducta humana o según los procesos naturales y pueden ser identificados, proporcionando evidencias para inferir qué ocurrió. 
V.METODOLOGÍA 


\section{V.1. Metodología general para el análisis técnico y tipológico}

Para la realización del análisis técnico y tipológico de las industrias de piedra tallada hemos utilizado la tipología elaborada por G. Martínez Fernández (1985), posteriormente revisada por J. Afonso Marrero (1993) y la ficha para el análisis técnico de los productos de talla elaborada por este autor en su tesis doctoral. Para una descripción más exhaustiva de cada una de las categorías nos remitimos a las tesis doctorales de ambos autores.

\section{1) CLASIIFICACIÓN. MATERIA PRIMA}

CLAC Clase
PTSI Sílex
PTCZ Cuarzo
PTCC Cuarcita
PTVO Volcánica
PTJA Jaspe
PTCA Caliza

CORTS Corteza

S Presencia de corteza

2) TECNOLOGÍA

SOPOS Soporte

$\begin{array}{ll}\text { TB } & \text { Tabla } \\ \text { TT } & \text { Tableta } \\ \text { ND } & \text { Nódulo } \\ \text { GJ } & \text { Guijarro } \\ \text { PT } & \text { Producto de talla } \\ \text { IT } & \text { Indeterminable }\end{array}$

TSOPS Soporte técnico 
PC Percutor

NC Núcleo

LC Lasca

LCP Lasca de preparación

LCR Lasca de regularización

LCRT Tableta de avivado de plano de percusión/presión

LCRS Semitableta de avivado de plano de percusión/presión

HP Hoja prismática

HPR Hoja prismática de regularización

HPC Hoja de cresta

HPM Hoja de media cresta

HPT Hoja de tercio de cresta

HA Hoja de arista

HN Hoja no prismática

HNI Hoja no prismática de preparación

HNR Hoja no prismática de regularización

HB Hoja/hojita de golpe de buril

ID Producto de talla indeterminado

IT Indeterminable

ET Esquirla térmica

TTALS Talón

PU Puntiforme

LI Liso

DI Diedro

FA Facetado

ES Espolón

AF Ausente por fractura

EF Eliminado por fractura

ER Eliminado por retoque

NLEVS Número de levantamientos

NARIS Número de aristas

TECNS Técnica de talla 
L Técnica lascar

K Técnica kombeba

P Técnica de hojas prismáticas

H Técnica de hojas no prismáticas

TRETS Retoque

TREAS Reavivado

S Presencia de reavivado en los filos de una pieza

TRECS Retoque cualitativo

$1 \quad$ Alta modificación secundaria

2 Media modificación secundaria

3 Baja modificación secundaria

TFRAS Fractura técnica

PROX Fractura proximal

DIST Fractura distal

PRDI Fractura Proximal-distal

LATE Fractura lateral

LAPR Fractura lateral-proximal

LADI Fractura lateral-distal

LAPD Fractura lateral-proximal-distal

BILA Fractura bilateral

BIPD Fractura bilateral-proximal-distal

TECOS Grado de conservación del soporte técnico

$\begin{array}{ll}\text { COM } & \text { Completo } \\ \text { INC } & \text { Incompleto } \\ \text { IPR } & \text { Fragmento proximal } \\ \text { IME } & \text { Fragmento mesial } \\ \text { IDI } & \text { Fragmento distal } \\ \text { ILO } & \text { Fragmento longitudinal } \\ \text { IPM } & \text { Fragmento proximal-mesial } \\ \text { IMD } & \text { Fragmento mesial-distal } \\ \text { ILP } & \text { Fragmento longitudinal-proximal } \\ \text { ILM } & \text { Fragmento longitudinal-mesial } \\ \text { ILD } & \text { Fragmento longitudinal-distal }\end{array}$


LTECS Longitud del soporte técnico

ATECS Anchura del soporte técnico

GTEMS Grosor máximo del soporte técnico

GTEBS Grosor del bulbo de percusión

GTEZS Grosor en mitad del soporte técnico

4) TIPOLOGÍA

TIPOC Tipología

Grupo tipológico 1. Lascas o fragmentos con retoque de uso y/o retoque continuo

1A Lasca o fragmento con retoque de uso

1 A1 L./f. con retoque de uso en el filo izquierdo

$1 \mathrm{~A} 2$ L./f. con retoque de uso en el filo izquierdo y en el extremo distal

1A3 L./f. con retoque de uso en el filo izquierdo, en el extremo distal y en el filo derecho

1A4 L./f. con retoque de uso en el filo izquierdo, en el extremo distal y en el filo derecho y extremo proximal

1 A5 L./f. con retoque de uso en el filo izquierdo y en el filo derecho

1 A6 L./f. con retoque de uso en el filo izquierdo, en el filo derecho y en el extremo proximal

1 A7 L./f. con retoque de uso en el filo izquierdo y en el extremo proximal

1 A8 L./f. con retoque de uso en el extremo distal

1 A9 L./f. con retoque de uso en el filo derecho y en el extremo distal

1 A10 L./f. con retoque de uso en el filo derecho, en el extremo distal y en el extremo proximal

1 A11 L./f. con retoque de uso en el extremo distal y en el extremo proximal

$1 \mathrm{~A} 12 \mathrm{~L}$./f. con retoque de uso en el filo derecho

1 A13 L./f. con retoque de uso en el filo derecho y extremo proximal

1 A14 L./f. con retoque de uso en el extremo proximal

1 A15 L./f. con retoque de uso en el filo transversal

1 A16 L./f. con retoque de uso en filos inorientables

1 A17 L./f. con retoque de uso en filo transversal y filo(s) inorientables

1B Lasca o fragmento con retoque continuo

1B1 L./f. con retoque simple

1B2 L./f. con retoque abrupto 
$1 B 3$ L./f. con retoque plano

$1 B 4$ L./f. con retoque sobreelevado

$1 B 5$ L./f. con retoque astillado

1 B6 L./f. con dos o más modos de retoque

Grupo tipológico 2. Hojas o fragmentos con retoque de uso y/o retoque continuo

2A Hoja o fragmento con retoque de uso

2A1 H./f. con retoque de uso en el filo izquierdo

$2 \mathrm{~A} 2 \mathrm{H}$./f. con retoque de uso en el filo izquierdo y en el extremo distal

$2 \mathrm{~A} 3 \mathrm{H}$./f. con retoque de uso en el filo izquierdo, en el extremo distal y en el filo derecho

2A4 H./f. con retoque de uso en el filo izquierdo, en el extremo distal y en el filo derecho y extremo proximal

$2 \mathrm{~A} 5 \mathrm{H}$./f. con retoque de uso en el filo izquierdo y en el filo derecho

$2 \mathrm{~A} 6 \mathrm{H}$./f. con retoque de uso en el filo izquierdo, en el filo derecho y en el extremo proximal

2A7 H./f. con retoque de uso en el filo izquierdo y en el extremo proximal

$2 \mathrm{~A} 8 \mathrm{H}$./f. con retoque de uso en el extremo distal

2 A9 H./f. con retoque de uso en el filo derecho y en el extremo distal

2A10 H./f. con retoque de uso en el filo derecho, en el extremo distal y en el extremo proximal

$2 \mathrm{~A} 11 \mathrm{H}$./f. con retoque de uso en el extremo distal y en el extremo proximal

$2 \mathrm{~A} 12 \mathrm{H}$./f. con retoque de uso en el filo derecho

$2 \mathrm{~A} 13 \mathrm{H}$./f. con retoque de uso en el filo derecho y extremo proximal

$2 \mathrm{~A} 14 \mathrm{H}$./f. con retoque de uso en el extremo proximal

$2 \mathrm{~A} 15 \mathrm{H}$./f. con retoque de uso en el filo transversal

$2 \mathrm{~A} 16 \mathrm{H}$./f. con retoque de uso en filos inorientables

$2 \mathrm{~A} 17 \mathrm{H}$./f. con retoque de uso en filo transversal y filo(s) inorientables

2B Hoja o fragmento con retoque continuo

2B1 H./f. con retoque simple

2B2 H./f. con retoque abrupto

2B3 H./f. con retoque plano

2B4 H./f. con retoque sobreelevado

2B5 H./f. con retoque astillado

2B6 H./f. con dos o más modos de retoque

\section{Grupo tipológico 3. Escotaduras}

3A Escotadura simple (una escotadura)

$3 \mathrm{~A} 1$ E. simple no retocada

$3 \mathrm{~A} 2$ E. simple retocada

$3 \mathrm{~A} 3$ E. simple retocada y retoque continuo 
3B Escotadura doble (dos escotaduras)

$3 B 1$ E. doble no retocada

3B2 E. doble retocada

3B3 E. doble no retocada y retocada

\section{Grupo tipológico 4. Denticulados}

4A Denticulados de baja modificación secundaria

4A1 D. simples de baja modificación secundaria

$4 \mathrm{~A} 2$ D. dobles de baja modificación secundaria

4A2A D. dobles opuestos

4A2B D. dobles convergentes

$4 \mathrm{~A} 3$ D. triples

4B Denticulados de alta modificación secundaria

4B1 D. simples o dobles asociados a retoque con delineación no denticulada y/o fractura técnica

4B2 D. simples o dobles articulados con retoque con delineación no denticulada y/o fractura técnica

4B3 D. simples opuestos a retoque con delineación no denticulada y/o fractura técnica

4B4 D. simples asociados y opuestos a retoque con delineación no denticulada y/o fractura técnica

4B5 D. simples articulados con y opuestos a retoque con delineación no denticulada y/o fractura técnica

4B6 D. simples o dobles asociados a, articulados con y opuestos a retoque con delineación no denticulada y/o fractura técnica

\section{Grupo tipológico 5. Truncaduras}

5A Truncadura simple

5 A1 T. simple proximal

5A1A T. simple proximal recta directa

5A1B T. simple proximal oblicua directa

5A1C T. simple proximal recta inversa

5A1D $T$. simple proximal oblicua inversa

$5 \mathrm{~A} 1 \mathrm{E} T$. simple proximal irregular directa

$5 \mathrm{~A} 2 \mathrm{~T}$. simples distales

5A2A T. simple distal recta directa

5A2B T. simple distal oblicua directa

5A2C T. simple distal recta inversa

5A2D $\mathrm{T}$. simple distal oblicua inversa 
5B Truncadura doble

5B1 Truncadura doble directa

Grupo tipológico 6. Hojitas de dorso

$6 \quad$ Hojita de dorso

Grupo tipológico 7. Geométricos

7A Triángulo

7B Trapecio

7C Segmento de círculo

Grupo tipológico 8. Elementos dentados

8A Elementos dentados en proceso de elaboración

8B E. d. triangulares

$8 \mathrm{C} \quad$ E. d. rectangulares

8D E. d. trapezoidales

$8 \mathrm{E} \quad$ E. d. semicirculares

$8 \mathrm{~F} \quad$ E. d. irregulares

$8 \mathrm{G}$ E. d. fracturados de forma no reconstruible

Grupo tipológico 9. Perforadores

9A Perforadores sin modificación secundaria (perforadores de uso)

9B Perforadores con modificación secundaria poco profunda

9C Perforadores con modificación secundaria profunda

$9 \mathrm{C} 1$ P. espesos

9C2 P. con modificación secundaria profunda sobre lasca

9C3 P. con modificación secundaria profunda sobre hoja

Grupo tipológico 10. Raspadores 
10A Raspadores delgados

10A1 $R$. delgados de frente no destacado

$10 \mathrm{~A} 2 \mathrm{R}$. delgados de frente destacado

10B Raspadores espesos

10B1 R. espesos de frente no destacado

10B2 R. espesos de frente destacado

Grupo tipológico II. Puntas de flecha

11A Puntas de flecha en proceso de elaboración

11B P. de f. de base cóncava

11C P. de f. de base plana

11D P. de f. de base triangular

$11 E \quad P$. de f. de base pedunculada

$11 F \quad P$. de f. de base no reconstruible

\section{Grupo tipológico 12. Puñales}

12A Puñales en proceso de elaboración

12B Puñales de base cóncava

12C Puñales de base plana

12D Puñales de base triangular

12D1 P. de base triangular simple

12D2 P. de base triangular con escotaduras

12E Puñales de base de lengüeta

$12 E 1$ P. de base de lengüeta simple

12E2 P. de base de lengüeta con escotaduras

12F Puñales de base irreconstruible

Grupo tipológico 13. Hojas con extremidad astillada y/o pulida

13 Hojas con extremidad astillada y/o pulida 


\section{Grupo tipológico 14. Astillados}

14A Astillados simples

14A1 A. simples delgados

14A2 A. simples espesos

14B Astillados dobles

14B1 A. dobles delgados

14B2 A. dobles espesos

TIIPOS Grado de conservación del tipo

$\begin{array}{ll}\text { C } & \text { Completo } \\ \text { I } & \text { Incompleto }\end{array}$

LTIIPS Longitud máxima del tipo

ATIPS Anchura máxima del tipo

GTIIPS Grosor máximo del tipo

\section{5) ALTERACIONES}

ALTTS Alteración térmica

S Alteración térmica

$\mathrm{T}$ Tratamiento térmico

ALTQS Alteración química

S Presencia de alteración química (pátina)

ALTMS Alteración mecánica

S Presencia de alteración mecánica

P Presencia de pulimento en filo o filos

\section{LUSTS Lustre}

C Lustre de cereal 
Margarita Sánchez Romero

I Lustre indefinido 


\section{V.2. EI análisis espacial del contexto arqueológico: técnicas y aplicaciones estadísticas}

El análisis espacial se efectúa por dos motivos: definir los límites espaciales de las áreas de actividad y la distribución de los distintos tipos de artefactos, de manera que nos permitan reconstruir la clase, la frecuencia y la organización espacial de las actividades que se realizan dentro de una comunidad y a través de ellas inferir otros fenómenos sociales y económicos (Carr 1984:106). Para ello hemos de comprobar la situación del material, es decir, si está distribuido aleatoriamente o si está agrupado, cuales son los límites espaciales de esa distribución o si aparecen asociados diversos tipos (Carr 1984:107).

El análisis de una distribución espacial debe realizarse en varias etapas:

1.-Determinar la influencia de los mencionados procesos post-deposicionales.

2.-Apreciar a priori, el tipo de hábitat y seleccionar las categorías de restos susceptibles de revelar los fenómenos socio-económicos.

3.-Efectuar un análisis espacial, utilizando los métodos apropiados.

4.-Interpretar las estructuras obtenidas (caracterizadas por una asociación representativa local de ciertas categorías de vestigios) en términos paletnológicos.

\section{V.2.1 Técnicas}

\section{V.2. I.a Mapas de distribución. La descripción observacional}

Los primeros contactos de la arqueología con el contexto se establecieron mediante el estudio de suelos de hábitat o de ocupación, centrándose en una simple descripción observacional 
de las plantas de repartición de materiales y estructuras reconocidas durante la excavación, entendiendo que éstos indicaban la organización del espacio. El objetivo básico era delimitar zonas por actividades, sin la utilización de técnicas ni métodos cuantitativos. Lumley y Bonne parten de la premisa de que la organización del espacio habitado aparece como un comportamiento típicamente humano y la evolución de las estructuras de hábitat a lo largo del Paleolítico Inferior y Medio muestra la evolución de las estructuras sociales, de esta manera analizan los suelos de habitación de Terra Amata, la gruta de Lazaret o la gruta de 1'Hortus (LUMLEY y BONNE 1976a; 1976b).

Uno de los primeros yacimientos que permitieron el desarrollo y la aplicación de técnicas de análisis espacial fue el asentamiento al aire libre magdaleniense de Pincevent. Leroi-Gourham y Brezillon (1966; 1972) plantean las bases de la reconstrucción etnográfica a partir de varios elementos clave: el análisis exhaustivo de los denominados vestigios fugaces (restos de ocre, trazas de carbón, cenizas, esquirlas de menos de un centímetro de diámetro) que si bien no tenían un interés individual, colectivamente revelaban las grandes líneas de organización del hábitat, las estructuras, así como la situación de diversos items individuales como guijarros, nódulos de sílex bruto, fragmentos de granito y rocas diversas, sílex tallado y fragmentos óseos. Se centraron fundamentalmente en tres hogares, alineados de nordeste a sudoeste, con grupos compactos de sílex bruto o tallado y restos óseos sobre un suelo de arcilla, el conjunto fue considerado como una estructura de habitación o cabaña (LEROI-GOURHAM y BREZILLON 1966; 1972) El objetivo era estudiar y evidenciar la jerarquización del espacio, entendiendo que el estudio de las estructuras de hábitat podría conducir a una definición funcional de las diferentes zonas delimitadas. Dentro de las técnicas se inicia la aplicación del remontaje (WÜNSCH 1991).

Revisiones posteriores de estos trabajos, como las realizadas por Johnson (1984) o Binford $(1988)^{13}$, ponen en duda alguna de las afirmaciones realizadas por los excavadores. Johnson realiza un análisis de correspondencia sobre este suelo de ocupación, interpretando el yacimiento como un área de mantenimiento con acumulo de residuos y fuego, que no confirma las propuestas de Leroi-Gourham y Brezillon, igualmente los análisis efectuados con el método

\footnotetext{
${ }^{13}$ Más adelante nos referiremos a los métodos y enfoques de estos autores.
} 
de "K-mean", tampoco confirmaban los datos de la interpretación cualitativa de la paleosuperficie (JOHNSON 1984; AMMERMAN et al. 1987; BIETTI 1993).

Por otra parte, y desde una perspectiva muy distinta, Binford discute un área que LeroiGourham había identificado como una casa con hogar interior y los desechos estructurados en anillo, mientras que para Binford esa estructuración del espacio correspondería a actividades realizadas al aire libre, interpretando que por la ubicación y disposición de los tres hogares y de los items reconocidos a su alrededor, su disposición estaría determinada por la dirección del viento y el humo que produciría (BINFORD 1988). Sin embargo pensamos que Binford realiza aquí una traslación mecánica entre el registro etnoarqueológico y el registro prehistórico que es muy difícil de sostener.

Las propuestas interpretativas de A. Leroi-Gourham y L.R. Binford sobre el suelo de ocupación de Pincevent fueron revisadas posteriormente por los discípulos de A. Leroi-Gourham (AUDOUZE 1987; JULIEN et al. 1987) llegando a la conclusión de que si bien los modelos de esta autor eran útiles para separar zonas de actividad dentro del yacimiento, los trabajos de Binford son bastante más precisos a la hora de interpretar cada una de esas áreas de actividad. La utilización por parte de Binford de las bases etnoarqueológicas ofrecen una explicación detallada de las relaciones existentes entre su contenido y las actividades humanas que las han creado (AUDOUZE 1987:350).

Algo más tarde se empezaron a utilizar técnicas como el análisis de regresión y el análisis de superficies de tendencia.

-El análisis de regresión se usa en el estudio de los mapas de distribución para examinar la forma en que la densidad de distribución de un cierto tipo de útil disminuye cuando nos alejamos de su centro de producción. Esto se realiza midiendo la proporción de un tipo de artefacto en varios lugares alrededor del centro (ORTON 1988).

-Elanálisis de superficie de tendencia consiste en realizar un mapa de curvas de nivel de la densidad de cada tipo de artefacto. Esta idea básica puede llevarse a cabo de dos formas 
distintas: la primera es una aproximación empírica en la que el mapa se divide en una serie de cuadrículas y se mide la densidad de cada cuadrícula. Dado que los valores no darían una superficie uniforme, se igualan promediando los valores de cuatro cuadros adyacentes, poniendo el resultado en el punto donde confluyen. De esta forma se puede elaborar un mapa de curvas de nivel uniforme. Sin embargo, existen problemas porque al elegir el tamaño de las cuadrículas los resultados que se producen son diferentes (ORTON 1988).

\section{V.2.I.b El análisis espacial estadístico}

La utilización de técnicas estadísticas introducidas por las nuevas corrientes de la Arqueología Espacial que se desarrollan a partir de principios de los 70. Pretendía llegar a una generalidad que proporcionara cierta objetividad que pudiese ser aplicada a la particularidad de los datos concretos, y fue el resultado del desarrollo general de la Arqueología durante los años 60. Por otra parte, el uso de estas técnicas requería asumir siempre una serie de supuestos, ya que cada método o procedimiento estaba capacitado para manejar un tipo de relaciones y no otro (KINTIGH y AMMERMAN 1982).

Los análisis espaciales en Arqueología son importantes por tres razones fundamentales (HODDER y ORTON 1990:12):

a) La investigación previa en este campo ha estado muy limitada en sus objetivos y métodos, con mucha frecuencia acríticos y con poca utilidad para una interpretación detallada.

b) Las valoraciones subjetivas de las distribuciones pueden resultar bastante erróneas.

c) Se necesitan algunos métodos para controlar y procesar la gran cantidad de información que se produce.

Los métodos de análisis espacial intentan poner en evidencia las estructuras de la distribución de un determinado resto material o de varias clases de ellos mediante baremos de concentración, dispersión, uniformidad o distribución aleatoria (DJINDJIAN 1991). 
La utilización de las técnicas cuantitativas empieza a considerarse como parte imprescindible en cualquier trabajo arqueológico, bajo la premisa de que existen una serie de factores que hacen coincidir Arqueología y Matemáticas, por ejemplo, la simple descripción del registro arqueológico que se mide en términos de cantidad y tamaño (SHENNAN 1992). La interpretación del registro arqueológico precisa de la identificación de una regularidad y por tanto es capaz de beneficiarse del enfoque cuantitativo (ORTON 1988). La objetividad que se consigue a través de los métodos estadísticos (o con la cuantificación) se deriva de la aceptación de la existencia de una relación de verdad entre las proposiciones matemáticas y la realidad, ya que dichas proposiciones no son generalizaciones empíricas, sino proposiciones analíticas abstractas vacías de un contenido empírico concreto (WÜNSCH 1989a; 1989b; 1991).

La primeras técnicas estadísticas se tomaron prestadas de las utilizadas en geografia y ecología durante las décadas de los años 50 y 60, con muy pocas modificaciones (ORTON 1988; BLANKHOLM 1991). Así, la definición de Odum de un ecosistema como una comunidad de organismos en un área determinada en interacción con el medioambiente físico, de forma que el flujo de energía posibilite una clara definición de las cadenas alimenticias, la diversidad biótica y el intercambio de materiales entre las partes vivientes y las no vivientes (ODUM 1971: cit. en BUTZER 1989:5-6, ORTON 1988), fue adaptado a las poblaciones humanas. Se introducen así, por primera vez, los métodos de coordenadas y celdillas.

Durante estos primeros momentos, la aproximación general consistía en seguir un procedimiento de tres pasos (BLANKHOLM 1991):

1) Test para comprobar la aleatoriedad o no de una distribución dada.

2) Identificación y delineación de los conjuntos no aleatorios o concentraciones.

3) Medidas o test de asociaciones espaciales o correlaciones entre tipos de artefactos. 
Esencialmente, los métodos utilizados están representados por la aplicación del análisis dimensional de la varianza (WHALLON 1973), el método de Dacey (DACEY 1973) o el análisis del vecino más próximo (WHALLON 1973; 1974; BLANKHOLM 1991).

A mediados de los 70 se empieza a mostrar un interés más claro y a hacer un esfuerzo por intentar aproximaciones más coherentes y relacionadas con la problemática de los datos arqueológicos. De esta manera se intenta una profundización teórica, metodológica y técnica, abriéndose dos vías de actuación; por un lado, se comienzan estudios sobre la formación del registro arqueológico, con una doble vertiente: el estudio de los procesos de formación tanto culturales como no culturales y el desarrollo de la Etnoarqueología y la investigación experimental de materiales y efectos postdeposicionales. Por otro lado, se desarrollan nuevas técnicas y metodologías más acertadas (BLANKHOLM 1991).

El principal problema metodológico que surgió deriva del intento de unificar áreas de actividad relativamente uniformes en tamaño, forma, densidad y composición, pretensión que fue pronto abandonada. Por otra parte, se toma conciencia de que es posible que un mismo patrón espacial determinado puede ser generado por diferentes procesos y actividades (BLANKHOLM 1991).

En resumen, durante estos años no hay reglas fijas para la aplicación de test de análisis espacial, pero se señalan ciertas proposiciones (BLANKHOLM 1991):

1) En los datos se buscan los patrones y estructuras susceptibles de ser interpretadas en términos de conducta.

2) La detección, estadísticamente significativa, de cualquier tipo de estructura o área, no tiene porqué ser necesariamente relevante a nivel conductual en relación con el comportamiento humano.

3) Una actividad o uso importante en lo que se refiere a la conducta, no tiene porqué ser significativa estadísticamente. 
Purante estos años, se producen revisiones del método del análisis dimensional de la varianza (NEWELL y DEKIN 1978) o del método de la distancia al vecino más próximo (PINDER et at. 1979; McNUTT 1981). Además, se desarrolla el método del índice A de asociación (HODDER y OKELL 1978) y el análisis de densidad local (JOHNSON 1984).

El final de los años 70 marcó un periodo de transición en el desarrollo de los análisis espaciales en todos los ámbitos de la investigación, ya que las experiencias en el trabajo práctico, los estudios experimentales y la etnoarqueología, se evaluaron cuidadosamente en lo que se refiere a teorías, métodos y técnicas (BLANKHOLM 1991).

A partir de los años 80 , se continua con las líneas de investigación referidas a la formulación de una adecuada estructura teórica para la investigación de los procesos de formación de yacimientos y del espacio usado y un creciente interés en la interpretación de los comportamientos actuales, con aproximaciones de carácter antropológico y etnológico (BLANKHOLM 1991). Los métodos se valoran en función de su habilidad para extraer información de relevancia en la resolución de problemas arqueológicos. Se empezaron a aplicar técnicas que utilizaban el análisis multivariante, sobre todo en lo que se refiere a la variabilidad entre conjuntos. Esto es debido a que ciertas actividades requieren el empleo de diversos equipos de herramientas y, a la inversa, existen diferentes actividades que reúnen uno o más equipos de herramientas idénticos. La mezcla de estos componentes aparecería en el registro arqueológico, es decir, en el suelo de ocupación, y podría dar lugar a errores (BINFORD 1988).

En la actualidad el máximo interés, en lo que se refiere a estudios de análisis espacial, se centra en desarrollar teorías, metodologías y técnicas que trabajen de manera más realista en la percepción de la naturaleza de los datos arqueológicos, incluyendo los procesos de formación del registro. 


\section{El análisis dimensional de la varianza}

El análisis dimensional de la varianza fue desarrollado por los estudios en ecología en los años 50. R. Whallon, considerado como uno de los pioneros de los estudios espaciales, tomó como premisa el argumento funcional de Binford (1973), es decir, que los artefactos, clasificados en diferentes grupos o conjuntos de útiles (tool-kits) y otros artefactos que aparecen juntos en los suelos de ocupación podrían estar diferencialmente distribuidos como consecuencia de haber sido usados conjuntamente en ciertas actividades. Era de esperar, por tanto, que se pudieran realizar inferencias concernientes a los patrones de actividad humana a través de la interpretación de esos conjuntos de útiles, teniendo en cuenta su contenido y su posición sobre el suelo de ocupación, mediante técnicas estadísticas (WHALLON 1973; 1974; BLANKHOLM 1991).

Como hemos visto, normalmente los ejemplos arqueológicos de análisis espacial se habían realizado mediante interpretaciones basadas en impresiones visuales, todos los items o artefactos de cada clase se situaban en un plano del área excavada, y cada clase era tratada por separado, pero como las similitudes en los patrones de distribución eran muy claras entre algunas clases, la unión de mapas podía servir para ilustrar las similitudes observadas. En el procedimiento estándar del análisis dimensional de la varianza, el grado de similaridad o disimilaridad entre distribuciones se juzga mediante la observación, al igual que si el patrón de distribución es significativo o no (WHALLON 1973; 1974).

Intentando dar una base más objetiva a la concentración o no de las distribuciones de material, R. Whallon propone la utilización de las bases estadísticas. Por ello considera el problema del análisis de los patrones espaciales en términos de una serie de tres pasos secuehciales, cada uno dependiente del anterior (WHALLON, 1973; 1974).

El primero es determinar si la distribución de artefactos o items de cada clase se considera como esencialmente aleatoria o muestra una significativa tendencia hacia una agrupación espacial o çoneentración en una escala menor al total del área analizada. El segunda paso sería elegir las chases 90 anteffotos que muestran una significativa tendencia a la concentración y reorganizar los datos originales en las que las similitudes o correlaciones se han basado, o $s \beta$ han visto más 
fuertemente reflejadas. Como paso final, las similitudes y correlaciones en la distribución espacial se calculan y se organizan en alguna forma, ya sea una matriz ordenada o un árbol definido por análisis cluster, de manera que los grupos de artefactos e items que se distribuyen similarmente sobre el área considerada se definan a través de las relaciones entre conjuntos o grupos (WHALLON 1973; 1974).

Estos tres pasos son el centro de un análisis de patrón espacial de los materiales arqueológicos. Lo crucial y distintivo de la tarea arqueológica al utilizar estos análisis, se basa en la interpretación de los resultados, en la formulación de hipótesis concernientes a los patrones de actividad humana prehistórica que han dejado restos arqueológicos estructurados en la forma que han sido analizados (WHALLON 1973; 1974).

R. Whallon enumera varios elementos que se pueden emplear rentablemente en las primeras fases del análisis, particularmente el situar los objetos individuales o los conjuntos enteros de items sobre un plano del área analizada para mostrar la forma de la distribución espacial, especialmente en relación a las estructuras prehistóricas que se han descubierto en el yacimiento, es decir, los mapas de distribución. Pero aunque reconoce que todos estos recursos son muy valiosos para la interpretación, advierte que el núcleo de una rigurosa aproximación al estudio espacial de los restos se basa en los estudios estadísticos (WHALLON 1973; 1974).

El análisis dimensional de la varianza utiliza los datos en forma de número de elementos por cuadrícula, las primeras aplicaciones con este método se basaban en la presencia/ausencia de los artefactos, aunque no se tenía en cuenta el número de objetos y los resultados eran muy sensibles al tamaño del yacimiento, de la cuadrícula y de la excavación (ORTON 1988).

El uso de datos en forma de número de items por cuadrícula da al análisis dimensional de la bvarianza una gran ventaja ya que, por este método, pueden ser analizados un conjunto substancial de útiles individuales e items que fueron excavados mediante cuadrículas y para los que nunca se tomaron las coordenadas exactas. En términos de una estrategia de recogida de datos, a menudo muy rápido y necesario (sobre todo en excavaciones de urgencia) es mucho más efectivo recoger los materiales por cuadrículas, ya que obtener las coordenadas de cada útil 
supone no sólo un gasto de tiempo enorme, sino que además a veces es poco factible. Sin embargo, el uso de cuadrículas plantea problemas concernientes a la forma del área excavada y a la precisión con la que se definan la escala y la forma de las concentraciones espaciales (WHALLON 1973; 1974).

La idea del análisis dimensional de la varianza está basada en el índice de dispersión. La probabilidad de que en una superficie previamente cuadriculada, una celda contenga exactamente $\mathrm{x}$ puntos viene dada por la función de Poisson. La característica de esta ecuación es que la varianza es igual a la media, así, en el caso de concentración, la varianza será superior a la media y en el caso de una distribución uniforme, será inferior. La relación entre varianza y media sería una estadística que permitiría saber si una distribución espacial estudiada puede ser considerada como una muestra de la distribución de Poisson (DJINDJIAN 1991).

El índice de dispersión varianza/media(n-1), donde $n$ es el número de celdas, es parecido a una distribución del chi-cuadrado con n-1 grados de libertad. El índice de dispersión toma valores elevados en la caso de que exista concentración y valores más pequeños en el caso de una distribución uniforme. Es evidente que el resultado del test depende del tamaño de la cuadrícula utilizada (DJINDJAN 1991).

R. Whallon propuso una mejora del método que estudia cómo varía el grado de asociación respecto al tamaño de la cuadrícula, por el que el número de cuadrículas a lo largo de la superficie elegida (cuadrado o rectángulo), debe ser múltiplo de dos; si la cuadrícula es rectangular, una dimensión debe ser dos veces la otra, por ejemplo 8 x 16, 64 x 128... El mecanismo del DAV requiere el cálculo de la media de los diferentes tamaños de bloques cuyo tamaño consiste en el doble de la cuadrícula mínima o del bloque más cercano y pequeño. Se necesita reagrupar los datos en bloques con áreas de $2,4,8,16,64 \ldots$ veces el área de la cuadrícula original. Esto significa por un lado que los bloques son alternativamente cuadrangulares y rectangulares y por otra, que sólo estos tamaños específicos del área son examinados para hallar el grado de concentración espacial. El alcance del tamaño de las posibles concentraciones se incrementa logarítmicamente al aumento del tamaño de los bloques, con la consecuente pérdida progresiva de fineza o precisión a la hora de detectar patrones espaciales. La observación de una 
concentración espacial significativa de algunos items en el bloque de tamaño 32, por lo tanto, no significa necesariamente que éste es el tamaño de la concentración, sino solamente que el tamaño puede estar en algún lugar del baremo entre un área de 16 a 64 veces el área de la cuadrícula original. El área de tamaño 32 es simplemente la mejor aproximación al tamaño real de la concentración (WHALLON 1973; 1974).

Obviamente existen algunas restricciones, como la forma de la mayoría de las excavaciones y de los suelos de ocupación, sin embargo se puede seleccionar la porción central de la ocupación excavada, dejando a un lado unas áreas periféricas menores y/o añadiendo algunas "falsas" cuadrículas. También es posible dividir una gran área en otras más pequeñas de la forma requerida. Estas subáreas pueden ser analizadas separadamente por este método y los resultados combinados con los de las otras áreas al final del análisis espacial, interrelacionando los distintos tipos de items. Es también posible de la misma manera tratar separadamente áreas no conectadas de una excavación y finalmente combinar los resultados (WHALLON 1973; 1974).

El grado de concentración de cada artefacto se calcula para cada tamaño de cuadrícula y se comparan las concentraciones de forma gráfica o tabular. Si existe una distribución no aleatoria de los mismos, la medida de la concentración produce un pico para un determinado tamaño de la cuadrícula indicando la escala del modelo en esa distribución (WHALLON 1973; 1974; ORTON 1988).

La media cuadrática o varianza representa el grado en el que los elementos se concentran en algunos bloques y están relativamente ausentes en otros. La varianza se halla como el cuadrado de la desviación típica. Cuanto mayor sea la dispersión de la distribución, mayor será la desviación típica (SHENNAN 1992)

La forma más lógica de aproximación es la del rectángulo o cuadrado debido a la reagrupación de las cuadrículas. Obviamente, sin embargo, es una aproximación bastante pobre a la forma real de la concentración, especialmente la rectangular ya que la forma de la concentración puede ser alargada pero orientada de distinta forma que la cuadrícula. 
Whallon llevó a la práctica este método con una serie de agrupaciones de tipos y encontró que todos presentaban un pico en el bloque de ocho cuadrículas. Esto sugirió que el mejor tamaño para un análisis de asociación es la cuadrícula de ocho metros. Los grupos de hallazgos determinados matemáticamente tenían así un significado físico real y una interpretación arqueológica razonable (WHALLON 1973; 1974; ORTON 1988).

El mecanismo del análisis dimensional de la varianza está limitado en la escala, o tamaño, del patrón espacial que puede ser detectado y definido. La escala mínima en la que la aleatoriedad de la distribución de los items puede ser determinada, es el tamaño de la unidad de cuadrícula mínima utilizada, e incluso para lograr una total seguridad y efectividad la concentración puede ser considerada a partir de un tamaño igual al doble de la unidad mínima, además al doblarse el tamaño de cada bloque, la precisión con la que se puede hallar la escala de los modelos disminuye al aumentar dicha escala. Igualmente, el número de items debe ser elevado. Por otro lado impone serias restricciones a la hora de excavar, ya que su forma es muy limitada, el análisis sólo se basa en cuadrados o rectángulos (WHALLON 1973; 1974; ORTON 1988; DJINDJIAN 1991).

El método sólo confirma expectativas de sentido común, es decir, conjuntos de elementos que pueden aparecer juntos en un yacimiento, como zonas de talla, hogares, zonas de desecho y no actividades resultantes de la asociación local de varios tipos, aunque demuestra que, matemáticamente, se pueden extraer modelos utilizables en otro tipo de situaciones (WHALLON 1973; 1974; ORTON 1988).

\section{El índice de la distancia al vecino más próximo}

Este análisis es probablemente el más conocido y ampliamente usado de todos los análisis espaciales hasta el momento, no sólo en Arqueología, sino también en Ecología y Geografia, su desarrollo original. Sintomático de su popularidad es el gran número de fórmulas que se han desarrollado a través de los años y los ajustes correctivos que se le han aplicado para superar sus desventajas (BLANKHOLM 1991:110). 
El análisis del vecino más próximo requiere las dos coordenadas de la posición exacta de cada elemento o ítem, pero se puede extender hasta trabajar con tres dimensiones. La diferencia básica en el tipo de dato necesitado es, obviamente, de central importancia en la consideración de la aplicación de uno de estos dos métodos. Esta técnica generalmente elimina los problemas de escala y forma (WHALLON 1973; 1974).

El método está basado en la medida de las distancias entre los objetos. El vecino más próximo de un utensilio cualquiera, llamado punto base, es simplemente el utensilio que está más cerca de él. Fue desarrollada por Clark y Evans (1954), ecólogos especialistas en vegetación, para analizar la dispersión de especies en una zona determinada. La primera etapa de aplicación de este método consistió en medir la distancia $r_{i}$ de cualquier punto i de una distribución espacial a su vecinoo más próximo, a continuación hay que comparar la media de las distancias observadas $\left(\mathrm{r}_{\mathrm{o}}\right)$ con la distancia media esperada $\left(\mathrm{r}_{\mathrm{e}}\right)$ si los puntos hubiesen sido distribuidos aleatoriamente (DJINDJIAN 1991).

La técnica funciona mediante tres pasos (BLANKHOLM 1991:110):

1) Test de significación de distribuciones no aleatorias.

2) Medida de la asociación de clases de artefactos, seguida de la ordenación o análisis cluster de los conjuntos de útiles.

3) Definición, descripción e interpretación de la configuración espacial de estos conjuntos de útiles.

El uso de las coordenadas exactas y de este método elimina las restricciones de forma del área que se considera. Cualquier área de excavación puede ser tratada con este método ya sea su forma regular o irregular, no hay necesidad de eliminar áreas ni de añadir otras "falsas", pero sin embargo es muy dificil poder combinar y comparar áreas separadas, incluso de la misma ocupación. Además existe otro problema, si se presentan varias escalas o patrones en la concentración de los datos, este proceso tratar con la escala más pequeña de una concentración 
significativa. Esto no es particularmente conveniente para detectar la aparición de concentraciones a gran escala, incluso aunque se extienda al análisis de las distancias al segundo, tercer o cualquier vecino más cercano (WHALLON 1974). Por otra parte, el método es global, es decir, calcula el total de la densidad y el vecino más próximo para un área entera (BLANKHOLM 1991:122).

Aunque es estadísticamente bueno, hay mejores caminos para medir la asociación entre artefactos y definir áreas de actividad, ya que como fue inicialmente diseñado para trabajar con una única clase de artefactos al mismo tiempo, la aplicación del coeficiente de Jaccard lo hace menos útil para detectar áreas de actividad y su composición (BLANKHOLM 1991).

\section{El test de patrón aleatorio y el test de presencia/ausencia}

M.F. Dacey inició una serie de trabajos de análisis espacial en el yacimiento de Sde Divshon, en Avadat (Israel) ${ }^{20}$. Analizó el mapa de distribución de tres tipos de útiles líticos: raederas, raspadores y buriles. Trabajó sobre la hipótesis de E. Marks (1971) que proponía que los raspadores y las raederas poseían distribuciones alejadas, mientras que raederas y buriles presentaban una asociación y distribución generalmente paralela. Estas asociaciones fueron realizadas exclusivamente de forma visual, Marks (1971) trataba la localización de cada útil como un punto representado por un símbolo, lo que significaba que cuando el mapa del área se dividía en subregiones, la localización de cada símbolo, y por tanto, de cada útil, estaba perfectamente señalada y asociada a una subregión (DACEY 1973).

Se trataban dos aspectos en estos mapas de distribuciones. En primer lugar, cada uno de los tres mapas de útiles se examinaba por separado para detectar los posibles patrones de distribución, después, se examinaban de dos en dos los mapas para comprobar si existía una distribución asociada de los útiles (DACEY 1973).

Por definición, un mapa que se compone de un conjunto de $\mathrm{n}$ puntos localizados en una zona o región $\mathrm{A}$, se dice que posee un patrón aleatorio cuando su extensión se produce por igual

\footnotetext{
${ }^{20}$ Este yacimiento fue excavado y estudiado por A.E. Marks. Para más información, ver MARKS 1971.
} 
en las subrregiones de la zona A. También por definición, siendo $M_{1}$ un mapa de $n_{1}$ puntos localizado dentro de una región A y siendo $M_{2}$ otro mapa de otros $n_{2}$ puntos también localizados en A, se dice que estos dos mapas carecen de asociación espacial cuando la localización de cada miembro de $\mathrm{M}_{1}$ es independiente de la localización de cualquiera de los de $\mathrm{M}_{2}$ y viceversa (DACEY 1973).

Los tres mapas de útiles fueron examinados para evidenciar los patrones aleatorios combinando el método de las cuadrículas con el test del análisis dimensional de la varianza. Mediante el sistema de cuadrículas, de forma y tamaño constante, el yacimiento fue dividido en 63 subzonas $^{21}$.

Para detectar la presencia de una asociación espacial, es decir, una relación sostenible y medible entre los útiles de dos cuadrículas, se usaba un mapa binario, para cada celda; se asigna un 0 si el número de útiles de un tipo en particular es menor que el de la media de todas las celdas, si es mayor o igual se asigna a la celda un 1. Para superponer los mapas binarios para dos tipos de útiles (A y B) se asignarán a las celdas los siguientes valores:

0 cuando las celdas tengan el valor 0 en los dos tipos de útiles

1 cuando las celdas tengan el valor 1 en los dos tipos de útiles

1-0 cuando tengamos un 1 en las celdas de tipo A y un 0 en las de tipo B

0-1 cuando tengamos un 0 en las celdas de tipo b y un 1 en las de tipo A (DACEY 1973)

Se utilizaron dos tipos de test para detectar la presencia o ausencia de asociaciones espaciales. El primer test tenía en cuenta sólo los valores de las celdas individuales, mientras que el segundo tomaba el valor de cada celda relacionándolo con los valores de las celdas contiguas, la existencia de asociación o no, podía ser detectada por uno de estos dos test y no por el otro (DACEY 1973).

\footnotetext{
${ }^{21}$ Como ya hemos visto con Whallon $(1973,1974)$ el método de las cuadrículas fue posteriormente estructurado de manera que cada una de las cuadrículas fuese el doble en tamaño de las que se situaban a su lado para aumentar la fiabilidad del desarrollo estadístico.
} 
El primero es una tabla de contingencia formada por el número de apariciones de los valores 0 y 1 , utilizando el método del chi-cuadrado. El segundo test usa mapas de $(+)$ y $(-)$ que se obtienen asignando $(+)$ a cada cuadrícula que contenga un valor como 0 ó 1, y $(-)$ a cada celda que contenga un valor de 1-0 ó 0-1. La unión se define por cada par de celdas que tengan un lado en común y el valor se asigna siguiendo el siguiente modelo:
$(+)$ si ambas tienen $(+)$
(-) si ambas tienen (-)
D si cada una tiene un signo distinto

La teoría que utiliza este test para demostrar la ausencia de asociación espacial en un mapa $(+,-)$ es la siguientes: el mapa se parcela en $n_{1}$ filas y $n_{2}$ columnas y tiene $v$ celdas que poseen el valor $(+)$ y w celdas que tienen el valor $(-)$, así que:

$$
\mathrm{v}+\mathrm{w}=\mathrm{n}_{1} \mathrm{n}_{2}=\mathrm{n}
$$

Además este mapa define $A=2 n_{1} n_{2}-\left(n_{1}+n_{2}\right)$ uniones. Hallándose después los valores esperados para cada caso. La hipótesis de una distribución aleatoria se sostiene si la diferencia entre los valores esperados y los observados son lo suficientemente pequeñas.

Existe una gran cantidad de formas y maneras de caracterizar la presencia de asociaciones espaciales, pero los tipos contrapuestos de asociaciones positivas y negativas (es decir, si aparecen o no) no se identifican en este tipo de análisis. Una consecuencia de este defecto es que el análisis tiene la capacidad de detectar sólo la presencia o ausencia de asociación espacial, pero no de identificar el tipo de asociación. Por otra parte el test de la ausencia de asociación espacial es dependiente del tamaño y forma de las celdas usadas para el análisis, así que es posible que se obtengan diferentes conclusiones al ser aplicados en distintos tipos de celdas (DACEY 1973).

\section{$\underline{\text { El análisis de correspondencias }}$}


El análisis de correspondencias fue desarrollado en la década de los años 30 , y desde los años 60 fue ampliamente usado por la Ecología de diferentes formas y bajo diferentes nombres. La Arqueología fue adoptando lentamente este método. La más temprana publicación de un ejemplo de aplicación pertenece a un ecológo (HILL 1974) y más tarde, I. Johnson lo usó como parte integrante de su análisis de densidad local en la década de los años 70 (BLANKHOLM 1991:92).

Sin embargo, la primera aplicación de análisis de correspondencias fue utilizada por Bolkiven (et al. 1982) en un artículo en el que se mostraban algunas aplicaciones sobre claros ejemplos arqueológicos; llegando incluso a probar que da mejores resultados en arqueología que en ecología ya que el método en general, parece ser más congruente con la naturaleza de los datos arqueológicos y los modelos conductuales que con los modelos ecológicos (BLANKHOLM 1991:92).

El potencial teórico de esta técnica y la capacidad práctica para el análisis espacial han de ser evaluadas con mayor detenimiento. El análisis de correspondencias es poco preciso a la hora de la localización de los centros de las áreas de deposición de clases individuales. Las principales áreas de actividad se detectan con cierta precisión, e igualmente es útil para la localización e interpretación de áreas de actividad que en la práctica arqueológica estándar podrían haber sido consideradas separadamente y como áreas de actividad distintas. Los resultados de los análisis realizados mediante este método pueden ser calificados de buenos (BLANKHOLM 1991:101).

\section{El análisis de densidad local}

El análisis de densidad local fue desarrollado por I. Johnson a mediados de los 70 como uno de los primeros métodos que posibilitaba tratar indistintamente con coordenadas o con celdillas. En un principio el interés de Johnson se inclinó hacia las celdillas, su noción básica es que el uso de pequeñas unidades de recogida de alta resolución podían suplantar a menudo a las coordenadas sin que se perdiera demasiada información (BLANKHOLM 1991:101). 
Este análisis es un medio para calcular la matriz de los coeficientes de asociación entre las distribuciones de un número de categorías de artefactos. Pretende ser un método que trabaje con dos aproximaciones distintas, lo estructural y lo funcional, y está desarrollado especialmente para el análisis espacial del hábitat. El principio del método de Johnson es medir la densidad local de los utensilios de tipo A en un círculo centrado en los alrededores de útiles de tipo B. La densidad local, por tanto, es igual al número de representantes de tipo A en el círculo con centro en $\mathrm{B}$, dividido por el área del círculo y calculando la media para todas las ocurrencias del tipo B (JOHNSON 1984; DJINDJIAN 1991).

Si comparamos la densidad local del tipo A en las cercanías del tipo B con la densidad del tipo A en el área entera (llamada densidad global), podremos ver si A aparece o no asociado a B. Si la diferencia entre la densidad local y la total es muy grande, sugiere que hay una asociación entre las distribuciones, es decir, los dos tipos diferentes están más cerca uno del otro de lo que razonablemente podría esperarse si uno (o ambos) estuvieran distribuidos aleatoriamente a lo largo del yacimiento (JOHNSON 1984; ORTON 1988).

A continuación se calcula el índice de coagrupamiento, C, que es el resultado de dividir la densidad local entre la densidad global. Los índices de coagrupamiento dependen de lo que entendamos, o estemos obligados a considerar como los límites de la excavación (JOHNSON 1984; ORTON 1988).

Otros problemas posibles serían, la elección del tamaño de los círculos utilizados para medir la densidad local; además, a menudo, es necesario eliminar algunas categorías de artefactos de pequeño tamaño, lo que puede desvirtuar los resultados (JOHNSON 1984; ORTON 1988).

Cuando los artefactos se sitúan por celdas Johnson recomienda tratar el registro como si todos los útiles de una celda se encontraran en el centro de la misma (JOHNSON 1984; ORTON 1988).

Se pueden crear mapas de densidad a partir de la distribución de los artefactos de una categoría (o de un grupo de categorías) tratando la superficie excavada como un eje de 
coordenadas XY y representando la densidad de los artefactos mediante curvas de nivel de dos o tres dimensiones (JOHNSON 1984).

En la práctica, este procedimiento es preciso en la localización de centros de distribución de categorías individuales con una distancia media de $0,86 \mathrm{~m}$., pero no es útil a la hora de detectar tendencias de distribución a través del yacimiento, o en el estudio de áreas de transición (BLANKHOLM 1991).

\section{El índice A de asociación}

I. Hodder introdujo en el estudio espacial de los yacimientos el índice de asociación; es un método no dependiente de la escala, como los anteriores, y no implica medidas de área o densidad, con lo que elimina los problemas de los límites (BLANKHOLM 1991:130). Hodder pretendía utilizar más información que la que se maneja en los métodos de cuadrículas o en los del vecino más próximo, así empezó a calcular la distancia media de los puntos en los que estaban localizados útiles del tipo A otros puntos del tipo A y a los puntos de tipo B, e igualmente con los puntos tipo B hacia los A (HODDER 1978; HODDER y OKELL 1978; HODDER y ORTON 1990).

El índice se calcula como la distancia media de A, dividida por la distancia media de A B, multiplicado por la distancia media de B a B, dividida por la distancia media de A B. Cuando se mezclan al azar las distribuciones de los tipos A y B, sin asociación o disociación, el resultado tendrá un valor alrededor de 1 , distribuciones cercanas pero separadas tienen valores menores de 1 y si los tipos A y B tienden a aparecer juntos, entonces A será mayor que 1 (HODDER 1978; HODDER y OKELL 1978; HODDER y ORTON 1990).

Hodder y Okell utilizan el test para analizar la asociación de dos distribuciones en contexto limitado. Está más próximo a la identificación de fuentes de abastecimiento, producción y difusión que al análisis espacial propiamente dicho. El objetivo de los autores es ofrecer un test estadístico sobre la asociación de dos distribuciones (HODDER y OKELL 1978; DJINDJAN 1991). 
Este método tiene ciertas ventajas sobre el del vecino más próximo, ya que no implica ninguna medida del área o la densidad, con lo que se evitan los problemas asociados a esta aplicación (Blankholm 1991:134)

Sin embargo, el hallar las distancia medias consume mucho tiempo, además sólo opera con un par de tipos a la vez y los autores no explican cómo crear o analizar grandes grupos de categorías interasociadas, cómo definir la extensión espacial de cada uno de los grupos (BLANKHOLM 1991), o cuánto debe aumentar para indicar una asociación significativa de A y B (HODDER 1978; HODDER y OKELL 1978; HODDER y ORTON; 1990).

Igualmente, para los autores, existen una serie de problemas, bien relacionados con los datos o bien relacionados con las técnicas que en algunas ocasiones impiden un desarrollo óptimo de estas técnicas estadísticas, entre ellos podríamos destacar los métodos de excavación, las pautas de erosión y destrucción de los yacimientos, los propios intereses de la actividad arqueológica y las mismas técnicas estadísticas que en su mayoría requieren una amplia base de datos. Por otra parte muchos de los test estadísticos, como hemos visto, requieren ciertas premisas e hipótesis sobre los datos que restan objetividad a los resultados y pueden llegar a mostrar simplemente lo que se quiere ver. Además, hay que tener en cuenta que diferentes procesos y fenómenos espaciales pueden producir distribuciones distintas y que procesos de dispersión pueden producir esquemas decrecientes similares (HODDER 1978; HODDER y OKELL 1978; HODDER y ORTON 1990). 


\section{$\underline{\text { El Presab }}$}

Es una técnica diseñada por H. P. Blankholm para trabajar con coordenadas y con celdas. El método difiere en su aproximación teorética. En lugar de tratar con densidades absolutas y relativas, o con la distancia al vecino más próximo, trabaja con categorías de presencia/ausencia de datos, al igual que el método de Dacey (DACEY 1973; BLANKHOLM 1991).

Es un proceso de múltiples pasos que implican una serie de técnicas entre las que se encuentra el análisis cluster. Los conjuntos están formados de acuerdo a composiciones categóricas bajo la única condición de que deben ser internamente homogéneos. Por esto, Presab es un método flexible que contiene un alto número de opciones libres en su operación y aplicación (BLANKHOLM 1991). Teóricamente es interesante visualizar los datos, ya que a veces artefactos con una gran frecuencia pueden distribuirse de forma homogénea sobre la mayor parte del suelo de ocupación, escondiendo la variación interesante que pueda existir entre otras categorías (PALLARES i AÑO 1993).

Actúa tanto con coordenadas como con celdilla. Cuando utiliza coordenadas es útil para identificar tanto lugares de actividad simple como áreas de actividad combinadas. Cuando utiliza celdillas es más útil para identificar áreas de actividad combinadas y algo menos para las distribuciones individuales (BLANKHOLM 1991).

\section{V.2.I.c La introducción del enfoque etnoarqueológico}

La carencia de contenido teórico de los métodos estadísticos referidos al análisis espacial se intentó solventar mediante la introducción de inferencias etnoarqueológicas. La premisa principal, que sostiene la paletnología, es que existe una relación real y efectiva (susceptible de ser contrastada positivamente) entre determinados atributos conductuales y determinados elementos materiales, suponiendo que las observaciones sobre la conducta de grupos primitivos actuales pueden facilitar el conocimiento de las conductas pasadas (WÜNSCH 1991). 
El interés del análisis espacial del hábitat en estas propuestas está basado en la importancia de la certificación paletnológica de las distribuciones espaciales. La Nueva Arqueología introdujo los nuevos métodos estadísticos al pretender un enfoque científico y convirtió el uso de estas técnicas en ideológicamente necesarias. Al adoptar una visión sistémica del pasado, como ya hemos referido, en la que imperaba el contexto adaptativo, es decir, cómo se relaciona la gente con su entorno y con otras poblaciones, las relaciones entre las variables que habían sido medidas en el registro arqueológico, se hicieron importantísimas (SHENNAN 1992). La introducción de las propuestas etnoarqueológicas supondrá un nuevo método de explicar las distribuciones de items, y por tanto las áreas de actividad prehistóricas.

\section{La identificación de zonas de actividad}

Como ya hemos definido, el estudio de la estructura del yacimiento, es decir, la distribución espacial de artefactos, restos y fauna en los yacimientos arqueológicos por medio de los datos etnográficos es una forma de conocer cómo organizaba el hombre primitivo su espacio de vida, dónde realizaba las distintas actividades y hasta que punto realizó un uso especializado del espacio (BINFORD 1988). L.R. Binford y R. Whallon utilizan un enfoque funcional en el que el máximo interés se centra en identificar áreas de actividad caracterizadas por conjuntos característicos de útiles, dentro de la tradición de la Nueva Arqueología (DJINDJIAN 1991).

Binford partió de una serie de ideas generales que pudieran determinar el tamaño, la forma y la estructura del yacimiento como, por ejemplo, la estructura y la estatura de sus habitantes, elemento que de ser comprobada su efectividad sería clave para hacer inferencias del pasado; afirmaba que la similitud que podemos encontrar entre las medidas de los espacios ocupados por la casa, las áreas dormitorio y el hogar exterior de distintos grupos de cazadores-recolectores se deben a que el factor que las condiciona es el mismo en todos los casos: el cuerpo humano. Para el autor se trata sencillamente de la cantidad de espacio que la gente necesita (BINFORD 1988). Sin embargo, nos parece limitado reconocer el cuerpo humano como único causante de la estructura o tamaño de un yacimiento arqueológico, ya que el verdadero factor condicionante sería el sistema social. 
El autor denomina rasgos a la serie de elementos que se distribuyen en el yacimiento: contenedores, estructuras, vasijas, útiles líticos, edificios... mientras que las áreas de uso y los caminos de circulación se denominan modelos de items y/o agrupaciones espaciales de artefactos, formando todos estos elementos la organización del yacimiento (BINFORD 1988:155-156). Para Binford lo importante es identificar áreas de actividad y para ello define una serie de conceptos previos: un equipo de herramientas es el conjunto de útiles empleados en la consecución de una tarea; una actividad es una serie de tareas integradas que se ejecutan generalmente en una secuencia temporal y de manera ininterrumpida (...); las áreas de actividad son lugares o superficies donde tienen lugar actividades tecnológicas, sociales o rituales (BINFORD 1988:158).

Asímismo, las áreas situadas dentro de los yacimientos pueden ser complejas, es decir, utilizadas para fines diversos, por lo que no existe necesariamente una relación exacta entre un lugar y un equipo de herramientas, o entre un espacio y una sola actividad. Binford centra su trabajo en el análisis de los módulos espaciales que subyacen en las estructuras de ubicación y disposición de las actividades (áreas de actividad) y en las asociaciones de items (equipos de herramientas) (BINFORD 1988).

En primer lugar revisa la utilización del espacio alrededor de un hogar. El modelo básico de un individuo que trabaja cerca del hogar es que se siente lateralmente para que tenga el espacio suficiente para trabajar; sin embargo, si se trata de un grupo de individuos su disposición será perpendicular al fuego y a cierta distancia, para que dispongan de espacio suficiente. El elemento fundamental a la hora de definir el espacio serían los desechos de las actividades y la disposición de los restos de talla. Los desechos de actividades relacionadas con la preparación de alimentos se estructuran en tres modelos básicos: el primero consiste en abandonar los items in situ, el segundo arrojarlos de forma individualizada y el tercero, arrojar un conjunto de items en masa. En el primer caso, los items permanecerían en el área inmediata al lugar donde fueron elaborados o trabajados, pero el resto son arrojados a la periferia de las áreas de trabajo (BINFORD 1988). 
La estructuración del espacio sería modificada, que no determinada como afirma Binford, por otra serie de factores como pueden ser la luz, el calor, la movilidad de los grupos o el tiempo de ocupación de un campamento.

Para Wünsch, la propuesta de Binford se basa únicamente en paralelismos tecnológicos y/o formales a partir de los cuales se infieren características funcionales u organizativas, de manera que no ofrece un instrumento analítico cuantitativo susceptible de ser aplicado a los datos arqueológicos, es decir, ofrece un cuerpo teórico pero sin instrumentos analíticos (WÜNSCH 1991).

Por otra parte, R. Whallon (1984) detecta que el fallo de la mayoría de los análisis cuantitativos es simplemente que los modelos y principios de la estadística y las matemáticas, en los términos en los que son aplicados sobre problemas arqueológicos, no son coherentes con las respuestas que se esperan de los datos, ni consecuentes con los procesos por los que se ha creado el registro arqueológico y por tanto no son congruentes con las estructuras o patrones de variabilidad inherentes en los datos arqueológicos (WHALLON 1984; DJINDJAN 1991).

La solución estaría en crear y desarrollar métodos analíticos que operen específicamente con los problemas que se están investigando. La Etnoarqueología puede darnos la clave para entender cómo se forman los suelos de ocupación y las formas de distribución del material que resultan de esos procesos. De los estudios etnoarqueológicos se han extraído datos muy interesantes (WHALLON 1984):

a) Hay un amplio margen de procesos que resultan en la deposición y distribución de materiales (artefactos y desechos) sobre un área de ocupación, y hay muchas variables que pueden afectar a este proceso.

b)Entre las variables tecnológicas implicadas podemos encontrar: 
1) diferentes grados de especificidad funcional entre tipos de objetos, mientras que algunos tipos poseen un rango bastante restrictivo en sus usos, otros son utilizados para una amplia variedad de actividades

2) diferente proporción de agotamiento o de rotura y desecho entre tipos de útiles y tipos de actividades

3) diferentes grado de reparación y reutilización de los útiles dependiendo del tipo de artefacto, de las actividades realizadas y del acceso a las materias primas

4) los diferentes espacios utilizados en las actividades requieren diferentes tamaños, formas y grados de separación entre áreas

5) diferentes patrones de consumo de las materias que han sido procesadas

c) Entre los factores sociales implicados están:

1) el tamaño del grupo social que ocupa o usa el yacimiento

2) la composición del grupo

3) la duración de la ocupación del yacimiento

4) el tamaño, forma y disposición de las distintas estructuras del yacimiento

5) patrones de movimiento dentro del asentamiento

6) patrones de distribución de la basura

d) La época del año (estación) puede influir en las actividades y la organización del espacio. 
e) Las perturbaciones post-deposicionales o alteración de los materiales (conservación diferencial, deposición geológica, actividades animales...) pueden influir fuertemente en la formación del registro arqueológico que queda.

Esta enumeración no es exhaustiva, pero implica una serie de importantes consecuencias para la distribución de materiales sobre suelos de ocupación. Una aproximación analítica apropiada para la definición de conjuntos debe ser capaz de operar con mucha libertad para acoger contrastes de forma, tamaño, densidad, composición y organización interna o estructura de los conjuntos que se identifican. Estas características deben ser consideradas como variables y no como factores que se mantienen constantes. Así surge el análisis cluster sin restricciones (WHALLON 1984).

\section{"Unconstrained clustering"}

Fue desarrollado por R. Whallon en la década de los 70, pero no se publicó hasta 1984 (WHALLON 1984). No es una técnica nueva en el sentido estricto de la palabra, sino que se refiere a un método de análisis espacial que incluye una serie de técnicas que operan bajo un mínimo de limitaciones (BLANKHOLM 1991).

Como hemos visto, la mayor parte de los métodos y técnicas de la década de los 70 operaban con grandes limitaciones teórica, metodológica y técnicamente. A partir de ahora se produce un cambio por el que se pasa de operar con tamaños, formas, densidades, composiciones y patrones internos de variación como factores más o menos constantes a tratar estos como si fuesen variables, en lo que se refiere a agrupaciones y áreas de actividad (BLANKHOLM 1991).

El método se articula en siete pasos (WHALLON 1984; DJINDJAN 1991):

1.- La distribución espacial de cada categoría de objetos se representa mediante curvas de nivel, obtenidas por diferentes métodos. La técnica manual más simple consiste en dar una valor a cada punto de una rejilla, calculado como el número de objetos contenidos en 
los cuatro cuadros adyacentes. Por interpolación lineal, las curvas de nivel se trazan manualmente.

2.- A cada punto-objeto, corresponde una densidad, la densidad de cada tipo de ítem se interpola de las curvas de nivel, creándose un vector de densidad en cada punto.

3.- Cada uno de esos vectores de densidad, se transforma en una vector de densidad "relativa" o proporcional mediante la división de cada valor entre la suma de todos los valores.

4.- Se realiza una tabla $\mathrm{n} \mathrm{x} p$, (en la que $\mathrm{n}$ es el número total de objetos y $\mathrm{p}$ el número de categorías de objetos). El análisis cluster es utilizado para combinar los puntos dados en grupos que tienden a ser homogéneos respecto a los vectores de densidad relativa.

5.- Los puntos se visualizan por un código de pertenencia a su clase que permite poner en evidencia las estructuras espaciales.

6.- Cada estructura espacial puede ser caracterizada por su tamaño, forma, densidad y composición.

7.- Cada estructura espacial se interpreta. La información generada en el paso anterior puede ser usada para la interpretación y reconstrucción del comportamiento o de los procesos que han creado la estructura espacial o la organización de los datos.

El método es teóricamente bueno y, probado con material etnoarqueológico, ha demostrado su potencial en la práctica. Es muy útil en la búsqueda de áreas de actividad combinadas y de la identificación de la tendencia de distribución sobre el suelo. Identifica con acierto áreas que probablemente podrían ser analizadas como unidades conductualmente significativas, y su habilidad de aproximación para determinar focos y pequeñas áreas de actividad es bastante prometedora. De todos modos por el momento es incapaz de definir distribuciones superpuestas (BLANKHOLM 1991). 


\section{$\underline{\text { La organización social de las actividades }}$}

En una perspectiva completamente distinta se pueden enmarcar los trabajos de Yellen (1977). Para el autor lo importante es descubrir la organización social de las actividades. Su estudio de los campamentos de los cazadores-recolectores !kung refleja una serie de ideas referidas a cómo los arqueólogos pueden utilizar los datos etnográficos: pueden elaborar modelos generales, plantear hipótesis, rebatirlas y realizar aproximaciones de laboratorio. En una situación etnográfica donde las "causas" (o respuestas) se conocen desde el principio, se pueden observar los "efectos" y los restos materiales que resultan. De forma que si bien es cierto que no se pueden hacer generalizaciones sobre la base de una única sociedad, sí se pueden evaluar modelos e hipótesis generales para el estudio de sociedades prehistóricas (cazadoras-recolectoras) (YELLEN 1977).

Para explicar su modelo, se basa en la observación directa de cómo se organizan las actividades y los individuos en un campamento !kung. Dentro de una estructura general Yellen consideró los factores que determinan dónde se llevaban a cabo cierta clase de actividades. Examinó críticamente las aproximaciones del análisis espacial en suelos de habitación del Paleolítico que eran tácitamente aceptados por los arqueólogos, concluyendo que se podían extraer una serie de consecuencias como que la forma más fiable de comprender las relaciones entre una actividad específica y dónde ocurrió es distinguir primero entre áreas que fueron utilizadas en común por todos los habitantes dentro de un campamento y aquellas que pertenecían a una sola familia nuclear. Más tarde habría que distinguir entre estas "áreas de familias nucleares" y áreas donde se llevaban a cabo actividades específicas y especializadas. La localización de estas áreas se lograría si se podían conocer y considerar factores como el contexto social en el que se habían desarrollado, la cantidad de espacio que necesitaban y el momento del día en el que se habían llevado a cabo. Para el autor, este conjunto bastante complejo de interacciones, acabaría con la noción simplista de que existen sencillas correlaciones entre una actividad específica y una sola localización (YELLEN 1977).

Los campamentos !kung son generalmente circulares en su configuración. Las cabañas están colocadas a lo largo de la circunferencia del círculo, con sus entradas mirando hacia el 
centro, y varían su tipo de acuerdo con la estación y la cantidad de tiempo que van a ser ocupadas. Durante la estación de lluvias, miden aproximadamente $2 \mathrm{~m}$. de alto por $2 \mathrm{~m}$. de diámetro; estas cabañas cupuladas, están construidas por ramas colocadas en círculo, inclinadas hacia dentro y atadas en el punto más alto del tejado. Este armazón se recubre con una fina capa de hierbas atada holgadamente dejando un pequeño espacio destinado a puerta. Por otro lado, en los campamentos temporales ocupados durante la estación seca, las cabañas consisten en unas pocas ramas frondosas colocadas sobre el suelo para dar sombra. Estas construcciones sirven igualmente como almacén para las pertenencias y para demarcar el área que pertenece a cada familia. Dentro de las cabañas se realizan muy pocas actividades y sólo durante las tormentas la gente duerme dentro (YELLEN 1977).

El hogar, que produce calor en las épocas de más bajas temperaturas, se usa para cocinar y sirve de foco de diversas actividades. Se sitúa en frente de cada una de las cabañas y está demarcado tanto por los restos de carbón, como por una pequeña depresión resultante del amontonamiento de carbones, cenizas y arena caliente durante la preparación de alimentos (YELLEN 1977).

Característica común de todos los campamentos son las distribuciones de desperdicios en el área inmediatamente alrededor de cada hogar. En la mayoría de los casos, estos desperdicios consisten en restos vegetales (generalmente nueces, frutas y piel de melón), fragmentos de huesos y residuos producto de actividades de manufactura como trozos de cáscara de huevo de avestruz, virutas de hueso y madera y fibras usadas para hacer cuerdas. Los martillos en piedra utilizados para partir nueces son los únicos artefactos que se dejan en el campamento cuando éste es abandonado y se volverán a usar cuando el campamento sea reocupado o se trasladarán al nuevo campamento que se sitúe cerca. Todo el grueso del material utilizado por los !kung, cuchillos de hierro, azuelas y hachas se traslada con sus usuarios (YELLEN 1977).

Cuanto más tiempo se ocupa un campamento o cuantas más cabañas tenga, mayor será la posibilidad de que resulte una organización circular del espacio. En los campamentos de inicios del invierno, ocupados por breves periodos cuando las lluvias han cesado, la vegetación natural suele ser incorporada en la estructura de las cabañas y las actividades de las familias nucleares se 
centran en pequeñas áreas naturales de sombra. En estos casos la forma de los campamentos, que tiende a seguir la distribución de arbustos frondosos y árboles pequeños, suele ser bastante irregular. Por el contrario, en campamentos ocupados por un gran número de familias y durante largos periodos de tiempo, la forma circular ideal está más cerca de obtenerse (YELLEN 1977).

Los campamentos !kung pueden dividirse en áreas comunales o domésticas. Las comunales incluyen tanto el espacio central del círculo de cabañas como el espacio que se articula alrededor del círculo de estructuras. El área doméstica o área familiar, en la mayoría de los casos bajo el dominio de una familia nuclear o adulto, incluye el hogar, la cabaña y el espacio que los rodea. Un individuo participa así en una división tripartita del espacio: el área que pertenece a él mismo y su familia, las áreas ocupadas por otras familias, y el área susceptible de ser ocupada por todos los miembros del campamento (YELLEN 1977).

Las cabañas normalmente están ocupadas por familias nucleares con el hombre, su esposa y los hijos de menor edad. Los jóvenes solteros del mismo sexo suelen vivir juntos en otra cabaña, mientras que las viudas, ocupan otra. Normalmente, las cabañas situadas cerca unas de otras, pertenecen a miembros de familias extendidas, de manera que la cabaña de un matrimonio suele estar en medio de la de las familias de ambos, al menos durante cierto tiempo (YELLEN 1977).

Yellen presenta primero una imagen idealizada de cómo se organizan las diversas actividades y después considera los factores que pueden distorsionarlas.

El primer elemento a considerar es si la actividad realizada implica a un solo núcleo familiar o al grupo entero. Algunas actividades, como la danza o la primera distribución de carne, son comunales e implican a uno o más miembros de cada familia, o incluso a todos los miembros del campamento. Estas actividades se realizan en el centro del campamento y suelen dejar muy pocos restos. Por el contrario, los individuos duermen y normalmente comen en el seno del núcleo familiar, desarrollando actividades que tienen lugar alrededor del hogar, ya que es aquí donde el alimento es cocinado, distribuido en partes individuales y consumido. La distribución de huesos y esquirlas de hueso resultante refleja la última etapa del proceso de distribución y consumo. Las 
actividades de manufactura se llevan a cabo en estos mismos lugares y los restos de cada tipo de trabajo también quedan alrededor de los hogares (YELLEN 1977).

Una de las consecuencias del conjunto de tareas en áreas de familias nucleares es la presencia de pequeños, pero homogéneos, conjuntos de restos materiales asociados a cada una de ellas; por ejemplo, alrededor de un hogar localizado en frente de una cabaña podemos encontrar vainas de judías, fragmentos de hueso, piel de melón y restos de actividades de manufactura. Debido a esta concentración dentro del contexto del núcleo familiar, algunas partes del campamento quedan completamente vacías de restos materiales. Dentro de las cabañas tienen lugar muy pocas actividades, por lo que no suelen quedar en su interior restos materiales (YELLEN 1977).

Sin embargo, existen una serie de factores que oscurecen la simple división de actividades entre familia y comunidad y la distribución entre áreas familiares y centro del campamento. Yellen describe algunas actividades que requieren mucho espacio y otras que dejan tantos restos que afectarían a la organización del área familiar, y por tanto se realizan fuera. Por ejemplo, el tratamiento de las pieles de grandes animales necesita que las mismas se extiendan horizontalmente para ser secadas, y esto además de ocupar mucho espacio, puede atraer a carnívoros. Así que, aunque sea una actividad de una familia en particular,se realiza normalmente en la parte de atrás de la cabaña del propietario de la piel. Igualmente también se llevan fuera las tareas que implican el calentamiento en fosas, como por ejemplo, el asado de las cabezas de los animales para el consumo en grandes depresiones rellenas de cenizas o el calentamiento de las raíces para su posterior transformación en carcajs (YELLEN 1977).

En este lugar, la mayor parte del año el cielo está despejado y la gente intenta permanecer a la sombra, lo que implica estar moviéndose en concordancia con los continuos cambios de sol y sombra. La cabaña proporciona sombra al área del hogar durante la mayor parte del día, pero cuando no lo hace, la gente cambia de sitio. El cambio puede ser simplemente hacia la parte posterior de la cabaña $\mathrm{o}$, durante breves periodos de tiempo, a la sombra de arbustos y árboles, con lo que muchas de las actividades que se realizarían dentro del círculo del hogar, se trasladan temporalmente fuera. Los juegos y el aprendizaje de los niños dentro o fuera del círculo de hogar 
familiar y la situación de algunos adultos que aunque poseen cabaña y hogar propio dependen para muchas actividades de otros grupos familiares pueden distorsionar profundamente el contexto (YELLEN 1977).

Por todos estos motivos es muy dificil predecir que sucederá en un campamento en particular, pero se podrían hacer algunas generalizaciones. En primer lugar, existe ${ }^{22}$ subyacente una distribución espacial para actividades específicas; la localización en la que una actividad tiene lugar no está situada al azar y los restos de varias clases de actividades forman conjuntos que pueden distinguirse en el suelo. En relación con la función y la localización, se podrían definir cuatro clases diferentes de áreas de actividad. La primera, situada en el centro del campamento, es el área de actividad comunal ${ }^{3}$, marcada en la mayoría de las ocasiones por la no existencia de restos. El segundo tipo sería el área de actividad del núcleo familiar que incluiría la cabaña, el hogar y los restos asociados y sería el lugar donde se realizarían la mayor parte de las actividades familiares. Fuera del círculo de cabañas podríamos distinguir dos clases de espacio, uno usado para conseguir sombra y otro para el secado de pieles y actividades similares. Yellen denomina a ambas áreas de actividades especializadas, para diferenciarlas de sus homólogas áreas nucleares (YELLEN 1977).

No hay distinción dentro del campamento entre áreas dedicadas a la subsistencia y áreas dedicadas a actividades de manufactura. Un individuo puede cocinar, preparar alimentos vegetales, hacer cuentas de collar con cáscaras de huevos de avestruz, fabricar anzuelos o hacer morteros dentro del área de actividad nuclear. De esta manera, los restos de manufactura se mezclan con desechos de huesos, cáscaras de nueces y otros restos de alimentos, e incluso si los !kung realizaran instrumentos de piedra tallada, seguramente encontraríamos los restos de este trabajo en los mismos lugares. Las áreas de actividades especializadas que resultan del movimiento en busca de sombra, son muy similares a las áreas nucleares, pero cuanto menos tiempo se permanezca en ellas, menos tareas estarán representadas. Así, una actividad concreta como es cascar nueces normalmente tendría lugar dentro del contexto de familia nuclear, y en

\footnotetext{
${ }^{22}$ Cursiva en el original (YELLEN 1977:95)

${ }^{23}$ Todas las denominaciones de las áreas están en cursiva en el original (YELLEN 1977:95)
} 
todos los campamentos donde se han comido nueces los restos aparecen alrededor del hogar, pero hemos de tener en cuenta que la gente también come nueces en las áreas de sombra o en las áreas de actividades especializadas (YELLEN 1977).

Con estos datos se pueden evaluar los distintos modelos que los arqueólogos suelen utilizar para detectar patrones de actividad en un yacimiento dado. Ya que, para el autor, la mayoría asume a priori que la mayor parte de las actividades tienen un propósito especial, están realizadas por grupos de trabajo específicos y las tareas individuales se separan espacialmente unas de otras. Watson, Le Blanc y Redman afirman a este respecto que varios miembros de una cultura pudieron realizar diferentes actividades en distintas partes del mismo yacimiento arqueológico y en el mismo momento temporal. La distribución horizontal resultante de los rasgos o vestigios culturales puede indicar o señalar áreas de actividad, como sacrificio de animales, cocina, descanso y fabricación de utensilios -que el arqueólogo interpretará probablemente, y de manera concreta, como diversas actividades de la misma gente (WATSON, LE BLANC y REDMAN 1974:133)

Para Yellen, el aspecto más engañoso de esta afirmación no sería sólo lo dmasiado simplista de su naturaleza, sino la afirmación de que la razón principal de la localización de una determinada actividad sean sus propias características antes que el contexto social en el que están envueltas. De esta creencia a priori pueden surgir serios errores, ya que se asume que los útiles que encontramos asociados en un contexto arqueológico, están relacionados con una sola tarea o forman parte de un único conjunto de útiles, como hemos observado en la definición de Whallon de conjuntos de útiles o "tool-kits", cuando, por ejemplo, se observa en los campamentos ¡kung que los martillos o yunques usados para cascar nueces se encuentran normalmente cerca de los hogares junto con altas concentraciones de huesos, lo que no significa necesariamente que exista una relación entre ambos items, sino que son marcadores físicos de diferentes actividades unidos tan sólo por el idéntico contexto social en el que se realizan. Se debe tener en cuenta que en sociedades con tecnologías relativamente simples en las que el individuo produce en primer lugar para sí mismo y su familia, una gran cantidad de actividades se realizan dentro del núcleo familiar (YELLEN 1977). 
Las variables de tipo social: tamaño del grupo, composición y duración de la ocupación, se reflejan como distribuciones de restos en los campamentos abandonados. Si se consideran las implicaciones arqueológicas de las observaciones etnográficas, se pueden sugerir una serie de estudios cuyas conclusiones podrían ser directamente usadas por los arqueólogos (YELLEN 1977).

La primera y más básica consecuencia se refiere a las diferentes formas en las que las unidades de análisis se definen. La variable con la que el tamaño de un campamento tiene una relación más fuerte es con el número total de habitantes (contando adultos y niños); mientras que la correlación entre el área total del campamento y el tamaño del grupo es muy alta. En un contexto arqueológico, sin embargo, el individuo es difícil de contabilizar, de aprehender, es muy dificil estimar el número total de miembros de una comunidad (YELLEN 1977).

Conociendo el número de cabañas y/o hogares es muy posible determinar arqueológicamente el número de unidades sociales representadas en un yacimiento. Así Yellen en su análisis utiliza el concepto de "unidad social" definido sobre la base de la ocupación de una cabaña, e incluso afirma que a través de una mejor correlación podría ser obtenido el número mínimo de individuos (YELLEN 1977).

Una segunda y más importante consideración implica la relación entre correlación y causalidad. En un lugar donde las características del terreno no imponen limitaciones en la organización del campamento, es obvio que en una correlación entre el tamaño del grupo y el área total del campamento, la forma del mismo es la variable independiente y el área total la variable dependiente. Es decir, en una ecuación de regresión que exprese la relación entre el área, o al menos el área estimada, es la variable conocida, ya que puede ser extraída a partir de la extensión de los restos, mientras que el tamaño de grupo es lo desconocido (YELLEN 1977).

Existe además un problema que está relacionado con la forma en la que se interpretan $a$ posteriori las categorías de análisis. En un nivel descriptivo o etnográfico, cuando sólo se considera a los !kung, el problema es irrelevante, el concepto de área nuclear, por ejemplo, es válido porque está basado en la observación directa. Si se examina un campamento !kung 
abandonado hace tiempo, puede que sea dificil intentar aislar las áreas nucleares individuales, pero no es necesario poner en cuestión la validez del concepto mismo. Sin embargo, al examinar un yacimiento arqueológico sin relación con los !kung, uno puede preguntarse si la idea del área nuclear es aplicable o no y si puede ser asumida a priori para el yacimiento. Esto implica identificar las características básicas y únicas de un área nuclear y mostrar cómo se pueden distinguir de las áreas de actividades especializadas. Este es el problema más fundamental: el cómo derivar hacia un sistema general desde una formulación específica, desde una perspectiva real, por tanto, es crucial determinar el uso analítico de cada formulación específica. Así, para propósitos descriptivos, la validez de establecer categorías de análisis con base a la observación puede ser aceptada, mientras que para objetivos arqueológicos, las técnicas de la derivación empírica de esas mismas unidades deben ser constantemente buscadas y revisadas (YELLEN 1977).

Se pueden agrupar las variables en dos categorías generales: variables sociales y variables materiales. El tamaño del grupo, la organización y la duración de la ocupación de un determinado lugar se incluirían dentro de la categoría social, mientras que el término material se referiría a los restos que se dejan en un campamento cuando se abandona y a su patrón de distribución espacial. En el centro del análisis subyace el interés por establecer la relación entre estas dos categorías de variables: por un lado, el número de habitantes o el grupo social implicado y la duración de la ocupación, y por otro los restos materiales observables. Establecer relaciones predictivas de esta naturaleza puede ser un instrumento muy útil para la interpretación arqueológica, y algunos estudios ya se han propuesto este objetivo ${ }^{24}$. Sin embargo, muestran ciertas debilidades, ya que no intentan establecer normas generales, sino que se reducen simplemente a realizar correlaciones sin ningún objetivo explicativo (YELLEN 1977).

Otra de las relaciones que se puede establecer es la duración de la ocupación con base en los restos materiales observables, aunque ésta es bastante dificil, ya que la cantidad de restos en

\footnotetext{
${ }^{24}$ Naroll estableció en 1962 una relación alométrica entre el área de ocupación de un yacimiento paleolítico y la población total sugiriendo que la población de un yacimiento prehistórico podía ser estimada en el orden de una décima parte del área ocupada en metros cuadrados (NAROLL 1962). Cook y Heizer repitieron el estudio de Naroll con la población aborigen de California y también encontraron una relación alométrica entre área total y población (COOK y HEIZER 1968)
} 
un determinado lugar está en relación tanto del tiempo de ocupación como del número de individuos presentes (YELLEN 1977).

Yellen, propone el modelo anular que permite predecir el tamaño del grupo mediante el anillo interno y la duración de la ocupación sobre la base del anillo externo. Estudió 16 campamentos !kung después de que sus ocupantes los hubieran abandonado y trató cada campamento como si se tratase de un suelo de ocupación prehistórico. Estableció un sistema de cuadrículas y todas sus características se describieron y trazaron al centímetro. Para los restos vegetales muy abundantes, como cáscaras de nuez, se trazaron las extensiones y cada una de ellas recibió una letra por orden alfabético, como también lo fueron los otros elementos característicos como cabañas, hogares y extensiones de carbón. Otras clases de restos vegetales, como la piel de melón, fueron tratadas como objetos independientes porque sólo se conservaban unos pocos. Todos los demás objetos como piedras para cascar nueces, tapaderas de latas, varas de madera o cáscaras de huevo de avestruz se numeraron y se recogió su posición. Todos los fragmentos de hueso se recogieron, etiquetaron e identificaron según las especies, posición anatómica y la manera en la que estaban fracturados (YELLEN 1977).

Una de las carencias del estudio es que no se pueden reproducir las condiciones geológicas, acidez del suelo, rapidez con que los materiales se entierran y similares factores que determinan el grado de preservación del material arqueológico. Aunque sí se tengan en cuenta para el análisis de los campamentos !kung elementos como las pisadas de animales (YELLEN 1977).

En cuanto a las variables sociales se decidió que para los campamentos reocupados, se establecería la duración de la ocupación como la suma de las ocupaciones individuales ya que, excepto en un caso, los grupos que los reocupaban eran los mismos. Como número de miembros se tomó el número más alto de individuos que habían ocupado el asentamiento. Los individuos casados y los individuos que ocupaban solos una cabaña fueron tomados como adultos, mientras que los niños que ocupaban una cabaña con sus padres fueron contabilizados como jóvenes. En esta categoría se incluían tanto los adolescentes como los niños más pequeños. La "unidad social" 
se definió como el grupo ocupante de una cabaña y su hogar y oscilaban en tamaño entre uno o dos adultos y cuatro niños (YELLEN 1977).

Se utilizan dos sistemas diferentes para subdividir el espacio en el campamento. El primero se basa en la delineación de una serie progresiva de unidades más pequeñas, empezando por la totalidad del campamento y moviéndose hacia las extensiones incluidas dentro de las cabañas. Se definen así cuatro áreas separadas (YELLEN 1977):

ALS (absolute limit of scatter=línea de límite de los restos): es la línea que incluye todo el campamento con todas las extensiones de desecho, la más grande y precisa de todas las áreas.

LMS (limit of most scatter=límite de la mayoría de los restos): se define de manera subjetiva, es susceptible de incluir todo el asentamiento, excepto los pocos restos y las extensiones de carbón que están claramente fuera del área del campamento. En todos los casos el porcentaje de restos entre el ALS y el LMS no supera el 5\%.

LNAT (limit of nuclear area, total=límite del área nuclear): esta línea incluye todas las cabañas con sus hogares asociados y los restos que están alrededor, comprende lo que el autor también ha denominado círculo de la cabaña.

LNAS (limit of nuclear area, scatter=límite de las extensiones de material dentro del área nuclear): las cabañas desaparecen mucho más rápido que los hogares o los restos asociados a ellas, así este área se configura en la base de las extensiones de material que quedan. Es muy útil para recalcular el area LNAT y la forma más apropiada para analizar suelos de ocupación paleolíticos.

El segundo sistema de subdivisión se basa en la identificación de diferentes conjuntos de material, como por ejemplo un hogar con fragmentos de hueso y cáscaras de nuez o un área de procesado de pieles. Esos conjuntos se denominan LS (limit scatters, extensiones limitadas) seguido de un número de identificación. Además, éstas pueden ser asociadas a areas nucleares 
(nuclear area), denominándose LS:NA o, a áreas de actividades especializadas (special activity areas), denominándose LS:SA. Para lograr el máximo uso arqueológico, las cabañas deben ignorarse cuando se analizan las LS.

A continuación, para cada una de las áreas definidas se toman dos medidas, el tamaño y la "riqueza" (número y variedad de restos), expresando el tamaño en metros cuadrados. La "riqueza" se mide mediante dos factores: el número de clases diferentes de restos y la cantidad de cada uno de ellos, pero tomándolo desde la perspectiva y concepto biológico de "diversidad de especies" para una determinada región geográfica. Así se pueden equiparar determinadas clases de restos, como huesos de puercoespín o piedras para partir nueces ... con especies individuales, Además, es fácilmente calculable. Para ello se utiliza la ecuación de Shanon-Weiner ${ }^{25}$.

Sin embargo no es útil a la hora de calcular otras superficies como cenizas o distribuciones de cáscaras de nuez. Para ello se crean cuadrículas de $10 \mathrm{~cm}^{2}$, después a cada superficie que cubra $1 \mathrm{~m}^{2}$ se le otorga una proporción arbitraria de 10, así, por ejemplo, para una LS que contenga 12 huesos de puercoespín, 4 fragmentos de asta, $0,72 \mathrm{~m}^{2}$ de cenizas y $0,58 \mathrm{~m}^{2}$ de cáscaras de nuez, el número de especies representadas será de 4 y el número de individuos dentro de cada especie será $12,4,7$ y 6 respectivamente. Se pueden aplicar así la ecuación anterior para relacionar items de distinta naturaleza y medida (YELLEN 1977).

De esta manera es posible establecer proporciones entre las distintas áreas nucleares, ocupadas bien por un sólo individuo o por varios, y áreas especializadas, dado un eje de coordenadas en el que la $\mathbf{x}$ representarían los $\mathrm{m}^{2}$ de extensión de cada área y la y representaría la "riqueza" de las áreas.

Por otra parte deben de considerarse otra serie de elementos clave como el tiempo de ocupación de cada una de las áreas o la relación entre el número de individuos y el área nuclear ocupada. En este caso deben tenerse en cuenta varios factores, el primero es que dada una familia con un número constante de miembros, el área ocupada permanecerá constante en los distintos

\footnotetext{
${ }^{25}$ La ecuación, conocida como Shanon-Weiner, está extraída por Yellen de McARTHUR, R.H. y McARTHUR, J.W. (1961)
} 
asentamientos: por otro lado el área ocupada no crece en proporción directa con el número de miembros, por ejemplo, un individuo no ocupa la mitad del espacio que dos, al igual que tres miembros no ocupan el triple espacio que uno solo (YELLEN 1977).

Considerando las anteriormente descritas áreas de sombra y las áreas de actividades especializadas, Yellen demuestra que ambas no se encuentran relacionadas con el número de individuos de la comunidad, sino más bien con la duración de la ocupación del campamento y el tiempo que tardan en acumularse demasiados restos en estas áreas como para seguir utilizándose (YELLEN 1977).

Por último Yellen plantea el modelo del anillo. Para ello subdivide el campamento en dos anillos concéntricos imaginarios. El anillo exterior comprende las áreas ALS y LNAT, es decir, el área total del campamento, mientras que el anillo interior coincide con el LNAT o el círculo de cabañas. Mientras que el anillo interior proporciona el tamaño del grupo, ya que cuando aumente el número de individuos aumentará el número de cabañas y por tanto la circunferencia; el anillo exterior, en principio, refleja la duración de la ocupación del campamento, ya que el número de áreas de actividades especializadas se comprende en este anillo y, como ya se ha indicado depende del tiempo de ocupación. Así si en una parte del campamento !kung lo que define el espacio es el número de individuos, en otra parte es el tiempo de ocupación, y ambas pueden ser determinadas por medio del número de restos materiales (YELLEN 1977).

La utilización arqueológica del modelo presenta diversas dificultades. En primer lugar la forma de las ocupaciones prehistóricas puede quedar modificada por accidentes geográficos como farallones y ríos o, por causas socioeconómicas; en segundo lugar no siempre se conoce la amplitud de la ocupación y, en tercer lugar el modelo del anillo pierde consistencia cuanto mayor sea el número de cabañas y habitantes, ya que se agranda el espacio central, normalmente desprovisto de restos significativos, desvirtuando los cálculos. Sin embargo sí se pueden establecer ciertas líneas de utilización; por ejemplo se puede distinguir fácilmente si hay conjuntos de materiales o si la dispersión es aleatoria. Si se pueden distinguir conjuntos se pueden medir (tanto en cuento a tamaño como "riqueza") y comparar con otros conjuntos. Además, partiendo del modelo del anillo el arqueólogo puede establecer una serie de cuestiones acerca de patrones 
de asentamiento e incluso sacar conclusiones acerca de la existencia de un modelo social igualitario o no, interpretado a través de estas "unidades básicas nucleares".

\section{V.2.1.d Un intento de fusión entre propuestas etnoarqueológicas y tipológicas}

En la misma línea de investigación del análisis espacial de los yacimientos encontramos los trabajos de E. Camili. Bajo premisas etnoarqueológicas, afirma que la observación etnográfica puede proporcionarnos una estructura parcial para el desarrollo de teorías generales sobre la conducta humana que puedan ser aplicadas al estudio de las industrias líticas, pero subraya dos factores determinantes en la variabilidad de los conjuntos: la historia de la ocupación del asentamiento y la función de los útiles; por tanto, el estudio debería enfocarse mediante dos perspectivas, el análisis espacial de las estructuras del yacimiento y la composición del conjunto de útiles (CAMILI 1989).

E. Camili parte de la base de que en los asentamientos que se emplean tecnologías organizadas de manera eficiente, las estrategias para la producción y mantenimiento de los útiles variarán funcionalmente entre distintos lugares, mientras que los útiles ya manufacturados, aparecerán en todos los conjuntos. La ocupación múltiple de un área de residencia con espacios para funciones específicas ha sido un elemento clave para definir sistemas de ocupación temporal de asentamientos. La distribución espacial de los artefactos, las estructuras y las distribuciones de desecho serán más grandes en las ocupaciones estacionales que en los asentamientos con ocupación ininterrumpida, ya que, en el caso de la reocupación, la relación entre área del asentamiento y abundancia de depósitos de debris depende del espacio adicional que requiera cada uno de los episodios de ocupación adicionales (CAMILI 1989).

Sin embargo, las diferencias de densidad de artefactos entre asentamientos de una sola ocupación o de varias ocupaciones vendrá condicionada por el grado de superposición de las distribuciones. En primer lugar, en yacimientos con ocupaciones múltiples, las distribuciones formadas por superficies continuadas de debrís caracterizadas por pequeñas superposiciones, pueden dar densidades comparables a las de una sola ocupación. En segundo lugar, el tamaño de asentamientos reocupados puede no ser necesariamente más grande que uno con una sola 
de la complementación entre el aislamiento de asociaciones de elementos significativas y el establecimiento de patrones de distribución y disposición de las diferentes categorías. Para ello se utilizan dos bloques de test: el método de los cuadrados y el método de las distancias (WÜNSCH 1989a, 1989b, 1991, WÜNSCH y GUILLAMON 1986).

Existen unas condiciones previas de aplicación del método:

*Que se realice el análisis de una unidad representativa de una determinada actuación socioeconómica (piso o nivel de ocupación).

*Que se realice sólo sobre aquellas categorías dotadas de significación y relevancia en términos de actividades.

*Que existan unos efectivos mínimos de las categorías a analizar ${ }^{27}$.

Como primer paso se propone hallar asociaciones de elementos significativas, mediante una matriz de contingencia que relacione de dos en dos las categorías. Para ello se utiliza el método de los cuadrados, test estadístico que como hemos visto con anterioridad utilizan los datos agrupados en celdas o cuadrículas y que analizan por un lado, el carácter aleatorio o no de las distribuciones de cada categoría a través de su comparación con distribuciones de igual densidad, y por otro la disposición en el espacio. Con el método de las distancias, se utilizan las disposiciones tridimensionales individualizadas de los restos recuperados, para hacer esto utilizan una remodelación del test del vecino más próximo (WÜNSCH 1989a, 1989b, 1991, WÜNSCH y GUILLAMON 1986).

Para poder comprender el carácter de las interrelaciones entre distintas categorías, es decir, si existe o no relación, se utiliza la distancia crítica de ruptura que consiste en observar el

\footnotetext{
${ }^{27}$ Wünsch pretende la creación de un sistema que sea, ante todo, objetivo y no se deje guiar por elementos subjetivos, como hemos visto en las críticas realizadas tanto a los trabajos de Leroi-Gourhan y Brezillón (1972) como a Ios trabajos de Binford (1993); sin embargo, entre estas condiciones previas al análisis figuran la elección de unidades representativas de actuaciones socioeconómicas o de las categorías dotadas de significación que constituyen elementos con gran carga subjetiva.
} 
ocupación, pero la densidad de artefactos en distribuciones superpuestas serán mucho más grande en los primeros que en los de una sola ocupación. La relación entre densidad de artefactos y tamaño del sitio se logra usando las medida de densidad de artefactos por unidad de área (CAMILI 1989).

La propuesta de E. Camili nos parece algo más interesante ya que juega con dos variables, ocupación espacial y conjuntos de útiles, pero sus supuestos acerca de cómo se se conservan los yacimientos en diferentes casos: ocupación continuada durante varios periodos, reocupaciones estacionales o una única ocupación ofrecen muy poca variabilidad y no son fiables.

V.2.I.e El análisis de las interrelaciones espaciales de los elementos arqueológicos: ANITES

Partiendo de una premisa básica, la existencia de una organización social del espacio ocupado, que debe entenderse como una modificación, organización y articulación del espacio en función de las necesidades socioeconómicas, lo que a su vez, se refleja arqueológicamente a través de la interrelación espacial de los restos materiales, Wünsch intenta crear un modelo cuyo objetivo básico central consiste en analizar la organización de los diferentes elementos arqueológicos (entendiendo por éstos el resultado de las actividades productivas y de mantenimiento desarrolladas por una comunidad) dentro de un espacio limitado, el asentamiento, a partir de sus interrelaciones en el marco de una unidad de base: el piso, nivel o suelo de ocupación $^{26}$ (WÜNSCH 1989a, 1989b, 1991).

Para ello propone el análisis de la interrelaciones espaciales de los elementos arqueológicos (ANITES) que incluye un tratamiento estadístico informatizado de los datos, mediante el cual los autores pretender objetivizar la información, utilizando la cuantificación (GUILLAMON y WÜNSCH 1986). ANITES pretende ofrecer una visión global analítica a través

\footnotetext{
${ }^{26} \mathrm{El}$ suelo de ocupación fue definido por Bordes como una superficie reconocible sobre la cual ha vivido el hombre paleolítico durante un lapso de tiempo lo suficientemente corto para que se pueda esperar deducir de la posición de los vestigios alguna cosa en relación a sus actividades (BORDES 1975:39). Un año más tarde Rigaud amplio el concepto definiéndolo como el resultado intacto o casi (intacto) de la ocupación de un yacimiento por un grupo humano durante un cierto periodo de tiempo (RIGAUD 1976:)
} 
solapamiento de las áreas de las distintas agrupaciones de categorías observadas (WÜNSCH 1989a, 1989b, 1991, WÜNSCH y GUILLAMON 1986).

\section{V.2.2. Aplicación de técnicas estadísticas al yacimiento de Los Castillejos}

La técnica estadística elegida para el análisis espacial de la industria lítica de Los Castillejos es el "K-means". La elección se debe a que es el procedimiento que más importancia concede al papel del arqueólogo en la interpretación, y el más flexible a la hora de los resultados. Es por esto que, por este proceso podemos obtener varias soluciones igualmente válidas, pero siempre será el arqueólogo el que controla y guía las operaciones lo que permite eligir la respuesta que más se adecue a su planteamiento teórico (Pallares i Año 1993:392). Además, en los test realizados por H.P. Blankholm ha sido calificado como bueno.

A pesar de que esta técnica ha sido muy usada por los arqueólogos durante dos décadas, no ha sido hasta recientemente cuando se ha explotado su potencial para el análisis espacial (BLANKHOLM 1991:62). A. J. Ammerman, K. W. Kintigh y J. F. Simek comprobaron la necesidad del desarrollo de nuevos métodos de análisis espacial que adaptaran de forma más lógica los datos arqueológicos y los objetivos propuestos. Su aproximación se basó entonces en los análisis cluster de k-means como un medio de realizar una aproximación más heurística (conductual) al estudio de los patrones espaciales en arqueología (AMMERMAN et al. 1987). Ellos desarrollan como alternativa el análisis espacial heurístico en el que se pretendía:

“... combinar la sofisticación intelectual de la aproximación intuitiva con la capacidad de procesar información y con los beneficios sistemáticos de los tratamientos cuantitativos." (Kintigh y Ammerman 1982:33)

Los autores puntualizan los tres componentes del análisis espacial heurístico; el primer problema es el del espacio, es decir, los datos y las relaciones entre éstos sobre los que se va a investigar, el segundo son los modelos hacia los que se dirige la búsqueda, y tercero el cuerpo de conocimientos sobre el análisis del contexto que no es lo suficientemente completo como para llegar directamente a la solución o es tan inadecuado que toda posible solución debe ser 
examinada para poder encontrar la más adecuada. El conocimiento sobre el problema es formulado en términos de roles conductuales, o simplemente conductas (KINGHTIN y AMMERMANN 1982: 33-34). En resumen, los roles heurísticos o conductuales deben ser tomados como las líneas guía derivadas del conocimiento contextual de la situación (BLANKHOLM 1991:62). Estas líneas guía servirán para la búsqueda de la más alta resolución de las estructuras subyacentes de los datos. En esencia no preocupa que algoritmos o que datos se desarrollan, ellos no pueden reemplazar el análisis humano y su conocimiento de fondo. El análisis humano será y deber ser siempre el control y la guía de estas operaciones. Después de todo es en la mente humana donde la mayoría de la información esencial y a menudo cualitativa, no susceptible a rápidos procesos de datos computerizados, es guardada y almacenada.

Los autores pretendían que el análisis pudiera contestar ciertas cuestiones (KINGHTIN y AMMERMANN 1982):

*Concentración o no de los conjuntos de útiles en el espacio.

*Forma y tamaño de las agrupaciones individuales.

की

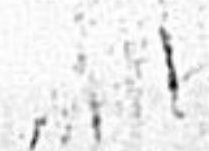

*Uniformidad o no del patrón interno de los conjuntos de útiles individuales:

*Localización de puntos que no se ajustan al patrón:y'análisis de los mismo para ver si forman un patrón uniforme a otra escala.

El objetivo de este método no es proporcionar un índice o comprobar el agrupamiento espacial, sino identificar los agrupamientos espaciales con las coordenadas de los items que los forman, mediante un análisis de conglomerados no jerarquico (Pallares 1993:392). El K-means es un forma de análisis cluster en el que se pone toda la atención en minimizar las variaciones dentro de los conjuntos, mientras que se maximizan las que existen entre los conjuntos. El método es partir desde un simple conjunto o grupo de puntos y proceder a subdividir este grupo para obtener otros conjuntos. El programa acepta como datos las coordenadas $\mathrm{X}, \mathrm{Y}$ de un conjunto de puntos que representan localizaciones de artefactos. Su objetivo es localizar la configuración 
óptima de conjuntos para conseguir el máximo número de agrupaciones, se definen círculos de puntos cuyo centro es la media de todas las coordenadas $\mathrm{X}$ e $\mathrm{Y}$ del mismo conjunto, mientras que el radio se mide mediante la raíz cuadrada de la desviación (AMMERMAN et al. 1987).

Técnicamente, el análisis "K-means" posee algunas ventajas ya que no tiene los problemas derivados del uso de sistemas de rejillas y porque no implica la necesidad de una determinada dimensión de las áreas (Blankholm 1991:63).

Sin embargo posee otros inconvenientes (Blankholm 1991:63):

1) Incluye una determinación de la asociación o composición espacial de artefactos de una determinada clase, por lo que es difícil establecer comparaciones entre tipos de artefactos individuales.

2) Puede poner de manifiesto superficies de tipos de artefactos individuales, pero como no puede averiguar la medida de la asociación espacial, no puede trabajar directamente con superficies de áreas de actividad.

3) No puede trabajar con distribuciones curvilíneas.

4) Debido al uso de la media de la raíz cuadrada tiene tendencia a "crear" áreas de actividad circulares.

5) Debido a los problemas asociados con el uso de la correlación y la regresión para las investigaciones espaciales en general, estos mecanismos deben considerarse sólo desde un punto de vista expositivo y descriptivo.

La mayoría de estos problemas podrían ser solucionados con el uso de técnicas alternativas, adicionales y complementarias y por la adopción de una actitud relajada ante los rendimientos estadísticos, considerándolos simplemente como descriptivos. 
La aplicación del "k-means" muestra que el método puede ser útil para señalar el centro de un lugar de actividades individuales con una media de precisión de $0.59 \mathrm{~m}$. Es también muy preciso a la hora de delinear áreas de actividad, en la medida que éstas están limitadas y definidas dentro de áreas de items conservados. Igualmente es positivo a la hora de dirigir la atención a áreas que pueden ser analizadas como unidades significativas conductualmente por sí mismas (Blankholm 1991:75).

Para esta, y para la aplicación de cualquier método o técnica, es importante señalar que el punto de partida es la actual disposición de los items en el yacimiento, no la actividad y las áreas funcionales ya definidas, delineadas y descritas. Esto es importante ya que de otra manera no sería un test real sino un intento de adaptar los análisis a las conclusiones ya hechas, con todo el potencial de argumentos circulares que esto implicaría (Blankholm 1991:64). 
VI. EL POBLADO DE “LOS CASTILLEJOS” EN EL MARCO DE LAS INVESTIGACIONES ARQUEOLÓGICAS EN EL SURESTE Y LA ALTA ANDALUCÍA 


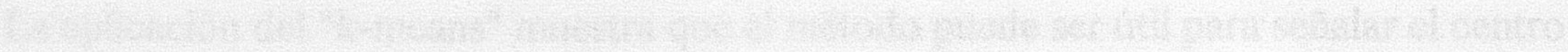

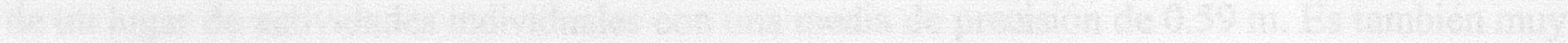

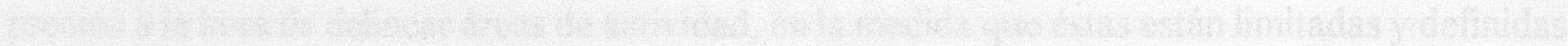
and a

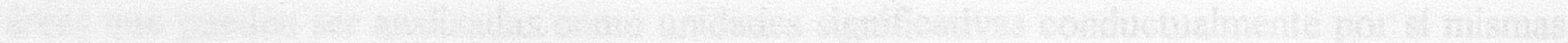
(n)

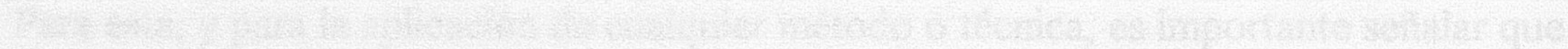

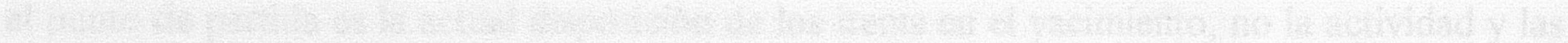
(20)

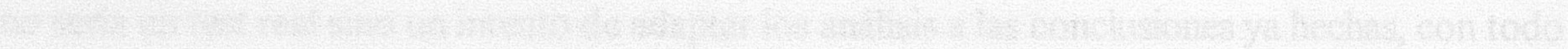

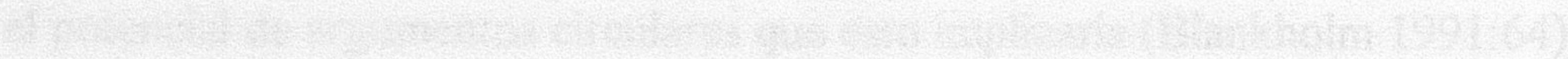

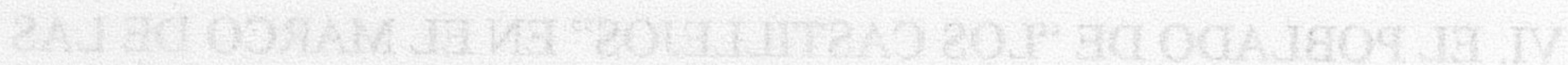

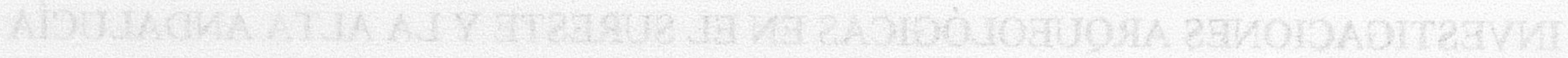




\section{1. La investigación arqueológica}

Pocas veces el estudio de un solo yacimiento arqueológico hace posible realizar, como veremos a continuación, un repaso a la historia de la investigación de la arqueología peninsular en general y de la arqueología andaluza en particular. En este sentido, el yacimiento de Los Castillejos de Las Peñas de los Gitanos en Montefrío (Granada) supone un caso excepcional, ya que, en él se han desarrollado diversas investigaciones a lo largo de más de un siglo, concretamente desde mediados del siglo XIX hasta las últimas campañas de excavación realizada entre los años 1991 y 1994, que nos permiten analizar de forma crítica los contenidos teóricometodológicos empleados, y que, obviamente, suponen un elemento básico de referencia en la configuración del actual del conjunto arqueológico de Las Peñas de los Gitanos.

Durante este periodo las líneas de investigación desarrolladas en el yacimiento han estado sometidas a las directrices de los diferentes enfoques teórico-metodológicos que en cada momento han configurado el devenir de la disciplina arqueológica de nuestro país. La larga tradición de las investigaciones realizadas en Las Peñas de los Gitanos de Montefrío ha generado diversas revisiones historiográficas (MERGELINA 1941-42; TARRADELL 1952; ARRIBAS y MOLINA 1975; 1979a; 1979b; MORENO 1982; AFONSO et al. 1995) suficientemente cualificadas, por lo que a continuación nos proponemos contextualizar la historia de las investigaciones, de tal forma que los diferentes programas de investigación desarrollados queden plenamente articulados, referenciados $\mathrm{y}$, por tanto, explicados, tanto dentro del discurso arqueológico dominante en cada momento como del contexto sociopolítico inherente a toda investigación.

Los primeros trabajos de investigación arqueológica realizados en el conjunto arqueológico de la Peñas de los Gitanos se enmarcan dentro del proceso de definición de la Prehistoria como periodo histórico y de la Arqueología como ciencia. En este sentido, durante la segunda mitad del siglo XIX, las concepciones derivadas del coleccionismo, del anticuarismo, de la geología y la paleontología van a marcar la metodología utilizada, principalmente orientada a lä 9 htención del artefacto. En lo referente a la Europa mediterránea, será el coleccionismo el prinqipjo de mayor trascendencia, entendiendo que el arqueólogo debe consagrar su labor al 
estudio de los vestigios monumentales y las obras del arte de la antigüedad (DE LAET 1981, TRIGGER 1992).

En este contexto de la segunda mitad del siglo XIX se encuadra, entre otras, la figura de Manuel de Góngora y Martínez, cuya obra Antigüedades Prehistóricas de Andalucía ${ }^{28}$ (1868) será punto de referencia posterior. Es aquí, donde por primera vez se da noticia de las Peñas de los Gitanos. Dentro del marco teórico en el que se mueve el autor, la visión teórico-metodológica utilizada va a implicar la obtención del objeto como fin último del proceso de la investigación, sin tener en cuenta otro tipo de información que ayude a la interpretación histórica, la lectura directa va a constituir, de esta forma, la base de la Arqueología de esta época (RUIZ RODRÍGUEZ et al. 1986a).

En general, y desde el punto de vista metodológico Góngora utiliza la descripción pormenorizada y un tanto novelada como rasgo básico de su trabajo, acompañado de un importante aparato gráfico por la propia naturaleza de los datos, y no sólo como mera ilustración. En el discurso expositivo de los hallazgos, que podemos utilizar para valorar la metodología desarrollada, comienza por el análisis geográfico, historia de la investigación, si la hubiera, descripción de todo lo hallado y un intento de clasificación cronológica y tipológica (PASTOR MUÑ̃Z y PACHÓN ROMERO 1991).

Góngora también presta atención al papel de la exploración y reconocimiento del territorio, sistematizando sus recorridos a base, por ejemplo, de las vías romanas. Por otra parte utiliza referencias etnológicas para la interpretación de los datos arqueológicos relacionando, por ejemplo, los restos arqueológicos de la Cueva de los Murciélagos (Albuñol, Granada) con la cultura Guanche o las producciones de cestería con las coetáneas (GONGORA 1868:41).

Así, y en cuanto a Las Peñas, Góngora hace referencia a la geografia del lugar y describe parte del material encontrado: El viajero, que saliendo de Granada con rumbo al Occidente, andadas seis leguas, llega al Tocón, encuentrase con un riachuelo en dirección de Norte a Sur,

\footnotetext{
${ }^{28} \mathrm{~A}$ pesar del título elegido por Góngora, su estudio se va a centrar básicamente en la Alta Andalucía.
} 
que corre entre las ásperas cañadas y cerros cubiertos de pinos. Alguna arrinconada casilla se divisa en aquella fragosidad; hasta que después de cinco fatigosos cuartos de legua, arroyo arriba, por aventurado camino, precipicios y cuestas violentísimas, descúbrense unas pequeñas vegas, circundadas por larga fila de muy valientes rocas á que dicen Las Peñas de los Gitanos, término y jurisdicción de Montefrío. Entre sus inmensas cortaduras y callejones hay numerosas cuevas. Alli he descubierto yo mismo huesos humanos, cascos de vasijas de barro ceniciento y armas de piedra, rotas en su mayor parte. Cinco de ellas conservo y en una resalta materia caliza, acumulada por la lenta acción de los siglo (...) (GÓNGORA 1868:57).

Desde la perspectiva anticuarista, dentro de la que podemos enmarcar el trabajo de Góngora, el objeto arqueológico es concebido como un fin en sí mismo. Esta visión de la arqueología ha tenido importantes consecuencias, entre las que podemos destacar el haber contribuido a generar una concepción de lo antiguo que ha ayudado a la continua destrucción del patrimonio histórico y más concretamente arqueológico (RUIZ RODRÍGUEZ et al. 1986a). Obviamente Gongora no debió ser consciente de las implicaciones de la concepción teóricometodológica que utilizaba, de hecho, a lo largo de su obra son continuas las referencias en defensa del patrimonio arqueológico, junto con muestras de impotencia e indignación. En este sentido, y en relación con el expolio continuado de las necrópolis, Gongora afirma lo siguiente: (...) iDescubridores felicísimos!, ;ignorantes del verdadero tesoro con que os brinda la fortuna!, irespetad este asilo de la muerte!, ideteneos un instante!, no paguéis tributo a la común ceguedad, por breves horas dejaz que la ciencia observe y anote (...). Más de cuarenta siglos han respetado esa necrópolis, no despedaceis vosotros en un día como dehementes e insensatos. ¡Más, ay, que poco saben los hombres de lo que vale mucho y de lo que nada vale! (GONGORA 1868:35-36).

Cuando visité por primera vez estos lugares, la codicia de dos jornaleros se ocupaba de desenvolver un dolmen. Huesos esparcidos, pedazos de vasos rotos y algunas armas de cobre que recogi con el mayor anhelo eran el fruto de semejante profanación (GONGORA 1868:97).

Desde el posicionamiento positivista la concepción del patrimonio utilizada y transmitida ha consistido en la valoración del objeto como fin último de la ciencia, desde esta perspectiva, el 
objeto era valorado estilísticamente en unos casos, y/o económicamente en otros, pero en última instancia siempre era concebido para ser atesorado, lo cual, ha generado el desarrollo del coleccionismo privado y público ${ }^{29}$. El propio Gongora, criticaba la forma en que se recuperaban los objetos, pero no hacia extensible la crítica al coleccionismo, ya que esa era su posición ante el documento.

Gracias a esta concepción del patrimonio se ha mitificado el objeto, fomentando tal y como afirma A. Carandini (...) el culto estético por la obra de excepcional valor, hasta hacer de ella un fetiche propuesto a las masas como objeto de culto, que por lo tanto puede ser venerado o profanado (...) (CARANDINI 1984:154). Por tanto, ya desde los inicios de la arqueología, las implicaciones sociopolíticas son evidentes. En la reflexión que acabamos de realizar, sería el desarrollo de una concepción de la cultura acorde con los intereses de la clase dirigente.

La primera excavación realizada en el yacimiento data de 1926 por encargo de la Junta Superior de Excavaciones y Antigüedades, y llevada a cabo por Cayetano de Mergelina. Con motivo de la publicación de los resultados, Mergelina hace una revisión del megalitismo en la Península Ibérica, dentro de un marco interpretativo en el que tienen primacía la idea de progreso y gradación de la cultura y el difusionismo, el aporte étnico o la invasión en este caso, como principio para explicar los cambios que se producen en la cultura prehistórica. En esta línea se argumenta: Se ha supuesto y se ha llegado a afirmar con todas las características de una realidad, la entrada de un nuevo pueblo, que aporta como bagaje importantes y nuevos aspectos culturales, y cuya influencia se deja sentir tan eficazmente sobre el viejo fondo indigena, que crea por decirlo así, nuevo estado de civilización en la península ${ }^{30}$. Se afirma que, a finales del Neolítico, en el SE. de la Península, irrumpen nuevos pueblos, constituyendo la entrada de ellos, lo que se ha llamado cultura del pueblo de Almería ${ }^{31}$, por ser esta región donde primeramente

\footnotetext{
${ }^{29}$ En este sentido interpretamos la concepción de la cultura expresada y trasmitida por los museos arqueológicos, en donde, por norma general, los objetos son expuestos de forma descontextualizada exaltando sus connotaciones estilísticas.

${ }^{30}$ Énfasis propio.

${ }^{31}$ Énfasis en el original.
} 
se observan los cambios de modalidades de un modo bien definido y claro (MERGELINA 194142:43).

Una vez instaurados en suelo andaluz, comenzaría una verdadera expansión $n^{32}$ hacia Europa, difundiéndose principalmente por vía marítima y cristalizando en las zonas costeras del Oeste a base de un concepto más desarrollado de megalitismo (Morbihan). De aquí, alcanzando el Mediodía francés, vuelve a penetrar en la Península a través de los dos grandes pasos pirenaicos, determinando como independientes de los restantes focos peninsulares el vasconavarro y el catalán. (MERGELINA 1941-42:62).

A la hora de analizar los sepulcros megalitos de Montefrío, Mergelina los integra dentro de una amplia región que incluiría desde los dólmenes almerienses hasta los extremeños, pasando por los focos de Granada, Antequera, la Janda, Sevilla y Huelva. Su análisis posterior de las distintas tumbas valora la orientación de las mismas, la descripción de las características constructivas, la disposición de los enterramientos, la composición del ajuar y el inventario de los monumentos.

En la terraza, que él denomina acrópolis de Guirrete por el cortijo de las inmediaciones, se desarrolló una campaña de excavación, en el año 1926, durante la cual se documentaron restos constructivos y se realizaron cortes en el relleno arqueológico acumulado por diferentes asentamientos al aire libre. Como resultado de las investigaciones se estableció la siguiente secuencia de ocupación (MERGELINA 1945-46):

-Un primer momento denominado neo-eneolítico, al que pertenecerían los dólmenes y que vendría definido por restos de cerámica y pedernal.

-Una segunda ocupación, calificada como hispánica, definida por los muros defensivos de la segunda línea de cierre de la acrópoli, y documentada por cerámica y monedas, y en la que se encontrarían indicios de contacto con el mundo romano.

\footnotetext{
${ }^{32}$ Énfasis nuestro.
} 
-La tercera fase visigoda con sepulturas con ajuares y cerámica de la época.

-Y una última fase de ocupación árabe.

En relación a la concepción teórica anteriormente comentada, en el plano metodológico, durante la segunda mitad del siglo XIX y primeros años del XX, las técnicas de campo presentan un desarrollo anárquico resultado de la concepción derivada de la búsqueda del objeto por el objeto. Los niveles de ocupación son asimilados a filones y la excavación arqueológica es, antes que nada, una recogida de objetos (COYE 1989).

En esta línea podemos encuadrar los trabajos de Gongora y en menor medida las excavaciones de Mergelina, quien desde el punto de vista metodológico parece poseer una cierta preocupación por desarrollar una excavación de carácter estratigráfico: A partir de estos muros defensivos tan interesantes, las excavaciones sobre la terraza indicada vino (sic) a darnos, la existencia de dos claros niveles y bien definidos (...). Primero, un nivel profundo, poco aislado del suelo rocosos, constituido por una tierra oscura y apelmazada en la que son abundantes, más que en la superficie, los hallazgos de fragmentos de cerámica neo-eneolítica, hachas en piedras duras, (...) Independientemente, podemos señalar otro nivel arqueológico, no tan claramente diferenciado en cuanto a una posible estratigrafía, pero sí definido, no sólo por los hallazgos de superficie, sino también por las ruinas de construcciones exhumadas (...) (MERGELINA 1945-46:20).

Tras la Guerra Civil la Arqueología española, entra en una etapa de estancamiento. El nuevo poder sustituye las instituciones dedicadas a la investigación prehistórica creadas durante la República, formando un nuevo organigrama basado en la Comisaría General de Excavaciones Arqueológicas, en donde se integraban los investigadores relacionados con la ideología impuesta por el régimen franquista ${ }^{33}$. Se crea la figura de comisario provincial encargado de la supervisión

\footnotetext{
${ }^{33}$ Desde esta perspectiva, las connotaciones ideológicas se encuentran presentes en las diversas publicaciones organizadas desde las nuevas instituciones arqueológicas, básicamente centralizadas en la Comisaría General de Excavaciones. No nos resistimos a introducir los comentarios reflejados en la memoria de actividades arqueológicas de los años 52-53 en donde la actividad arqueológica prácticamente adquiere connotaciones rituales: La Comisaría General regaló a Su Santidad una colección de sus publicaciones, y
} 
y control de los diferentes restos arqueológicos aparecidos. Afirma Martínez de Santa-Olalla Vino la Comisaría General de Excavaciones Arqueológicas a recoger una herencia brillante, la de la Junta Superior de Excavaciones y Antigüedades (...). Interrumpida por nuestra guerra, se piensa en remozarla, sobre todo, salvando ciertos inconvenientes de lentitud que tiene la vieja Junta, entregando todas las riendas y directrices del trabajo arqueológico de campo y de salvación y acrecentamiento del Patrimonio Arqueológico Nacional a una Comisaría (...).

Digo que revolucionaria en la vida arqueológica española, porque la Comisaría se propone, desde un principio, ver de incorporar a la vida arqueológica activa a todos los españoles dispuestos, con buena voluntad y honestidad, a trabajar en la defensa y acrecentamiento del Patrimonio Arqueológico. Pensó que todos, absolutamente todos los españoles, por muy altos y perfectos en su formación científica o por muy modestos que fueran, tenian un papel y un papel importante y transcendental en el quehacer arqueológico de cada día.

Por ello, nuestra Comisaría (...) trató de conseguir una gran red, cuanto más tupida mejor, con las Comisarías Provinciales, Insulares y Locales que vigilara los campos de España y que fuera salvándolos.(MARTÍNEZ SANTA-OLALLA 1947:53-54).

Como hemos observado, estos comisarios provinciales en la mayoría de los casos no son arqueólogos profesionales, sino aficionados que colaboraban "desinteresadamente", lo cual, evidentemente, implicaba una falta de rigor metodológico, y contribuyó a la desprofesionalización de la arqueología. Un simple recorrido por la bibliografía de aquellos años, nos evidencia como la arqueología es considerada una actividad secundaria ejercida básicamente por médicos, abogados, farmacéuticos, ingenieros, maestros, y otros.

Del mismo modo, la mayor parte de los cambios en el mundo académico se produjeron al final de la guerra civil, por un lado se produjo el exilio de un gran número de intelectuales, alguno de especial incidencia en el panorama de la investigación arqueológica, como P. Bosch

recibió la Bendición Apostólica, junto con encendidos elogios por la labor realizada (N.A.H. II, 1955, pág. 251). 
Gimpera y, por otro, se generó la reorganización de las instituciones. El mencionado Julio Martínez de Santaolalla ocupó, de manera no oficial, la antigua cátedra de Historia Primitiva de Obermaier, que a partir de entonces pasará a denominarse de Etnología y Prehistoria. Fue nombrado director de la Sociedad Española de Antropología, Etnografía y Prehistoria (S.E.A.E.P.), y pasó a controlar la mayor parte de las publicaciones que sobre Arqueología se editaban en Madrid, entre las que destacan Informes y Memorias de la Comisaría General de Excavaciones Arqueológicas, Acta Arqueológica Hispánica o Actas y Memorias de la Sociedad Española de Antropología, Etnografía y Prehistoria (DÍAZ-ANDREU 1993).

Mientras tanto en Barcelona, aparece la figura de Martín Almagro Basch, que ocupó el puesto del exiliado Pere Bosch Gimpera como catedrático de la Universidad de Barcelona. Fue nombrado director del Museo Arqueológico, reabierto en 1940, y comenzó la publicación de la revista Ampurias; al mismo tiempo que se hizo cargo de las excavaciones en la ciudad de Ampurias. M. Almagro Basch transformó la arqueología catalana, que se había caracterizado hasta la Guerra Civil por mantener las bases nacionalistas, en una arqueología al servicio del Estado (DÍAZ-ANDREU 1993).

Dentro de este contexto, se desarrollan nuevos trabajos de excavación en el conjunto arqueológico de Los Castillejos, desarrollados por M. Tarradell, que por durante unos años estuvo al frente de un fugaz Servicio de Investigación Arqueológica creado por la Diputación Provincial. Tarradell va a intervenir básicamente en la cueva de las Cabras, la cueva de la Alondra, la raja de la Mora, la cueva Negra y cueva Alta, realizando también diversas catas en el poblado de los Castillejos; frente a las excavaciones anteriormente analizadas, durante esta nueva fase el interés estratigráfico aparece mucho más afianzado, determinando las áreas donde intervenir para lograr este objetivo. A nivel secuencial en el poblados se diferenciaron tres niveles de ocupación, que son analizados en función del sistema de los paralelos. Por otra parte, una de las características, generalizadas durante este periodo, en las excavaciones sería la falta de una planificación y unps objetivas grmios ing intervención, exceptuando su encuadre cronológico, es decir, las excavácíones se realizan sin que estén encuadradas dentro de proyectos de investigación, simplemente el interés qup suscita un determinado yacimiento, ya sea por razones historiográficas o por coyunturas puntuales, genera una intervención inmediata. Desde esta 
perspectiva Tarradell argumenta lo que sigue: En octubre de 1946, cuando estaba a nuestro cargo el efimero Servicio de Investigaciones Arqueológicas de Granada, realizamos una prospección con el fin de reconocer las cuevas señaladas por Gongora y que no habían sido excavadas. Pronto nos dimos cuenta de que el lugar merecía una campaña, que se inició inmediatamente (TARRADELL 1952:50).

En esta misma línea debemos destacar la labor de M. Gómez-Moreno. Su principal aportación consiste en la descripción exhaustiva en formas, construcción y medidas de las sepulturas megalíticas de El Rodeo y La Camarilla, adscribiendolas tras el estudio de los materiales a las últimas fases del Neolítico. En la línea, tan usada en la época, de establecer paralelos, Gómez-Moreno compara estas sepulturas con las cercanas de la necrópolis de Antequera. Así, describe En el valle de la Camarilla distínguese porción de ellos pequeños, como lo son las tumbas subyacentes, que no sobresalen del suelo; medirán un metro de alto por tres de ancho, y son de cantos rodados bastante parejos. Los sepulcros se componen de dos partes: cámara y callejón. Éste es angosto y bajo, con sus paredes inclinadas y enlosado; al fin ábrese una puerta, menor de un metro en altura por lo común, de forma trapezoidal, disminuida de abajo a arriba en un tercio, y tallada en una sola piedra, cuidando que su intradós formara superficies curvas, lo mismo que en Antequera (GÓMEZ MORENO 1949:352). Ya en el poblado de "Los Castillejos", recogió fragmentos de cerámica neolítica e ibérica y describió dos lienzos de la muralla (GÓMEZ MORENO 1949:356).

Durante los años 40, cabe destacar las aportaciones realizadas por Vera y George Leisner. Los trabajos de estos investigadores alemanes concluirán en la realización de un corpus sobre tumbas megalíticas ibéricas, continuando la labor de L. Siret, cuya documentación sistematizaron y publicaron. Desde un punto de vista metodológico, los Leisner, recogen los caracteres estructurales de los sepulcros megalíticos realizando planimetrías en planta y en sección, así como algunas reconstrucciones. En Die Megalithgraber der Iberischen Halbinsel. Der Süden (LEISNER y LEISNER 1943) presentan los caracteres tipológicos de las tumbas relacionados con los ajuares funerarios encontrados en ellas, tal y como ya había realizado Siret. 
Para ello dividen el estudio y la descripción de las tumbas en tres grandes grupos; por un lado las de cámara rectangular con puerta perforada, por otro las de cámara rectangular sin puerta perforada y por último las de cámara trapezoidal.

Tras sus trabajos de excavación a lo largo de todo el sur de la Península Ibérica, consideraron que los sepulcros megalíticos y sus correspondientes ajuares neolíticos tendrían unos orígenes indígenas en los pastores nómadas de las tierras del interior, mientras que los tholoi, con ajuares eneolíticos, tendrían un marcado carácter exótico; estas tesis fueron acogidas favorablemente por la mayoría de autores alemanes y portugueses (ARRIBAS y MOLINA 1984).

Los años 1953 y 1954 fueron claves para la arqueología española. En estos momentos se convocó la oposición a la cátedra que Martínez Santa-Olalla había ocupado oficiosamente y fue ganada por M. Almagro Basch, que fue sustituido en Barcelona por Pericot, discípulo de Bosch Gimpera. De esta manera empezó el declive de la importancia de Martínez Santa-Olalla dentro del panorama arqueológico español. La llegada de Almagro a Madrid trajo, como una de las consecuencias más importantes, la creación del Departamento de Prehistoria del CSIC (DÍAZANDREU 1993).

Durante el año 1953, se celebró en Granada el Primer Curso Internacional de Arqueología de Campo patrocinado por la Comisaría General de Excavaciones Arqueológicas y bajo la dirección de Julio Martínez Santa-Olalla. F. Presedo, en una nota publicada en el Noticiario Arqueológico Hispánico (1955), justifica la celebración del Curso de esta forma: Por razones obvias para todo el que conozca de cerca la realidad de las excavaciones realizadas en España hasta la fecha, era necesario elevar el nivel cientifico de los excavadores nacionales, poniendo ante su vista una excavación modélica del tipo de las realizadas en Suiza y Alemania principalmente (PRESEDO 1955:252).

La elección de la provincia de Granada queda igualmente justificada de esta manera: Para el Primer Curso Internacional de Arqueología de Campo se escogió la provincia de Granada, provincia que desde hacía mucho tiempo sufría un cierto abandono en las actividades arqueológicas nacionales. Por la enorme variedad de sus yacimientos ofrecía una antología 
arqueológica de gran importancia, además de un interés turístico excepcional, no desaprovechable en una actividad de carácter europeo (PRESEDO 1955:252).

Como actividades incluidas dentro de la programación del congreso se eligió el conjunto arqueológico de las Peñas de los Gitanos (Montefrío, Granada) para realizar varias excavaciones demostrativas. En este sentido, el profesor holandés Van Giffen excavó un dolmen y D. Vicente Ruiz Argilés excavó el poblado del Bronce Mediterráneo, dedicándose una jornada a las excavaciones de la cueva, poblado y dólmenes. De los trabajos realizados por Van Giffen no se dispone de documentación, ya que los diarios de excavación que redactó no pudieron recuperarse a pesar de los intentos de A. Arribas (ARRIBAS y MOLINA 1979a). El yacimiento incluso se fotografió desde el aire, ya que el Ministerio del Aire puso a disposición del curso un avión para hacer fotografia arqueológica sobre diversos yacimientos (PRESEDO 1955). Sin embargo, no ha quedado ningún documento escrito sobre las conclusiones a las que se llegó en las reuniones posteriores.

Queda, por tanto, claro que desde la propia dirección de la Comisaría General de Excavaciones, se reconocía la problemática metodológica de las intervenciones arqueológicas realizadas durante esta etapa, problemática que, por otra parte, tiene su origen en la propia estructura organizativa, caracterizada como anteriormente indicábamos por la desprofesionalización de la actividad arqueológica.

A partir de 1965, coincidiendo con el intento de apertura política y despegue económico, se impone un nuevo modelo metodológico de análisis de la cultura material. Se produce un vuelco en la matriz arqueológica dominante, pasando de una perspectiva historicista a un modelo positivista en donde la contrastación empírica y la fijación de una cronología van a ser los nuevos objetivos en torno a los que van a girar las investigaciones. En este sentido la excavación estratigráfica será la expresión más clara de esta nueva tendencia ampliamente desarrollada durante la década de los 70 .

Con esta nueva visión del desarrollo teórico-metodológico en Arqueología se va a institucionalizar un modelo de publicación de los resultados obtenidos en las excavaciones, se 
comienza describiendo el yacimiento y su entorno geográfico y geológico, posteriormente se describe la técnica de excavación utilizada, los diferentes cortes y sus estratigrafias, así como los materiales asociados, acompañado del estudio comparativo y se termina estableciendo una propuesta cronológica, que constituye el objeto final del trabajo.

En esta línea podemos encuadrar las primeras campañas de excavación desarrolladas por el Departamento de Prehistoria y Arqueología de la Universidad de Granada en el poblado de Los Castillejos durante 1971 y 1974, campañas que van a consistir en la realización de cuatro cortes planteados en función de los resultados obtenidos en las campañas de excavación realizadas por Tarradell en 1946-47 (ARRIBAS y MOLINA 1975, 1979a, 1979b). Así mismo, se realizó un sondeo estratigráfico en la Cueva de las Tontas con el objetivo de comparar los resultados obtenidos con los de los niveles inferiores del poblado (TORRE SANTANA 1984).

El proceso de excavación tuvo como objetivo la obtención de una secuencia estratigráfica detallada, ya que hasta ese momento no se contaba en el Sur con una buena adscripción temporal de los fósiles directores con los que se definía las fases culturales de la Prehistoria Reciente. Se diferenciarán diversas fases de ocupación definidas por estratos a los cuales quedarían asociados los diversos conjuntos materiales aparecidos. La secuencia de Montefrío integraba seis fases. La más antigua del yacimiento es la I, representada por los estratos I y II y quedaría fechada en un Neolítico Tardío, aproximadamente en torno al 3000 a. C.; la fase II (estratos III y IV) ocuparía el Neolítico Final y estaría enmarcada entre el 2800 a. C. y el 2600 a. C.; la fase III (estrato V), comprendería el Cobre Antiguo y Medio, la fase IV correspondería a un Cobre Pleno (estratos VIa y VIb) en un momento paralelo a Millares II; y por último, la fase V (estratos VII, VIII y IX) pertenece al Cobre Tardío-Final, mientras la fase VI (estrato X) se inicia con la fundación de un hábitat íbero-romano (ARRIBAS y MOLINA 1979b).

Existe un estudio pormenorizado de los diferentes elementos hallados en el registro, haciendo un especial hincapié en las producciones de tipo cerámico, que son correlacionadas con las aparecidas en de otros yacimientos andaluces, siendo esta una de las características más significativas, ya que por primera vez los paralelos se realizan entre las producciones cerámicas 
de diversos ámbitos culturales de la península, sobre todo de la Baja Andalucía y el Sureste (ARRIBAS y MOLINA 1979a).

Como apéndice del estudio se desarrollan estudios parciales sobre la geología de las Peñas de los Gitanos (RUIZ BUSTOS 1979a: 147-149), la utilización de micasquistos en la fabricación de la cerámica (RUIZ BUSTOS 1979b:151-152) y los restos faunísticos aparecidos (UERPMANN 1979:153-168) sin que esta información quede integrada dentro de la explicación global del desarrollo cultural.

De esta forma la intervención arqueológica resolvía por una parte, y en términos secuenciales, la sucesión entre la Cultura de las Cuevas y la Edad del Cobre, y por otra, se definía un desarrollo cultural de la edad del Cobre diferente al llamado Horizonte de los Millares; en esta misma línea se caracterizaban las influencias de las sociedades argáricas sobre las poblaciones megalíticas finales. Todo ello ha contribuido a que la secuencia de Los Castillejos de las Peñas de los Gitanos haya sido usada, posiblemente de modo abusivo, como elemento de referencia aplicable a toda la Península.

Dentro de este contexto de la investigación del conjunto arqueológico de las Peñas habría que destacar diversos trabajos realizados como el estudio de la industria lítica de las campañas de 1971 y 1974 (MARTÍNEZ FERNÁNDEZ 1985), posteriormente completada en aspectos técnicos de la producción neolítica (AFONSO MARRERO 1993), el análisis del material óseo trabajado (SALVATIERRA CUENCA 1982), así como los conjuntos de materiales pertenecientes a la excavación realizada por M. Tarradell durante 1946-1947 (MORENO ONORATO 1982) o los de la Cueva de las Tontas (TORRE SANTANA 1984).

Por tanto, esta nueva etapa de la investigación que se inicia en los años 70 supone un salto cualitativo desde el momento en el que se establece el contexto temporal necesario para la ordenación espacio-temporal de los procesos históricos.

Con posterioridad a la intervención anteriormente descrita, y dentro de un marco teórico y político completamente diferente, caracterizado en el ámbito político, por el desarrollo del 
modelo autonómico en la gestión del patrimonio arqueológico ${ }^{34}$, y en el plano teóricometodológico, por la diversidad y riqueza de enfoques, se ha desarrollado recientemente una campaña de excavación de urgencia entre 1991 y 1994, motivada por la actividad clandestina de los expoliadores que habían alterado gravemente los depósitos arqueológicos, así como las cubiertas de protección colocadas para cubrir las zonas excavadas entre 1971-1974, lo cual ha hecho necesario el desarrollo de diversas actuaciones de protección y acondicionamiento que se han centrado en el poblado prehistórico de los Castillejos. Los objetivos de la actuación han sido los siguientes (RAMOS et al. 1994):

-Completar la secuencia estratigráfica definida en campañas anteriores y proceder a un análisis detallado para así poder aproximarse al estudio del proceso de producción en cada una de las fases.

-Documentar la articulación del hábitat con la unidad geomorfológica sobre la que se asienta.

-Reconstruir la evolución del paisaje a través del estudio de diferentes muestras faunísticas, carpológicas, antracológicas y sedimentológicas.

- Articular diversas actividades de conservación y restauración y preparar el interior de la estructura de protección con paneles informativos con fines pedagógicos y para su visita.

Se han desarrollado diversos trabajos de conservación, básicamente en el poblado de Los Castillejos, que han consistido en:

${ }^{34}$ En lo que se refiere a Andalucía, la aprobación del Estatuto se produjo en diciembre de 1981, mientras que el traspaso de competencias en materia de arqueología no se completó hasta 1984. Esta transformación de la estructura político-administrativa del país, va a generar que los problemas planteados en Arqueología desde la investigación a la conservación y los modelos de intervención presenten características y planteamientos diferentes en cada una de las comunidades autónomas. 
a) Cierre preventivo de los sondeos estratigráficos realizados en la zona oriental del poblado de Los Castillejos de las Peñas de los Gitanos durante las campañas de 1971-1974.

b) Limpieza de perfiles y reestructuración del corte $1 \mathrm{c} / 6$, cuyo perfil oriental, muestra una de las más importante secuencia arqueológicas de la Prehistoria Reciente peninsular.

c) Levantamiento de una cubierta metálica autosoportante sobre el corte $1 \mathrm{c} / 6$, que incluye una bóveda, un pasillo de acceso con baranda y suelo metálico, ventanas y paneles de fibra translúcidos que garantizan la iluminación y ventilación.

d) Planificación y ejecución de las obras de desagüe y canalización que garanticen la desviación de las aguas hacia aquellas zonas en donde no puedan afectar a los perfiles y estructuras excavadas en el corte $1 \mathrm{c} / 6$.

e) Acondicionamiento del interior del espacio cubierto (corte 1c/6) con una baranda y un suelo metálico, así como el cubrimiento de los perfiles laterales con placas de madera, debido a la inestabilidad que presentan por la presencia de fosas medievales y romanas.

f) Delimitación de un itinerario de acceso a la zona cubierta, evitando la aglomeración de personas en el lado oriental del corte, bajo el que se sitúa el perfil principal.

g) En otras zonas del yacimiento se han acondicionado y limpiado diversas estructuras funerarias.

h) Señalización informativa de la necrópolis dolménica de La Camarilla y del poblado de Los Castillejos ${ }^{35}$.

Desde nuestra perspectiva, entendemos que una de las directrices más importantes de la política arqueológica debe primar el desarrollo de líneas de investigación relacionadas con la

\footnotetext{
${ }^{35}$ Información obtenida de la ficha diagnóstico (CÁMARA y AFONSO 1995).
} 
conservación y restitución social del patrimonio arqueológico. En este sentido, el modelo de arqueología andaluza presenta un importante déficit, ya que, por una parte, se ha diferenciado entre arqueología de investigación y arqueología de gestión, y por otra, no ha existido la voluntad política necesaria para conseguir un verdadero programa de conservación del patrimonio. 


\section{VI.2 Correlación entre las distintas estratigrafías entre las distintas campañas de excavación del yacimiento de Los Castillejos}

Para futuros trabajos resultará fundamental la correlación estratigráfica entre todos los cortes realizado en base a dos elementos fundamentales:

a) En primer lugar la conexión entre los diversos sondeos realizados entre 1971 y 1974 y que fue obra de F. Molina González teniendo en cuenta la conexión entre los diferentes perfiles estratigráficos y los materiales (cerámica pintada, campaniforme marítimo, brazaletes de concha, brazaletes de caliza, peines de hueso, puntas de flecha, placas de arquero, cuernecillos, pesas ovales y circulares, crecientes, fuentes carenadas, fuentes de borde engrosado, fuentes de borde carenado, y orzas entre otros) incluidos en cada uno de los niveles en la zona oriental (cortes 1a, 1c, 6, 2, 7 y 3).

La correlación en la zona occidental, donde además se localizaron niveles posteriores a los excavados en el corte 1c/6 (TORRE PEÑA 1978; AGUAYO 1984) se realizó en base sobre todo a los materiales encontrados.

b) La obtención de una secuencia más precisa y amplia en el corte 1c/6 durante la campaña de excavaciones de 1991 a 1994, ha permitido, además, completar la correlación con los diferentes sondeos, de manera que en casi todos los niveles distinguidos en éstos han podido ser adscritas por J.A. Cámara Serrano a una de las fases estratigráficas del corte $1 \mathrm{c} / 6$, siguiendo de nuevo los perfiles en la zona occidental y la adscripción de F. Molina González en la oriental.

De esta manera se ha podido obtener una cierta visión de conjunto del poblado en las fases del Cobre y del Bronce, lo que nos podrá servir para completar la información de aquellos niveles que en el corte $1 \mathrm{c} / 6$ han sido más afectados por la actividad de los excavadores clandestinos.

En conclusión, para comprender la adscripción de materiales que se realiza en esta Tesis Doctoral, debemos no sólo tener en cuenta la seriación estratigráfica sugerida tras las nuevas 
excavaciones (RAMOS et al. 1994; AFONSO et al. 1995), sino recordar que cuando se puso en duda la correlación entre las diferentes campañas y sus publicaciones correspondientes (MARTÍNEZ NAVARRETE 1984:58-59, nota 34) ${ }^{36}$, lo que se hizo fue simplemente confundir las diferentes periodizaciones culturales y su nomenclatura con pequeñas variaciones según el estado de la investigación, con una secuencia estratigráfica que nunca se modificó, como se demuestra si se presta atención a los diferentes perfiles publicados (ARRIBAS y MOLINA 1979a; 1979b) y que incluso tras las nuevas excavaciones, sólo ha sufrido subdivisiones, en el caso de los niveles ya conocidos y una ampliación de la secuencia hacia el Neolítico antiguo como resultado de la mayor profundidad que han alcanzado los trabajos en los sondeos estratigráficos (RAMOS et al. 1994).

Al objeto de facilitar la lectura de los resultados de nuestros trabajos y de otros que se han realizado sobre fauna (UERPMANN 1979; ZIEGLER 1990; RIQUELME 1996) ofrecemos aquí dos tablas sobre las correlaciones entre las fases culturales definidas en cada publicación (Tabla 1), así como las correlaciones estratigráficas entre los diferentes cortes de 1971-1974 y las fases estratigráficas definidas entre 1991-1994 (Tabla 2) en cuyos comentarios incluimos las valoraciones de G. Martínez Fernández (1985) y J.A. Afonso Marrero (1993).

${ }^{36}$ En la publicación de Martínez Navarrete, la correlación entre los estratos es totalmente errónea al proceder no de su estudio en los perfiles sino de no haber tenido en cuenta su propia correlación entre las fases que muestra que la fase III del 78, se convierte en las fases III-IV del 79. Al revisar la estratigrafia, no ha descompuesto el estrato VI en VINB y VINA, así el VINB sí corresponde a la fase I, pero el VINA corresponde a la fase II, con lo que el resto de la correspondencia entre fases y estratos queda descolocada. 
VII. CARACTERIZACIÓN DE LOS CONTEXTOS ARQUEOLÓGICOS 


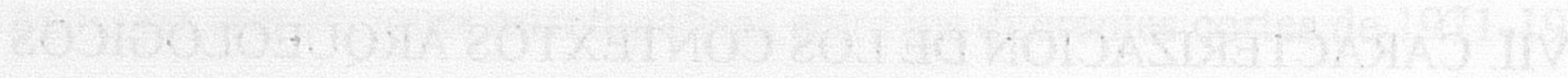




\section{VII.1. Estudio descriptivo del material lítico}

\section{VII.1.1. Fase 1: Neolítico antiguo}

En la fase 1 se han estudiado un total de 576 piezas líticas, todas ellas en sílex. De ellas $47(8,15 \%)$ poseen corteza. La alteración térmica ha afectado a 180 piezas $(31,25 \%)$, mientras que $253(43,92 \%)$ han sido tratadas térmicamente. Sólo $12(2,08 \%)$ se han visto afectadas por la alteración química. Otras $2(0,34 \%)$ han sufrido alteración mecánica. Hay 47 esquirlas térmicas $(8,15 \%)$.

Del total de piezas estudias, $90(15,62 \%)$ están completas y el resto, $486(84,37 \%)$ incompletas.

El análisis tecnológico nos ha permitido identificar 4 (0,69\%) núcleos 3 para lascas y sólo 1 para hojas, los cuatro con tratamiento térmico. Además, se ha documentado una tableta y un bloque de materia prima que había estallado por la acción del fuego, que nos puede proporcionar información acerca de cómo llega la materia prima al yacimiento. Las hojas y las lascas se reparten de la siguiente manera, 170 hojas $(29,51 \%)$ y 308 lascas $(53,47 \%)$. Los productos de talla indeterminados son $35(6,07 \%)$ y hay $2(0,34 \%)$ indeterminables (gráf. 1$)$.

Hay 248 productos de talla sin talón ( $43,05 \%$ ), todos ellos ausentes por fractura. De los 227 talones existentes (39,40\%), $170(29,51 \%)$ son lisos, 43 (7,46\%) puntiformes, 13 diedros $(2,25 \%)$ y sólo $1(0,17 \%)$ facetado (gráf. 2$)$.

Las hojas prismáticas son 168 que suponen el 29,16\% del total de la industria, y el 35,14\% de los productos de talla. La longitud máxima es de 4,56 cm., la anchura máxima es $1,96 \mathrm{~cm}$. Como podemos observar, la longitud más utilizada en las hojas, en el $41,93 \%$ de las mismas, es de entre 3-4 cm., prácticamente todas las hojas $(90,31 \%)$ se mueven en anchuras de 1 a $1,5 \mathrm{~cm}$. (grafs. $3,{ }^{3}$, 
Existen 102 piezas retocadas (17,70\%). Los soportes sobre los que se han realizado los útiles se reparten de esta manera; sobre núcleo $6(5,58 \%)$, sobre hoja $77(75,49 \%)$ y sobre lasca $19(18,62 \%)$ (gráf. 6).

En cuanto a la clasificación tipológica, señalaremos que se han estudiado 8 lascas con retoque de uso $(7,84)$ y otras 8 con retoque continuo $(7,84)$. Las hojas con retoque de uso son $64(63,72 \%)$ y 11 con retoque continuo $(10,78 \%)$.

Se han encontrado 3 perforadores, dos sobre lasca y uno sobre hoja. En lo que se refiere al grupo tipológico 10 , los raspadores, nos encontramos con uno de los elementos más interesantes de la industria lítica de las fases neolíticas. De los 6 raspadores espesos de frente no destacado nucleiformes, 5 (el 4,90\% del total de útiles) podrían ser considerados como encendedores (Martínez Fernández 1991), ya que poseen una serie de retoques en el filo que no pueden ser producto del trabajo como cepillo. Algunos de ellos han podido ser utilizados como núcleo, pero más tarde han sido reavivados y utilizados como encendedores. Por otro lado, es igualmente interesante el grupo 14, los astillados, de los que se ha encontrado uno nucleiforme (graf.7).

\section{VII.1.2. Fase 2: Neolítico antiguo}

De la fase 2 se han analizado un total de 360 piezas, todas ellas en sílex. De ellas 23 $(6,38 \%)$ poseen cortex. La alteración térmica ha afectado a 142 piezas $(39,44 \%)$, mientras 155 $(43,05 \%)$ han sido tratadas térmicamente; 42 piezas $(11,66 \%)$ se han visto afectadas por la alteración química. Sólo en $1(0,27 \%)$ han sufrido alteración mecánica. Hay 20 esquirlas térmicas $(5,5 \%)$.

Del total de piezas estudias, $70(19,44 \%)$ están completas y el resto, $290(80,55 \%)$ incompletas.

El análisis tecnológico nos ha proporcionado 1 percutor $(0,27 \%), 4(1,11 \%)$ núcleos, 2 con tratamiento térmico y otro con alteración térmica, de los que 3 para lascas y 1 para hojas. Las 
hojas son $131(36,38 \%)$ y 183 las lascas $(50,83 \%)$. Los productos de talla indeterminados son 16 $(4,44 \%)$ y hay $1(0,27 \%)$ indeterminables (fig. 8$)$.

Hay 165 productos de talla sin talón $(45,83 \%)$, de los talones existentes $108(73,5 \%)$ son lisos, 27 (18,4\%) puntiformes, 10 (6,8\%) diedros y 2 facetados (fig.9).

Las hojas prismáticas son 129 que suponen el 35,83\% del total de la industria, y el 39,09\% de los productos de talla. La longitud máxima es de $6,05 \mathrm{~cm}$. y la anchura máxima es $2,90 \mathrm{~cm}$., 07 $\mathrm{cm}$. La longitud más utilizada para las hojas, en el $43,75 \%$ de las mismas, es de entre $3-4 \mathrm{~cm}$. Prácticamente todas las hojas (87,50\%) se mueven en anchuras de 0,5 a 1,5 cm. (grafs.10, 11 y 12). Entre las hojas se han localizado hojas prismáticas de preparación de frentes y de regularización de núcleos.

Existen 69 piezas retocadas $(19,16 \%)$. Los soportes sobre los que se han realizado los útiles se reparten de esta manera; sobre núcleo $4(5,79 \%)$, sobre hoja $48(69,56 \%)$ y sobre lasca $16(23,18 \%)$. Hay 1 útil $(1,44 \%)$ realizado en un producto de talla indeterminable (gráf. 13).

En cuanto a la clasificación tipológica, señalaremos que se han estudiado 5 lascas con retoque de uso $(7,24 \%)$ y otras 7 con retoque continuo $(10,14 \%)$. Las hojas con retoque de uso son $39(56,52 \%)$ y 6 con retoque continuo $(8,69 \%)$.

Se han encontrado una escotadura escotadura simple retocada, un trapecio, 2 perforadores, uno sobre lasca y otro sobre hoja. En el grupo 10, los raspadores, hemos encontrados 7 espesos de frente no destacado nucleiformes, (el 2,89\% del total de útiles) que podrían ser considerados como encendedores. Alguno de ellos están realizados sobre núcleos reciclados. Del grupo 14, los astillados, se ha detectado uno simple delgado de frente no destacado (gráf. 14).

\section{VII.1.3 Fase 3: Neolítico antiguo}

En la fase 3 se han estudiado un total de 258 piezas líticas, todas ellas en sílex. De ellas $9(3,48 \%)$ poseen corteza. La alteración térmica ha afectado a 92 piezas $(35,95 \%)$, mientras que 
$122(47,28 \%)$ han sido tratadas térmicamente. $26(10,07 \%)$ se han visto afectadas por la alteración química. Hay 24 esquirlas térmicas $(9,30 \%)$.

Del total de piezas estudias, $58(22,48 \%)$ están completas y $168(65,11 \%)$ incompletas.

El análisis tecnológico nos ha permitido identificar 1 percutor $(0,38 \%), 5(2,32 \%)$ núcleos 2 para lascas y 3 para hojas. Las hojas y las lascas se reparten de la siguiente manera, 89 hojas $(34,49 \%)$ y 118 lascas $(45,73 \%)$. Los productos de talla indeterminados son $14(5,42 \%)$ y hay $4(1,55 \%)$ indeterminables (gráf. 15$)$.

Hay 111 productos de talla sin talón $(43,02 \%)$, todos ellos ausentes por fractura, menos uno eleminado por retoque. De los 94 talones existentes (36,43\%), 72 (76,59\%) son lisos, 20 $(7,75 \%)$ puntiformes y 2 diedros $(0,77 \%)$ (gráf. 16).

Las hojas prismáticas son 89 que suponen el 34,49\% del total de la industria, y el 40,09\% de los productos de talla. La longitud máxima es de $5,64 \mathrm{~cm}$. y la anchura máxima es $2,06 \mathrm{~cm}$. Como podemos observar, la longitud más utilizada en las hojas, en el 33,33\% de las mismas, es de entre 2-3 cm., prácticamente todas las hojas $(76,16 \%)$ se mueven en anchuras de 0,5 a $1,5 \mathrm{~cm}$. (Gráf. 17,18 y19)

Existen 59 piezas retocadas $(22,86 \%)$. Los soportes sobre los que se han realizado los útiles se reparten de esta manera; sobre núcleo $1(1,72 \%)$, sobre hoja $52(89,65 \%)$ y sobre lasca $5(8,62 \%)$ (gráf. 20$)$.

En cuanto a la clasificación tipológica, señalaremos que se ha estudiado 1 lasca con retoque de uso $(1,72 \%)$ y otras 4 con retoque continuo $(6,89 \%)$. Las hojas con retoque de uso son $43(74,13 \%)$ y 8 con retoque continuo $(13,79 \%)$.

Se ha encontrado una escotadura simple retocada, 1 perforador sobre hoja con modificación secundaria profunda y un raspador nucleiforme espeso de frente no destacado (gráf. 21) 


\section{VII.1.4 Fase 4: Neolítico antiguo}

Esta fase, de muy larga duración, no se ha podido subdividir debido a la perduración de alguna de sus estructuras. Por ello analizamos los dos momentos documentados, subfases $a$ y b, por separado.

\section{Fase $4 a$}

En la fase 4a se han estudiado un total de 579 piezas líticas, todas ellas en sílex. De ellas $31(5,35 \%)$ poseen cortex. La alteración térmica ha afectado a 221 piezas $(38,16 \%)$, mientras que $347(59,93 \%)$ han sido tratadas térmicamente. Sólo $3(0,5 \%)$ se han visto afectadas por la alteración química. En 2 más $(0,34 \%)$ se ha podido detectar el lustre producido por el trabajo del cereal. Otras $2(0,34 \%)$ han sufrido alteración mecánica. Hay 26 esquirlas térmicas $(4,4 \%)$.

Del total de piezas estudias, 84 (16,24\%) están completas y el resto, $433(83,75 \%)$ incompletas.

El análisis tecnológico nos ha permitido identificar 2 percutores $(0,34 \%)$, uno incompleto y otro completo, $12(2,07 \%)$ núcleos 11 para lascas y sólo 1 para hojas, todos ellos con tratamiento térmico. Las hojas y las lascas se reparten de la siguiente manera, 218 hojas (37,65\%) y 280 lascas $(48,35 \%)$. Los productos de talla indeterminados son $31(5,35 \%)$ y hay $8(1,38 \%)$ indeterminables (gráf. 22).

Hay 270 productos de talla sin talón $(54,21 \%)$, todos ellos ausentes por fractura. De los 228 talones existentes $(45,78 \%), 192(38,55 \%)$ son lisos, 35 (7,02\%) puntiformes y sólo 1 $(0,20 \%)$ diedro (gráf. 23$)$.

Existen 88 piezas retocadas $(15,19 \%)$, de las que 15 (17,04\%) están completas y 73 $(82,95 \%)$ incompletas. Entre las hojas se han localizado cuatro hojas prismáticas de regularización de núcleos.

Las hojas prismáticas son 218 que suponen el $37,65 \%$ del total de la industria, y el 40,59\% de los productos de talla. Debido al interés que poseemos en estudiar las fracturas a las que son 
sometidas intencionalmente algunas hojas para la fabricación de determinados útiles, hemos tomado la longitud de todas ellas aunque no estén completas. La longitud máxima es de $5,92 \mathrm{~cm}$., estando la media en $2,28 \mathrm{~cm}$. La anchura máxima es $1,88 \mathrm{~cm}$. y la media $1,05 \mathrm{~cm}$. En cuanto al grosor, el máximo es de $0,9 \mathrm{~cm}$. y el medio es $0.28 \mathrm{~cm}$.

Como podemos observar, la longitud más utilizada en las hojas, en el $70,22 \%$ de las mismas, es de entre 1-3 cm., prácticamente todas las hojas $(93,42 \%)$ se mueven en anchuras de 1 a $1,5 \mathrm{~cm}$; el grosor de la mayoría está entre $0,1-0,5 \mathrm{~cm}$ (gráfs. 24,25 y 26).

Los soportes sobre los que se han realizado los útiles se reparten de esta manera; sobre núcleo $1(1,13 \%)$, sobre hoja $67(77,27 \%)$ y sobre lasca 19 (21,59\%) (gráf. 27).

En cuanto a la clasificación tipológica, señalaremos que se han estudiado 4 lascas con retoque de uso y otras 8 con retoque continuo, lo que proporciona un total de 12 lascas con retoque $(13,63 \%)$. Las hojas con retoque de uso son 58 y 9 con retoque continuo, el total de las hojas retocadas es de $67(76,13 \%)$.

Se han encontrado 2 perforadores, ambos con modificación secundaria profunda, uno sobre hoja y otro sobre lasca.

En lo que se refiere al grupo tipológico 10, los raspadores, nos encontramos con uno de los elementos más interesantes de la industria lítica de las fases neolíticas. Los 5 raspadores espesos de frente no destacado nucleiformes (el 2,27\% del total de útiles) podrían ser considerados como encendedores (Martínez Fernandez 1991), ya que poseen una serie de retoques en el filo que no pueden ser producto del trabajo como cepillo. Algunos de ellos han podido ser utilizados como núcleo, pero más tarde han sido reavivados y utilizados como encendedores.

Por otro lado, es igualmente interesante el grupo 14, los astillados, de los que se han detectado dos, un astillado simple delgado y otro nucleiforme. Hay además dos núcleos para lasca que se han transformado en astillados. Morfológicamente son muy parecidos a los raspadores 
nucleiformes mencionados anteriormente, pero su característica principal es que presentan un retoque sobreelevado pasando a abrupto opuesto al astillado. Posiblemente fuesen utilizados como cincel para madera actuando en forma de palanca (gráf. 28).

\section{Fase $4 b$}

De la fase $4 \mathrm{~b}$ se han analizado un total de 1197 piezas, todas ellas en sílex. De ellas 52 $(4,34 \%)$ poseen cortex. La alteración térmica ha afectado a 452 piezas $(37,76 \%)$, mientras 730 $(60,98 \%)$ han sido tratadas térmicamente. Sólo $6(0,5 \%)$ se han visto afectadas por la alteración química y en 1 más $(0,08 \%)$ se ha podido detectar el lustre producido por el trabajo del cereal. Otras $3(0,25 \%)$ han sufrido alteración mecánica. Hay 41 esquirlas térmicas $(3,4 \%)$.

Del total de piezas estudias, $166(13,86 \%)$ están completas y el resto, $1031(86,13 \%)$ incompletas.

El análisis tecnológico no ha proporcionado ningún percutor, $26(2,17 \%)$ núcleos, todos ellos con tratamiento térmico (fig. 9) 17 para lascas y 9 para hojas. Las hojas son 461 (38,51\%) y 617 las lascas $(51,54 \%)$. Los productos de talla indeterminados son $32(2,67 \%)$ y hay 11 $(0,91 \%)$ indeterminables (gráf. 29).

Hay 598 productos de talla sin talón (59,95\%) 587 ausentes por fractura, y sólo 1 con el talón eliminado por retoque, de los 480 talones existentes $(40,10 \%), 412$ (34,41\%) son lisos, 63 $(5,26 \%)$ puntiformes, y $5(0,41 \%)$ diedros (gráf. 30$)$.

Existen 218 piezas retocadas $(18,21 \%)$ de las que $50(22,93 \%)$ están completas y 168 $(77,06 \%)$ incompletas. Entre las hojas se han localizado 2 hojas prismáticas de regularización de núcleos.

Las hojas prismáticas son 459 que suponen el $38,34 \%$ del total de la industria, y el $41,35 \%$ de los productos de talla. La longitud máxima es de $5,49 \mathrm{~cm}$., estando la media en $2,56 \mathrm{~cm}$. La anchura máxima es $2,34 \mathrm{~cm}$. y la media $1,07 \mathrm{~cm}$. En cuanto al grosor, el máximo es de 1,3 cm. y el medio es $0.91 \mathrm{~cm}$. 
La longitud más utilizada para las hojas, en el $72,98 \%$ de las mismas, es de entre $1-3 \mathrm{~cm}$. Prácticamente todas las hojas ( $91,79 \%$ ) se mueven en anchuras de 0,5 a $1,5 \mathrm{~cm}$.; el grosor del $95,11 \%$ de las hojas está entre $0,1-0,5 \mathrm{~cm}$ (gráfs. 31,32 y 33).

Los soportes sobre los que se han realizado los útiles se reparten de esta manera; sobre núcleo $7(3,21 \%)$, sobre hoja $184(84,40 \%)$ y sobre lasca $26(11,92 \%)$. Hay 1 útil $(0,45 \%)$ realizado en un producto de talla indeterminado (gráf. 34).

En cuanto a la clasificación tipológica, señalaremos que se han estudiado 7 lascas con retoque de uso y otras 13 con retoque continuo, lo que proporciona un total de 20 lascas con retoque $(9,17 \%)$. Las hojas con retoque de uso son 161 y 23 con retoque continuo, el total de las hojas retocadas es de $184(84,40 \%)$.

Se han encontrado 2 perforadores, uno con modificación secundaria profunda sobre hoja y otro que presenta la particularidad de haber sido realizado sobre un núcleo de hojitas reciclado.

En el grupo 10, los raspadores, hemos encontrados 10 espesos de frente no destacado nucleiformes, (el 4,58\% del total de útiles) que podrían ser considerados como encendedores. Alguno de ellos están realizados sobre núcleos reciclados (fig. 35).

Del grupo 14 , los astillados, se han detectado dos, un astillado simple delgado y otro espeso (gráf. 35).

\section{VII.1.5 Fase 5: Neolítico antiguo}

En la fase 5 se han estudiado un total de 176 piezas líticas, todas ellas en sílex. De ellas $4(2,27 \%)$ poseen corteza. La alteración térmica ha afectado a 44 piezas (25\%), mientras que 95 $(53,79 \%)$ han sido tratadas térmicamente. $13(7,3 \%)$ se han visto afectadas por la alteración química. Otras $2(1,13 \%)$ han sufrido alteración mecánica. Hay 7 esquirlas térmicas $(3,97 \%)$.

Del total de piezas estudias, $47(26,70 \%)$ están completas y $121(68,75 \%)$ incompletas. 
El análisis tecnológico nos ha permitido identificar 5 (2,84\%) núcleos 4 para lascas y sólo 1 para hojas. Las hojas y las lascas se reparten de la siguiente manera, 85 hojas $(48,29 \%)$ y 70 lascas $(39,77 \%)$. Los productos de talla indeterminados son $9(5,11 \%)$ (graf. 36 )

Hay 80 productos de talla sin talón (45,45\%), uno de ellos, eliminado por retoque. De los 75 talones existentes $(42,61 \%), 51(68 \%)$ son lisos, $10(5,68 \%)$ puntiformes y $13(7,38 \%)$ diedros (gráf. 37)

Las hojas prismáticas son 85 que suponen el $48,29 \%$ del total de la industria, y el 54,86\% de los productos de talla. La longitud máxima es de 5,04 cm.y una anchura máxima es 1,66 cm. Como podemos observar, la longitud más utilizada en las hojas, en el 50,00\% de las mismas, es de entre 3-4 cm., prácticamente todas las hojas ( $93,75 \%$ ) se mueven en anchuras de 0,5 a $1,5 \mathrm{~cm}$. (Graf. 38,39 y 40 )

Los soportes sobre los que se han realizado los útiles se reparten, sobre hoja $50(89,28 \%)$ y sobre lasca $6(10,71 \%)$ (gráf. 41 ).

En cuanto a la clasificación tipológica, señalaremos que hemos identificado 2 lascas con retoque de uso $(3,57 \%)$ y otras 2 con retoque continuo $(3,57 \%)$. Las hojas con retoque de uso son $38(67,85 \%)$ y 10 con retoque continuo $(17,85 \%)$. Se ha encontrado una escotadura simple retocada, 3 perforadores uno sobre lasca y dos sobre hojas (graf. 42).

\section{VII.1.5 Fase 6: Neolítico antiguo}

En la fase 6 se han estudiado un total de 85 piezas líticas. De ellas $4(4,70 \%)$ poseen corteza. La alteración térmica ha afectado a 34 piezas $(40 \%)$, mientras que $42(49,41 \%)$ han sido tratadas térmicamente. $9(10,85 \%)$ se han visto afectadas por la alteración química. Hay 1 esquirla térmica $(1,17 \%)$.

Del total de piezas estudias, $12(14,11 \%)$ están completas y $66(77,64 \%)$ incompletas. . 
El análisis tecnológico nos ha permitido identificar 2 (2,35\%) núcleos. Las hojas y las lascas se reparten de la siguiente manera, 34 hojas (40\%) y 40 lascas $(47,05 \%)$. Los productos de talla indeterminados son $6(7,05 \%)$.

Hay 43 productos de talla sin talón (50,58\%). De los 31 talones existentes $(36,47 \%), 25$ $(80,64 \%)$ son lisos y $6(7,05 \%)$ puntiformes.

Las hojas prismáticas son 34 que suponen el $40 \%$ del total de la industria, y el $42,05 \%$ de los productos de talla. La longitud máxima es de $3,35 \mathrm{~cm}$. y la anchura máxima es $1,56 \mathrm{~cm}$.

Existen 23 piezas retocadas $(27,05 \%)$. Los soportes sobre los que se han realizado los útiles se reparten, sobre hoja $16(69,56 \%)$ y sobre lasca $7(30,43 \%)$.

En cuanto a la clasificación tipológica, señalaremos que hemos identificado 2 lascas con retoque de uso $(8,69 \%)$ y otras 4 con retoque continuo $(17,39 \%)$. Las hojas con retoque de uso son $12(52,17 \%)$ y 4 con retoque continuo $(17,39 \%)$. Además hay un perforador sobre lasca.

\section{VII.1.7 Fase 7: Neolitico medio}

En la fase 7 se han estudiado un total de 300 piezas líticas, todas ellas en sílex. De ellas $14(4,66 \%)$ poseen corteza. La alteración térmica ha afectado a 94 piezas $(31,33 \%)$, mientras que $190(63,33 \%)$ han sido tratadas térmicamente. $43(14,13 \%)$ se han visto afectadas por la alteración química. Otra más $(0,33 \%)$ ha sufrido alteración mecánica. Hay 2 esquirlas térmicas $(0,66 \%)$.

Del total de piezas estudiadas, 81 (27\%) están completas y $185(61,66 \%)$ incompletas.

El análisis tecnológico nos ha permitido identificar 11 (3,66\%) núcleos, 5 para lascas y 6 para hojas. Las hojas y las lascas se reparten de la siguiente manera, 133 hojas $(44,33 \%)$ y 124 lascas $(41,33 \%)$. Los productos de talla indeterminados son $22(7,33 \%)$ y hay $4(1,33 \%)$ indeterminables (gráf. 43) 
Hay 109 productos de talla sin talón $(36,21 \%)$, todos ellos ausentes por fractura. De los 163 talones existentes (54,33\%), $103(63,19 \%)$ son lisos, 34 (20,8\%) puntiformes, $11(6,74 \%)$ diedros y 3 facetados $(1,84)$ (gráf. 44)

Las hojas prismáticas son 133 que suponen el 44,33\% del total de la industria, y el 47,51\% de los productos de talla. La longitud máxima es de $5,42 \mathrm{~cm}$. y la anchura máxima es $2,32 \mathrm{~cm}$. Como podemos observar, la longitud más utilizada en las hojas, en el 51,61\% de las mismas, es de entre 3-4 cm., prácticamente todas las hojas $(61,29 \%)$ se mueven en anchuras de 1 a $1,5 \mathrm{~cm}$ (graf. 45,46 y 47 )

Existen 83 piezas retocadas $(27,66 \%)$. Los soportes sobre los que se han realizado los útiles se reparten de esta manera; sobre núcleo $3(3,70 \%)$, sobre hoja $63(77,77 \%)$ y sobre lasca 15 (18,51\%) (gráf. 48).

En cuanto a la clasificación tipológica, señalaremos que se han estudiado 4 lasca con retoque de uso $(4,93 \%)$ y otras 5 con retoque continuo $(6,17 \%)$. Las hojas con retoque de uso son $49(60,49 \%)$ y 14 con retoque continuo $(17,28 \%)$.

Se ha encontrado un denticulado simple de baja modificación secundaria $(1,2 \%)$, un trapecio (1,2\%), un perforador sobre hoja (1,2\%) y 8 raspadores (9,63\%) (fig. 49 ).

\section{VII.1.8 Fase 8: Neolítico medio}

En la fase 8 se han estudiado un total de 409 piezas líticas, todas ellas en sílex. De ellas $20(4,88 \%)$ poseen cortex. La alteración térmica ha afectado a 138 piezas $(33,74 \%)$, mientras que $227(55,50 \%)$ han sido tratadas térmicamente. 62 piezas $(15,15 \%)$ se han visto afectadas por la alteración química. Hay 10 esquirlas térmicas $(2,44 \%)$.

Del total de piezas estudias, $117(28,60 \%)$ están completas y $243(59,41 \%)$ incompletas.

El análisis tecnológico nos ha permitido identificar 1 percutor $(0,24 \%), 18(5,37 \%)$ núcleos 5 para lascas y 13 para hojas. Las hojas y las lascas se reparten de la siguiente manera, 
186 hojas $(45,47 \%)$ y 155 lascas $(37,89 \%)$. Los productos de talla indeterminados son 32 $(7,82 \%)$ y hay $3(0,73 \%)$ indeterminables (gráf. 50$)$.

Hay 152 productos de talla sin talón $(37,16 \%)$, todos ellos ausentes por fractura. De los 188 talones existentes $(45,96 \%), 143(76,06 \%)$ son lisos, $39(20,74 \%)$ puntiformes , $5(1,22 \%)$ diedros y un facetado $(0,24 \%)$ (gráf. 51)

Las hojas prismáticas son 186 que suponen el $45,47 \%$ del total de la industria, y el $49,86 \%$ de los productos de talla. La longitud máxima es de $5,85 \mathrm{~cm}$. y la anchura máxima es $1,97 \mathrm{~cm}$. Como podemos observar, la longitud más utilizada en las hojas, en el $46,15 \%$ de las mismas, es de entre 3-4 cm., la mayor parte de las hojas $(53,84 \%)$ se mueven en anchuras de 1 a $1,5 \mathrm{~cm}$. (graf. 52,53 y 54 )

Existen 119 piezas retocadas (29,09\%). Los soportes sobre los que se han realizado los útiles se reparten de esta manera; sobre núcleo $2(1,68 \%)$, sobre hoja $96(80,67 \%)$ y sobre lasca $14(11,7 \%)$ (gráf. 55).

En cuanto a la clasificación tipológica, señalaremos que se han distinguido 4 lascas con retoque de uso $(3,36 \%)$ y otras 10 con retoque continuo $(8,40 \%)$. Las hojas con retoque de uso son $74(62,18 \%)$ y 22 con retoque continuo $(18,48 \%)$.

Se ha encontrado 1 escotadura simple retocada $(0,84 \%)$, un trapecio $(0,84 \%), 3$ perforadores $(2,52 \%)$, dos sobre hojas con modificación secundaria profunda y otro con modificación secundaria poco profunda y dos raspadores nucleiformes delgados $(1,68 \%)$, uno con frente destacado y el otro con frente no destacado, ambos son reciclados de núcleos (graf.56).

\section{VII.1.9. Fase 9: Neolítico medio}

En la fase 9 se han analizado un total de 1449 piezas, todas ellas en sílex. De ellas 47 $(3,24 \%)$ poseen cortex. La alteración térmica ha afectado a 438 piezas (30,22\%), mientras 917 $(63,28 \%)$ han sido tratadas térmicamente. Sólo 69 (4,7\%) se han visto afectadas por la alteración 
química y otras $11(0,75 \%)$ han sufrido alteración mecánica. En 3 más $(0,20 \%)$ se ha podido detectar el lustre producido por el trabajo del cereal. Hay 79 esquirlas térmicas $(5,4 \%)$

Del total de piezas estudias, $210(17,26 \%)$ están completas y el resto, $1006(83,91 \%)$ incompletas.

En el análisis tecnológico se han encontrado 7 percutores $(0,48 \%)$ y $33(2,27 \%)$ núcleos tratados térmicamente (fig. 12). Las hojas son $573(39,54 \%)$ y 561 las lascas $(38,71 \%)$. Los productos de talla indeterminados son $167(11,52 \%)$ y hay 16 (1,10\%) indeterminables (graf. 57).

Entre las hojas se han localizado 18 hojas prismáticas de regularización de núcleos, y otra más de descortezado. En este sentido se ha encontrado un núcleo preparado en un primer intento y abandonado después, otros dos con preparación del frente y del plano de percusión.

Hay 615 productos de talla sin talón (54,23\%), de ellos 606 ausentes por fractura y 9 con el talón eliminado por retoque. De los 519 talones existentes $(45,76 \%), 404(35,62 \%)$ son lisos, $105(9,25 \%)$ puntiformes, $5(0,44 \%)$ diedros y $5(0,44 \%)$ facetados (graf. 58$)$.

Existen 214 piezas retocadas $(14,76 \%)$ de las que $40(18,69 \%)$ están completas y 174 $(81,30 \%)$ incompletas.

Las hojas prismáticas son 563 que suponen el 39,54\% del total de la industria, y el 43,27\% de los productos de talla. La longitud máxima es de 7,56 cm., estando la media en 2,64 cm. La anchura máxima es 5,09 cm. y la media 1,07 cm. En cuanto al grosor, el máximo es de 1,6 cm. y el medio es $0.29 \mathrm{~cm}$.

Se detecta un aumento de la longitud con respecto al Neolítico Antiguo y una disminución del grosor medio de las hojas, mientras que la anchura es similar. 
La longitud más encontrada en las hojas, en el 69,61\% de las mismas, es de entre $2-4 \mathrm{~cm}$. Prácticamente todas las hojas $(93,94 \%)$ se mueven en anchuras de 0,5 a 1,5 cm; el grosor del $94,77 \%$ de las hojas está entre 0,01-0,5 cm (graf. 59, 60 y 61).

Los soportes sobre los que se han realizado los útiles se clasifican así; sobre núcleo 4 $(1,86 \%)$, sobre hoja $181(84,50 \%)$ y sobre lasca $27(12,61 \%)$. Hay 1 útil $(0,46 \%)$ realizado en un producto de talla indeterminado, y otro $(0,46 \%)$ sobre indeterminable (graf. 62).

En cuanto a la clasificación tipológica, señalaremos que se han estudiado 10 lascas con retoque de uso y otras 9 con retoque continuo, lo que proporciona un total de 20 lascas con retoque $(8,87 \%)$. Las hojas con retoque de uso son 113 y 50 con retoque continuo, siendo el total de las hojas retocadas de $163(76,16 \%)$.

Se ha encontrado un denticulado de baja modificación secundaria, 5 truncaduras simples y 8 perforadores todos ellos con modificación secundaria profunda sobre hoja.

En el grupo 10, los raspadores, hemos encontrados 8 espesos de frente no destacado nucleiformes que podrían ser considerados como encendedores y otros dos que podrían funcionar como los escoplos para madera mencionados anteriormente. Alguno de ellos son núcleos reciclados.

Se han encontrado 5 astillados, 3 dobles y 2 simples (graf. 63).

\section{VII.1.10. Fase 10: Neolítico medio}

Fase 10 a

En la fase 10 a se han estudiado un total de 487 piezas líticas, todas ellas en sílex. De ellas $35(7,18 \%)$ poseen cortex. La alteración térmica ha afectado a 202 piezas $(41,47 \%)$, mientras que $152(31,22 \%)$ han sido tratadas térmicamente. $86(17,65 \%)$ se han visto afectadas por la alteración química. Una $(0,20 \%)$ han sufrido alteración mecánica. Hay 17 esquirlas térmicas $(3,49 \%)$. 
Del total de piezas estudias, 151 (31\%) están completas y 271 (55,64\%) incompletas.

El análisis tecnológico nos ha permitido identificar 3 percutores $(0,61 \%), 13(2,66 \%)$ núcleos 5 para lascas y 8 para hojas. Las hojas y las lascas se reparten de la siguiente manera, 166 hojas $(34,08 \%)$ y 238 lascas $(48,87 \%)$. Los productos de talla indeterminados son $42(8,62 \%)$ y hay $4(0,82 \%)$ indeterminable (gráf. 64).

Hay 176 productos de talla sin talón $(36,13 \%)$, todos ellos ausentes por fractura. De los 235 talones existentes $(48,25 \%), 191(81,27 \%)$ son lisos, $36(15,3 \%)$ puntiformes, 7 diedros $(2,97 \%)$ y dos facetados $(0,85 \%)$ (gráf. 65$)$.

Las hojas prismáticas son 164 que suponen el $33,67 \%$ del total de la industria, y el 36,77\% de los productos de talla. La longitud máxima es de $5,76 \mathrm{~cm}$. y la anchura máxima es $1,99 \mathrm{~cm}$. Como podemos observar, la longitud más utilizada en las hojas, en el $76,18 \%$ de las mismas, es de entre $2-4 \mathrm{~cm}$., prácticamente todas las hojas $(85,70 \%$ ) se mueven en anchuras de 0,5 a $1,5 \mathrm{~cm}$. (Grafs. 66, 67 y 68)

Existen 107 piezas retocadas $(21,97 \%)$. Los soportes sobre los que se han realizado los útiles se reparten de esta manera; sobre núcleo $1(0,93 \%)$, sobre hoja $81(75,7 \%)$ y sobre lasca $22(20,56 \%)$ (gráf. 69).

En cuanto a la clasificación tipológica, se ha estudiado 8 lasca con retoque de uso $(7,47 \%)$ y otras 14 con retoque continuo (13,08\%). Las hojas con retoque de uso son 62 $(57,94 \%)$ y 13 con retoque continuo $(12,14 \%)$.

Se ha encontrado 1 escotadura simple retocada $(0,93 \%), 5$ perforadores $(4,67 \%)$ todos con modificación secundaria profunda, cuatro sobre hoja y uno sobre lasca, dos raspadores $(1,86 \%)$ de frente no destacado, uno espeso y el otro delgado, dos astillados $(1,86 \%)$, ambos simples, uno delgado y otro espeso (graf.70).

Fase $10 \mathrm{~b}$ 
En la fase $10 \mathrm{~b}$ se han estudiado un total de 897 piezas líticas, todas ellas en sílex. De ellas $30(3,34 \%)$ poseen corteza. La alteración térmica ha afectado a 416 piezas $(46,37 \%)$, mientras que $225(25,08 \%)$ han sido tratadas térmicamente. 198 (22,05\%) se han visto afectadas por la alteración química. En 2 más $(0,22 \%)$ se ha podido detectar el lustre producido por el trabajo del cereal. Otras $3(0,33 \%)$ han sufrido alteración mecánica. Hay 35 esquirlas térmicas $(3,90 \%)$.

Del total de piezas estudias, $160(17,83 \%)$ están completas y 642 (71,57\%) incompletas.

El análisis tecnológico nos ha permitido identificar 5 percutores (0,55\%), 26 (2,87\%) núcleos 11 para lascas y 15 para hojas. Las hojas y las lascas se reparten de la siguiente manera, 285 hojas $(31,71 \%)$ y 484 lascas $(53,95 \%)$. Los productos de talla indeterminados son 56 $(6,24 \%)$ y hay $6(0,66 \%)$ indeterminable (gráf.71).

Hay 458 productos de talla sin talón $(51,05 \%)$, todos ellos ausentes por fractura. De los 323 talones existentes (36\%), 249 (77,08\%) son lisos, 56 (17,33\%) puntiformes, 12 diedros $(3,71 \%)$ y 6 facetados $(1,85 \%)$ (gráf. 72$)$.

Las hojas prismáticas son 285 que suponen el 31,77\% del total de la industria, y el 34,54\% de los productos de talla. La longitud máxima es de $4,71 \mathrm{~cm}$. y la anchura máxima es $2,08 \mathrm{~cm}$. Como podemos observar, la longitud más utilizada en las hojas, en el $45,45 \%$ de las mismas, es de entre 3-4 cm., la mayor parte de las hojas $(54,54 \%)$ se mueven en anchuras de 1 a $1,5 \mathrm{~cm}$. (73, 74 y 75$)$.

Existen 151 piezas retocadas (16,83\%) Los soportes sobre los que se han realizado los útiles se reparten de esta manera; sobre núcleo $3(1,98 \%)$, sobre hoja $122(80,79 \%)$ y sobre lasca $26(17,21 \%)$ (gráf. 76).

En cuanto a la clasificación tipológica, se han identificado 11 lascas con retoque de uso (7,28\%) y otras 15 con retoque continuo (9,93\%). Las hojas con retoque de uso son $97(64,23 \%)$ y 21 con retoque continuo $(13,90 \%)$. 
Se ha encontrado un geométrico $(0,66 \%)$, tres perforadores $(1,98 \%)$ y tres raspadores $(1,98 \%)$ (graf. 77$)$.

\section{VII.1.11. Fase 11: Neolitico medio}

\section{Fase 11a}

En la fase 11a se han estudiado un total de 2767 piezas líticas, todas ellas en sílex. De ellas $203(7,33 \%)$ poseen corteza. La alteración térmica ha afectado a 890 piezas $(32,16 \%)$, mientras que $602(21,75 \%)$ han sido tratadas térmicamente. $429(15,5 \%)$ se han visto afectadas por la alteración química. Otras $12(0,43 \%)$ han sufrido alteración mecánica. Hay 86 esquirlas térmicas $(3,1 \%)$.

Del total de piezas estudiadas, $474(17,13 \%)$ están completas y $2041(73,76 \%)$ incompletas.

$\mathrm{El}$ análisis tecnológico nos ha permitido identificar 15 percutores $(0,54 \%), 82(2,96 \%)$ núcleos. Las hojas y las lascas se reparten de la siguiente manera, 819 hojas $(29,59 \%)$ y 1609 lascas $(58,14 \%)$. Los productos de talla indeterminados son $107(3,86 \%)$ y hay $45(1,62 \%)$ indeterminable (gráf.78).

Hay 1484 productos de talla sin talón $(53,63 \%)$, dos de ellos eliminados por retoque y los restantes, ausentes por fractura. De los 939 talones existentes $(33,93 \%), 797(81,68 \%)$ son lisos, $125(4,51 \%)$ puntiformes, 17 diedros (1,81\%) (gráf. 79 ).

Las hojas prismáticas son 816 que suponen el 29,49\% del total de la industria, y el $32 \%$ los productos de talla. La longitud máxima es de $7,46 \mathrm{~cm}$. y la anchura máxima es $4,06 \mathrm{~cm}$. Como podemos observar, la longitud más utilizada en las hojas, en el 42,22\% de las mismas, es de entre 3-4 cmp prácticamente todąs las hojas $(87,40 \%$ ) se mueven en anchuras de 0,5 a 1,5 cm. (graf. $89 p 81 Y 82$ 
Existen 524 piezas retocadas $(19,12 \%)$. Los soportes sobre los que se han realizado los útiles se reparten de esta manera; sobre núcleo $4(0,76 \%)$, sobre hoja $441(84,16 \%)$ y sobre lasca $78(2,78 \%)$ (gráf. 83 ).

En cuanto a la clasificación tipológica, hemos identificado 31 lascas con retoque de uso $(5,91 \%)$ y otras 39 con retoque continuo $(7,44 \%)$. Las hojas con retoque de uso son 363 $(69,27 \%)$ y 70 con retoque continuo $(13,35 \%)$.

Se ha identificado una escotadura simple retocada $(0,19 \%)$ sobre hoja prismática, nueve erforadores, dos de ellos de uso sobre hoja prismática $(1,71 \%)$, uno con modificación secundaria poco profunda sobre lasca, y seis con modificación secundaria profunda, tres sobre lasca y tres sobre hoja. Hay además, 5 raspadores $(0,95 \%)$, dos delgados de frente no destacado, un delgado de frente destacado y dos espesos de frente no destacado. Por último, hay 5 astillados $(0,95 \%)$, 3 simples delgados, uno simple espeso y uno reciclado de núcleo, doble espeso (gráf. 84).

\section{Fase $11 b$}

En la fase 11 a se han estudiado un total de 3870 piezas líticas, todas ellas en sílex. De ellas $333(8,60 \%)$ poseen corteza. La alteración térmica ha afectado a 1274 piezas $(32,91 \%)$, mientras que $954(24,65 \%)$ han sido tratadas térmicamente. $669(17,2 \%)$ se han visto afectadas por la alteración química. Otras $6(0,15 \%)$ han sufrido alteración mecánica. Hay 74 esquirlas térmicas $(1,9 \%)$.

Del total de piezas estudiadas, 648 (16,74\%) están completas y $2956(76,38 \%)$ incompletas.

El análisis tecnológico nos ha permitido identificar 15 percutores $(0,38 \%), 132(32,41 \%)$ núcleos. Las hojas y las lascas se reparten de la siguiente manera, 941 hojas $(24,31 \%)$ y 2508 lascas $(64,80 \%)$. Los productos de talla indeterminados son $135(3,48 \%)$ y hay $45(1,62 \%)$ indeterminable (gráf. 85). 
Hay 2181 productos de talla sin talón $(56,35 \%)$, dos de ellos eliminados por retoque y los restantes, ausentes por fractura. De los 1268 talones existentes (32,76\%), $1098(86,59 \%)$ son lisos, 143 (11,27\%) puntiformes, 25 diedros (1,97\%) (gráf. 86)

Las hojas prismáticas son 940 que suponen el $24,28 \%$ del total de la industria, y el $26,68 \%$ los productos de talla. La longitud máxima es de $9,47 \mathrm{~cm}$. y la anchura máxima es $4,32 \mathrm{~cm}$. Como podemos observar, la longitud más utilizada en las hojas, en el $41,13 \%$ de las mismas, es de entre $2-3 \mathrm{~cm}$., prácticamente todas las hojas $(88,60 \%)$ se mueven en anchuras de 0,5 a $1,5 \mathrm{~cm}$. (grafs. 87,88 y 89 ).

Existen 727 piezas retocadas (18,78\%). Los soportes sobre los que se han realizado los útiles se reparten de esta manera; sobre núcleo $8(1,12 \%)$, sobre hoja $548(77,18 \%)$ y sobre lasca $154(21,8 \%)$ (gráf. 90).

En cuanto a la clasificación tipológica, hemos identificado 68 lascas con retoque de uso $(9,29 \%)$ y otras 72 con retoque continuo $(10,84 \%)$. Las hojas con retoque de uso son 496 $(67,88 \%)$ y 65 con retoque continuo $(8,30 \%)$.

Se han identificado ocho perforadores, $(1,12 \%)$ con modificación secundaria profunda, dos sobre lasca y seis sobre hoja. Hay además, 12 raspadores (1,69\%), siete delgados de frente no destacado, cuatro espesos de frente no destacado y uno espeso de frente destacado. Por último, hay 6 astillados $(0,84 \%), 4$ simples delgados, dos simples espeso, 3 de ellos se han reciclado de núcleo (gráf.91).

\section{VII.1.12. Fase 12: Neolítico tardio}

En la fase 12 se han estudiado un total de 1041 piezas líticas, todas ellas en sílex. De ellas $39(3,74 \%)$ poseen cortex. La alteración térmica ha afectado a 315 piezas $(30,25 \%)$, mientras que $343(33,27 \%)$ han sido tratadas térmicamente. $58(5,5 \%)$ se han visto afectadas por la alteración química. Dos poseen lustre de cereal $(0,19 \%)$. Otra $(0,09 \%)$ han sufrido alteración mecánica. Hay 15 esquirlas térmicas $(1,44 \%)$. 
Del total de piezas estudias, $352(34,15 \%)$ están completas y 643 (62,38\%) incompletas.

El análisis tecnológico nos ha permitido identificar 2 percutores $(0,19 \%), 39(3,74 \%)$ núcleos. Las hojas y las lascas se reparten de la siguiente manera, 194 hojas (18,63\%) y 760 lascas (73\%). Los productos de talla indeterminados son $11(1,05 \%)$ y hay $8(0,76 \%)$ indeterminables (gráf. 92).

Hay 458 productos de talla sin talón (43,99\%), todos ellos ausentes por fractura. De los 407 talones existentes (39,09\%), $346(85,01 \%)$ son lisos, $41(10,07 \%)$ puntiformes y 20 diedros $(1,92 \%)$ (gráf. 93)

Las hojas prismáticas son 194 que suponen el 18,63\% del total de la industria, y el 22,37\% de los productos de talla. La longitud máxima es de $6,62 \mathrm{~cm}$. y la anchura máxima es $2,26 \mathrm{~cm}$. Como podemos observar, la longitud más utilizada en las hojas, en el $48,14 \%$ de las mismas, es de entre 2-3 cm., la mayor parte de las hojas $(66,50 \%)$ se mueven en anchuras de 1 a $1,5 \mathrm{~cm}$. (94,95 y 96$)$.

Existen 122 piezas retocadas $(11,83 \%)$. Los soportes sobre los que se han realizado los útiles se reparten de esta manera; sobre núcleo $4(3,27 \%)$, sobre hoja $76(62,29 \%)$ y sobre lasca $42(34,42 \%)$ (gráf. 97).

En cuanto a la clasificación tipológica, se han identificado 20 lasca con retoque de uso $(16,39 \%)$ y otras 14 con retoque continuo $(11,47 \%)$. Las hojas con retoque de uso son 48 $(39,34 \%)$ y 18 con retoque continuo $(14,75 \%)$, una de ellas puede ser considerada elemento de hoz, posee lustre de cereal.

Se han encontrado 2 escotaduras dobles no retocadas $(1,63 \%)$, cuatro perforadores, uno con modificación secundaria poco profunda sobre indeterminado y tres con modificación secundaria sobre hoja $(3,27 \%)$, hay 6 raspadores, todos ellos delgados de frente no destacado, uno de ellos reciclado de núcleo (4,91\%). Cuatro truncaduras (3,27\%), dos proximales oblícuas, una de ellas es un elemento de hoz con lustre de cereal y dos distales rectas, un segmento de 
círculo $(0,81 \%)$, un denticulado simple de baja modificación secundaria $(0,81 \%)$ y cuatro astillados simples (3,27\%) (fig.98).

\section{VII.1.13. Fase 13: Neolítico tardio}

En la fase 13 se han estudiado un total de 1355 piezas líticas, todas ellas en sílex. De ellas $65(5,79 \%)$ poseen corteza. La alteración térmica ha afectado a 341 piezas $(25,16 \%)$, mientras que $176(12,98 \%)$ han sido tratadas térmicamente. $155(11,4 \%)$ se han visto afectadas por la alteración química.Hay tres piezas con lustre de cereal $(0,22 \%)$. Hay 25 esquirlas térmicas $(1,54 \%)$.

Del total de piezas estudias, $178(13,13 \%)$ están completas $616(45,46 \%)$ incompletas.

El análisis tecnológico nos ha permitido identificar 2 percutores $(0,14 \%), 42(3,06 \%)$ núcleos 11 para lascas y 31 para hojas. Las hojas y las lascas se reparten de la siguiente manera, 252 hojas $(18,59 \%)$ y 912 lascas $(67,30 \%)$. Los productos de talla indeterminados son 60 $(4,42 \%)$ y hay $39(2,87 \%)$ indeterminables (gráf.99).

Hay 663 productos de talla sin talón $(48,92 \%)$, todos ausentes por fractura, menos 4 eliminados por retoque. De los 519 talones existentes $(38,30 \%), 433(83,42 \%)$ son lisos, 49 $(3,61 \%)$ puntiformes, 29 diedros $(5,58 \%)$ y 9 facetados $(0,66 \%)$ (gráf. 100$)$.

Las hojas prismáticas son 252 que suponen el 18,59\% del total de la industria, y el 20,58\% de los productos de talla. La longitud máxima es de $6,62 \mathrm{~cm}$. y la anchura máxima es $2,26 \mathrm{~cm}$.** $\mathrm{cm}$. Como podemos observar, la longitud más utilizada en las hojas, en el $38,46 \%$ de las mismas, es de entre $2-3 \mathrm{~cm}$., la mayor parte de las hojas $(80,76 \%)$ se mueven en anchuras de $0,5 \mathrm{a} 1,5 \mathrm{~cm}$. $(101,102$ y 103$)$.

Existen 190 piezas retocadas (14,06\%). Los soportes sobre los que se han realizado los útiles se reparten de esta manera; sobre núcleo $4(21 \%)$, sobre hoja $138(72,63 \%)$ y sobre lasca 57 (30\%) (gráf. 104). 
La clasificación tipológica, queda de esta manera 26 lascas con retoque de uso (13,68\%) y otras 17 con retoque continuo (8,94\%). Las hojas con retoque de uso son $96(50,52 \%)$ y 19 con retoque continuo $(10 \%)$.

Se han encontrado 2 escotaduras, una doble retocadas y otra simple retocada (1,05\%), siete perforadores, todos con modificación secundaria profunda, 5 sobre hoja y 2 sobre lasca $(3,68 \%)$, hay 3 raspadores, todos ellos delgados de frente no destacado, uno de ellos reciclado de núcleo $(1,57 \%)$. Una truncadura distal oblícua $(0,52 \%)$, con lustre, posible elemento de hoz, dos geométricos, un trapecio y un segmento de círculo con lustre $(1,05 \%)$, un denticulado simple de baja modificación secundaria con lustre $(0,52 \%)$ y catorce astillados simples $(7,36 \%)$ (fig. 105).

\section{VII.1.14. Fase 14: Neolitico tardio}

En la fase 14 se han estudiado un total de 1471 piezas líticas, todas ellas en sílex. De ellas $148(10,08 \%)$ poseen corteza. La alteración térmica ha afectado a 536 piezas $(36,43 \%)$, mientras que $120(8,15 \%)$ han sido tratadas térmicamente. $237(16,08 \%)$ se han visto afectadas por la alteración química. Otra $(0,06 \%)$ han sufrido alteración mecánica. Hay 43 esquirlas térmicas $(2,92 \%)$.

Del total de piezas estudias, 307 (20,87\%) están completas y el resto, $988(67,16 \%)$ incompletas.

El análisis tecnológico nos ha permitido identificar 11 percutores $(0,74 \%), 65(4,41 \%)$ núcleos . Las hojas y las lascas se reparten de la siguiente manera, 334 hojas $(22,70 \%)$ y 880 lascas $(59,82 \%)$. Los productos de talla indeterminados son $69(4,69 \%)$ y hay $68(4,62 \%)$ indeterminable (gráf. 106).

Hay 750 productos de talla sin talón (51,39\%), ausentes por fractura, menos 5. De los 458 talones existentes $(31,13 \%), 428(93,44 \%)$ son lisos, $17(3,71 \%)$ puntiformes, $7(1,52 \%)$ diedros y un facetado $(0,21 \%)$ (gráf. 107) 
Las hojas prismáticas son 334 que suponen el 22,70\% del total de la industria, y el 27,03\% de los productos de talla. La longitud máxima es de $7,13 \mathrm{~cm}$. y la anchura máxima es 2,80 $\mathrm{cm}$.Como podemos observar, la longitud más utilizada en las hojas, en el $46,80 \%$ de las mismas, es de entre $2-3 \mathrm{~cm}$., prácticamente todas las hojas (76,59\%) se mueven en anchuras de 0,5 a 1 cm., pero aumenta la proporción de hojas más anchas (graf. 108, 109 y110).

Existen 323 piezas retocadas (21,95\%). Los soportes sobre los que se han realizado los útiles se reparten de esta manera; sobre núcleo $2(0,61 \%)$, sobre hoja $225(69,65 \%)$, sobre indeterminados $3(0,92 \%)$ y sobre lasca $102(31,57)$ (gráf. 111).

En cuanto a la clasificación tipológica, se han encontrado 54 lascas con retoque de uso $(16,71 \%)$ y otras 43 con retoque continuo (13,31\%). Las hojas con retoque de uso son 174 $(53,86 \%)$ y 34 con retoque continuo $(10,52 \%)$.

Se han encontrado 1 escotadura $(0,30 \%)$, nueve perforadores $(2,78 \%)$, hay 4 raspadores $(1,23 \%)$, un geométrico, trapezoidal $(0,30 \%)$, y tres puntas de flecha $(0,92 \%)$ (fig. 112$)$.

\section{VII.1.15. Fase 15: Neolítico final}

En la fase 15 se han estudiado un total de 635 piezas líticas, todas ellas en sílex. De ellas $71(11,18 \%)$ poseen corteza. La alteración térmica ha afectado a 169 piezas $(26,61 \%)$, mientras que $90(14,17 \%)$ han sido tratadas térmicamente. $113(17,7 \%)$ se han visto afectadas por la alteración química. Hay 4 esquirlas térmicas $(0,62 \%)$.

Del total de piezas estudias, $124(19,52 \%)$ están completas y $463(72,91 \%)$ incompletas.

El análisis tecnológico nos ha permitido identificar 2 percutores $(0,31 \%), 28(4,40 \%)$. Las hojas y las lascas se reparten de la siguiente manera, 168 hojas $(26,45 \%)$ y 385 lascas $(60,62 \%)$. Los productos de talla indeterminados son $42(6,61 \%)$ y hay $6(0,94 \%)$ indeterminables (gráf.113). 
Hay 341 productos de talla sin talón $(53,70 \%)$, todos ellos ausentes por fractura. De los 212 talones existentes $(33,38 \%), 193(91,03 \%)$ son lisos, $12(5,66 \%)$ puntiformes, 7 diedros $(3,3 \%)$ (gráf. 114).

Las hojas prismáticas son 164 que suponen el 25,82\% del total de la industria, y el 27,56\% de los productos de talla. La longitud máxima es de 4,17 cm. y la anchura máxima es 4,04 cm. Como podemos observar, la longitud más utilizada en las hojas, en el 47,05\% de las mismas, es de entre 3-4 cm., la mayor parte de las hojas $(52,94 \%)$ se mueven en anchuras de 0,5 a $1 \mathrm{~cm}$. $(115,116$ y 117$)$

Existen 127 piezas retocadas (20\%). Los soportes sobre los que se han realizado los útiles se reparten de esta manera; sobre núcleo 2 (1,57\%), sobre hoja $96(75,59 \%)$, sobre indeterminados $2(1,57 \%)$ y sobre lasca $27(21,25 \%)$ (gráf. 118).

En cuanto a la clasificación tipológica, se han encontrado 16 lascas con retoque de uso $(12,59 \%)$ y otras 9 con retoque continuo $(7,08 \%)$. Las hojas con retoque de uso son $61(48,03 \%)$ y 30 con retoque continuo $(23,62 \%)$.

Se han encontrado 1 escotadura $(0,78 \%)$, cuatro perforadores $(3,14 \%)$, hay dos raspadores $(1,57 \%)$, dos puntas de flecha $(1,57 \%)$, y dos astillados $(1,57 \%)$ (fig. 119).

\section{VII.1.16. Neolítico final}

\section{Fase 16a}

En la fase 16a se han estudiado un total de 434 piezas líticas, todas ellas en sílex. De ellas $19(4,37 \%)$ poseen corteza. La alteración térmica ha afectado a 52 piezas $(11,98 \%)$, mientras que $8(1,84 \%)$ han sido tratadas térmicamente. $20(4,6 \%)$ se han visto afectadas por la alteración química. En una $(0,23 \%)$ se ha podido detectar el lustre producido por el trabajo del cereal. 
El análisis tecnológico nos ha permitido identificar 22 núcleos (5,06\%) núcleos. Las hojas y las lascas se reparten de la siguiente manera, 94 hojas $(21,65 \%)$ y 211 lascas $(48,61 \%)$. Los productos de talla indeterminados son $35(8,06 \%$ ) (gráf.120).

Hay 84 productos de talla sin talón (19,35\%), todos ellos ausentes por fractura y dos eliminado por retoque. De los 116 talones existentes (26,72\%), 90 (77,55\%) son lisos, 9 (2,07\%) puntiformes, 3 diedros $(0,69 \%)$ y un facetado $(0,23 \%)$ (gráf.121).

Las hojas prismáticas son 83 que suponen el 19,12\% del total de la industria, y el 24,41\% de los productos de talla. Al ser tan escaso el número de hojas completas, estas han sido incorporasdas al análisis y los gráficos de la fase siguiente, la 16b.

Existen 89 piezas retocadas (20,50\%). Los soportes sobre los que se han realizado los útiles se reparten de esta manera; sobre núcleo $2(2,24 \%)$, sobre hoja $51(57,30 \%)$ y sobre lasca $28(31,46 \%), 4(4,49 \%)$ sobre indeterminados y $1(1,12)$ sobre indeterminable (gráf. 122).

En cuanto a la clasificación tipológica, que se ha estudiado hay 9 lascas con retoque de uso $(10,11 \%)$ y otras 19 con retoque continuo $(21,34 \%)$. Las hojas con retoque de uso son 12 $(13,48 \%)$ y 29 con retoque continuo $(32,58 \%)$.

Se han encontrado 2 trapecios $(2,24 \%)$, dos raspadores $(2,24 \%)$, tres escotaduras simples retocadas $(3,37 \%)$, una hoja de extremidad astillada y/pulida $(1,12 \%)$, dos truncaduras distales $(2,24 \%)$, tres elementos dentados en proceso de elaboración (3,37\%), dos perforadores $(2,24 \%)$ y tres astillados $(3,37 \%)$ (graf. 123 )

\section{Fase $16 b$}

En la fase 16 se han estudiado un total de 1074 piezas líticas, todas ellas en sílex. De ellas $152(14,15 \%)$ poseen cortex. La alteración térmica ha afectado a 313 piezas $(29,14 \%)$, mientras que $667(62,10 \%)$ han sido tratadas térmicamente. $223(29,76 \%)$ se han visto afectadas por la 
alteración química. Otras $2(0,18 \%)$ han sufrido alteración mecánica. Hay 12 esquirlas térmicas $(1,11 \%)$.

El análisis tecnológico nos ha permitido identificar 7 percutores $(0,65 \%), 68$ núcleos $(6,33 \%)$. Las hojas y las lascas se reparten de la siguiente manera, 343 hojas $(31,93 \%)$ y 579 lascas $(53,91 \%)$. Los productos de talla indeterminados son $58(5,40 \%)$ y hay $7(0,65 \%)$ indeterminable (gráf. 124)

Hay 550 productos de talla sin talón $(51,21 \%), 9$ de ellos eliminados por retoque y los retantes ausentes por fractura. De los 372 talones existentes (34,98\%), 327 (87,90\%) son lisos, $26(6,98 \%)$ puntiformes y $10(2,68 \%)$ diedros (gráf. 125$)$

Las hojas prismáticas son 333 que suponen el 31,00\% del total de la industria, y el 33,97\% de los productos de talla. La longitud máxima es de $7,44 \mathrm{~cm}$. La anchura máxima es $3,70 \mathrm{~cm}$.

Como podemos observar, la longitud más utilizada en las hojas, en el 39,39\% de las mismas, es de entre 3-4 cm., prácticamente todas las hojas (72,72\%) se mueven en anchuras de 1 a $2 \mathrm{~cm}$. (graf. 126,127 y 128).

Existen 276 piezas retocadas $(25,69 \%)$. Los soportes sobre los que se han realizado los útiles se reparten de esta manera; sobre núcleo $4(1,44 \%)$, sobre hoja 194 (70,28\%) y sobre lasca 67 (24,27\%) (gráf. 129)

En cuanto a la clasificación tipológica, se han identificado 30 lascas con retoque de uso $(10,86 \%)$ y otras 34 con retoque continuo (12,31\%). Las hojas con retoque de uso son 112 $(40,57 \%)$ y 70 con retoque continuo $(25,36 \%)$.

Además, hemos identificado 4 geométricos trapezoidales (1,44\%), 8 perforadores $(2,89 \%)$, uno sobre lasca y los restantes sobre hojas, todos ellos con modificación secundaria profunda. Sólo hemos identificado 1 raspador delgado de frente no destacado $(0,36 \%), 14$ puntas de flecha $(5,07 \%)$ de las que 5 están en proceso de fabricación, otras cinco tienen la base cóncava, 
Espacios de producción y uso de los útiles de piedra tallada del Neolítico

tres más son de base plana y una es de base no reconstruible. Por último hemos identificado 5 $(1,81 \%)$ astillados, dos simples delgados y tres dobles espesos (fig. 130) 


\section{2 Descripción de los complejos estructurales de las fases neolíticas del yacimiento de Las Peñas de los Gitanos (Montefrío, Granada)}

El yacimiento de Los Castillejos de las Peñas de los Gitanos presenta una amplia secuencia cultural en la que se han distinguido cuatro grandes períodos cronoculturales neolíticos. A continuación desarrollamos una descripción especialmente de los complejos estructurales documentados en las diferentes fases constructivas y que han sido utilizados en el análisis contextual que hemos realizado. Hemos tomado como punto de partida la descripción realizada en el trabajo de Afonso et al. 1995, aunque introduciendo diversos cambios, sobre todo en la asignación de determinadas estructura a según que fases:

Fase I (4000-3800 a.c.). Ha sido considerada Neolítico Antiguo Avanzado o Neolítico Medio Inicial e incluye 5 momentos constructivos. A nivel de la cultura material mueble incluye los únicos restos de cerámica con decoración cardial recuperado en las excavaciones recientes (Afonso et al.1995).

El primer momento de ocupación (Fig. 3) del poblado de Los Castillejos se inicia con el acondicionamiento del espacio. En este sentido, se acondiciona la superficie formada por bloques irregulares de piedra resultado del desplazamiento y derrumbe parcial de las paredes rocosas del entorno. Utilizando tierra natural de tonalidad anaranjada y textura arenosa se dispusieron las primeras estructuras que se han conservado, tras la acumulación posterior, en diferente grado.

La primera de estas estructuras viene definida por un gran hogar/horno 119 (Fig.3) realizado mediante un anillo de barro, presenta una forma ovalada y un diámetro máximo de 1,20 $\mathrm{m}$. En su anillo de barro aparece un pequeño hoyo con una profundidad de unos $20 \mathrm{~cm}$. y un diámetro de unos $25 \mathrm{~cm}$. destinado posiblemente a sostener un recipiente. Otra estructura perteneciente a esta fase constructiva es un hogar 121 (Fig.3) de pequeñas dimensiones realizado en barro, con forma ovalada y bolsadas de cenizas, se halla muy alterado por estructuras posteriores.

El segundo momento constructivo (Fig. 4) se caracteriza por la continuidad de la 
El segundo momento constructivo (Fig. 4) se caracteriza por la continuidad de la estructura 119 a la que se suman en la zona occidental nuevas estructuras. El hogar-horno 115 de forma ovalada, consta de anillo realizado con barro y piedras, se asienta directamente contra la roca, así mismo presenta un relleno con cenizas. Su diámetro máximo es de aproximadamente de 1,50 m. Al igual que la estructura 119 este hogar-horno presenta en su anillo un pequeño hoyo 116 de forma circular destinado a la sujeción de recipientes. Posee un diámetro aproximado de unos $25 \mathrm{~cm}$. Otra estructura perteneciente a esta fase aunque de más problemática definición debido a las limitaciones del área excavada es la número 120 , consistente en un anillo de barro con un relleno diverso mal definido.

El anillo de esta última estructura formará parte en un tercer momento (Fig.5) de la estructura 129. Nos referimos a un banco, formado por una capa de barro amarillo, que delimita un área semicircular al sur de la zona excavada. A esta estructura se le adosa un hogar $\mathbf{1 3 0}$ de pequeñas dimensiones realizado con barro amarillo. En su interior se han documentado cenizas. Otra estructura sería el hogar/horno 114 situado sobre el anterior hogar-horno 119. La técnica constructiva es similar a la ya descrita. Esta formado por un anillo de barro de forma avalada con un diámetro máximo de $1,50 \mathrm{~m}$. Su interior aparece relleno con ceniza apelmazada.

En un cuarto momento constructivo, de una mayor duración aunque de difícil subdivisión, se han incluido un total de 10 estructuras. Su historia puede sintetizarse en función de la evolución alrededor del hogar/horno 124. Ha sido realizado mediante una fosa y un anillo de barro anaranjado. Su diámetro máximo documentado es de 1,60 m. Esta estructura convivirá en un primer momento (4a) (Fig. 6 ) con una serie de pavimentos superpuestos $(127,128)$ realizados con una capa de barro amarillo. Así mismo, se documenta al sur de la zona excavada y de forma parcial otra estructura de combustión la número $\mathbf{1 1 2}$ formada por una anillo de barro y piedra relleno de cenizas. Presenta una forma circular y un diámetro aproximado de 1,25 m. La última de la estructuras de esta subfase corresponde a un banco 113 realizado con barro apisonado.

En la segunda subfase (4b) (Fig.7) además del hogar-horno 124 ya descrito aparecen las siguientes estructuras. El hogar-horno 111 presenta una forma ovalada, realizado sobre fosa presenta una anillo de barro grueso e irregular que en determinadas zonas conecta con la 
inferiores a los anteriores, su diámetro máximo es de unos $85 \mathrm{~cm}$. Esta formado por una fosa y un anillo de barro de forma circular. Otra estructura sería la $\mathbf{1 1 0}$ constituido por un banco de forma rectangular realizado en barro amarillo. Presenta en su superficie dos depresiones posiblemente relacionadas con la sujeción de vasijas. Otro banco perteneciente también a esta subfase sería el 118. Sobre ella aparece una fôsa 117 rellena de cenizas.

En el quinto constructivo momento de esta fase I (Fig.8) prácticamente todo el extremo norte y este del área excavada aparece sellado por un pavimento de barro amarillo(125) en el que se localizaron agujeros para poste o para pequeños contenedores. También se documentan varias estructuras 106, 108, 109 aproximadamente circulares y de pequeñas dimensiones entre 50 y 60 $\mathrm{cm}$ de diámetro máximo, y realizadas utilizando anillos de barro. Su funcionalidad no ha sido definida con exactitud pudiendo haber sido hoyos para poste o para contenedores.

Esta fase acaba con el momento que ha sido denominado 6 y que supone el abandono del área excavada. Incluye diversas tierras anaranjadas acumuladas en el sentido de la pendiente creada por los estrados precedentes. Sobre ellas el uso del espacio volvió a ser similar aunque las alternancias de nivelaciones y hogares/hornos serían en adelante más esporádicas y estas últimas estructuras tendrían mayor entidad.

Fase II (3800-3500 a.c.). Como hemos dicho tras estas primeras estructuras de combustión este espacio permanecerá mucho tiempo ocupado por estructuras similares (hogares/hornos) en las que la piedra va desapareciendo en su construcción y en cuyo interior se han documentado, entre la ceniza que a menudo conservaban, abundantes semillas, pudiéndose pensar en el torrefactado del cereal. Esta fase incluye 5 momentos constructivos.

En relación al material cerámico abundan los fragmentos decorados con incisiones e impresiones a punzón, siendo muy abundantes los fragmentos de vasos ovoides de tamaño considerable con toda su superficie cubierta de cordones lisos y decorados, elementos que son muy frecuentes en la denominada Cultura de las Cuevas andaluza (Navarrete 1976) y que se constatan también en otras zonas del conjunto de Las Peñas de los Gitanos como son Cueva Negra (Mergelina, 1941-42) y la Cueva de Las Tontas (Arribas y Molina, 1979a; 1979b; Torre, 
Negra (Mergelina, 1941-42) y la Cueva de Las Tontas (Arribas y Molina, 1979a; 1979b; Torre, 1984).

En el primer momento constructivo de esta segunda fase (Fig.9)se documenta la construcción de un nuevo hogar/horno 107 formado por un anillo de barro grueso sitiado en la zona central del área excavada. Presenta una forma ovalada y un diámetro máximo de 1,75 m. Asociado al hogar-horno aparece un pavimento (123) de barro horadado por lo que parecen hoyos para postes. Así mismo, se documenta otro gran hogar/horno (122) compartimentado, realizado igualmente mediante un anillo de barro. En el límite sureste de la zona excavada aparece un hogar 40 completamente relleno de ceniza muy blanca que cabe atribuir a una combustión continuada. Finalmente debemos destacar los restos de un banco (131) formado por una capa de barro anaranjado.

En un segundo momento constructivo (Fig.10) se documenta los restos de un zócalo realizado con dos hiladas de pequeñas piedras sin relleno interior. Presenta una dirección esteoeste y una fosa de cimentación. Este zócalo parece dividir el espacio de forma que al norte nos encontramos con las siguientes estructuras: un banco realizado con barro amarillo apisonado 102 y un contendor 104 de forma posiblemente ovalada formado por una estructura de barro sobreelevada y hueca en su interior sin relleno, por tanto. Al sur del zócalo la estructura 40 probablemente seguiría en uso. Otro extraño contenedor rectangular $\mathbf{1 0 5}$ apareció en el extremo más occidental.

En el tercer momento constructivo de esta fase (Fig. 11), y progresivamente todo el área noreste queda ocupada por grandes hogares/hornos 98, 99, 132, 96, 38 y 39. Todos ellos presentan la misma técnica constructiva descrita para fases anteriores, son realizados, por tanto, mediante un anillo de barro amarillento y con forma ovalada. En algunos casos se ha podido documentar una fosa previa a la construcción del anillo, tal es el caso de la estructura 132,98,96, esta última además presenta el anillo compartimentado. Especial interés muestra la estructura 39 que presenta evidencias de haber sido reestructurada y ampliada llegando a poseer un diámetro máximo de 1,90 m. Así mismo, en la mayoría de estos hogares-horno aparecen bolsadas de cenizas en su interior. 
En la zona occidental aparecen los restos de posiblemente dos hoyos de poste con tendencia circular, alineados con el gran bloque de roca. Un cambio sedimentario asociado a los hoyos de poste sugiere el límite del área de hogares 98, 99, 132, 96 y 39 respecto al área ocupada por el hogar-horno 38.

En un cuarto momento constructivo podemos diferenciar dos grandes submomentos . En la primer de ellas, concretamente el denominado submomento 10a (Fig.12), continua en uso la estructura 39 ya descrita en la fase anterior, aunque en este momento aparece asociada la estructura de barro 85 realizada posiblemente para sostener recipientes. El diámetro máximo del interior del anillo es de unos 25-30 cm. Así mismo, aparece los restos de un zócalo de piedra 89 del que se ha documentado su fosa de construcción. El zócalo presenta una dirección noroestesudeste. Además del hogar-horno 39 se han documentado otros dos hogares/hornos 95, 97. El primero de ellos aparece mal conservado debido a construcciones posteriores. El hogar-horno 97 aparece mejor conservado habiendose documentado en su interior un bolsada de cenizas. Por último hay que destacar la estructura $\mathbf{9 4}$ definida como banco y realizada mediante una capa apisonada de piedras y barro.

En el segundo submomento $10 \mathrm{~b}$ (Fig.13) se mantienen el zócalo 89 como estructura que delimita el espacio. Así mismo se mantiene el banco 94 que presenta asociada la estructura 90 relacionada posiblemente con la sujeción de vasijas. Otra estructura que igualmente sigue funcionando es el contenedor 85. La estructuras nuevas que aparecen en este momento son el hogar-horno 91 realizado mediante un anillo de barro. En su interior presenta una bolsada de cenizas. Su diámetro máximo es de unos $70 \mathrm{~cm}$. aproximadamente.

Otra estructura perteneciente a este momento sería el pavimento (92) situado al norte y compuesto de una capa de barro. Asociado a este pavimento aparece el hoyo de poste 93 que presenta una forma circular y un diámetro de unos $15 \mathrm{~cm}$.

En el quinto momento constructivo presenta dos submomentos (Fig.14). El primero de ellos (Fig. ) viene definido por la construcción de un zócalo de piedras $88 \mathrm{mal}$ conservado. Presenta una dirección noreste-suroeste y consta de dos hiladas de piedra. Al norte del zócalo 
Espacios de producción y uso de los útiles de piedra tallada del Neolítico

aparecen las estructuras 84 definida como silo que aparece relleno de piedras y la estructura 86 que corresponde a un banco. Al sur del zócalo aparece un hogar-horno 37 de forma ovalada y realizado mediante fosa, plataforma y anillo de barro. En la zona excavada posee un diámetro de aproximadamente $1,40 \mathrm{~m}$.

El segundo submomento viene definido por la permanencia de las estructuras descritas anteriormente y por la estructura 82 constituida por un banco realizado con barro y piedras que, como hipótesis, podríamos relacionar con la molienda (Fig.15).

Durante un momento indeterminado de esta fase II debió construirse el murete de contención sobre los bloques caídos al sur y que ya fue identificado en las campañas anteriores (Arribas y Molina 1979a). Dada su situación sobre la roca sólo podemos ofrecer un término ante quem para su asignación cronocultural.

Fase III (3500-3200 a.c.) Los niveles de ocupación situados por encima suponen la aparición de las primeras grandes fosas e incluyen 3 momentos constructivos. Lógicamente continúa la tendencia a abandonar la zona más septentrional en la que la cornisa del farallón queda a muy baja altura, al acumularse progresivamente los sedimentos como resultado de la actividad cotidiana y los frecuentes derrumbes y reestructuraciones, lo que imposibilitaría los movimientos. Por ello no es extraño que a medida que el piso subía de nivel y se iba superando la altura de los bloques caídos en el sur las estructuras relacionadas con la actividad humana se desplazaran hacia esta segunda zona. El extremo norte se aprovechará para una fosa (77) en la que se localizaron abundantes restos humanos, algunos articulados, pero sin deposición cuidada. Lamentablemente las filtraciones de tierra exterior a través de los agujeros de la cornisa impidieron la continuación de los trabajos en esa zona, sobre todo teniendo en cuenta las fisuras que presentaba el farallón norte con riesgo de desprendimiento de algunos pequeños bloques.

En cuanto al material, si bien perviven formas de botella y globulares, se hacen más frecuentes ahora unas cazuelas con inflexión marcada.

El primer momento constructivo de esta fase (Fig.16) supone la transición en la 
transformación del uso del espacio e incluye una gran estructura oblonga de compleja construcción 36 y que presenta fosa, base o calzos de piedras irregulares y plataforma de grandes lajas de piedra cubierta por dos capas de barro rojo y amarillo. Su eje máximo este -oeste presenta un longitud de 1,25 m. Aproximadamente. La presencia junto a ella de sílex alterado térmicamente y la misma alteración de los sedimentos parecen mostrar que se trata de una estructura relacionada con la combustión. En el extremo occidental otra plataforma de barro más pequeña y de forma circular 73 se relaciona con un arco de piedras que pudieron servir de banco 74. Al norte otras estructuras definen un área de combustión con un hogar central 76, de forma ovalada aparece muy afectado por las construcciones posteriores. Su construcción se ha realizado mediante un fondo de barro engrosado en sus bordes. Así mismo aparecen cenizas tanto en su interior como exterior. Otras estructuras son el hoyo de poste $\mathbf{7 8}$ formado por pequeñas piedras alteradas por las construcciones posteriores y el banco/pavimento $\mathbf{7 9}$ parcialmente destruido por las fosas posteriores. Su construcción se ha realizado mediante piedras recubiertas de barro apisonado. El primero de los grandes silos $\mathbf{8 0}$ se sitúa al norte del área excavada. En planta presenta una forma circular con un diámetro aproximado de $40 \mathrm{~cm}$.

En un segundo momento constructivo de esta fase (Fig. 17) los silos aún de mediano tamaño se generalizan $\mathbf{7 5}$ y $\mathbf{8 1}$ caracterizándose por presentar grandes revocos de barło amarillento o anaranjado para su impermeabilización. Estructuras más problemáticas se sitúan sobre el área de combustión central anterior, especialmente una presunta zanja $\mathbf{7 2}$ que parece haberse producido por el hundimiento del piso sobre el silo 81 en el que además se aprecian abundantes reestructuraciones. Otra estructura correspondiente a este momento sería los restos de hogar $\mathbf{6 6}$ muy alterados por construcciones posteriores, este sentido, tan solo se ha podido definir un segmento de circulo realizado en barro. No obstante, a medida que se ganaba terreno al caos de bloques las áreas destinadas a esta actividad parecen desplazarse hacia el sur, donde constatamos los restos de un hogar $\mathbf{2}$ también muy mal conservado aunque en este caso la causa ha sido el agujeros abiertos por los furtivos. Del hogar tan solo se conservan una plataforma de barro anaranjado sobre la que se documenta restos de cenizas. Asociado a este hogar aparece un contenedor 81 realizado mediante lajas hincadas verticalmente y apoyadas en los bloques caídos de rocas. Sin embargo hay que decir que es también en esta zona donde al realizarse menos fosas en los estratos posteriores se conservaron mejor los restos de las actividades productivas. 
El último momento constructivo (Fig. 18) de esta tercera fase contempla la generalización de los silos que se cortan unos a otros lo que dificulta la subdivisión del período, aunque en esencia podemos distinguir una serie de silos más antiguos $19,33,61,67,68,69,70$ y otros algo más recientes 62, 64. La técnica constructiva es similar a la descrita anteriormente. Los silos consisten en una fosa de diferente tamaño que en algunas ocasiones presenta una capa de revoco que la impermeabiliza. En su relleno interior sobre todo en las capas más altas suele localizarşe una gran concentración de piedras.

Fase IV (3200-2800 a.c.) La generalización y el mayor tamaño de las fosas piriformes, identificación de algunas estructuras de habitación y el dominio casi absoluto de las formas abiertas carenadas, de paredes casi rectas, en la cerámica caracteriza esta fase del poblado de Los Castillejos, tradicionalmente denominada del Neolítico Final y situađa en la transición del IV al III milenio a.c.

En un primer momento constructivo (Fìg. 19) se documenta el pavimento de barro 58 al que se asocian un pequeño hogar circular 57 realizado mediante anillo de barro pero sin fosa y de base plana similar a los documentados después en momentos calcolíticos. Su diâmetro mâximo es de $75 \mathrm{~cm}$ aproximadamente. Así mismo se documentan dos contenedores 59, 60 realizados mediante piedras hincadas verticalmente. En relación con los silos aparecen dos 63,65 de similares características a los descritos. Se documentan en este periodo cabañas adosadas al farallôn en forma de chozas con su techumbre sostenida por postes.

En un segundo momento constructivo se han diferenciado dos submomentos. En el primero de ellos (Fìg.20) se documentan restos de un pavimento 54 realizado con barro amarilla. Aparece igualmente restos un banco 56 al norte, y un un pequeño silo 47. En la zona sureste se documenta un pequeño hoyo de poste 30 realizado mediante piedras hincadas que delimitan un espacio circular. Así mismo, en esta zona se ha documentado una estructura 29 cuya funcionalidad no ha sido definida debido al agujero realizado por los furtivos. Consta de pequeñas piedras trabadas con barro incluyendo algunos molinos reutilizados.

En el segundo submomento (Fig.21) prácticamente todo el espacio del área excavada 
queda ocupado por silos $18,20,46,2344,47,53,5524,41,26,25$ lo que sugiere un área especializada dentro del poblado. Los silos una vez abandonados son sellados con piedras que los colman perfectamente, o rellenados con basura, lo que hace que contengan abundante material. La continua sucesión de silos cortándose unos a otros puede contribuir a la mezcla parcial de material, sobre todo si la tierra producto de la excavación de algunos se arrojó como material de relleno de otro, aunque también nos ayuda a determinar su secuencia constructiva.

En estos momentos los revocos, cuando se conservan $18,24,26,44$ ya no son $\tan$ potentes lo que repercute en una mayor capacidad de estos silos. Sólo en el caso del silo $\mathbf{2 5}$ adosado al farallón sur constatamos la existencia de una cantidad apreciable de grano, aun cuando se ha procedido a flotar la mayor parte de la tierra. Además de los silos también se documentan restos de un pavimento 54 realizado con barro amarillo.

En esta fase $I V$ a las formas carenadas las acompañan además fragmentos decorados con triángulos incisos rellenos de puntos impresos y sobre todo cerámicas pintadas en rojo o negro formando figuras geométricas ya presentes en las antiguas excavaciones de Tarradell en Cueva Alta dentro del conjunto de Las Peñas de los Gitanos (Tarradell 1952, fig. 8; Moreno 1982, fig. 2d) y documentándose en Los Castillejos en 1971 (Arribas y Molina 1979a, fig. 31:132, 1979b, fig. 5c). En el sílex, las hojas de cresta se hacen más abundantes, demostrando la consolidación de un cambio fundamental en la técnica frecuentemente resaltado (Martínez 1985; Afonso 1993). 


\section{VIII.3 Aplicación estadística: metodología y resultados}

Una vez analizados y caracterizados los items y estructuras que van a ser nuestro objeto de estudio, pasamos a continuación a aplicar la técnica estadística elegida para nuestro trabajo. Como hemos explicado en el capítulo dedicado al análisis estadístico, hemos elegido la técnica k-means debido a sus buenos resultados en los test a los que ha sido sometida (Blankholm 1991) y porque es el procedimiento que más importancia concede al papel del arqueólogo en la interpretación, y el más flexible a la hora de los resultados. Es por esto que, por este proceso podemos obtener varias soluciones igualmente válidas, pero siempre será el arqueólogo el que controla y guía las operaciones lo que permite eligir la respuesta que más se adecue a su planteamiento teórico.

El análisis K-means ha sido aplicado utilizando el paquete de software Arcospace 3.0 (Blankholm y Price 1991) con bases de datos constituidas por las coordenadas $\mathrm{x}, \mathrm{y}$ de cada uno de los items líticos. Al estar nuestra industria recogida por conjuntos debíamos transformar estos en puntos en el espacio. Las coordenadas de los conjuntos correspondían a las unidades sedimentarias que se reconocieron en el transcurso de la excavación del yacimiento. A cada uno de los items que componían estos lotes, se les halló la coordenada $\mathrm{x}, \mathrm{y}$ mediante un programa informático para números aleatorios, al no ser excesivamente extensas las unidades sedimentarias, los items quedan situados en una situación bastante aproximada a la que poseían en el momento de su recogida.

La técnica ha sido utilizada para el análisis total de la industria cada una de las fases estratigráficas, además hemos analizado también la producción laminar y el resto de la producción para ver si había diferencias entre las dos técnicas de producción. En algunas fases al estar la industria demasiado extendida y no dar resultados con la aplicación de todo el conjunto de la producción, se ha analizado la industria retocada y en los casos en los que el número de útiles (aparte de hojas y lascas de retoque continuo o de uso) era mayor, también se ha realizado el análisis para identificar áreas en las que estos tipos estuvieran reunidos.

La libertad que el investigador tiene con esta técnica, hace que sea necesario introducir, 
en el transcurso del análisis, el número de conjuntos que probablemente resultarán finalmente. Por consiguiente, primero hay que situar cada uno de los items en las plantas que vamos a analizar (figs. 22 a 230) valorar visualmente los conjuntos que pudieran existir y añadir a este número uno o dos más. Nosotros ploteamos los items sobre las plantas mediante el programa Surfer 6 . Después de esto el número exacto de conjuntos vendrá dado por la inflexiones de la curva resultante de la representación del Log (\%SEE) contra el número de cluster (graf. 126 a 159) ${ }^{35}$. Este método de identificar los niveles de agrupación significativos es bastante subjetivos, en la mayoría de las ocasiones resulta satisfactorio, pero puede representar un problama en los cásos en los que la representación del $\log (\% \mathrm{SEE})$ muestre un punto gradual sin ningún punto de inflexión marcado (Pallarés 1993:398).

Tras la introdución de estos datos, la técnica k-means realiza un análisis cluster no jerarquico que minimiza la varianza intragrupo, maximizando al mismo la variación entre conjuntos. Estos conjuntos son descritos con claridad en tablas (tablas 3 a 238) en las que se muestra la densidad de cada uno de los conjuntos (nbar,nstd), su compactación (RMSbar,RMSstd), la tendencia lineal o no de los conjuntos (r2wbar, $\mathrm{r} 2 \mathrm{wstd})$. Dentro de cada uno de los niveles de agrupación, se señala el número de elementos por conjunto y su extensión.

Por otra parte, esta técnica tiende a crear áreas de actividad circulares como se demuestra en la representación de las agrupaciones más significativas (figs. 231 a 354), aunque este modelo pueda fucionar para ciertas distribuciones, en conjuntos de datos de forma lineal $\mathrm{u}$ oval, los grupos pueden aparecer subdivididos en varios grupos.

${ }^{35}$ Comunicación personal de H.P. Blankholm 
VIII. CONCLUSIONES: PROPUESTAS PARA AVANZAR EN EL ÁMBITO DE LA METODOLOGÍA Y EN EL CONOCIMIENTO DE LA ORGANIZACIÓN DE LAS SOCIEDADES PREHISTÓRICAS

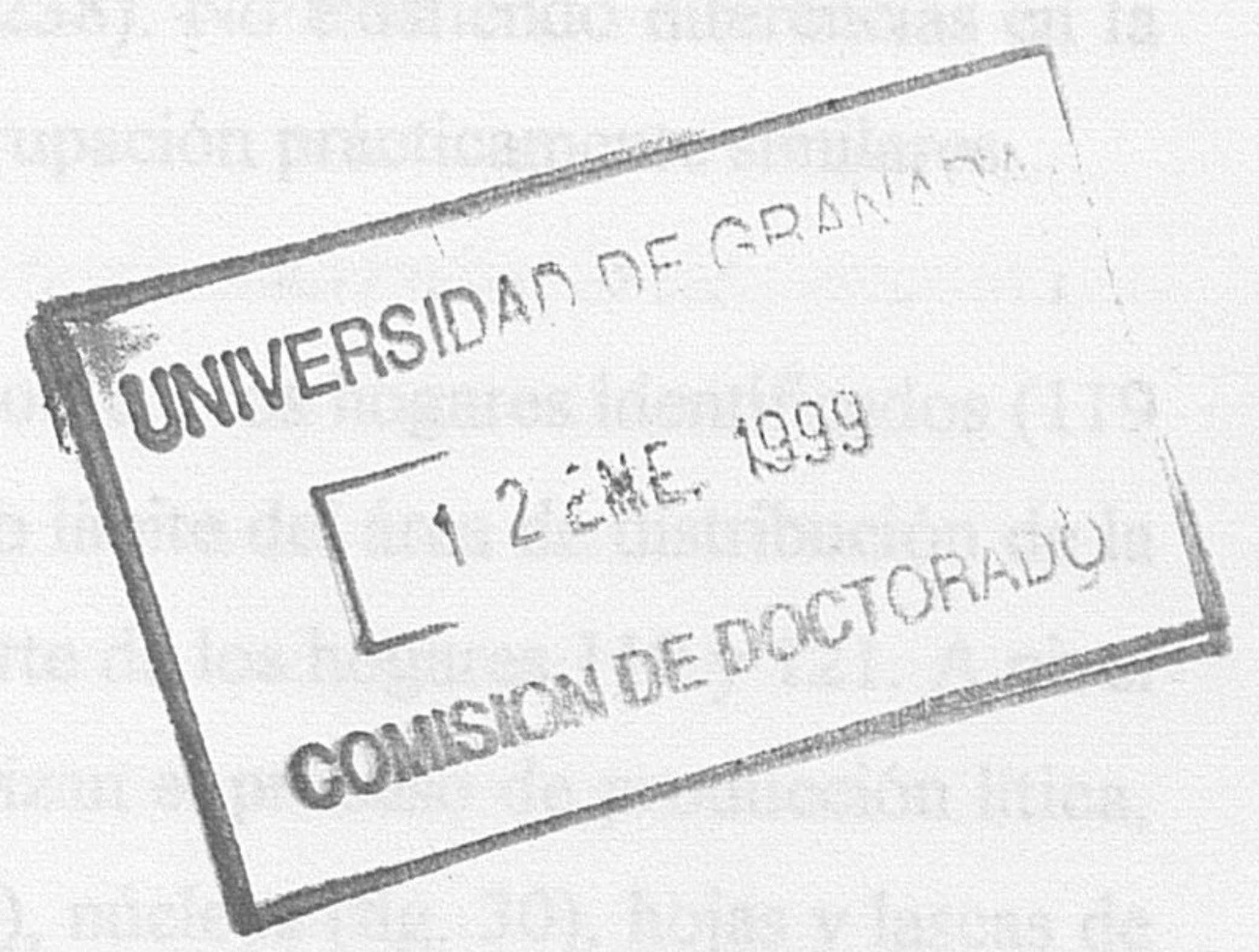




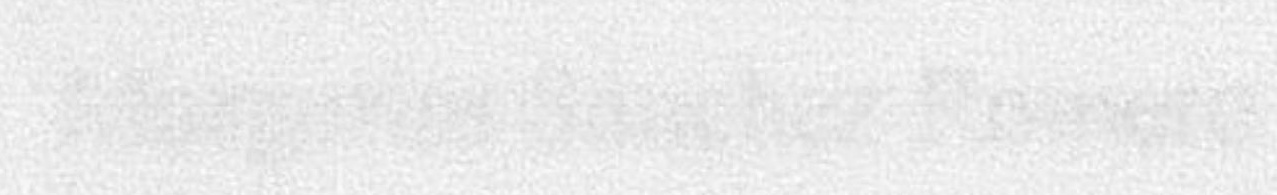

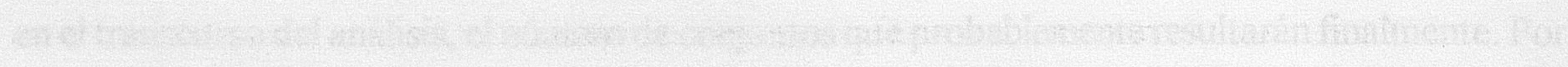

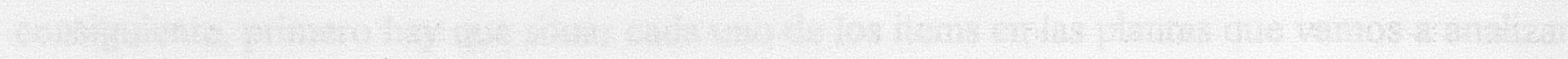

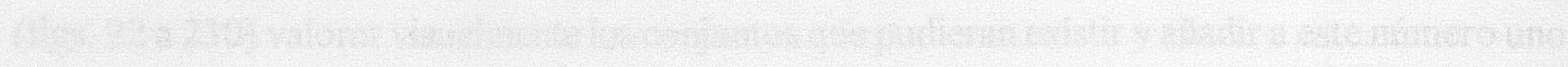

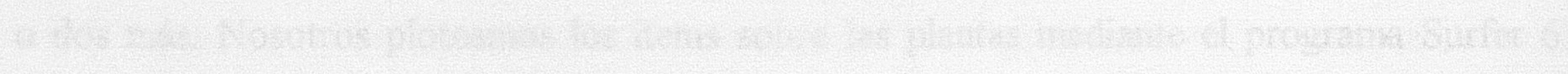
$\operatorname{lng} 20$

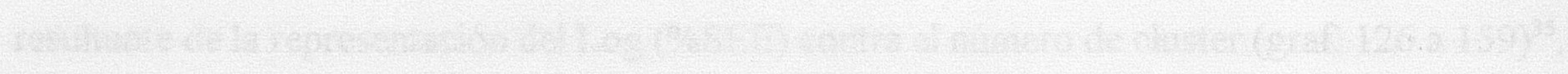

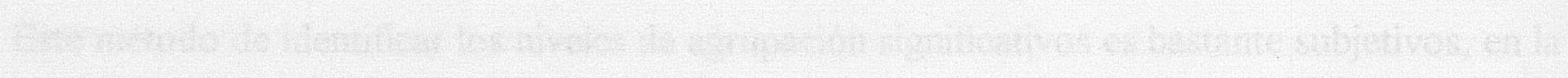

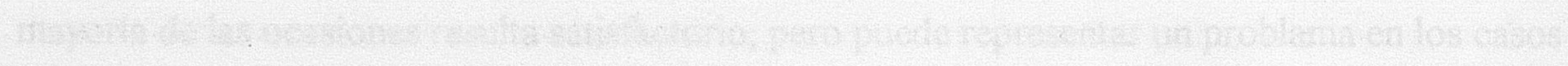
2.

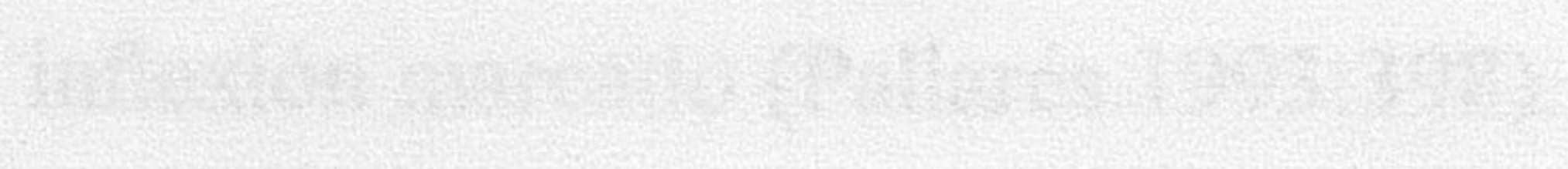

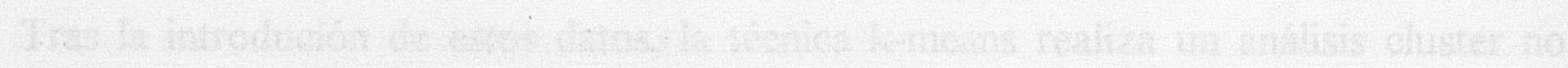

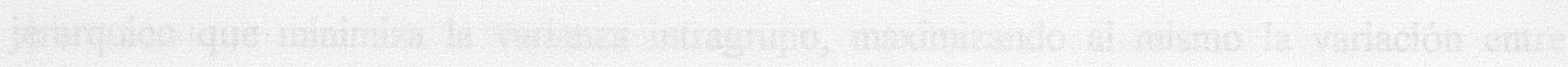

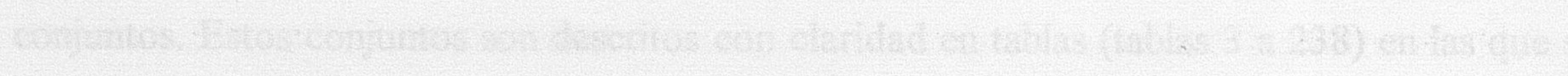

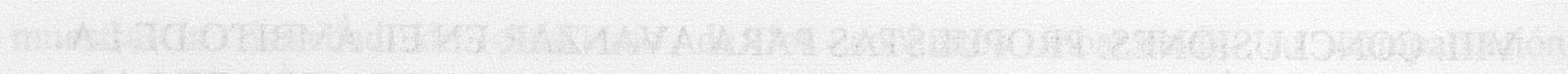

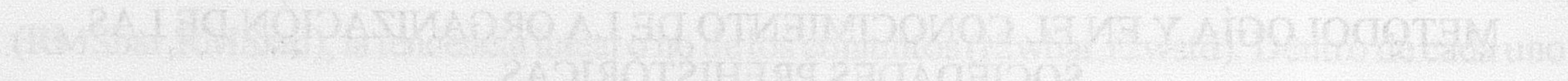

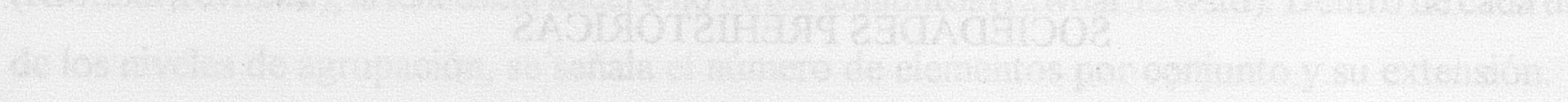

2.

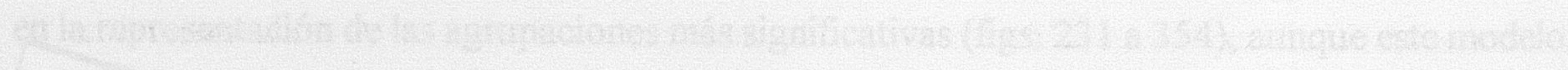

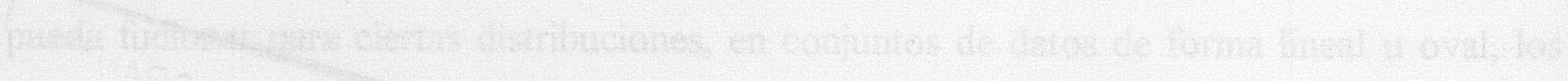

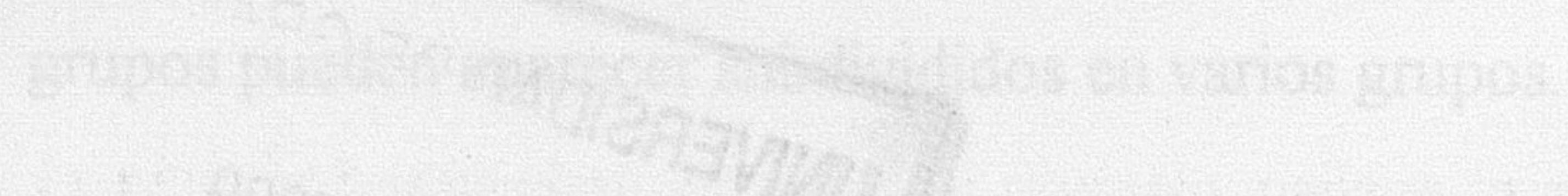

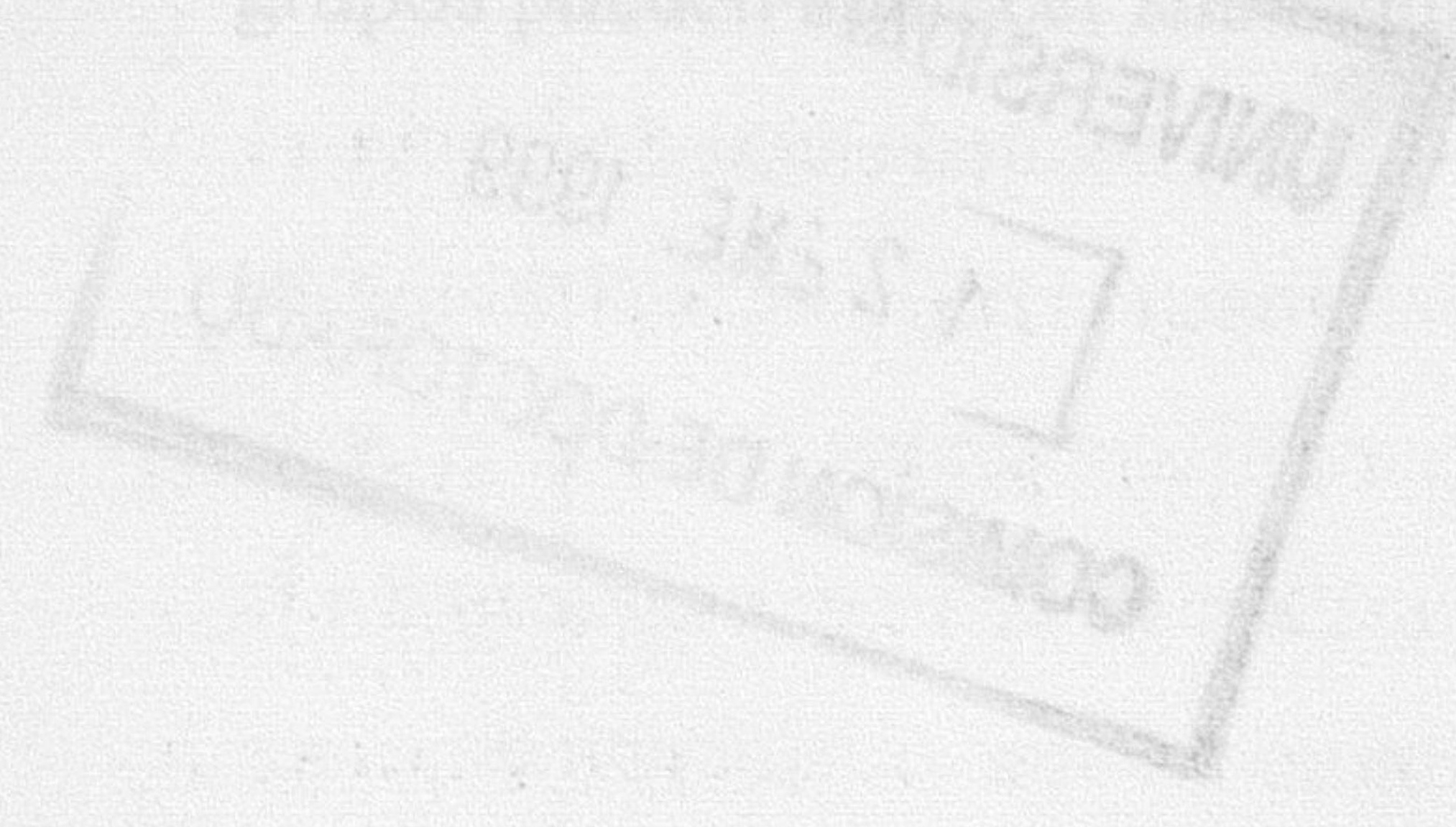

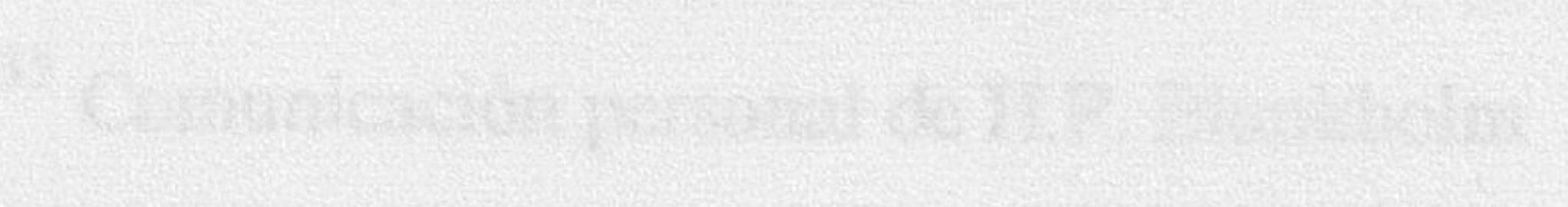

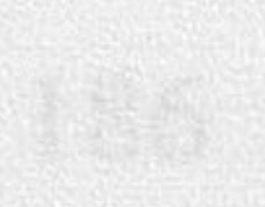


El análisis de los contextos arqueológicos del poblado de Los Castillejos de las Peñas de los Gitanos ha sido realizado en función de los dos elementos básicos que definen a la categoría de contexto arqueológico. Por una parte, el análisis de las propiedades de sus componentes, y por otra, su distribución espacial.

\section{Neolítico antiguo}

En relación con la primera fase identificada ha sido cinco los momentos constructivos definidos equiparables a fases estratigráficas..

En la fase estratigráfica 1, la relación existente entre el total de la industria lítica y la planta correspondiente se obtiene superponiendo la transparencia correspondiente a la fase 1 , con la figura 22. A partir de esta planta de distribución general de toda la industria lítica se ha realizado el análisis estadístico K-means ha proporcionando tres niveles de agrupación significativos (figs. 231, 232, 233), correspondientes a dos, cuatro y seis agrupaciones respectivamente. La relación entre los tres niveles de agrupación y las estructuras identificadas en esta fase se obtiene superponiendo la transparencia de la fase 1 , con cada una de las figuras.

Así mismo, puede establecerse la relación existente entre la producción lascar y laminar y sus correspondientes niveles de agrupación (figs. 234-238). No existiendo diferencias en la distribución de cada una de las técnicas con niveles de agrupación prácticamente similares.

La concentración de la industria se desarrolla en torno a los hogares identificados (119 y 121), quedando el caos de bloques situado al sur, como límite del área de distribución de la industria, apareciendo las mayores concentraciones al norte de los hogares 119 y 121. A nivel técnico, la aparición de todos los elementos que caracterizan el proceso de producción lítica, materia prima no modificada (fig. 30), percutores (fig.29), núcleos (fig. 30), hojas y lascas de preparación y regularización o de descortezado, indican que se desarrollan tareas de talla de útiles. 
Así mismo, una parte básica del proceso de producción viene definida por los hogares en donde los núcleos de sílex (el 100\% de los encontrados) fueron tratados térmicamente antes de la extracción de soportes. Igualmente, la documentación de toda otra serie de elementos líticos tales como perforadores, raspadores, astillados y hojas y lascas con retoque, junto con restos del desarrollo de otras actividades (huesos de animales) demostrarían que el área estudiada responde a un área donde se desarrollan actividades diferentes, que probablemente pudieron poseer un carácter comunal.

En la fase estratigráfica 2, la distribución del total de industria lítica en relación con las unidades estructurales identificadas puede verse en la superposición de la transparencia 2 sobre la fig. 33. Así mismo, la relación entre la producción laminar y lascar puede establecerse superponiendo la misma transparencia sobre las figs. 42 y 43 .

El análisis estadístico K-means ha proporcionado dos niveles de agrupación para las tres distribuciones indicadas, para la producción total figs. 239-240, para la producción laminar figs. 241-242, y por último, para el resto de la industria figs. 243-244. Los niveles de agrupación significativos demuestran en los tres casos una relación directa con el hogar 119 y con el grupo de estructuras que se establecen en torno al hogar 115, estructuras 116 y 120. Esta coincidencia entre la distribución total de la industria y la producción laminar y lascar, demuestra su homogeneidad.

En esta fase también se documentan todos los elementos que caracterizan el proceso de producción lítica, al igual que ocurría en la fase anterior. En cuanto a la distribución de hojas y lascas con retoque, hojas y lascas sin retoque, así como los tipos el patrón de distribución es similar siendo el hogar 119 y el hogar 115, las estructuras que centralizan la distribución de los elementos líticos identificados. Al igual que en la fase anterior el caos de bloque sigue siendo el límite del área de producción.

La aparición de otros útiles de piedra, indicarían así mismo el desarrollo de otras actividades diferentes de la producción lítica, conformando un área polifuncional. 
La fase estratigráfica 3 presenta unas características muy parecidas a las dos anteriormente descritas. La distribución tanto del total de la producción lítica como la distribución laminar y lascar, presenta un patrón de distribución asociado a los hogares identificados, sobre todo al hogar 130. Los niveles de asociación identificados por el programa informático marcan que las concentraciones presentan una dirección suroeste-noreste (fig. 246-247) creando zonas intermedias en donde la distribución decrece con fuerza y que pudieran estar relacionadas con zonas de paso o con zonas relacionadas con otras actividades

La distribución del resto de items líticos de esta fase (figs. 45-52), presentan un patrón muy similar al descrito para fases anteriores. Al igual que en estas, se documenta el proceso de producción lítica desde la preparación del núcleo hasta los soportes y útiles.

La fase estratigráfica 4a sigue con las mismas características definidas en fases anteriores, la distribución de los items líticos se concentra en torno a los hogares/horno 112, 124, 126 y sobre los pavimentos 127,128 y113. En el hogar/horno 112, la concentración de items líticos es inferior. Esto puede apreciarse en la superposición de la transparencia con las plantas de distribución total de la producción, con las de la producción laminar y con las de producción lascar (figs. 252-258). Los niveles de agrupación identificados (2,3 y 4 para la producción total; dos y seis para la producción laminar y dos y cinco para la producción lascar) corroboran la asociación entre las estructuras identificadas y la distribución de los elementos líticos.

Así mismo, parece documentarse una discontinuidad en la distribución de elementos líticos entre la estructura 124,126, 127, 128 y 113 frente al hogar 112, en cualquiera de las plantas de distribución de la producción lítica puede apreciarse que existe una franja entre los dos grupos de estructuras señalados. Este hecho, se relacionaría con una compartimentación del espacios. Las diferencias apreciadas entre los conjuntos líticos de ambas unidades son básicamente de tipo cuantitativo, aunque bien es cierto que las áreas excavadas son espacialmente diferentes.

La distribución de las lascas y hojas sin retoque, lascas y hojas con retoque, núcleos y tipos, siguen el patrón descrito. 
Por otro lado, se documentan de nuevo, todos los elementos que caracterizan el proceso de producción lítica (fig. 73-74). El elemento más significativo sería la concentración de tipos en torno a los hogares 124 y 126, frente al hogar 122 que tan sólo presenta un raspador nucleiforme que hemos considerado encendedor.

En la fase $4 b$, de nuevo la aparición de diversos hogares/horno asociados a otras estructuras como los banco 110 y118 marcan el elemento de referencia a partir del cual se distribuye la, en este caso, numerosa industria lítica. En este momento, al subir el nivel de ocupación la zona del bloque de caos va suiendo paulatinamente ocupada; en este sentido, la distribución total de la industria, así como la distribución de la producción lascar y laminar, presenta una gran homogeneidad sobre el área excavada, si exceptuamos el ángulo noreste, ocupado por el hogar 124 y el área situada al sur, en donde el caos de bloque sigue delimitando la zona ocupada.

Las concentraciones significativas marcan, así mismo, la homogeneidad en la distribución, en este sentido, tanto la industria total (figs. 259-260), como la producción lascar (figs.263-264) y laminar (261-262) presentan niveles de agrupación muy similares.

De nuevo, el resto de elementos líticos identificados (figs.67-74) corroboran el patrón de distribución descrito.

En la fase estratigráfica 5, la distribución de industria lítica presenta unas características diferentes a las hasta ahora descritas en las fases anteriores (figs. 77,86 y 87). Frente a las concentraciones asociadas a hogares/horno de las fases anteriores, durante este momento la más importante de las distribuciones de industria lítica, desde un punto de vista cualitativo, aparece situada en el ángulo sureste de la zona excavada; no obstante, también aparecen agrupaciones asociadas, en este caso, a estructuras que no han sido definidas con claridad, tal es el caso de las estructuras 106, 108 y 109. Así queda puesto de manifiesto en los niveles de agrupación significativos realizados por el programa informático (figs. 265-270). 
Este patrón de distribución se confirma en el resto de elementos líticos documentados (figs. 89-96).

La concentración en áreas muy concretas del espacio parece indicar un cambio en el uso del espacio excavado frente a la fase anterior en donde la práctica totalidad del espacio aparecía con una distribución homogénea de conjuntos líticos.

A nivel técnico, en el ángulo sureste se documentan los elementos característicos del proceso productivo de útiles de piedra tallada, así mismo los tipos documentados pertenecen a este espacio.

Desde una perspectiva general, estas primeras cinco fases constructivas, se caracterizan por áreas en las que se han desarrollado actividades múltiples entre las que destacan la talla de sílex, acompañado del tratamiento térmico del sílex, siendo precisamente los hogares/hornos, los elementos más característicos en torno a los que se organizan las distribuciones líticas. Asímismo se documenta el desarrollo de otras actividades asociadas a instrumentos líticos entre las que podemos destacar el trabajo de la madera.

El uso del espacio parece haber sido comunal, aunque en algunos casos, como en las fases 4a y 5 , podrían identificarse áreas domésticas, pero su definición está condicionada al estudio del resto de conjuntos materiales documentados.

\section{Neolítico medio}

En la fase estratigráfica 7, de nuevo el área de hogares/ hornos, como definidores estructurales del espacio, vuelven a ser los elementos de referencia; en este sentido, la industria lítica se organiza en torno a los hogares $107,122,40$ y sobre el pavimento 123 (figs. 271-276).

Existe una zona en donde no aparecen items líticos coincidiendo con el gran bloque de piedra situado en la zona central del área excavada, en este sentido, parece existir un área que, con dirección noroeste-sureste, estaría marcando dos zonas diferentes en cuanto a la distribución 
lítica, lo que a su vez podría marcar dos áreas de actividad diferentes, o cuando menos, posiblemente compartimentadas.

La distribución del resto de elementos líticos y su relación con las unidades estructurales identificadas, continua el mismo patrón anteriormente definido, no obstante, hay que destacar que todos los tipos identificados se sitúan asociados a la zona de hogares/horno.

Así mismo, también se documentan los elementos característicos del proceso de producción lítica.

Durante la fase 8, el zócalo 103 marca de forma clara una compartimentación del espacio que aparece corroborada con la distribución de la industria lítica (figs.277-283); en este sentido, al norte del zócalo se documenta la más importante distribución lítica frente a la zona sur en donde existe un importante vacio que tan sólo se ve alterado por una distribución lítica asociada al hogar 40. Este hecho queda puesto de manifiesto en los análisis de concentraciones líticas (figs. 100-107).

El resto de elementos líticos identificados siguen el mismo patrón de distribución concentrándose, por tanto, en torno al hogar 40, o bien situandose al norte del zócalo 103. Destacan así mismo los tipos identificados situados de forma mayoritaria al norte del zócalo.

$\mathrm{Al}$ igual que las fases anteriores, se documentan todos los elementos relacionados con el proceso de producción lítica. Destacando en esta fase la gran cantidad de núcleos documentados.

En la fase 9 , el área excavada de nuevo aparece ocupada por grandes hogares/hornos 39 , 96, 98, 99, 132, 88. La distribución de la industria lítica es bastante homogenea (figs. 110, 119 y 120), ocupando toda la zona excavada, asociandose las concentraciones más importantes a los hogares/horno, tal y como aparece en las figuras 284 a 292.

El resto de distribuciones de elementos líticos, hojas y lascas no retocadas (111 y 114), hojas y lascas retocadas $(112,113,115,116)$, tipos (117) y núcleos (118), presentan un patrón 
similar. Destacando, sin embargo, la abundancia de núcleos. Al igual que en el resto de fases se vuelven a documentar los elementos característicos del procesos e producción lítica. Así mismo, es relevante el volumen de industria lítica correspondiente a esta fase. Probablemente esta sea una de las fases más características de una ocupación comunal del espacio.

En la fase 10a, de nuevo la aparición de un zócalo en dirección noroeste-sudeste, delimita el espacio situandose las distribuciones de industria lítica al este del zócalo, tal y como puede establecerse en la superposición de la transparencia correspondiente sobre las figuras 121, 129 y 130. En este sentido, al este del zócalo los conjuntos de industria lítica aparecen asociados al hogar 39, 95 y 97, así como superpuestos a la estructura 94 .

De igual forma, el resto de elementos que caracterizan a esta fase presentan una distribución similar a la descrita (figs. 122 a 129), también destacamos la importante cantidad de núcleos documentados lo que implicaría, junto a otros elementos, una producción lítica importante. Así mismo aparecen otros tipos, perforadores y astillados, que implican el desarrollo de otras actividades.

En la fase 10 b, de nuevo el zócalo 89 , define la organización del espacio, separando en este caso dos áreas de distribución de industria lítica, (figs. 132, 141 y 142), la situada al este, aparece asociada a las estructuras $85,91,92,94$, frente a los conjuntos situados al oeste en donde en el espacio excavado no se ha identificado ninguna estructura.

El resto de industria lítica aparece distribuida a ambos lados del zócalo, documentándose todos los elementos característicos del proceso de producción lítica. Destaca en este sentido, la abundancia de núcleos documentados.

La fase 11a aparece definida estructuralmente por un zócalo con dirección norestesuroeste que parece dividir el espacio en dos unidades diferentes (figs. 143, 152 y 153), no obstante la distribución de los útiles líticos como las agrupaciones realizadas con el k-means, parecen no responder a esta diferenciación del espacio (fig.305-311). 
La distribución parece bastante homogénea, siendo uno de los puntos de mayor concentración el asociado al hogar 37, en esta fase destaca el gran número de núcleos documentados en toda la zona. El resto de elementos líticos (figs. 144-151) presentan un patrón de distribución similar.

La fase $11 \mathrm{~b}$ al igual que ocurría en la 11a se caracteriza por una distribución homogénea de la industria documentada, exceptuando el área suroeste en donde el número de conjuntos líticos disminuye, en esta fase desaparece el zócalo anterior y se documenta una nueva estructura (82) (fig. 154, 163 y 164).

Los niveles significativos de agrupación documentados, presentan un aspecto heterogéneo, sin que se puedan hacer precisiones en cuanto a su organización (figs. 312-319).

En cuanto al resto de elementos líticos, presentan una distribuciones similares, destacando especialmente la gran cantidad de núcleos documentada, así como la abundancia de industria recuperada (figs. 155-162). De nuevo se documentan todos los elementos característicos del proceso de producción lítica desde los núcleos hasta los desechos de talla, pasando por las lascas de regularización, de preparación, etc.

\section{Neolítico tardío}

En la fase 12 la industria lítica aparece mayoritariamente situada en el ángulo noroeste asociada a la estructura 80 y a la 36 (fig. 165, 174 y 175). Así mismo aparecen algunos conjuntos relacionados con el hogar central y diversos conjuntos en la zona oeste del área excavada. Así aparece confirmado por las agrupaciones realizadas por el análisis estadístico (figs. 320 a 328). Llama especialmente la atención la concentración de industria lítica asociada a al estrcutura 36 , ya que presenta unas características constructivas especiales, vease descripción de estructuras, de tal forma que parece una estructura especialmente diseñada para el tratamiento térmico; esta misma estructura, presenta asociados una gran cantidad de núcleos. 
Se documentan todos los elementos característicos de la producción lítica, entre los que destacaría la citada estructura 36 , y otros elementos que señalarían el desarrollo de otro tipo de actividades diferentes.

El resto de elementos líticos confirmarían la distribución ya observada (figs. 166-173)

En cuanto a la fase estratigráfica 13, la industria lítica aparece asociada mayoritariamente a la zona noreste y a las estructuras 66,72 y 85 ; así mismo aparece otra concentración entorno a la 34 y 35 (fig. 176a, 176b, 185a, 185b, 186a y 186b). Las concentraciones más importantes que hemos descrito aparecen en las figuras 329 a 333 .

El resto de elementos líticos presenta una distribución similar (fig. 177-184). Destaca especialmente la concentración de tipos en el ángulo noreste, así como la distribución de núcleos.

En la fase 14, la industria lítica aparece asociada a las estructuras documentadas, básicamente silos, (fig. 187, 196 y 197) este hecho, implica que existen procesos de mezcla de materiales, por tanto las distribuciones no son necesariamente significativas, esto aparece reflejado en la distribución de agrupaciones realizada por el programa informático (figs. 334-338).

La distribución quedaría igualmente confirmada por el resto de la industria lítica (figs. 188-195).

\section{Neolítico Final}

La industria lítica de la fase estratigráfica 15 se concentra en torno a las estructuras documentadas en el ángulo noroeste (fig. 198a, 198b, 207a, 207b, 208a, 208b). Este hecho aparece corroborado por las concentraciones del análisis estadístico (fig. 339-343).

En esta fase, al igual que en la anterior, la gran cantidad de silos debe haber provocado la mezcla de materiales con lo que las distribuciones y agrupaciones no tienen necesariamente que ser significativas. 
Igualmente existe la totalidad de materriales que forman parte del proceso de producción lítica. El resto de la industria lítica presenta los mismos patrones de distribución (figs. 200-206).

En la fase 16a, la distribución aparece concentrada en tres puntos, suroeste, en la zona oeste y en la zona noroeste, así aparece reflejado en las figuras $209,218,219,344,345,346,347$. $\mathrm{Al}$ igual que ocurre en las fases anteriores al existir numerosos silos, la posibilidad de la mezcla de materiales son grandes.

Aparecen todos los elementos característicos de la producción lítica. La existencia del hoyo de furtivos nos imposibilita diferenciar áreas de actividad.

En la fase $16 \mathrm{~b}$ al igual que en la fase anterior, los conjuntos líticos aparecen asociados a estructuras identificados como silos (fig, en este caso concreto a las estructuras 24,20 y 46 . Este es el resultado de los conjuntos del análisis estadístico (figs. 348-354). Las continuas construcción de silos ha debido de alterar los depósitos al igual que en fases anteriores. De igual menera el hoyo de furtivos nos impide delimitar áreas de actividad concretas, tan sólo agrupaciones puntuales.

Además, encontramos los elementos de la producción lítica y el resto de las distribuciones nos indican el mismo patrón de distribución.

\section{El tratamiento térmico del sílex}

Como hemos visto, muchas de las piezas estudiadas han recibido tratamiento térmico. Esto y su ubicación en una zona de hogares que posiblemente fue utilizada para tallar, nos hace plantearnos el problema del papel de las estructuras de combustión en el tratamiento térmico del sílex.

El interés científico en la actualidad se basa en los trabajos que insertan los hogares dentro de cadenas operativas de trabajo, ya sea para la preparación de alimentos, el trabajo del sílex, etc. 
Espacios de producción y uso de los útiles de piedra tallada del Neolítico

Esta utilización del fuego implica estar en posesión de una visión precisa del campo de sus posibilidades tecnológicas en el marco de una economía particular (Taborin 1989).

El hecho de que se encuentren con tanta frecuencia restos de la talla de piedra cerca de hogares, ha sido explicado de muy diversas formas, entre ellas, el que se deba a una simple cuestión de comodidad: el tallador encuentra la luz y el calor del fuego (Pigeot 1987). Sin embargo, uno de los aspectos más interesantes a la hora de estudiar las estructuras de combustión, es su utilización como elemento fundamental en el trabajo del sílex. El calentamiento de este material para mejorar su respuesta al trabajo se documenta desde el Paleolítico Medio, aunque el verdadero tratamiento térmico no aparece hasta el Paleolítico Superior (Perles 1977; Pigeot 1987).

Las conclusiones alcanzadas desde la Arqueología Experimental han sido de vital importancia a la hora de poder documentar los posibles cambios introducidos intencional o accidentalmente en el comportamiento mecánico de la roca. El hecho de que el tratamiento térmico aumente o disminuya la fragilidad y la resistencia a la presión determinará una mayor o menor facilidad a la hora de la talla (Mazo Pérez 1991).

Existen dos elementos fundamentales a considerar en este aspecto: la presión y la tensión que puede soportar el sílex y cómo esta varía según se aplique o no calor sobre la roca. Un sílex no tratado puede resistir entre 3000 y 3600 atmósferas, mientras que se aumenta entre un $25 \%$ y un $40 \%$ si se produce un calentamiento con un enfriamiento gradual posterior. Si por el contrario el enfriamiento se produce bruscamente, la resistencia se reducirá a 1700-2000 atmósferas (Purdy y Brooks 1971; Mazo Pérez 1991).

Por otra parte, y en lo que se refiere a la tensión, los sílex que se calientan hasta los $350^{\circ}$ y se enfrían paulatinamente se fracturan con una presión de 100 atmósferas, mientras que si el enfriamiento se produce de forma brusca sólo resisten 80 atmósferas. Los sílex que no se han calentado resisten hasta 180 atmósferas antes de fracturarse (Purdy y Brooks 1971; Mazo Pérez 1991). 
Las modificaciones producidas por el calentamiento intencional o no del sílex se pueden establecer en varias categorías (Mazo Pérez 1991). Alteración térmica, se denomina así a la modificación superficial, en forma de levantamiento, cambio de color o aparición de brillo, o intensa, en forma de fractura o alteración de las propiedades mecánicas, producida como consecuencia de procesos térmicos, accidentales o intencionales, bruscos o progresivos, controlados o no, a los que pueden verse sometidos los materiales silíceos (Mazo Pérez 1991:60); el cuarteado es la alteración térmica que se produce como consecuencia de la exposición directa al fuego de una pieza lítica. Dependiendo de la duración de la exposición y de la intensidad del agente, la alteración puede ser superficial o profunda (Mazo Pérez1991:75). Según Bernaldo de Quirós forma un reticulado anguloso, con bordes redondeados y alteración posterior, generalmente en forma de pátina asociada. Puede producir desprendimientos de fragmentos de la pieza (Bernaldo de Quiros et al. 1981:21).

El levantamiento térmico es el fragmento que salta, marginal o profundo, producido en la superficie del silex, que tiene su origen en los bruscos y repetidos cambios de temperatura a los que puede verse sometida intencional o accidentalmente una masa silícea (Mazo Pérez 1991:90). Existen dos subtipos de levantamientos: semiesféricos y elipsoidales que tienen su origen en procesos térmicos diferentes. Los levantamientos semiesféricos son superficiales y de pequeño tamaño, dejan una cubeta de superficie lisa y a veces brillante, con una corona interna frecuente. La causa es un calentamiento excesivo seguido de un enfriamiento rápido y localizado en el punto en el que salta la esquirla (Bernaldo de Quiros et al. 1981:21). Los elipsoidales presentan las siguientes características irregulares o no, a veces parecidos a los semiesféricos, pero que afectan más a la superficie de la pieza. La parte interna del negativo es rugosa. Están causados por el hielo. Pueden aparecer acompañados de fracturas longitudinales (Bernaldo de Quiros et al. 1981:21).

Por último, el elemento central de nuestro análisis es el tratamiento térmico, se denomina así al proceso intencional controlado al que se somete una masa silícea con objeto de producir mejoras en su comportamiento mecánico, destinadas a facilitar las operaciones de manufactura y retoque. Estas modificaciones, que generalmente se traducen en un aumento de la fragilidad $y$ en una marcada tendencia a obtener esquirlamientos de escasa variabilidad, pueden 
Espacios de producción y uso de los útiles de piedra tallada del Neolítico

condicionar la ratio y el tipo de terminación de los productos del proceso laboral posterior (Mazo Pérez 1991:111).

Las características del tratamiento térmico van a ser diferentes según el objetivo perseguido en la posterior manufactura del sílex (Perles 1977):

-uso de variaciones en la velocidad de calentamiento y enfriamiento del sílex.

-uso de variaciones en la intensidad del calentamiento.

-uso de variaciones en la naturaleza de las materias primas utilizadas.

Por ejemplo, la técnica que provoca un calentamiento y enfriamiento rápido, conducirá a la fragmentación de los bloques de materias primas; más tarde el recalentamiento progresivo modificará las cualidades internas del bloque (en particular, las cualidades de la talla) sin provocar modificaciones externas (sólo el aspecto y la coloración) (Perles 1977).

Hay dos variables fundamentales a tener en cuanta en el proceso de tratamiento térmico: el tiempo de exposición y la temperatura alcanzada. La temperatura elevada provoca la pérdida de buena parte del agua existente en la estructura del sílex, es decir, del agua contenida en las moléculas del mismo. En experimentos realizados en laboratorio se detectó que el tratamiento ideal se conseguía si el calentamiento se realizaba muy lentamente, durante un mínimo de diez 10 horas (de 20 a 70 normalmente), con una temperatura de unos $200^{\circ} \mathrm{C}$, seguido de un enfriamiento también lento (Perles 1977, Pigeot 1987).

Las fases de esta operación pueden determinarse con bastante precisión El sílex, tratado en un baño de arena a una temperatura superior a $200^{\circ} \mathrm{C}$ (la temperatura necesaria podría alcanzar los $300^{\circ} \mathrm{C}$ para ciertas muestras) sufre una transformación en su textura: un grano más fino y sobre la fractura fresca un aspecto lustroso, un poco graso, a veces casi vitreo, muy diferente de la misma muestra en bruto. No sólo el sílex así tratado se talla major, sino que también es posible hacer, mediante retoques por presión, objetos que son prácticamente 
imposibles de hacer con sílex no tratado (Bordes 1967: cit. en Perles 1977). Bordes calculó que el sílex sufría, en el curso de su tratamiento, una pérdida de agua evaluada en un $0,4 \%$ de su peso inicial (Perles 1977).

Si se consiguen las condiciones óptimas se produce una recristalización del material silíceo donde las fibras o los microcristales se hacen más gordos, de lo que resulta una disminución de la tensión de los cristales, que da un aspecto más grueso y más apagado a la pieza, aumentando la elasticidad del material (Perles 1977).

Alrededor de los $250^{\circ} \mathrm{C}$ el sílex se enrojece ligeramente (por la migración del hierro hacia la superficie). A más altas temperaturas la calidad del sílex se va deteriorando irremediablemente (recordemos que a $574^{\mathrm{a}} \mathrm{C}$ se produce la transformación en cuarzo) (Perles 1977).

Una de las cuestiones fundamentales planteadas es cómo evaluar y comprender la mejora de la talla por presión, después de calentar el sílex. Para contestar estos interrogantes diversos autores han propuesto métodos que pudieran valorar esta mejora. A principios de los 70 se realizaron una serie de experimentos que pretendían definir las modificaciones de las rocas silíceas que habían sido sometidas a un calentamiento intencional y, en un segundo plano, reconocer las mejores aptitudes para la talla y el retoque de estos materiales (Inizan et al. 1976-77).

Los experimentos fueron todos realizados mediante calor indirecto con las muestras introducidas en un lecho de arena y con fuego eléctrico. Se detectaron una serie de modificaciones (Inizan et al. 1976-77):

-pérdida de peso en función de la temperatura, -modificación del color, -aparición de lustre tras la fractura o retoque.

Las preguntas que se intentaban contestar eran las siguientes (Inizan et al. 1976-77): 
1.-Cuáles son las condiciones óptimas de calor necesarias para una mejora del retoque por presión.

2.-Mediante qué medios se consiguieron.

3.-Cuáles son las posibilidades para un tipologista de detectar este modo de preparación.

4.-Cuáles son las materias primas que sufren una mejora tras haber sido calentadas.

Los resultados y conclusiones expuestos por los autores son los siguientes (Inizan et al. 1976-77):

-El óptimo tratamiento para el retoque debe alcanzar entre $280^{\circ} \mathrm{C}$ y $350^{\circ} \mathrm{C}$

-Las modificaciones de color están siempre en función de los óxidos metálicos y es proporcional a la intensidad del lustre.

-El peso perdido ronda el $0,2 \%$, aunque este dato se caracteriza por su inestabilidad.

Además del aumento de la fragilidad, que como ya hemos dicho mejora sensiblemente la talla del producto, tiene lugar un proceso de endurecimiento y pérdida de peso, aptitudes que están más relacionadas con las condiciones de uso del producto fabricado, elementos fundamentales en la producción, por ejemplo, de puntas de flecha ya que, la mayor fragilidad del soporte silíceo permite la talla de artefactos con filos mucho más delgados, facilitando la penetrabilidad, al mismo tiempo que, una vez utilizados, se facilita que éstos se partan. La mayor dureza, a su vez, permite penetrar con mayor facilidad una mayor gama de materiales. Por último, la pérdida de peso posibilita el uso de vástagos más pequeños para conseguir el equilibrio del proyectil (Afonso 1993:368).

El mismo autor hace hincapié en que la técnica neolítica de talla mediante presión requiere que un material tan duro como el sílex reciba algún tipo de tratamiento que facilite su fractura. 
En los conjuntos neolíticos, la presencia de núcleos tratados térmicamente (incluso con cortex) parece indicar un uso de la técnica desde los primeros momentos del proceso productivo. Por contra, en asentamientos calcolíticos sólo encontramos el tratamiento térmico en los productos de talla, lo que pone en evidencia el uso de esta técnica sobre soportes y previo al momento de la modificación secundaria de los mismos (Afonso 1993).

En la misma línea de experimentación se han realizado una serie de estudios termodilatométricos y magnéticos con temperaturas que van desde los $150^{\circ} \mathrm{C}$ a los $600^{\circ} \mathrm{C}$, es decir, desde el calentamiento intencionado de un útil preciso a la quema accidental en un hogar prehistórico. La termodilatometría consiste en registrar las variaciones de dimensión de una muestra de material a estudiar en el curso de un ciclo de calentamiento, mientras que el estudio magnético trata de detectar las variaciones de las trazas de hierro después de quemar ciertos sílex particularmente ricos en este elemento (Chantret et al. 1989). 
BIBLIOGRAFÍA 
and

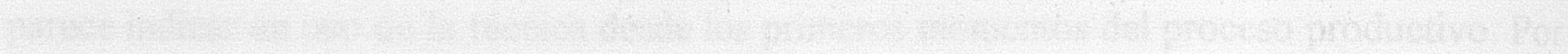

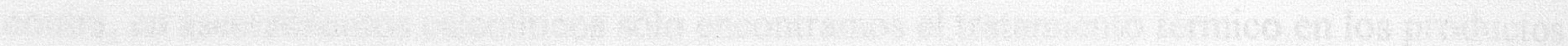
Then

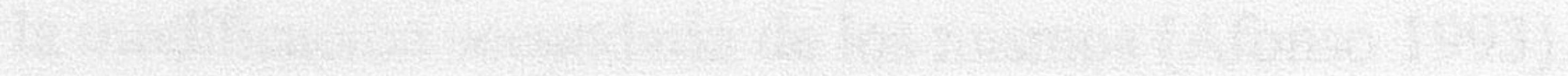

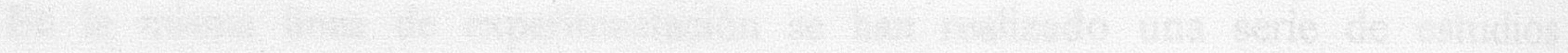

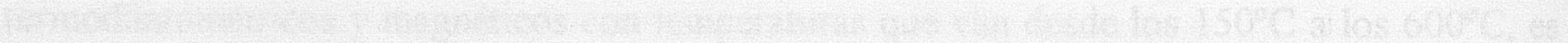

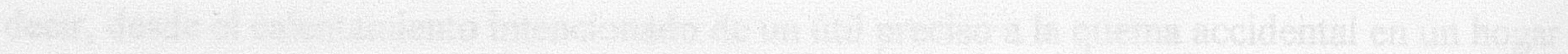
(20)

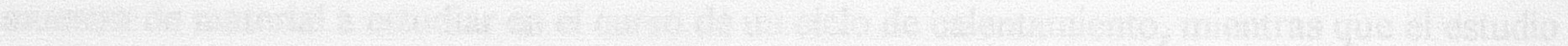
(20) and 
ADANEZ PAVÓN, J (1986) Nuevas generaciones de análisis espacial y arqueología contextual: una crítica, Arqueología espacial 7, pp. 7-20

AFONSO MARRERO, J.A. (1993) Aspectos técnicos de la producción lítica de la Prehistoria reciente de la Alta Andalucía y el Sureste. Tesis doctoral. Universidad de Granada. Granada.

AFONSO MARRERO, J.A., MOLINA GONZÁLEZ, F., CÁMARA SERRANO, J.A., MORENO QUERO, M., RAMOS CORDERO, U., RODRÍGUEZ ARIZA, MO. (1995) Espacio y Tiempo. La secuencia en Los Castillejos de las Peñas de los Gitanos (Montefrío, Granada), I Congrés del Neolitic a la Península Ibérica. Formació e implantació de les comunitats agrícoles (Gavà-Bellaterra, 1995). Actes. Vol. I. (J. Bosch y M. Molist, orgs.), Rubricatum 1:1, Gavà. pp. 297-304.

AGUAYO, P. (1984) La transición de la Edad del Cobre a la Edad del Bronce en la provincia de Granada, Actas del congreso "Homenaje a Luis Siret", (1934-1984), Sevilla, pp. 262-270.

AMMERMAN, A.J., KINTIGH, K.W., SIMEK, J.F. (1987) Recent developments in the application of the $k$-means approach to spatial analysis, en The human uses of flint and chert, (G. de Sieveking y M.H. Newcomer, eds.), Cambridge University Press, pp.211216.

ANDREFSKY, W. (1994a) The geological ocurrence of lithic material and stone tools production strategies, Geoarchaeology 9:5, pp. 375-391

ANDREFSKY, W. (1994b) Raw-material availability and the organization of technology, American Antiquity 59:1, pp. 21-34

ARGELÉS, T., BONET, A., CLEMENTE, I., ESTEVEZ, J., GIBAJA, J., LUMBRERAS, L., PIQUÉ, R., RIOS, M., TAULÉ, M., TERRADAS, X., VILÁ, A. y WÚNSCH, C. (1995) Teoría para una práxis. Spelendor "realitatis", Trabhalos de Antropologia e etnologia, 35 1, $1^{\circ}$ Congreso de Arqueología peninsular (Porto, 12-18 de Octubre 1993), Porto, 1995, 501-507

ARRIBAS, A., MOLINA, F. (1975) El poblado de Los Castillejos, en las Peñas de los Gitanos (Montefrío, Granada). Resultados de las campañas de 1971 y 1974, XIV Congreso Nacional de Arqueología (Vitoria, 1975), Zaragoza, 1977, pp. 389-406.

ARRIBAS, A., MOLINA, F. (1979a) El poblado de "Los Castillejos" en las Peñas de los Gitanos (Montefrio, Granada). Campaña de 1971. Cuadernos de Prehistoria de la Universidad de Granada, Serie monográfica 3, Granada. 
ARRIBAS, A., MOLINA, F. (1979b) Nuevas aportaciones al inicio de la metalurgia en la Península Ibérica. El poblado de "Los Castillejos" de Montefrío (Granada), en The origins of Metallurgy in Atlantic Europe, (M.Ryan, ed.), Dublín, pp.7-34.

AUDOUZE, F. (1985) L'apport des sols d'habitat à l'etude de l'outillage lithique, en $L a$ signification culturelle des industries lithiques, Actes du Colloque de Liege, (M. Otte, ed.) Studia Praehistorica Belgica 4, B.A.R. International Series 239, pp. 57-68

AUDOUZE, F. (1987) Des modeles et des faits: les modeles de A. Leroi-Gourham et de L. Binford confrontés aux résultats recents, B.S.P.F. 84, pp. 343-352

BALIBAR, E. (1976) Acerca de los conceptos fundamentales del materialismo histórico, Para leer El Capital (L.Althusser, E. Balibar, eds.), México (16ª edición), pp. 217-335.

BANESSZ, L.; HROMADA, J.; KOZLOWSKI, J.; SOBCZYK, K. y BAWLIKOWSKI, M. (1995) Site formation in loess areas: a case study from Moravany-Zakovska, Western Slovakia, Geoarchaeology 10:4, pp.237-255

BARTON, C.M. y CLARK, G.A. (1993) Cultural and natural formation processes in late quaternary cave and rockshelter sites of western Europe and the near east,(P. Goldberg, D.T. Nash y M.D. Petraglia, eds.) Monographs in World Archaeology(P. Goldberg, D.T. Nash y M.D. Petraglia, eds.) Monographs in World Archaeology 17, pp. 33-52

BATE, L.F. (1982) Relación general entre teoría y método en arqueología. Teorías, métodos y técnicas en arqueología, Reimpresiones de antropología americana, México, pp. 3-51.

BATE, L.F. (1992) "Del registro estático al pasado dinámico": entre un salto mortal y un milagro dialéctico, Boletín de antropología americana 26, pp.49-67

BATE, L.F. (1998) El proceso de investigación en arqueología, Crítica, Barcelona

BAR YOSEF, O. (1993) Site formation processes fom a Levantine viewpoint, Formation processes in archaeological context (P. Goldberg, D.T. Nash y M.D. Petraglia, eds.) Monographs in World Archaeology 17, pp. 13-32

BAZILE, F., GUILLERAULT, P., MONNET, C., ONORATINI, G. (1989) Nouvelle approches des foyers paleolithiques: l'exemple de Fontgrasse (Vers-Pont-du-Gard-Gard), en Nature et fonction des foyers préhistoriques, Actes du Colloque International de Nemours, 1987. (M. Olive y Y. Taborin, dirs) Mémoires du Musée de Préhistoire d'Ile de France n 2 , Nemours.

BECK, Ch. y JONES, G.T. (1990) Toolstone selection and lithic technology in Early Great Basin Prehistory, Journal of field archaeology 17:3, pp. 283-299 
BERNALDO DE QUIROS, F., CABRERA, V., CACHO, C., VEGA, L.G. (1981) Proyecto de análisis técnico para las industrias líticas, Trabajos de Prehistoria 38, pp. 9-37, Madrid.

BIETTI, A (1995) Nuove prospettive nelle analisi di correlazioni spaziali in preistoria, Archeologia e calcolatori 4, Firenze, pp.39-60.

BINDER, D. (1991) Faits techniques et explotation du milieu. Les outillages lithiques. Répartition des vestiges lithiques au sol, en Une économie de chasse au neolithique ancien. La grotte lombard à Saint-Vallier-de-Thiey (Alpes-Maritimes), (D. Binder, dir.), Monographie du CRA nº 5, París, pp. 65-70.

BINFORD, L.R. (1962) Archaeology as Anthropology, en An Archaeological perspective (L.R. Binford, ed.), New York, 1972, pp. 20-32.

BINFORD, L.R. (1964) A consideration of archaeological research design, en $A n$ Archaeological perspective (L.R. Binford, ed.), New York, 1972, pp. 135-163.

BINFORD, L.R. (1965) Archaeological systematic and the study of culture process, en $A n$ Archaeological perspective (L.R. Binford, ed.), New York, 1972, pp. 195-207.

BINFORD, L.R. (1968) Methodological considerations of the archaeological use of Ethnografic data, en An Archaeological perspective (L.R. Binford, ed.), New York, 1972, pp. 59-67.

BINFORD, L.R. (1972) An Archaeological perspective (L.R. Binford, ed.), New York.

BINFORD, L.R. (1973) Interassemblage variability -the Mousterian and the functional argument, en The explanation of Culture Change, (C. Renfrew, ed.), Duckworth, London.

BINFORD, L.R. (1988) En busca del pasado. Descifrando el registro arqueológico. Crítica, Barcelona.

BINFORD, L.R., BINFORD, S.R. (1966) A preliminary analysis of functional variability in the Mousterian of Levallois facies, en Working at Archaeology (L.R. Binford, ed.), Studies in Archaeology, Academic Press, New York, 1983, pp. 71-124.

BINFORD, L.R., BINFORD, S.R. (1975) Utensilios de piedra y conducta humana. Biología y cultura, Introducción a la Antropología biológica y social, (AA.VV.), Blume, Madrid, pp. 174-184.

BLANKHOLM, H. (1991) Intrasite spatial analysis in theory and practice, Aarhus University Press, Aarhus

BLANKHOLM, H. y PRICE, T.D. (1991) Arcospace Ver. 3.0, Aarhus University Press, Aarhus 
BORDES, F. (1950) Principes d'une methode d'étude des techniques de debitage et de la typologie du Paleolithique ancien et moyen. L'Anthropologie 54, pp. 19-34.

BORDES, F. (1961) Typologie du Paleolithique ancian et moyen, Bourdeaux.

BORDES, F. (1975) Sur la notion de sol d'habitat en Prehistoire paleolithique, B.S.P.F. 72, pp. $139-143$.

BORDES, F. (1983) Leçon sur le Paleolithique en Europe, tome II: Le Paleolithique en Europe, Cahiers du Quaternaire 7, Bordeaux.

BORDES, F. (1984) Venticinco años después: El complejo Musteriense revisado, Trabajos de Prehistoria 40, pp. 247-264.

BORDES, F., BOURGON, M. (1951) Le complexe mousterien: Moustériens, Levalloisien et Tayacien. L'Anthropologie 55, pp. 1-23.

BREZILLON, M. (1977) La dénomination des objets de pierre taillé. Materiaux pour un vocabulaire des prèhistoriens de langue française. Gallia Préhistoire IV supplément, París.

BUTZER, K.W. (1989) Arqueología. Una ecología del hombre, Bellaterra, Barcelona.

CAHEN, D., KARLIN, C. (1980) Nouvelles voies pour l'etude des pierres tailles, Préhistoire et technologie lithique, Publications de I'URA 28: cahier 1, CNRS, París, pp. 24-27.

CAHEN, D., GYSELS, J. (1983) Techniques et fonctions dans l'industrie lithique du groupe de Blicquy (Belgique), Traces d'utilisation sur les outils neolithiques du Proche Orient, Travaux de la Maison de I'Orient, pp. 37-51.

CAMARA SERRANO, J.A., AFONSO MARRERO, J.A. (1995) El Conjunto Arqueológico de Las Peñas de los Gitanos (Montefrío, Granada). Anexo I a la Ficha diagnóstico del Conjunto Arqueológico de las Peñas de los Gitanos de Montefrío (Arquitecto D. Pedro Salmerón Escobar, Consejería de Cultura. Dirección General de Bienes Culturales, Granada.

CAMILI, E. (1989) The occupational history of sites and the interpretation of prehistoric technological systems: an example from Cedar Mesa, Utah, Intrasite spatial analysis in $\operatorname{archaeology}(\mathrm{H}$. Hietala, ed.) New directions in archaeology, Cambridge University Press, pp. 17-26.

CARANDINI,(1984) Arqueología y cultura material, Mitre, Barcelona. 
CARR, Ch. (1984) The nature of organization of intrasite archaeological records and spatial analytic approaches to their investigation, Advances in archaeological method and theory, vol. 7 , pp. 103-222

CARBONELL, E. (1987) Metodología. Concepto de microespacio y métodos de análisis, Coloquio sobre el microespacio (Teruel, 1987). Arqueología Espacial 11. Intervenciones, Teruel, pp. 15-77.

CARBONELL, E., MARTÍNEZ MORENO, J, MORA TORCAL, R., MURO MORALES, I. (1986) Conceptos básicos en el análisis espacial, Coloquio sobre el microespacio 1 (Teruel, 1986). Arqueología Espacial 7. Aspectos generales y metodológicos, Teruel, pp. 33-42.

CHANTRET, F., COUTERNE, A., DALY, L., MAUGER, M.(1989) Etude thermodilatométrique et variations des propriétés magnétiques en fonction de la température de silex de différentes origines, en Nature et fonction des foyers préhistoriques, Actes du Colloque International de Nemours, 1987 (M. Olive y Y. Taborin, dirs), Mémoires du Musée de Préhistoire d'Ile de France, n 2, Nemours.

CHILDE, G. (1975) Los orígenes de la civilización, F.C.E., México

CLARK, G. (1980) Arqueología y sociedad, Akal, Madrid

CLARK, J.E. (1986) Another look at small debitage and microdebitage, Lithic technology 15:1, pp. $21-33$

CLARK, P.J., EVANS, F.C. (1954) Distance to nearest neighbour as a mesure of spatial relationship in populations, Ecology 35, pp. 445-453.

CLARKE, D.L. (ed) (1977) Spatial Archaeology, Academic Press, London.

CLOSE, A.C. (1996) Carry that weight: the use and transportation of stone tools, Current anthropology $37: 3$, pp. 545-553

COLLINS, D. (1986) Paleolithic europe. A theoretical and systematic study, Clayhanger Books, Devon.

COOK, S.F., HEIZER, R.F. (1968) Relationship among houses, settlement areas and population in oboriginal California, en Settlement archaeology (K.C. Chang, ed.), Palo Alto: National Press.

CORCHÓN, Ma .S. (1982) Estructuras de combustión en el Paleolítico: A propósito de un hogar de doble cubeta de la Cueva de las Caldas (Oviedo). Zephyrus XXXIV-XXXV, pp. 2747. 
COYE, N. (1989) Une conscience pour le foullier: Methode et techniques de terrain en archaeologie préhistorique avant 1950, Travaux du L.A.P.M.O., Aix-en-Provence, pp. 7 28.

DACEY, M.F. (1973) Statistical test of spatial association in the locations of tool types, American Antiquity, vol. 38:3, pp.32:3, pp. 320-328

DÍAZ-ANDREU, M. (1993) Theory and ideology in archaeology: Spanish archaeology under the Franco régime, Antiquity 67, Oxford, pp. 74-82.

DIBBLE, H.L.; CHASE, P.G.; McPHERRON, S.P. y TUFFREAU, A. (1997) Testing the reality of a "living floor" with archaeological data, American Antiquity 62:4, pp. 629-651

DJINDJIAN, F. (1991) Methode pour l'archéology, París.

DOMMASNES, L.H. (1990) Feminist archaeology: critique or theory building?, Writing the past in the present (F. Baker y J. Thomas, eds.), pp. 24-31

DUNNELL, R.C. y STEIN, J.K. (1989) Theoretical issues in the interpretation of microartefacts, Geoarchaeology 4:1, pp. 31-42.

EBERT, J.I. (1992) Distributional archaeology

ERLANDSON, J.M. y ROCKWELL, T.K. (1987) Radiocarbon reversal and stratigraphic discontinuities: the effects of natural formation porcesses on coastal California archaeological sites, (Nash y Petraglia, eds.) BAR International Series, pp. 51-73

FARIZY, C. (1991) Spatial organization and middle palaeolithic open air sites, Origini, XIV:1, pp. 39-51

FLADMARK, K.R. (1982) Microdebitage analysis: initial considerations, Journal of archaeological science 9 , pp. 205-220.

FLANNERY, K. V. (1973) Archaeology with a capital "S", Research and theory in current archaeology (Ch. Redman, ed.), Wllley Interscience, New York, pp. 47-53.

FORTEA PÉREZ, J. (1973) Los complejos microlaminares y geométricos del Epipaleolítico Mediterráneo Español, Memorias del Seminario de Prehistoria y Arqueología 4, Universidad de Salamanca.

GALLAY, A. (1989) Vivre autour d'un feu. Recherche d'une problématique d'analyse archéologique, en Nature et fonction des foyers préhistoriques. Actes du Colloque International de Nemours, 1987. (M. Olive y Y. Taborin dirs.) Mémoires du Musée de Préhistoire d'Ile de France, $\mathrm{n}^{\circ}$ 2, Nemours. 
GANDARA, M. (1987) Teorías de la observación en arqueología, Boletín de Antropología Americana 15, Madrid

GARCÍA BARBA, C., AFONSO MARRERO, J.A. y MARTÍNEZ FERNÁNDEZ, G. (e.p.) La modificación primaria en el proceso de la producción lítica. El caso de la producción laminar solutrense de la cueva de Malalmuerzo (Moclín, Granada)

GILMAN GUILLÉN, A. (1988) Enfoques teóricos en la arqueología de los ochenta, Revista de Occidente 81, pp. 47-61.

GOMEZ-MORENO, M. (1949) Monumentos arquitectónicos de la provincia de Granada, Misceláneas. Historia-Arte-Arqueología. Primera Serie. La Antigüedad, Madrid, 1949, pp. 346-390.

GONGORA Y MARTÍNEZ, M. de, (1868). Antigüedades Prehistóricas de Andalucía, Madrid.

GOLBERG, P; NASH D.T. y PETRAGLIA, M.D. (1993) Formation processes in archaeological context, Monographs in World Archaeology 17

GRIFFITHS, D.R.; BERGMAN, C.A.; CLAYTON, C.J.; OHNUMA, K.; ROBINS, G.V. y SEELEY, N.J. (1987) Experimental investigation of the heat treatment of flint, The human uses of flint and chert, (G.de G. Sieveking y M.H. Newcomer, eds.), Cambridge University Press, pp. 43-52

GUILLAMON, C., WÜNSCH, G. (1986) Cap a una "objetivació" de la dimensió espacial en Arqueología, Coloquio sobre el microespacio 1 (Teruel, 1986). Arqueología Espacial 7. Aspectos generales y metodológicos, Teruel, pp. 21-32.

HASSAN, F.A. (1978) Sediments in archaeology: methods and implications for paleoenvironmental and cultural analysis, Journal of field archaeology 5, pp. 197-213.

HAYDEN, B. y CANNON, A. (1983) Where the garbage goes: refuse disposal inthe Maya Highlands, Journal of anthropological archaeology 2:2, pp.117-163

HILL, M.O. (1974) Correspondence analysis: a neglected multivariate method, Journal of the Royal Statistical society 31, pp. 520-524.

HODDER, I.R. (1982) The present past. An introduction to Anthropology for Archaeology, London.

HODDER, I.R. (1984) Archaeology in 1984, Antiquity LVIII:222, pp. 25-32.

HODDER, I.R., ORTON, C. (1990) Análisis espacial en Arqueología, Crítica, Barcelona 
HOLE, F.D. (1961) A classification of pedotrubations and some other processes and factors of soil formation to isotropism and anisotropoism, Soils science 91, pp. 375-377

INIZAN, M.L., ROCHE, H., TIXIER, J. (1976-77) Avantages d'un traitement thermique pour la taille des roches silicieuses, Quaternaria XIX, Roma, pp. 1-18.

ISAAC, G. L. Traces of Oleistocene hunters: A East African exemple, Man the hunter, (R.B. Lee, I. De Vore, eds.), New York, pp. 253-261.

JOHNSON, G.A. (1977) Aspects of regional analysis in Archaeology, Annual review of Anthropology 6, pp. 479-508.

JOHNSON, I. (1984) Cell frecuency recording and analysis of artifact distributions, Intrasite spatial analysis in archaeology $(\mathrm{H}$. Hietala, ed.) New directions in archaeology, Cambridge University Press, pp. 75-96.

JULIEN, M., KARLIN, C., BODU, P. (1987) Pincevent: Oú en est le modèle théorique aujourd'hui?, B.S.P.F. 84, pp. 335-342.

KARLIN, C., NEWCOMER, M. (1982) Interpreting flake scatters: an exemple from Pincevent, Studia Praehistorica Belgica 2, pp. 159-165.

KINTIGH, K.W., AMMERMAN, A.J. (1982) Heuristic approaches to spatial analysis in archaeology, American Antiquity 47, pp. 31-63.

LAET, S. de (1983) La Arqueología y la Prehistoria, en Corrientes de la investigación en las ciencias sociales (M. Freedman, S.J. de Laet y G. Barraclough, dirs), Madrid, pp. $233-$ 293.

LARSON, M.L. (1992) Site formation processes in the cody and early plans archaic levels at the laddie Creek Site, Wyoming, Geoarchaeology 7:2, pp.103-120

LEISNER, G., LEISNER, V. (1943) Die Megalithgräber der Iberischen Halbinsel. Der Süden, Römisch-Germanische Forschungen 17, Berlín.

LEROI-GOURHAM, A. (1962) Apparition des techniques, Historie générale des techniques, tome I: Les origenes de la civilisation technique, Paris, P.U.F. 74.

LEROI-GOURHAM, A., BREZILLON, M. (1966) L' habitation magdalenienne ${ }^{\circ} 1$ de Pincevent près Montereau (Seine-et-Marne), Gallia Prehistoire IX, fasc.2, pp. 263-271. 
LEROI-GOURHAM, A., BREZILLON, M. (1972) Fouilles de Pincevent. Essai d'analyse ethnographique d'un habitat magdalénien (la section 36), VII Supplement à Gallia Préhistoire, CNRS.

LIZCANO, R.; GÓMEZ, E.; CÁMARA, J.A.; AGUAYO, M.; ARAQUE, D.; BELLIDO, I.; CONTRERAS, L.; HERNÁNDEZ, M.; IZQUIERDO, M. y RUIZ, J. (1991) 1 1 Campaña de excavación de urgencia en el pabellón polideportivo de Martos (Jaén), Anuario Arqueológico de Andalucía III, pp. 278-291

LOPEZ, F.; FOURNIER, P.; BAUTISTA, C.P. (1988) Contextos arqueológicos y contextos momento. El caso de la alfarería otomí del valle del mexquital, Boletín de antropología americana 17, pp. 99-131

LULL, V. (1988) Hacia una teoría de la representación en arqueología, Revista de Occidente 81, Madrid, pp. 62-72

LUMLEY, H. de, BOONE, Y. (1976a) Les structures d'habitat au Paléolithique inférieur, La préhistoire française, tome I, (H. de Lumley, dir.) Editions du CNRS, París, pp. 625-643.

LUMLEY, H. de, BOONE, Y. (1976b) Les structures d'habitat au Paléolithique inférieur, La préhistoire française, tome I, (H. de Lumley, dir.) Editions du CNRS, París, pp. 644-655.

MARKS, A.E. (1971) Settlement patterns and intrasite variability in the central Negev, Israel, American Anthropologist, 73, pp. 1237-1244.

MARTÍNEZ FERNÁNDEZ, G. (1985) Análisis tecnológico y tipológico de las industrias de piedra tallada del Neolítico, Edad del Cobre y Edad del Bornce de la Alta Andalucía, Tesis doctoral, Universidad de Granada.

MARTÍNEZ FERNÁNDEZ, G. (1991) Late Prehistory blade production in Andalusia, en VI Flint International Symposium, (Abstracts), (M.A. Bustillo y A. Ramos, eds.), Madrid, pp. 300-304.

MARTÍNEZ FERNÁNDEZ, G. (1995-96) Apuntes de Prehistoria I, Departamento de Prehistoria y Arqueología, Universidad de Granada.

MARTÍNEZ FERNÁNDEZ, G., AFONSO MARRERO, J.A. (1994) Sobre el concepto de producción lítica, $I^{a}$ Reunión de trabajo sobre aprovisionamiento de recursos líticos en la Prehistoria (Valencia 1994), Valencia, (en prensa).

MARTÍNEZ NAVARRETE, $M^{a}$.I. (1984) El comienzo de la metalurgia en la provincia de Madrid: La Cueva y el Cerro de Juan Barbero (Tielmes, Madrid), Trabajos de Prehistoria 41, Madrid, pp. 17-128. 
MARTÍNEZ NAVARRETE, M.I. (1989) Una revisión crítica de la prehistoria española: la Edad del Bronce como paradigma, Sigto XXI, Madrid.

MARTÍNEZ SANTA-OLALLA, J. (1947) La Comisaría General de Excavaciones Arqueológicas. Balance de la labor realizada, Crónica del II Congreso Arqueológico del Sudeste Español, Albacete, pp. 53-59.

MAZO PÉREZ, C. (1991) Glosario y cuerpo bibliográfico de los estudios funcionales en Prehistoria, Universidad de Zaragoza.

McANANY, P.A. (1988) The effects of lithic procurement strategies on tool curation and recicling, Lithic technology 17:1, pp. 3-11

McARTHUR, R.H., McARTHUR, J.W. (1961) On bird species diversity, Ecology 42(3), pp. 594-598

McBREARTY, S.; BISHOP, L.; PLUMMER, T.; DEWARD, R. y CONARD, N. (1998) Tods underfoot: human trampling as an agent of lithic artifact edge modification, American Antiquity 63:1, pp. 108-129

McNUTT, C.M. (1981) Nearest neighbour, boundary affect and the old Flag Trick: a general solution, American Antiquity 46, pp. 571-591.

MERGELINA, C. de (1941-1942) La estación arqueológica de Montefrío (Granada).I. Los dólmenes, Boletín del Seminario de Arte y Arqueología, fasc. XXVIII-XXX, tomo VIII, Valladolid, pp.33-106.

MERGELINA, C. de (1945-1946) La estación arqueológica de Montefrío (Granada).II. La acrópoli de Guirrete (Los Castillejos), Boletían del Seminario de Arte y Arqueología, fasc. XL-XLII, tomo XII, Valladolid, pp.15-26.

MERINO, J.M. (1980) Tipología lítica, Munibe, Suplemento 4, San Sebastian.

MILLER, A. (1993) Microartifacts as a reflection of cultural factors in site formation, Formation processes in archaeological context, (P. Goldberg, D.T. Nash y M.D. Petraglia, eds.) Monographs in World Archaeology 17, pp. 141-148

NASH, D.T. (1993) Distinguishing stone artifacts from naturefacts created by rockfall process,

Formation processes in archaeological context, (P. Goldberg, D. T. Nash y M.D. Petraglia, eds.) Monographs in World Archaeology 17, pp. 125-138

NASH y PETRAGLIA (1987) Natural formation processes and the archaeological record: present problems and future requisites . (D.T. Nash y M.D. Petraglia, eds.) BAR International Series, pp. 186-204 
Espacios de producción y uso de los útiles de piedra tallada del Neolítico

NARROLL, R. (1962) Floor area and settlement population, American Antiquity 24(4), pp. 587589.

NEWELL, R.R., DEKIN, A.A. (1978) An integrative strategy for the definition os behaviourally meaningful archaeological units, Paleohistoria XX, pp. 7-38.

NEWMAN, J.R. (1994) The effects of distance on lithic material reduction technology, Journal of field archaeology 21:4, pp. 491-501

ORTON,C. (1988) Matemáticas para arqueológos, Alianza Editorial, Madrid.

PALLARES i AÑO, M. (1993) Cuestiones teórico-metodológicas sobre el estudio de la organización espacial de los asentamientos de comunidades cazadoras-recolectoras, Aplicaciones informáticas en Arqueología: Teoría y sistemas (L. Valdés, ed.), pp. 387408.

PASTOR MUÑOZ, M., PACHON ROMERO, J.A. (1991) Estudio preliminar, en Antigüedades Prehistóricas de Andalucía, (M. Góngora y Martínez, 1868), Granada.

PERLES, C. (1977) Prehistoire du feu. Masson. París

PIE, J. y VILÁ, A. (1991) Relaciones entre objetivos y métodos en el estudio de la industria lítica, Treballs d'Arqueologia 1, Tecnología y cadenas operativas líticas, pp. 271-278

PIGEOT, N. (1987) La taille des roches dures, Le feu apprivoisé. Le fau dans la vie quotidienne des hommes prehistoriques (AA.VV.), Museé de Préhistoire d'Ile-de-France, pp. 42-43.

PINDER, D., SHANIDA, I. GREGORY, D. (1979) The nearest neighbour statistic: archaeological applications and new developmentes, American Antiquity 44, pp. 430-445.

PRESEDO, F. (1955) Primer Curso Internacional de Arqueología de Campo. Noticiario Arqueológico Hispánico II, Madrid, pp. 252-254

PRETEL, D. (1994) De la "filosofia del marxismo" a la filosofia de Marx, Publicaciones para el debate, Barcelona

PROUDFOOT, V.B. (1981) Archaeological space, Journal of Historical Geography 7, pp. 303306.

PURDY, B.A., BROOKS, D.E. (1971) Thermal alteration of silica minerals. An archaeological approach, Science 173, pp. 322-325. 
RAMOS CORDERO, U., AFONSO MARRERO, J.A., CáMARA SERRANO, J.A., MOLINA GONZÁLEZ, F., MORENO QUERO, M. (en prensa) "Trabajos de acondicionamiento y estudio científico en el yacimiento de Los Castillejos de las Peñas de los Gitanos (Montefrio, Granada) Anuario Arqueológico de Andalucía, 1994 (en prensa).

RAMOS MILLAN, A. (1984) La identificación de las fuentes de suministro de un asentamiento prehistórico. El abastecimiento de rocas silíceas para manufacturas talladas. Coloquio sobre distribución y relaciones entre los asentamientos (Teruel, 1984). Arqueología Espacial 1, Aspectos generales y metodológicos, Teruel, pp. 107-134.

RAMOS MILLAN, A. (1986) La explotación de recursos líticos por las comunidades prehistóricas. Un estudio de economía primitiva. Cuadernos de Prehistoria de la Universidad de Granada 11, Granada, pp. 237-271.

RIGAUD, J. Ph. (1976) Les structures d'habitat d'un niveau de Périgordieu supérieur du Flageolet I (Bézenac, Dordogne), en Les structures d'habitat au Paleolithique Supérieur, (A. Leroi-Gourham, ed.). IXé Congres UISPP, Colleque XIII, Nice, pp.93-102.

RIQUELME CANTAL, J.A. (1996) Contribución al estudio arqueofaunistico durante el Neolítico y la Edad del Cobre en las Cordilleras Béticas: el yacimiento arqueológico de los Castillejos de Las Peñas de los Gitanos, Montefrío (Granada) Tesis doctoral inédita, Universidad de Granada.

ROSE, A.M. (1986) Cities of clay: the geoarchaeology of tells, University of Chicago Press, Chicago.

ROYER, C. (1876) Les âges préhistoqriques, La Philosiphie positive, Marzo-Abril 1876.

REID, J.J.; SCHIFFER, M.B. y NEFF, J.M. (1979) Archaeological considerations of intrasite sampling, Sampling in Archaeology (J.W. Mueller, ed.), pp. 209-224

RUIZ BUSTOS, A. (1978) Informe sobre la utilización de micaesquistos en la fabricación de la cerámica, El poblado de Los Castillejos en las Peñas de los Gitanos (Montefrío, Granada) Campaña de excavaciones de 1971. El corte número I, Cuadernos de Prehistoria de la Universidad de Granada. Serie Monográfica nº 3, pp. 151-152.

RUIZ ZAPATERO, G. (1991) Teoría y metodología en arqueología, XX Congreso Nacional de Arqueología, Santander, 25-28 de Septiembre 1989, Zaragoza, 1991, 5-21.

RUIZ ZAPATERO, G., BURILLO, F. (1988) Metodología para la investigación en Arqueología territorial, Munibe Suplemento 6, pp. 45-64.

RUIZ RODRÍGUEZ, A., MOLINOS MOLINOS, M., NOCETE CALVO, F., CASTROLOPEZ, M. (1986b) Concepto de producto en Arqueología, Coloquio sobre el microespacio 1 
(Teruel, 1986). Arqueología Espacial 7. Aspectos generales y metodológicos, Teruel, pp. 63-80.

SACKETT, J.R. (1968) Method and theory of Upper Paleolithic archaeology in Southwestern France. New perspectives in Archaeology, (L. Binford y S. Binford eds.), pp. 61-83.

SACKETT, J.R. (1981) From de Mortillet to Bordes: a century of French Palaeolithic research, en Towards a History of Archaeology, (G. Daniel ed). Thames and Hudson, London.

SALVATIERRA CUENCA, V. (1982) La evolución de la industria ósea del Neolitico al Bronce en Granada, Tesis doctoral inédita, Universidad de Granada.

SANOJA, M. (1984) La inferencia en la arqueología social, Boletín de antropología americana 10, pp.35-44

SAVELLE, J.M. (1987) Natural formation processes and snow-based sites: examples from artic Canada, (Nash y Petraglia, eds.) BAR International Series, pp. 30-50

SCHIFFER, M.B. (1972) Archaeological contex and systemic context, American Antiquity 37 , pp. 156-165

SCHIFFER, M.B. (1976) Behavioral archaeology, Studies in archaeology, Academis Press.

SCHIFFER, M.B. (1987) Formation processes of the archaeological record, University of New Mexico Press.

SCHIFFER, M.B. (1988) The structure of archaeological theory, American Antiquity 53,3, pp. 461-485.

SCHIFFER, M.B. (1991) Procesos de formación del registro arqueológico, Boletín de antropología americana $23, \mathrm{pp} .39-45$

SHARER, R.J., ASHMORE, W. (1979) Fundamentals of archaeology, The Benjamin/Cummings Publishing Company.

SHELLEY, Ph. (1990) Variation in lithic assemblages: an experiment, Journal of field archaeology 17:2, pp.187-193

SHENNAN, S. (1992) Arqueología analítica, Crítica, Barcelona.

SHERWOOD, S.; SIMEK, J.F.; POLHEMUS, R.R. (1995) Artifact size and spatial process: macro and microartifacts in a Mississipian House, Geoarchaeology 10:6, pp.429-455. 
SHICK, K.D. (1987) Experimentally-derived criteria for assessing hydrologic disturbance of archaeological sites, (Nash y Petraglia, eds.) BAR International Series, pp. 86-107

SMITH, P.E.L. (1966) Le Solutréen en France, Public. de L'Institut de Préhistoire de L'Université de Bordeaux, Memoire 5.

SONNEVILLE-BORDES, D. de (1974-1975) Les Listes-types. Observations de méthode. Quaternaria XVIII, pp.9-43.

SPAULDING, A.C. (1953) Statistical techniques for the discovery of artifacs types, American antiquity 18 , pp. 305-313.

STEIN, J.K. (1987) Deposits for archaeologist, Advances in archaeological method and theory 11, pp. 337-395

STRUEVER, S. (1968) Problems, method and organization: a disparity in the growth of archaeology. En: Anthropological archaeology in the Americas (B.J. Meggers, ed.), The anthropological society of Washington, pp. 131-151

TABORIN, Y. (1989) Le foyer: document et concept, en Nature et fonction des foyers préhistoriques. Actes du Colloque International de Nemours, 1987, (M. Olive y Y. Taborin dirs.), Mémoires du Musée de Préhistoire d'Ile de France, nº 2, Nemours.

TARRADELL, M. (1952) La Edad del Bronce en Montefrío (Granada). Resultados de las excavaciones en yacimientos de las Peñas de los Gitanos, Ampurias XIV, Barcelona, pp. 49-80

TAYLOR, S. (1990) "Brothers" in arms? Feminism, post-structuralism, and the "Rise of Civilization", Writing the past in the present (F. Baker y J. Thomas, eds.), pp. 32-41

TRIGGER, B. (1978) No longer from another planet, Antiquity LII, pp. 193-198.

TRIGGER, B. (1992) Historia del pensamiento arqueológico, Crítica, Barcelona.

TRIGGER, B. (1995) Expanding middle range theory, Antiquity 69:264, pp. 449-458.

TRINGHAM, R.E. (1991) Households with Faces: The Challenge of Gender in Prehistoric Architectural Remains, Engendering archaeology: Women and Prehistory (J.M. Gero y M.W.Conkey, eds.), pp. 93-131

TORRE SANTANA, Ma.P. de la (1984) La Cueva de las Tontas en la estación arqueológica de las Peñas de los Gitanos (Montefrío, Granada), Cuadernos de Prehistoria de la Universidad de Granada 9, Granada, pp. 242-277. 
Espacios de producción y uso de los útiles de piedra tallada del Neolítico

UERPMANN, H.P. (1978) Informe sobre los restos faunísticos del Corte ${ }^{\circ} 1$, El poblado de Los Castillejos en las Peñas de los Gitanos (Montefrio, Granada) Campaña de excavaciones de 1971. El corte número 1, Cuadernos de Prehistoria de la Universidad de Granada. Serie Monográfica $n^{\circ} 3$, pp. 153-168.

VILLENEUVE, L., FARIZY, C. (1989) Les témoins de combustion du gisement moustérien de Champlost (Yonne), en Nature et fonction des foyers préhistoriques. Actes du Colloque International de Nemours, 1987. (M. Olive y Y. Taborin dirs.), Mémoires du Musée de Préhistoire d'Ile de France, $\mathrm{n}^{\circ} 2$, Nemours.

WATSON, P.J., LeBLANC, S.A., REDMAN, Ch.L. (1974) El método científico en Arqueología, Alianza Universidad, Madrid.

WATTEZ, J. (1988) Contribution à la connaissance des foyers préhistoriques par l'étude des cendres. Bulletin de la Société Préhistorique Française, tome 85, n 9, París, pp. 352366.

WHALLON, R. (1973) Spatial analysis of ocupation floors I: application of dimensional analysis of variance, American Antiquity 38, pp. 266-278

WHALLON, R. (1974) Spatial analysis of ocupation floors II: the application of nearest neighour analysis, American Antiquity 39, pp. 16-34

WHALLON, R. (1984) Unconstrained clustering for the analysis of spatial distributions in Archaeology, Intrasite analysis in Archaeology (H. Hietala, ed.) Cambridge, pp. 242-277.

WHITE, L.A. (1974) El concepto de cultura, en El concepto de cultura: textos fundamentales (J.S. Kahn, ed.) Barcelona, pp. 129-155.

WHITE, L.A. (1992) La energía y la evolución de la cultura, en Antropología. Lecturas. Segunda edición (P. Bohannan y M. Glazer, eds.), Barcelona, pp. 129-155.

WOOD, W.R. y JOHNSON, D.L. (1978) A survey of disturbance processes in archaeological site formation, Advances in archaeological method and theory 1, pp. 315-381

WRIGHT, R.P. (1991) Women's Labor and Pottery Production in Prehistory, Engendering archaeology: Women and Prehistory (J.M. Gero y M.W.Conkey, eds.), pp. 194-223

WÜNSCH, G. (1987) Metodología. Concepto de microespacio y métodos de análisis, Coloquio sobre el microespacio (Teruel, 1987). Arqueología Espacial 11. Intervenciones, Teruel, pp. 15-77.

WÜNSCH, G. (1989a) La organización interna de los asentamientos de comunidades cazadorasrecolectoras: el análisis de las interrelaciones espaciales de los elementos arqueológicos, Trabajos de Prehistoria 46, Madrid, pp. 13-33. 
WÜNSCH, G. (1989b) Cuantificación en arqueología. El análisis de las interrelaciones espaciales de los elementos arqueológicos, Revista de Arqueología 95, pp. 5-9.

WÜNSCH, G. (1991) Del estudio de la organización espacial al análisis de las interrelaciones espaciales de los elementos arqueológicos, en Arqueología. Nuevas tendencias, (A. Vilá, coord.), CSIC, Madrid, pp. 195-208.

WÜNSCH, G., GUILLAMÓN, C. (1986) Aproximació critica a l'analisi "sincrónica" dels assentaments de Caçadors-Recollectors, Coloquio sobre el microespacio 1 (Teruel, 1986). Arqueología Espacial 7. Aspectos generales y metodológicos, Teruel, pp. 51-62.

YELLEN, J.E. (1977) Archaeological approaches to the present. Models for reconstructing the past, Academic Press.

ZIEGLER, R. (1990) Tierrestre aus der prähistorischen Siedlung Los Castillejos bei Montefrío (Prov. Granada), Studien über frühe Tierknochenfundenvon der Iberischen Halbinsel 12, München, pp. 1-46. 
GRÁFICOS 


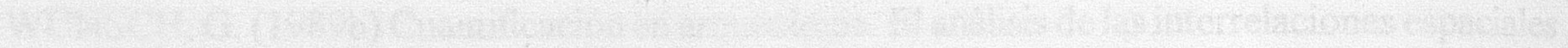

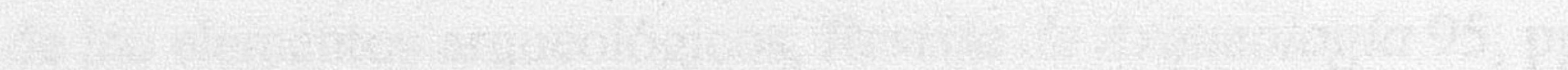

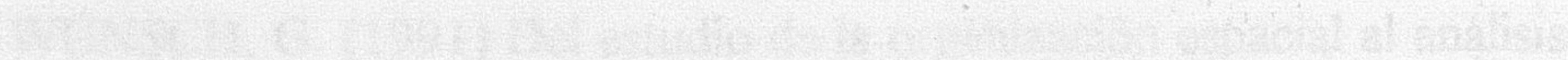

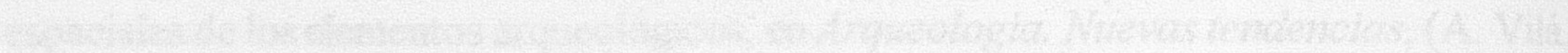

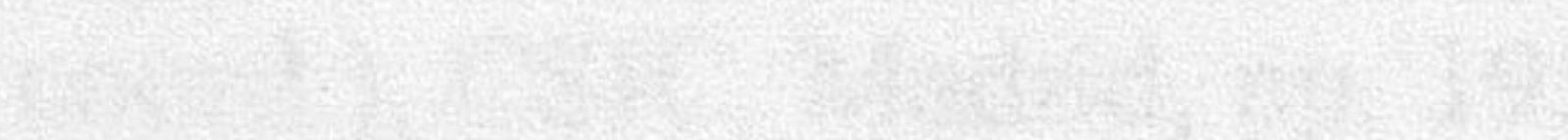

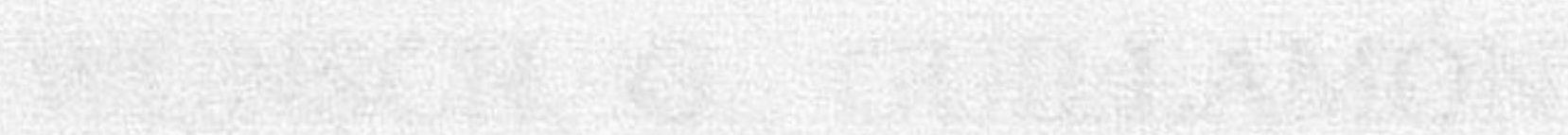

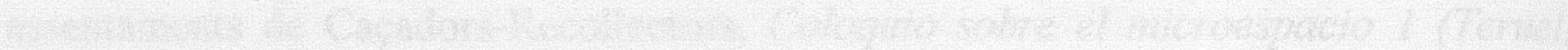

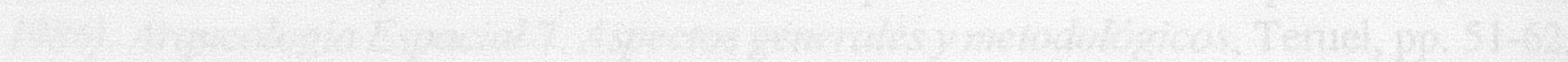

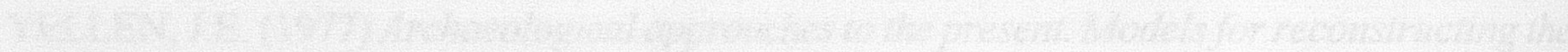

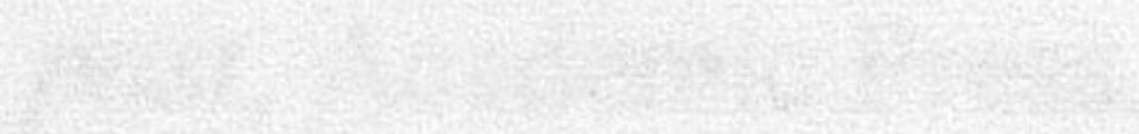

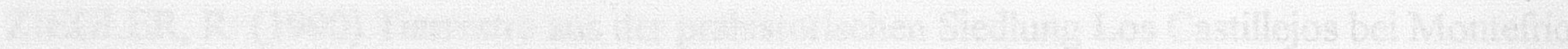

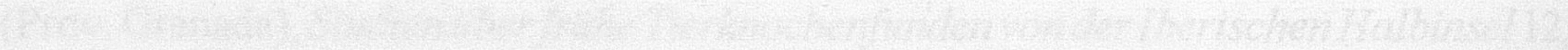

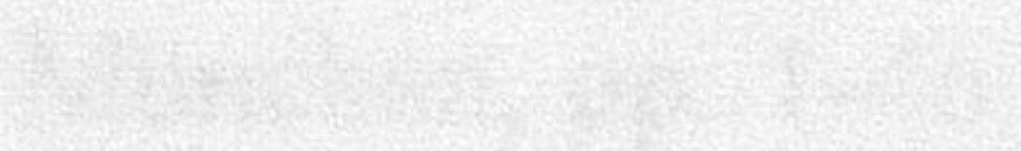

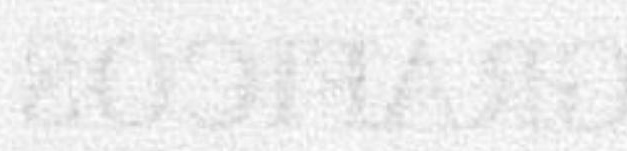


Graf. 1. Fase estratigráfica 1. Total de la industria

Graf. 2. Fase estratigráfica 1. Presencia y tipos de talón

Graf. 3. Fase estratigráfica 1. Hojas prismáticas. Longitudes

Graf. 4. Fase estratigráfica 1. Hojas prismáticas. Anchura

Graf. 5. Fase estratigráfica 1. Hojas prismáticas. Relación longitud-anchura

Graf. 6. Fase estratigráfica 1. Distribución de soportes

Graf. 7. Fase estratigráfica 1. Distribución de tipos

Graf. 8. Fase estratigráfica 2. Total de la industria

Graf. 9. Fase estratigráfica 2. Presencia y tipos de talón

Graf. 10. Fase estratigráfica 2. Hojas prismáticas. Longitudes

Graf. 11. Fase estratigráfica 2. Hojas prismáticas. Anchura

Graf. 12. Fase estratigráfica 2. Hojas prismáticas. Relación longitud-anchura

Graf. 13. Fase estratigráfica 2. Distribución de soportes

Graf. 14. Fase estratigráfica 2. Distribución de tipos

Graf. 15. Fase estratigráfica 3. Total de la industria

Graf. 16. Fase estratigráfica 3. Presencia y tipos de talón

Graf. 17. Fase estratigráfica 3. Hojas prismáticas. Longitudes

Graf. 18. Fase estratigráfica 3. Hojas prismáticas. Anchura

Graf. 19. Fase estratigráfica 3. Hojas prismáticas. Relación longitud-anchura

Graf. 20. Fase estratigráfica 3. Distribución de soportes

Graf. 21. Fase estratigráfica 3. Distribución de tipos

Graf. 22. Fase estratigráfica $4 a$. Total de la industria

Graf. 23. Fase estratigráfica 4a. Presencia y tipos de talón

Graf. 24. Fase estratigráfica 4a. Hojas prismáticas. Longitudes

Graf. 25. Fase estratigráfica 4a. Hojas prismáticas. Anchura

Graf. 26. Fase estratigráfica 4a. Hojas prismáticas. Relación longitud-anchura

Graf. 27. Fase estratigráfica 4a. Distribución de soportes

Graf. 28. Fase estratigráfica 4a. Distribución de tipos

Graf. 29. Fase estratigráfica 4 b. Total de la industria

Graf. 30. Fase estratigráfica 4b. Presencia y tipos de talón

Graf. 31. Fase estratigráfica 4b. Hojas prismáticas. Longitudes

Graf. 32. Fase estratigráfica 4b. Hojas prismáticas. Anchura

Graf. 33. Fase estratigráfica 4b. Hojas prismáticas. Relación longitud-anchura

Graf. 34. Fase estratigráfica 4b. Distribución de soportes

Graf. 35. Fase estratigráfica 4b. Distribución de tipos

Graf. 36. Fase estratigráfica 5. Total de la industria

Graf. 37. Fase estratigráfica 5. Presencia y tipos de talón

Graf. 38. Fase estratigráfica 5. Hojas prismáticas. Longitudes

Graf. 39. Fase estratigráfica 5. Hojas prismáticas. Anchura

Graf. 40. Fase estratigráfica 5. Hojas prismáticas. Relación longitud-anchura

Graf. 41. Fase estratigráfica 5. Distribución de soportes

Graf. 42. Fase estratigráfica 5. Distribución de tipos

Graf. 43. Fase estratigráfica 7. Total de la industria

Graf. 44. Fase estratigráfica 7. Presencia y tipos de talón

Graf. 45. Fase estratigráfica 7. Hojas prismáticas. Longitudes

Graf. 46. Fase estratigráfica 7. Hojas prismáticas. Anchura

Graf. 47. Fase estratigráfica 7. Hojas prismáticas. Relación longitud-anchura 
Graf. 48. Fase estratigráfica 7. Distribución de soportes

Graf. 49. Fase estratigráfica 7. Distribución de tipos

Graf. 50. Fase estratigráfica 8. Total de la industria

Graf. 51. Fase estratigráfica 8. Presencia y tipos de talón

Graf. 52. Fase estratigráfica 8. Hojas prismáticas. Longitudes

Graf. 53. Fase estratigráfica 8. Hojas prismáticas. Anchura

Graf. 54. Fase estratigráfica 8. Hojas prismáticas. Relación longitud-anchura

Graf. 55. Fase estratigráfica 8. Distribución de soportes

Graf. 56. Fase estratigráfica 8. Distribución de tipos

Graf. 57. Fase estratigráfica 9. Total de la industria

Graf. 58. Fase estratigráfica 9. Presencia y tipos de talón

Graf. 59. Fase estratigráfica 9. Hojas prismáticas. Longitudes

Graf. 60. Fase estratigráfica 9. Hojas prismáticas. Anchura

Graf. 61. Fase estratigráfica 9. Hojas prismáticas. Relación longitud-anchura

Graf. 62. Fase estratigráfica 9. Distribución de soportes

Graf. 63. Fase estratigráfica 9. Distribución de tipos

Graf. 64. Fase estratigráfica 10a. Total de la industria

Graf. 65. Fase estratigráfica 10a. Presencia y tipos de talón

Graf. 66. Fase estratigráfica 10a. Hojas prismáticas. Longitudes

Graf. 67. Fase estratigráfica 10a. Hojas prismáticas. Anchura

Graf. 68. Fase estratigráfica 10a. Hojas prismáticas. Relación longitud-anchura

Graf. 69. Fase estratigráfica 10a. Distribución de soportes

Graf. 70. Fase estratigráfica 10a. Distribución de tipos

Graf. 71. Fase estratigráfica 10b. Total de la industria

Graf. 72. Fase estratigráfica 10b. Presencia y tipos de talón

Graf. 73. Fase estratigráfica $10 \mathrm{~b}$. Hojas prismáticas. Longitudes

Graf. 74. Fase estratigráfica 10b. Hojas prismáticas. Anchura

Graf. 75. Fase estratigráfica 10b. Hojas prismáticas. Relación longitud-anchura

Graf. 76. Fase estratigráfica 10b. Distribución de soportes

Graf. 77. Fase estratigráfica 10b. Distribución de tipos

Graf. 78. Fase estratigráfica 11a. Total de la industria

Graf. 79. Fase estratigráfica 11a. Presencia y tipos de talón

Graf. 80. Fase estratigráfica 11a. Hojas prismáticas. Longitudes

Graf. 81. Fase estratigráfica 11a. Hojas prismáticas. Anchura

Graf. 82. Fase estratigráfica 11a. Hojas prismáticas. Relación longitud-anchura

Graf. 83. Fase estratigráfica 11a. Distribución de soportes

Graf. 84. Fase estratigráfica 11a. Distribución de tipos

Graf. 85. Fase estratigráfica 11b. Total de la industria

Graf. 86. Fase estratigráfica 11 b. Presencia y tipos de talón

Graf. 87. Fase estratigráfica 11 b. Hojas prismáticas. Longitudes

Graf. 88. Fase estratigráfica 11b. Hojas prismáticas. Anchura

Graf. 89. Fase estratigráfica 11 b. Hojas prismáticas. Relación longitud-anchura

Graf. 90. Fase estratigráfica 11b. Distribución de soportes

Graf. 91. Fase estratigráfica 11b. Distribución de tipos

Graf. 92. Fase estratigráfica 12. Total de la industria

Graf. 93. Fase estratigráfica 12. Presencia y tipos de talón

Graf. 94. Fase estratigráfica 12. Hojas prismáticas. Longitudes 
Graf. 95. Fase estratigráfica 12. Hojas prismáticas. Anchura

Graf. 96. Fase estratigráfica 12. Hojas prismáticas. Relación longitud-anchura

Graf. 97. Fase estratigráfica 12. Distribución de soportes

Graf. 98. Fase estratigráfica 12. Distribución de tipos

Graf. 99. Fase estratigráfica 13. Total de la industria

Graf. 100. Fase estratigráfica 13. Presencia y tipos de talón

Graf. 101. Fase estratigráfica 13. Hojas prismáticas. Longitudes

Graf. 102. Fase estratigráfica 13. Hojas prismáticas. Anchura

Graf. 103. Fase estratigráfica 13. Hojas prismáticas. Relación longitud-anchura

Graf. 104. Fase estratigráfica 13. Distribución de soportes

Graf. 105. Fase estratigráfica 13. Distribución de tipos

Graf. 106. Fase estratigráfica 14. Total de la industria

Graf. 107. Fase estratigráfica 14. Presencia y tipos de talón

Graf. 108. Fase estratigráfica 14. Hojas prismáticas. Longitudes

Graf. 109. Fase estratigráfica 14. Hojas prismáticas. Anchura

Graf. 110. Fase estratigráfica 14. Hojas prismáticas. Relación longitud-anchura

Graf. 111. Fase estratigráfica 14. Distribución de soportes

Graf. 112. Fase estratigráfica 14. Distribución de tipos

Graf. 113. Fase estratigráfica 15. Total de la industria

Graf. 114. Fase estratigráfica 15. Presencia y tipos de talón

Graf. 115. Fase estratigráfica 15. Hojas prismáticas. Longitudes

Graf. 116. Fase estratigráfica 15. Hojas prismáticas. Anchura

Graf. 117. Fase estratigráfica 15. Hojas prismáticas. Relación longitud-anchura

Graf. 118. Fase estratigráfica 15. Distribución de soportes

Graf. 119. Fase estratigráfica 15. Distribución de tipos

Graf. 120. Fase estratigráfica 16a. Total de la industria

Graf. 121. Fase estratigráfica 16a. Presencia y tipos de talón

Graf. 122. Fase estratigráfica 16a.Distribución de soportes

Graf. 123. Fase estratigráfica 16a.Distribución de tipos

Graf. 124. Fase estratigráfica 16b. Total de la industria

Graf. 125. Fase estratigráfica 16b. Presencia y tipos de talón

Graf. 126. Fase estratigráfica $16 \mathrm{~b}$. Hojas prismáticas. Longitudes

Graf. 127. Fase estratigráfica 16b. Hojas prismáticas. Anchura

Graf. 128. Fase estratigráfica 16b. Hojas prismáticas. Relación longitud-anchura

Graf. 129. Fase estratigráfica 16b. Distribüción de soportes

Graf. 130. Fase estratigráfica 16b. Distribución de tipos

Graf. 131. Fase estratigráfica 1. Distribución de la industria

Graf. 132. Fase estratigráfica 1. Distribución de la producción laminar

Graf. 133. Fase estratigráfica 1. Distribución de la producción lascar

Graf. 134. Fase estratigráfica 2. Distribución de la industria

Graf. 135. Fase estratigráfica 2. Distribución de la producción laminar

Graf. 136. Fase estratigráfica 2. Distribución de la producción lascar

Graf. 135. Fase estratigráfica 3. Distribución de la industria

Graf. 136. Fase estratigráfica 3. Distribución de la producción laminar

Graf. 137. Fase estratigráfica 3. Distribución de la producción lascar

Graf. 138. Fase estratigráfica 4a. Distribución de la industria

Graf. 139. Fase estratigráfica 4a. Distribución de la producción laminar 
Graf. 140. Fase estratigráfica 4a. Distribución de la producción lascar

Graf. 141. Fase estratigráfica 4b. Distribución de la industria

Graf. 142. Fase estratigráfica 4b. Distribución de la producción laminar

Graf. 143. Fase estratigráfica 4b. Distribución de la producción lascar

Graf. 144. Fase estratigráfica 5. Distribución de la industria

Graf. 145. Fase estratigráfica 5. Distribución de la producción laminar

Graf. 146. Fase estratigráfica 5. Distribución de la producción lascar

Graf. 147. Fase estratigráfica 7. Distribución de la industria

Graf. 148. Fase estratigráfica 7. Distribución de la producción laminar

Graf. 149. Fase estratigráfica 7. Distribución de la producción lascar

Graf. 150. Fase estratigráfica 8. Distribución de la industria

Graf. 151. Fase estratigráfica 8. Distribución de la producción laminar

Graf. 152. Fase estratigráfica 8. Distribución de la producción lascar

Graf. 153. Fase estratigráfica 9. Distribución de la industria

Graf. 154. Fase estratigráfica 9. Distribución de la producción laminar

Graf. 155. Fase estratigráfica 9. Distribución de la producción lascar

Graf. 156. Fase estratigráfica 9. Distribución de tipos

Graf. 157. Fase estratigráfica 10a. Distribución de la producción laminar

Graf. 158. Fase estratigráfica 10a. Distribución de la producción lascar

Graf. 159. Fase estratigráfica 10b. Distribución de la industria

Graf. 160. Fase estratigráfica 10b. Distribución de la producción laminar

Graf. 161. Fase estratigráfica 10b. Distribución de la producción lascar

Graf. 162. Fase estratigráfica 11a. Distribución de la industria

Graf. 163. Fase estratigráfica 11a. Distribución de la producción laminar

Graf. 164. Fase estratigráfica 11a. Distribución de la producción lascar

Graf. 165. Fase estratigráfica 11 b. Distribución de hojas retocadas

Graf. 166. Fase estratigráfica $11 \mathrm{~b}$. Distribución de lascas retocadas

Graf. 167. Fase estratigráfica 11b. Distribución de tipos

Graf. 168. Fase estratigráfica 12. Distribución de la industria

Graf. 169. Fase estratigráfica 12. Distribución de la producción laminar

Graf. 170. Fase estratigráfica 12. Distribución de la producción lascar

Graf. 171. Fase estratigráfica 13. Distribución de la producción laminar

Graf. 172. Fase estratigráfica 13. Distribución de la producción lascar

Graf. 173. Fase estratigráfica 13. Distribución de tipos

Graf. 174. Fase estratigráfica 14. Distribución de la producción laminar

Graf. 175. Fase estratigráfica 14. Distribución de la producción lascar

Graf. 176. Fase estratigráfica 14. Distribución de tipos

Graf. 177. Fase estratigráfica 15. Distribución de la producción laminar

Graf. 178. Fase estratigráfica 15. Distribución de la producción lascar

Graf. 179. Fase estratigráfica 16a. Distribución de la producción laminar

Graf. 180. Fase estratigráfica 16a. Distribución de la producción lascar

Graf. 181. Fase estratigráfica 16a: Distribución de tipos

Graf. 182. Fase estratigráfica 14. Distribución de la producción laminar

Graf. 183. Fase estratigráfica 14. Distribución de la producción lascar

Graf. 184. Fase estratigráfica 14. Distribución de tipos 


\section{CLASIFICACIÓN TECNOLÓGICA}

\section{TOTAL DE LA INDUSTRIA LITICA}

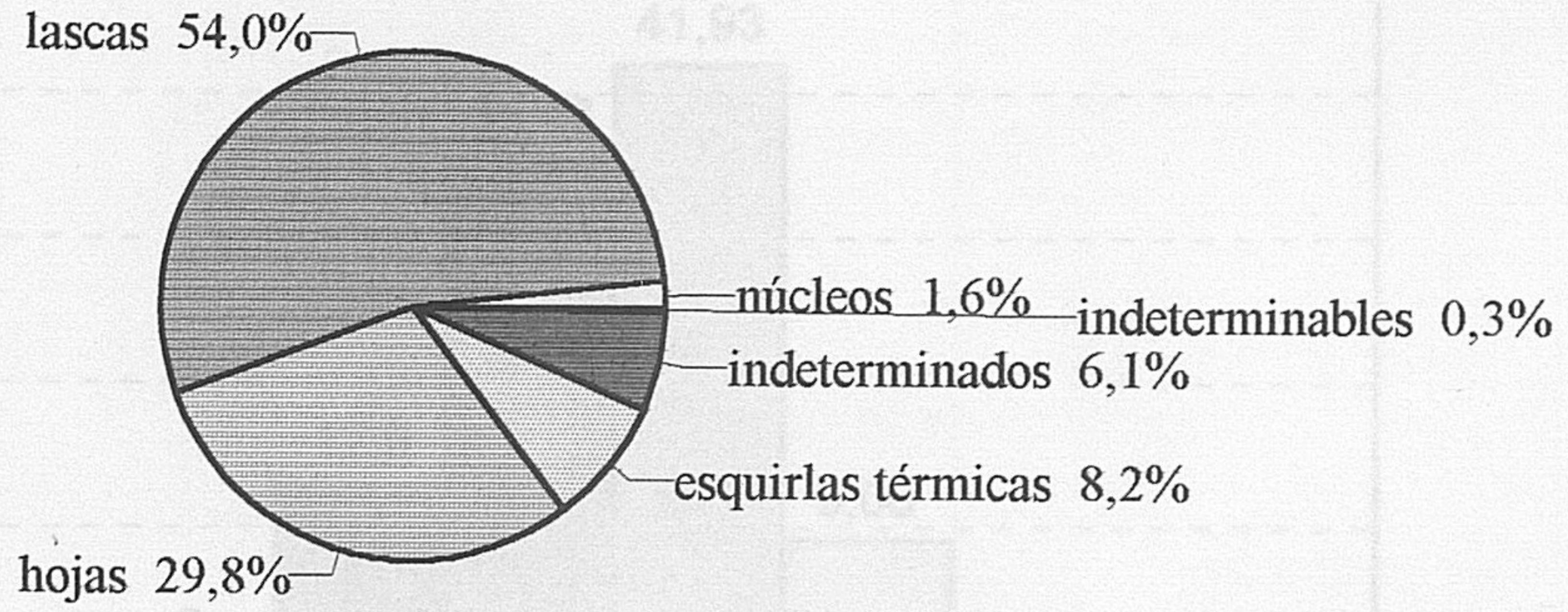

Gráfico 1. Fase estratigráfica 1. Neolítico antiguo

\section{PRESENCIA Y TIPOS DE TALON}

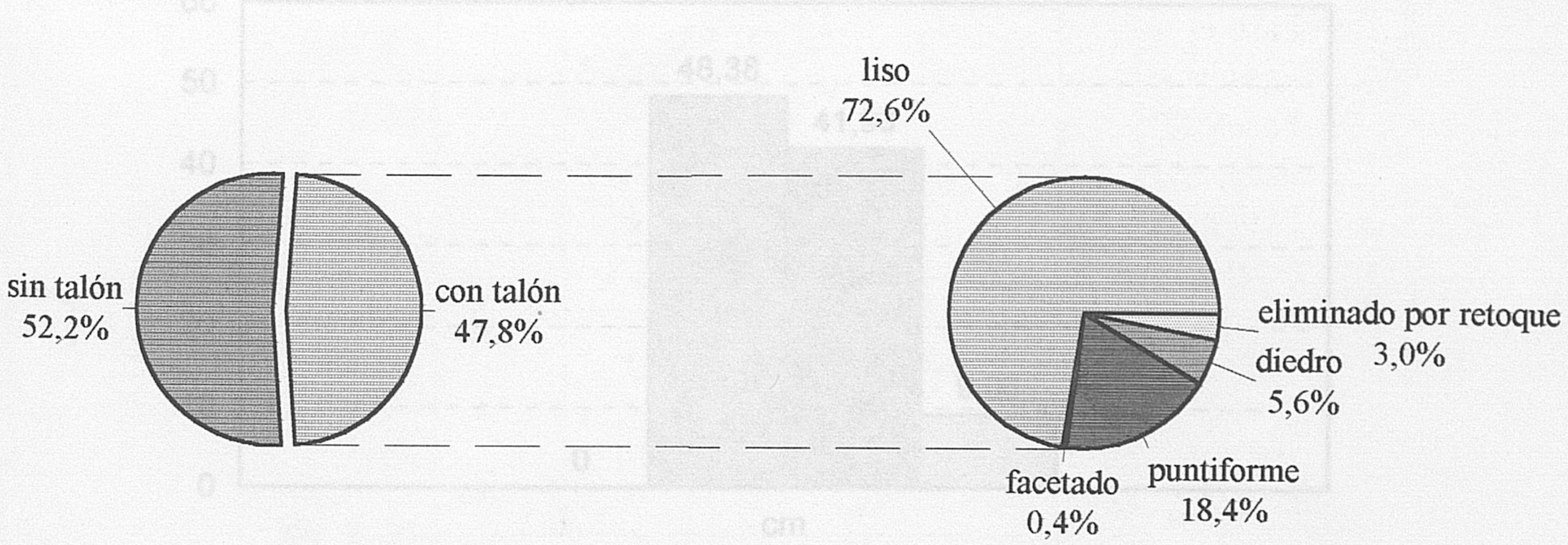

Fase estratigráfica 1. Neolítico antiguo Gráfico 2 


\section{CLASIFICACIÓN TECNOLÓGICA}

HOJAS PRISMÁTICAS. LONGTUUDES

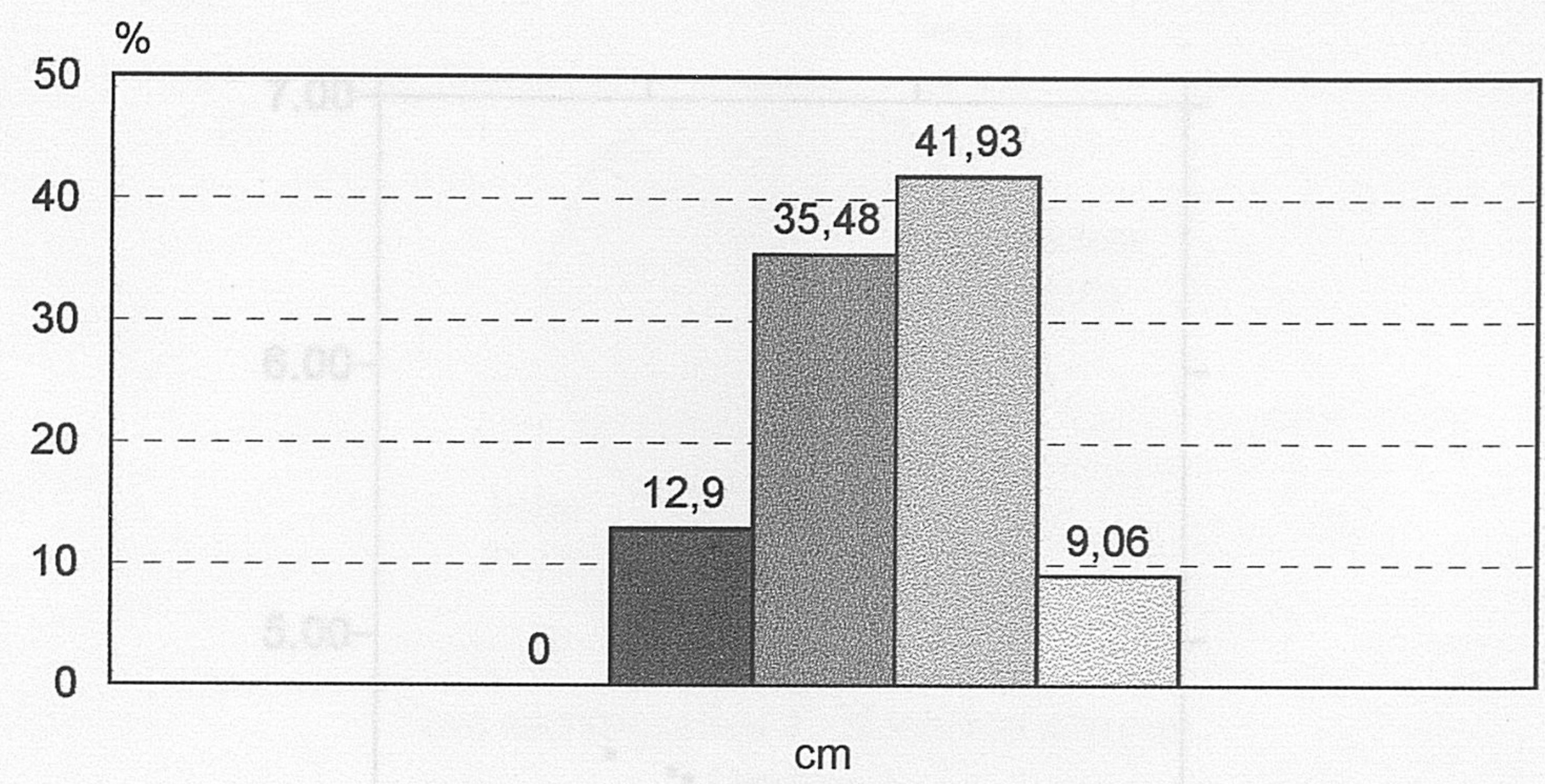

$\begin{array}{lllll}0-1 & 1-2 & 2-3 & 3-4 & 4-5\end{array}$

Fase estratigráfica 1. Neolítico antiguo

Gráfico 3

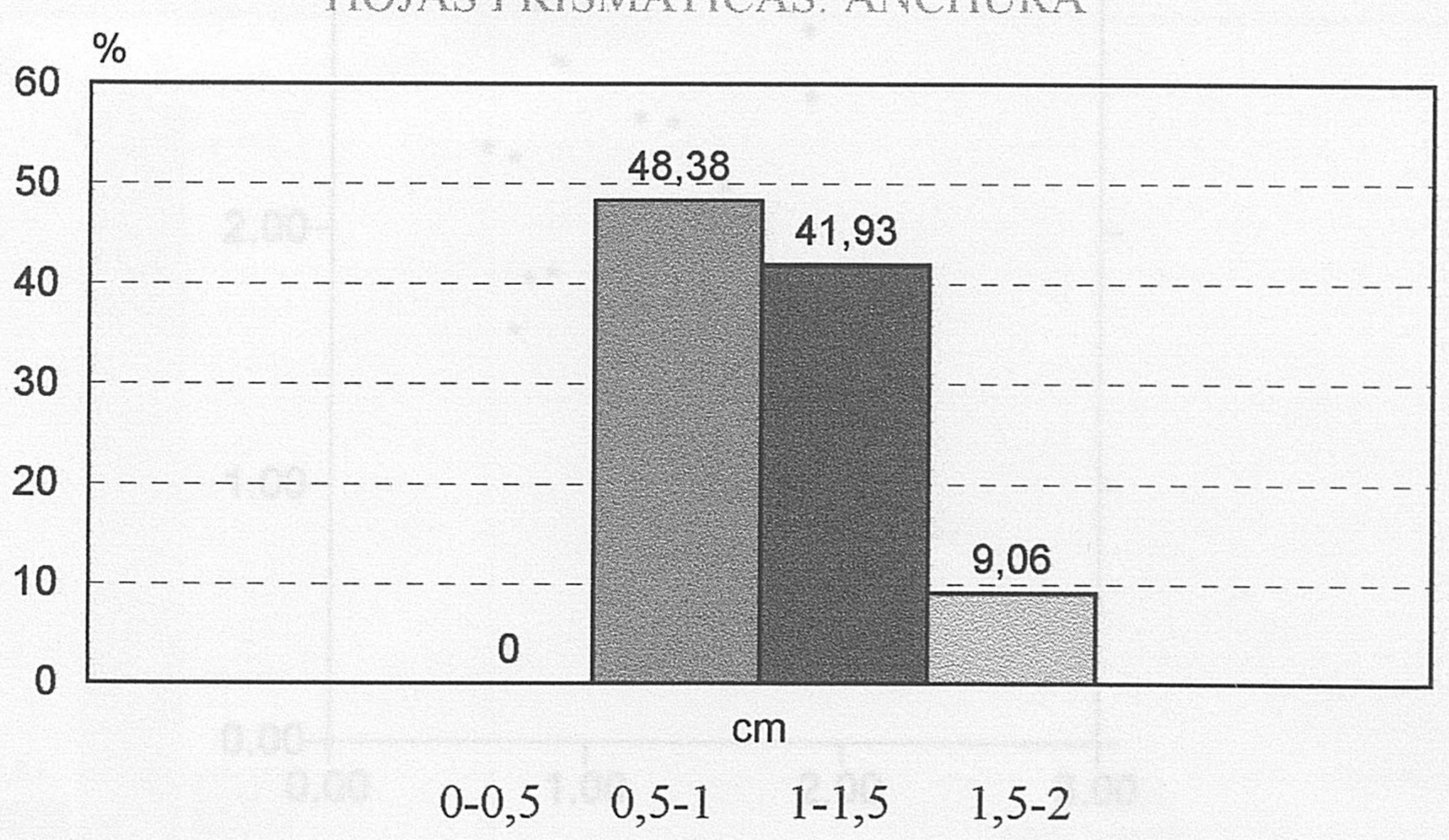

Fase estratigráfica 1. Neolítico antiguo Gráfico 4 
longitud en $\mathrm{cm}$.

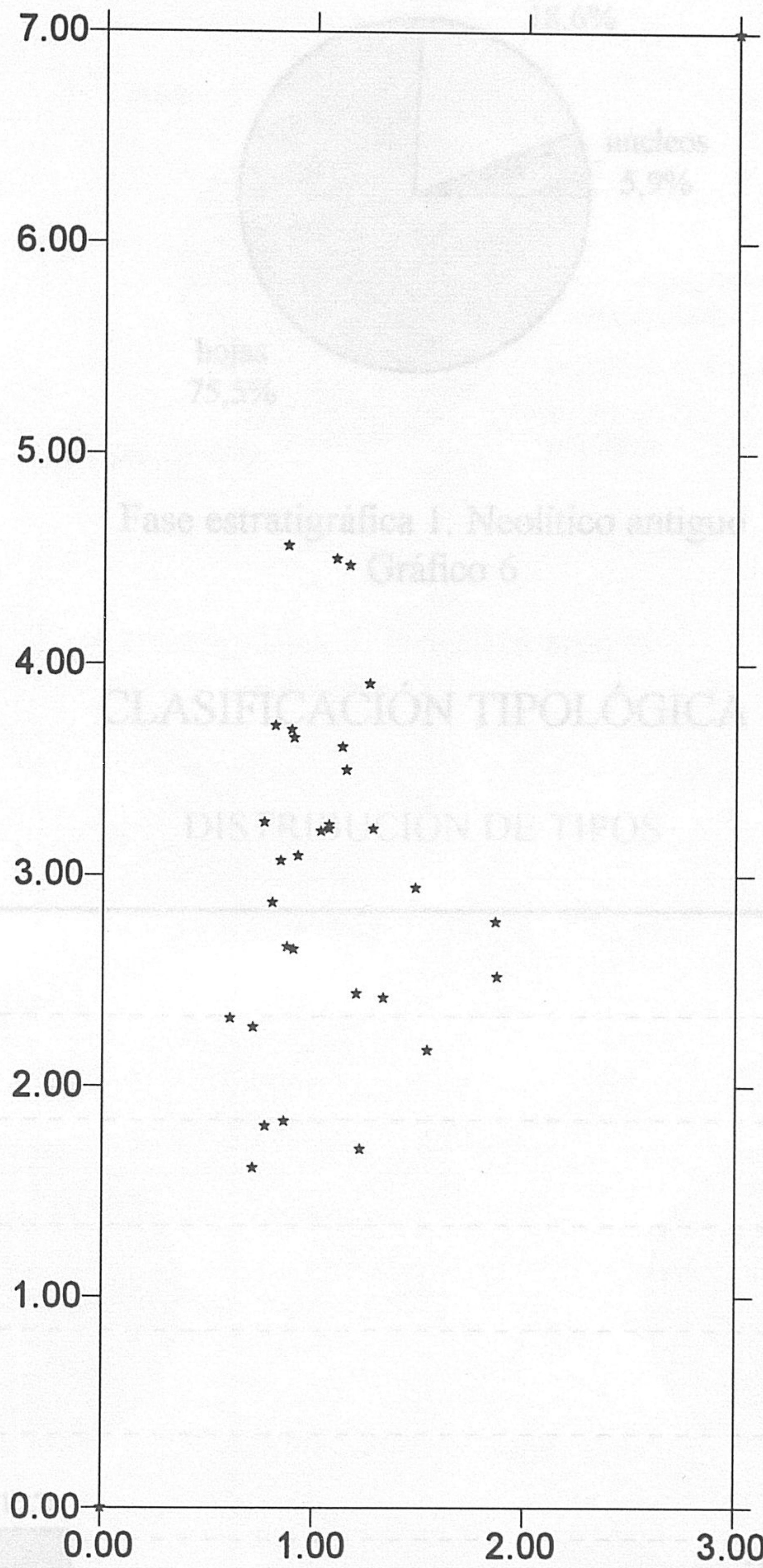

anchura en $\mathrm{cm}$.

Fase estratigráfica 1. Hojas prismáticas. Relación longitud-anchura

Graf. 5 


\section{CLASIFICACIÓN TECNOLÓGICA}

\section{DISTRIBUCION DE SOPORTES}

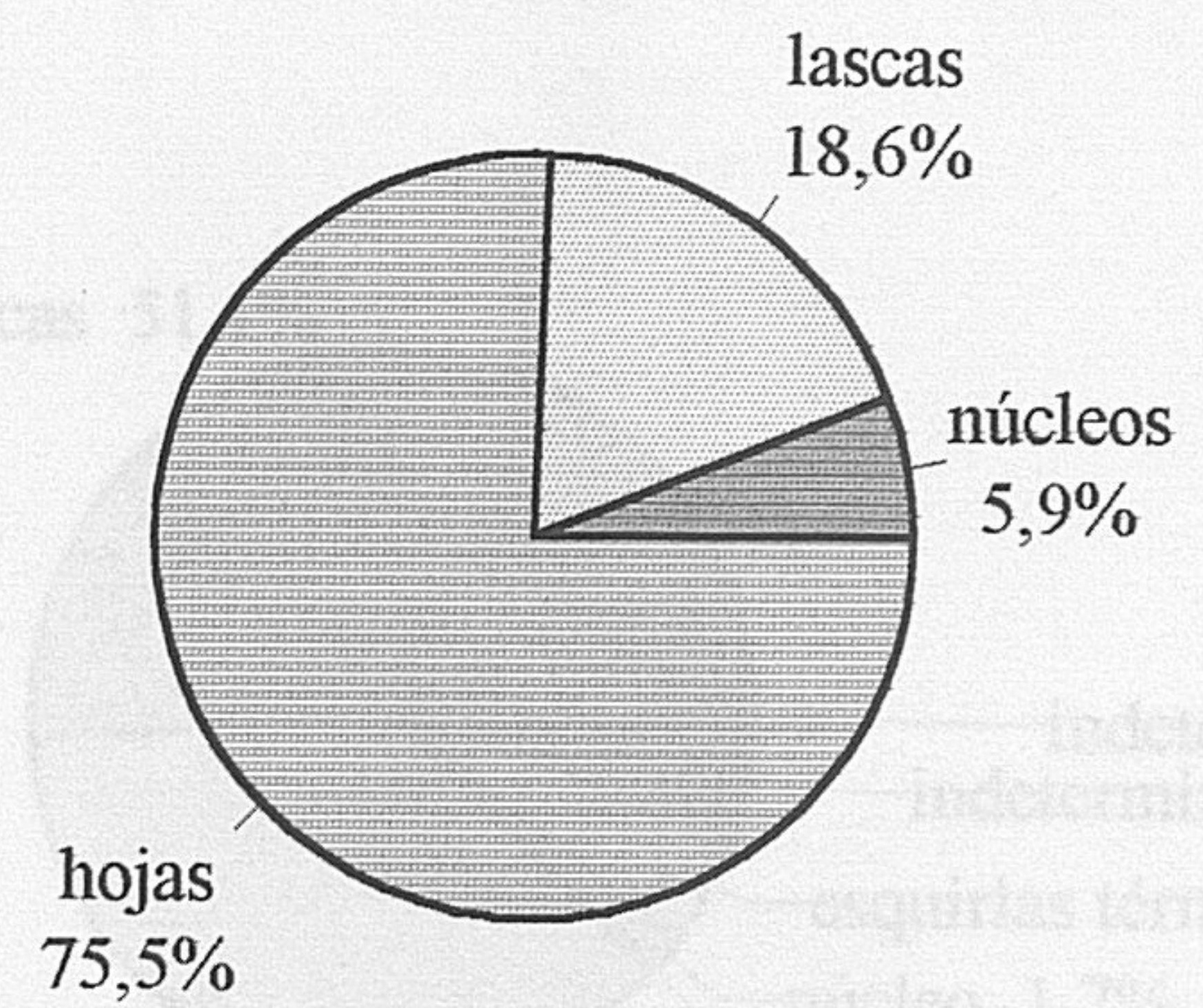

Fase estratigráfica 1. Neolítico antiguo Gráfico 6

\section{CLASIFICACIÓN TIPOLÓGICA}

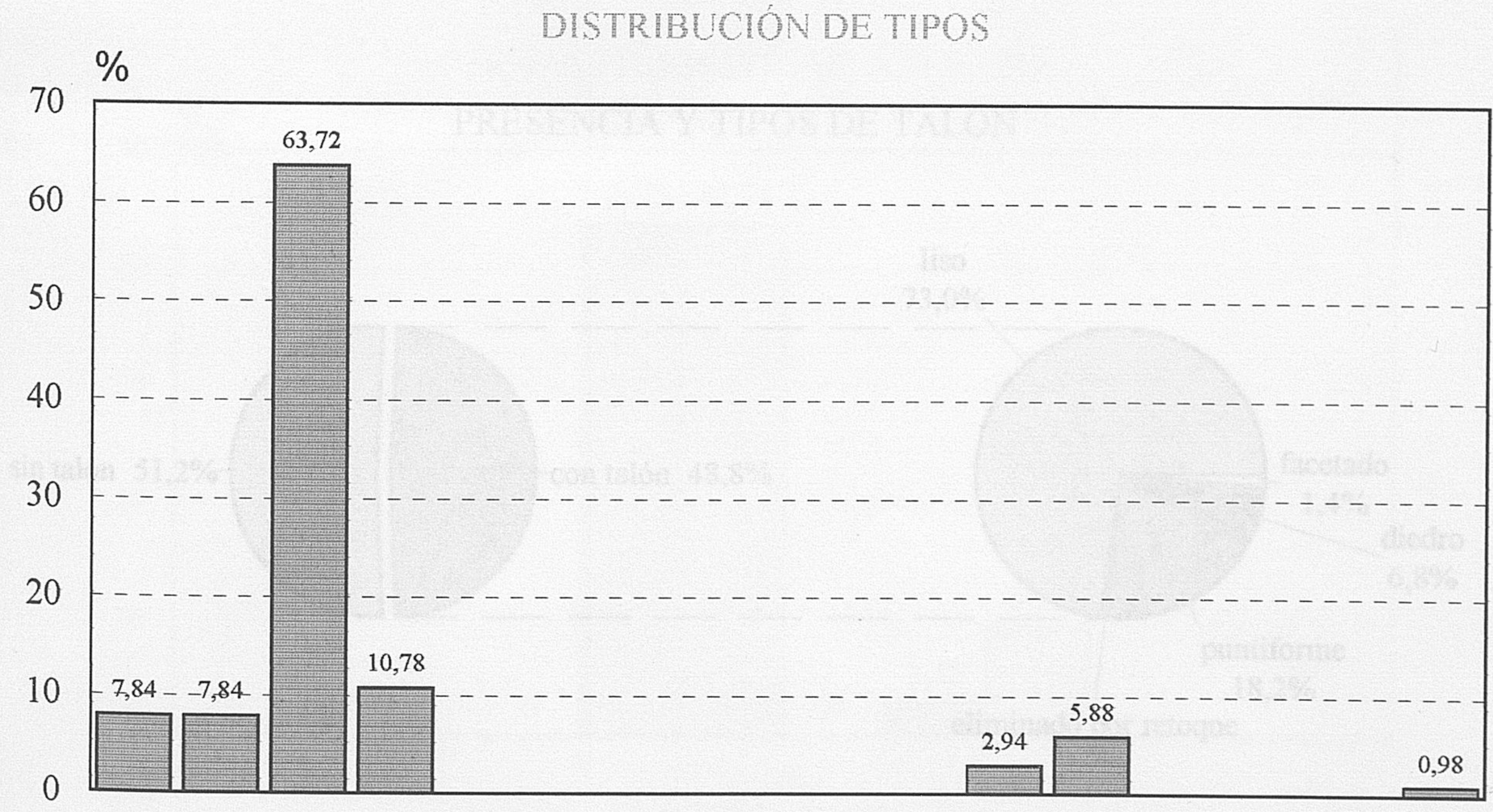

Tipo 1a Tipo 1 b Tipo 2a Tipo 2b Tipo 3 Tipo 4 Tipo 5 Tipo 6 Tipo 7 Tipo 8 Tipo 9 Tipo 10 Tipo 11 Tipo 12 Tipo 13 Tipo 14

Fase estratigráfica 1. Neolítico antiguo Gráfico 7 


\section{CLASIFICACIÓN TECNOLÓGICA}

\section{TOTAL DE LA INDUSTRIA}

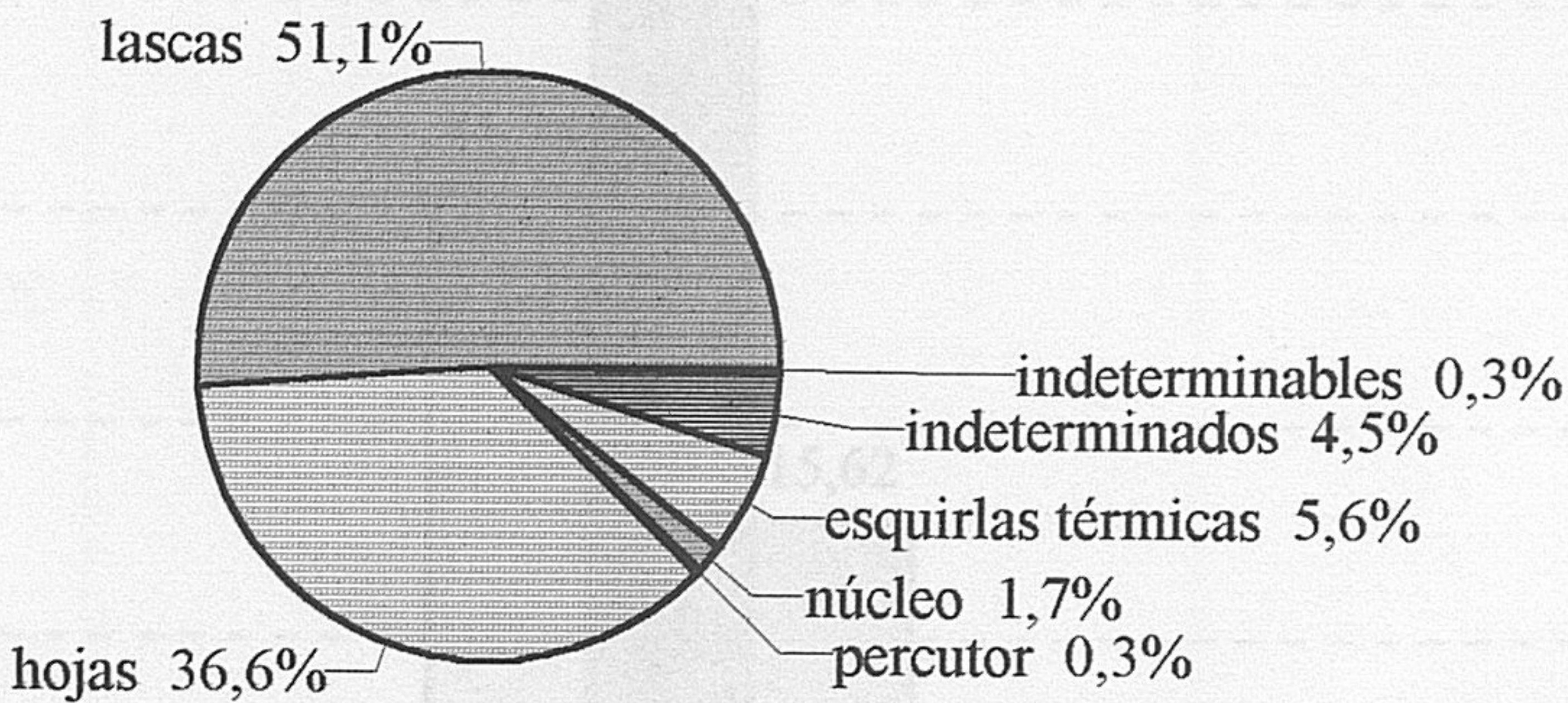

Fase estratigráfica 2. Neolítico antiguo

Gráfico 8.

\section{PRESENCIA Y TIPOS DE TALON}

sin talón $51,2 \%$

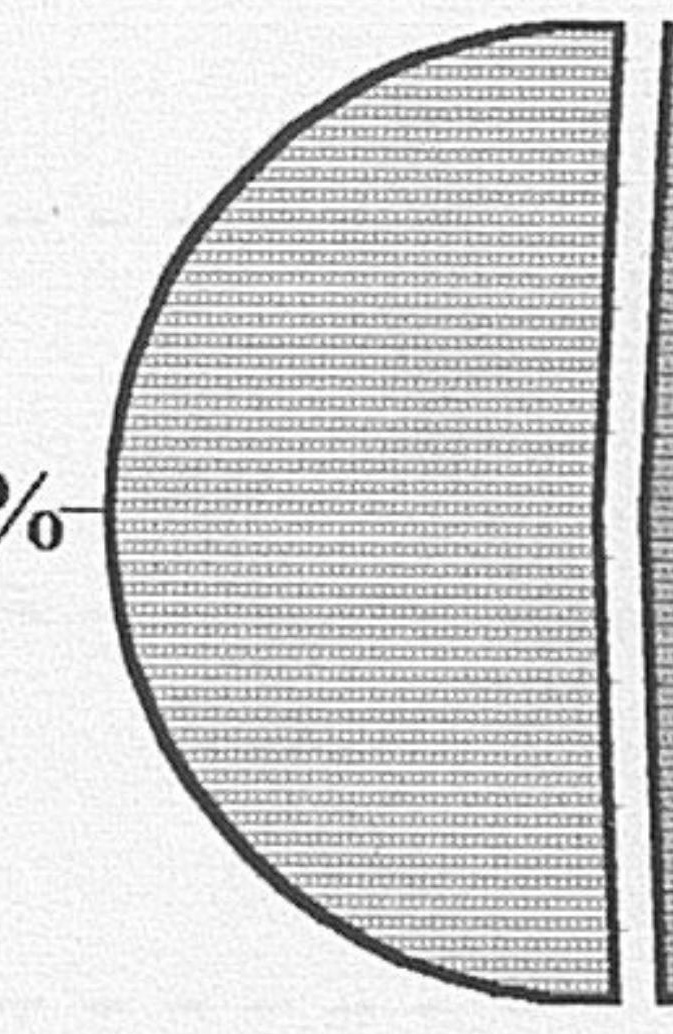

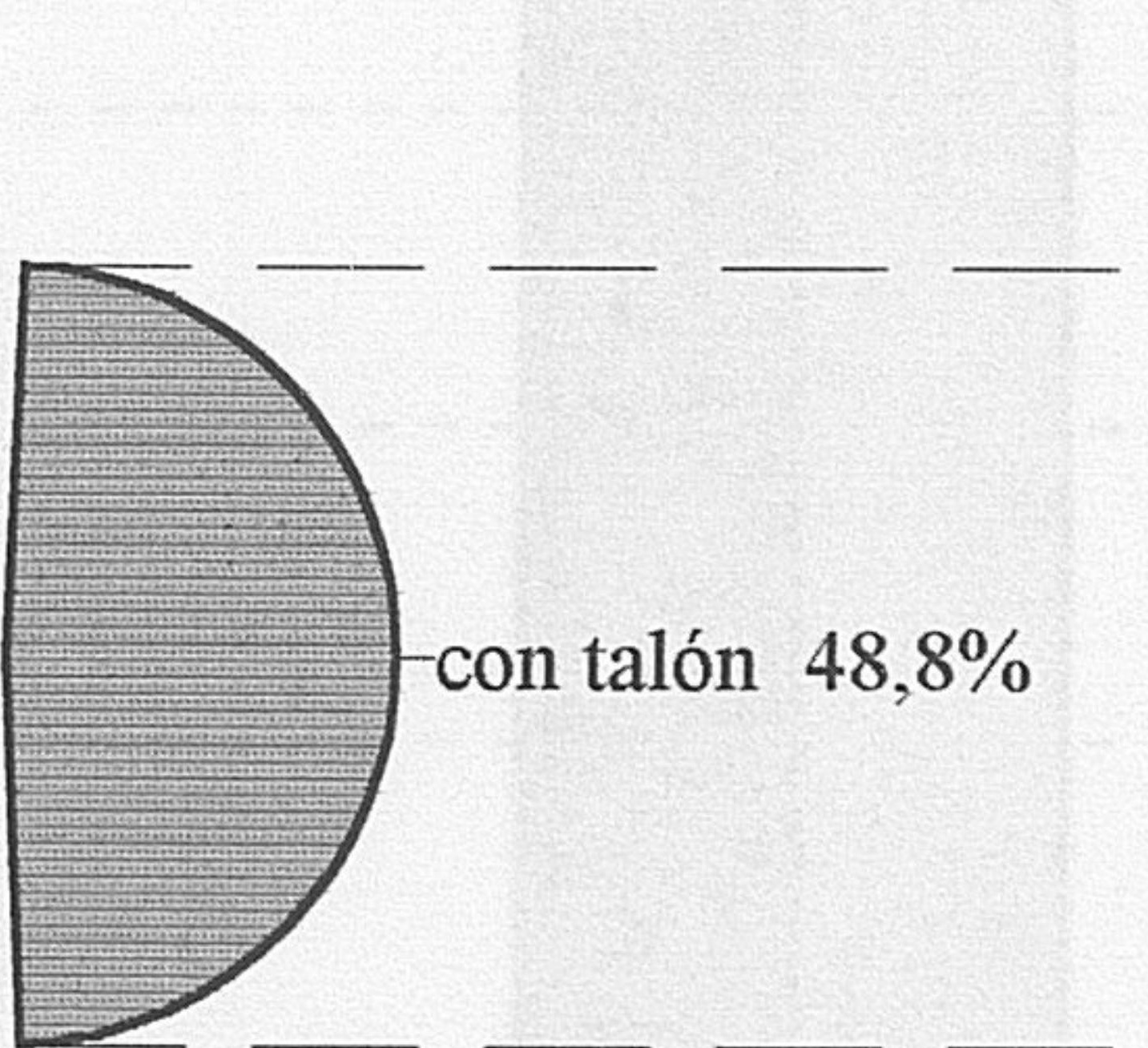

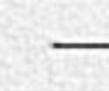

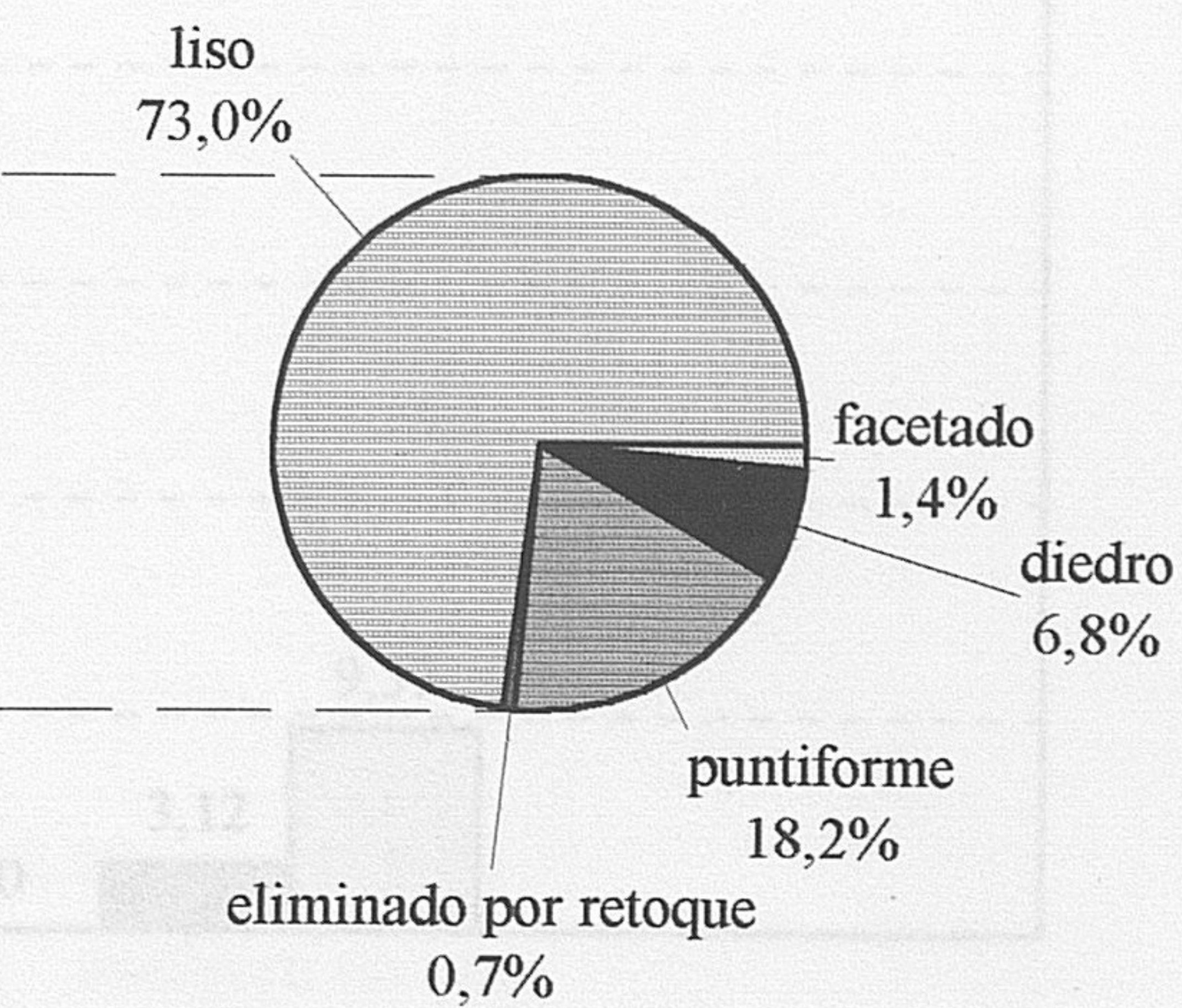

Fase estratigráfica 2. Neolítico antiguo Gráfico 9 


\section{CLASIFICACIÓN TECNOLÓGICA}

HOJAS PRISMÁTICAS. LONGITUDES

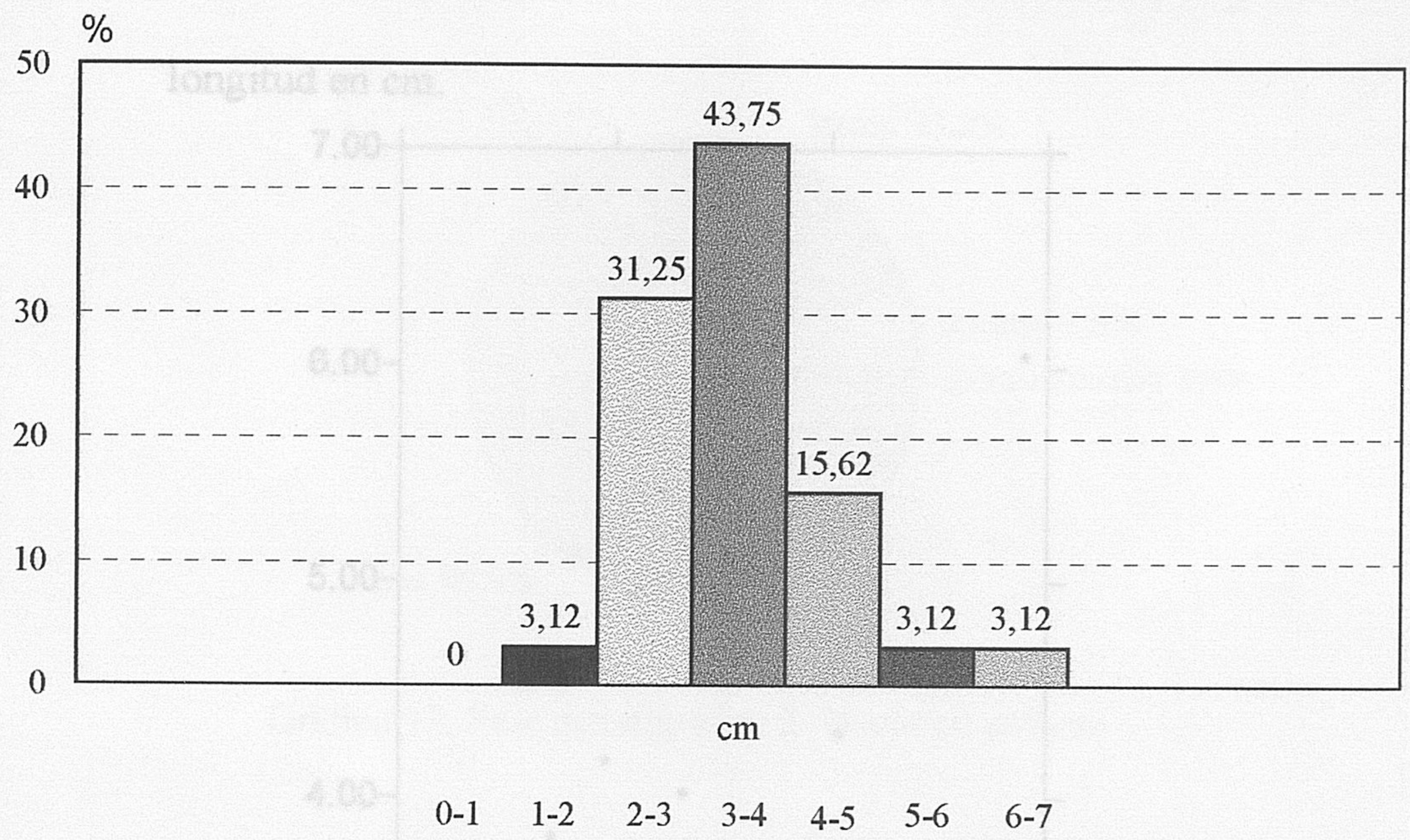

Gráfico 10. Fase estratigráfica 2. Neolítico antiguo

HOJAS PRISMÁTICAS. ANCHURA

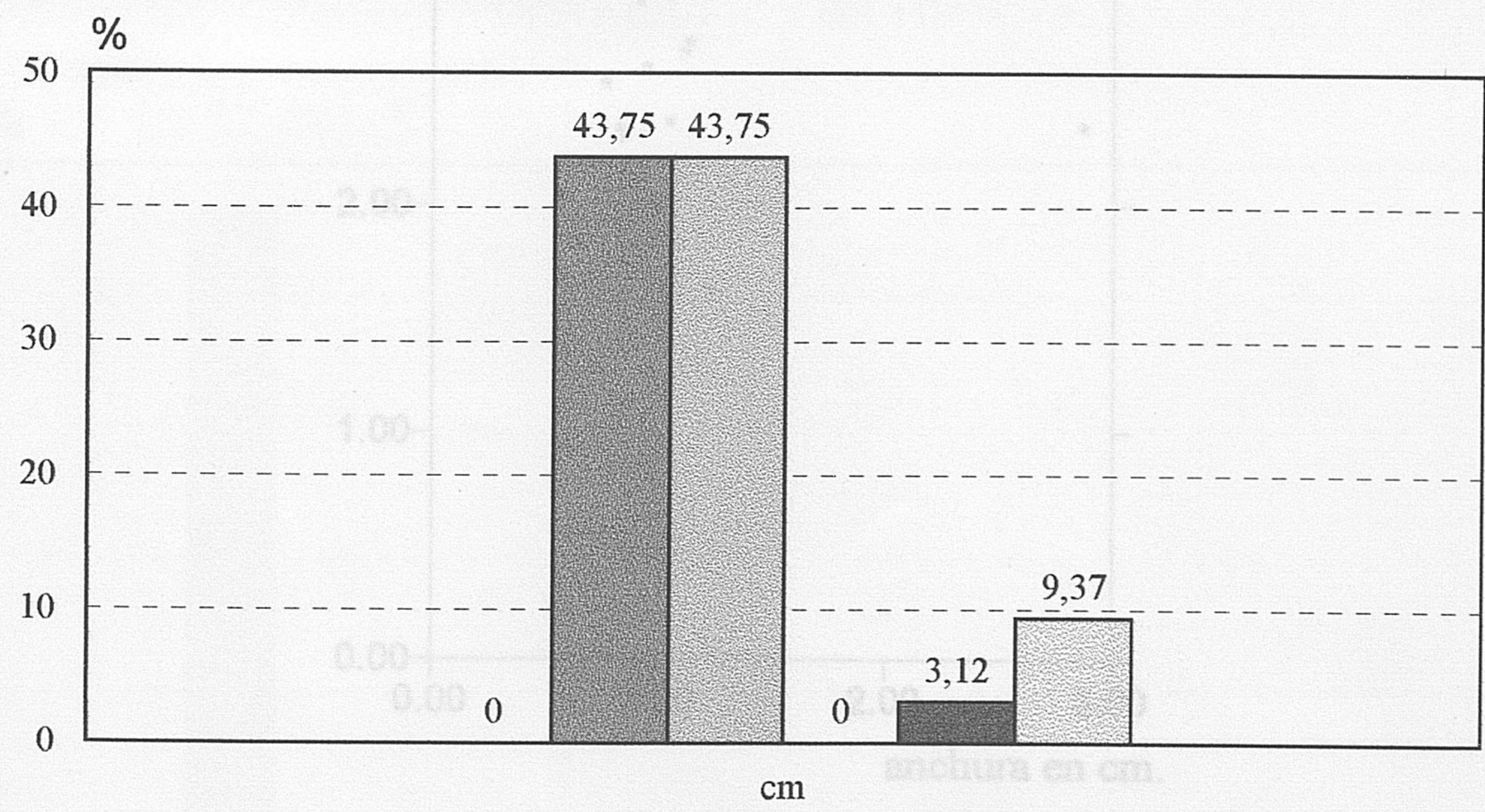

$0-0,5 \quad 0,5-1 \quad 1-1,5 \quad 1,5-2 \quad 2-2,5 \quad 2,5-3$

Gráfico 11. Fase estratigráfica 2. Neolítico antiguo 
longitud en $\mathrm{cm}$.

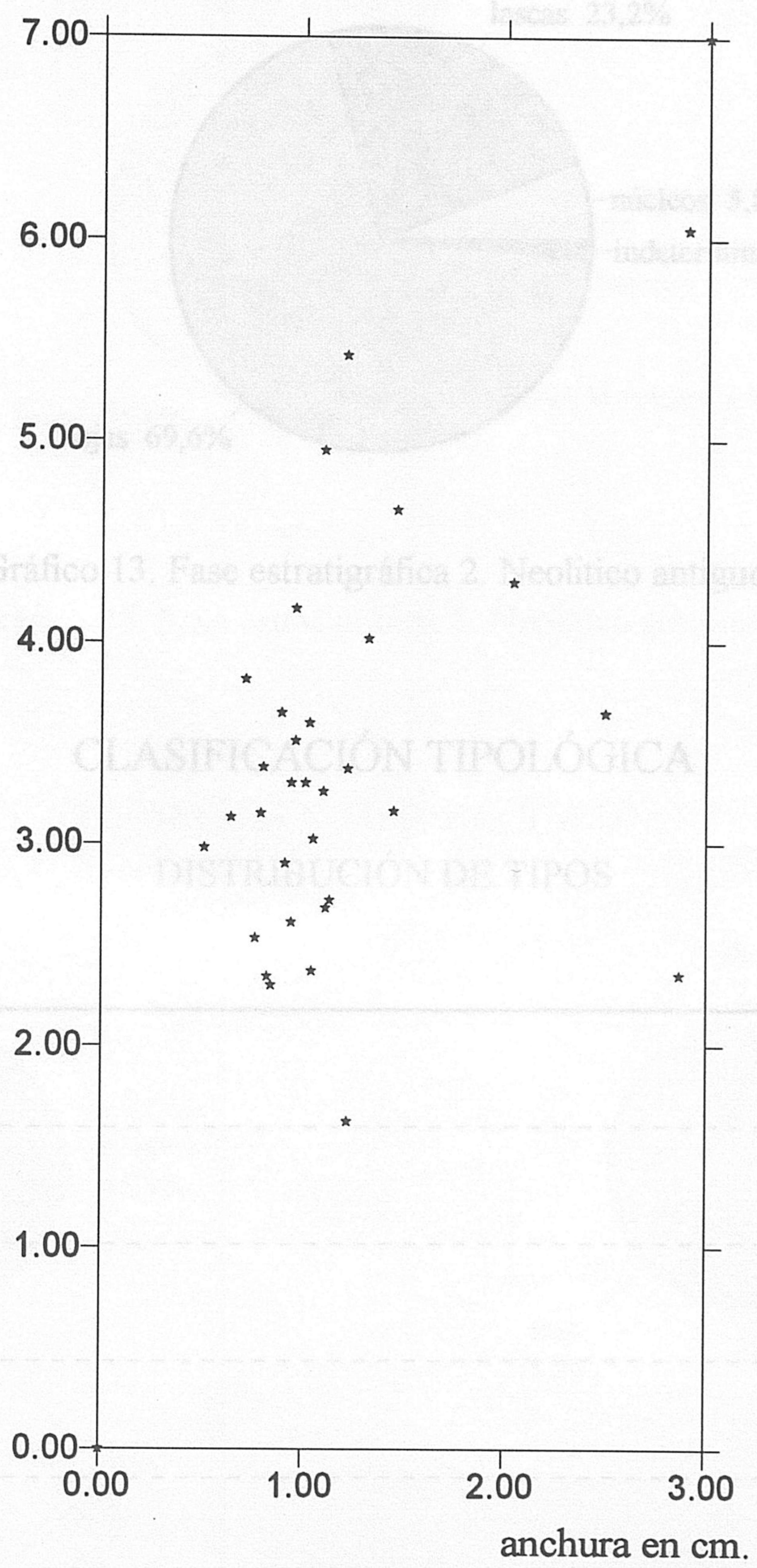

Fase estratigráfica 2. Hojas prismáticas. Relación longitud anchura Graf. 12 


\section{CLASIFICACIÓN TECNOLÓGICA}

\section{DISTRIBUCIÓN DE SOPORTES}

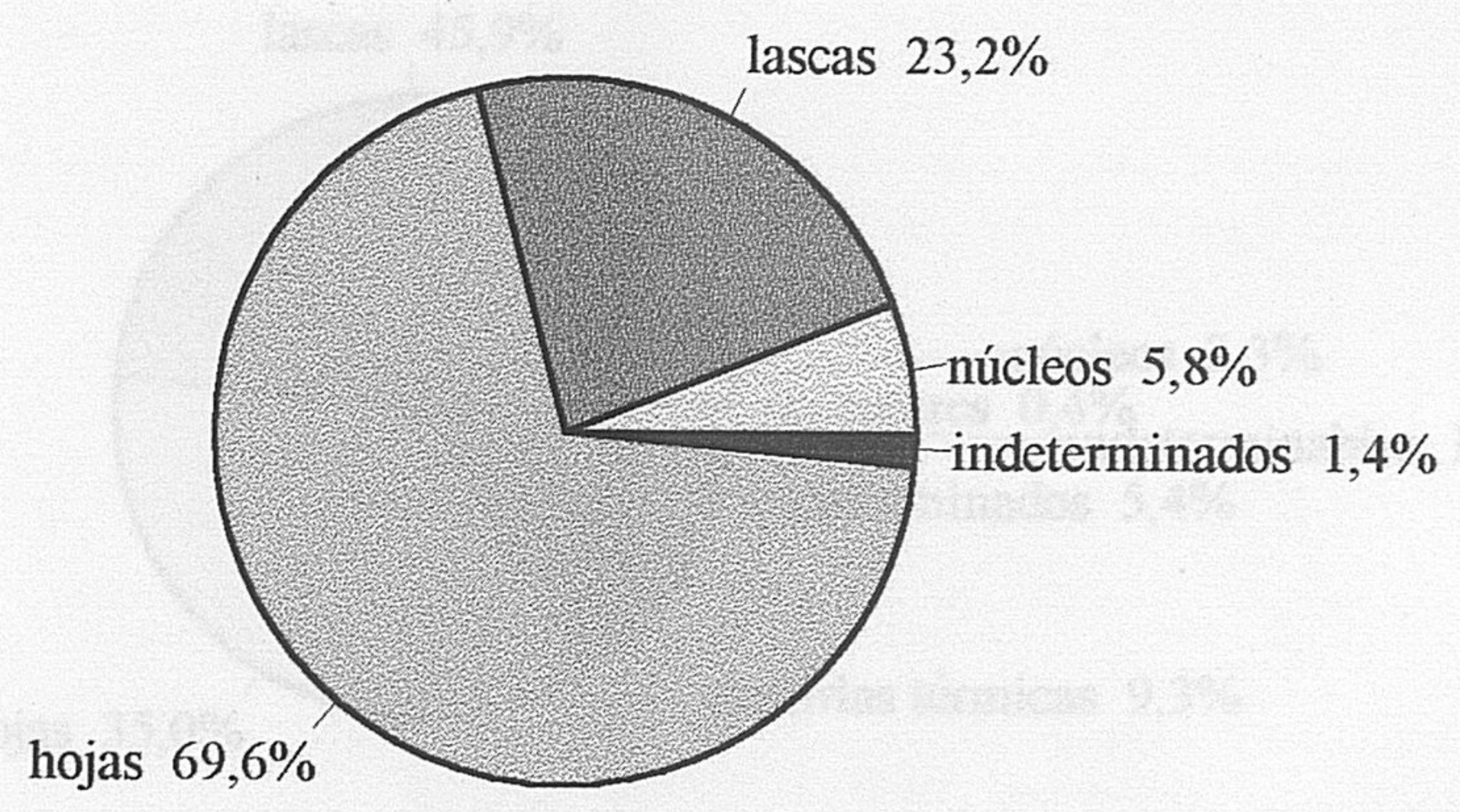

Gráfico 13. Fase estratigráfica 2. Neolítico antiguo

\section{CLASIFICACIÓN TIPOLÓGICA}

\section{DISTRIBUCIÓN DE TIPOS}

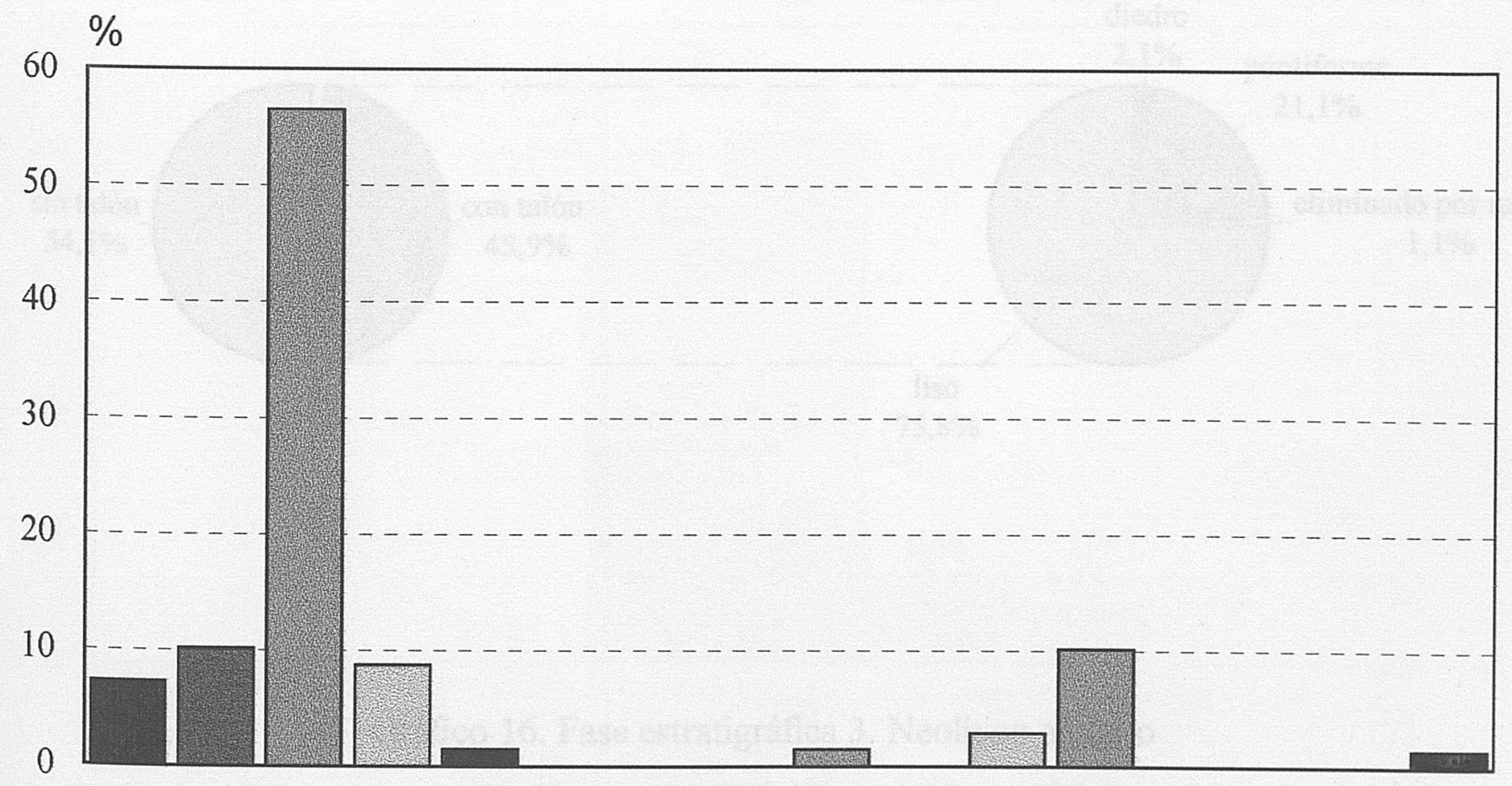

Tipo 1a Tipo 1 b Tipo 2a Tipo 2b Tipo 3 Tipo 4 Tipo 5 Tipo 6 Tipo 7 Tipo 8 Tipo 9 Tipo 10 Tipo 11 Tipo 12 Tipo 13 Tipo 14

Gráfico 14. Fase estratigráfica 2. Neolítico antiguo 


\section{CLASIFICACIÓN TECNOLÓGICA}

TOTAL DE LA INDUSTRIA

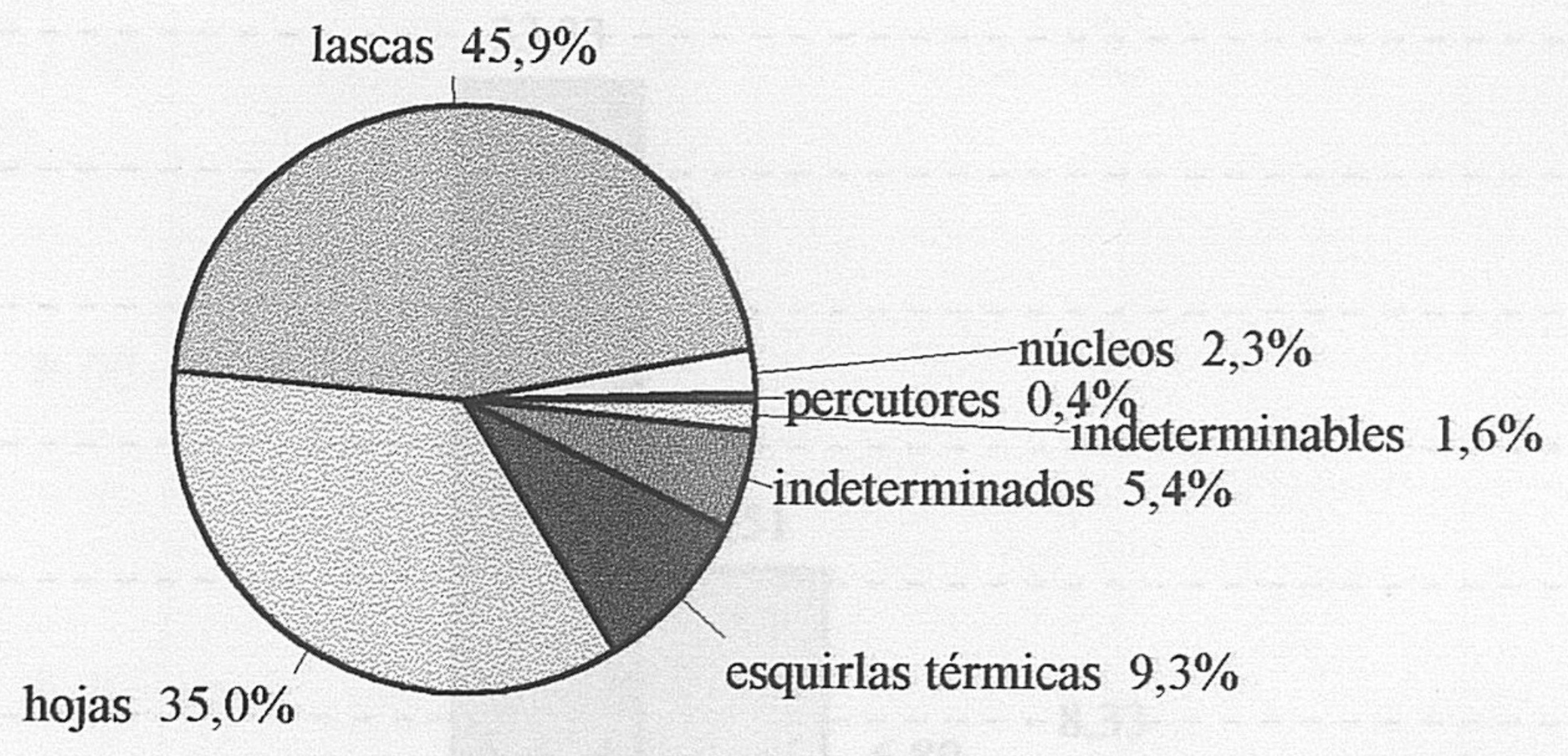

Gráfico 15. Fase estratigráfica 3. Neolítico antiguo

\section{PRESENCIA Y TIPOS DE TALÓN}

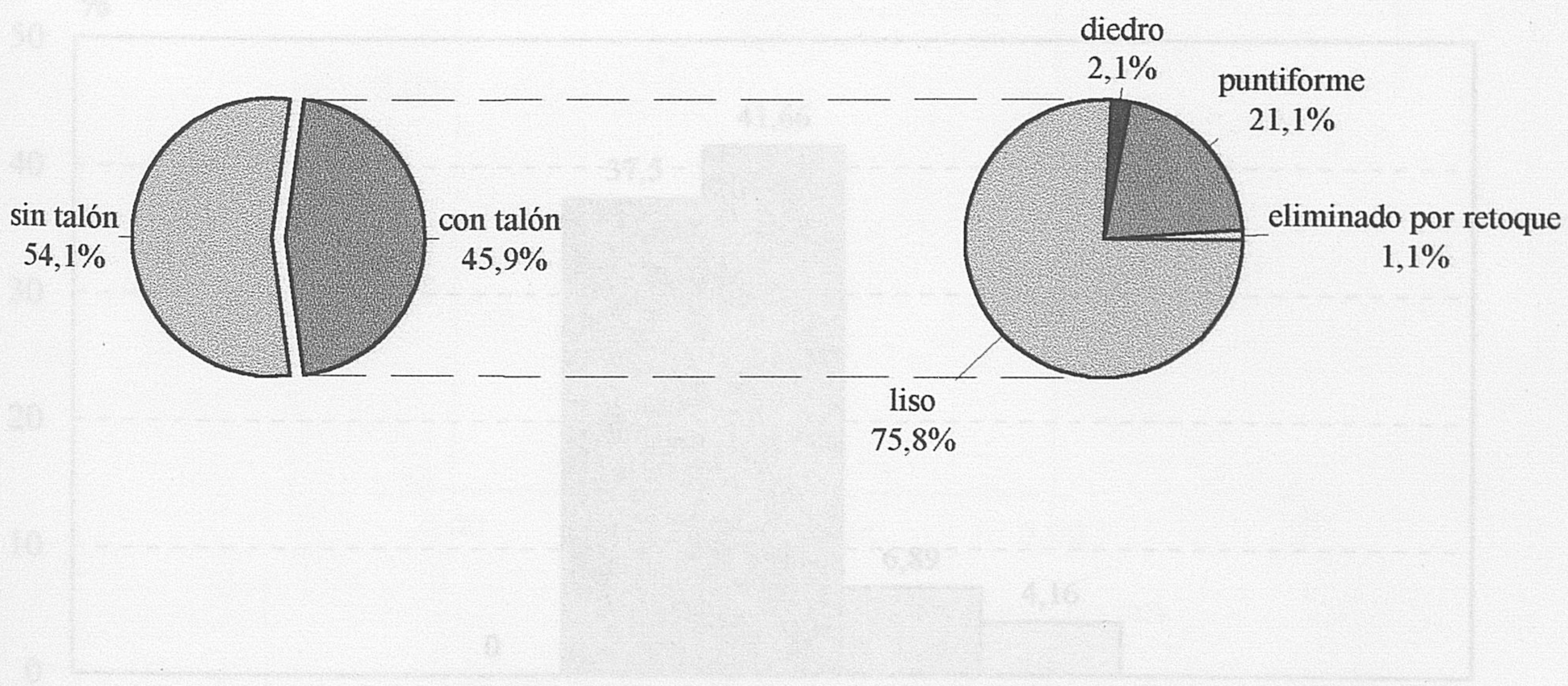

Gráfico 16. Fase estratigráfica 3. Neolítico antiguo 


\section{CLASIFICACIÓN TECNOLÓGICA}

\section{HOJAS PRISMÁTICAS. LONGTUUDES}

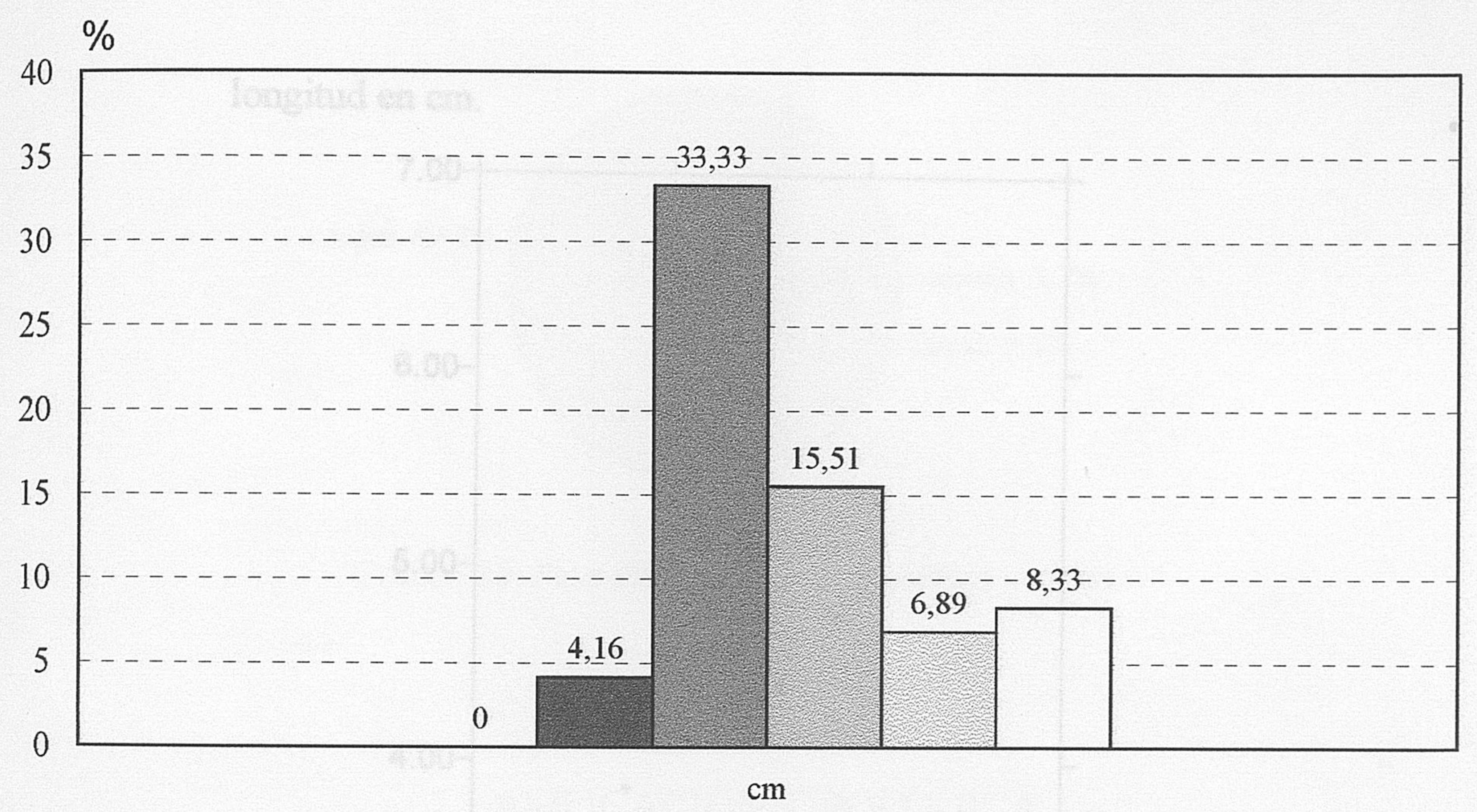

$\begin{array}{llllll}0-1 & 1-2 & 2-3 & 3-4 & 4-5 & 5-6\end{array}$

Gráfico 17. Fase estratigráfica 3. Neolítico antiguo

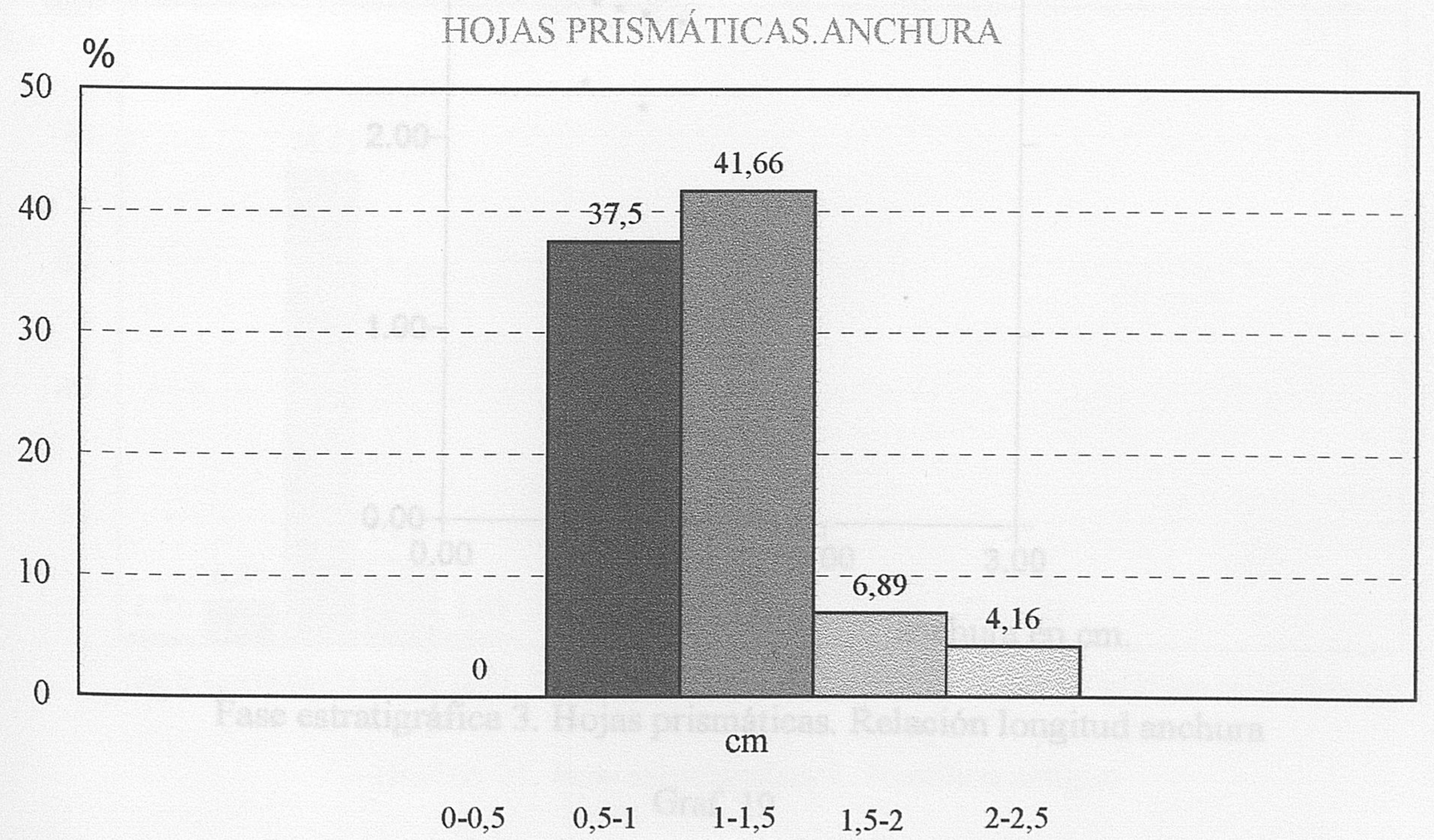

Gráfico 18. Fase estratigráfica 3. Neolítico antiguo 
longitud en $\mathrm{cm}$.

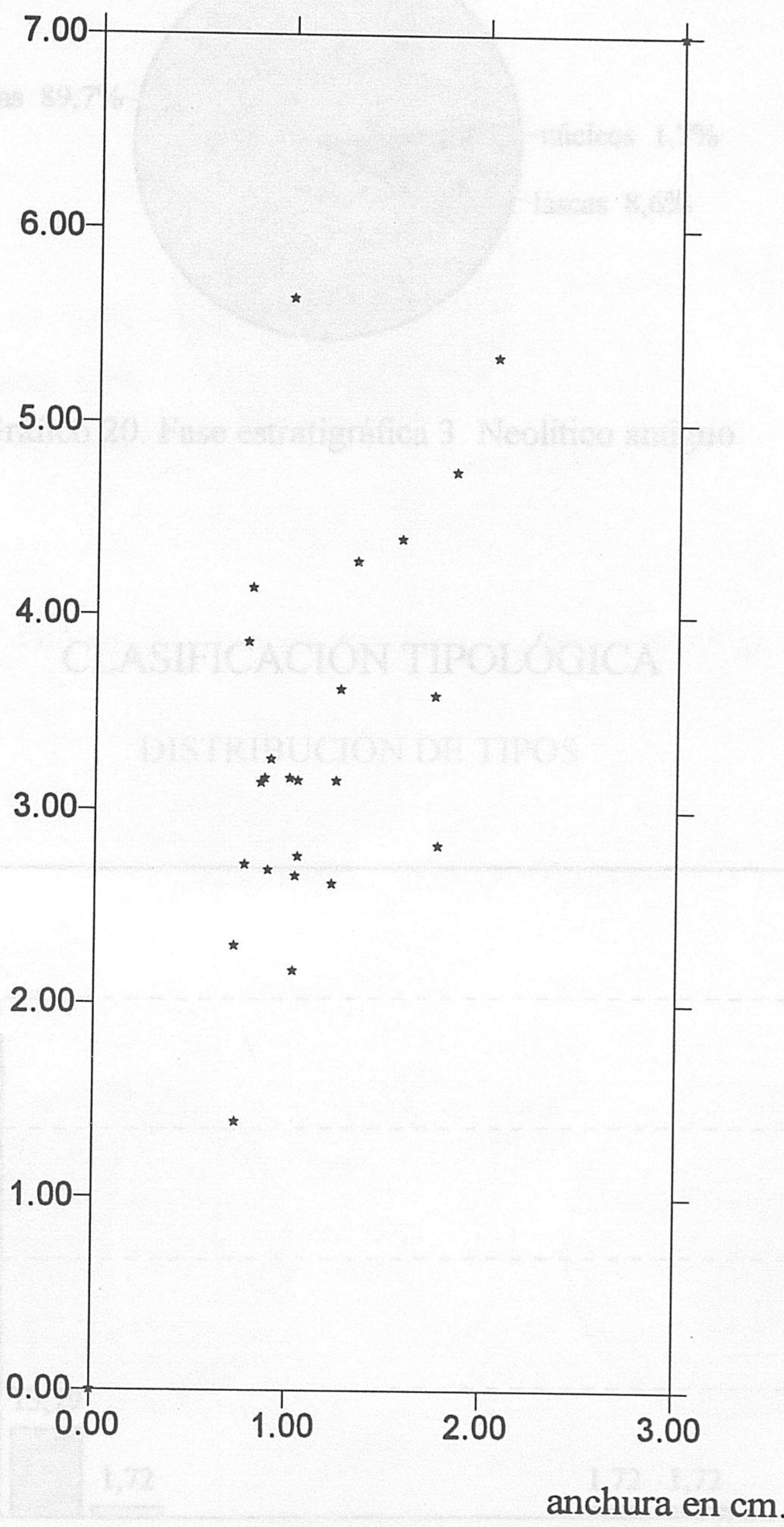

Fase estratigráfica 3. Hojas prismáticas. Relación longitud anchura Graf. 19 


\section{CLASIFICACIÓN TECNOLÓGICA}

\section{DISTRIBUCIÓN DE SOPORTES}

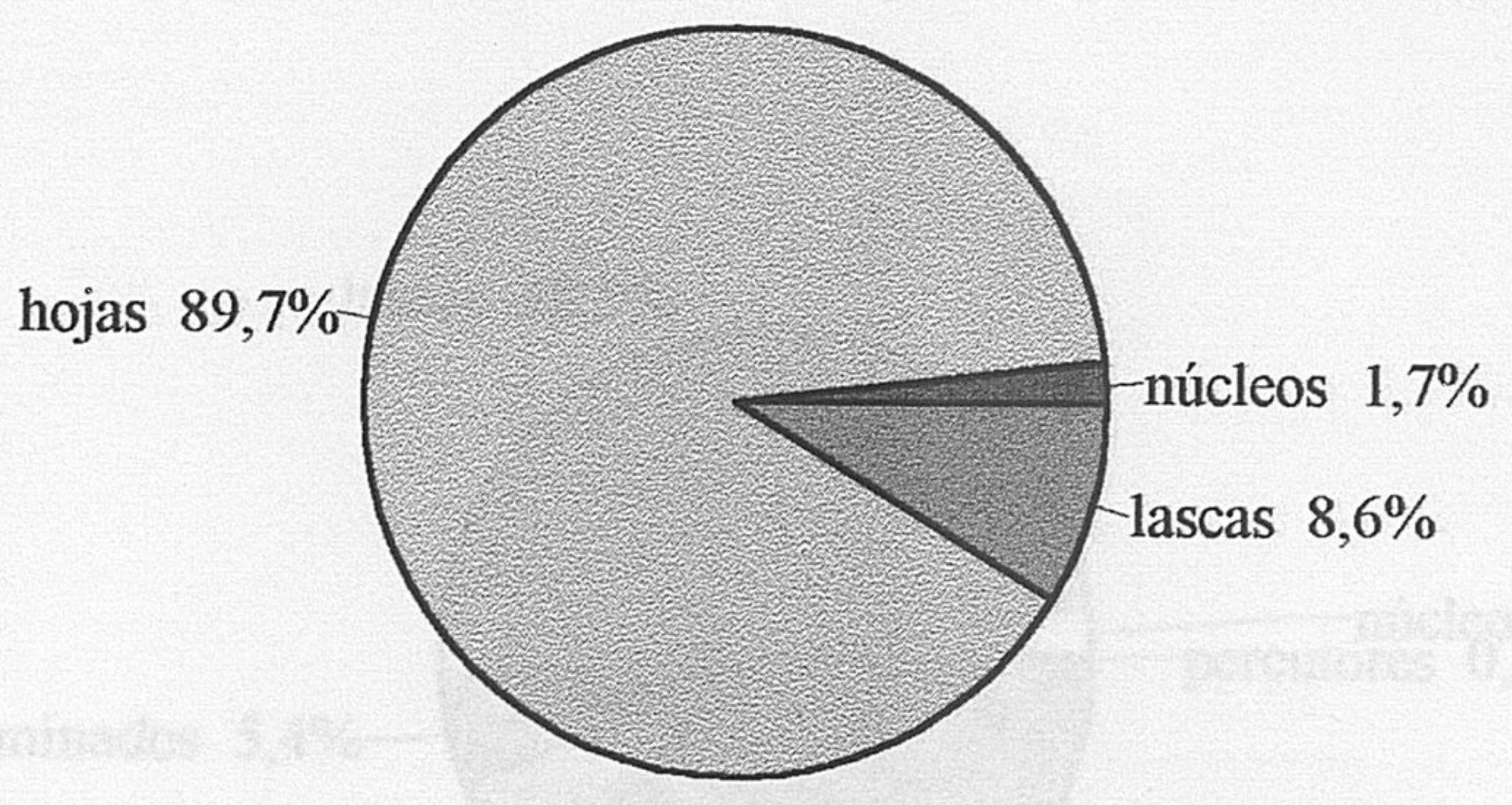

Gráfico 20. Fase estratigráfica 3. Neolítico antiguo

\section{CLASIFICACIÓN TIPOLÓGICA}

\section{DISTRIBUCIÓN DE TIPOS}

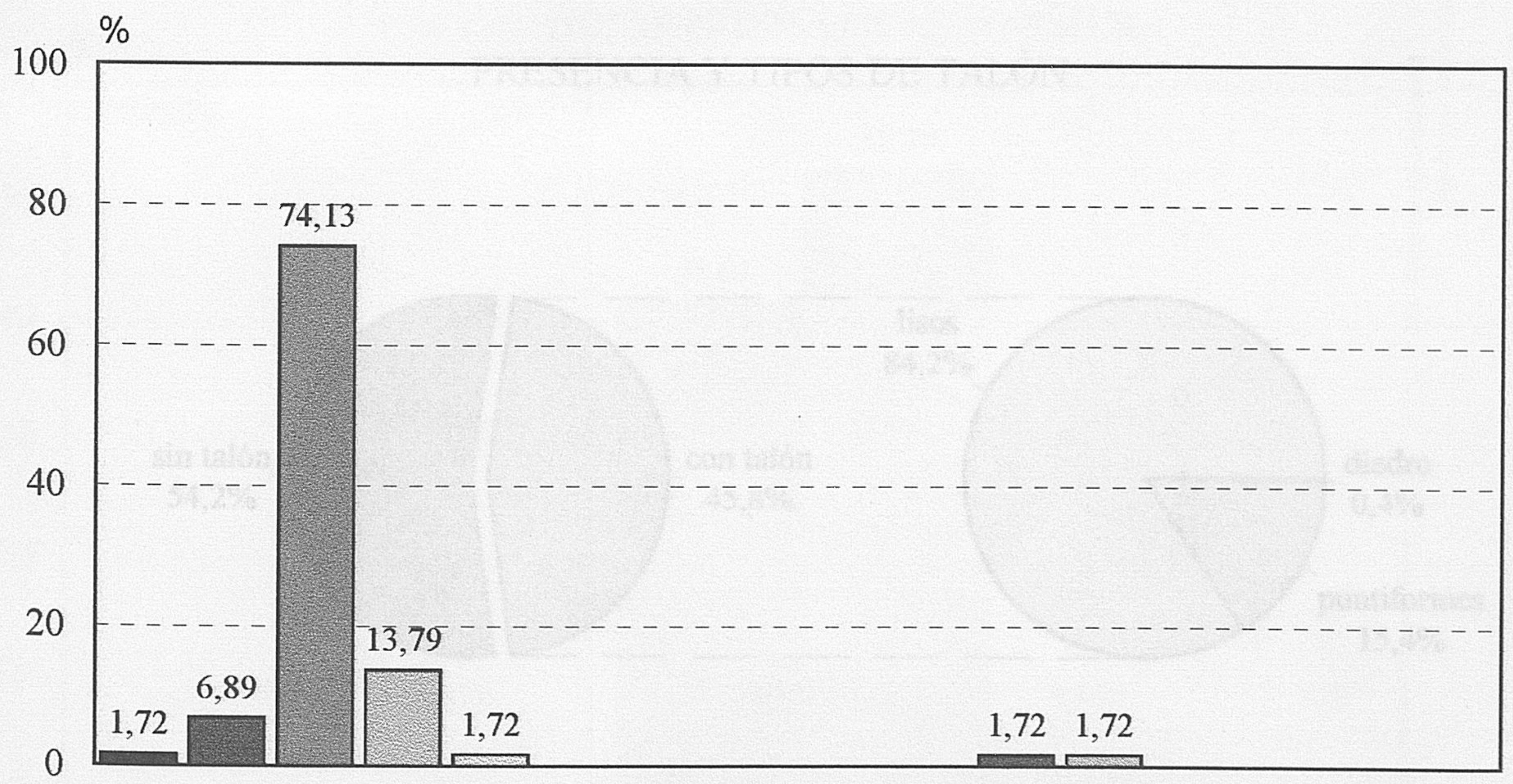

Tipo 1a Tipo $1 \mathrm{~b}$ Tipo 2a Tipo 2b Tipo 3 Tipo 4 Tipo 5 Tipo 6 Tipo 7 Tipo 8 Tipo 9 Tipo 10 Tipo 11 Tipo 12 Tipo 13 Tipo 14

Gráfico 21. Fase estratigráfica 3. Neolítico antiguo 


\section{CLASIFICACIÓN TECNOLÓGICA}

\section{DISTRIBUCION DE LA INDUSTRIA}

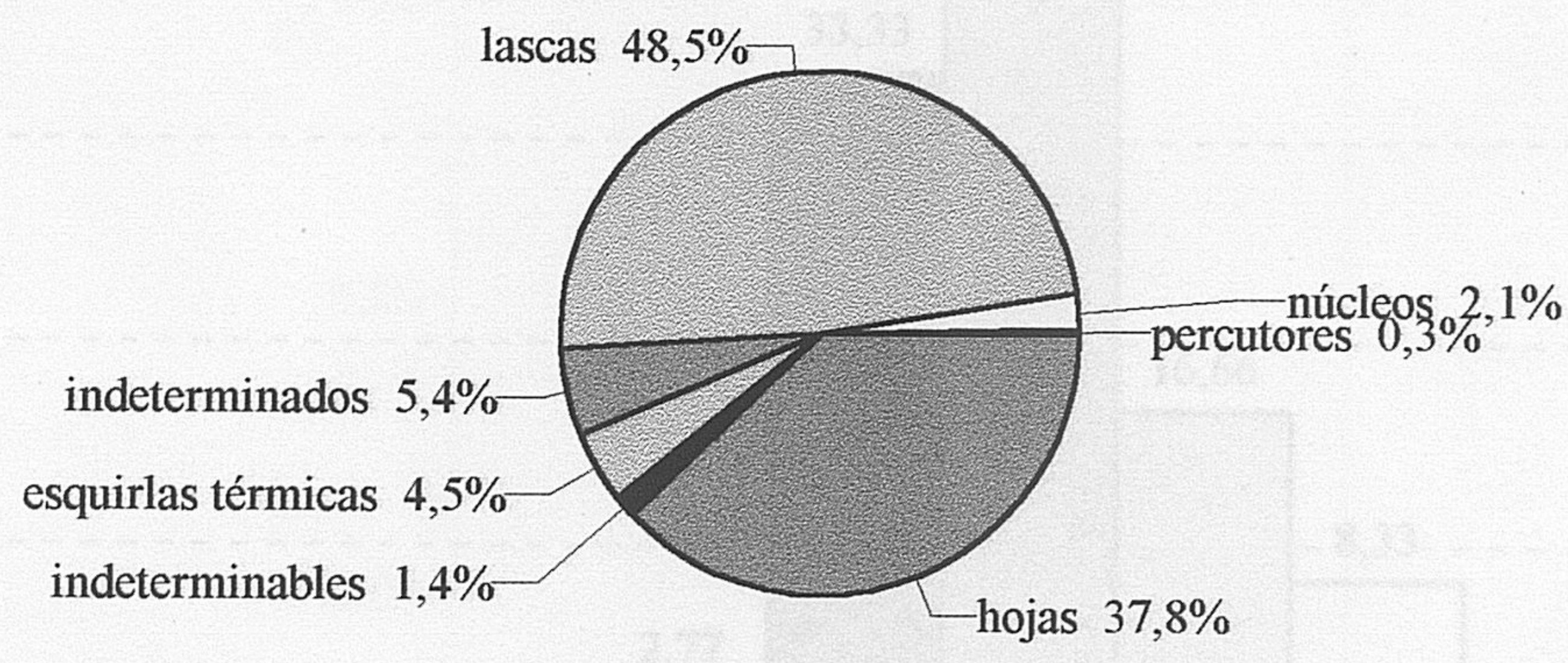

Gráfico 22. Fase estratigráfica 4a. Neolítico antiguo

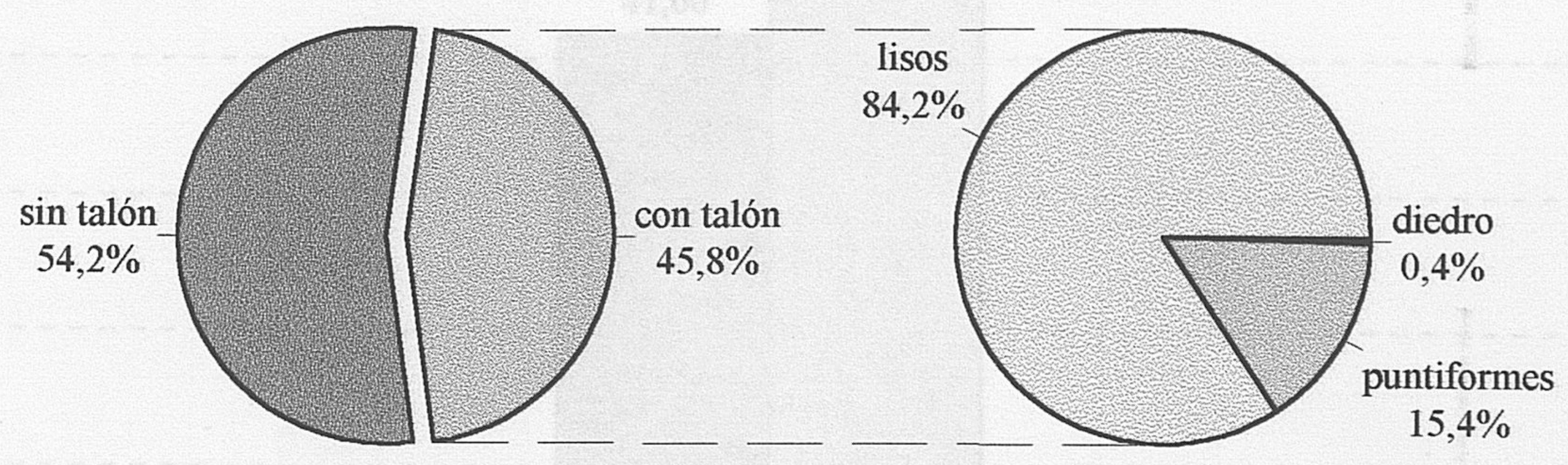

Gráfico 23. Fase estratigráfica 4a. Neolítico antiguo 


\section{CLASIFICACIÓN TECNOLÓGICA}

\section{HOJAS PRISMÁTICAS. LONGITUDES}

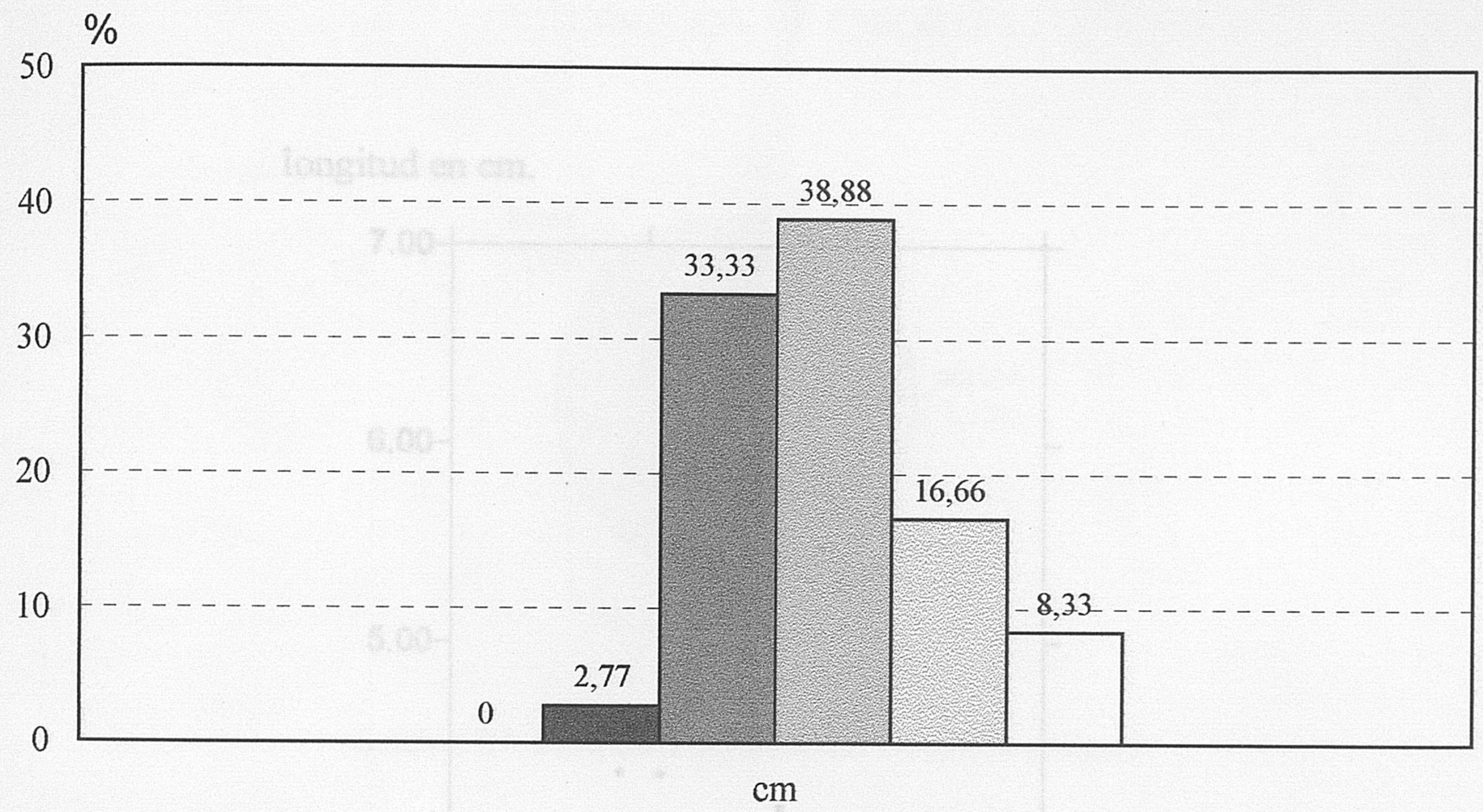

$0-1 \quad 1-2 \quad 2-3 \quad 3-4 \quad 4-5 \quad 5-6$

Gráfico 24. Fase estratigráfica 4a. Neolítico antiguo

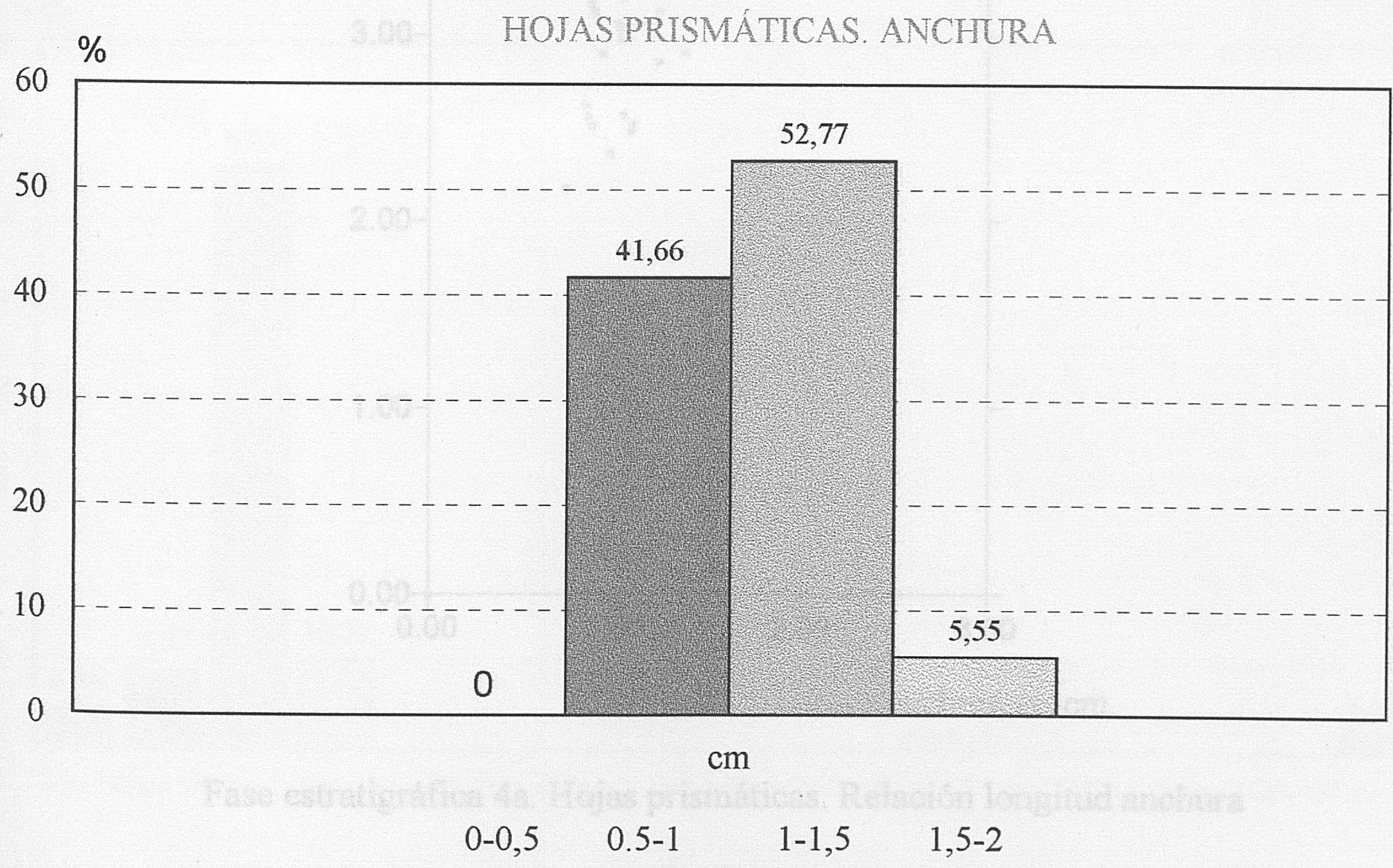

Gráfico 25. Fase estratigráfica 4a. Neolítico antiguo 
longitud en $\mathrm{cm}$.

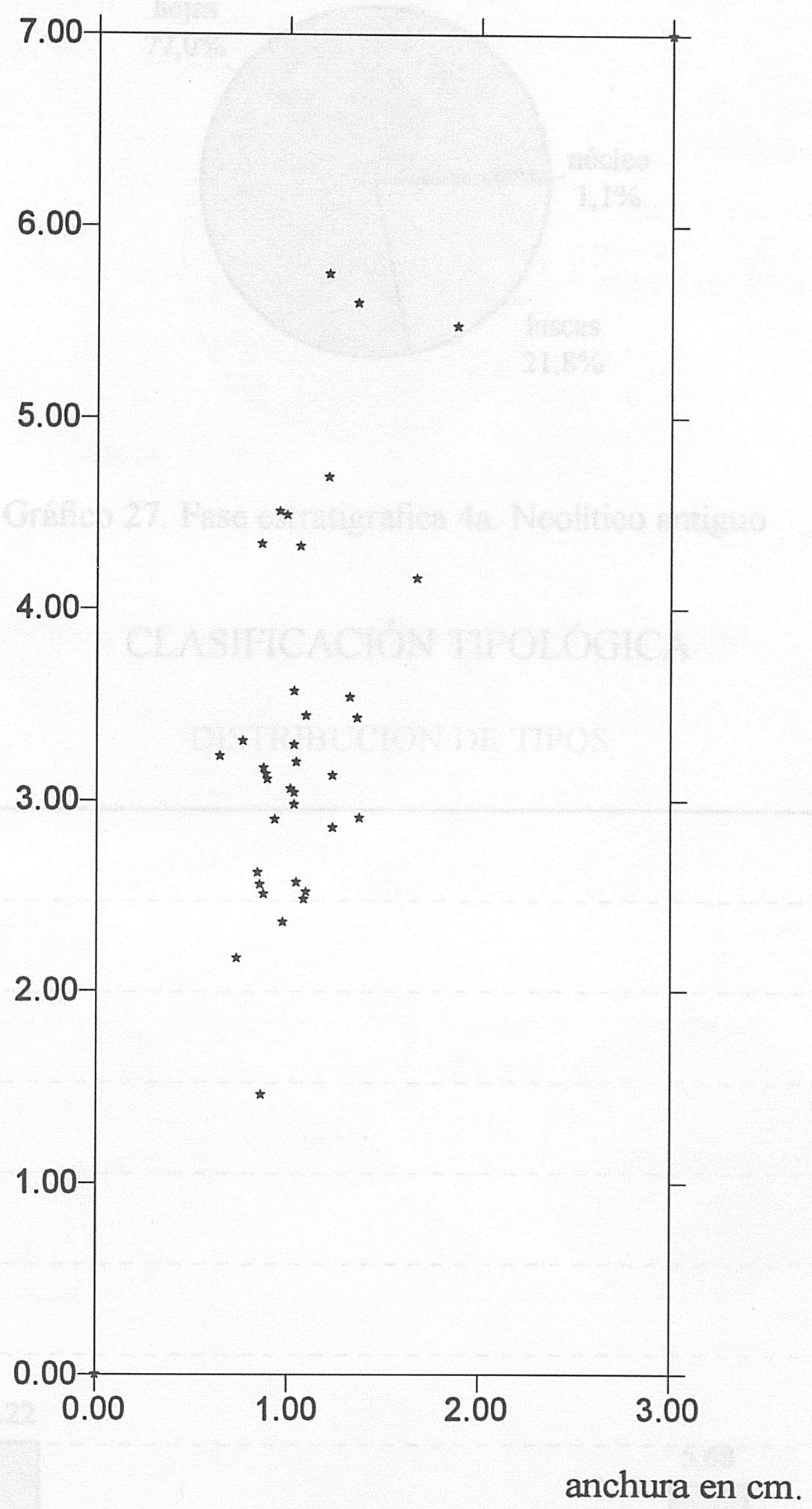

Fase estratigráfica 4a. Hojas prismáticas. Relación longitud anchura Graf. 26 


\section{CLASIFICACIÓN TECNOLÓGICA}

\section{DISTRIBUCIÓN DE SOPORTES}

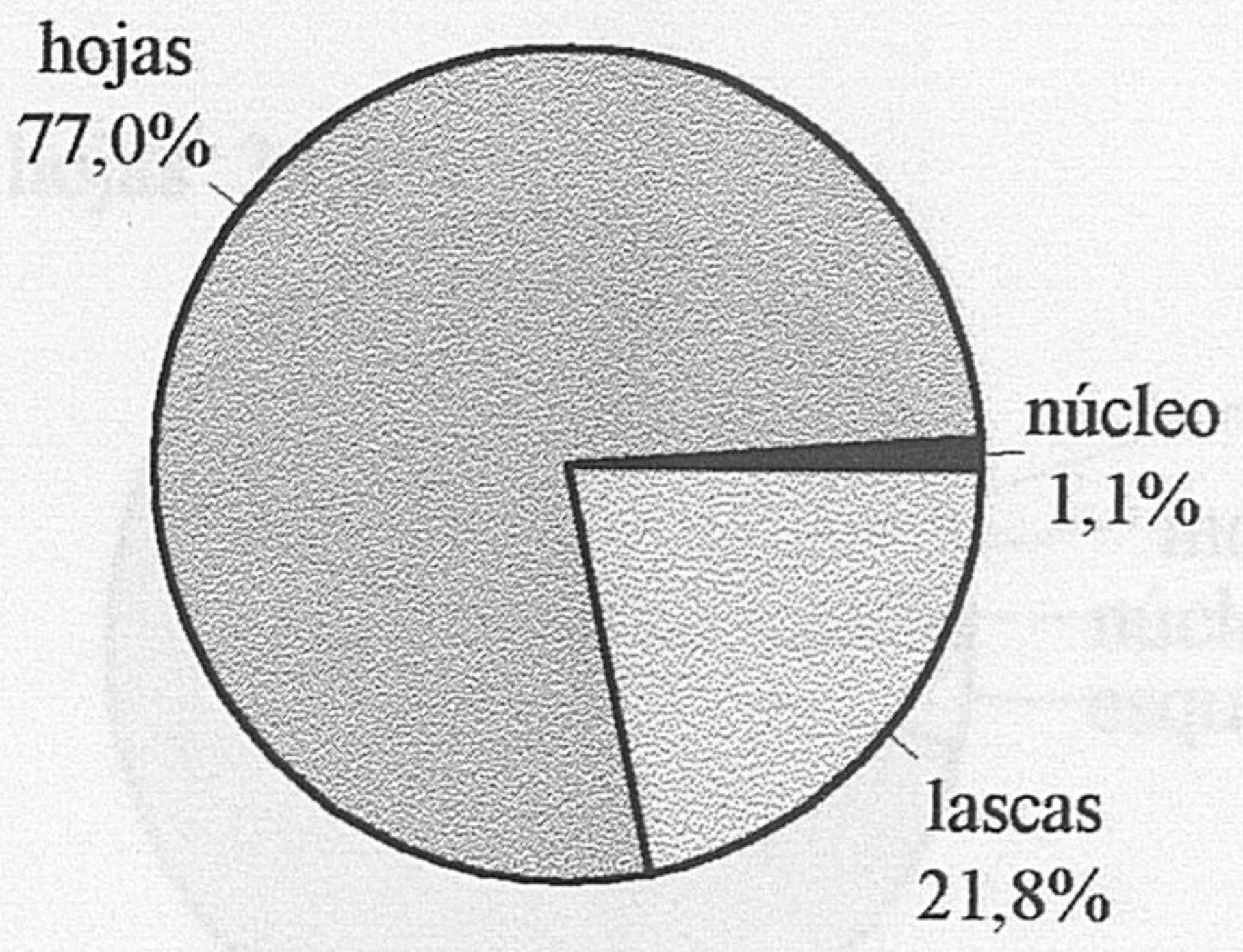

Gráfico 27. Fase estratigráfica 4a. Neolítico antiguo

\section{CLASIFICACIÓN TIPOLÓGICA}

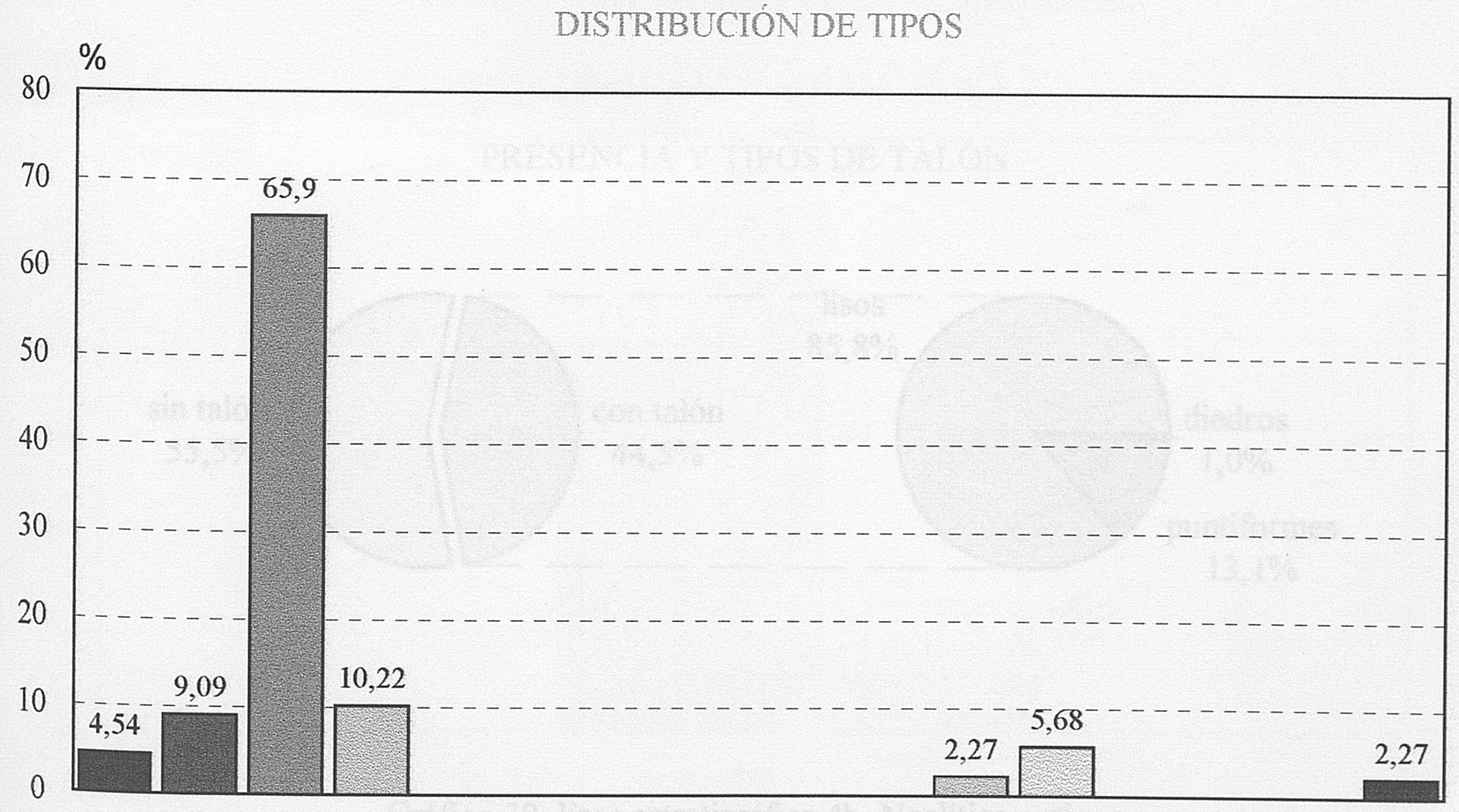

Tipo 1aTipo 1bTipo 2aTipo 2b Tipo 3 Tipo 4 Tipo 5 Tipo 6 Tipo 7 Tipo 8 Tipo 9 Tipo 10Tipo 11Tipo 12Tipo 13Tipo 14

Gráfico 28. Fase estratigráfica 4a. Neolítico antiguo 


\section{CLASIFICACIÓN TECNOLÓGICA}

\section{DISTRIBUCION DE LA INDUSTRIA}

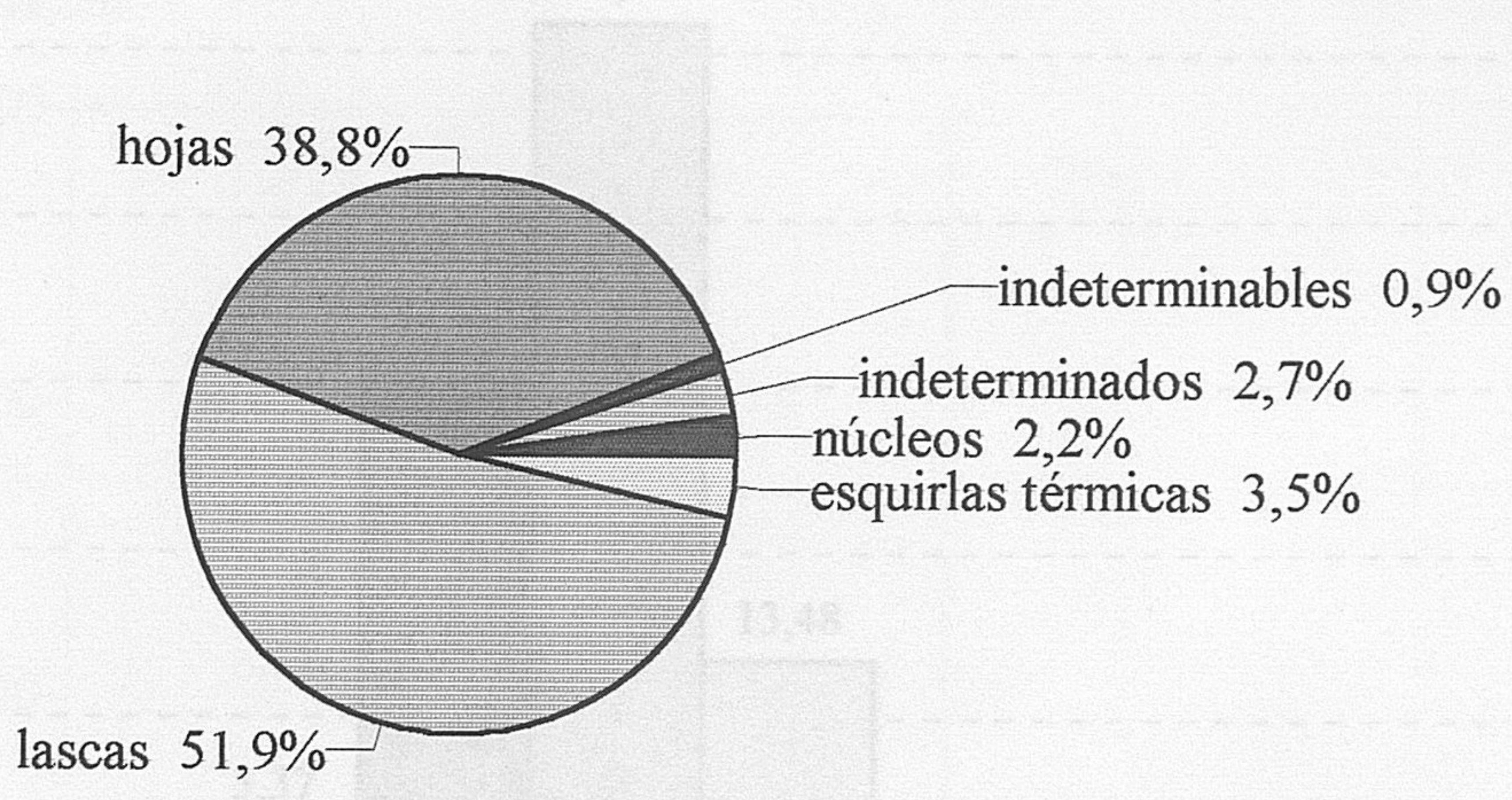

Gráfico 29. Fase estratigráfica 4b. Neolítico antiguo

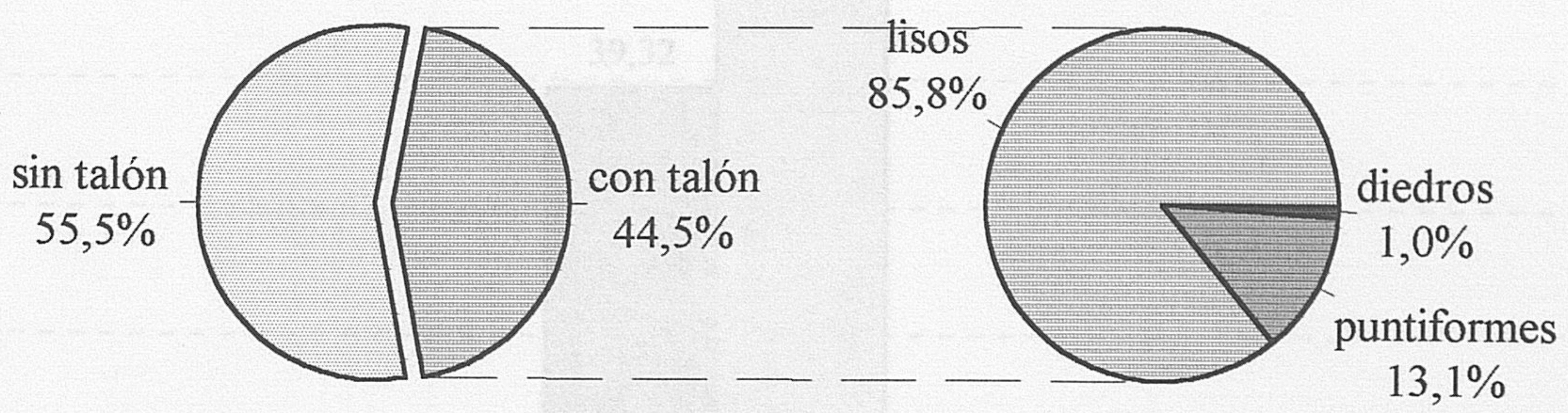

Gráfico 30. Fase estratigráfica 4b. Neolítico antiguo 
CLASIFICACIÓN TECNOLÓGICA

HOJAS PRISMÁTICAS

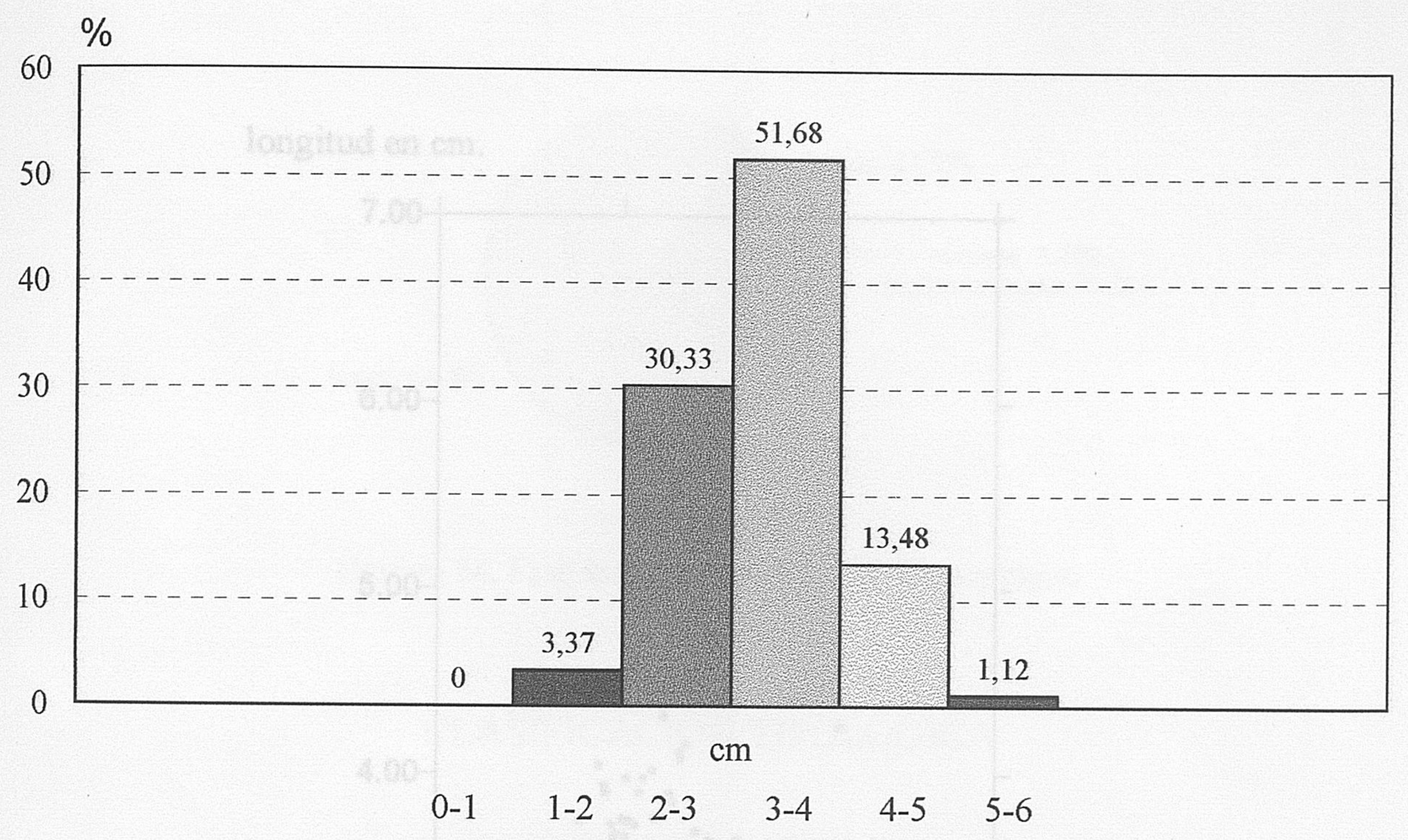

Gráfico 31. Fase estratigráfica 4b. Neolítico antiguo

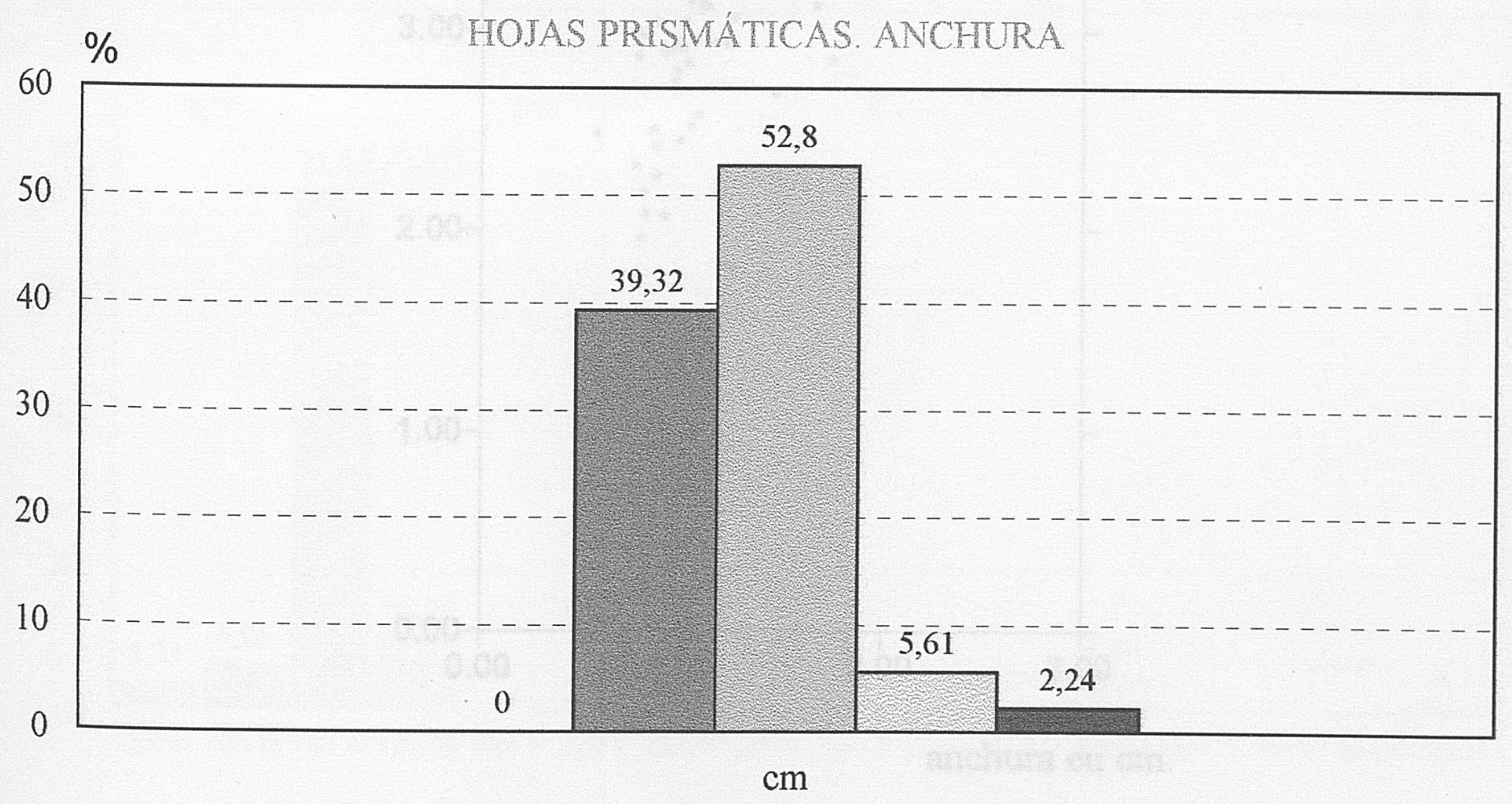

$$
\begin{array}{lllll}
0-0.5 & 0,5-1 & 1-1,5 & 1,5-2 & 2-2,5
\end{array}
$$

Gráfico 32. Fase estratigráfica 4b. Neolítico antiguo 
longitud en $\mathrm{cm}$.

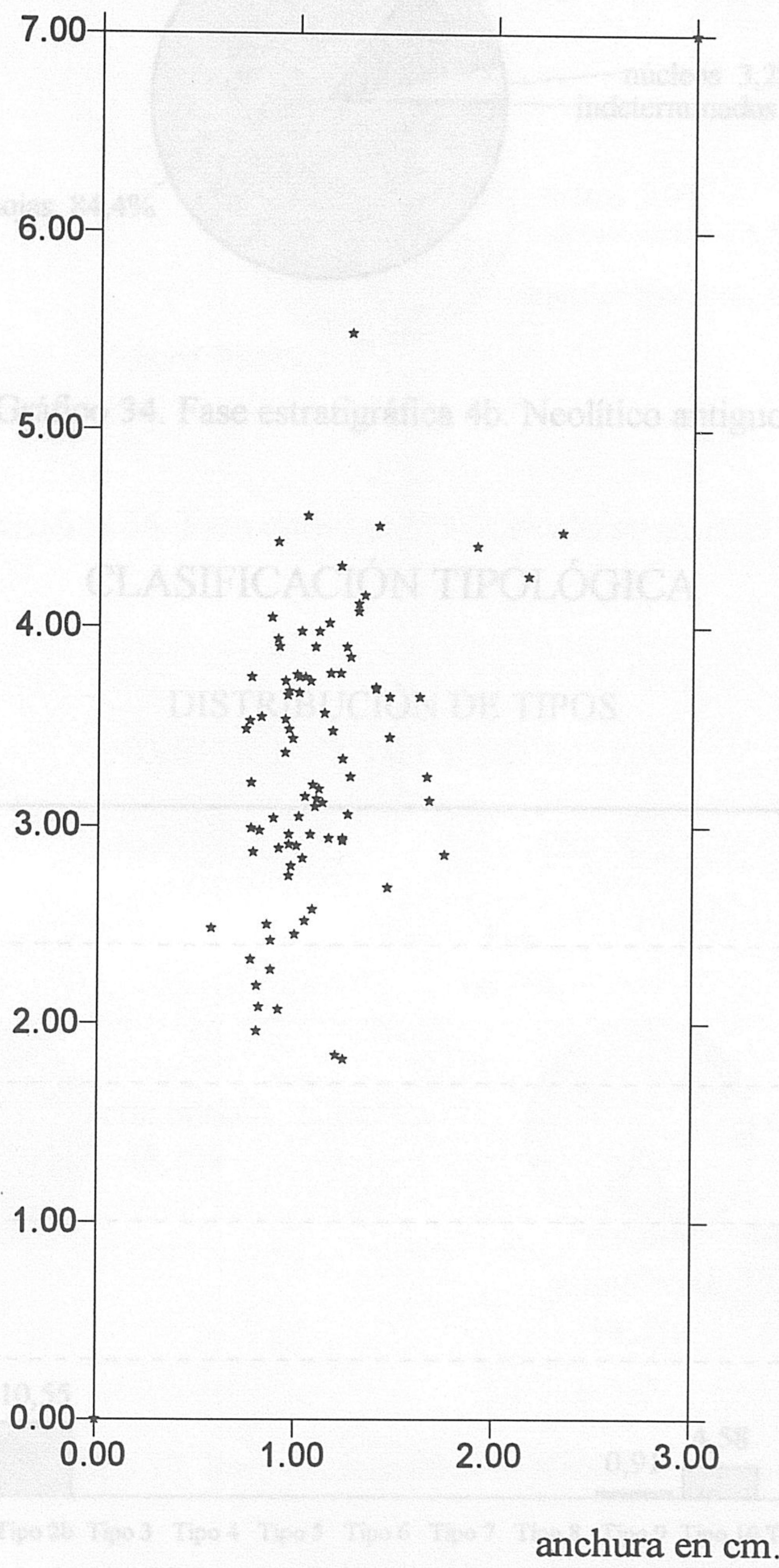

Fase estratigráfica 4b. Hojas prismáticas. Relación longitud anchura

Graf. 33 


\section{CLASIFICACIÓN TECNOLÓGICA}

\section{DISTRIBUCIÓN DE SOPORTES}

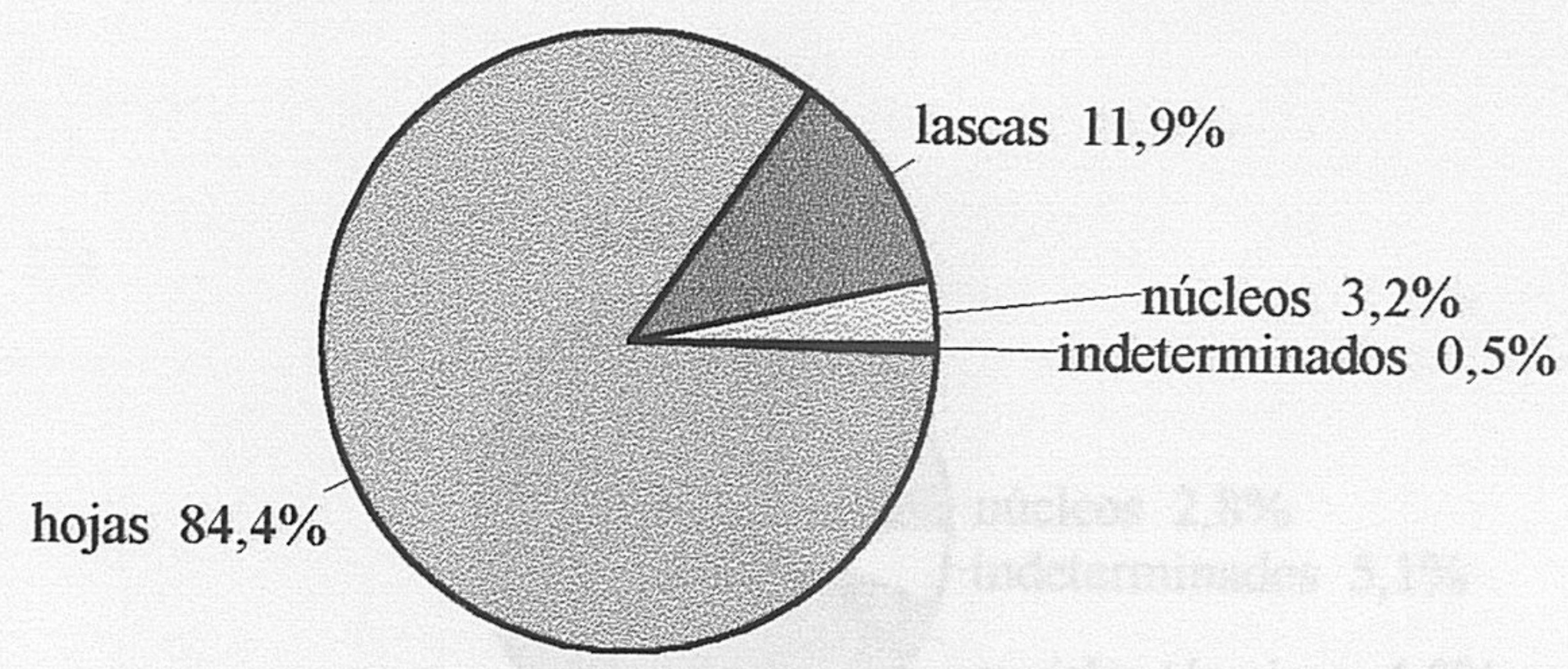

Gráfico 34. Fase estratigráfica 4b. Neolítico antiguo

\section{CLASIFICACIÓN TIPOLÓGICA}

\section{DISTRIBUCIÓN DE TIPOS}

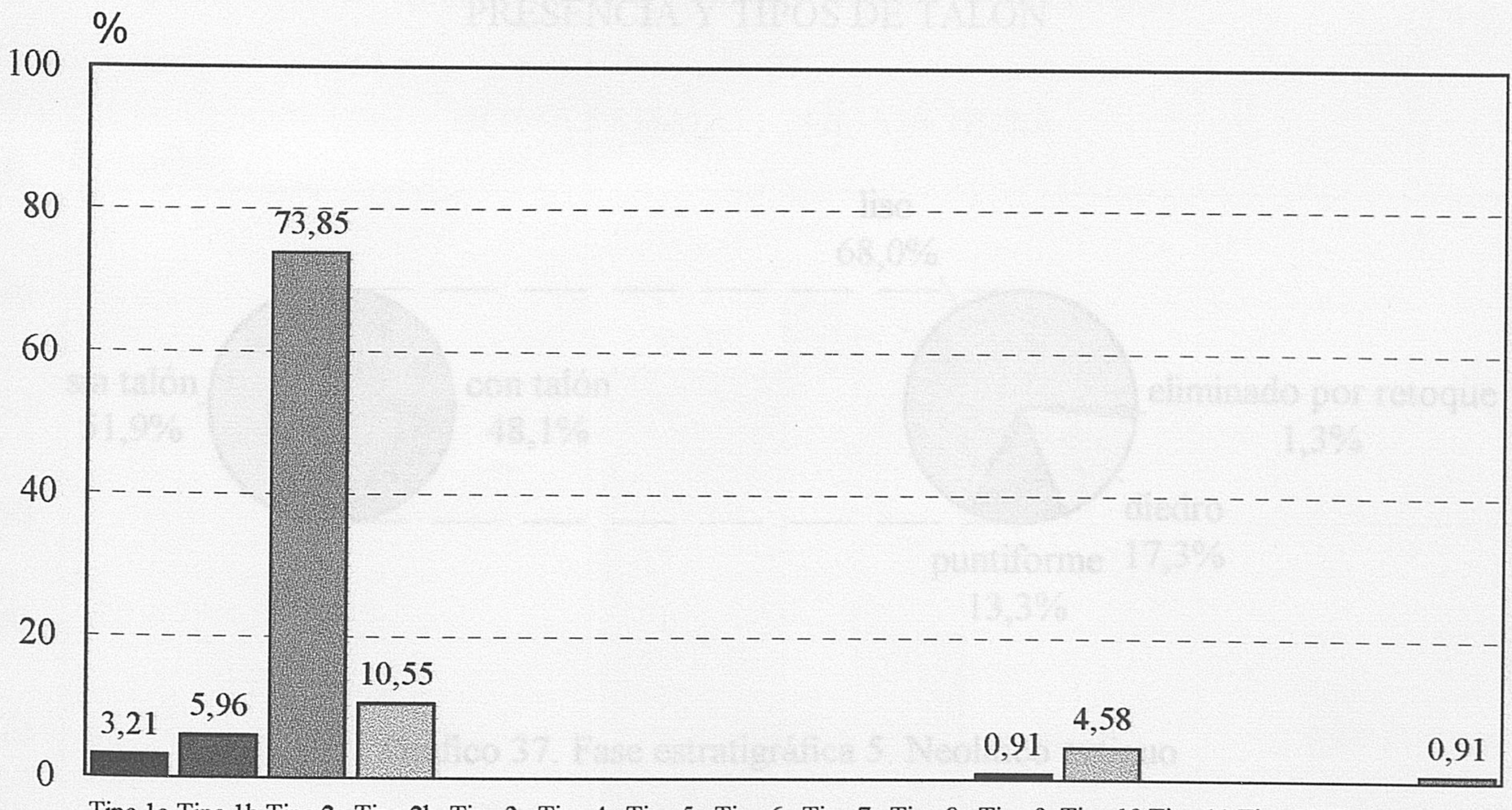

Tipo 1a Tipo $1 \mathrm{~b}$ Tipo 2a Tipo 2b Tipo 3 Tipo 4 Tipo 5 Tipo 6 Tipo 7 Tipo 8 Tipo 9 Tipo 10 Tipo 11 Tipo 12 Tipo 13 Tipo 14

Fase estratigráfica 4b. Neolítico antiguo 


\section{CLASIFICACIÓN TECNOLÓGICA}

\section{TOTAL DE LA INDUSTRIA}

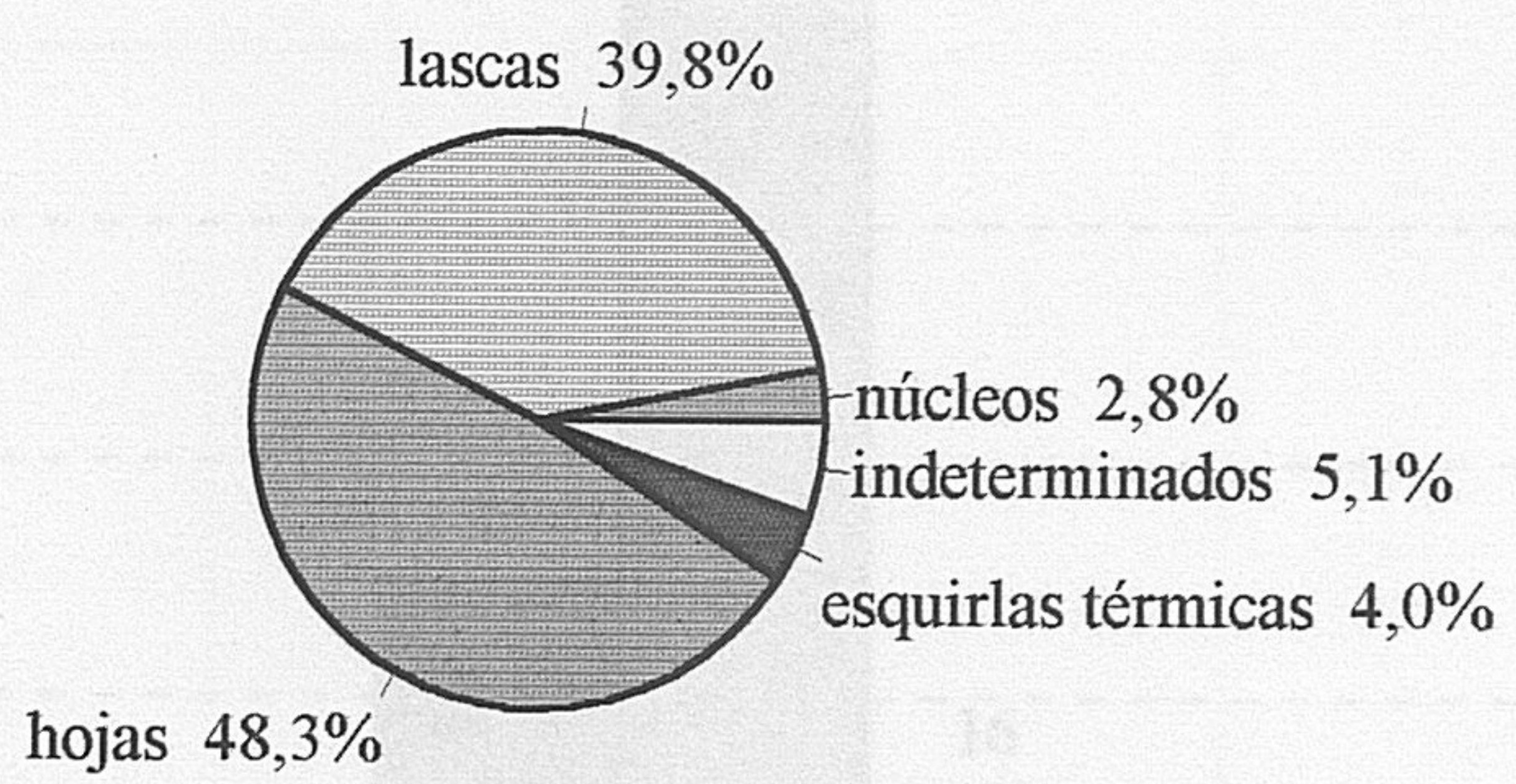

Gráfico 36. Fase estratigráfica 5. Neolítico antiguo

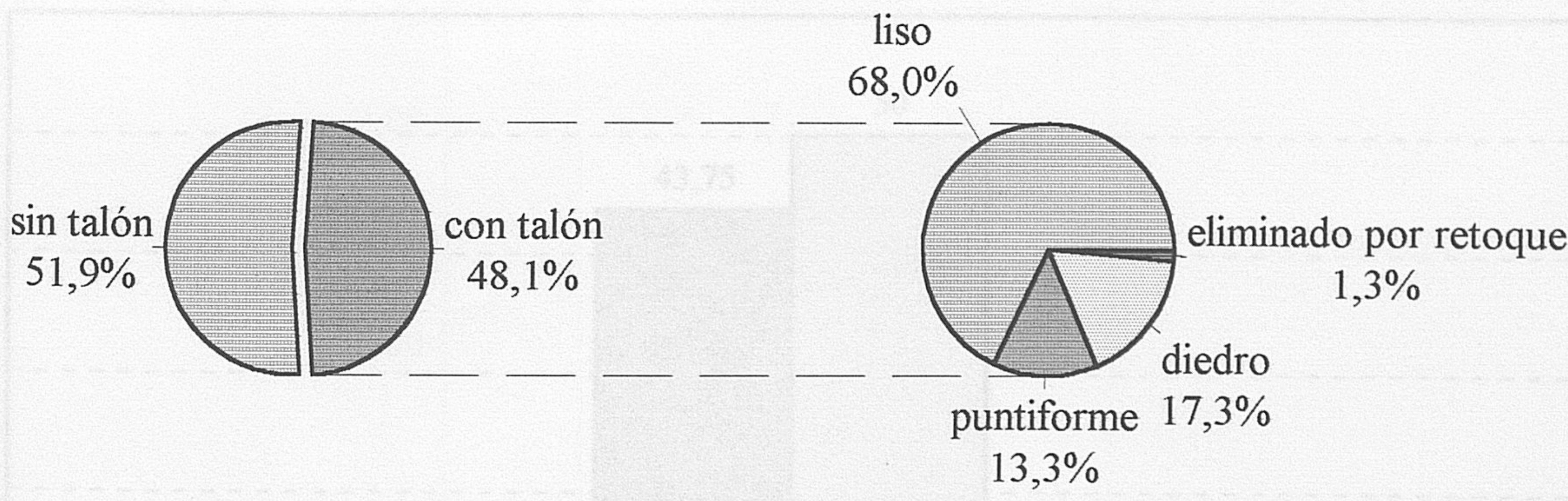

Gráfico 37. Fase estratigráfica 5. Neolítico antiguo 


\section{CLASIFICACIÓN TECNOLÓGICA}

\section{HOJAS PRISMÁTICAS LONGITUDES}

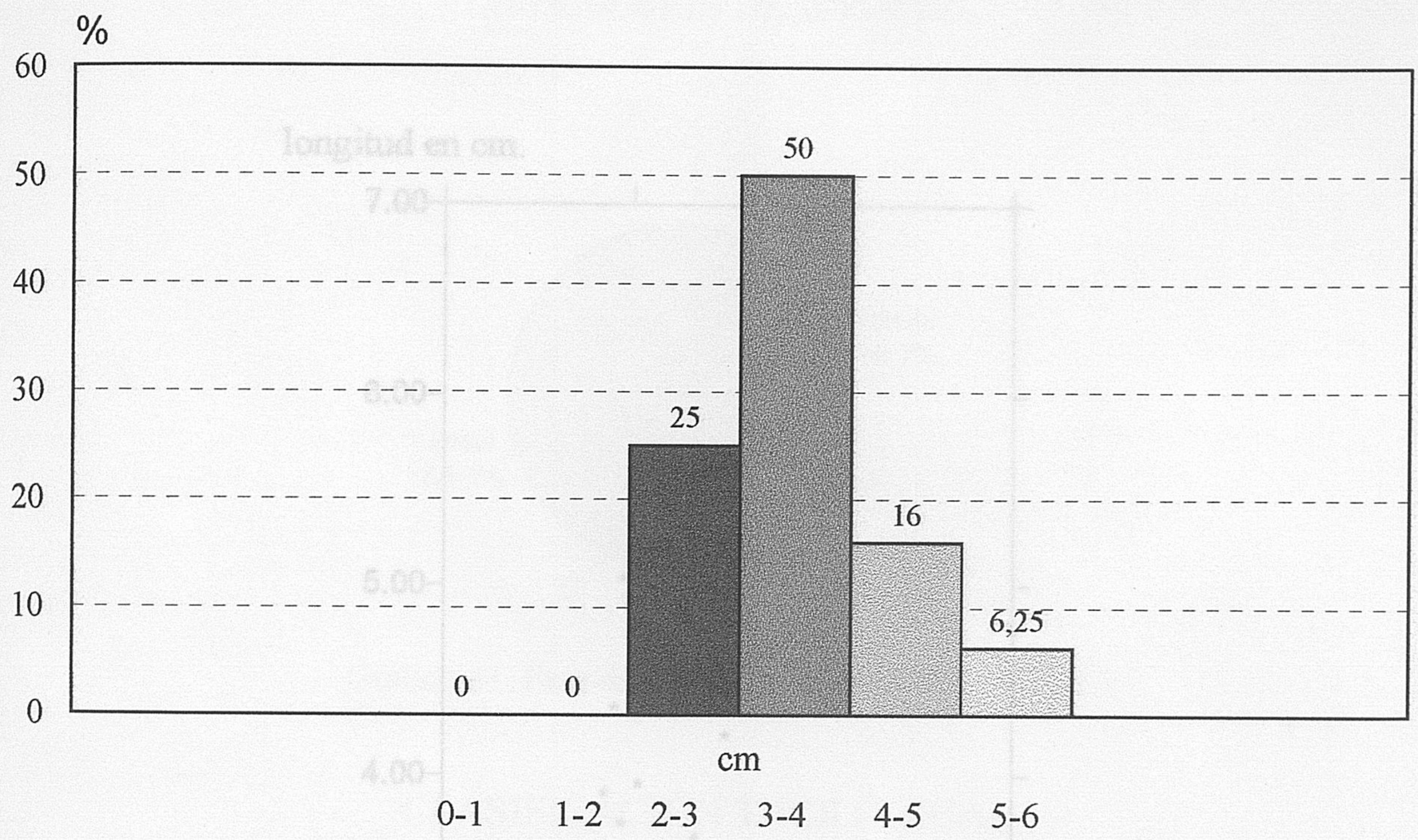

Gráfico 38. fase estratigráfica 5.Neolítico antiguo

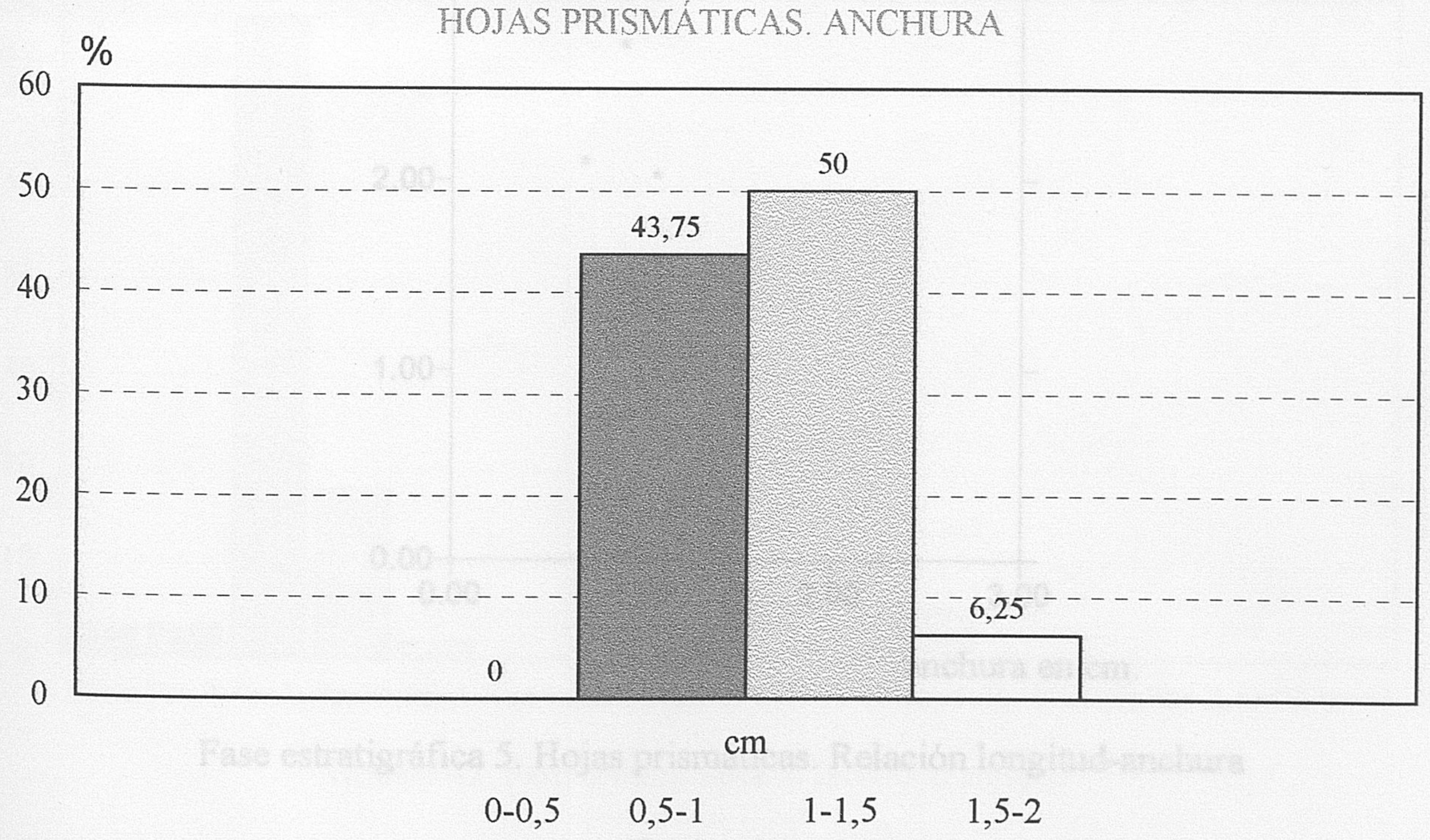

Gráfico 39. Fase estratigráfica 5. Neolítico antiguo 
longitud en $\mathrm{cm}$.

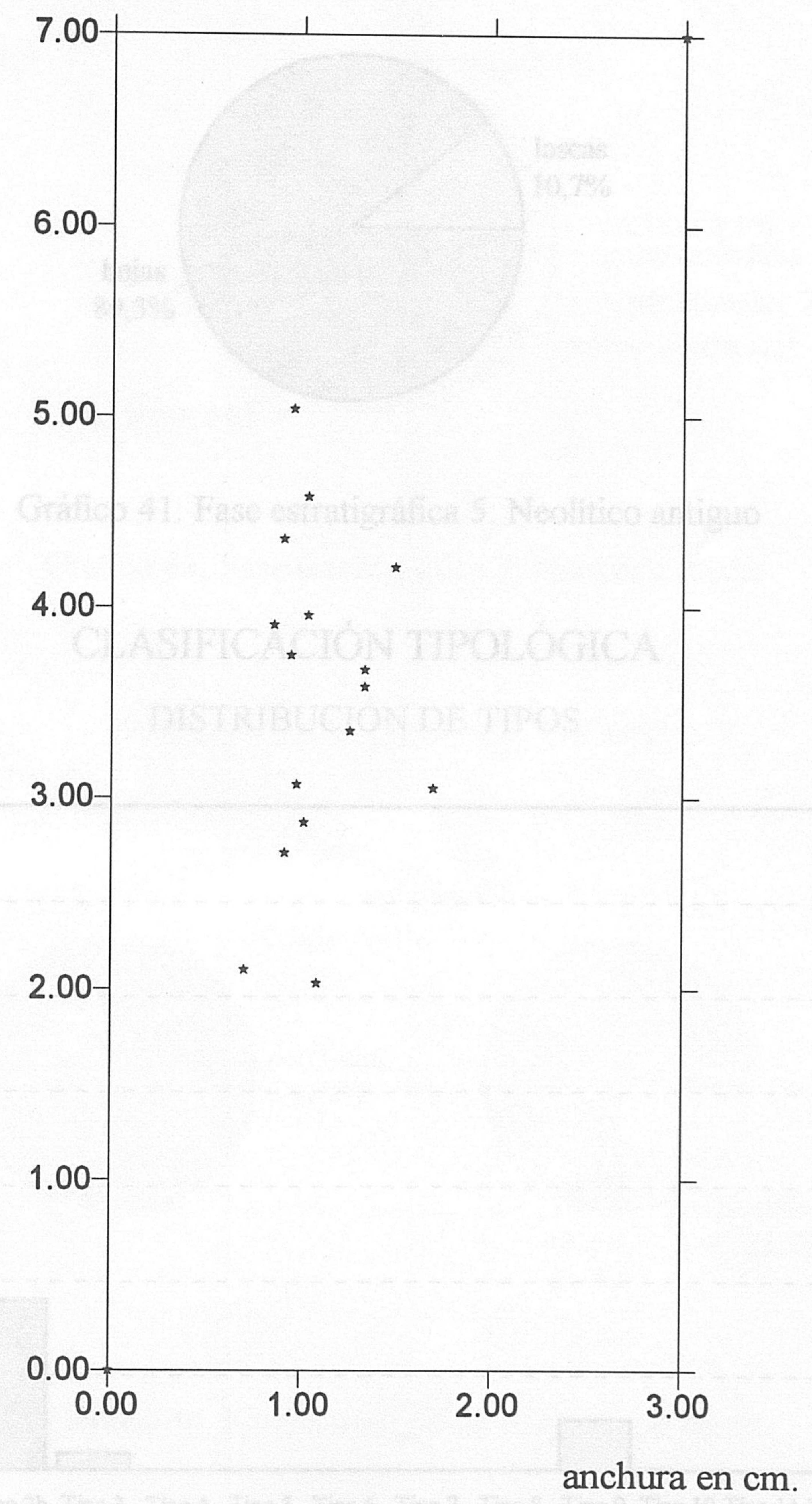

Fase estratigráfica 5. Hojas prismáticas. Relación longitud-anchura 


\section{CLASIFICACIÓN TECNOLÓGICA}

\section{DISTRIBUCIÓN DE SOPORTES}

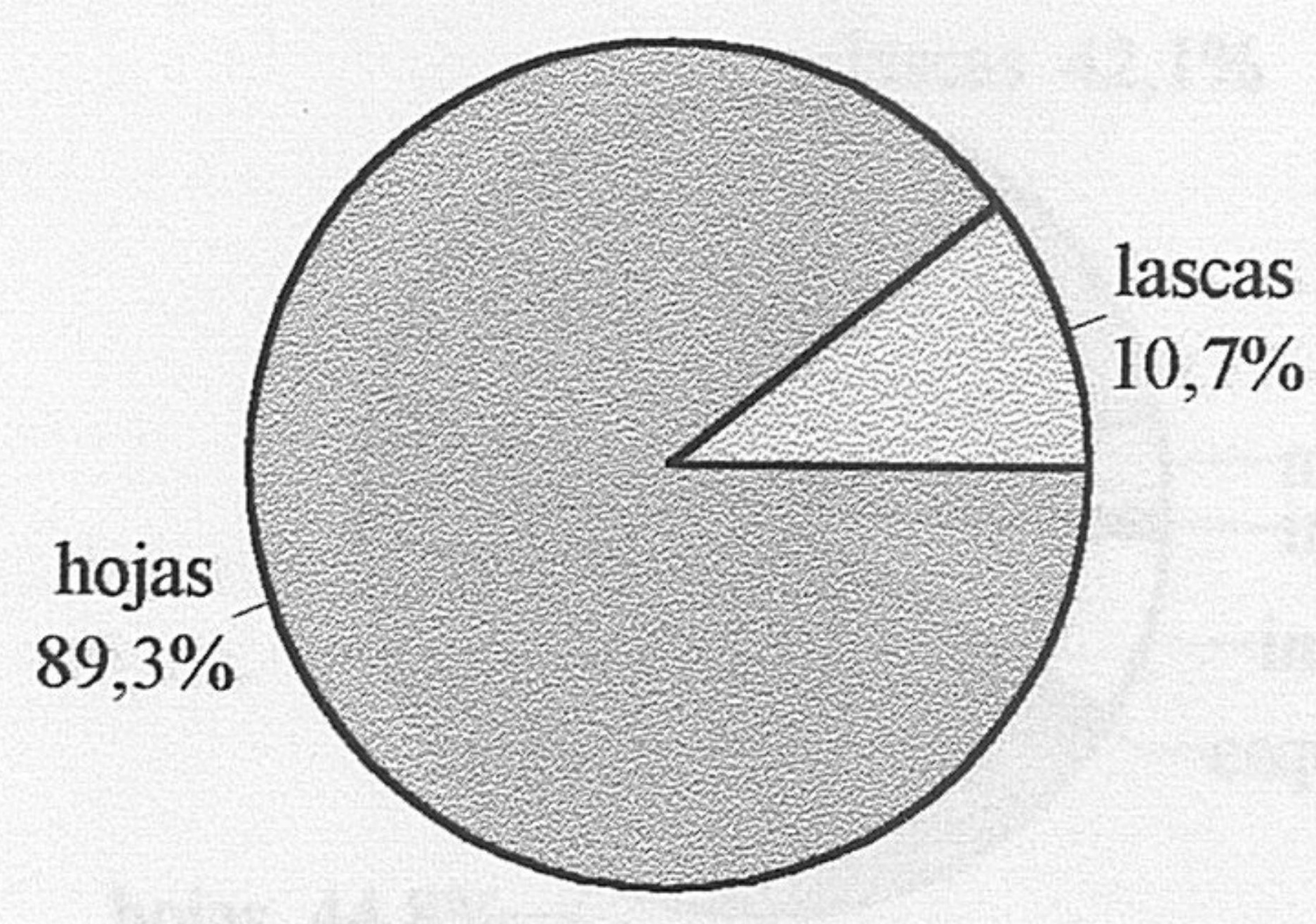

Gráfico 41. Fase estratigráfica 5. Neolítico antiguo

\section{CLASIFICACIÓN TIPOLÓGICA}

DISTRIBUCION DE TIPOS

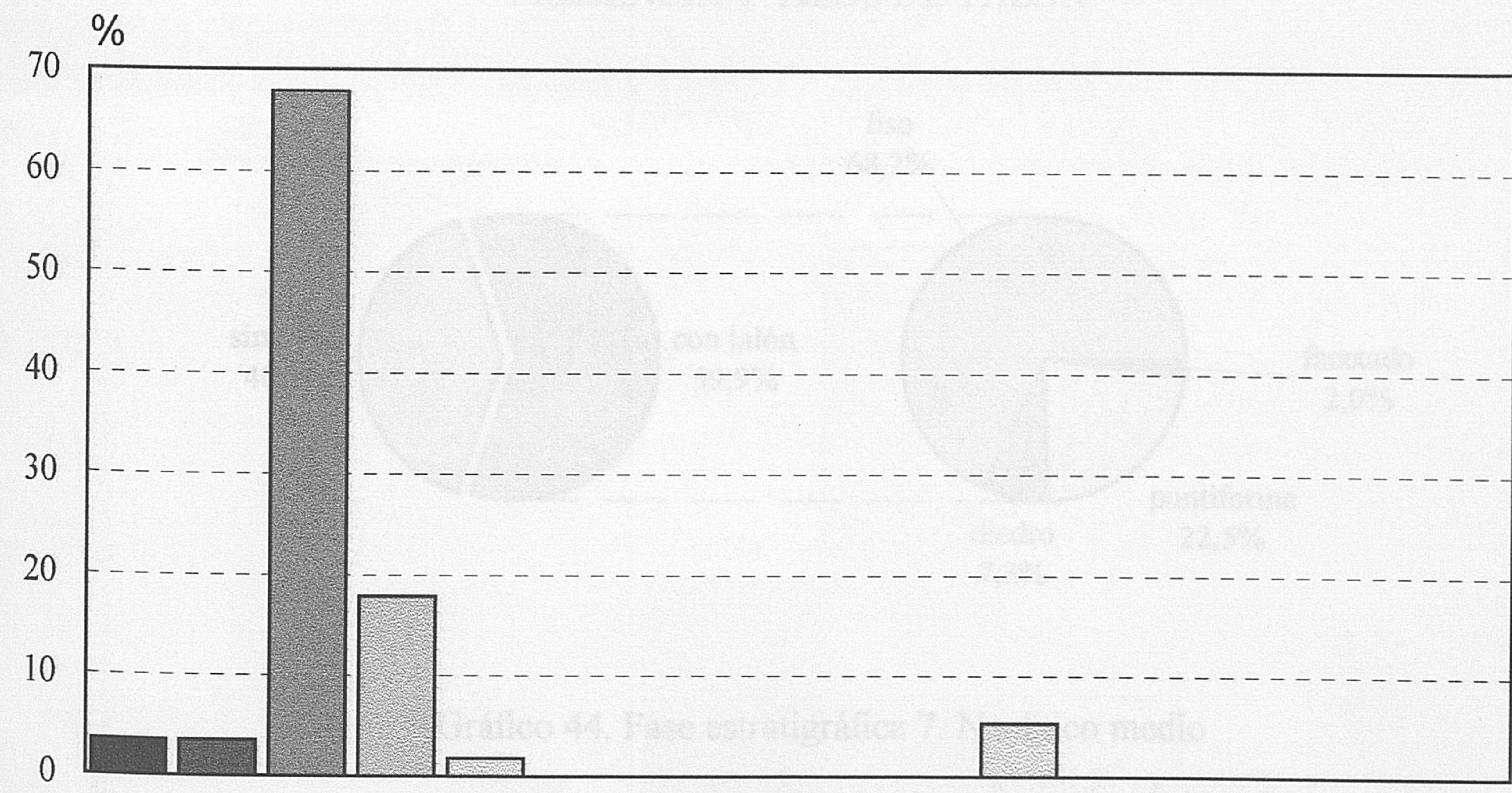

Tipo 1a Tipo 1b Tipo 2a Tipo 2b Tipo 3 Tipo 4 Tipo 5 Tipo 6 Tipo 7 Tipo 8 Tipo 9 Tipo 10 Tipo 11 Tipo 12 Tipo 13 Tipo 14

Gráfico 42. Fase estratigráfica 5. Neolítico antiguo 


\section{CLASIFICACIÓN TECNOLÓGICA}

\section{TOTAL DE LA INDUSTRIA}

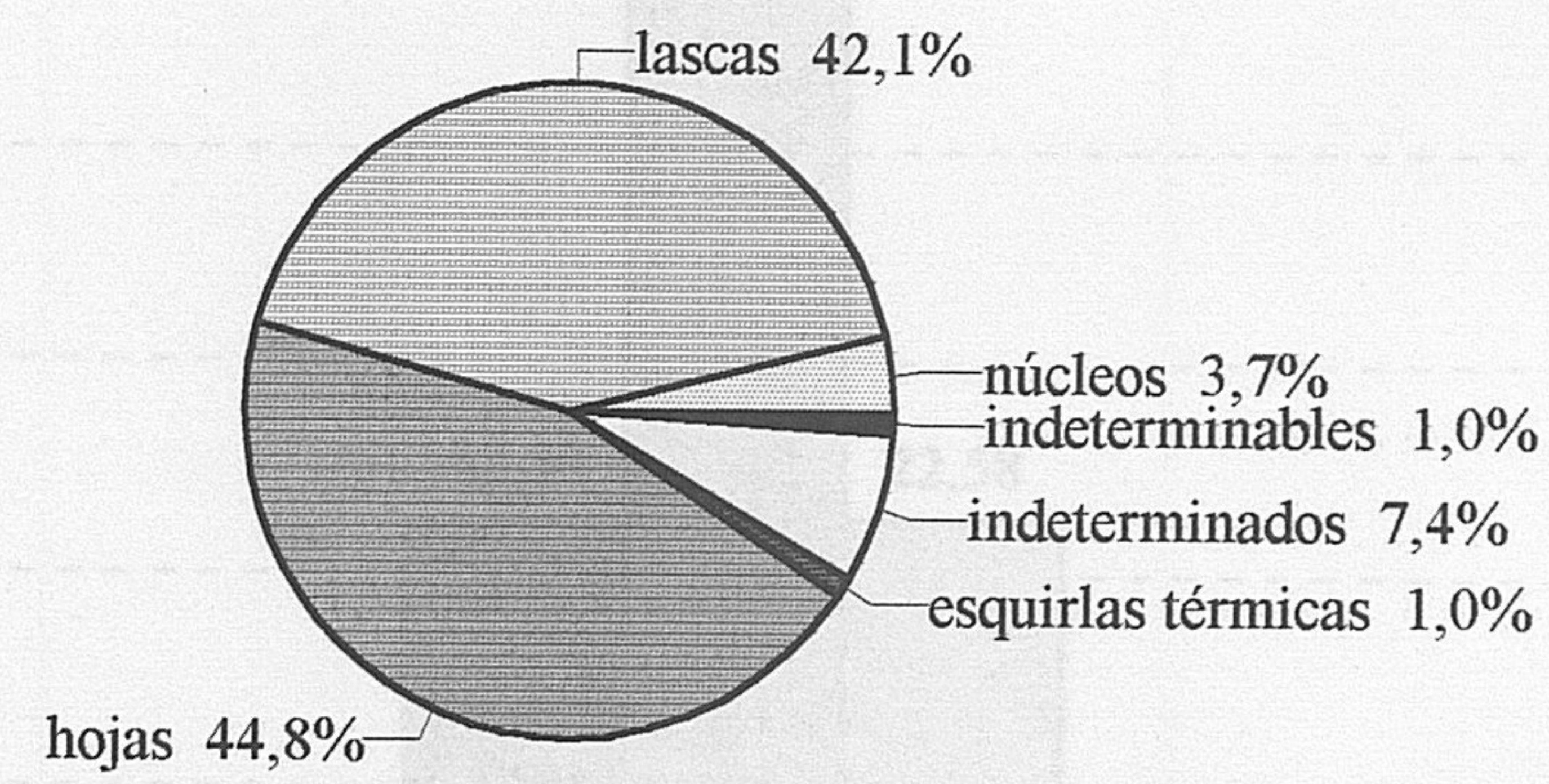

Gráfico 43. Fase estratigráfica 7. Neolítico medio

\section{PRESENCIA Y TIPOS DE TALÓN}

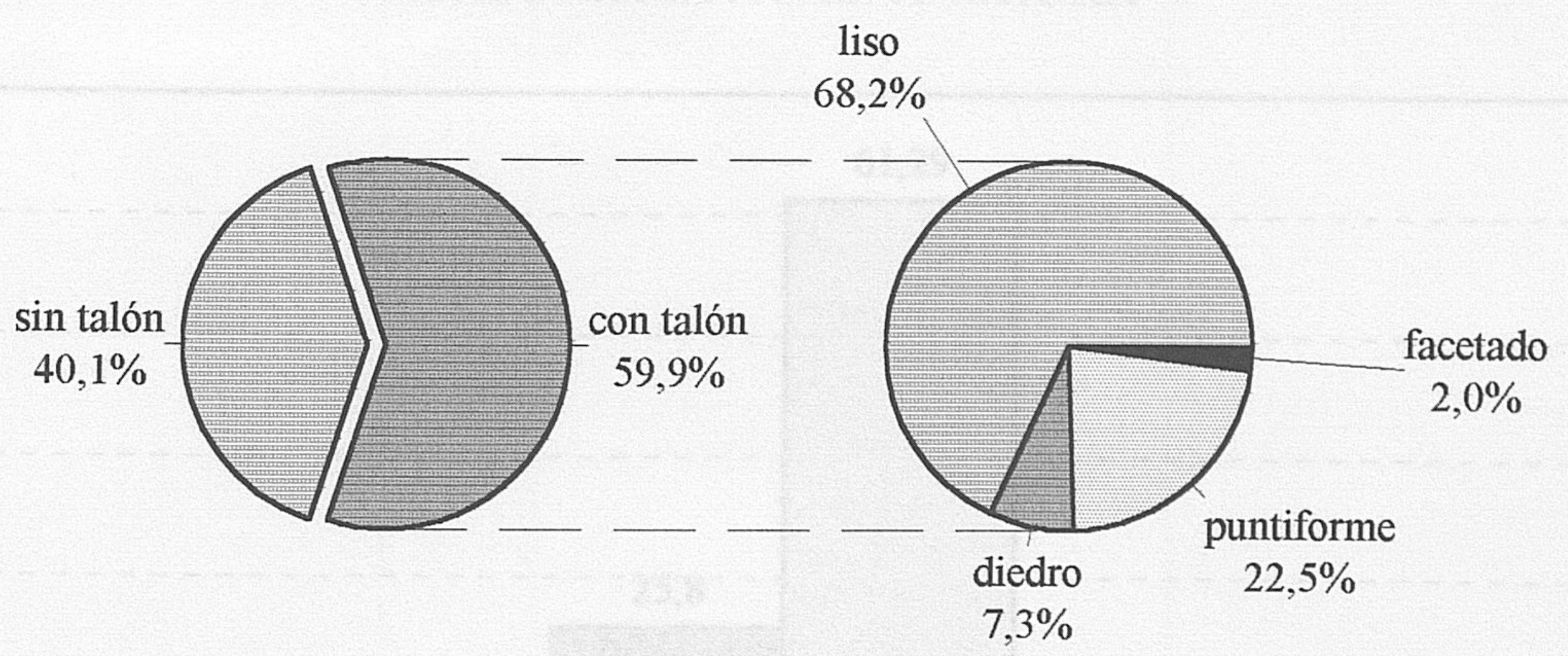

Gráfico 44. Fase estratigráfica 7. Neolítico medio 


\section{CLASIFICACIÓN TECNOLÓGICA}

\section{HOJAS PRISMÁTICAS LONGITUDES}

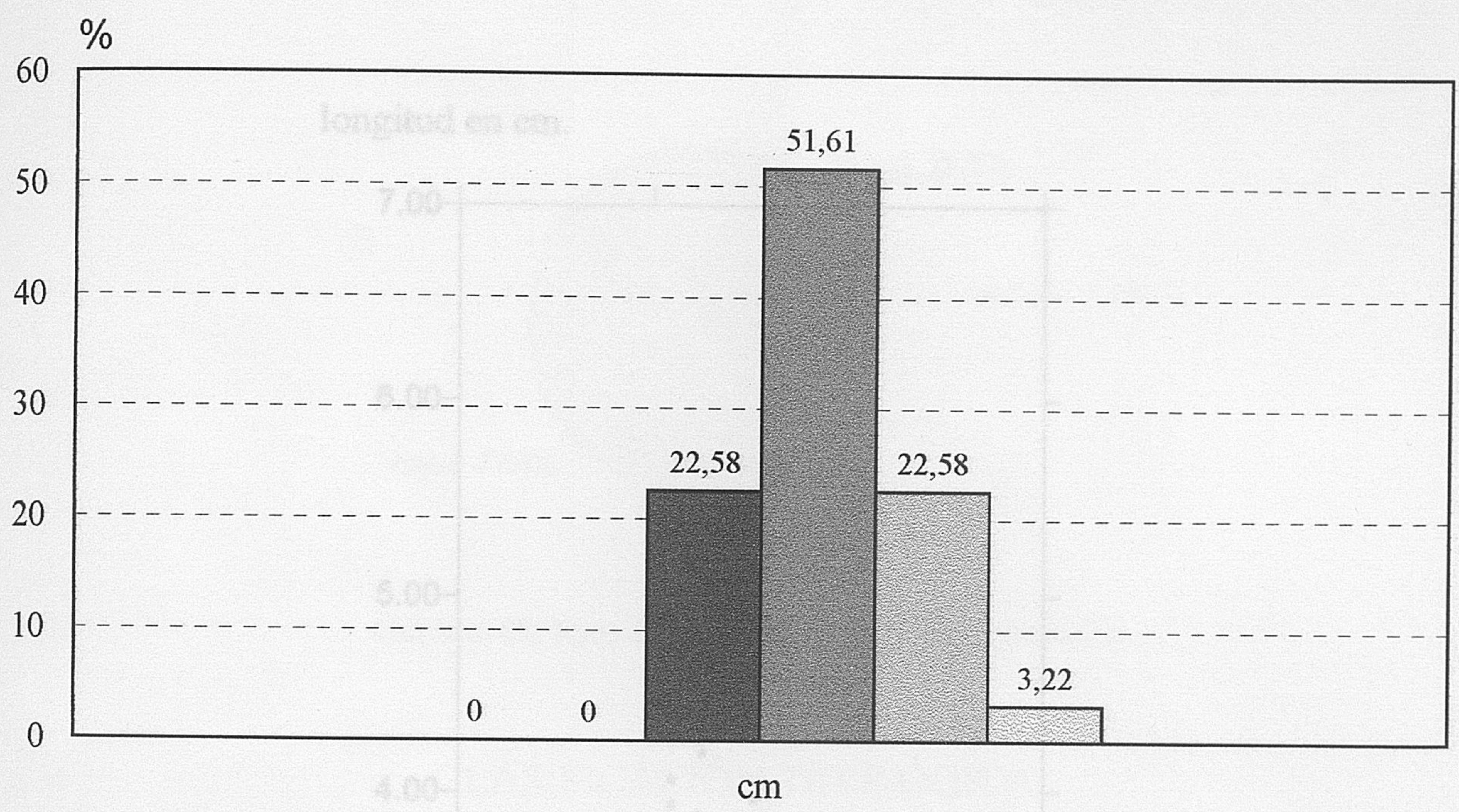

$\begin{array}{llllll}0-1 & 1-2 & 2-3 & 3-4 & 4-5 & 5-6\end{array}$

Gráfico 45. Fase estratigráfica 7. Neolítico medio

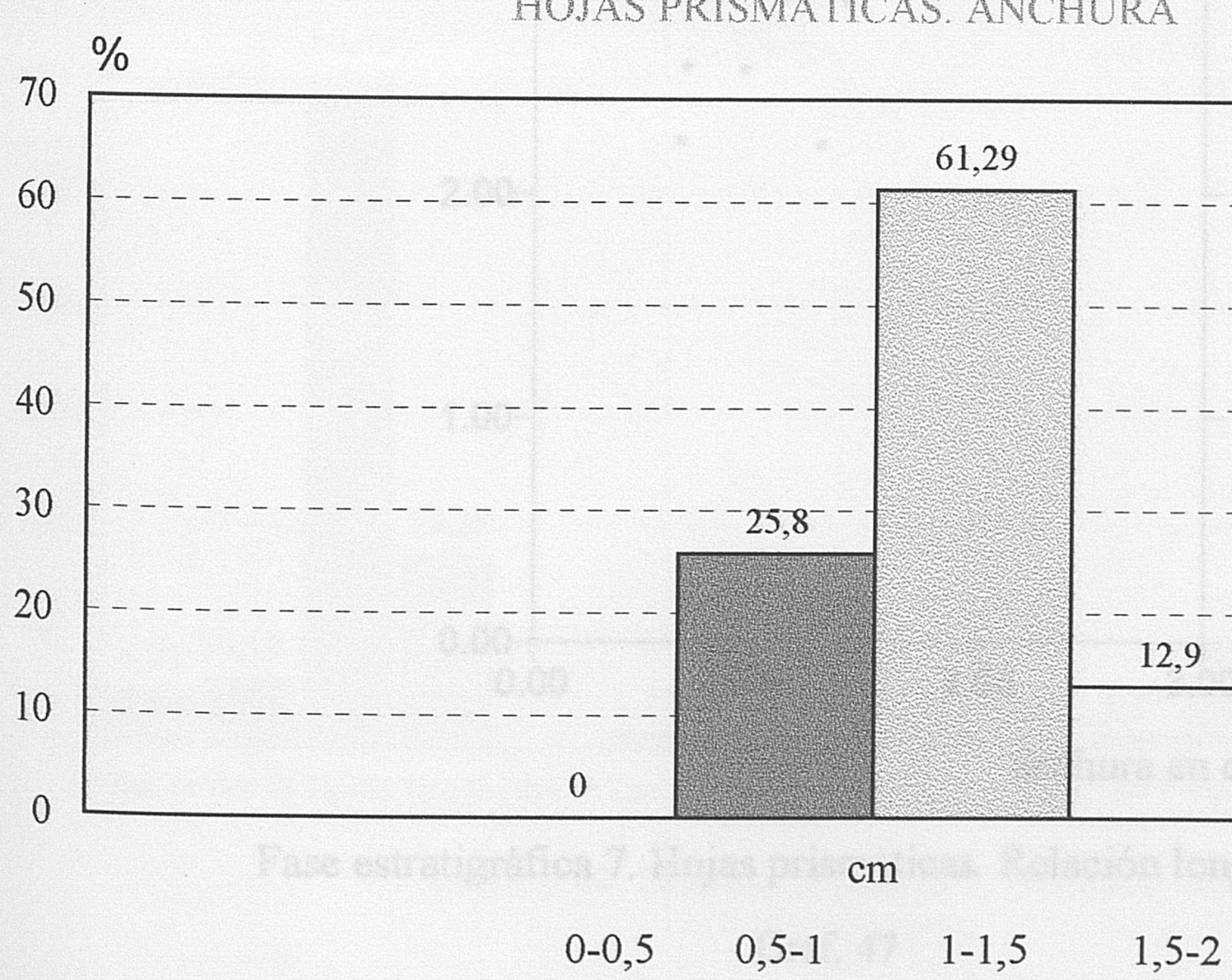

Gráfico 46. Fase estratigráfica 7. Neolítico medio 


\section{longitud en $\mathrm{cm}$.}

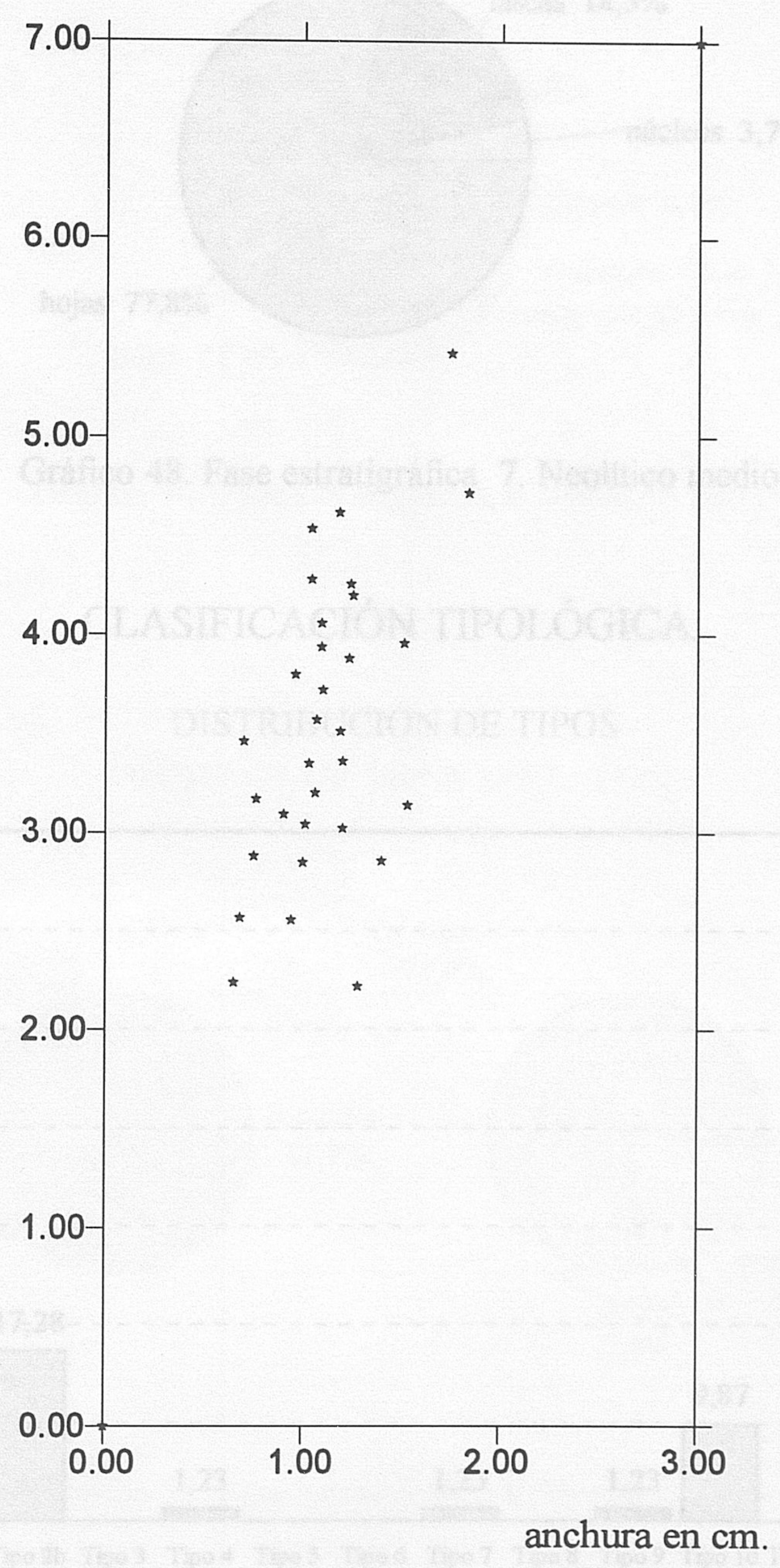

Fase estratigráfica 7. Hojas prismáticas. Relación longitud anchura Graf. 47 


\section{CLASIFICACIÓN TECNOLÓGICA}

\section{DISTRIBUCION DE SOPORTES}

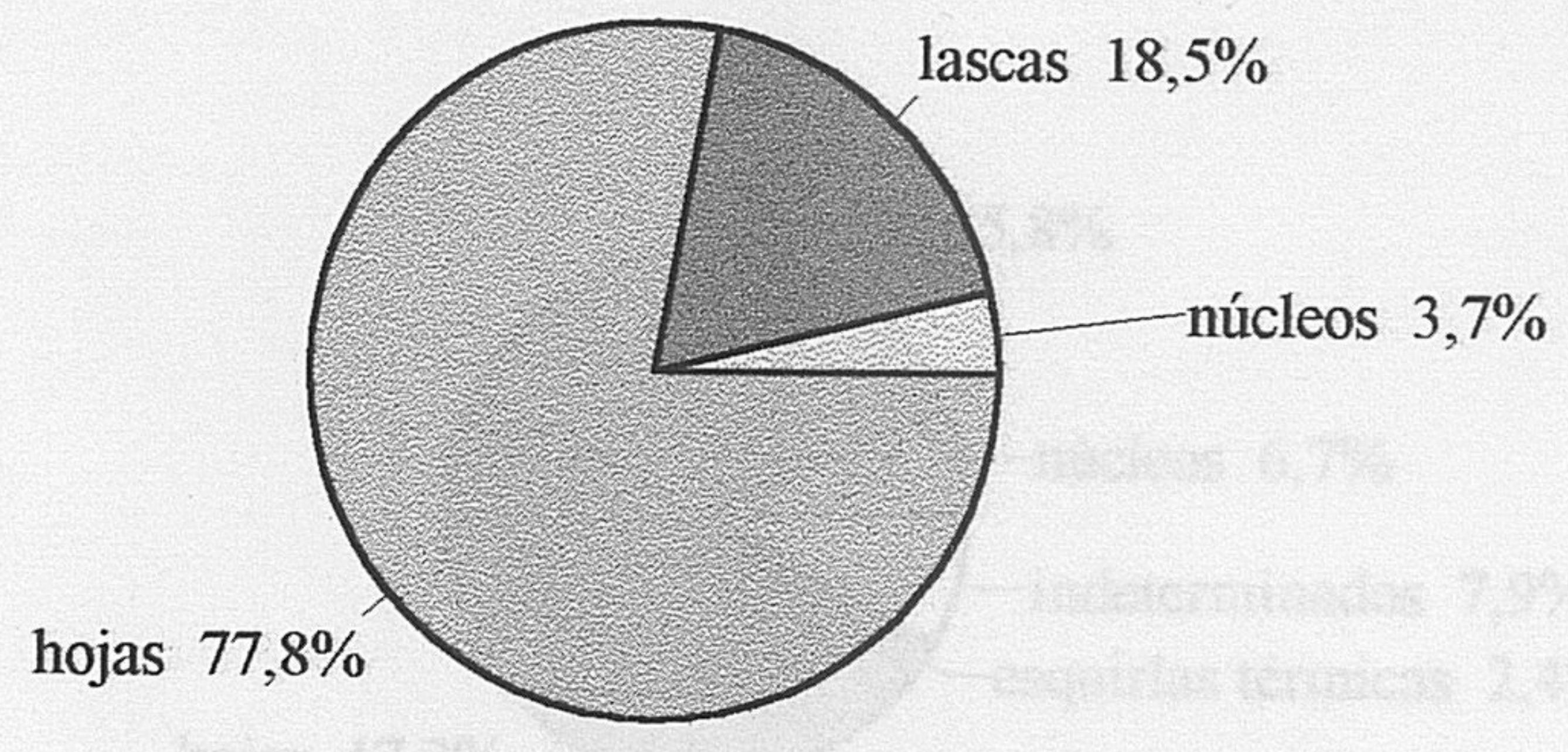

Gráfico 48. Fase estratigráfica 7. Neolítico medio

\section{CLASIFICACIÓN TIPOLÓGICA}

\section{DISTRIBUCION DE TIPOS}

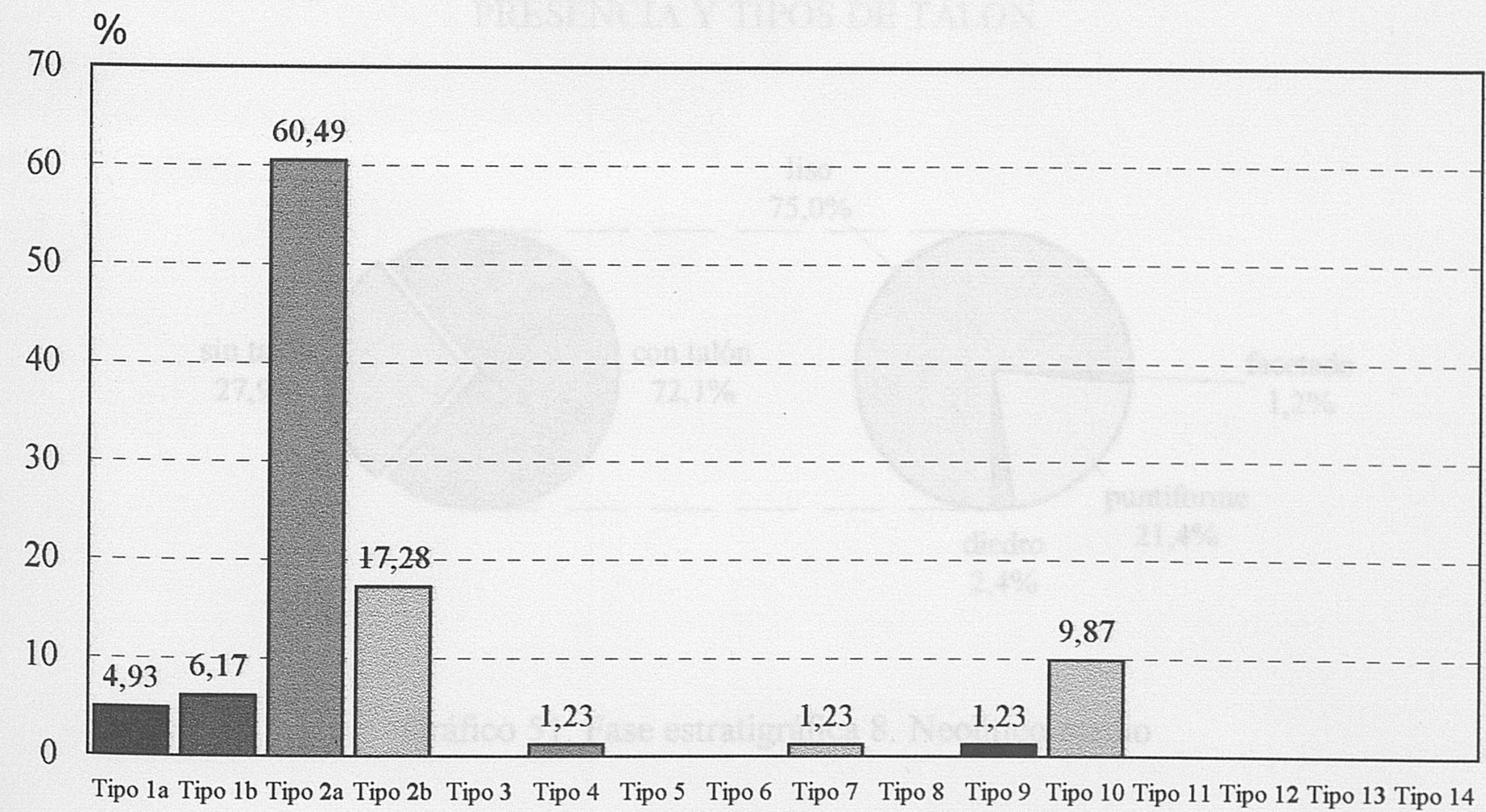

Gráfico 49. Fase estratigráfica 7. Neolítico medio 


\section{CLASIFICACIÓN TECNOLÓGICA}

\section{TOTAL DE LA INDUSTRIA}

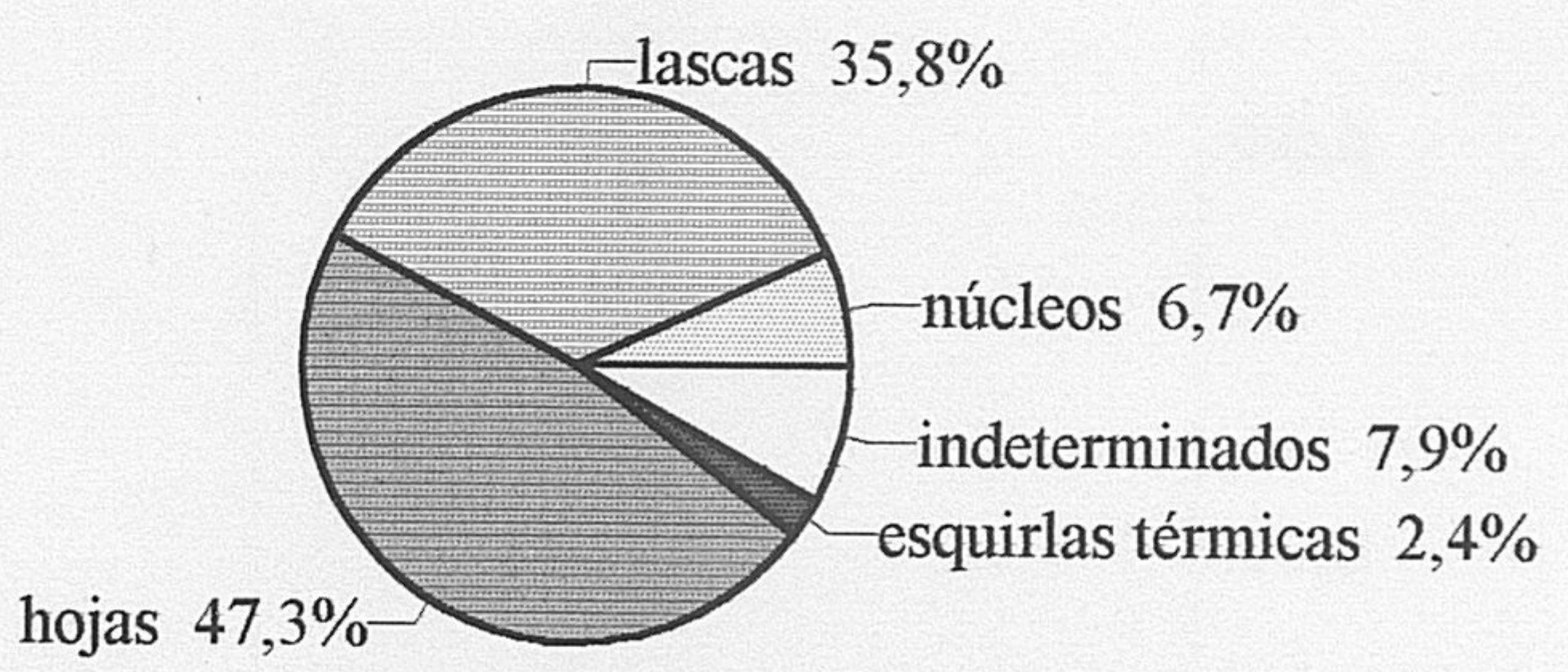

Gráfico 50. Fase estratigráfica 8. Neolítico medio

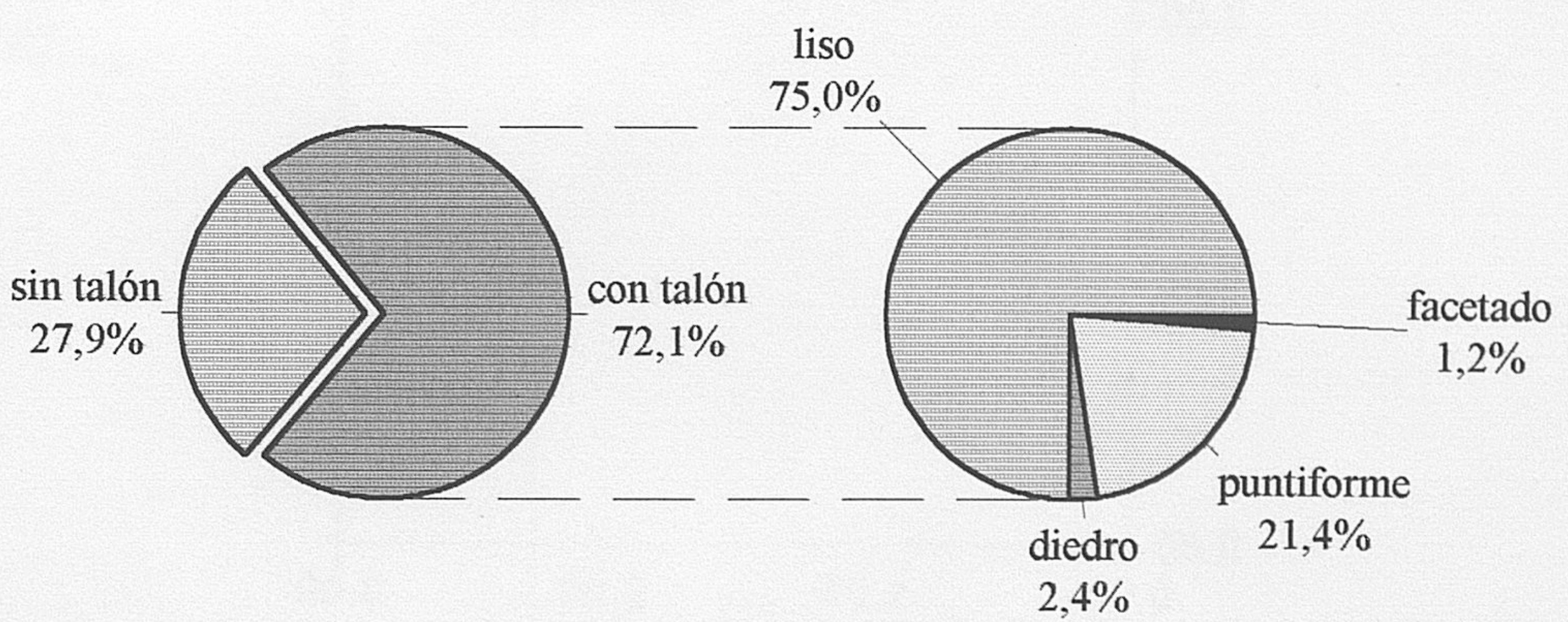

Gráfico 51. Fase estratigráfica 8. Neolítico medio 
longitud en $\mathrm{cm}$.

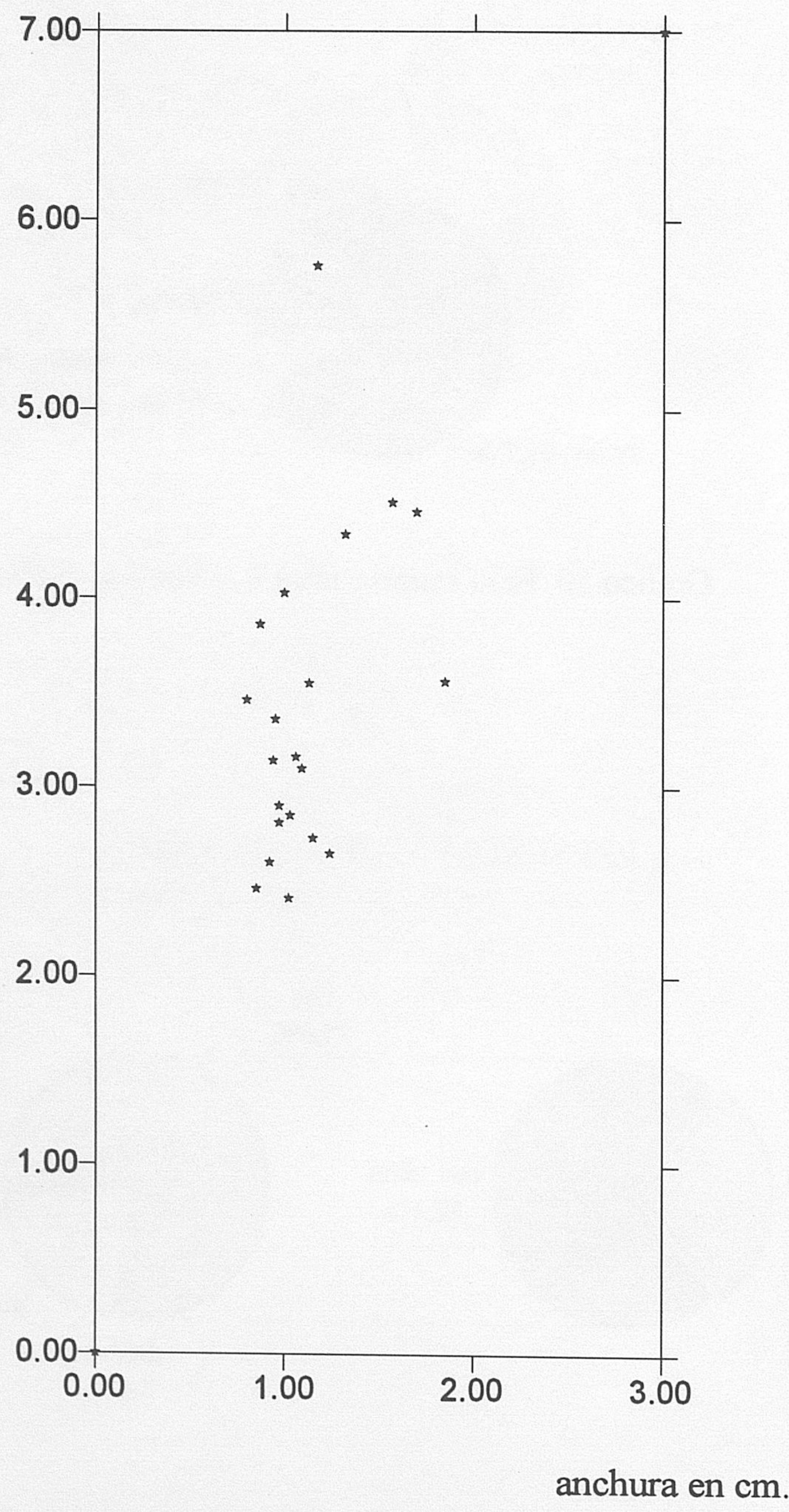

Fase estratigráfica 10a. Hojas prismáticas. Relación longitud-anchura

Graf. 68 


\section{CLASIFICACIÓN TECNOLÓGICA}

\section{HOJAS PRISMÁTICAS LONGITUDES}

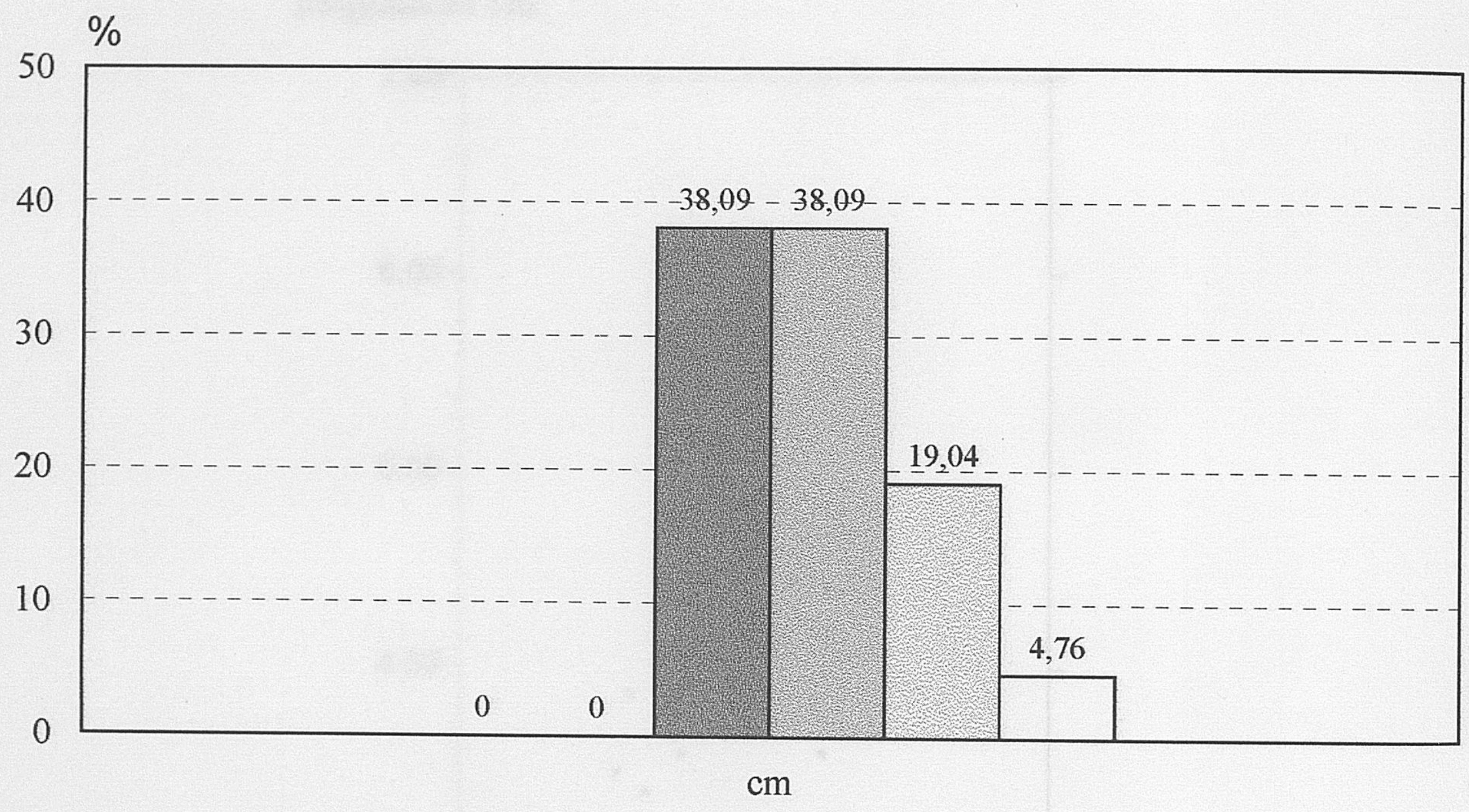

$0-1 \quad 1-2 \quad 2-3 \quad 3-4 \quad 4-5 \quad 5-6$

Gráfico 66. Fase estratigráfica 10a. Neolítico medio

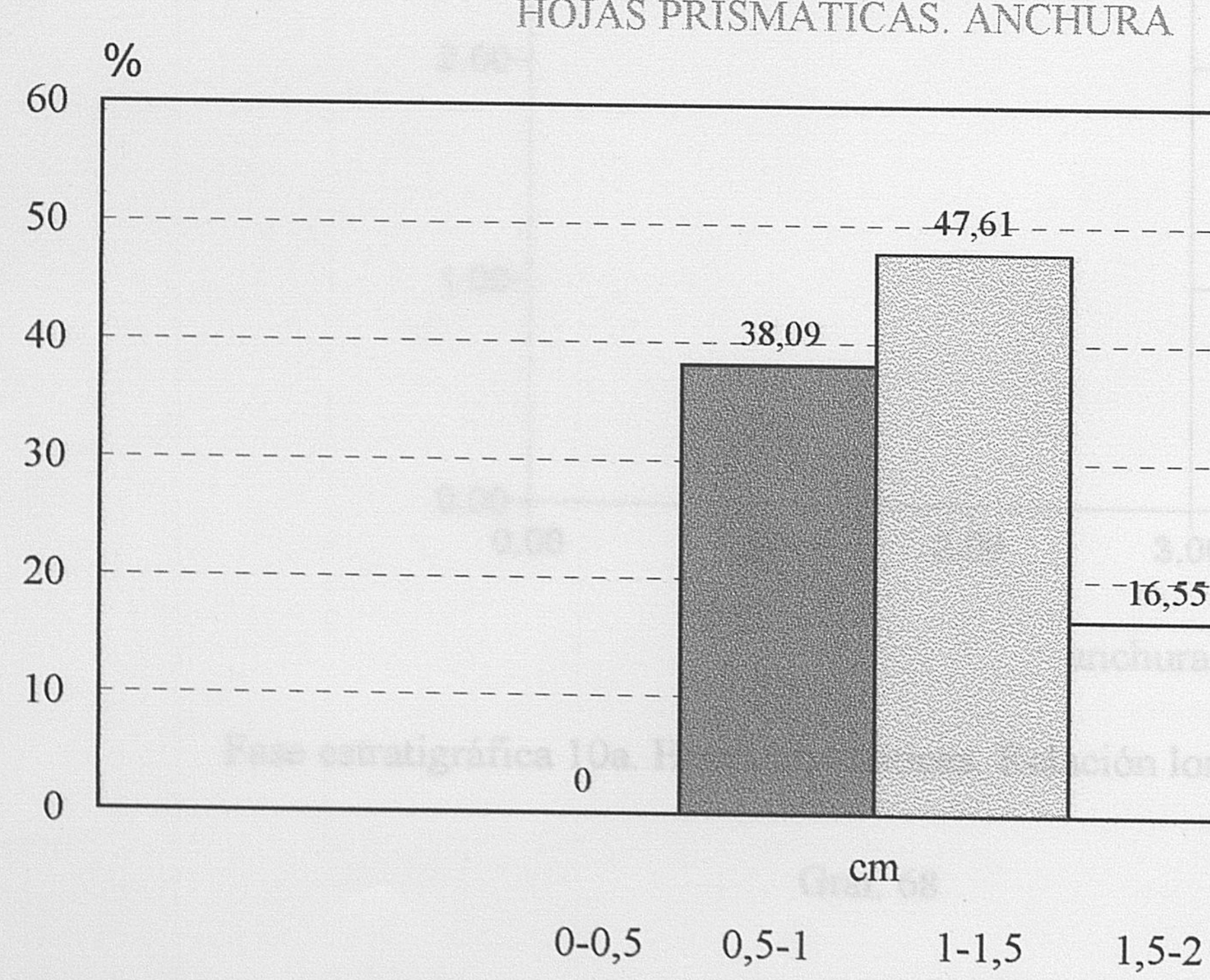

Gráfico 67. Fase estratigráfica 10a. Neolítico medio 


\title{
CLASIFICACIÓN TECNOLÓGICA
}

\author{
TOTAL DE LA INDUSTRIA
}

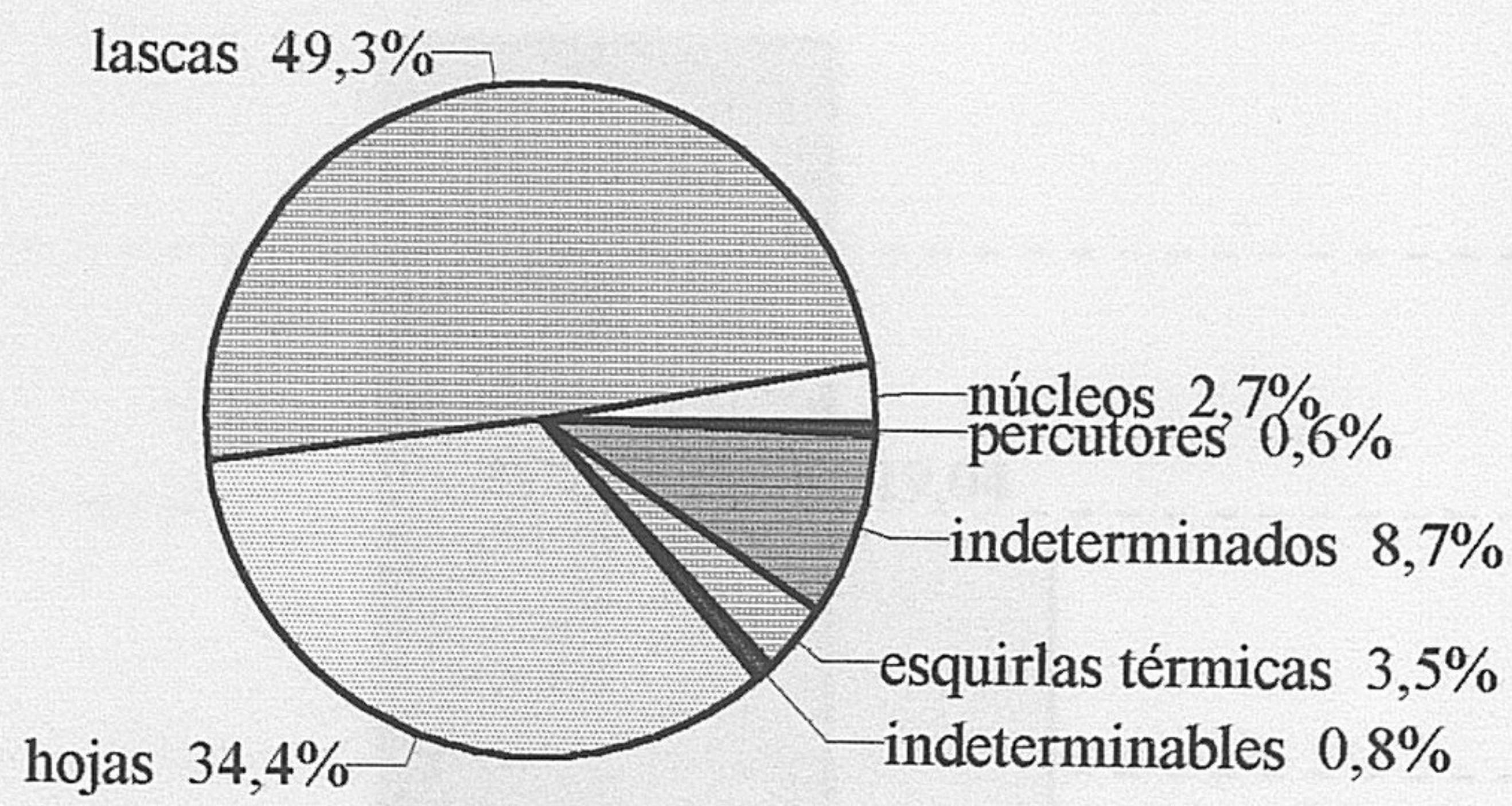

Gráfico 64. Fase estratigráfica 10a. Neolítico medio

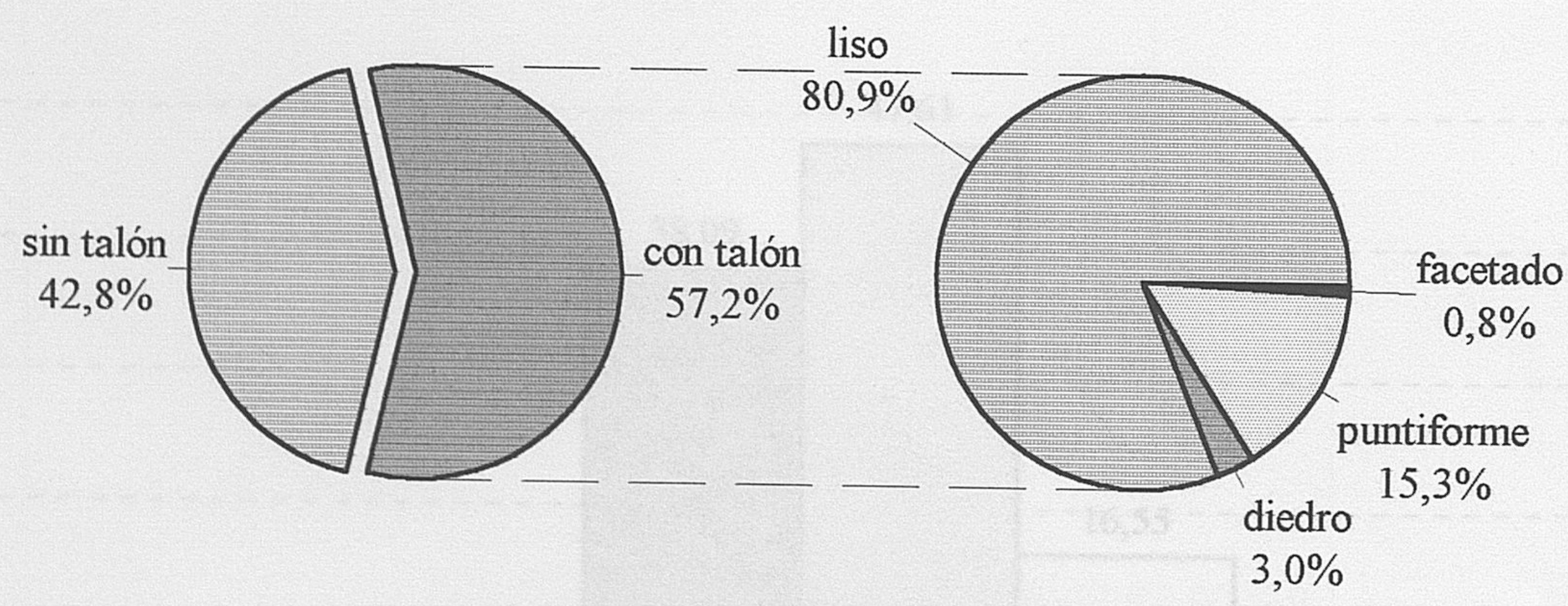

Gráfico 65. Fase estratigráfica 10a. Neolítico medio 


\section{CLASIFICACIÓN TECNOLÓGICA}

\section{DISTRIBUCIÓN DE SOPORTES}

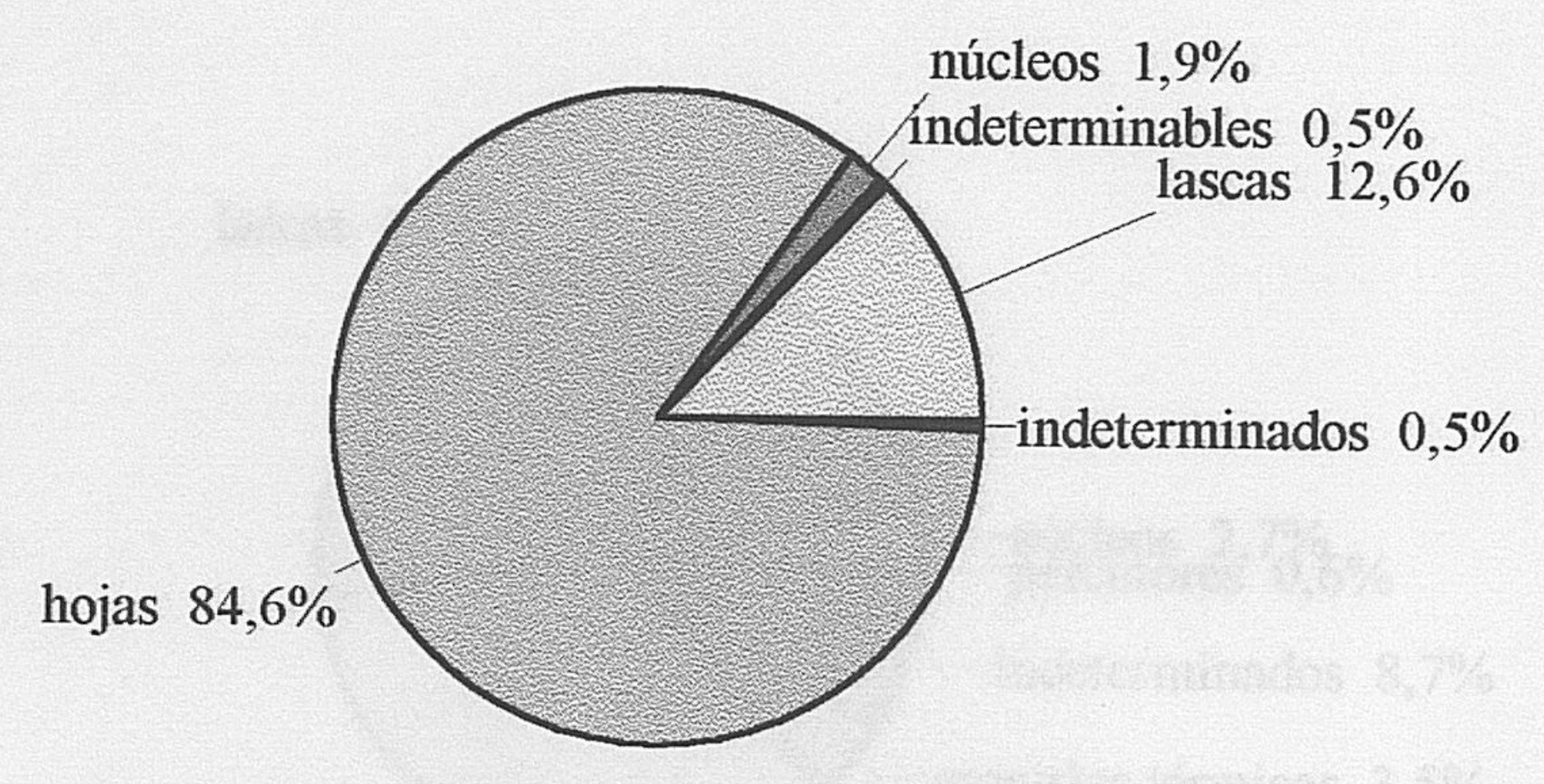

Gráfico 62. Fase estratigráfica 9. Neolítico medio

\section{CLASIFICACIÓN TIPOLÓGICA}

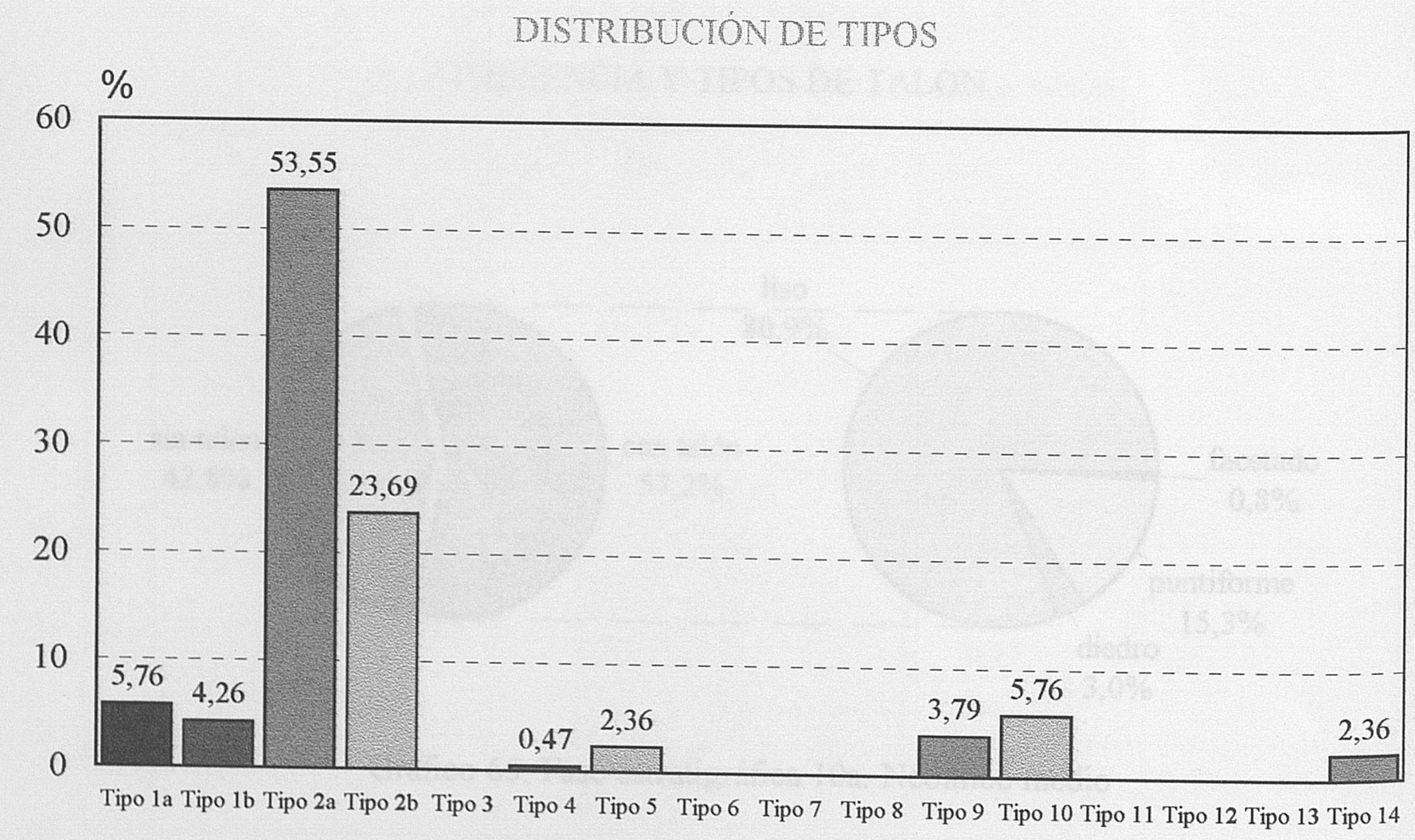

Gráfico 63. Fase estratigráfica 9. Neolítico medio 
longitud en $\mathrm{cm}$.

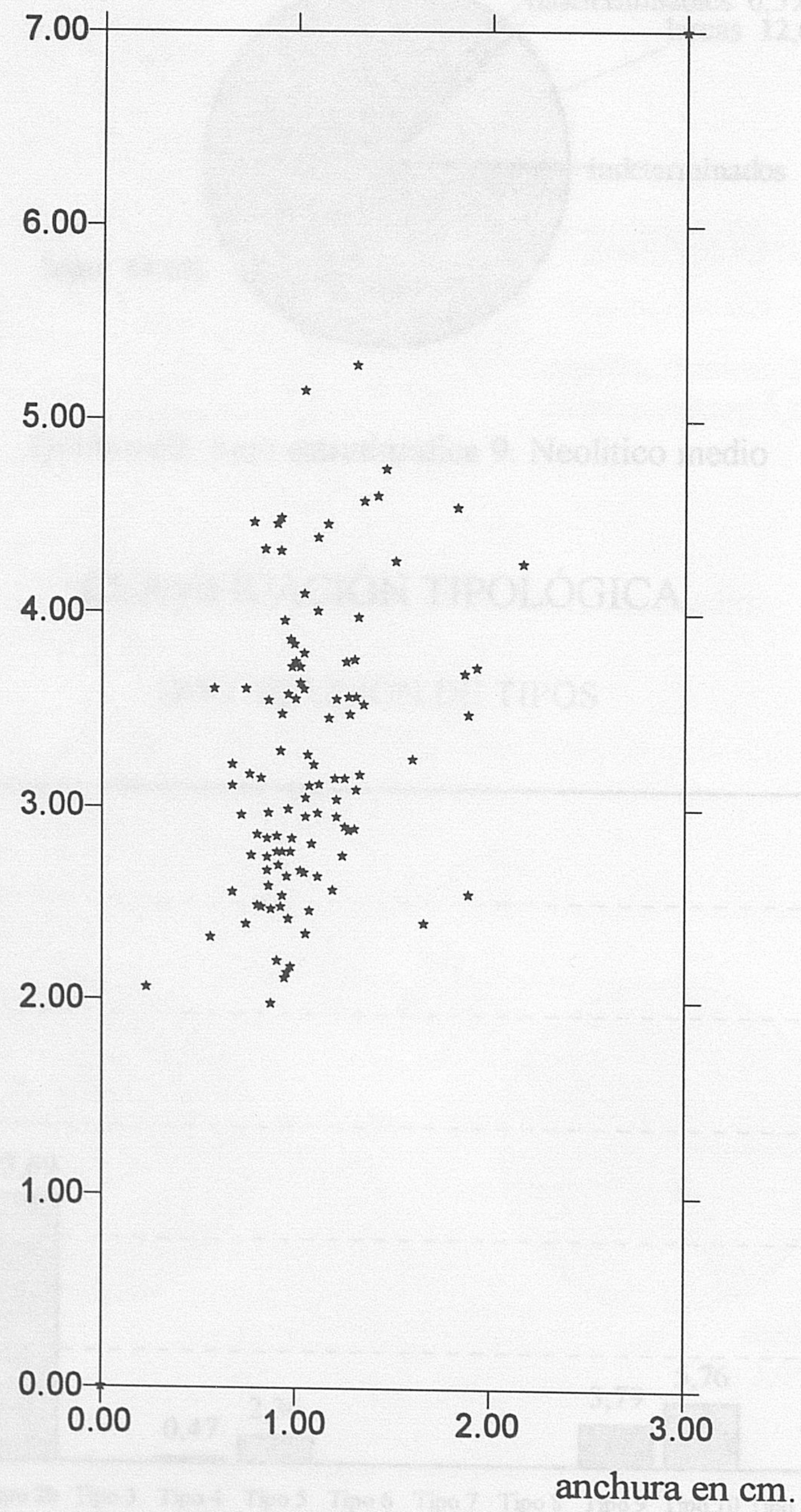

Fase estratigráfica 9. Hojas prismáticas. Relación longitud-anchura Graf. 61 


\section{CLASIFICACIÓN TECNOLÓGICA}

\section{HOJAS PRISMÁTICAS LONGITUDES}

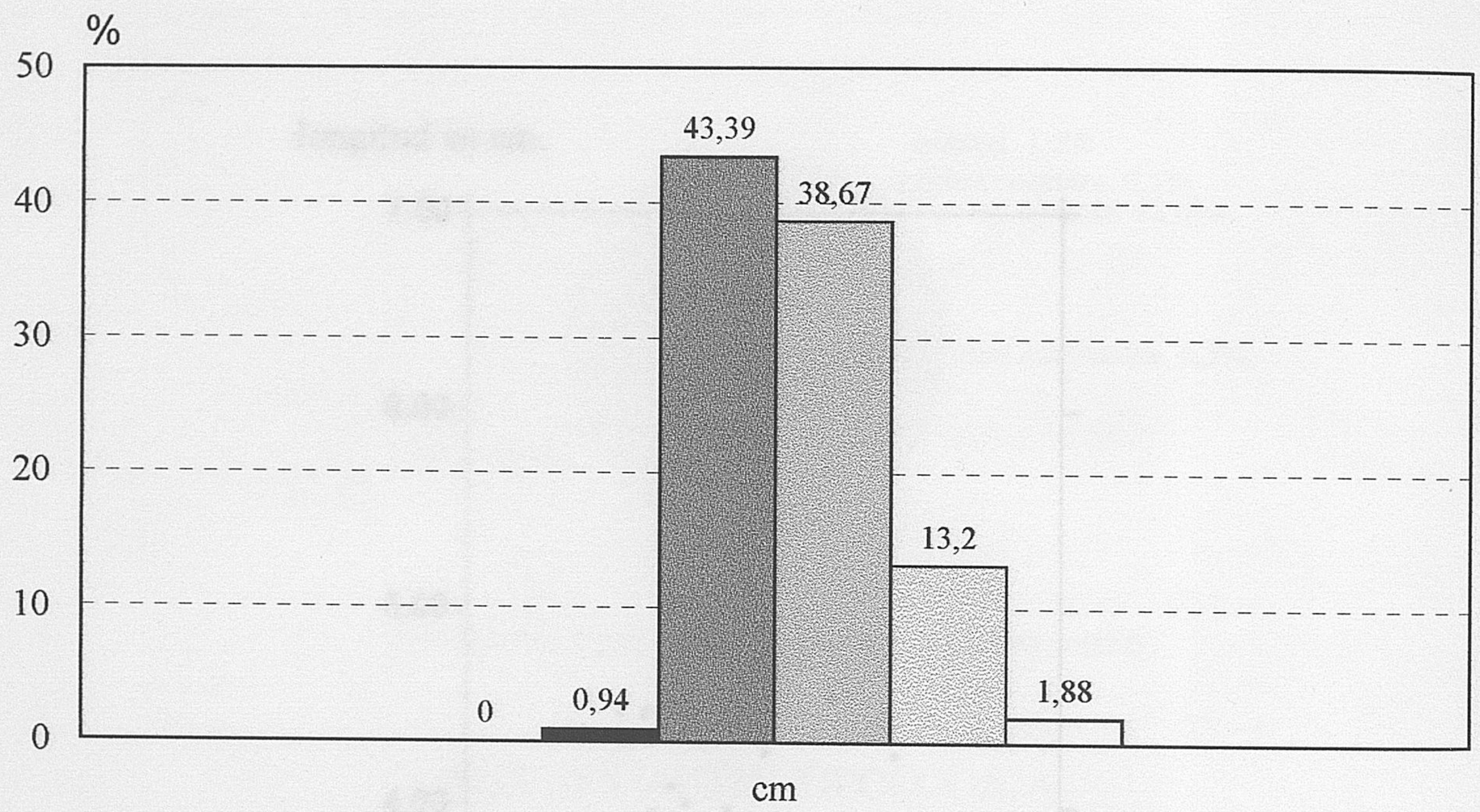

$\begin{array}{llllll}0-1 & 1-2 & 2-3 & 3-4 & 4-5 & 5-6\end{array}$

Gráfico 59. Fase estratigráfica 9. Neolítico medio

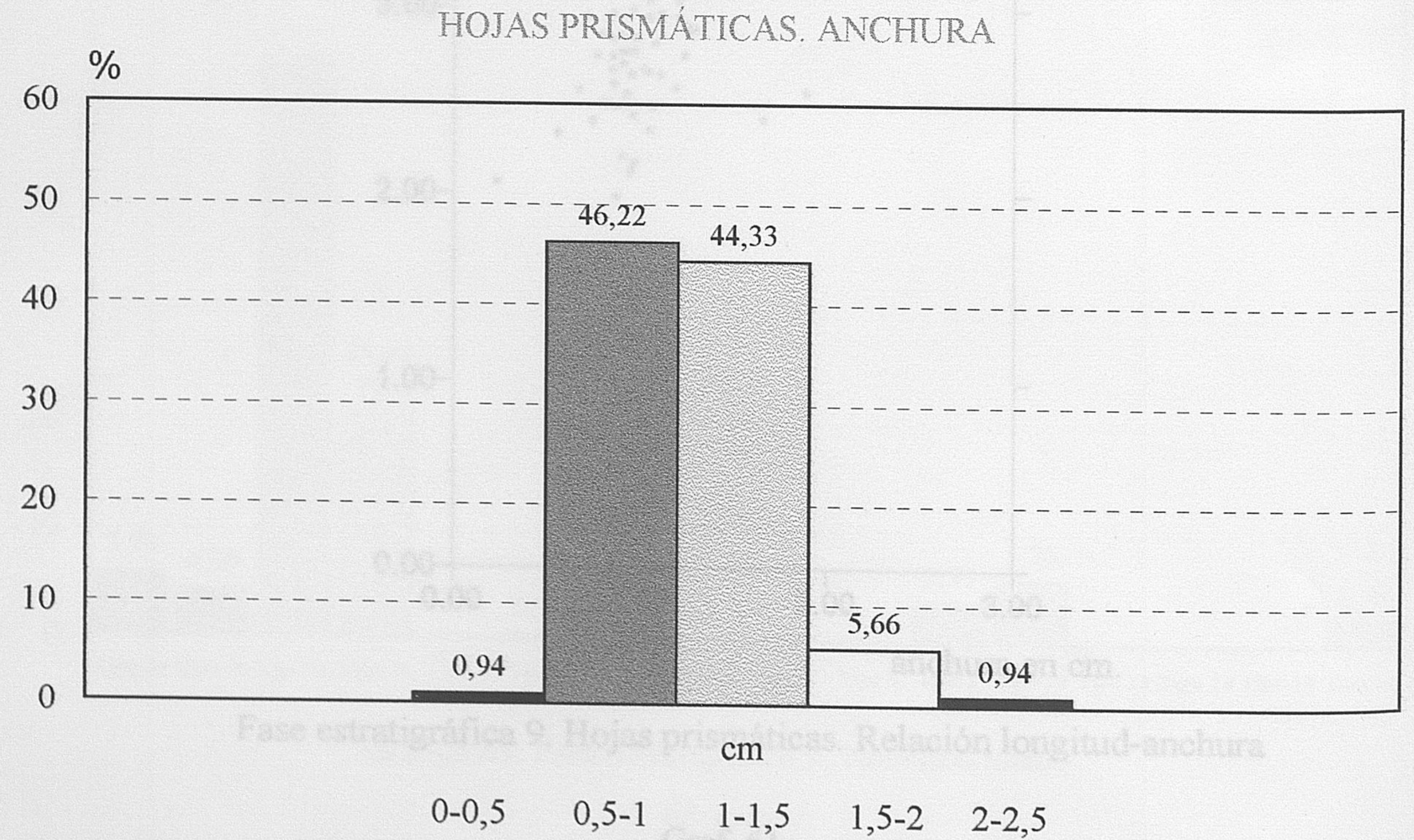

Gráfico 60. Fase estratigráfica 9. Neolítico medio 


\section{CLASIFICACIÓN TECNOLÓGICA}

\section{TOTAL DE LA INDUSTRIA}

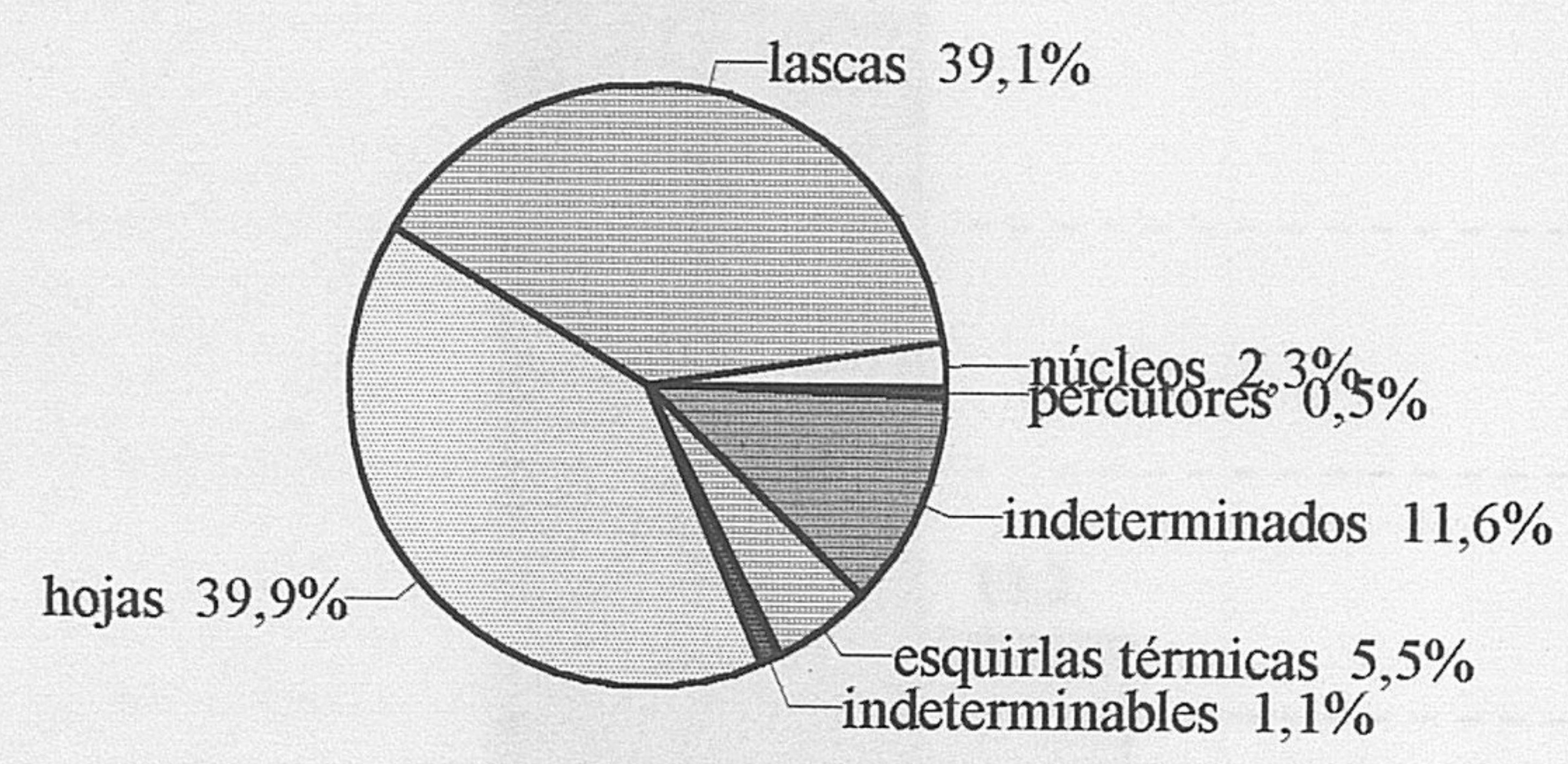

Gráfico 57. Fase estratigráfica 9. Neolítico medio

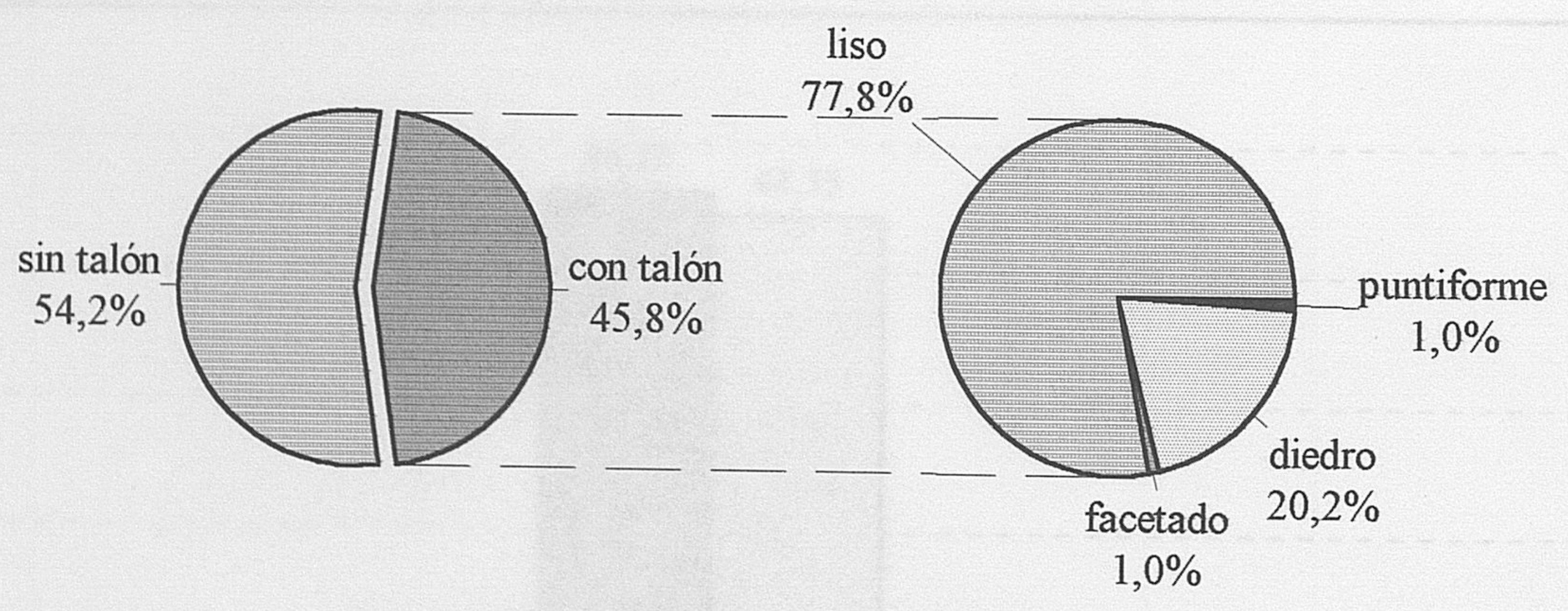

Gráfico 58. Fase estratigráfica 9. Neolítico medio 


\section{CLASIFICACIÓN TECNOLÓGICA}

\section{DISTRIBUCION DE SOPORTES}

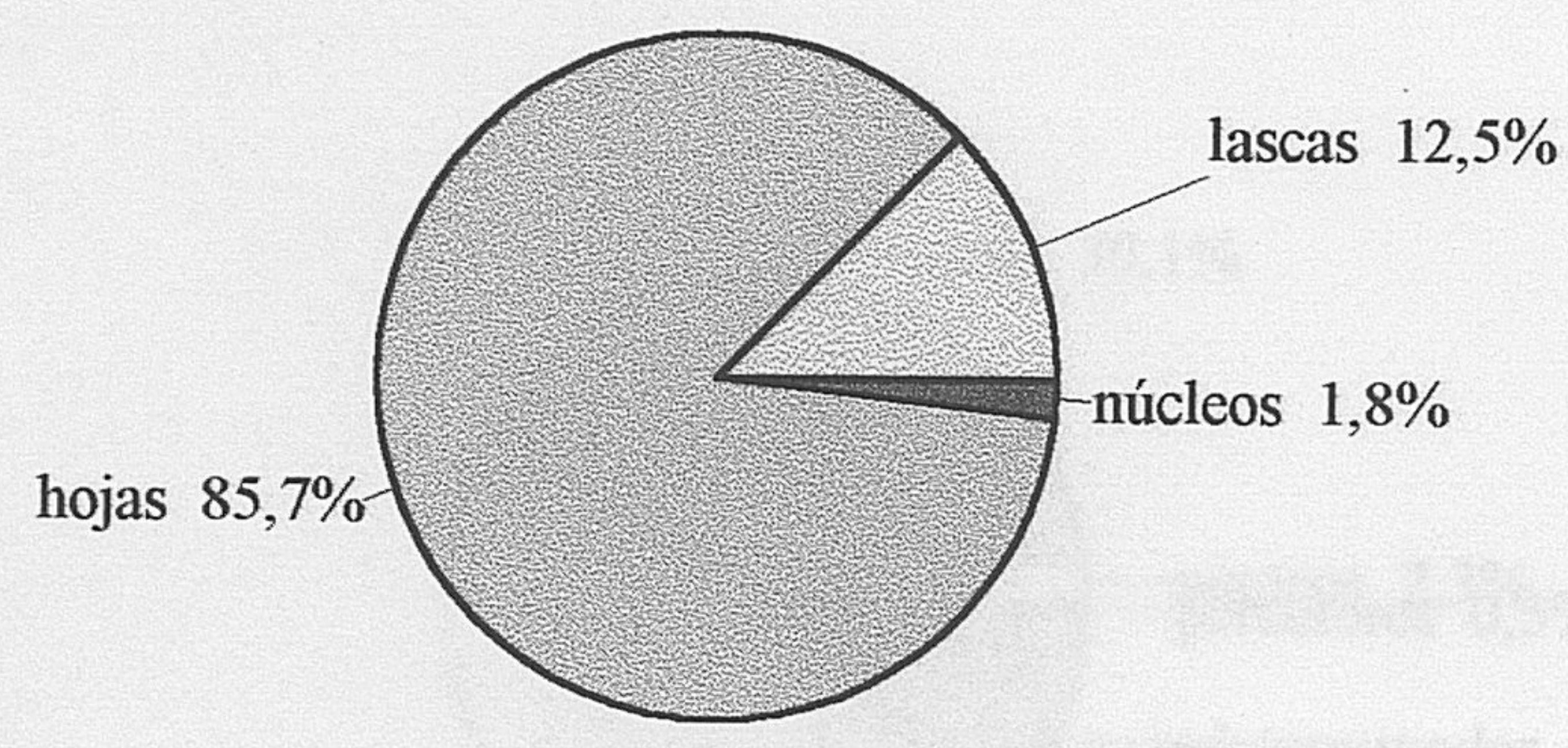

Gráfico 55. Fase estratigráfica 8. Neolítico medio

\section{CLASIFICACIÓN TIPOLÓGICA}

\section{DISTRIBUCION DE TIPOS}

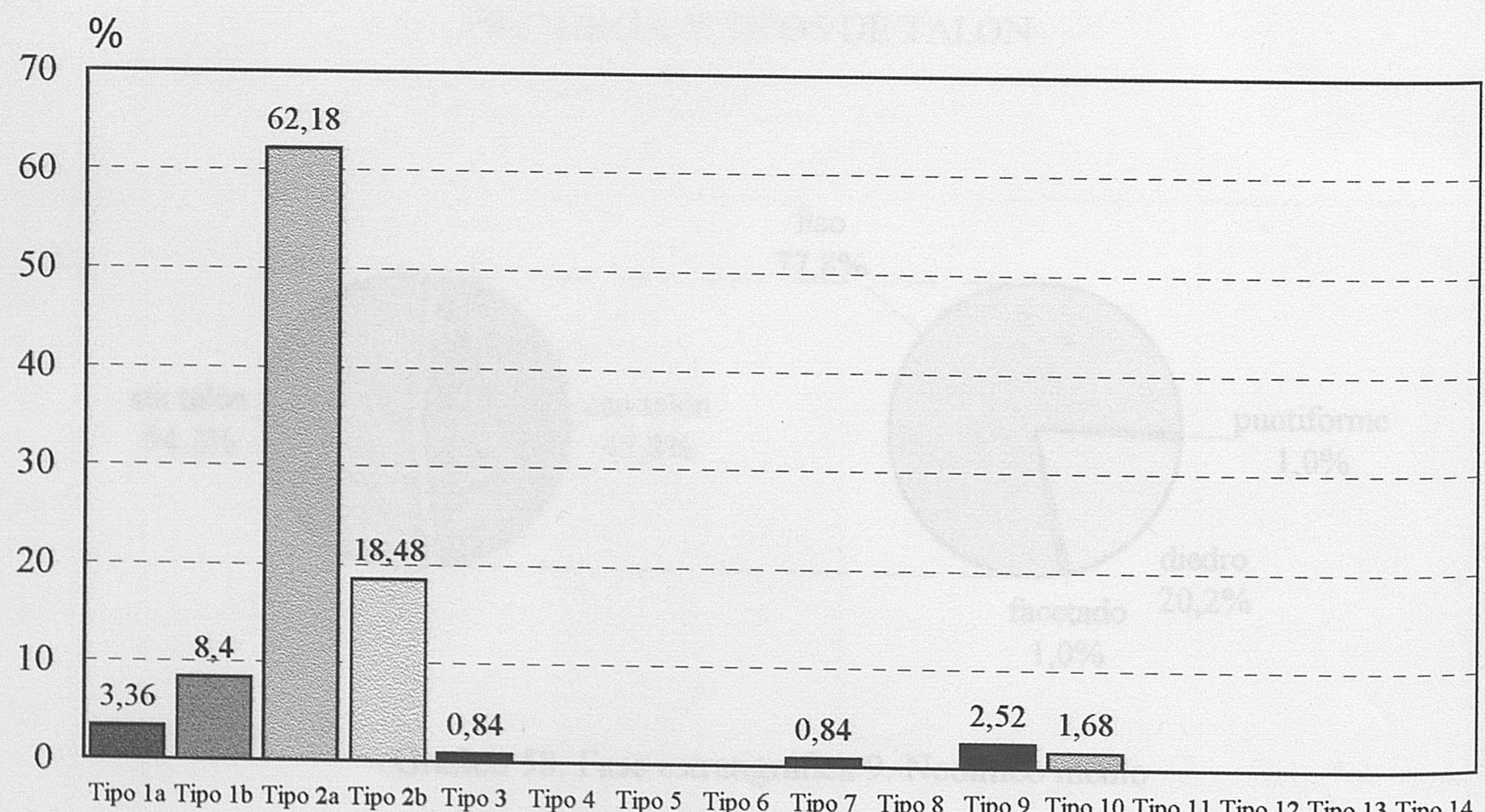

Gráfico 56. Fase estratigráfica 8. Neolítico medio 
longitud en $\mathrm{cm}$.

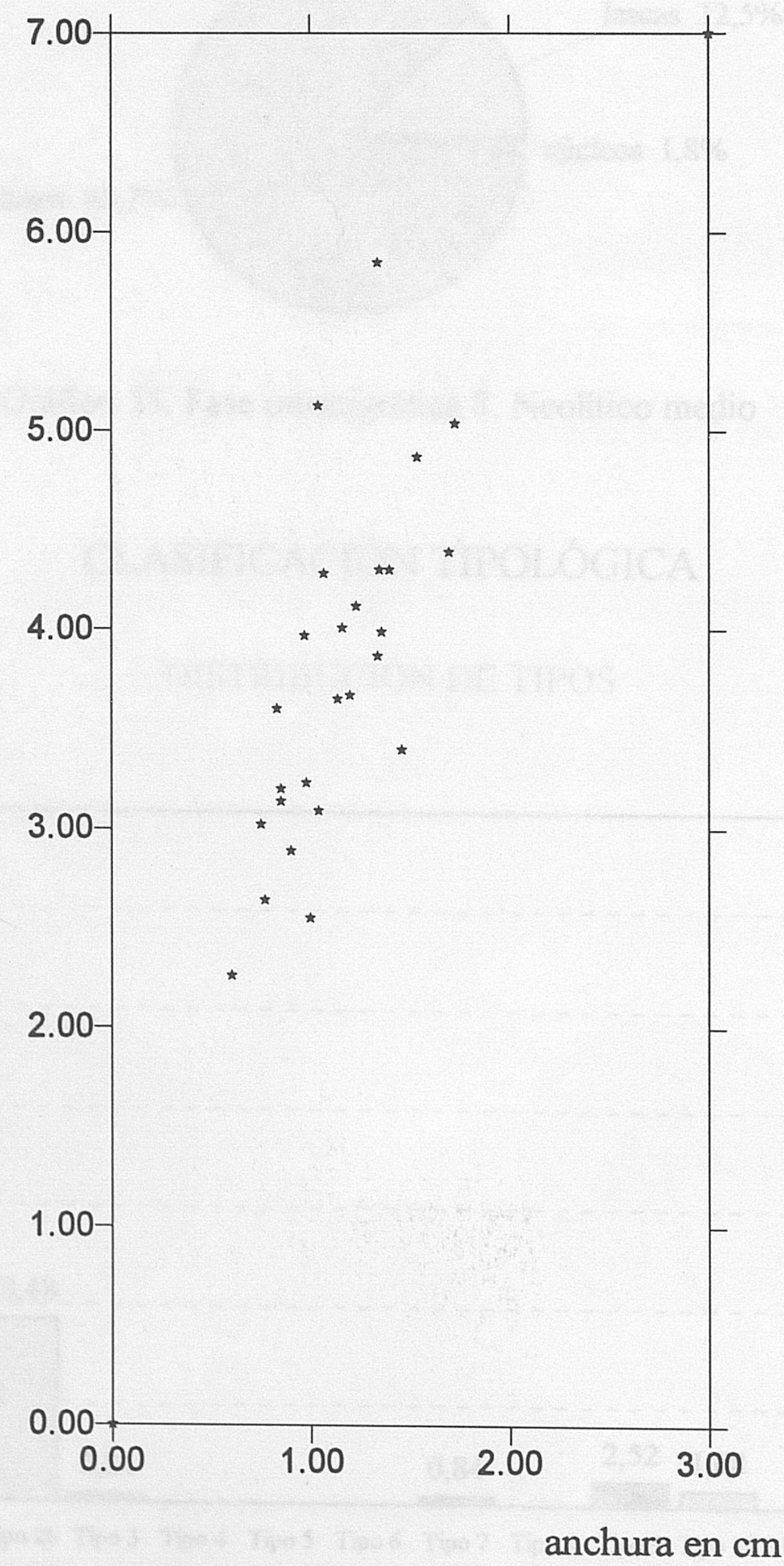

Fase estratigráfica 8. Hojas prismáticas. Relación longitud anchura

Graf. 54 


\section{CLASIFICACIÓN TECNOLÓGICA}

\section{HOJAS PRISMÁTICAS LONGTUUDES}

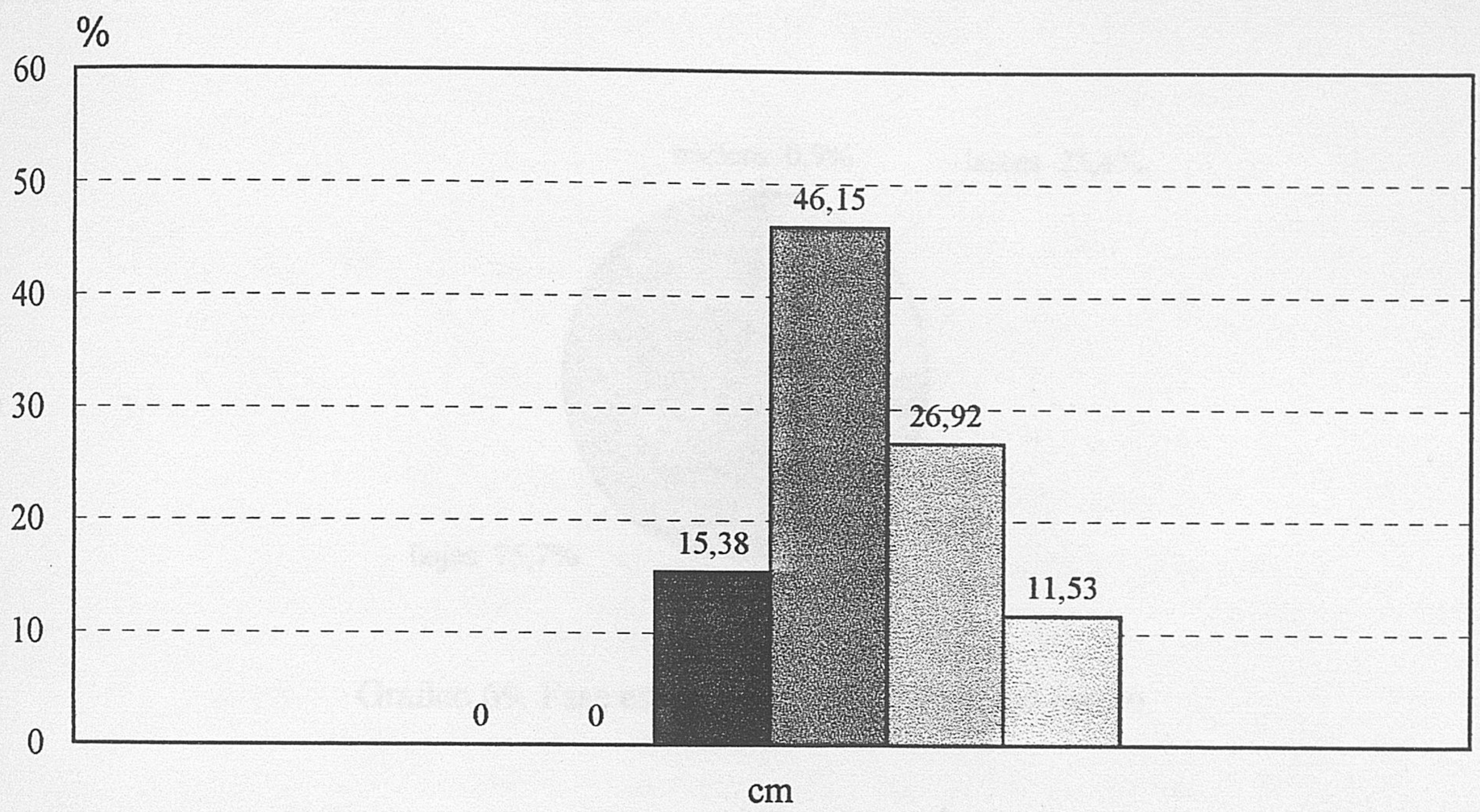

$0-1 \quad 1-2 \quad 2-3 \quad 3-4 \quad 4-5 \quad 5-6$

Gráfico 52. Fase estratigráfica 8. Neolítico medio

HOJAS PRISMÁTICAS. ANCHURA

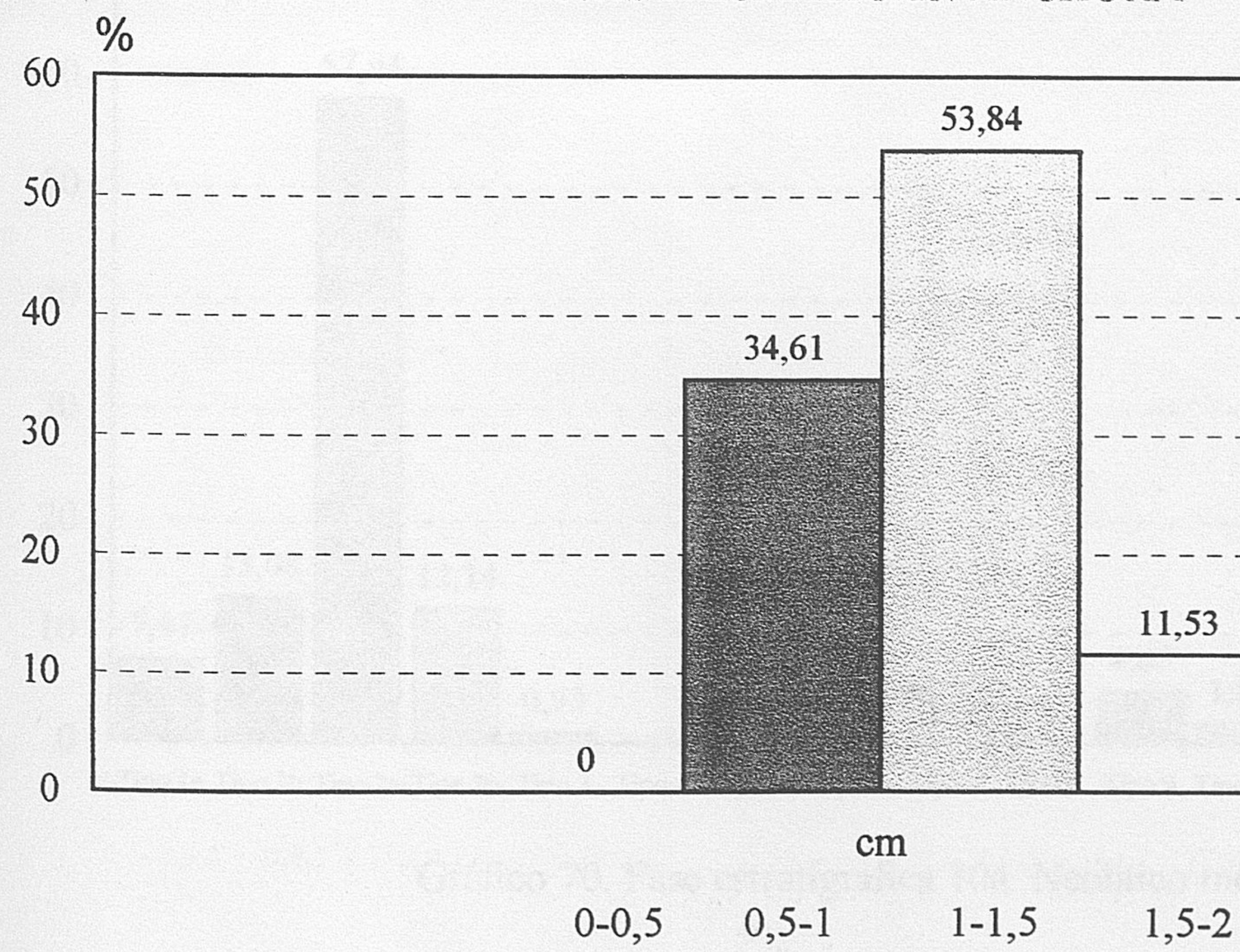

Gráfico 53. Fase estratigráfica 8. Neolítico medio 


\section{CLASIFICACIÓN TECNOLÓGICA}

\section{DISTRIBUCION DE SOPORTES}

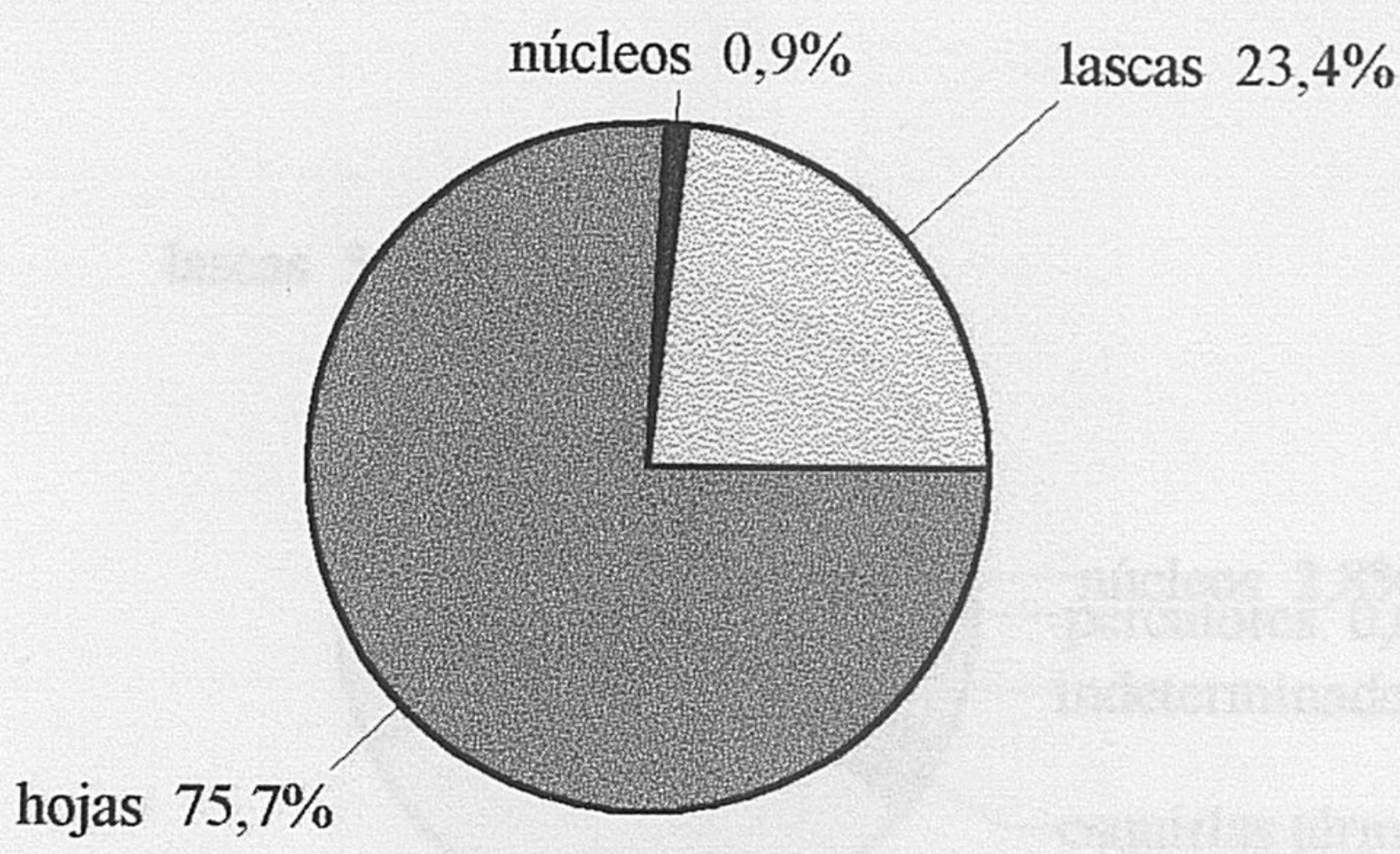

Gráfico 69. Fase estratigráfica 10a. Neolítico medio

\section{CLASIFICACIÓN TIPOLÓGICA}

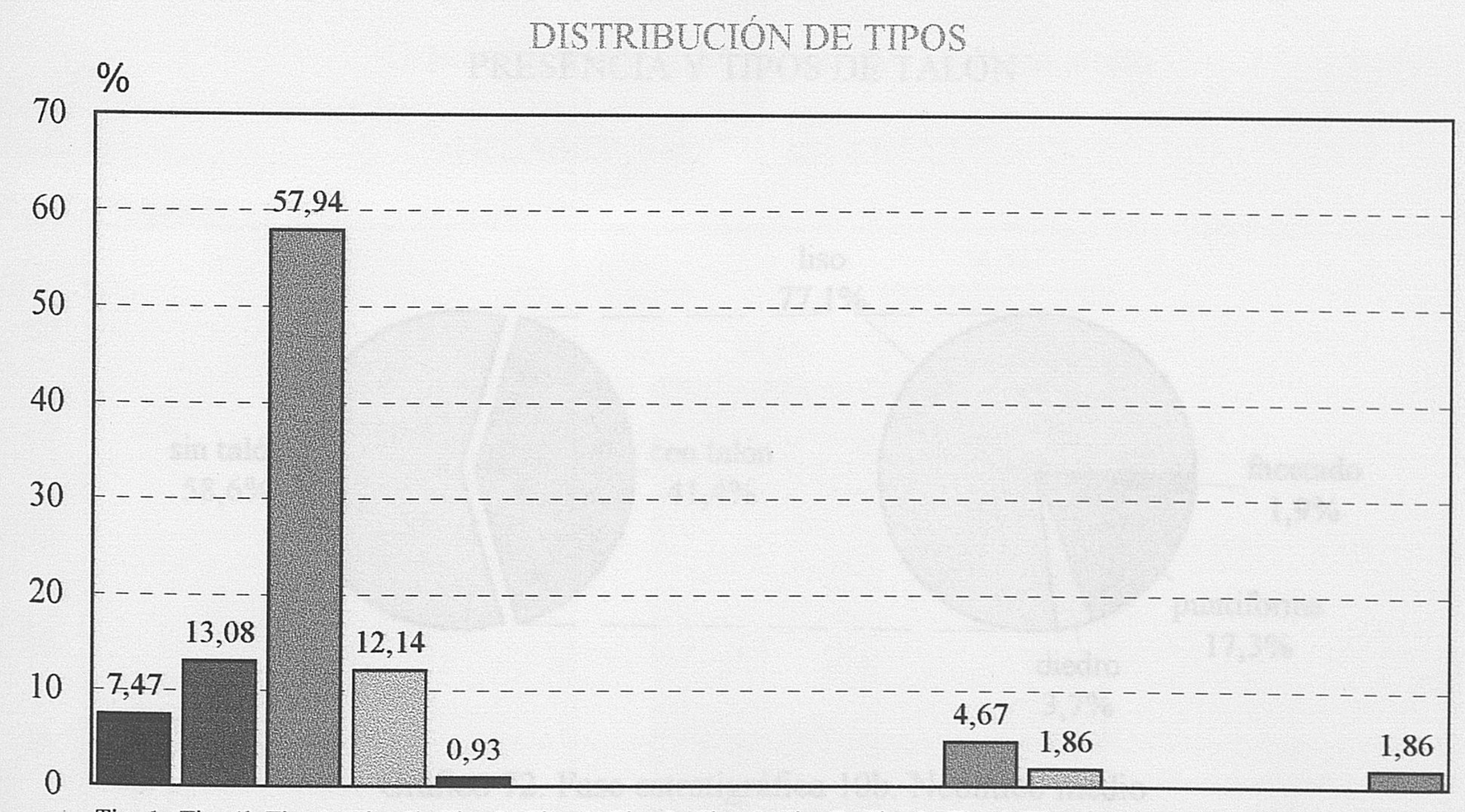

Tipo 1a Tipo 1b Tipo 2a Tipo 2b Tipo 3 Tipo 4 Tipo 5 Tipo 6 Tipo 7 Tipo 8 Tipo 9 Tipo 10 Tipo 11 Tipo 12 Tipo 13 Tipo 14

Gráfico 70. Fase estratigráfica 10a. Neolítico medio 


\section{CLASIFICACIÓN TECNOLÓGICA}

\section{TOTAL DE LA INDUSTRIA}

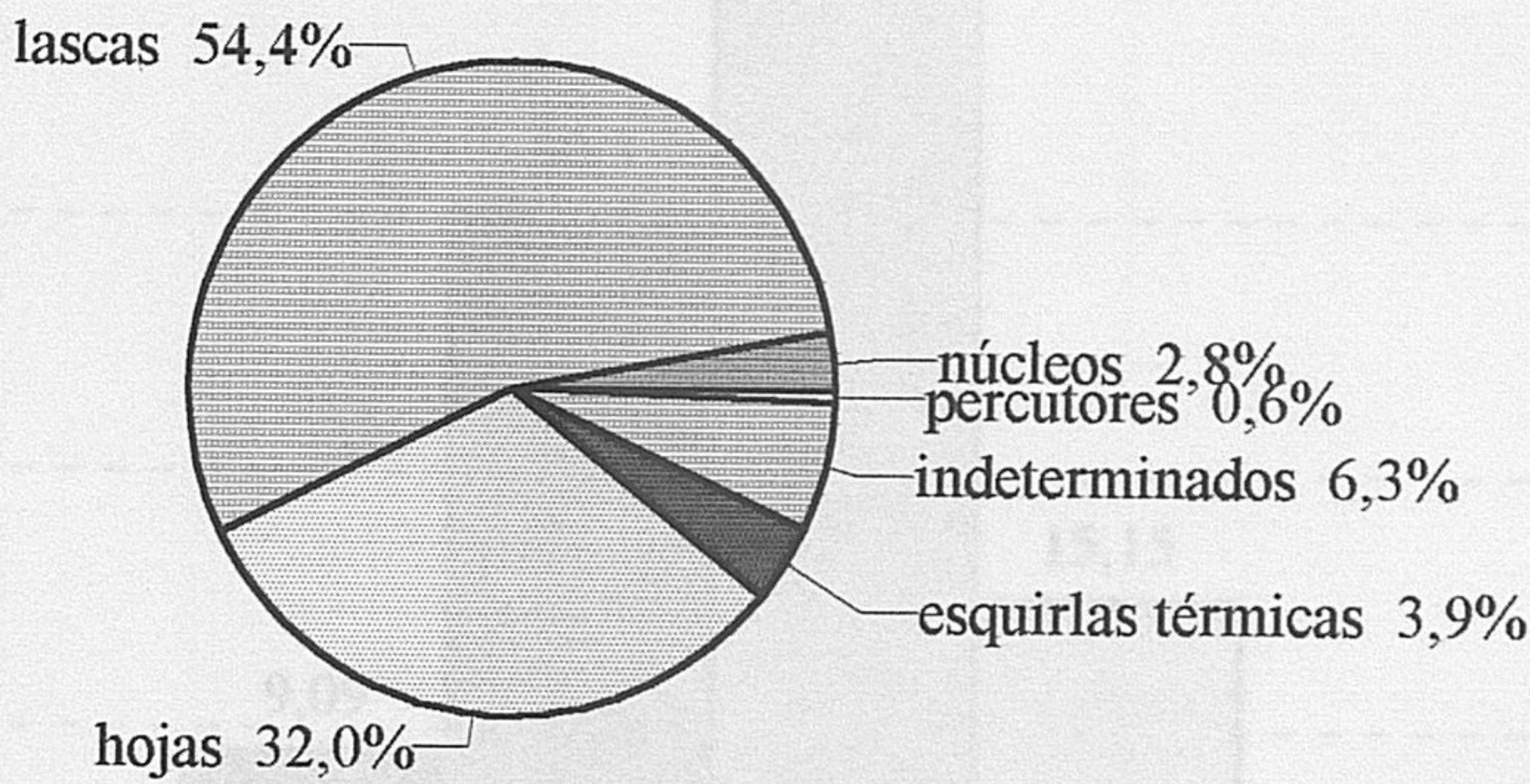

Gráfico 71. Fase estratigráfica 10b. Neolítico medio

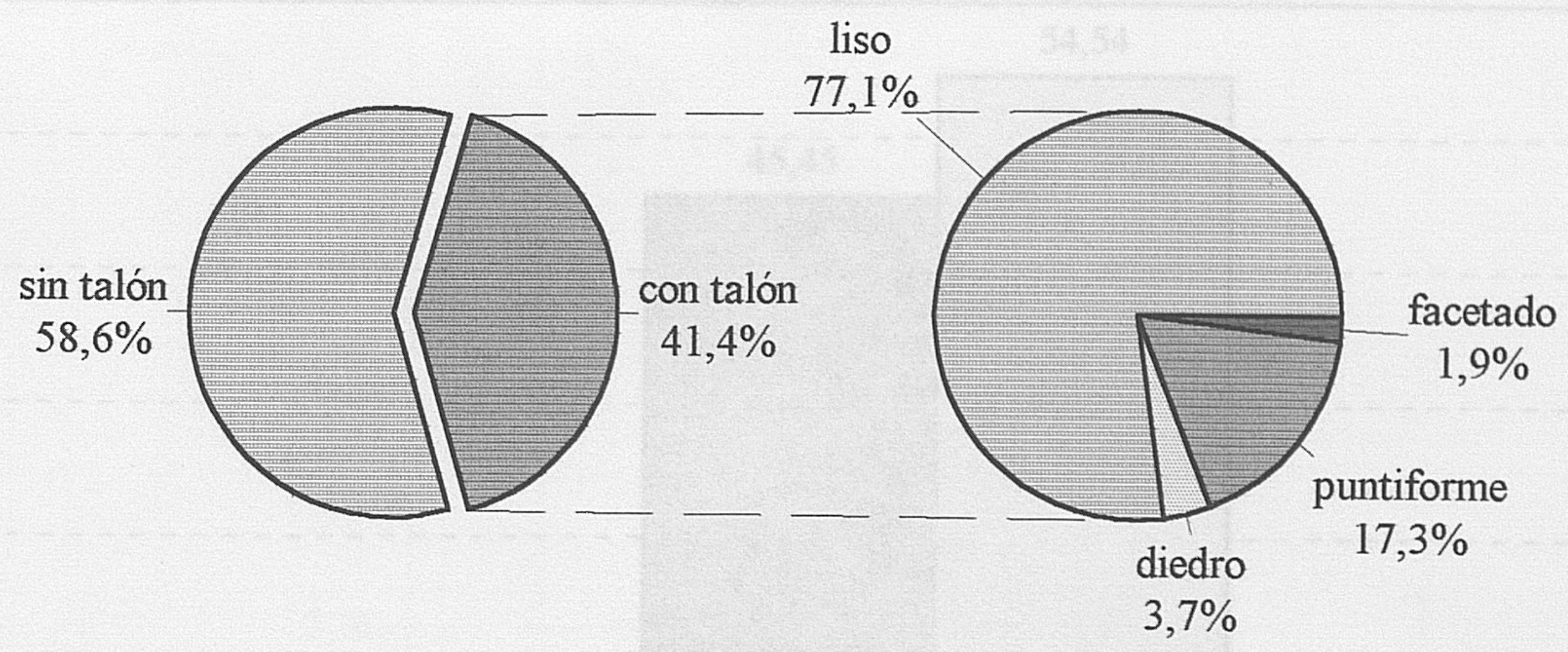

Gráfico 72. Fase estratigráfica 10b. Neolítico medio 


\section{CLASIFICACIÓN TECNOLÓGICA}

\section{HOJAS PRISMÁTICAS LONGITUDES}

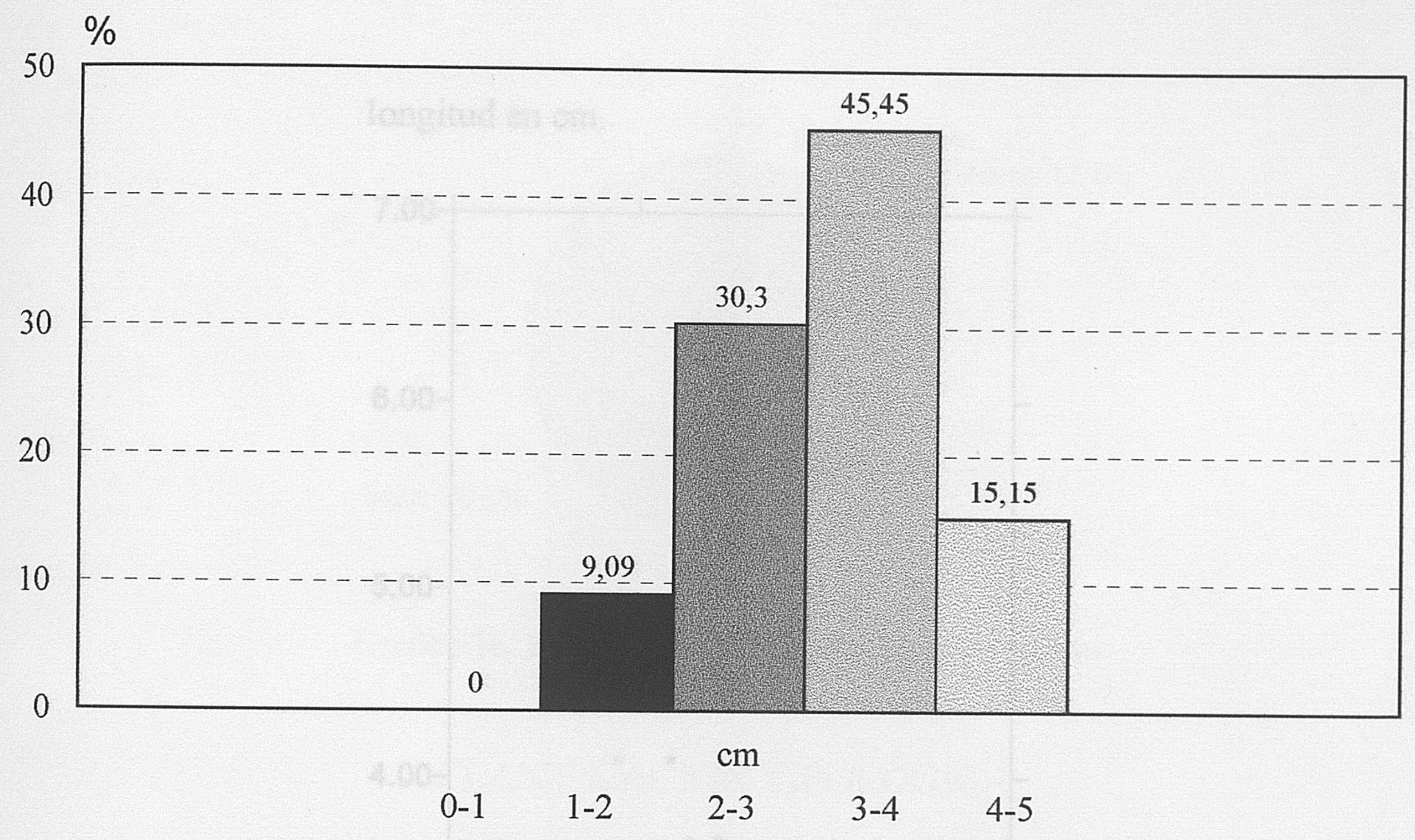

Gráfico 73. Fase estratigráfica 10b. Neolítico medio

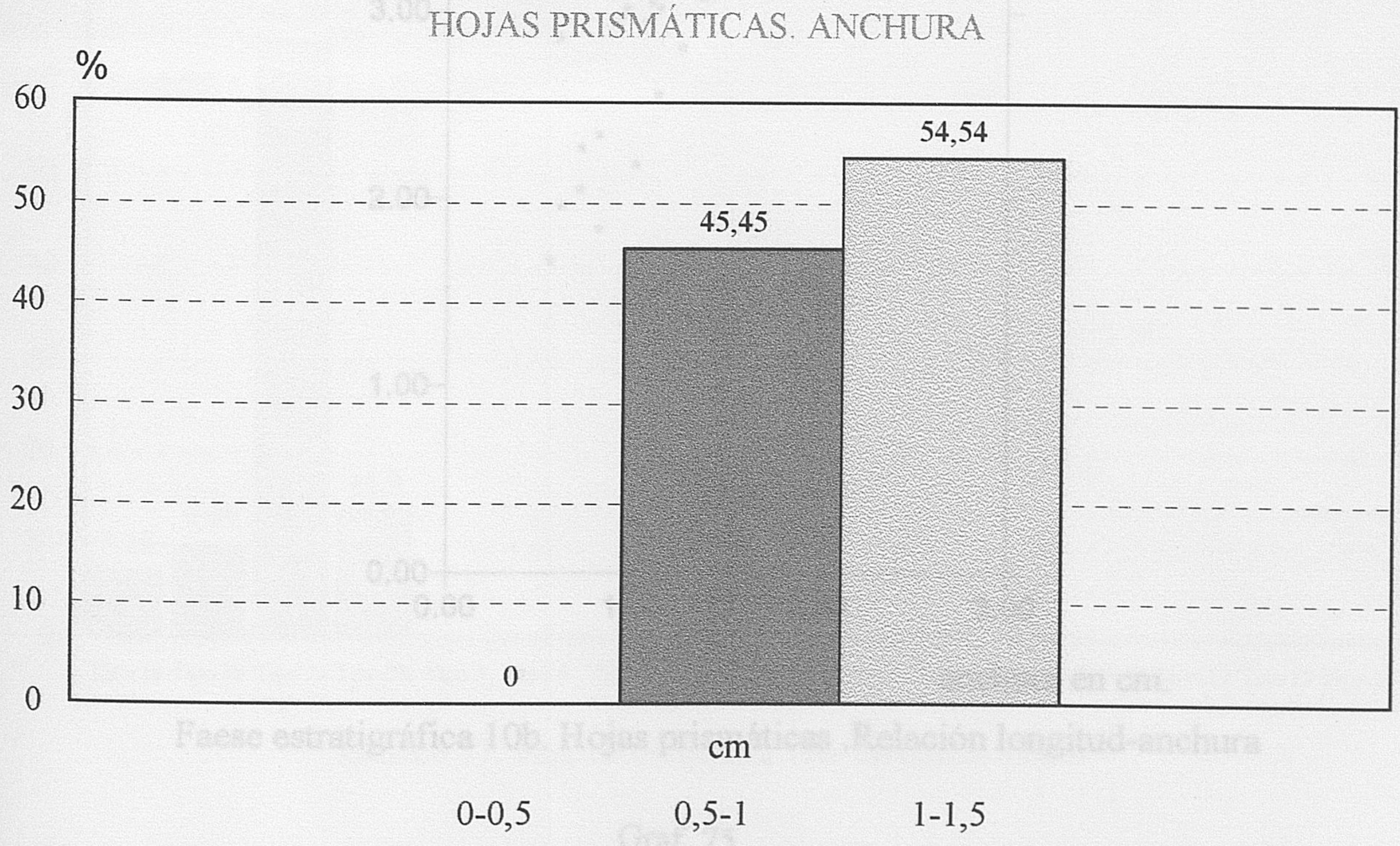

Gráfico 74. Fase estratigráfica 10b. Neolítico medio 
longitud en $\mathrm{cm}$.

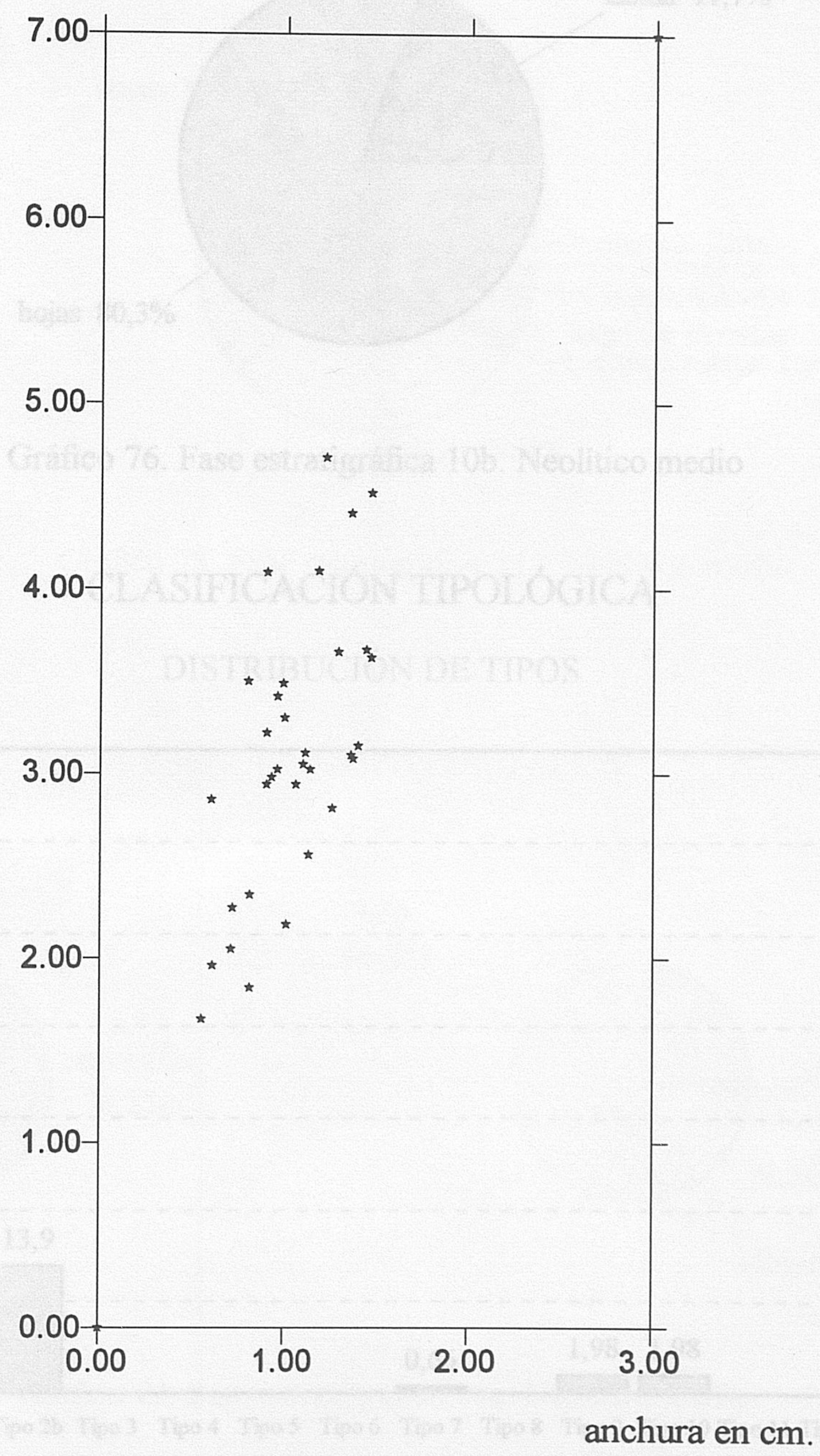

Faese estratigráfica 10b. Hojas prismáticas .Relación longitud-anchura

Graf. 75 


\section{CLASIFICACIÓN TECNOLÓGICA}

\section{DISTRIBUCION DE SOPORTES}

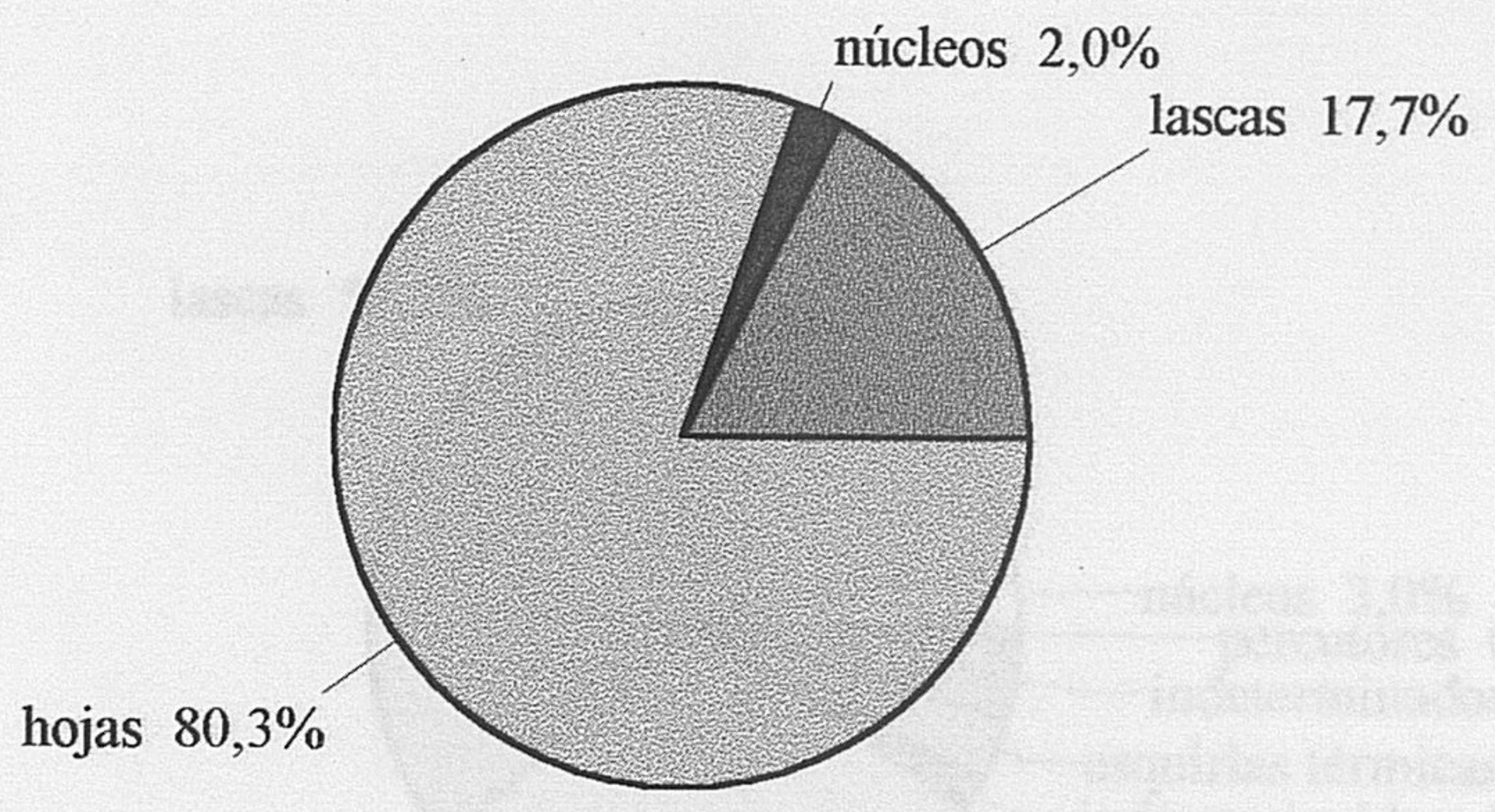

Gráfico 76. Fase estratigráfica 10b. Neolítico medio

\section{CLASIFICACIÓN TIPOLÓGICA}

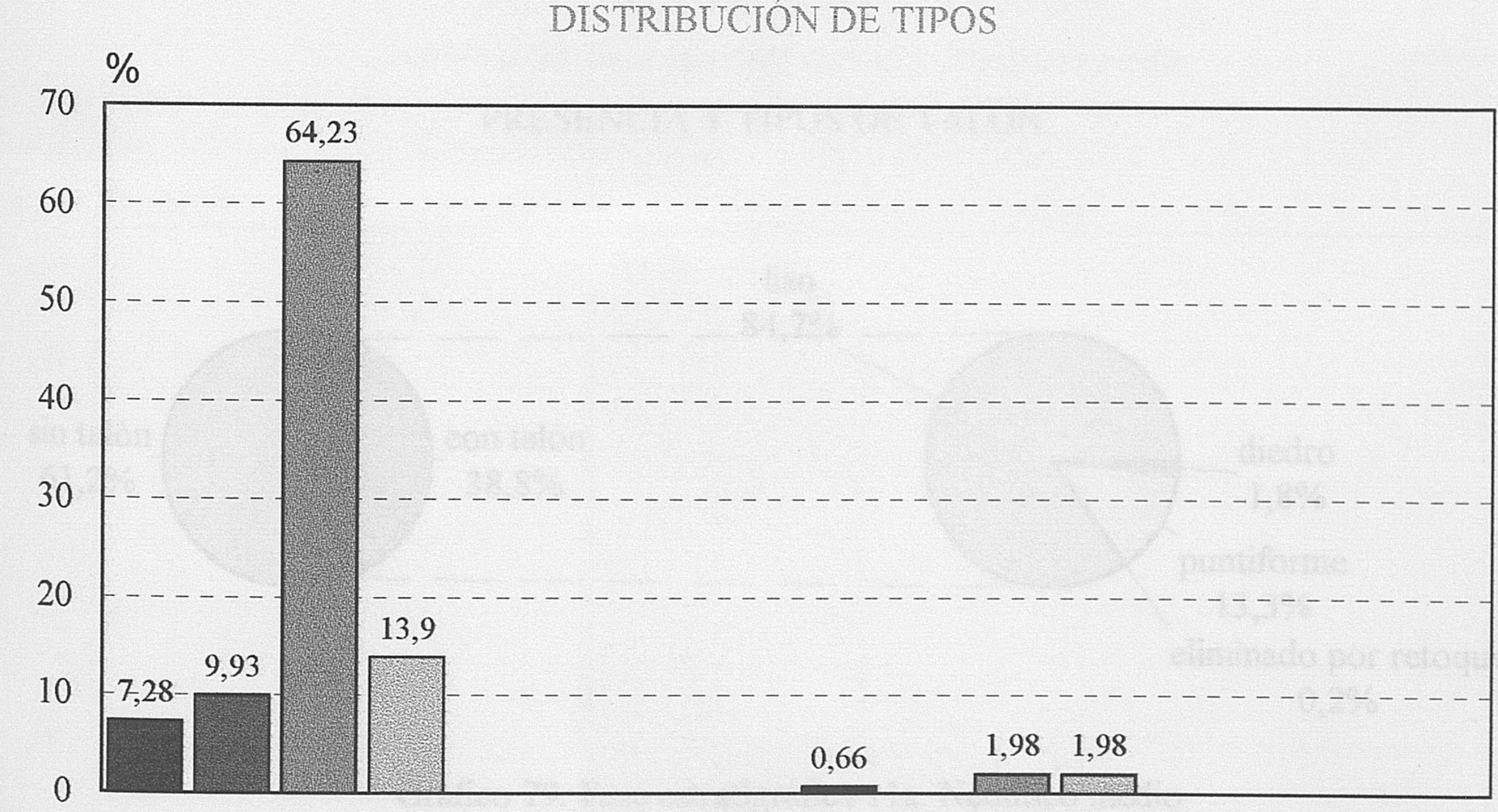

Tipo 1a Tipo $1 \mathrm{~b}$ Tipo 2a Tipo 2b Tipo 3 Tipo 4 Tipo 5 Tipo 6 Tipo 7 Tipo 8 Tipo 9 Tipo 10 Tipo 11 Tipo 12 Tipo 13 Tipo 14

Gráfico 77. Fase estratigráfica 10b. Neolítico medio 


\section{CLASIFICACIÓN TECNOLÓGICA}

\section{TOTAL DE LA INDUSTRIA}

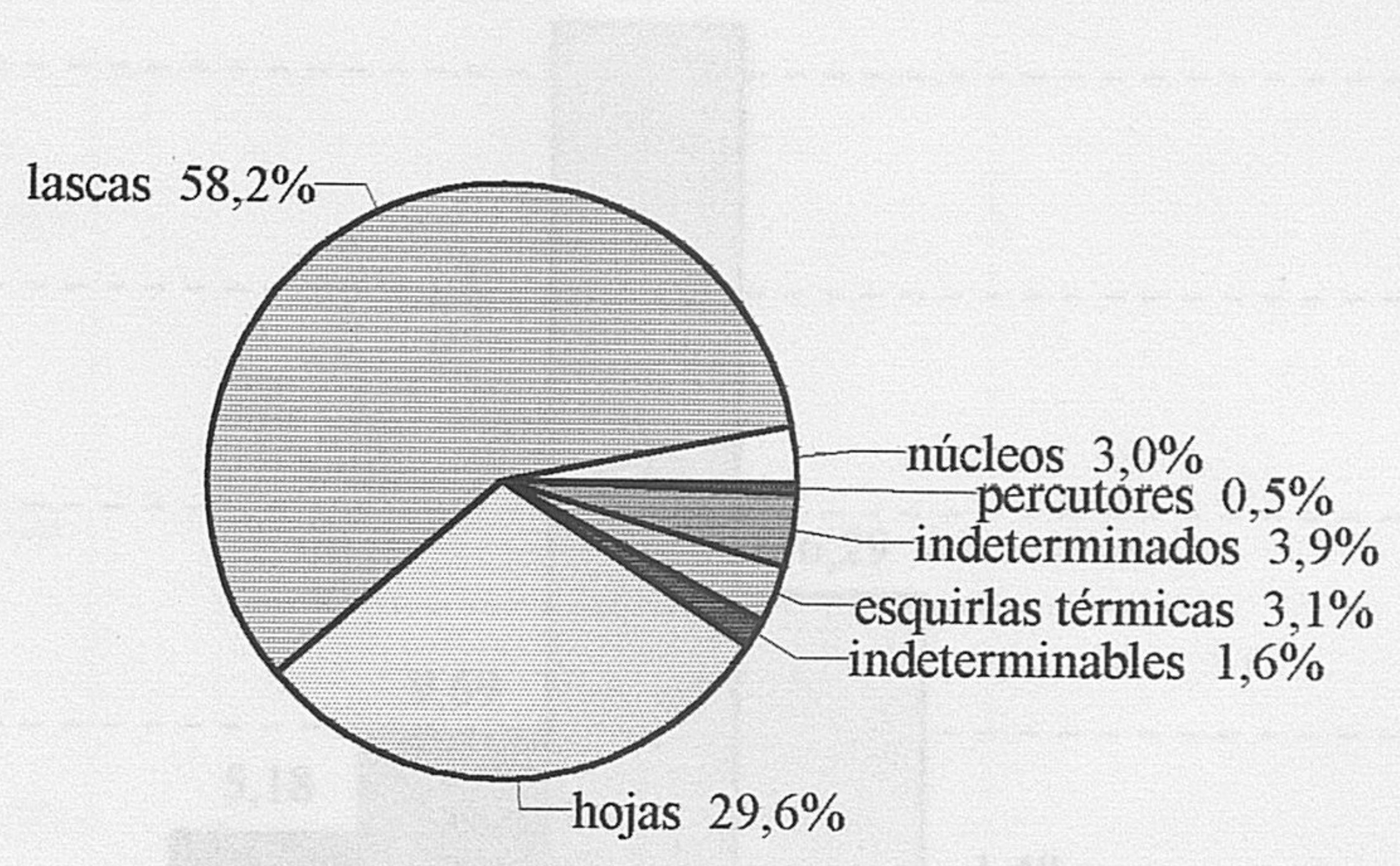

Gráfico 78. Fase estratigráfica 11a. Neolítico medio

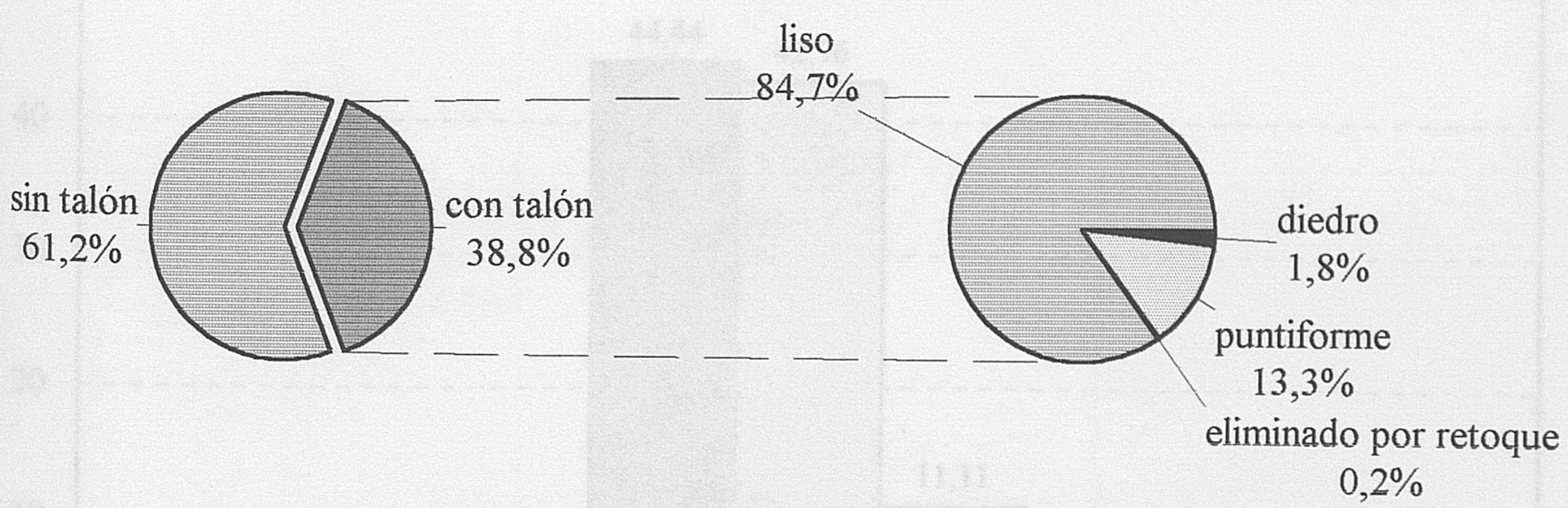

Gráfico 79. Fase estratigráfica 11a. Neolítico medio 


\section{CLASIFICACIÓN TECNOLÓGICA}

\section{HOJAS PRISMÁTICAS LONGITUDES}

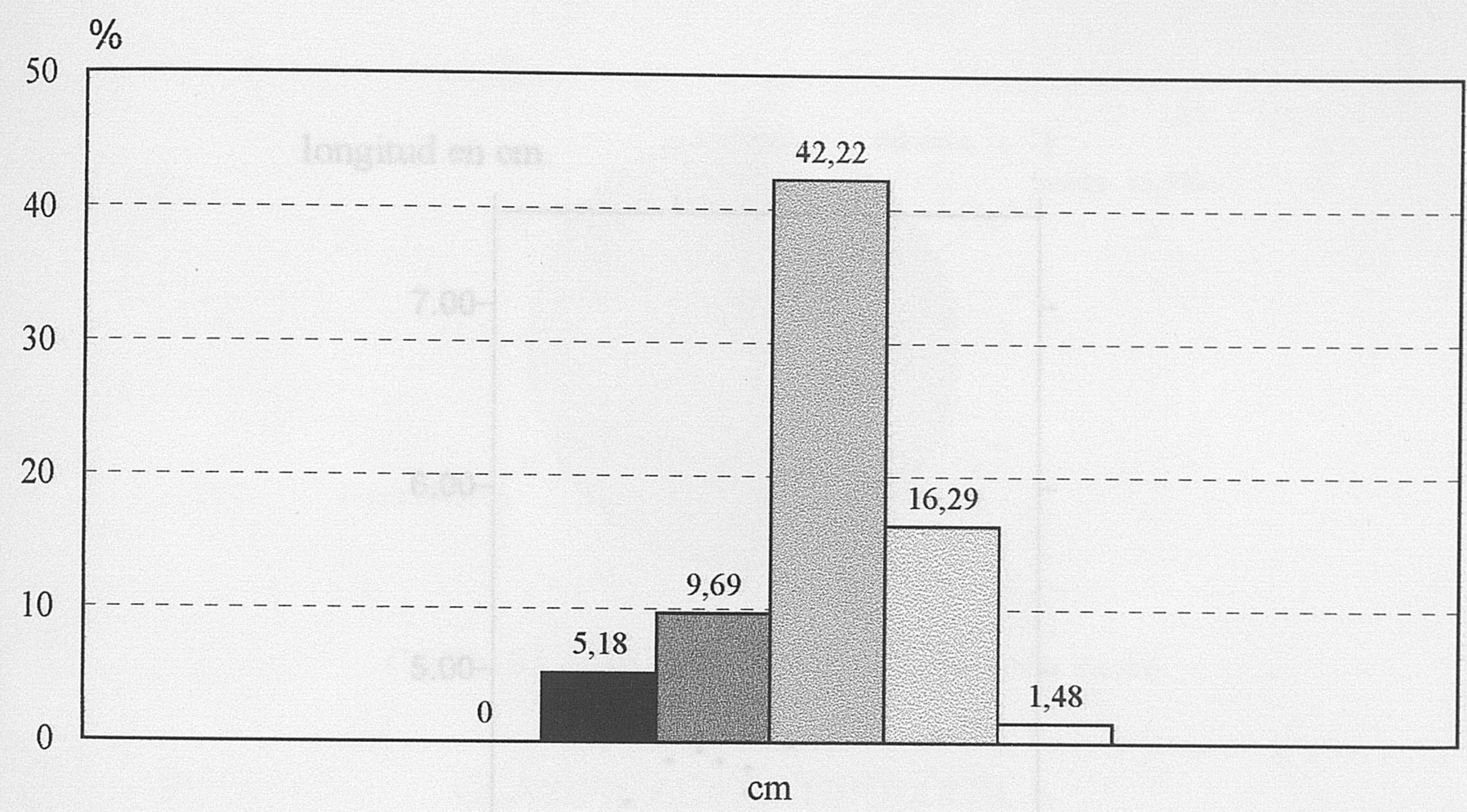

$0-1 \quad 1-2 \quad 2-3 \quad 3-4 \quad 4-5 \quad 5-6$

Gráfico 80. Fase estratigráfica 11a. Neolítico medio

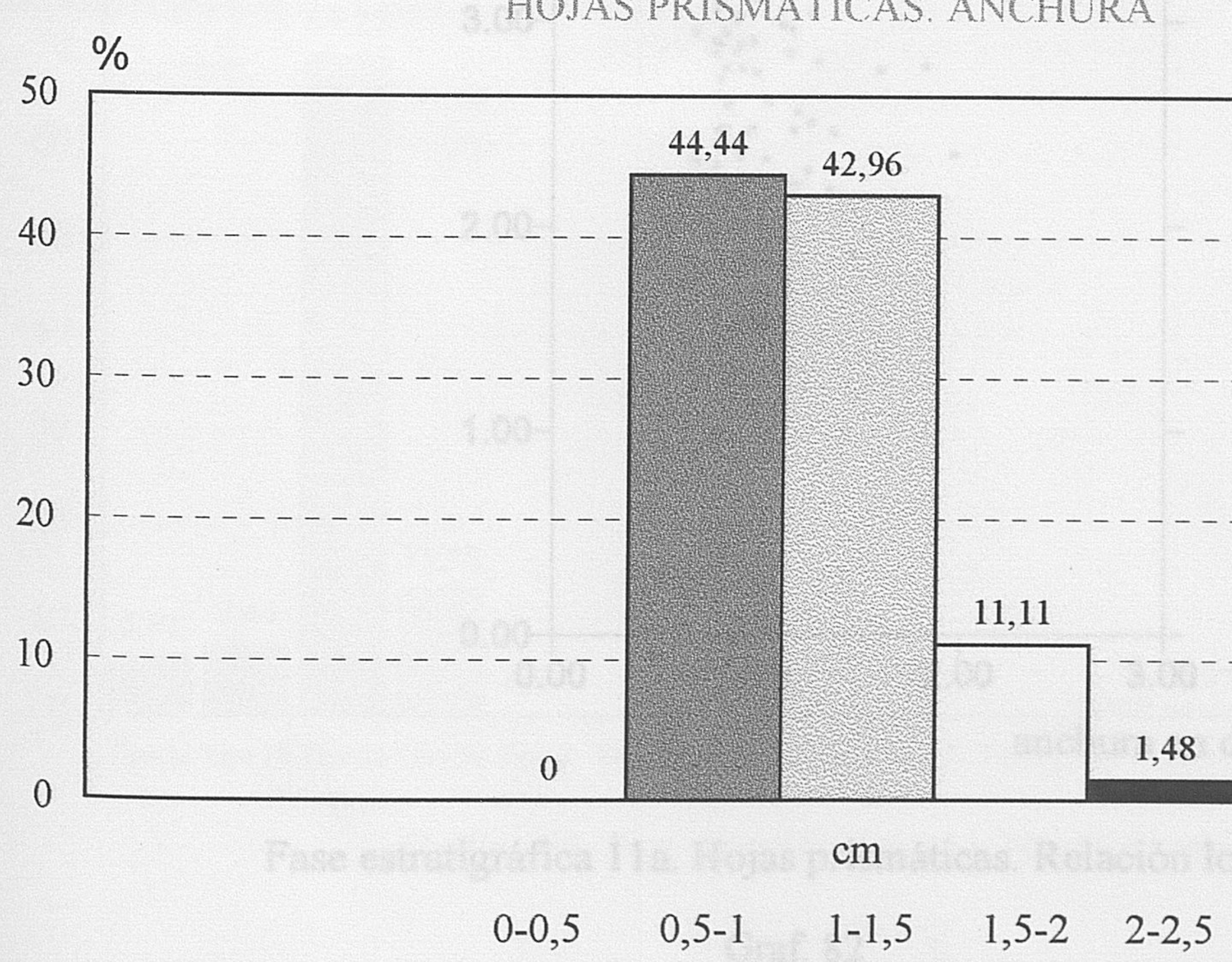

Gráfico 81Fase estratigráfica 11a. Neolítico medio 
longitud en $\mathrm{cm}$.

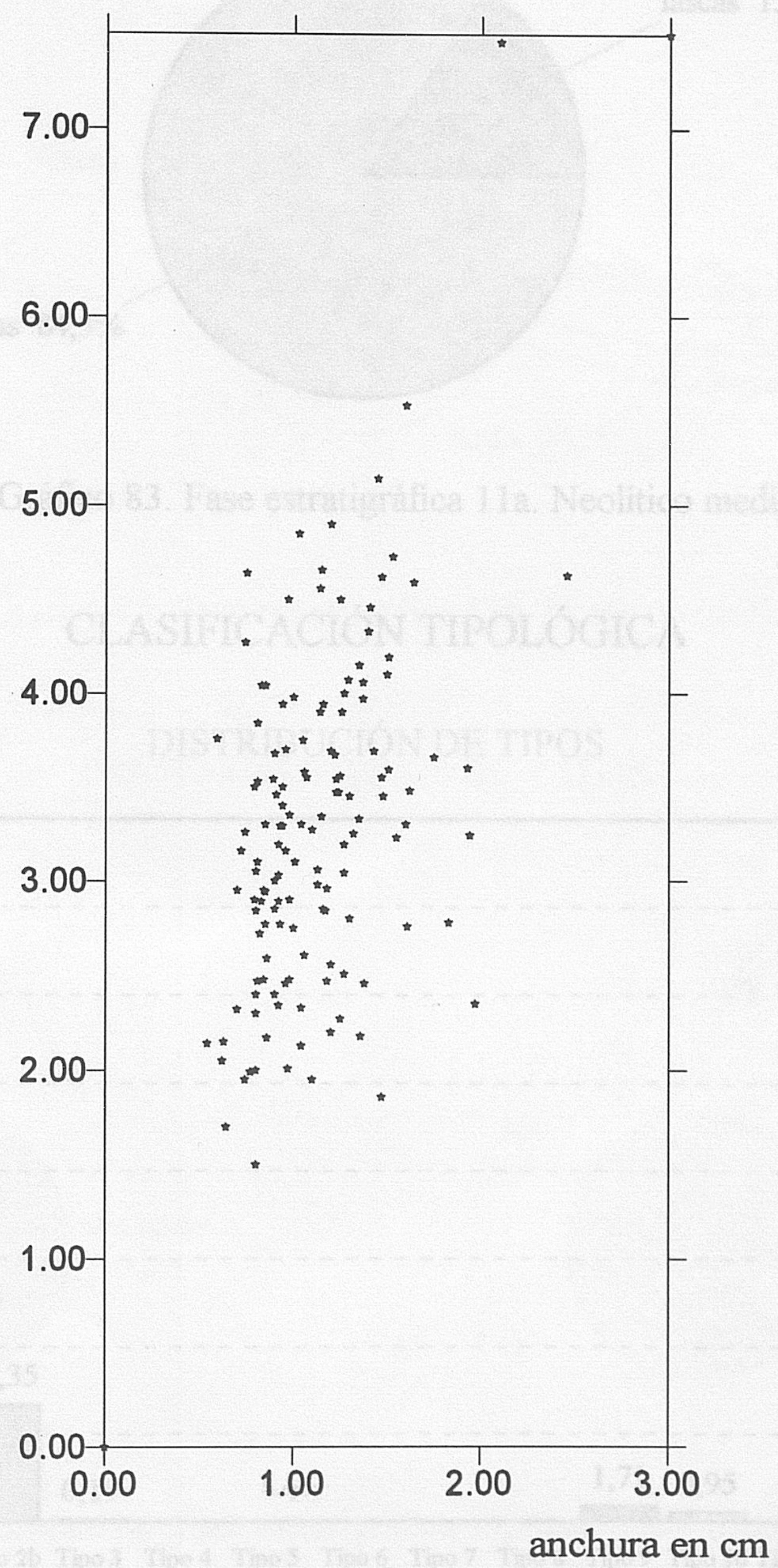

Fase estratigráfica 11a. Hojas prismáticas. Relación longitud anchura Graf. 82 


\section{CLASIFICACIÓN TECNOLÓGICA}

\section{DISTRIBUCIÓN DE SOPORTES}

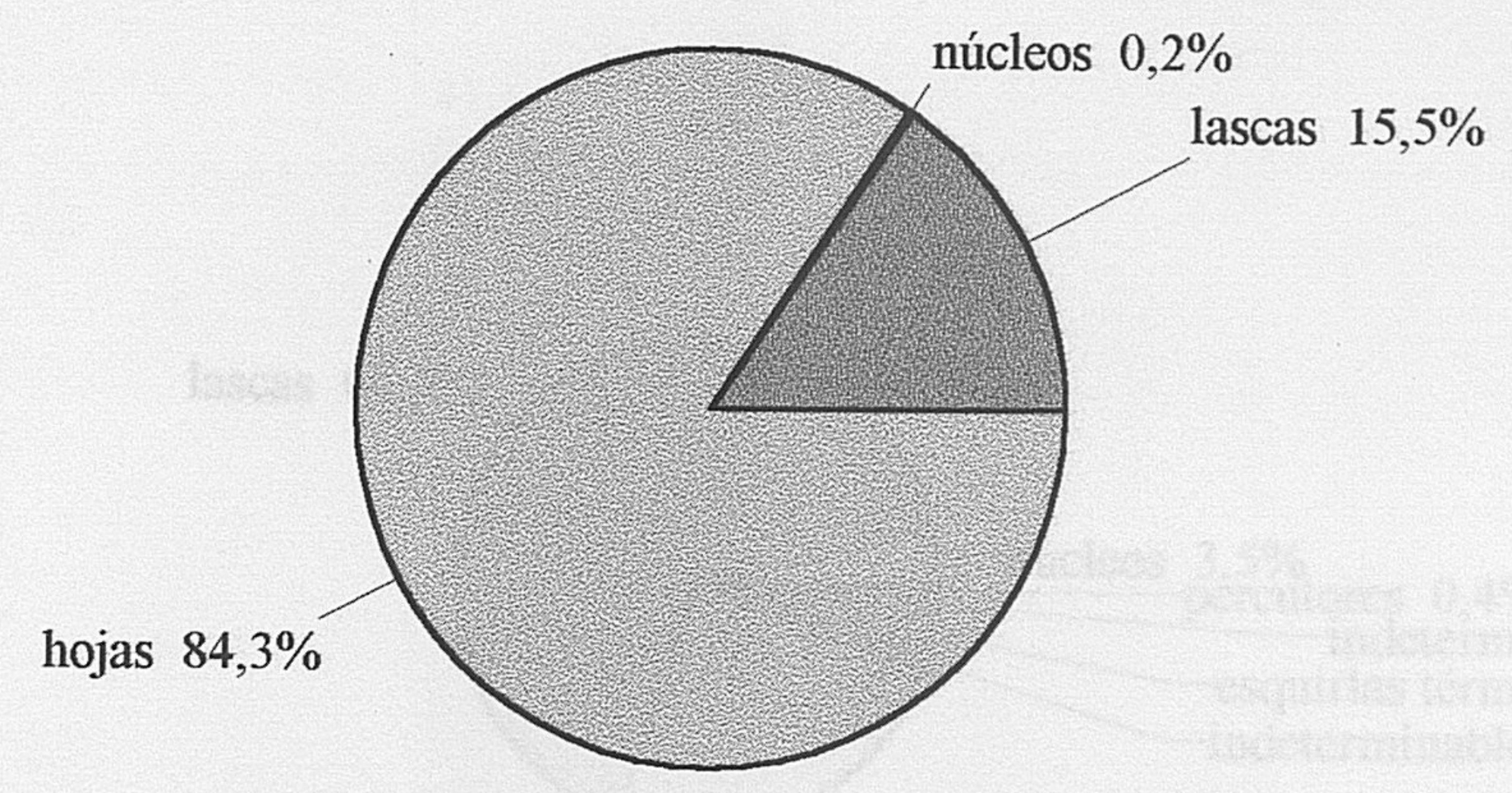

Gráfico 83. Fase estratigráfica 11a. Neolítico medio

\section{CLASIFICACIÓN TIPOLÓGICA}

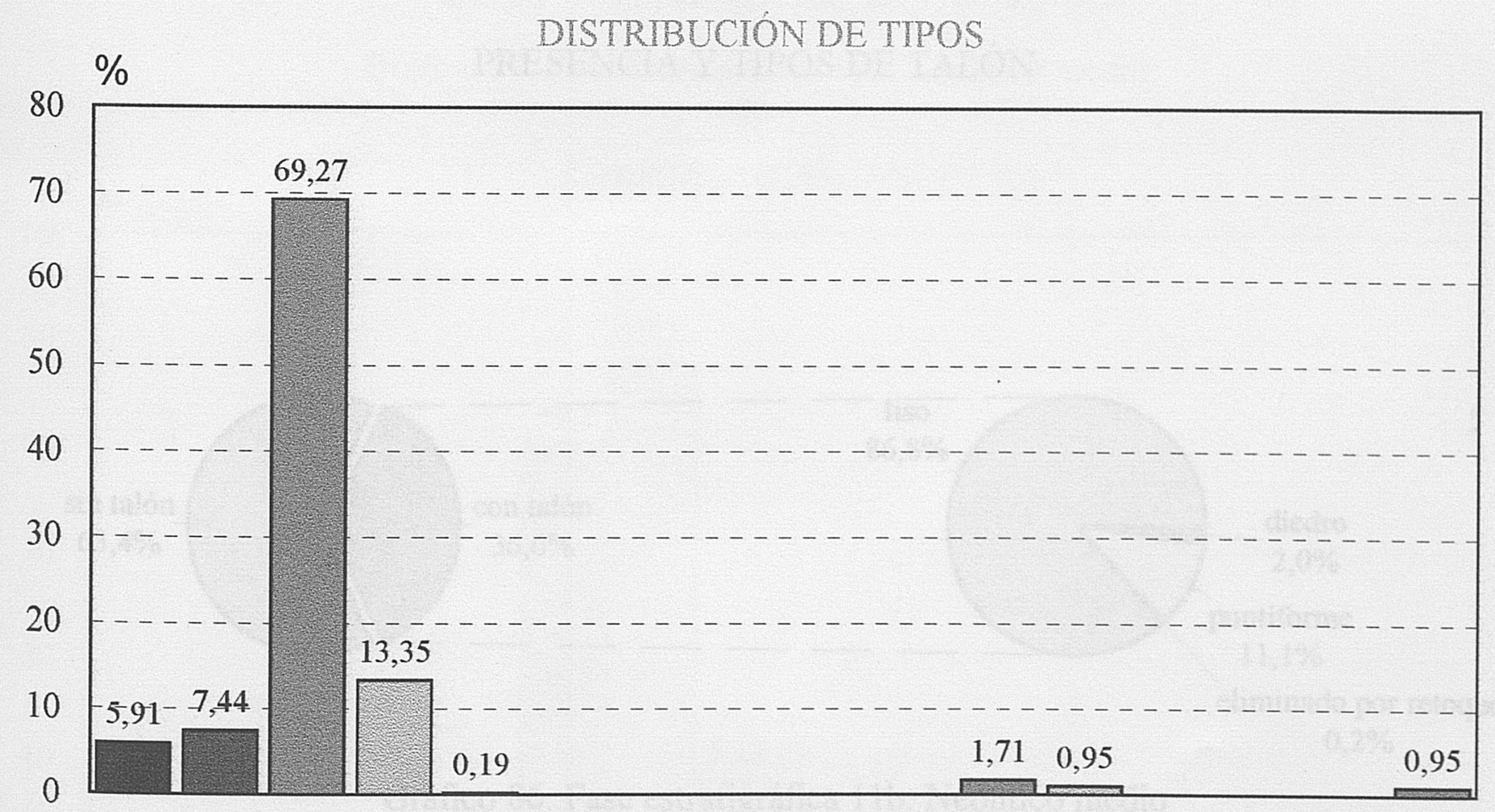

Tipo 1a Tipo $1 \mathrm{~b}$ Tipo 2a Tipo 2b Tipo 3 Tipo 4 Tipo 5 Tipo 6 Tipo 7 Tipo 8 Tipo 9 Tipo 10 Tipo 11 Tipo 12 Tipo 13 Tipo 14

Gráfico 84. Fase estratigráfica 11a. Neolítico medio 


\title{
CLASIFICACIÓN TECNOLÓGICA
}

\author{
TOTAL DE LA INDUSTRIA
}

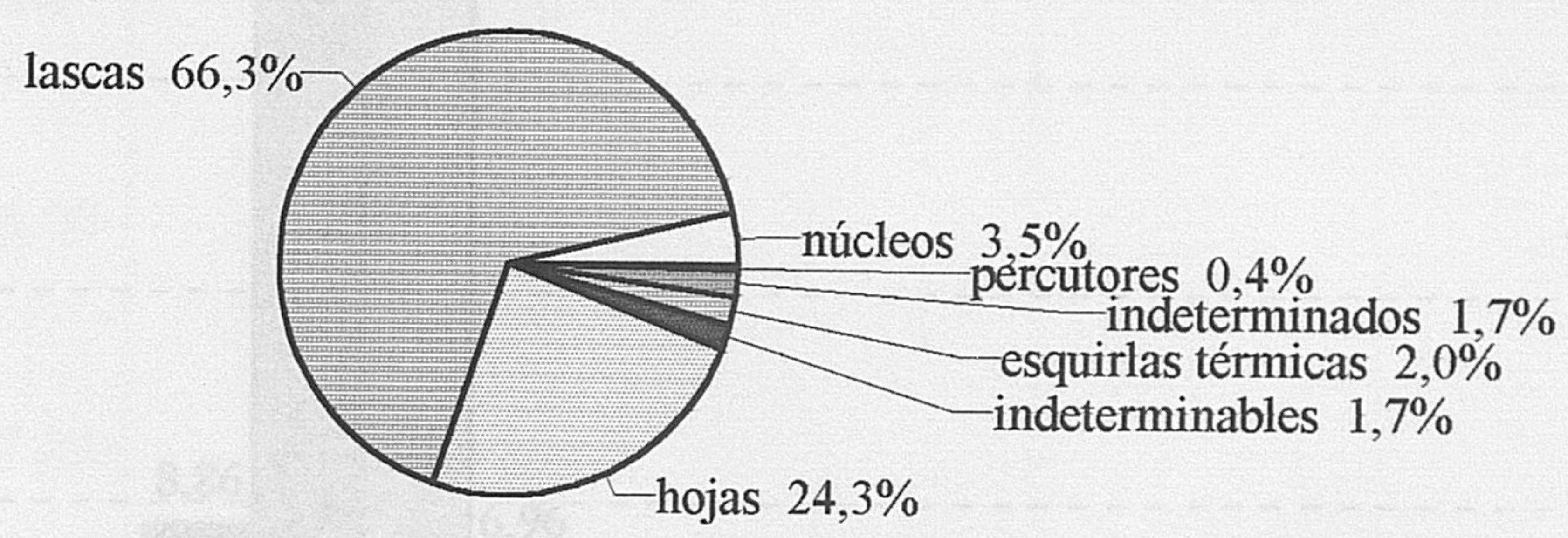

Gráfico 85. Fase estratigráfica 11b. Neolítico medio

\section{PRESENCIA Y TIPOS DE TALÓN}

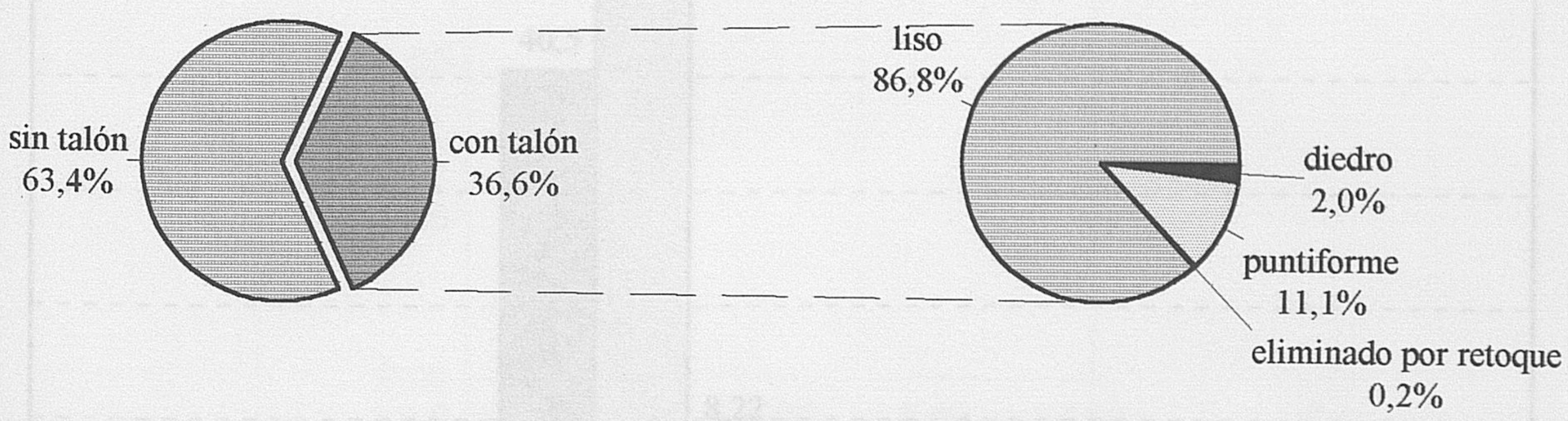

Gráfico 86. Fase estratigráfica 11b. Neolítico medio 


\section{CLASIFICACIÓN TECNOLÓGICA}

\section{HOJAS PRISMÁTICAS LONGITUDES}

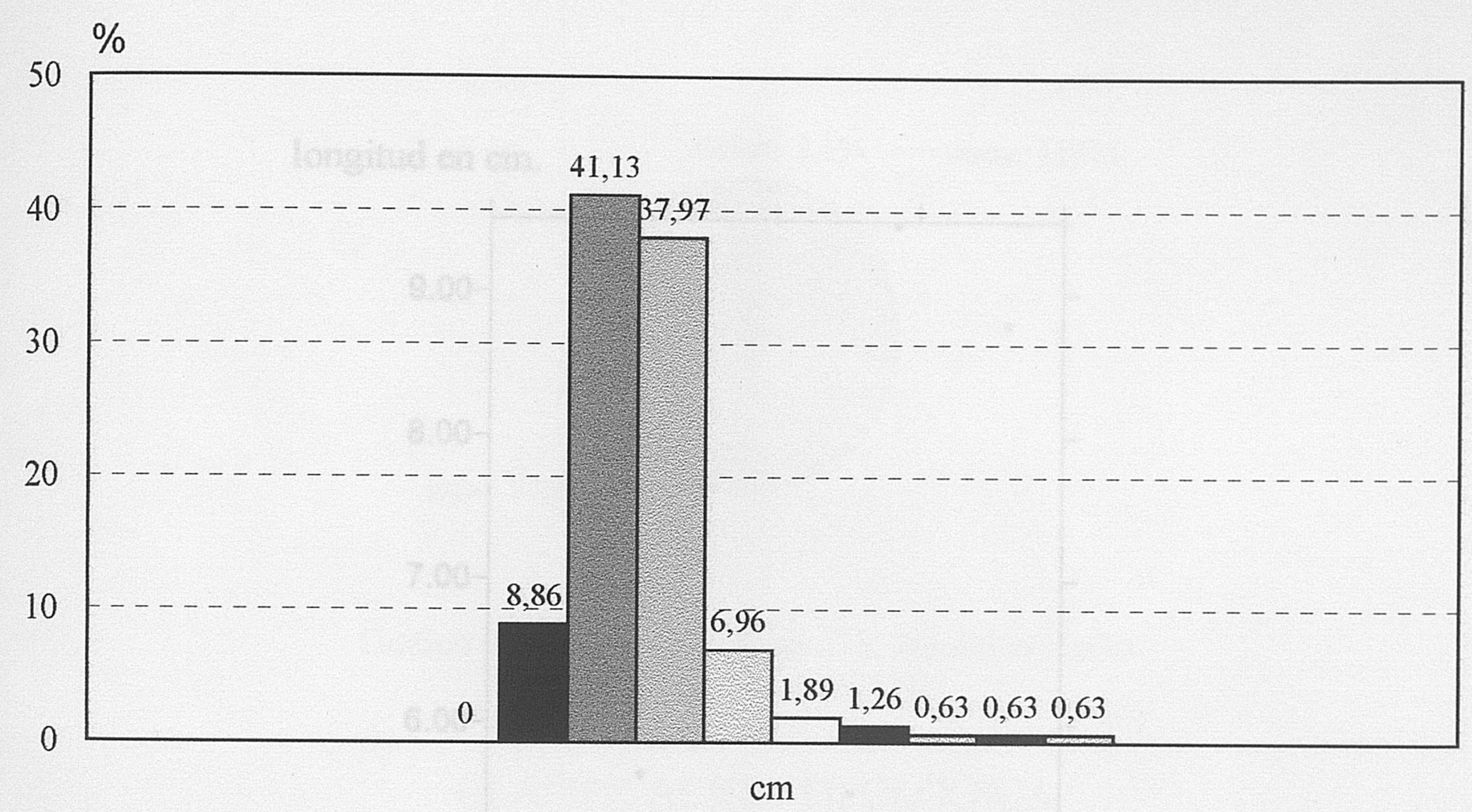

$\begin{array}{llllllllll}0-1 & 1-2 & 2-3 & 3-4 & 4-5 & 5-6 & 6-7 & 7-8 & 8-9 & 9-10\end{array}$

Gráfico 87. Fase estratigráfica 11 b. Neolítico medio

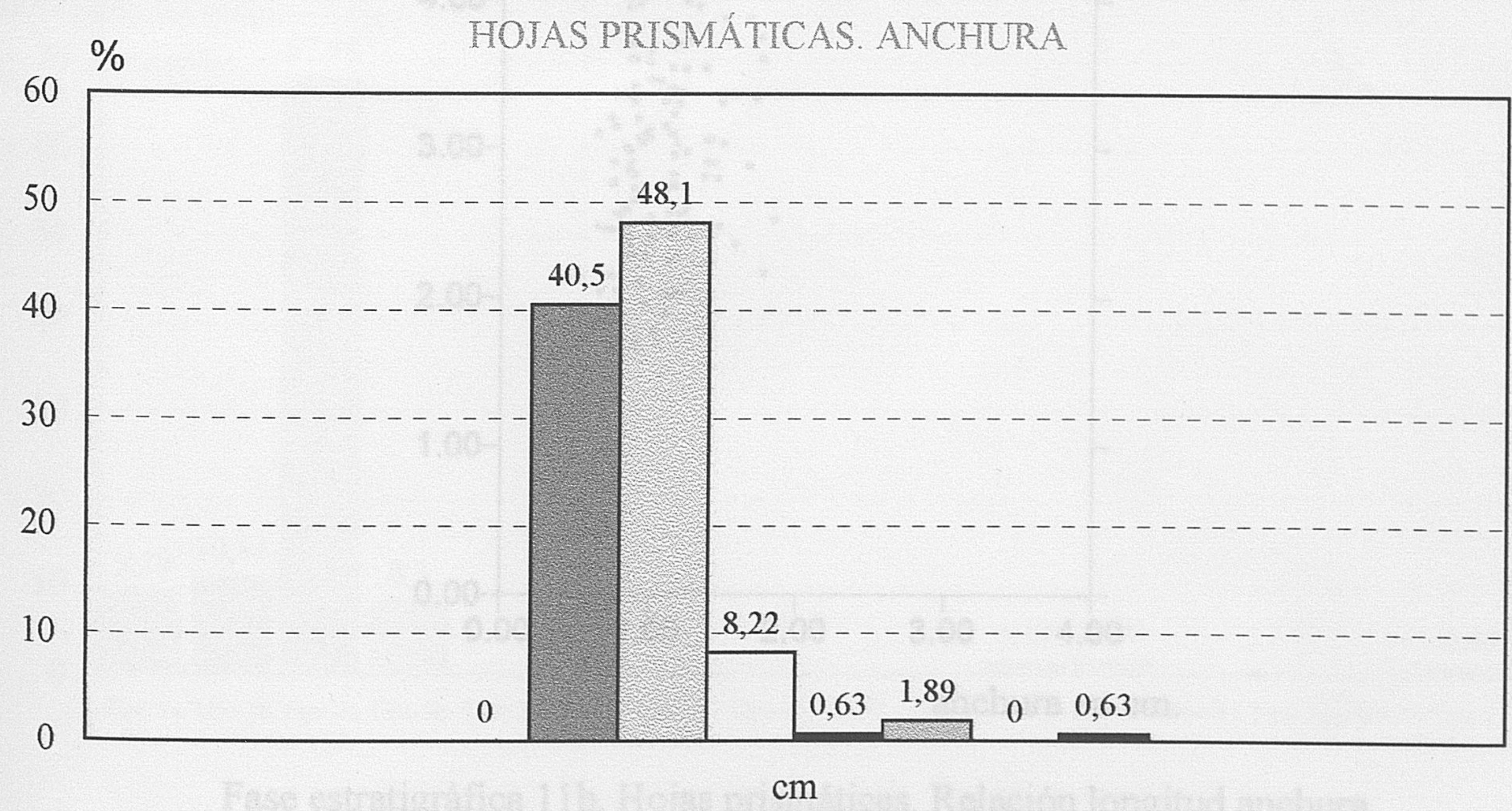

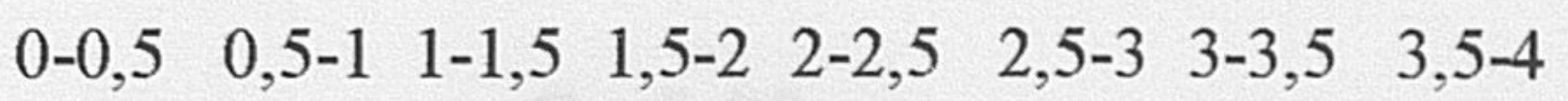

Gráfico 88. Fase estratigráfica 11b. Neolítico medio 
longitud en $\mathrm{cm}$.

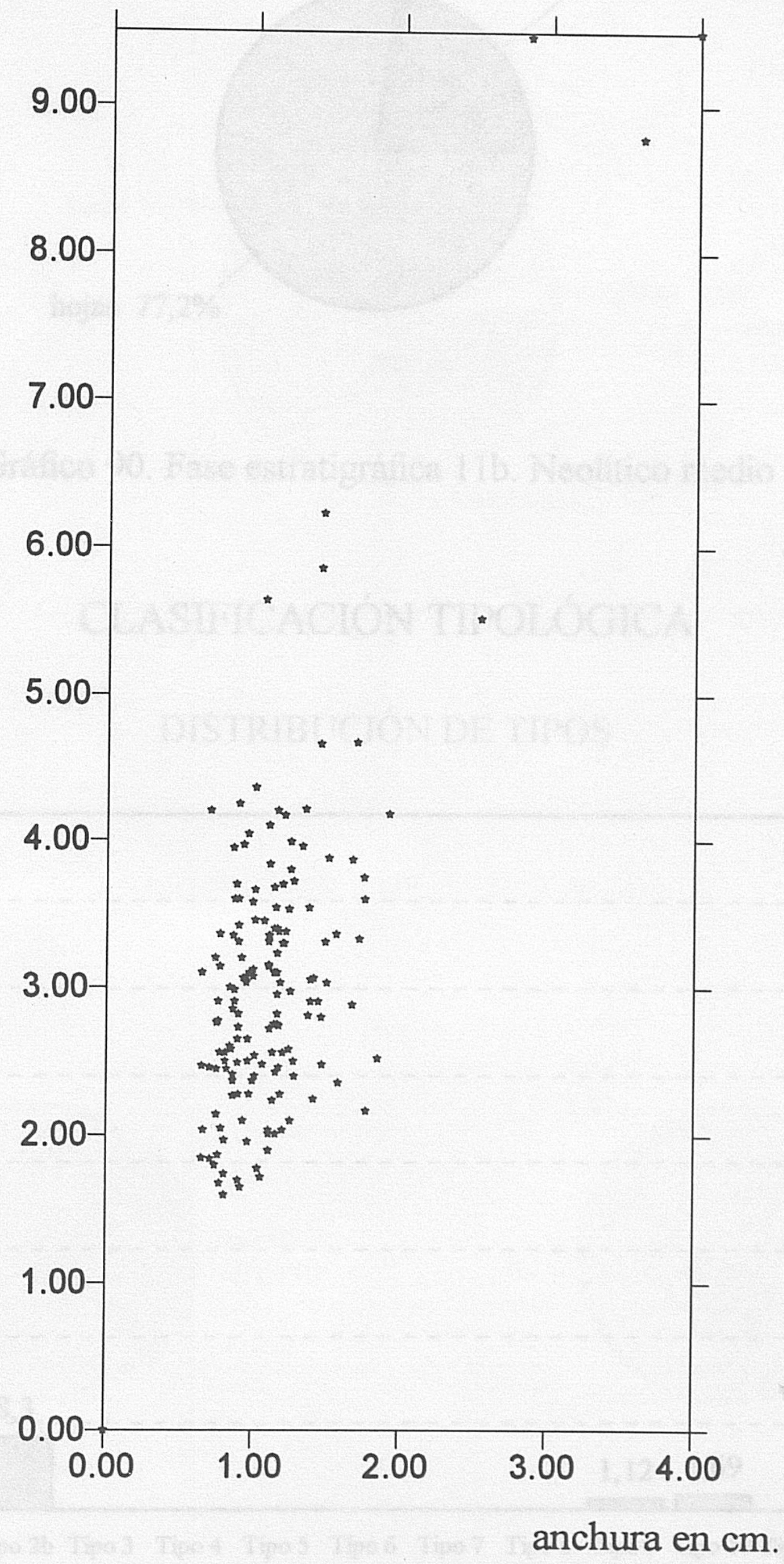

Fase estratigráfica $11 \mathrm{~b}$. Hojas prismáticas. Relación longitud anchura Graf. 89 


\section{CLASIFICACIÓN TECNOLÓGICA}

\section{DISTRIBUCIÓN DE SOPORTES}

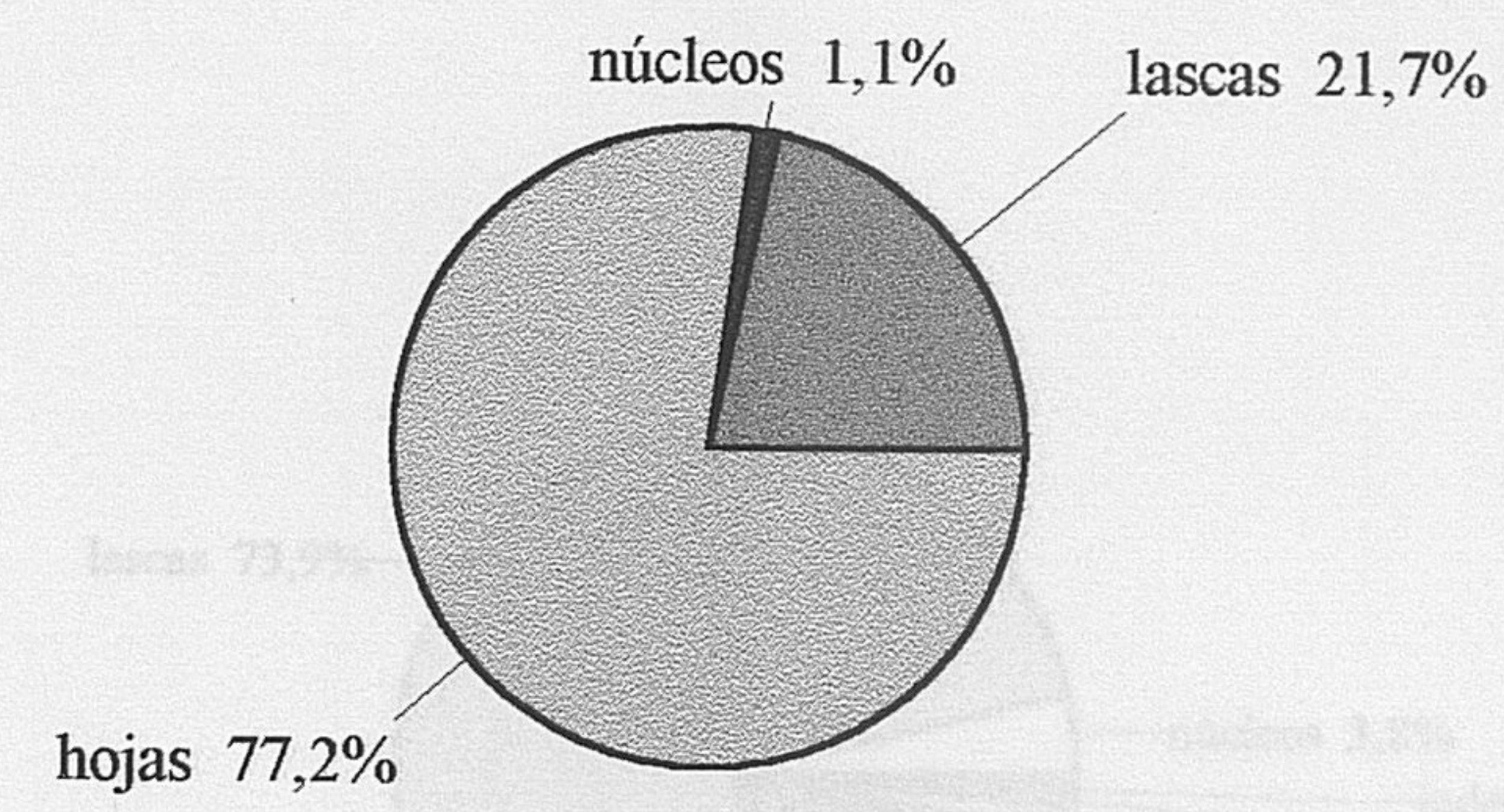

Gráfico 90. Fase estratigráfica 11b. Neolítico medio

\section{CLASIFICACIÓN TIPOLÓGICA}

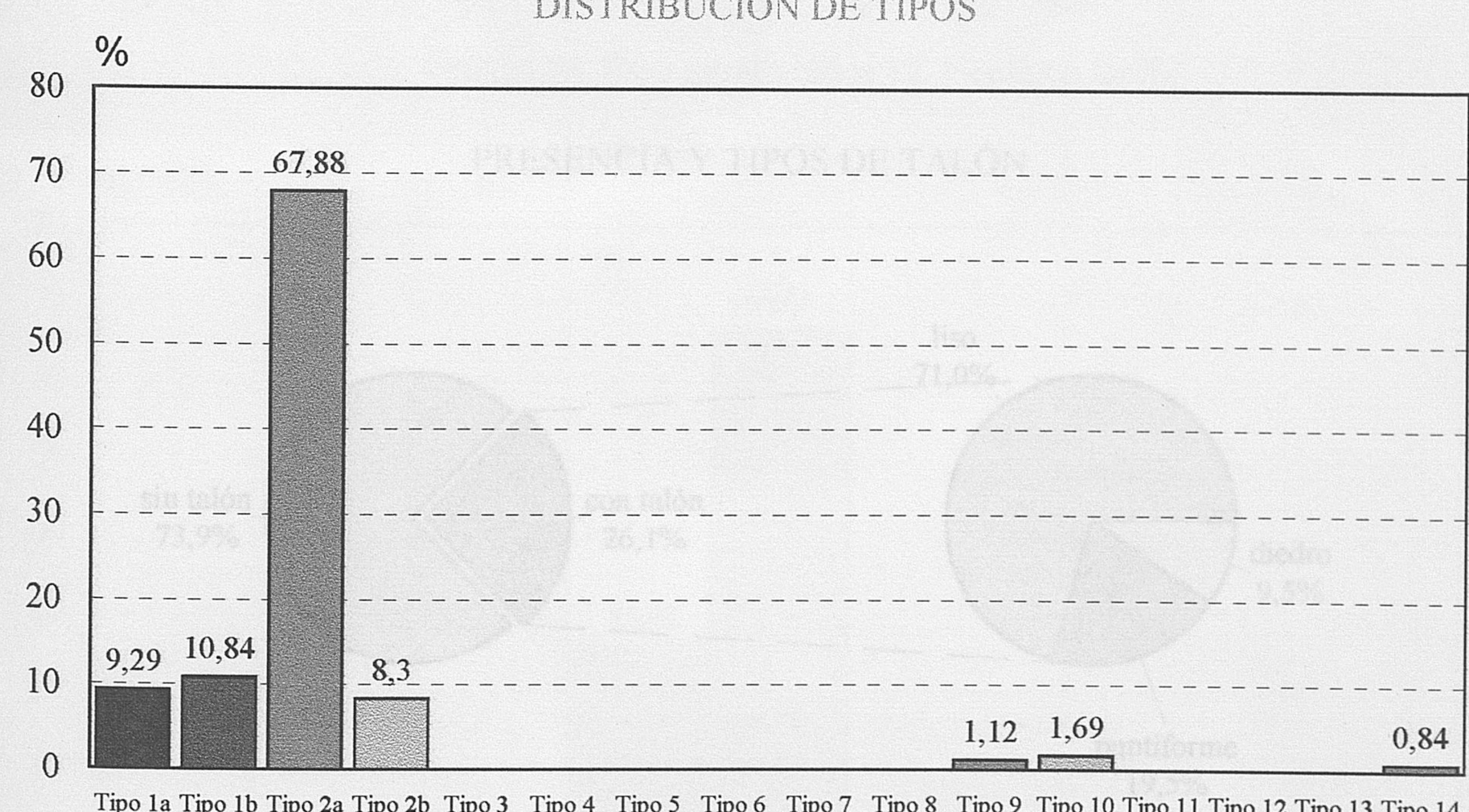

Gráfico 91. Fase estratigráfica 11b. Neolítico medio 


\title{
CLASIFICACIÓN TECNOLÓGICA
}

\author{
TOTAL DE LA INDUSTRIA
}

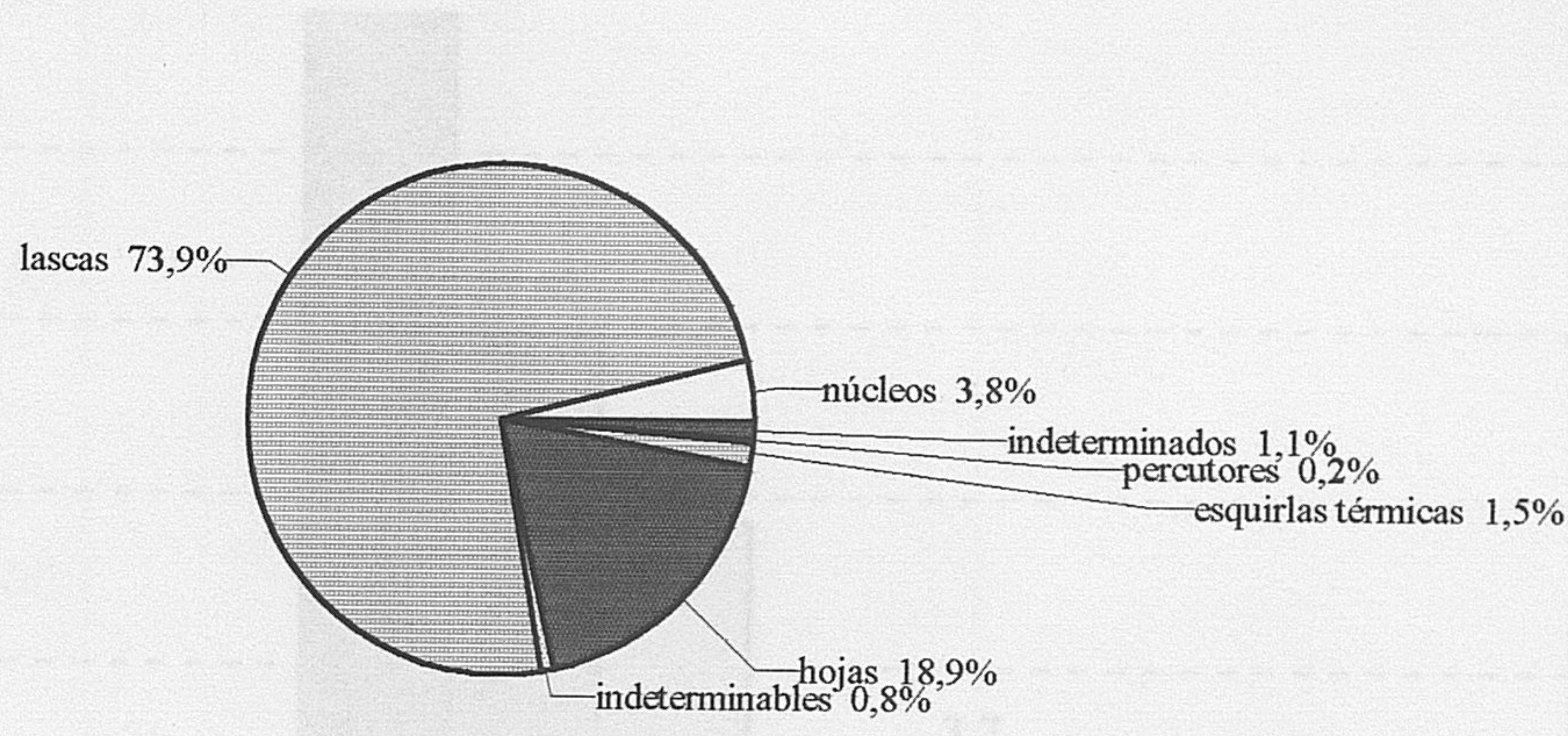

Gráfico 92. Fase estratigráfica 12. Neolítico tardío

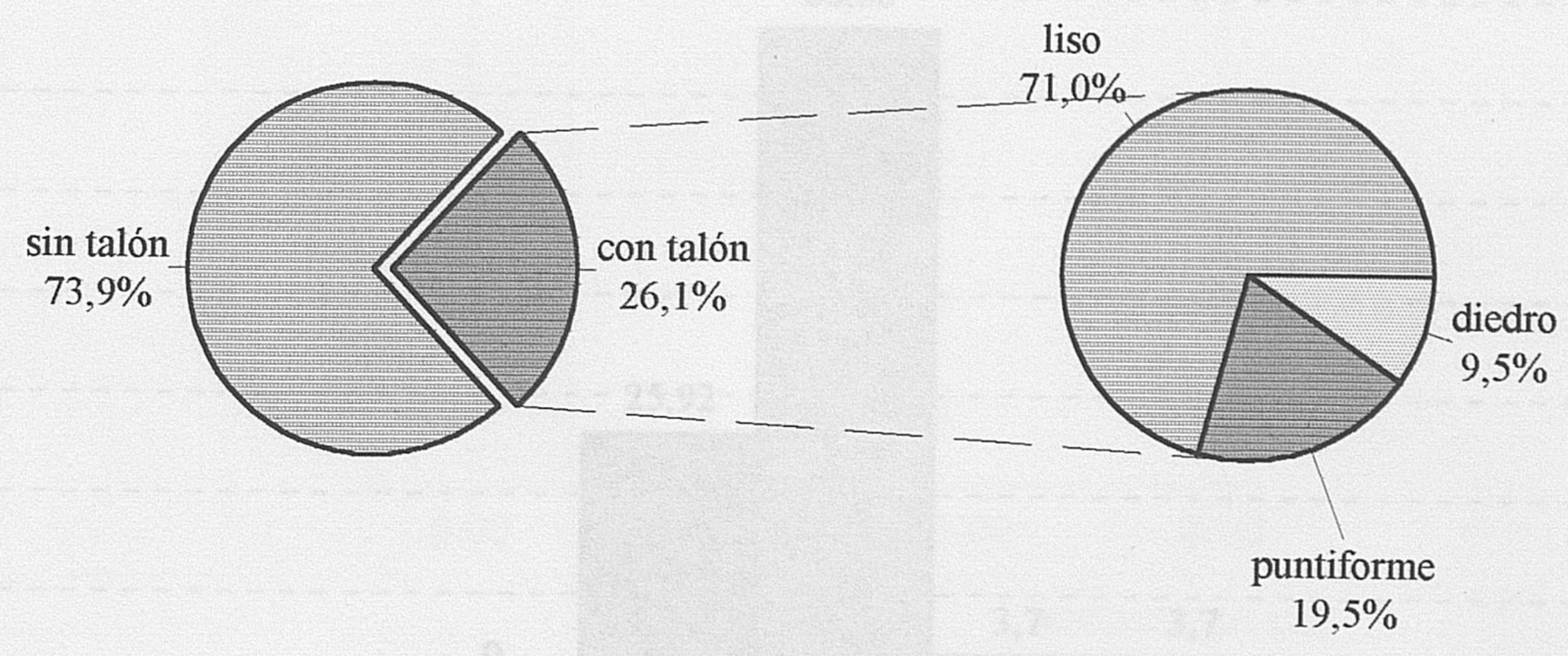

Gráfico 93. Fase estratigráfica 12. Neolítico tardio 


\section{CLASIFICACIÓN TECNOLÓGICA}

HOJAS PRISMÁTICAS. LONGITUDES

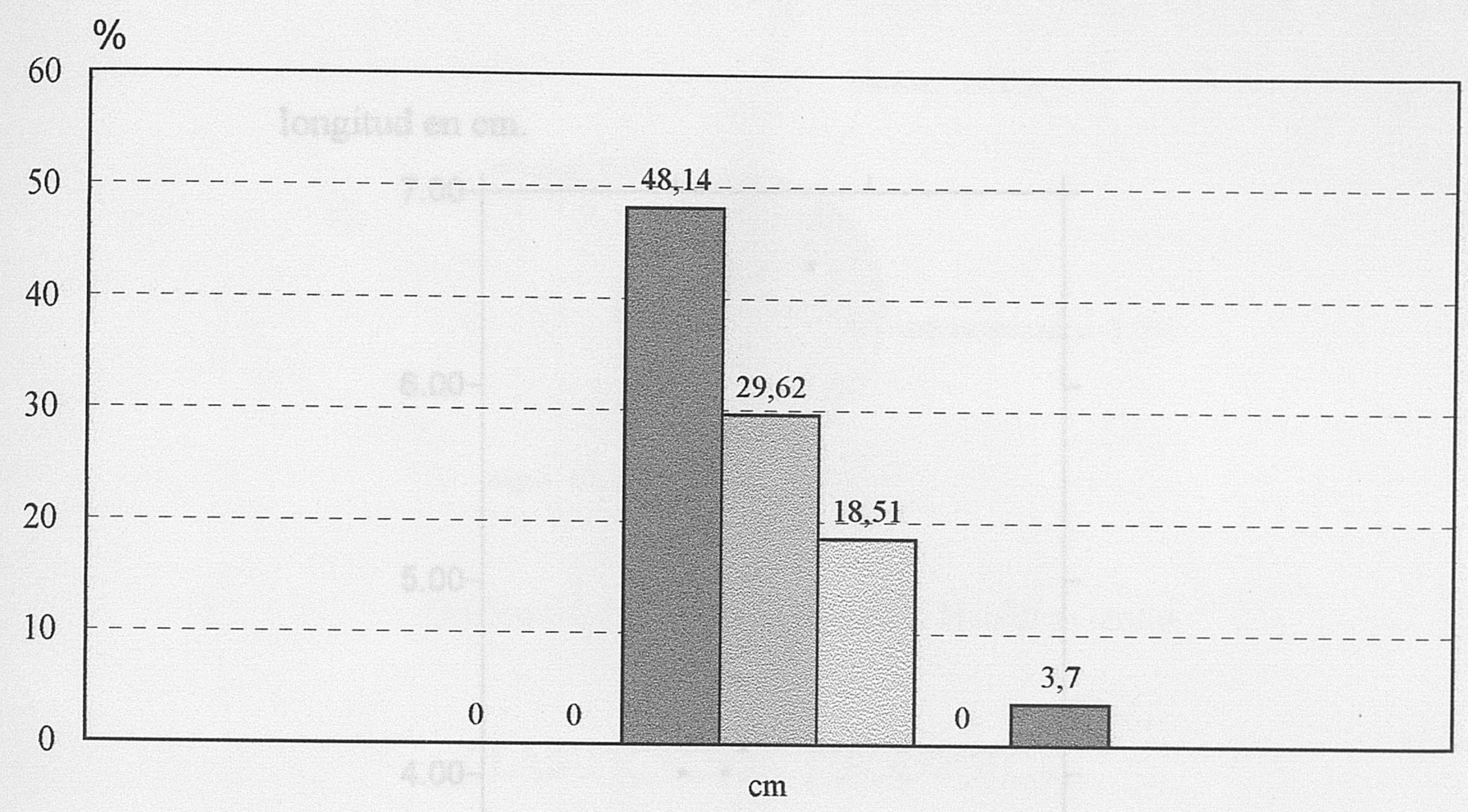

$\begin{array}{lllllll}0-1 & 1-2 & 2-3 & 3-4 & 4-5 & 5-6 & 6-7\end{array}$

Gráfico 94. Fase estratigráfica 12. Neolítico tardío

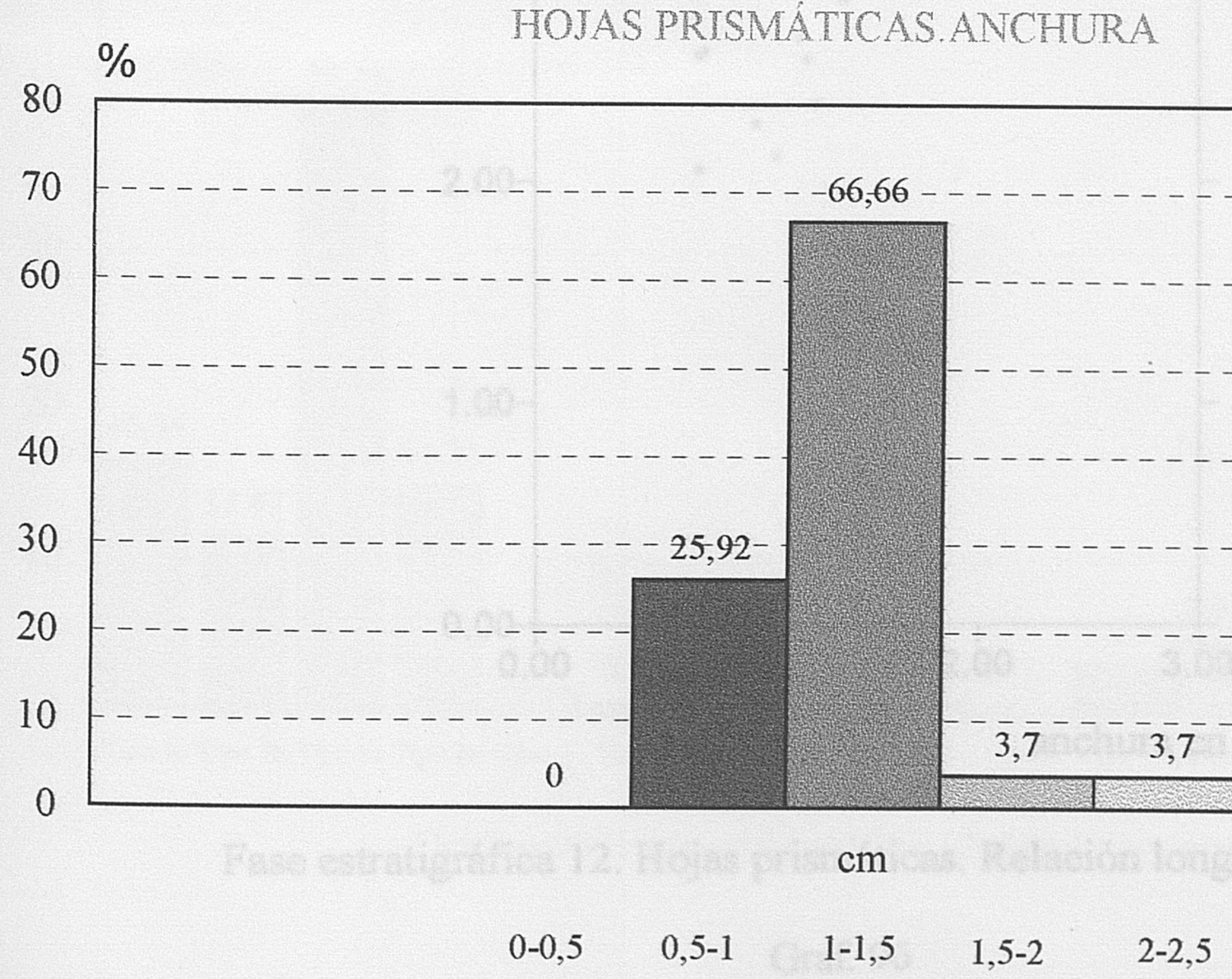

Gráfico 95. Fase estratigráfica 12. Neolítico tardio 
longitud en $\mathrm{cm}$.

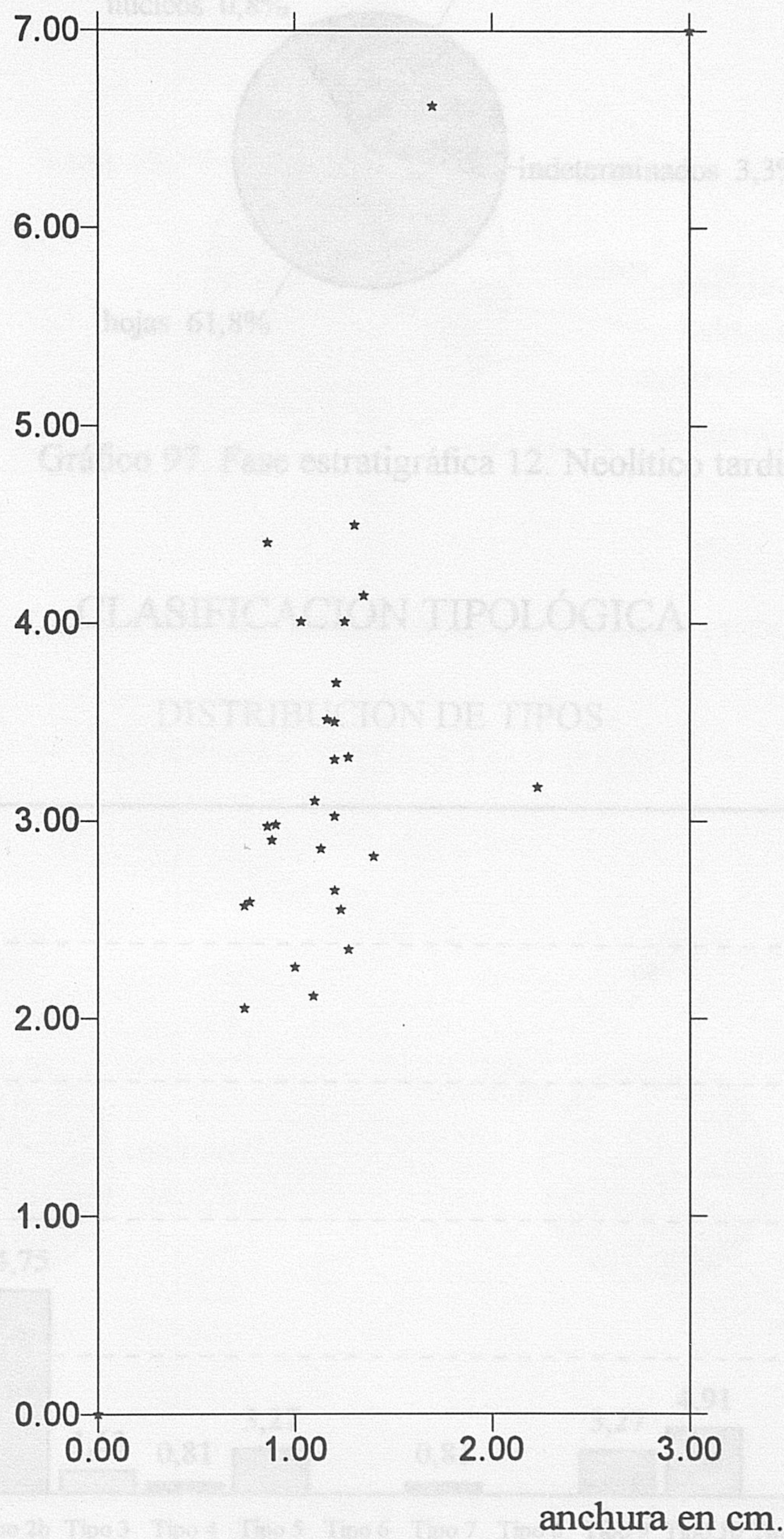

Fase estratigráfica 12. Hojas prismáticas. Relación longirtud-anchura Graf. 96 


\section{CLASIFICACIÓN TECNOLÓGICA}

\section{DISTRIBUCIÓN DE SOPORTES}

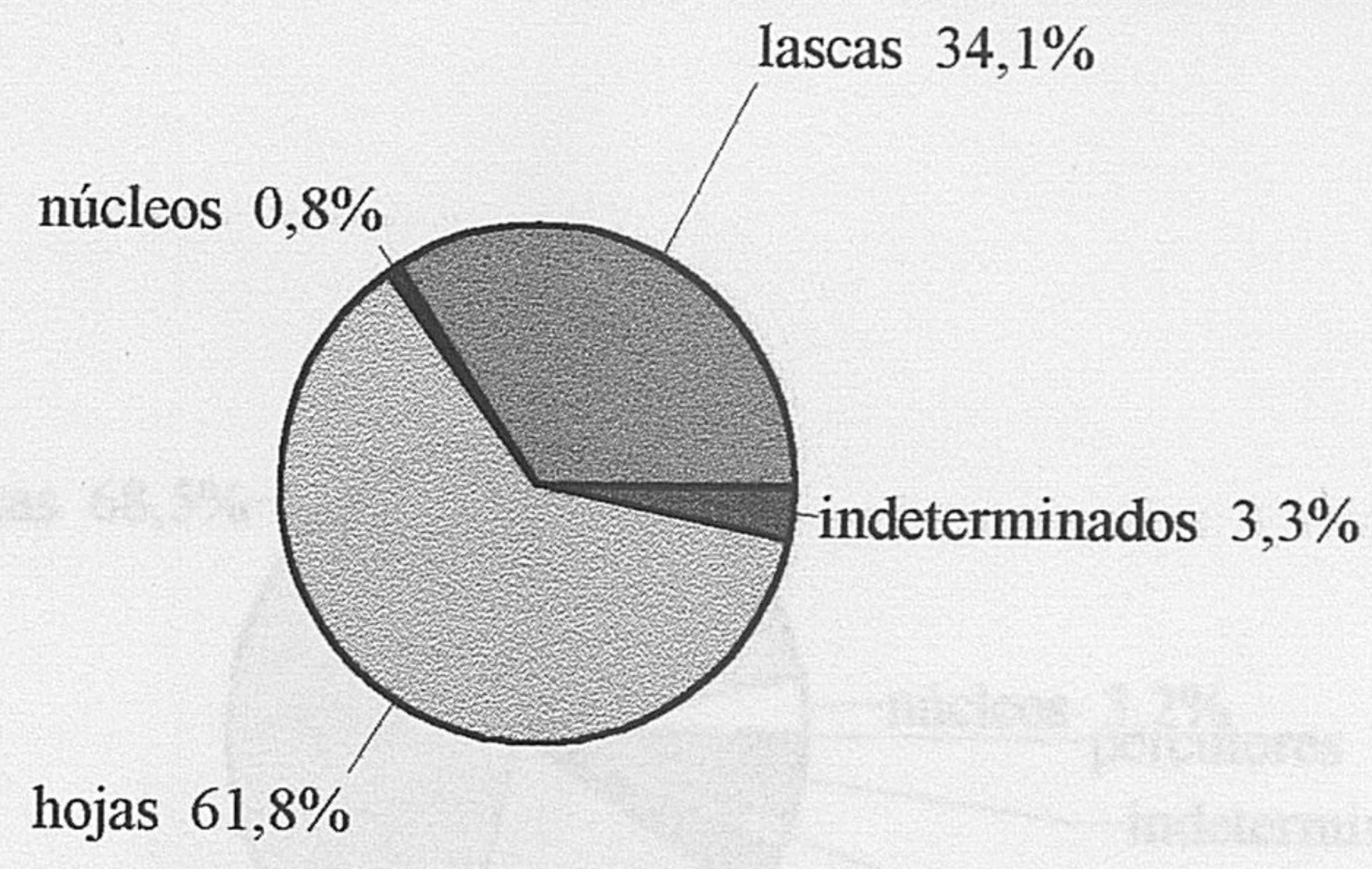

Gráfico 97. Fase estratigráfica 12. Neolítico tardio

\section{CLASIFICACIÓN TIPOLÓGICA}

\section{DISTRIBUCIÓN DE TIPOS}

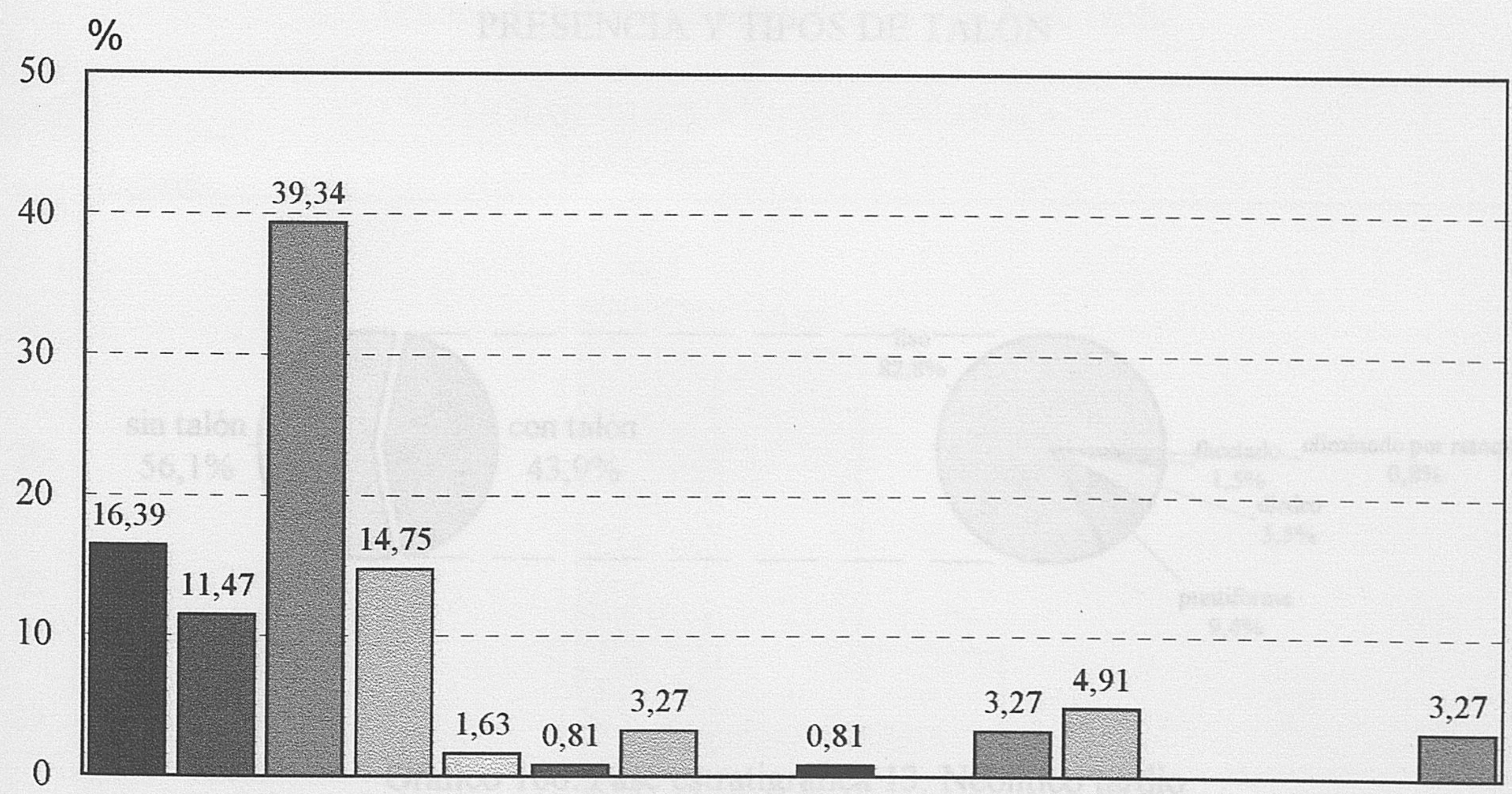

Tipo 1a Tipo $1 \mathrm{~b}$ Tipo 2a Tipo $2 \mathrm{~b}$ Tipo 3 Tipo 4 Tipo 5 Tipo 6 Tipo 7 Tipo 8 Tipo 9 Tipo 10 Tipo 11 Tipo 12 Tipo 13 Tipo 14

Gráfico 98. Fase estratigráfica 12. Neolítico tardio 


\section{CLASIFICACIÓN TECNOLÓGICA}

\section{TOTAL DE LA INDUSTRIA}

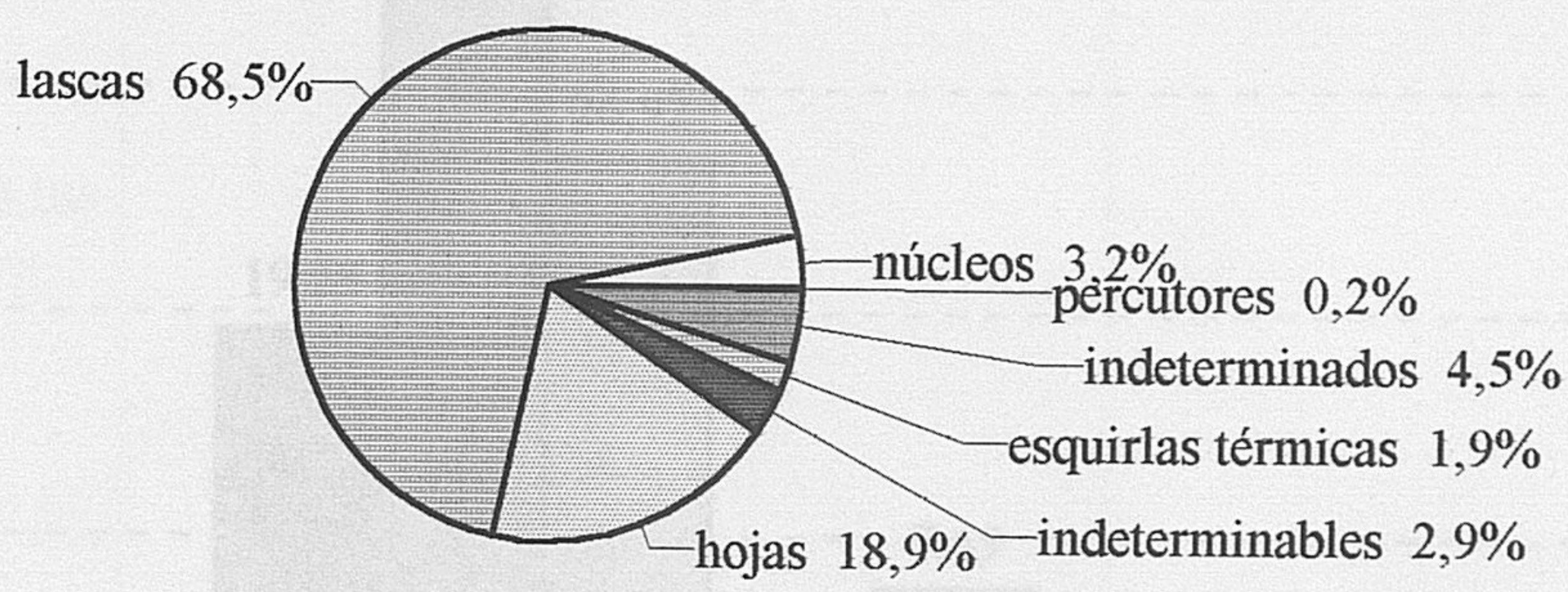

Gráfico 99. Fase estratigráfica 13. Neolítico tardío

\section{PRESENCIA Y TIPOS DE TALÓN}

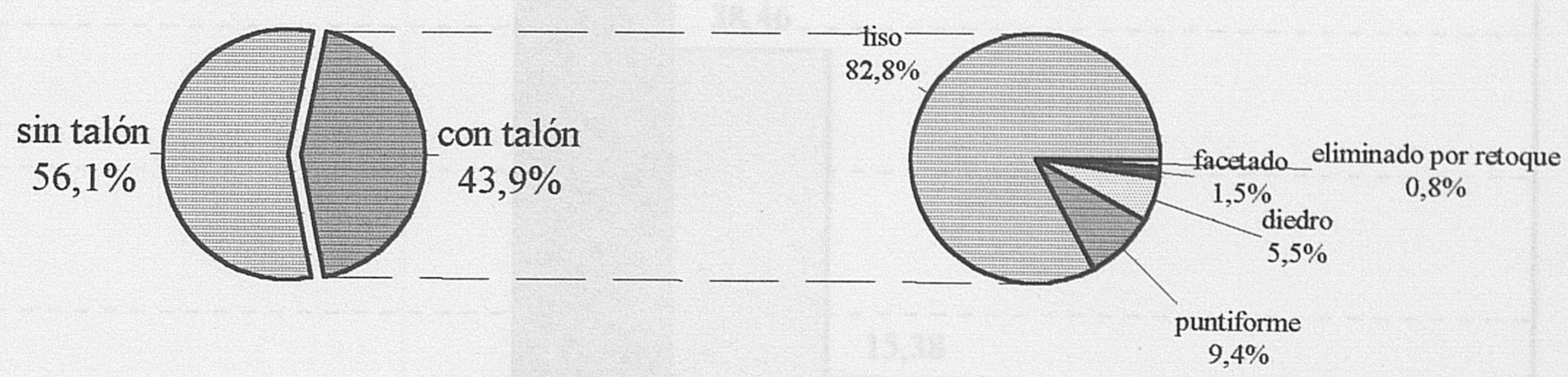

Gráfico 100. Fase estratigráfica 13. Neolítico tardio 


\section{CLASIFICACIÓN TECNOLÓGICA}

\section{HOJAS PRISMÁTICAS LONGITUDES}

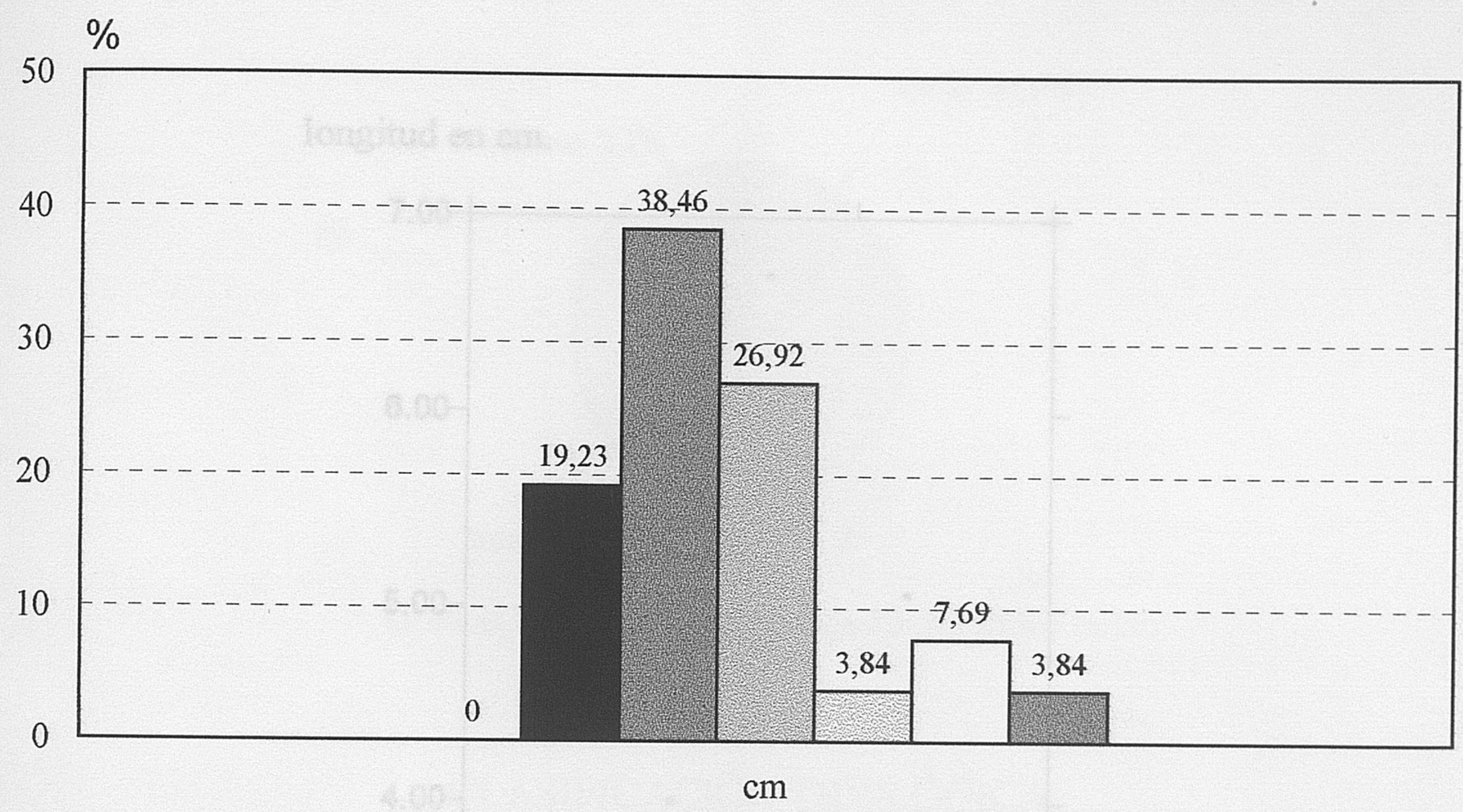

$\begin{array}{lllllll}0-1 & 1-2 & 2-3 & 3-4 & 4-5 & 5-6 & 6-7\end{array}$

Gráfico 101. Fase estratigrafica 13. Neolitico tardio

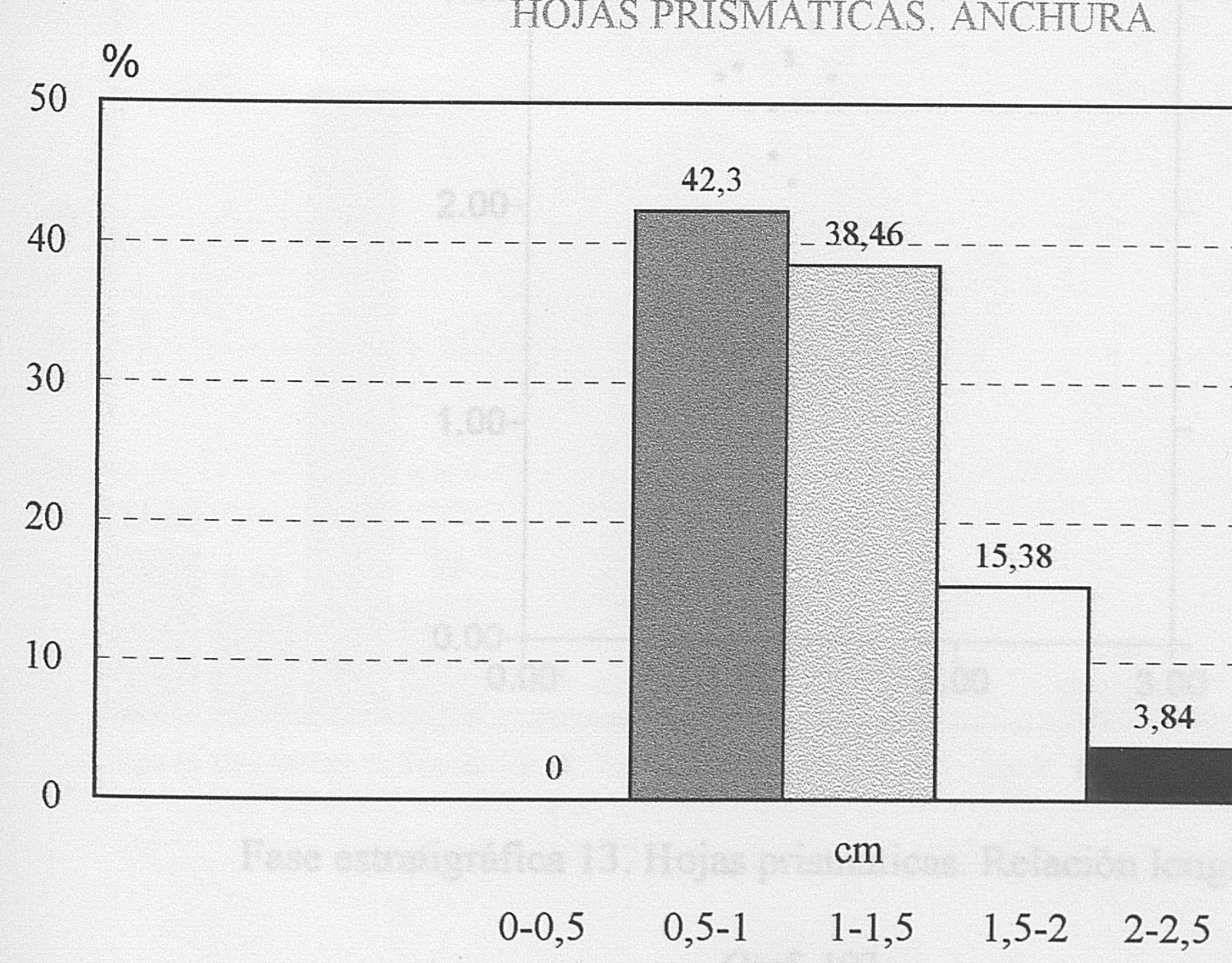

Gráfico 102. Fase estratigráfica 13. Neolítico tardio 
longitud en $\mathrm{cm}$.

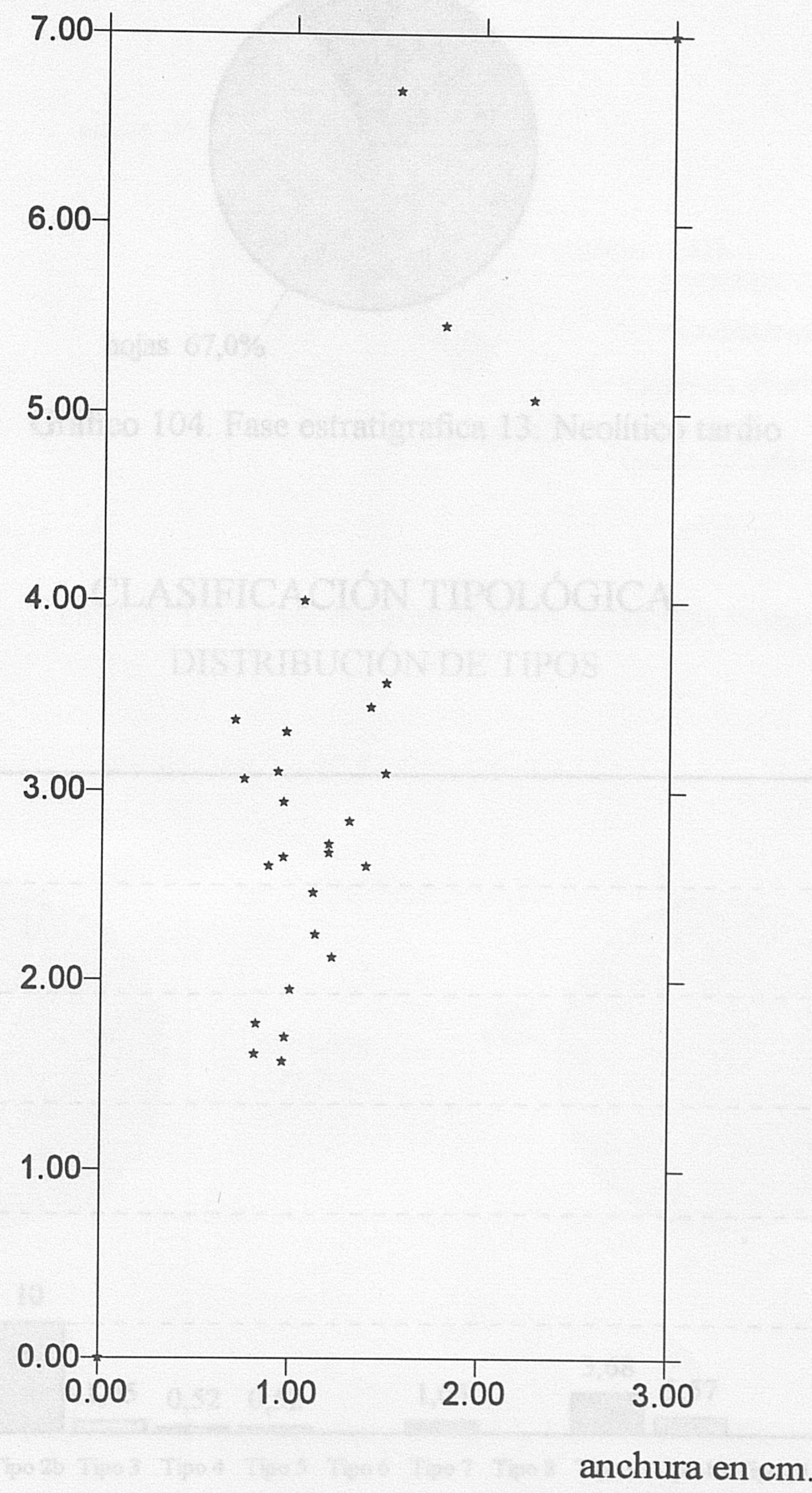

Fase estratigráfica 13. Hojas prismáticas. Relación longitud-anchura

Graf. 103 


\section{CLASIFICACIÓN TECNOLÓGICA}

\section{DISTRIBUCIÓN DE SOPORTES}

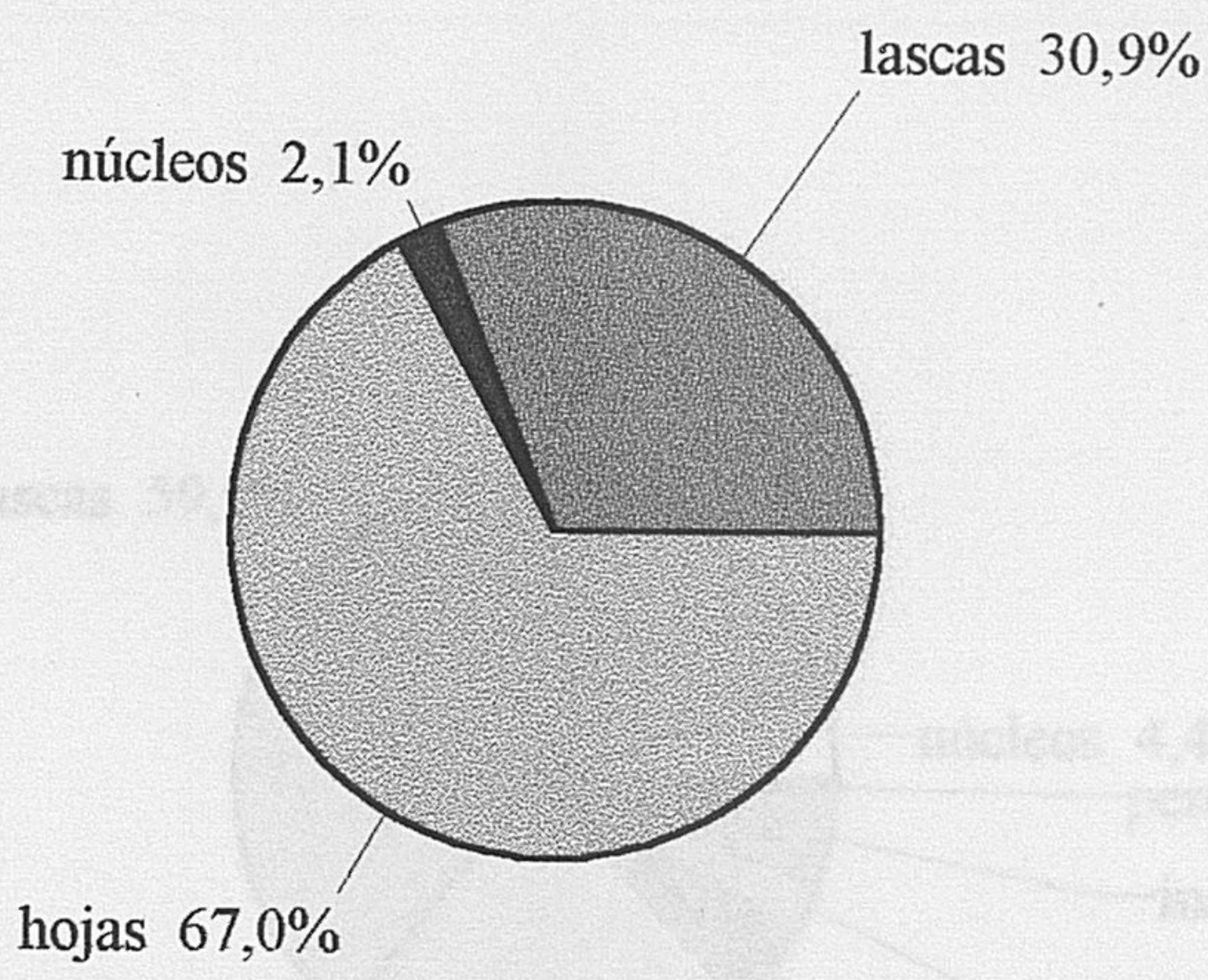

Gráfico 104. Fase estratigrafica 13. Neolítico tardio

\section{CLASIFICACIÓN TIPOLÓGICA}

DISTRIBUCIÓN DE TIPOS

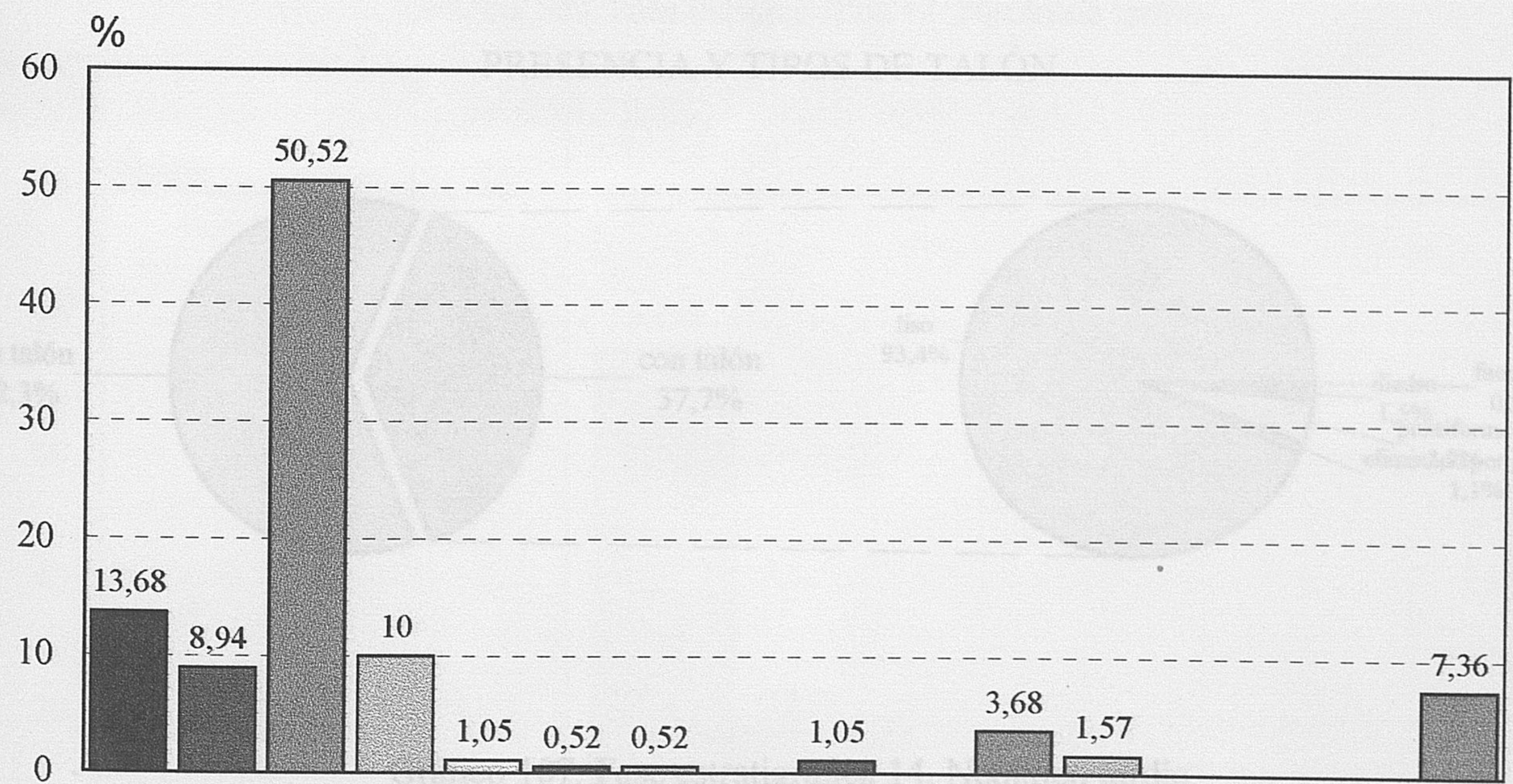

Tipo 1a Tipo $1 \mathrm{~b}$ Tipo 2a Tipo 2b Tipo 3 Tipo 4 Tipo 5 Tipo 6 Tipo 7 Tipo 8 Tipo 9 Tipo 10 Tipo 11 Tipo 12 Tipo 13 Tipo 14

Grafico 105. Fase estratigráfica 12. Neolítico tardio 


\section{CLASIFICACIÓN TECNOLÓGICA}

HOJAS PRISMÁTICAS LONGITUDES

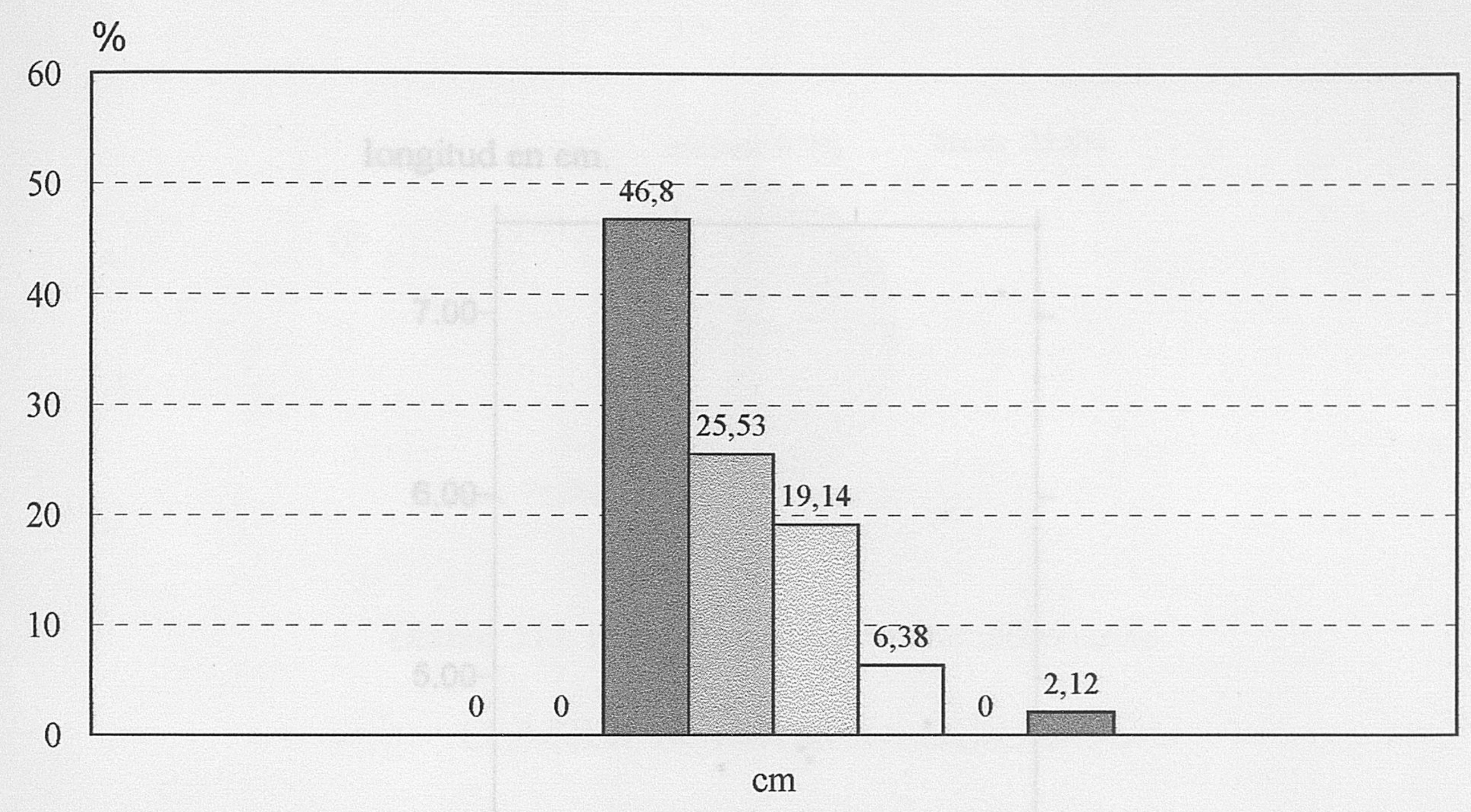

$\begin{array}{llllllll}0-1 & 1-2 & 2-3 & 3-4 & 4-5 & 5-6 & 6-7 & 7-8\end{array}$

Grafico 108. Fase estratigrafica 14. Neolitico tardio

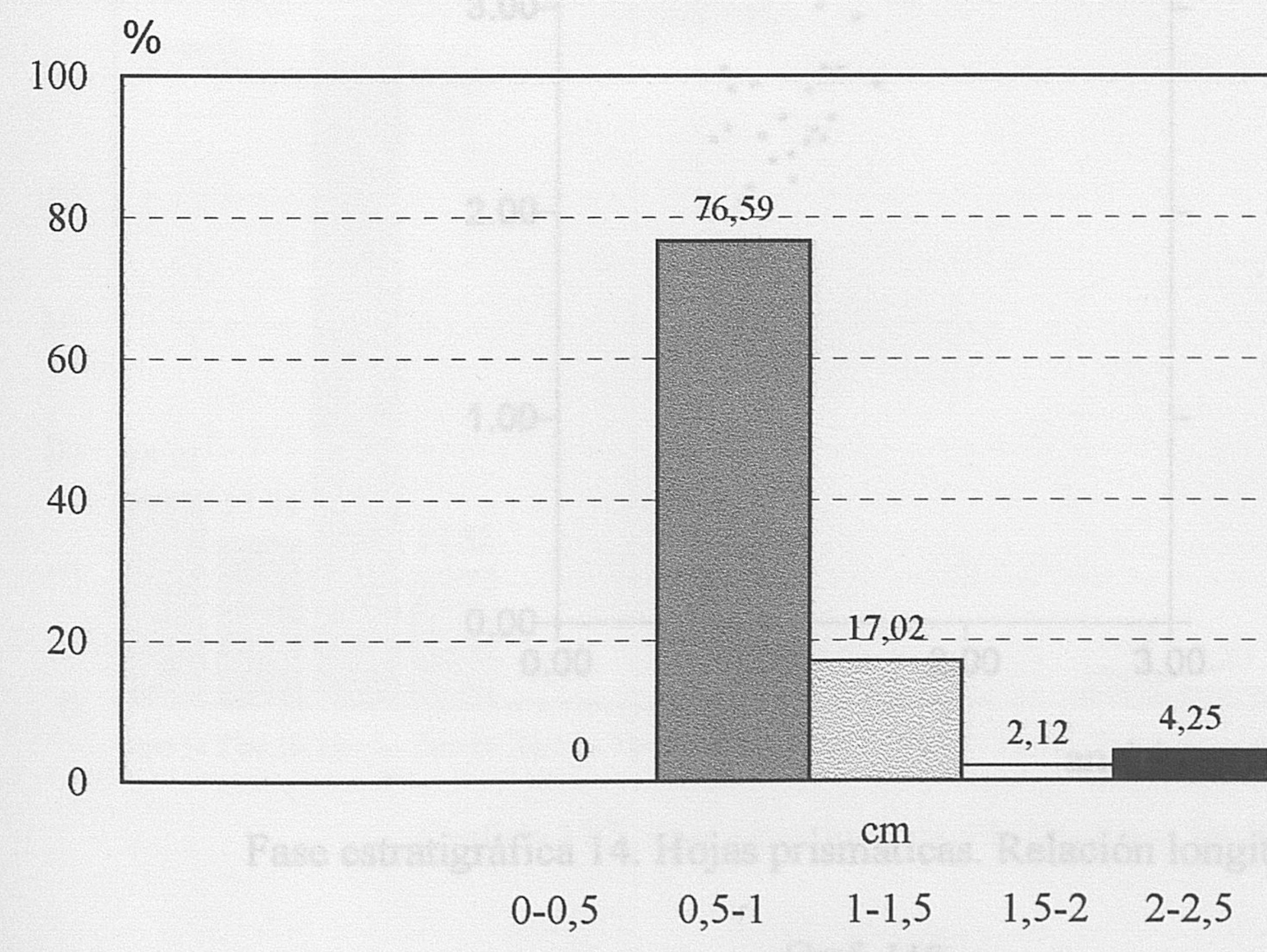

Grafico 109. Fase estratigráfica 14. Neolítico tardio 
longitud en $\mathrm{cm}$.

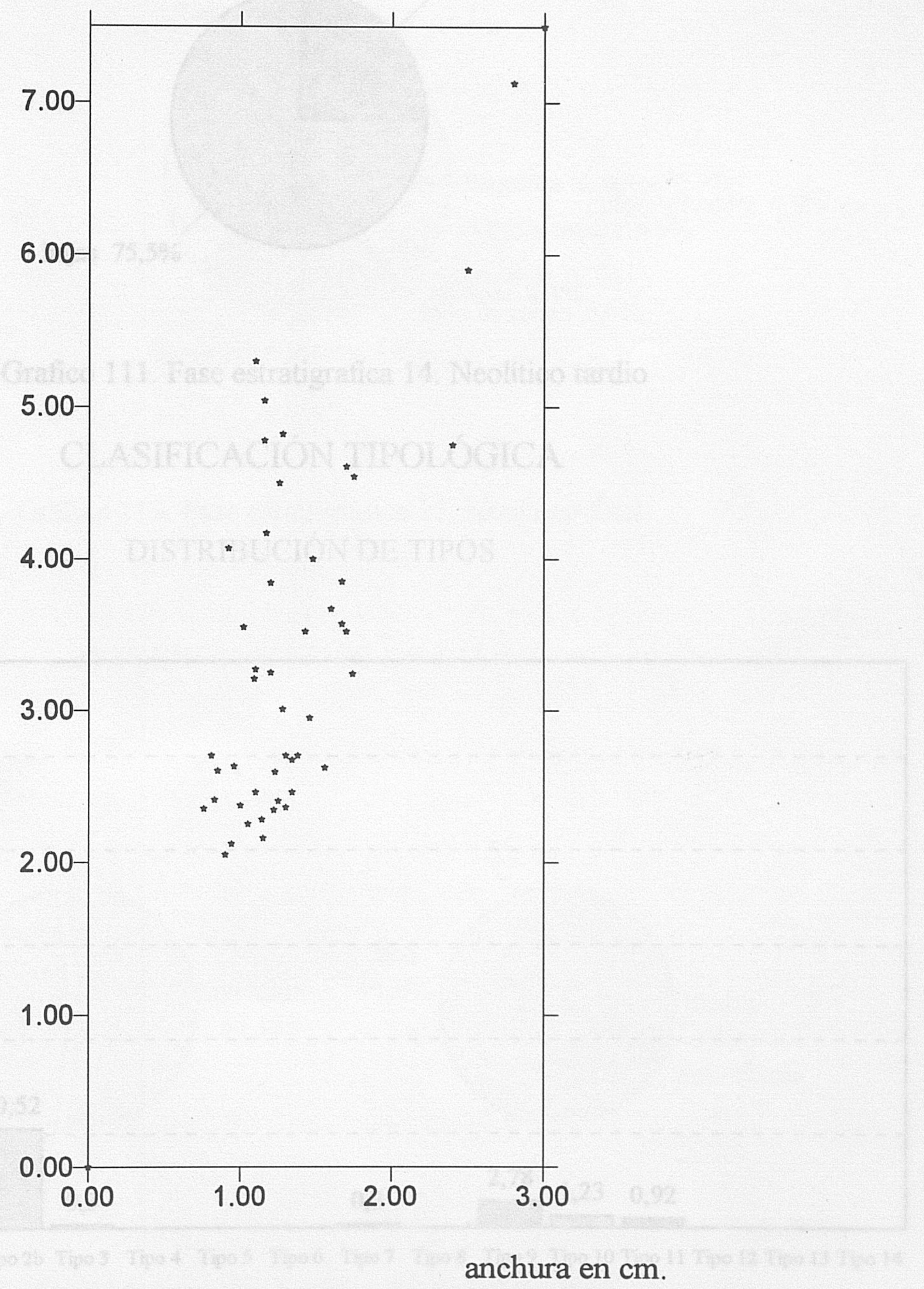

Fase estratigráfica 14. Hojas prismáticas. Relación longitud-anchura

Graf. 110 


\section{CLASIFICACIÓN TECNOLÓGICA}

\section{DISTRIBUCION DE SOPORTES}

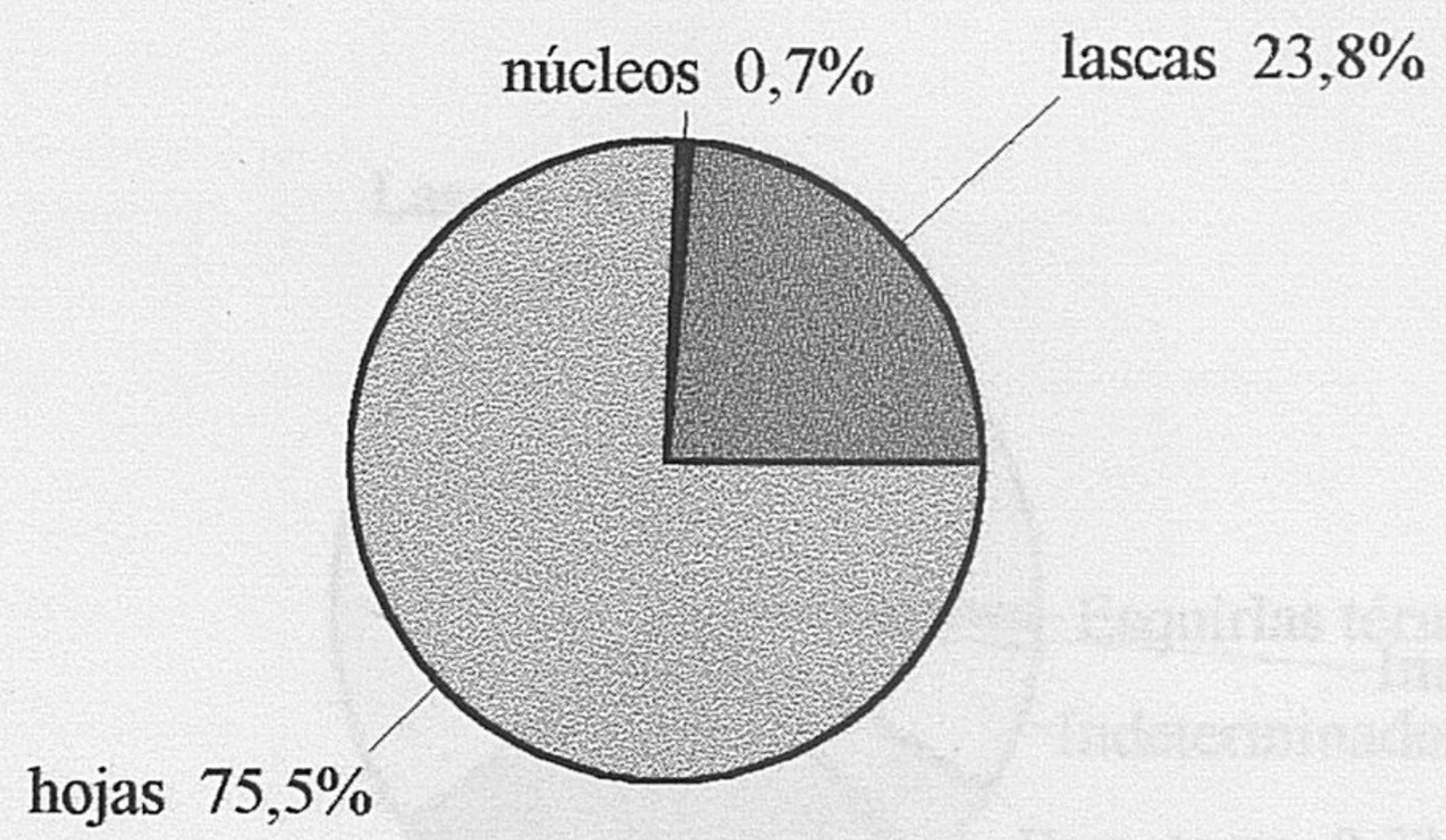

Grafico 111. Fase estratigrafica 14. Neolítico tardio

\section{CLASIFICACIÓN TIPOLÓGICA}

\section{DISTRIBUCIÓN DE TIPOS}

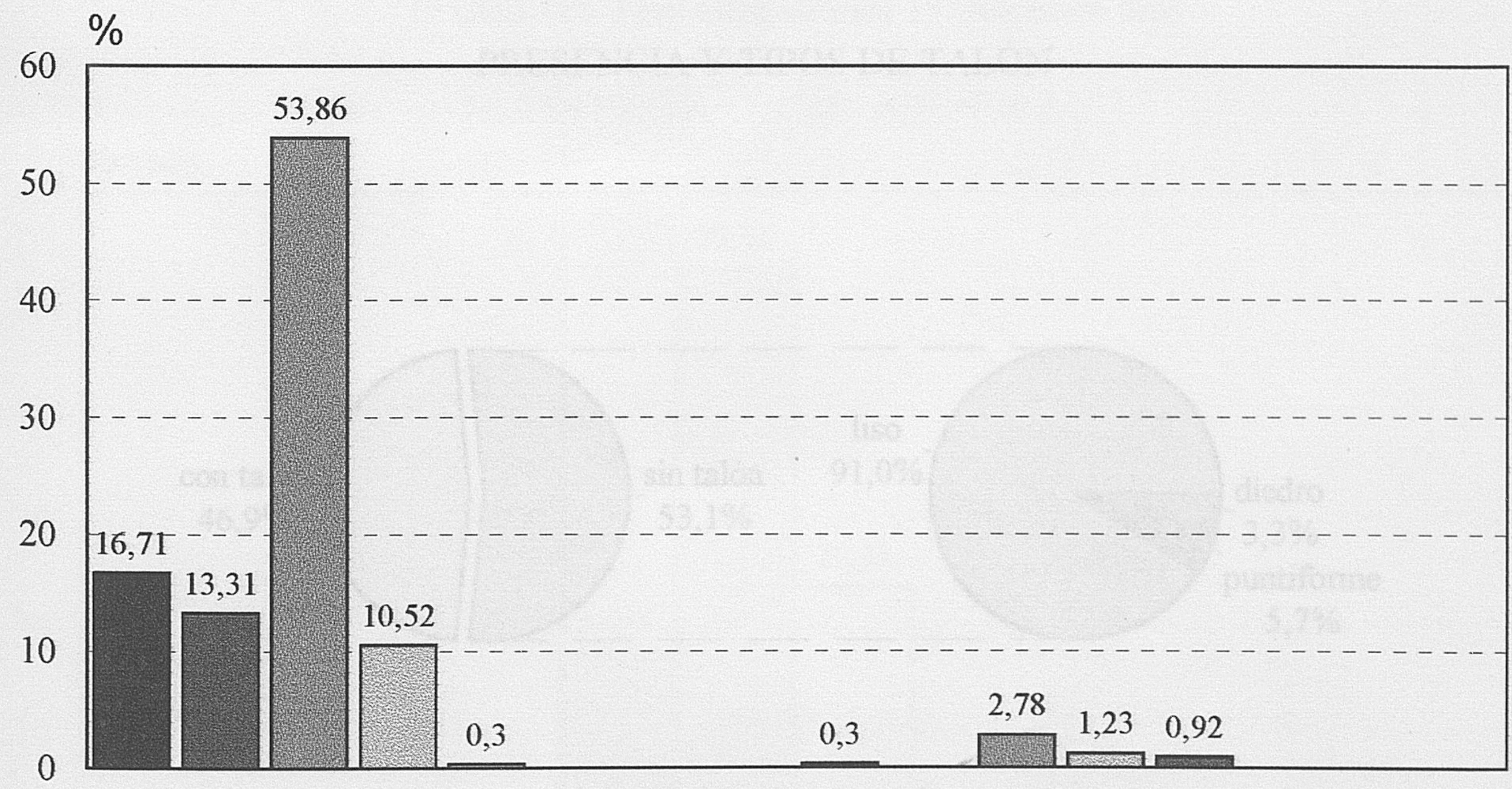

Tipo 1a Tipo 1b Tipo 2a Tipo 2b Tipo 3 Tipo 4 Tipo 5 Tipo 6 Tipo 7 Tipo 8 Tipo 9 Tipo 10 Tipo 11 Tipo 12 Tipo 13 Tipo 14

Grafico 112. Fase estratigráfica 14. Neolítico tardio 


\section{CLASIFICACIÓN TECNOLÓGICA}

\section{DISTRIBUCIÓN DE LA INDUSTRIA}

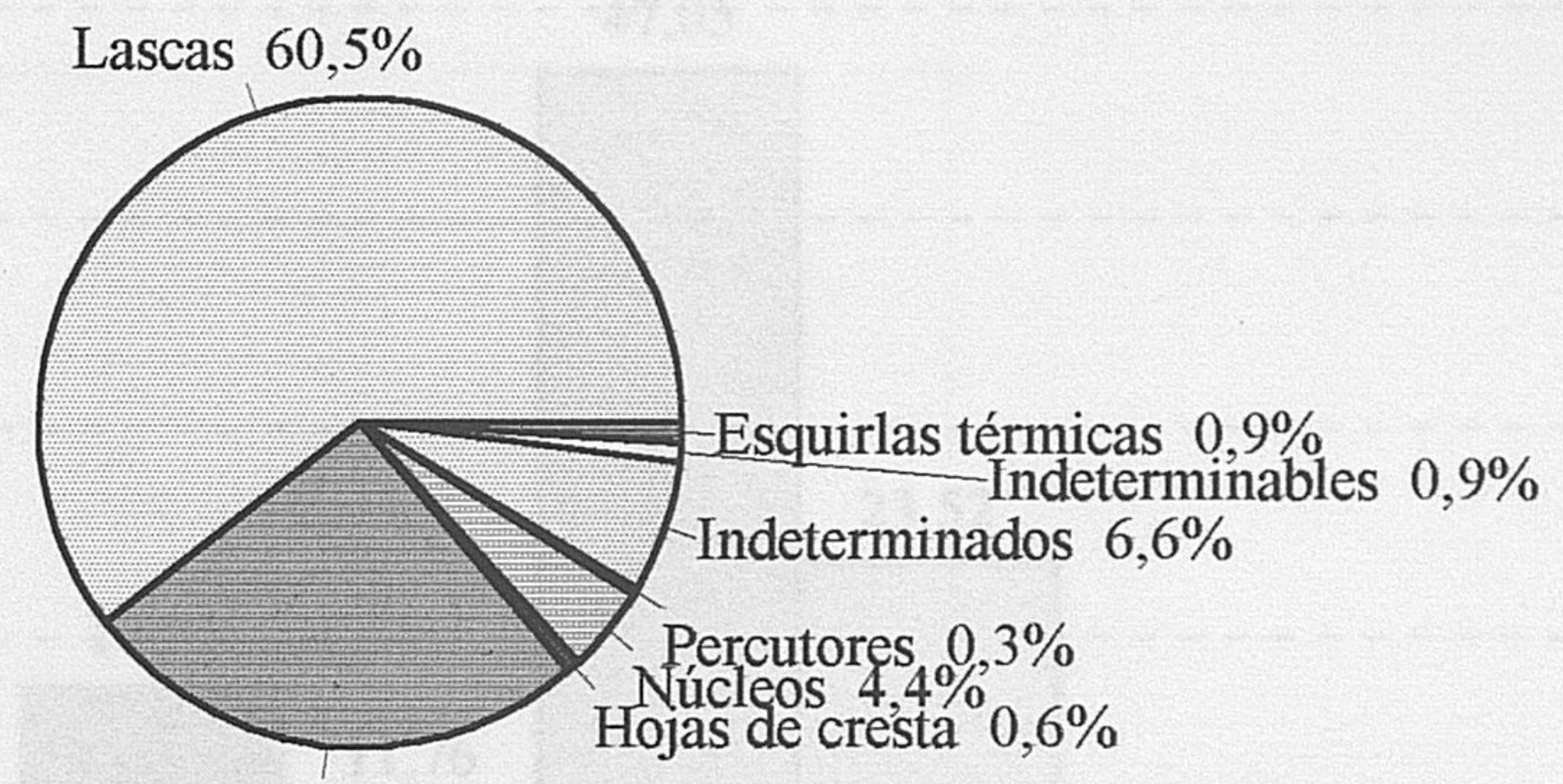

Hojas prismáticas $25,8 \%$

Grafico 113. Fase estratigrafica 15. Neolitico final

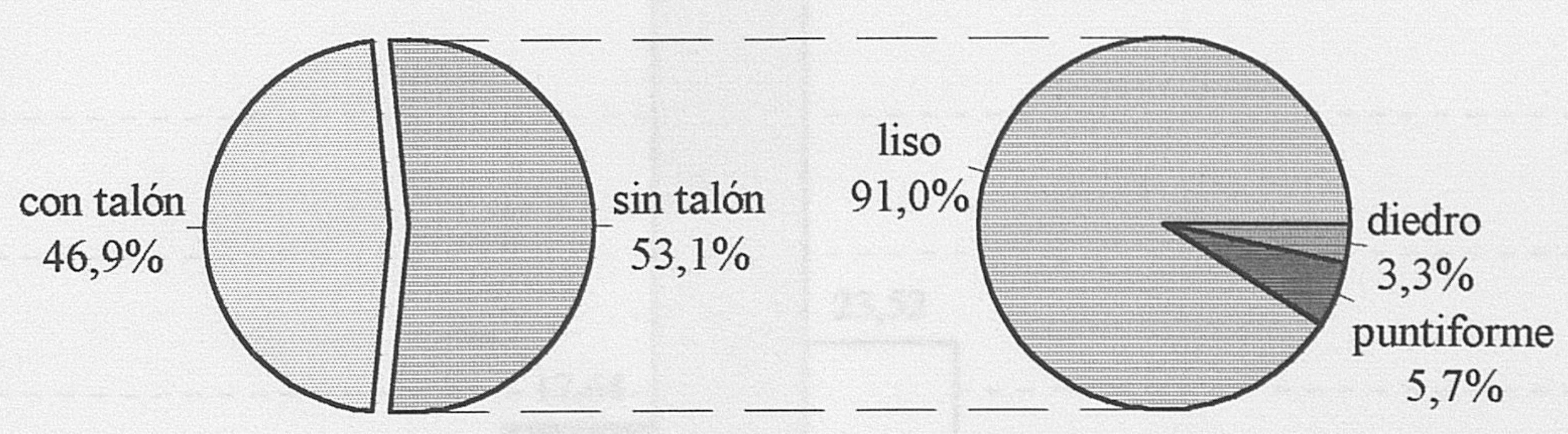

Gráfico 114. Fase estratigráfica 15. Neolítico final 


\section{CLASIFICACIÓN TECNOLÓGICA}

\section{HOJAS PRISMÁTICAS LONGITUDES}

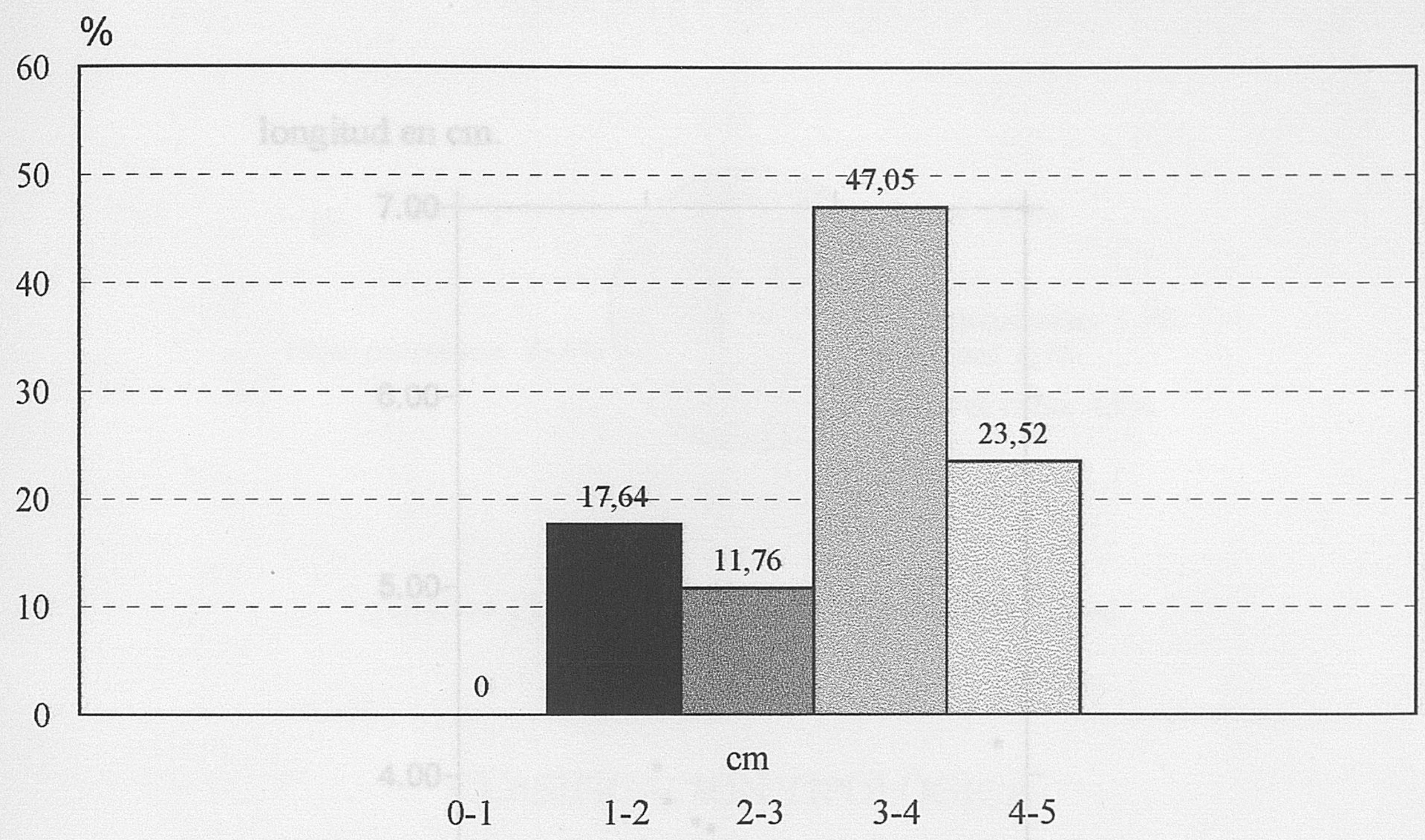

Grafico 115. Fase estratigrafica 15. Neolitico final

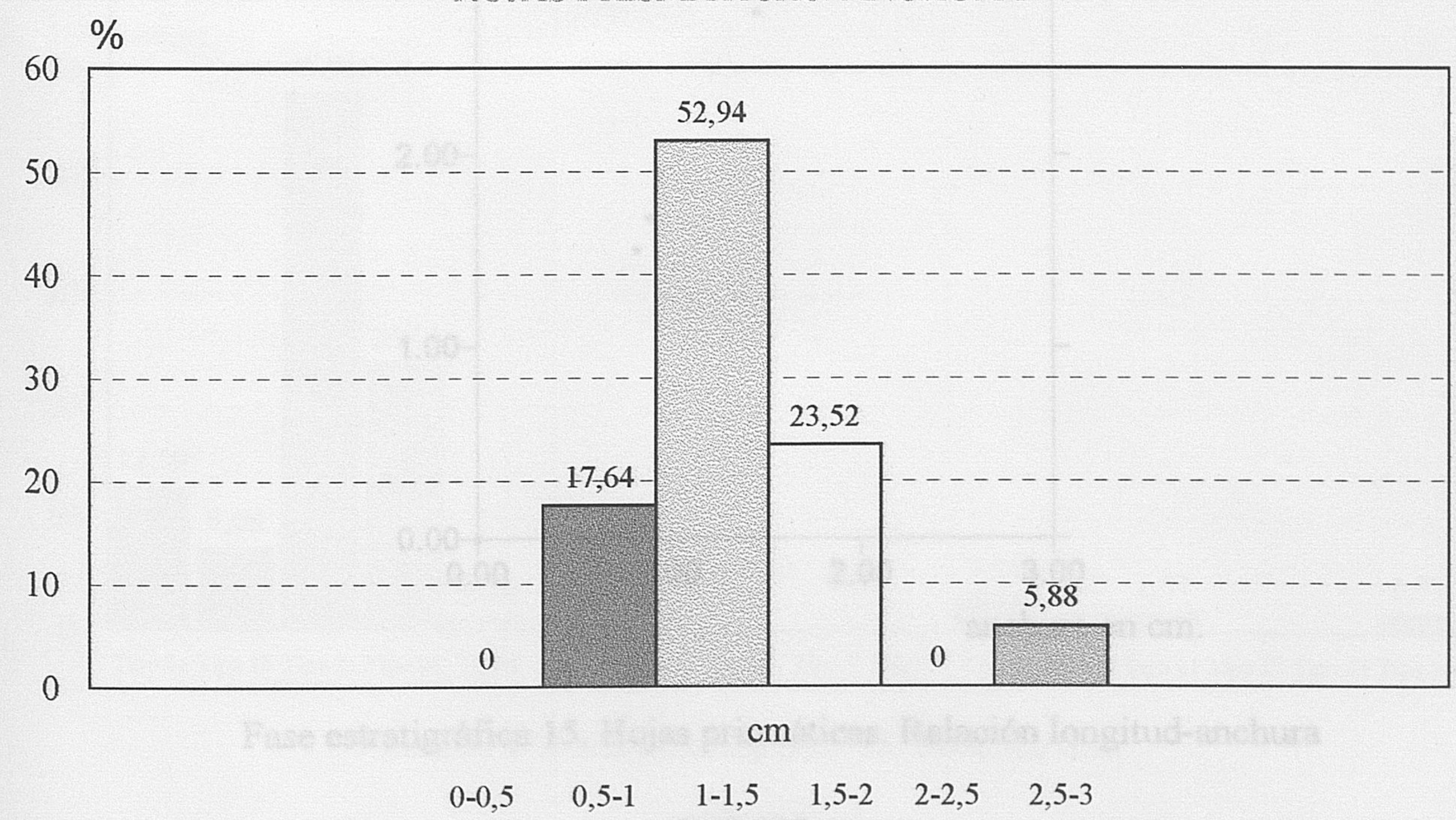

Grafico 116. Fase estratigráfica 15. Neolítico final 
longitud en $\mathrm{cm}$.

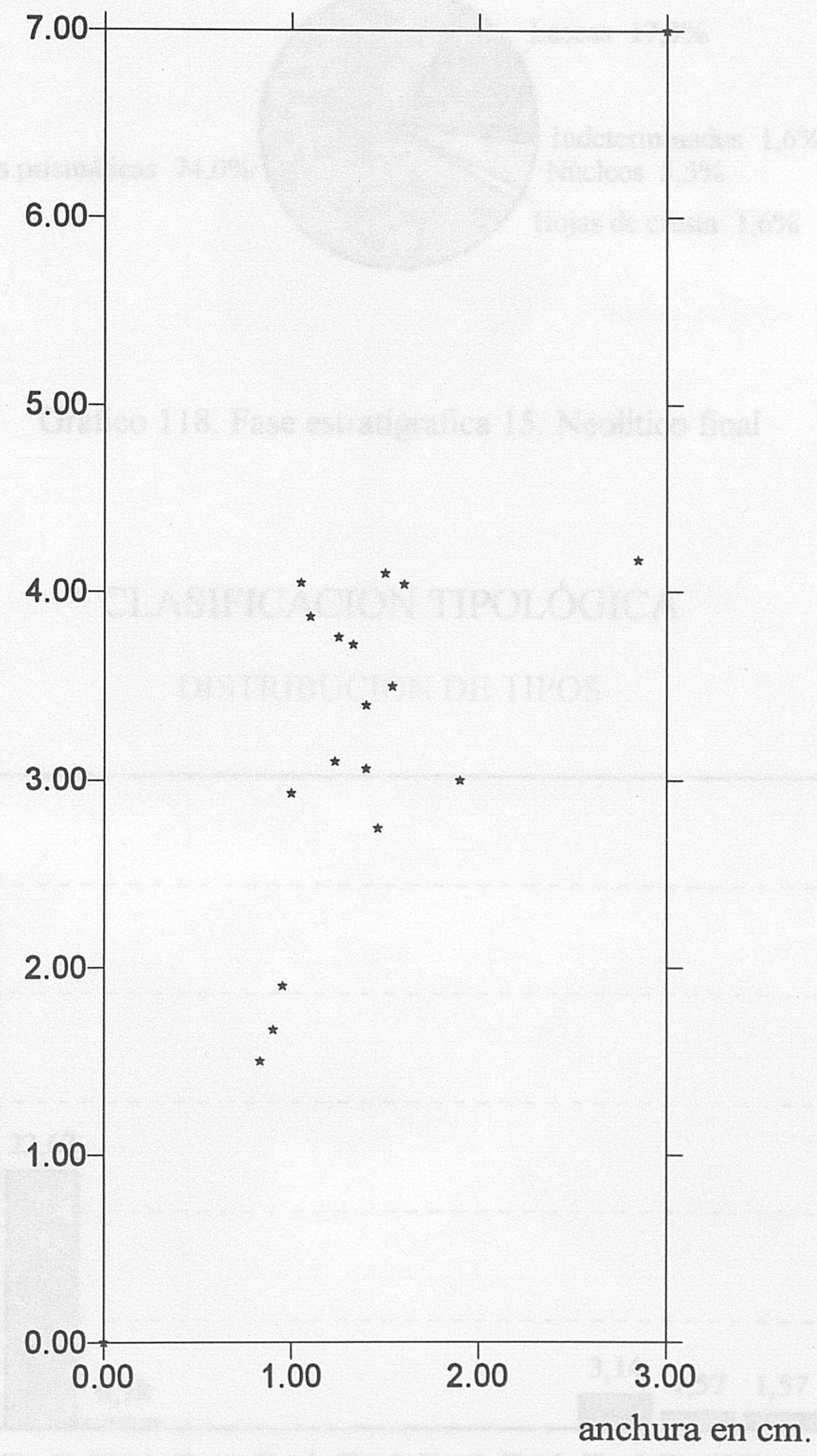

Fase estratigráfica 15. Hojas prismáticas. Relación longitud-anchura

Graf. 117 


\section{CLASIFICACIÓN TECNOLÓGICA}

\section{SOPORTES DE LOS ÚTILES}

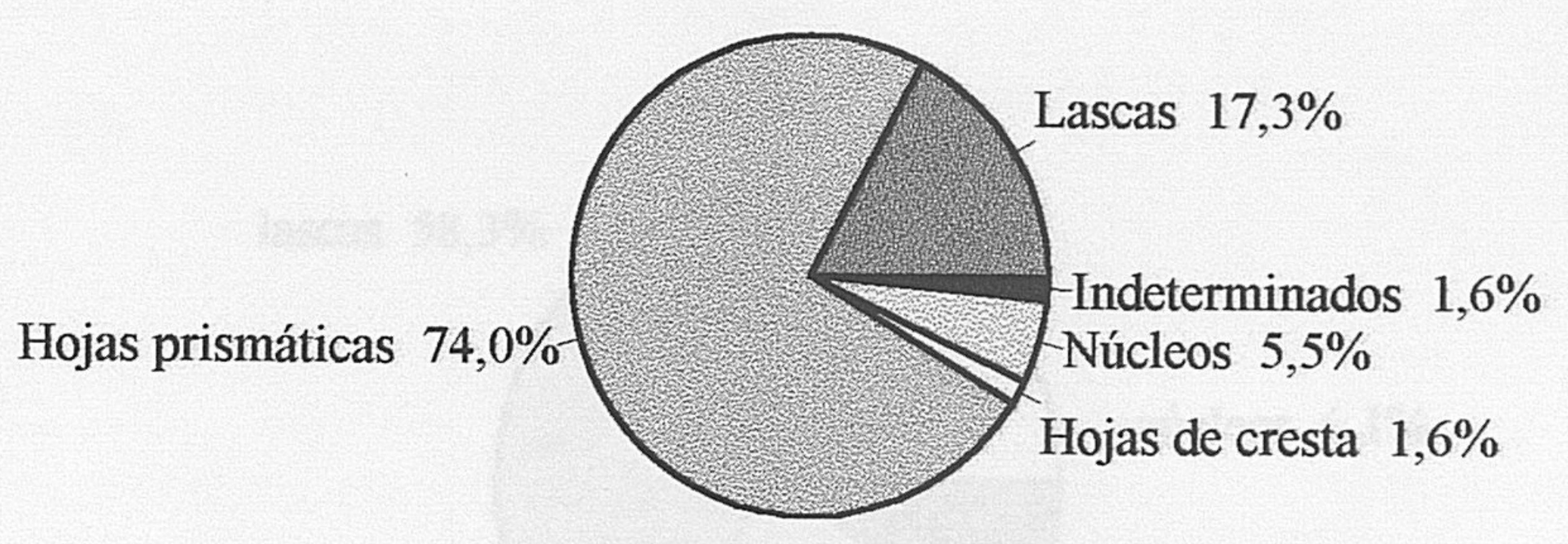

Grafico 118. Fase estratigrafica 15. Neolitico final

\section{CLASIFICACIÓN TIPOLÓGICA}

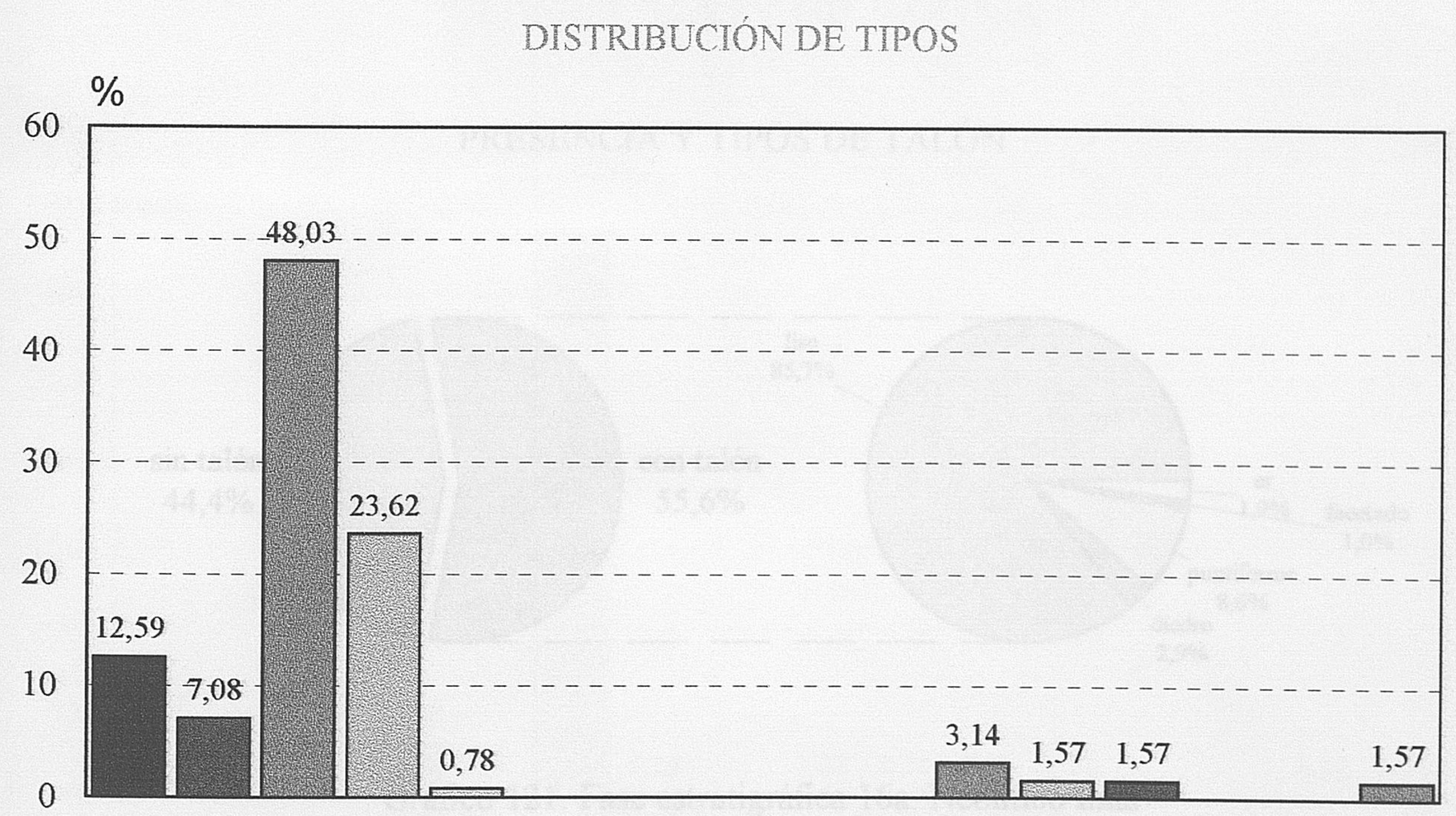

Tipo 1a Tipo $1 \mathrm{~b}$ Tipo 2a Tipo 2b Tipo 3 Tipo 4 Tipo 5 Tipo 6 Tipo 7 Tipo 8 Tipo 9 Tipo 10 Tipo 11 Tipo 12 Tipo 13 Tipo 14

Grafico 119. Fase estratigráfica 15. Neolítico final 


\title{
CLASIFICACIÓN TECNOLÓGICA
}

\author{
TOTAL DE LA INDUSTRIA
}

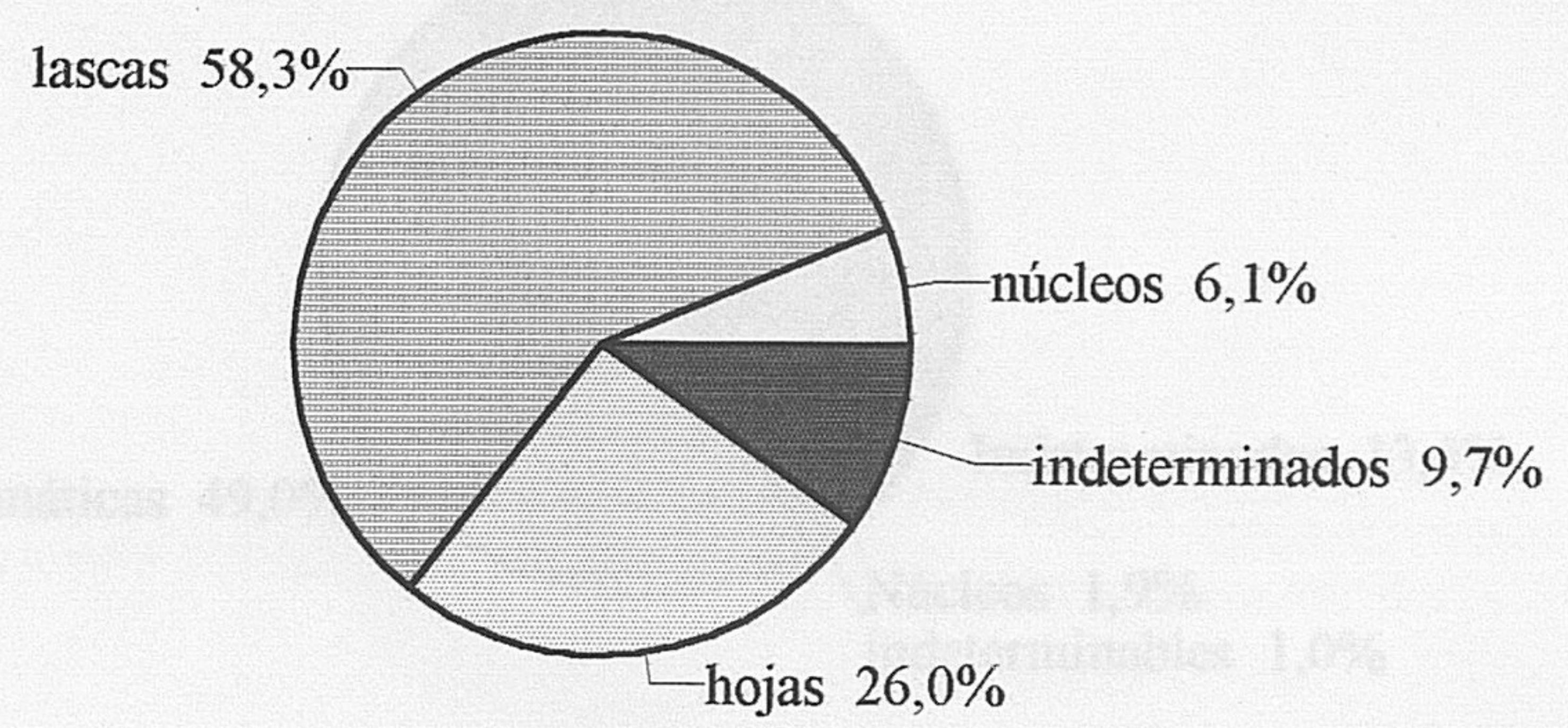

Gráfico 120. Fase estratigráfica 16a. Neolítico final

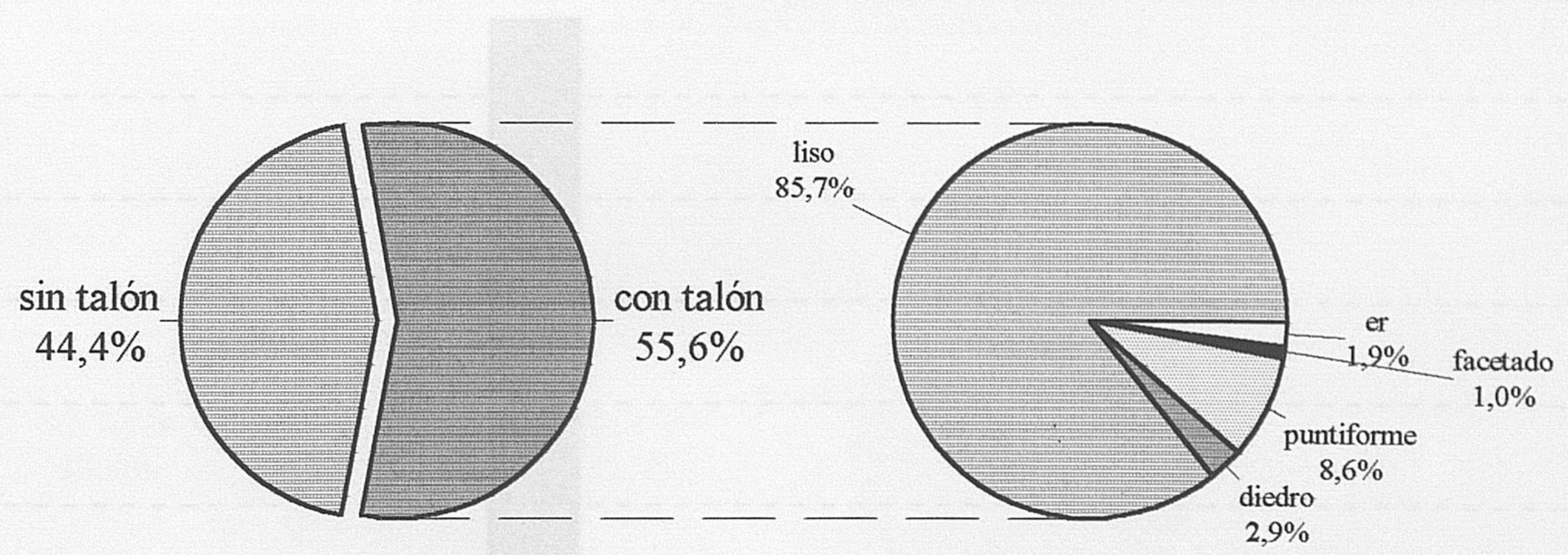

Gráfico 121. Fase estratigráfica 16a. Neolítico final 


\section{CLASIFICACIÓN TECNOLÓGICA}

\section{SOPORTES DE LOS UTTILES}

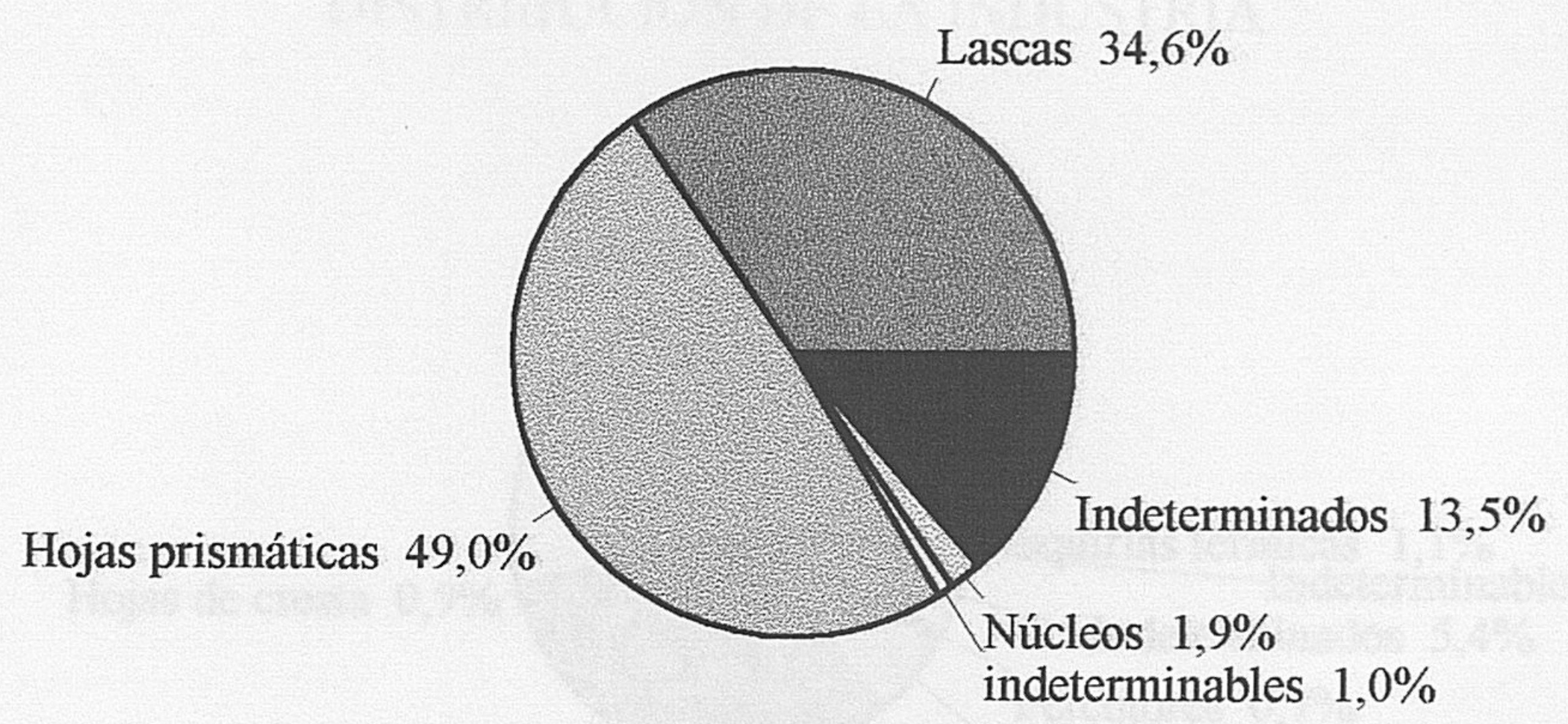

Gráfico 122. Fase estratigráfica 16a. Neolitico final

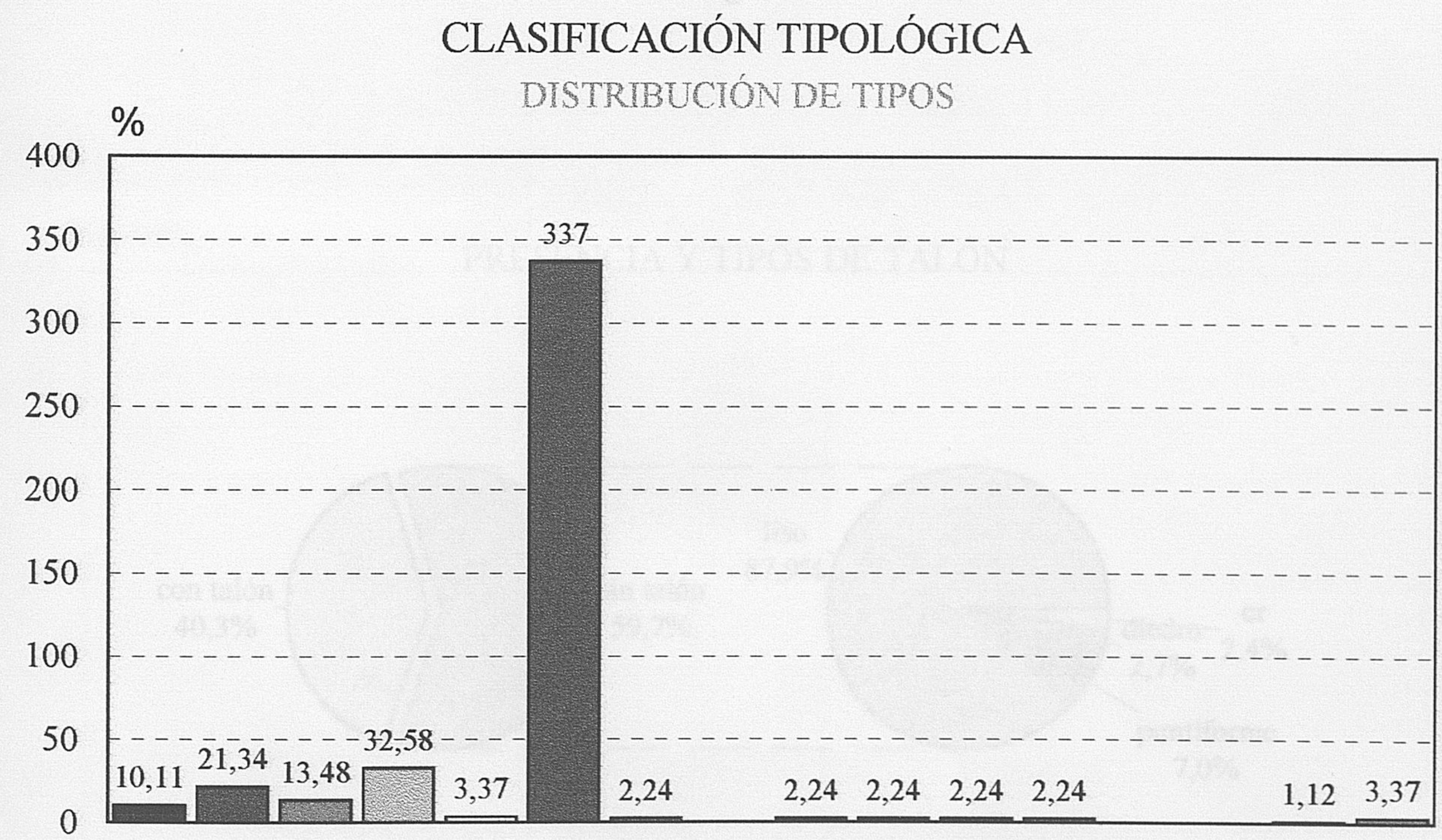

Tipo 1a Tipo $1 \mathrm{~b}$ Tipo 2a Tipo 2b Tipo 3 Tipo 4 Tipo 5 Tipo 6 Tipo 7 Tipo 8 Tipo 9 Tipo 10 Tipo 11 Tipo 12 Tipo 13 Tipo 14

Grafico 123. Fase estratigráfica 16a. Neolítico final 


\section{CLASIFICACIÓN TECNOLÓGICA}

\section{DISTRIBUCIÓN DE LA INDUSTRIA}

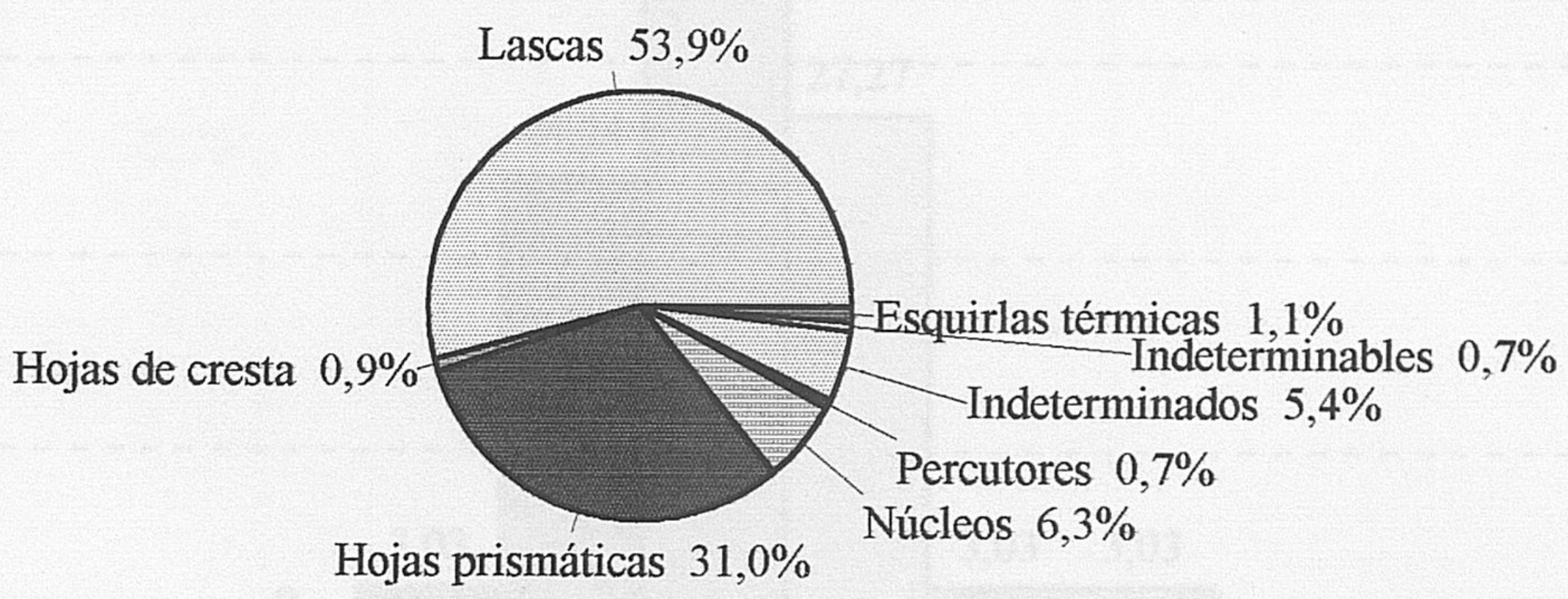

Grafico 124. Fase estratigrafica 16b. Neolitico final

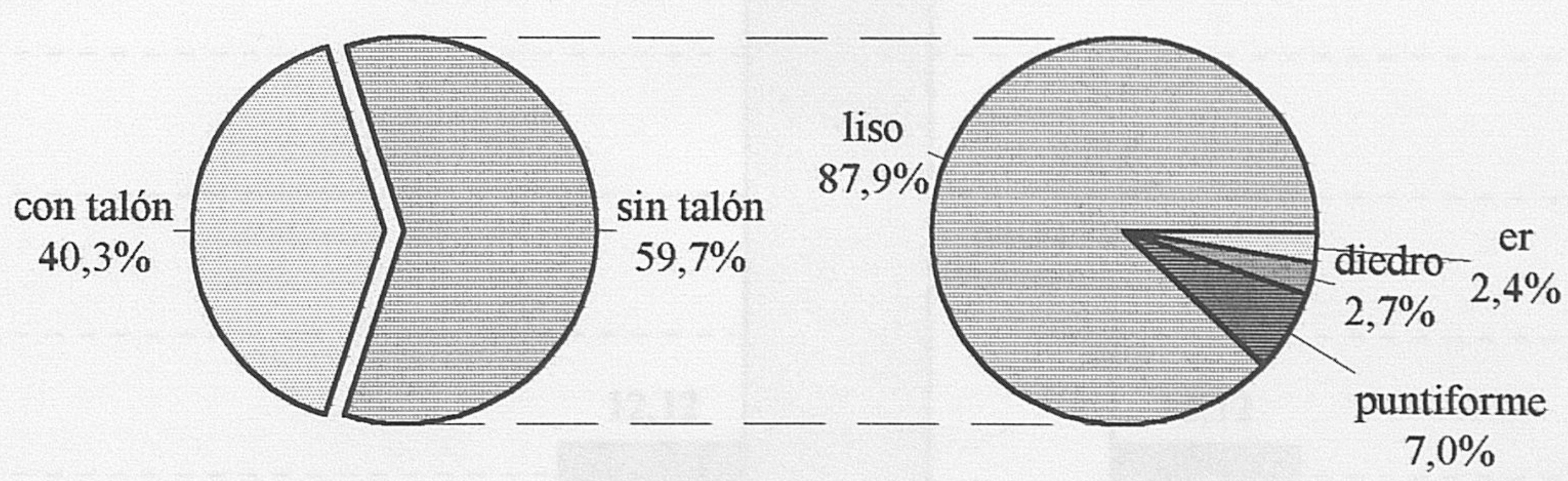

Grafico 125. Fase estratigráfica 16b. Neolítico final 


\section{CLASIFICACIÓN TECNOLÓGICA}

\section{HOJAS PRISMÁTICAS LONGITUDES}

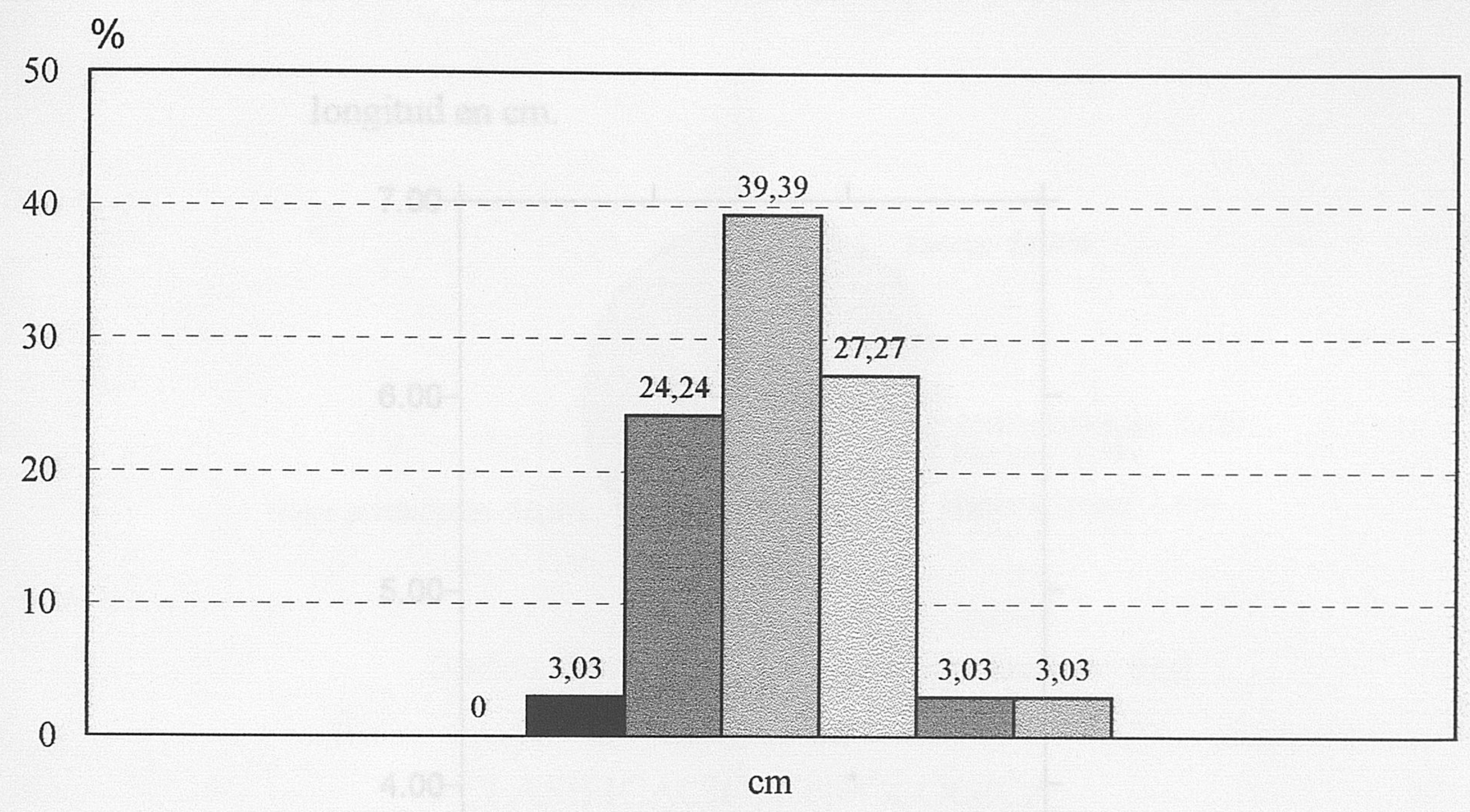

$\begin{array}{lllllll}0-1 & 1-2 & 2-3 & 3-4 & 4-5 & 5-6 & 6-7\end{array}$

Grafico 126. Fase estratigrafica 16b. Neolitico final

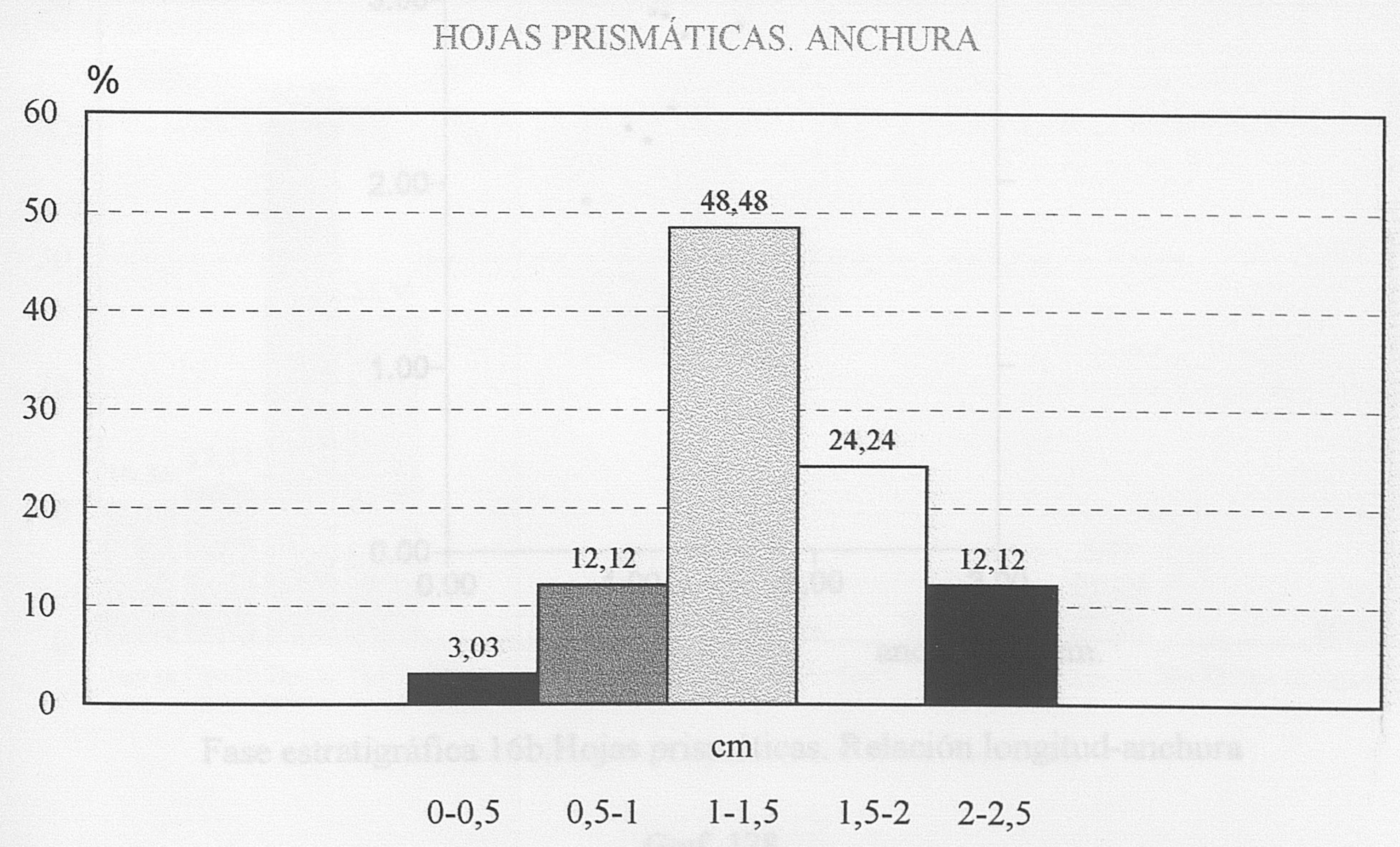

Grafico 127. Fase estratigráfica 16b. Neolítico final 
longitud en $\mathrm{cm}$.

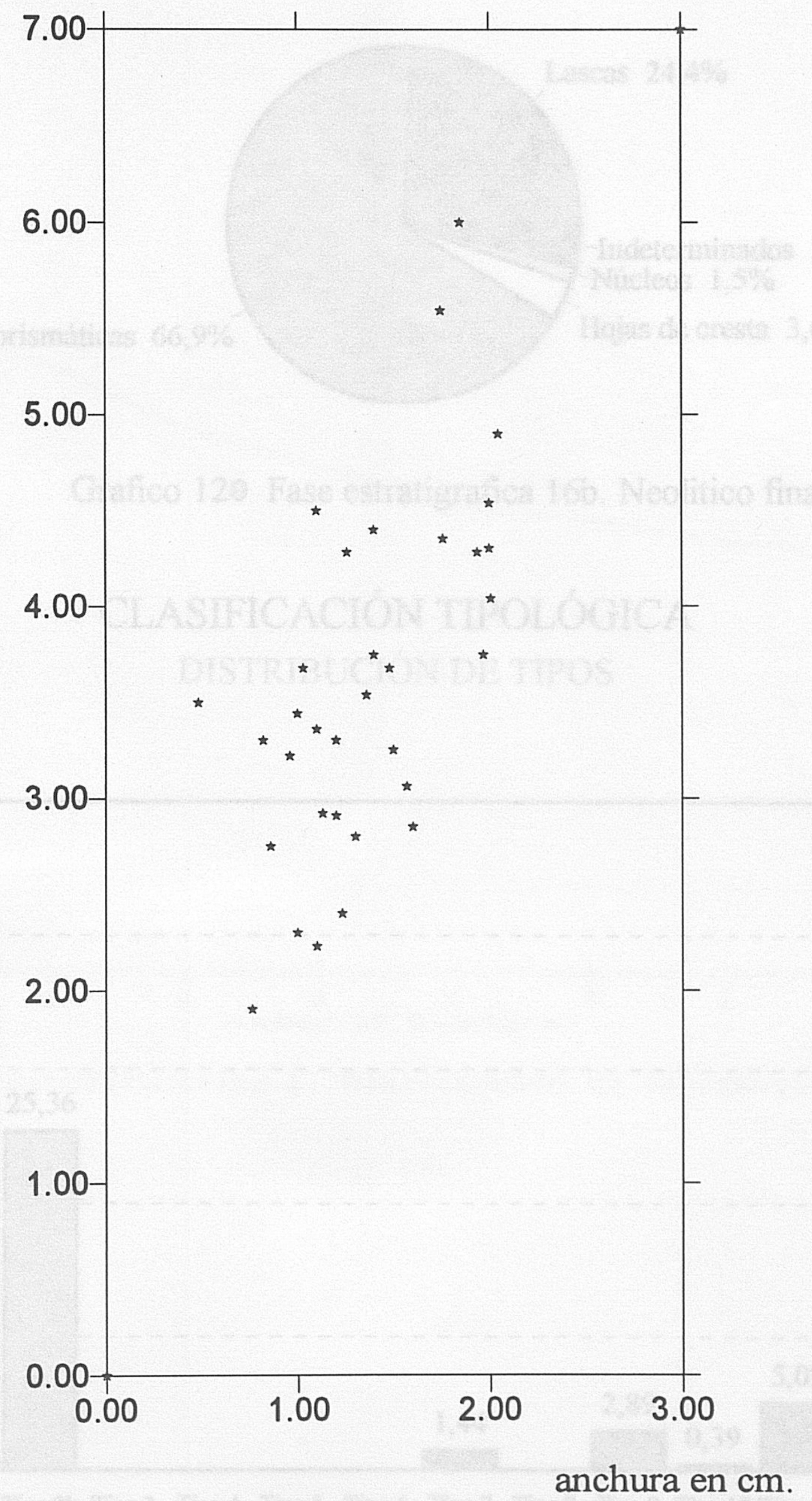

Fase estratigráfica 16b.Hojas prismáticas. Relación longitud-anchura

Graf. 128 


\section{CLASIFICACIÓN TECNOLÓGICA}

\section{SOPORTES DE LOS ÚTILES}

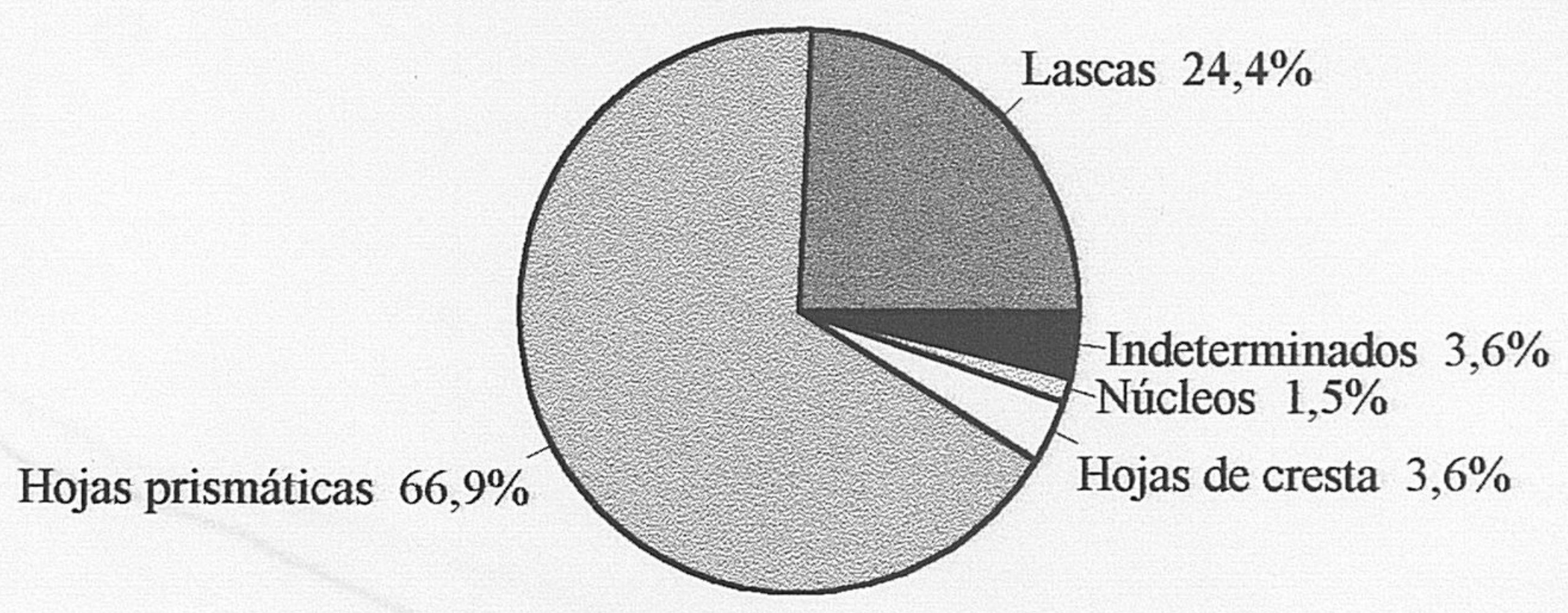

Grafico 129 Fase estratigrafica $16 b$. Neolitico final

\section{CLASIFICACIÓN TIPOLÓGICA}

DISTRIBUCIÓN DE TIPOS

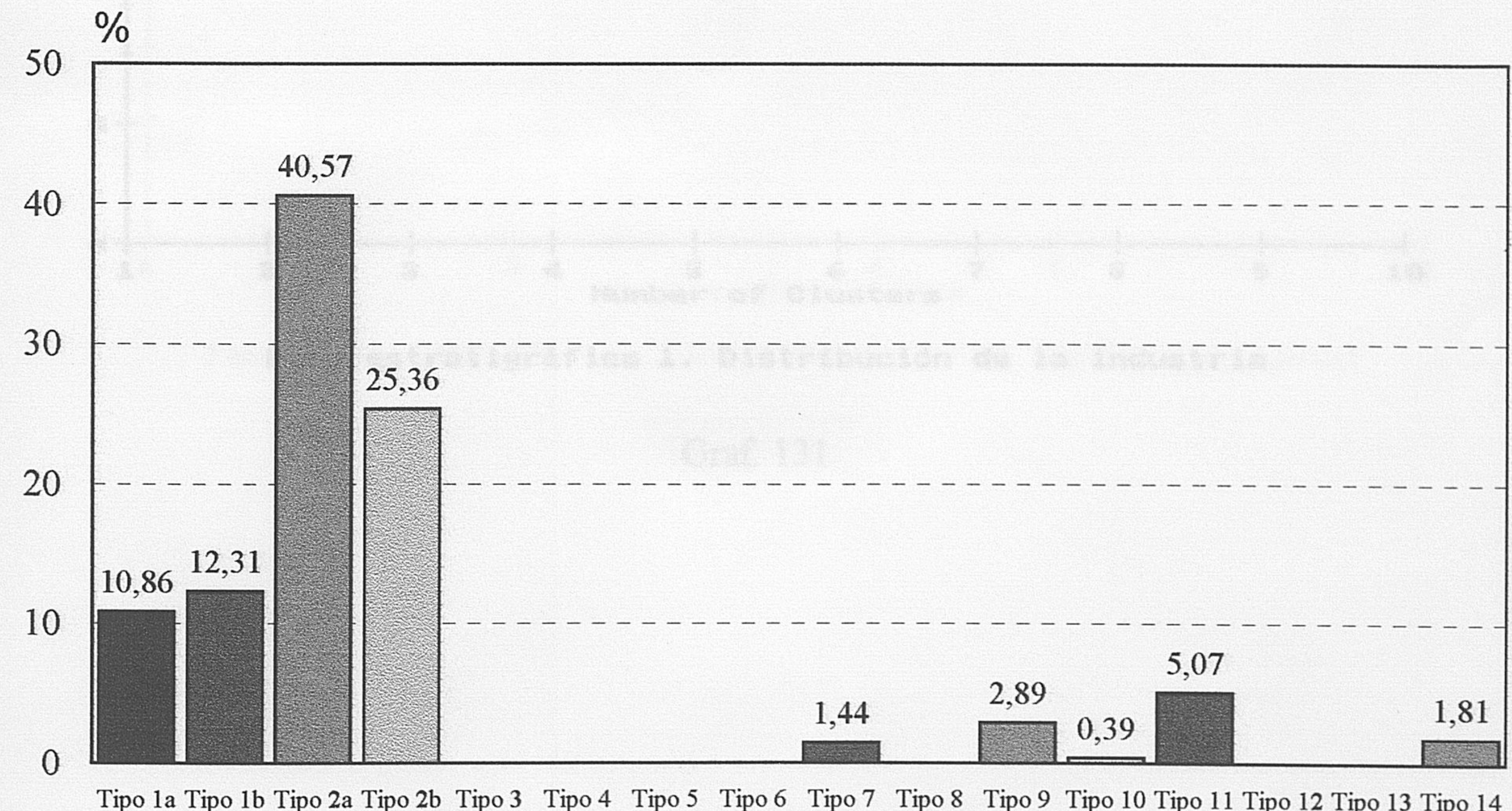

Grafico 130. Fase estratigráfica 16b. Neolítico final 


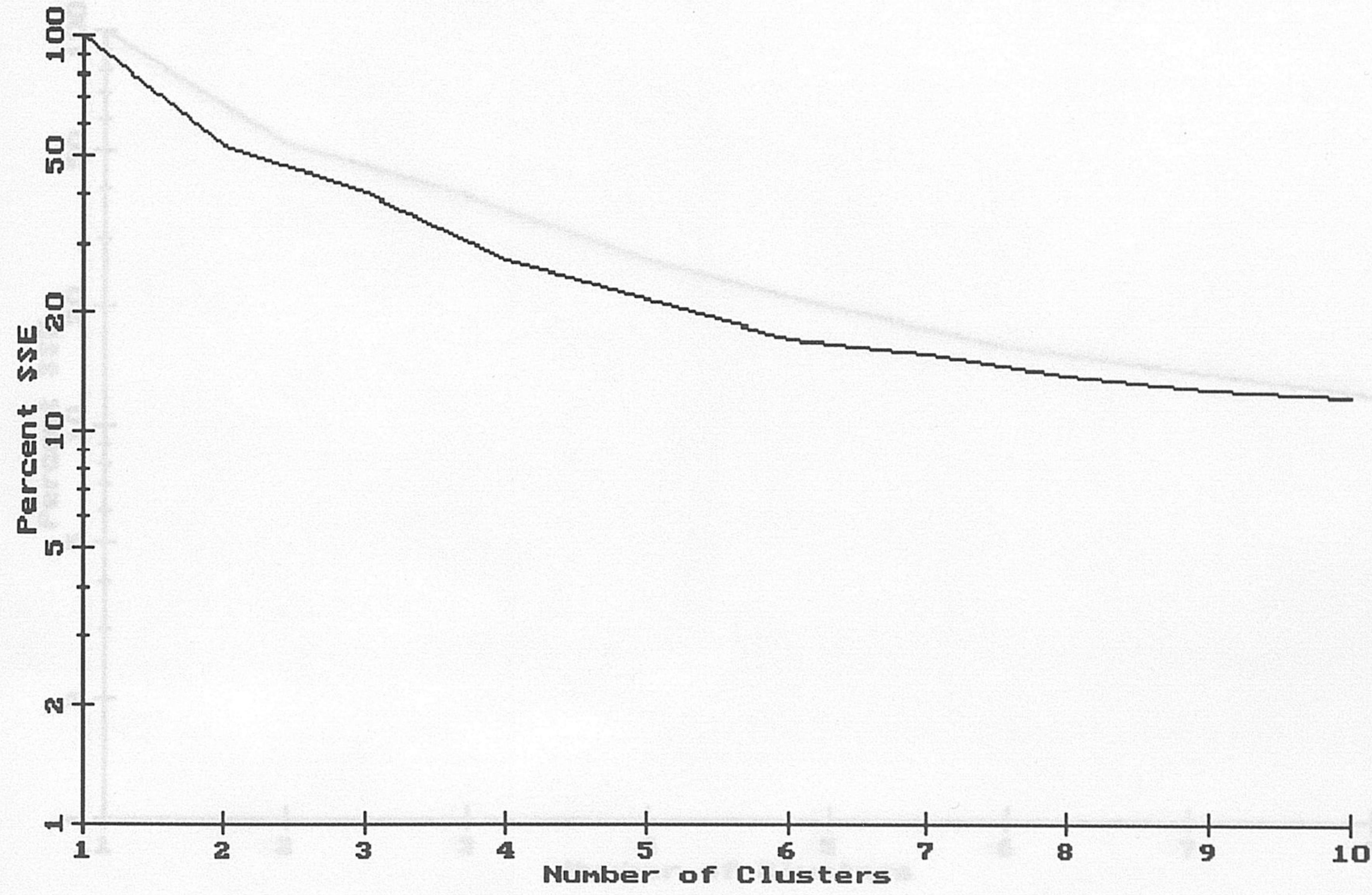

Fase estratigrafica 1. Distribucion de la industria

Graf. 131 


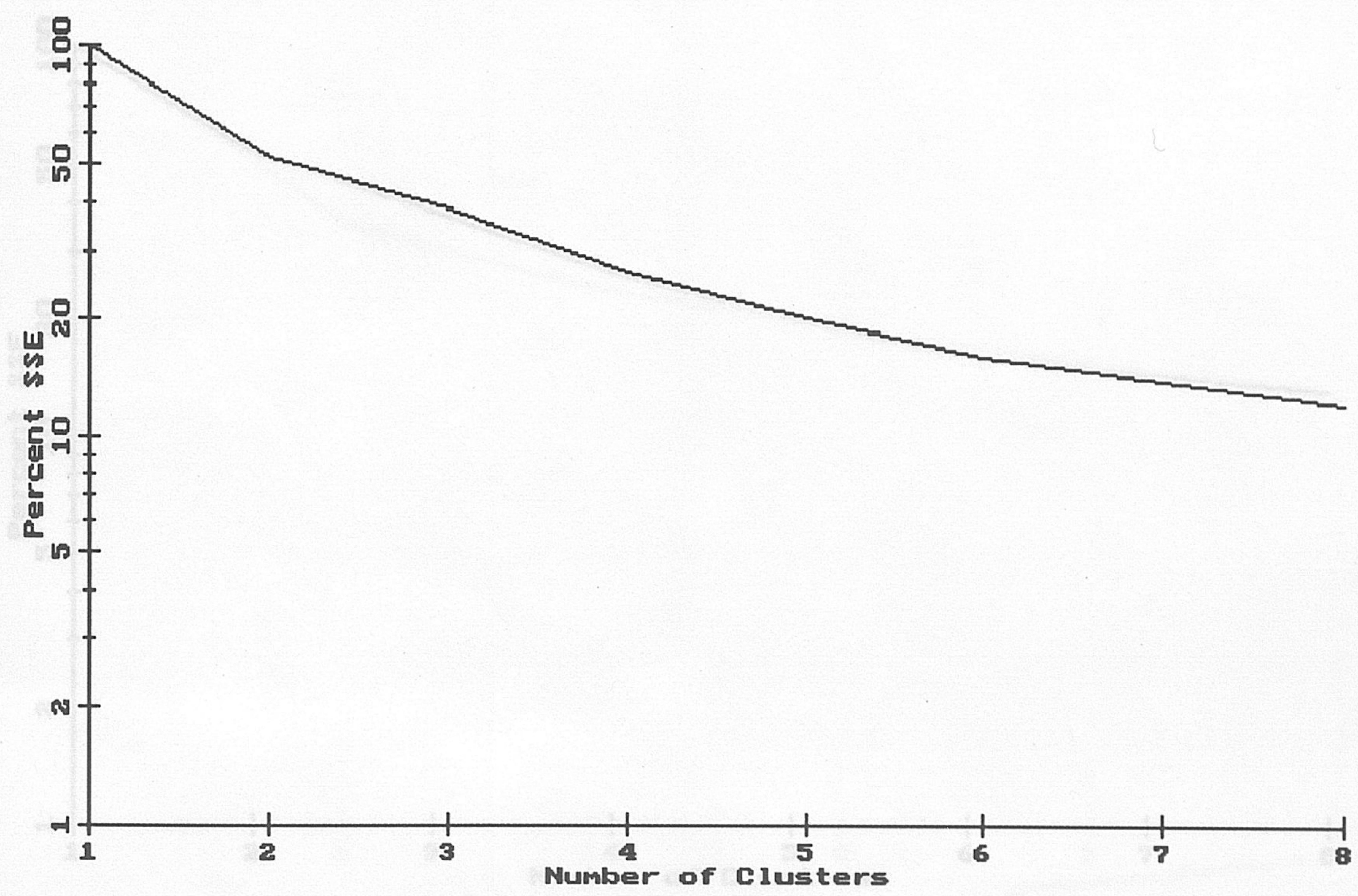

Fase estratigrafica 1. Disthibución de la proclucción lascar

Graf. 132 


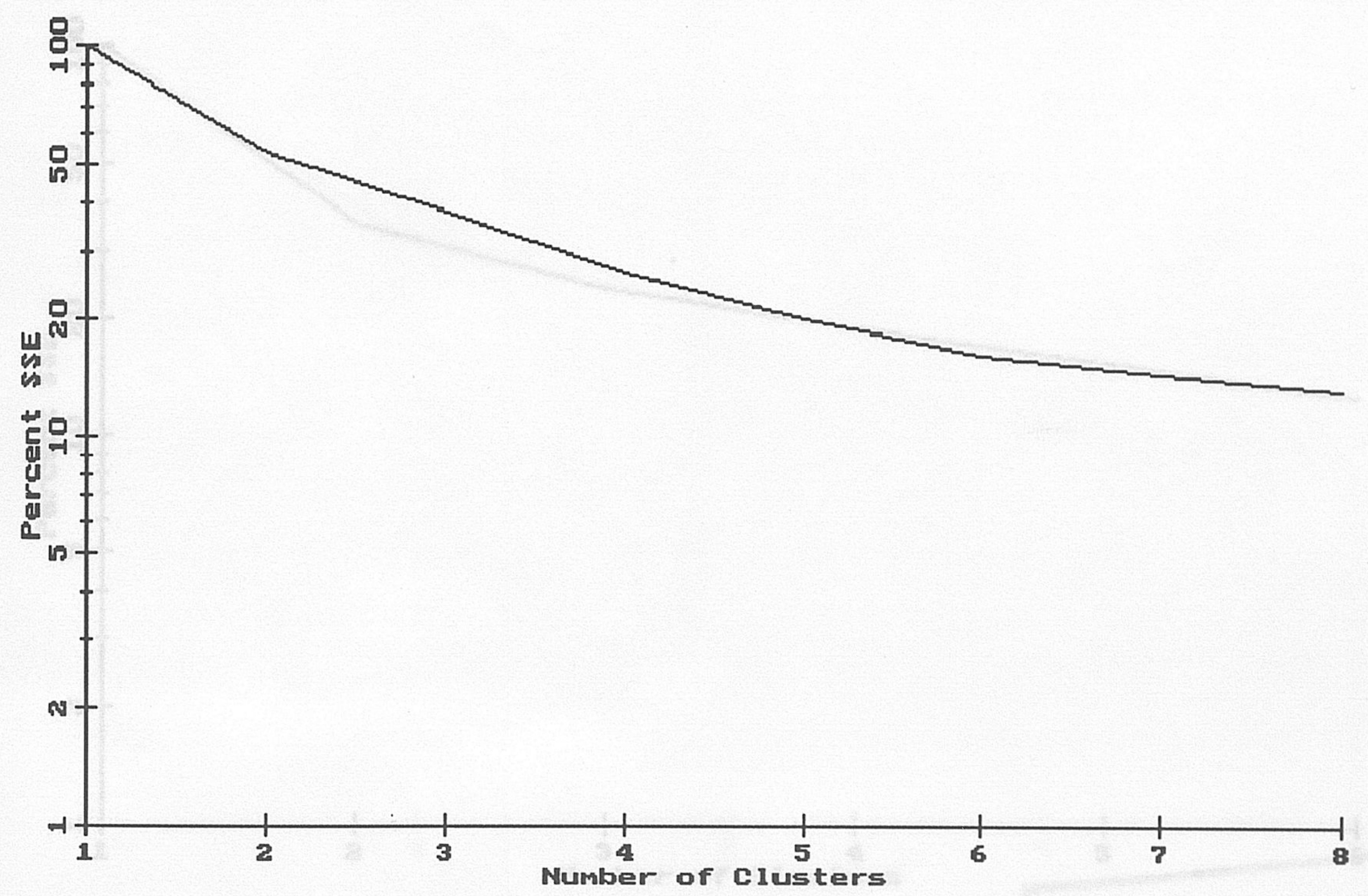

Fase estratigrafica 1. Distribución de la producción laminar

Graf. 133 


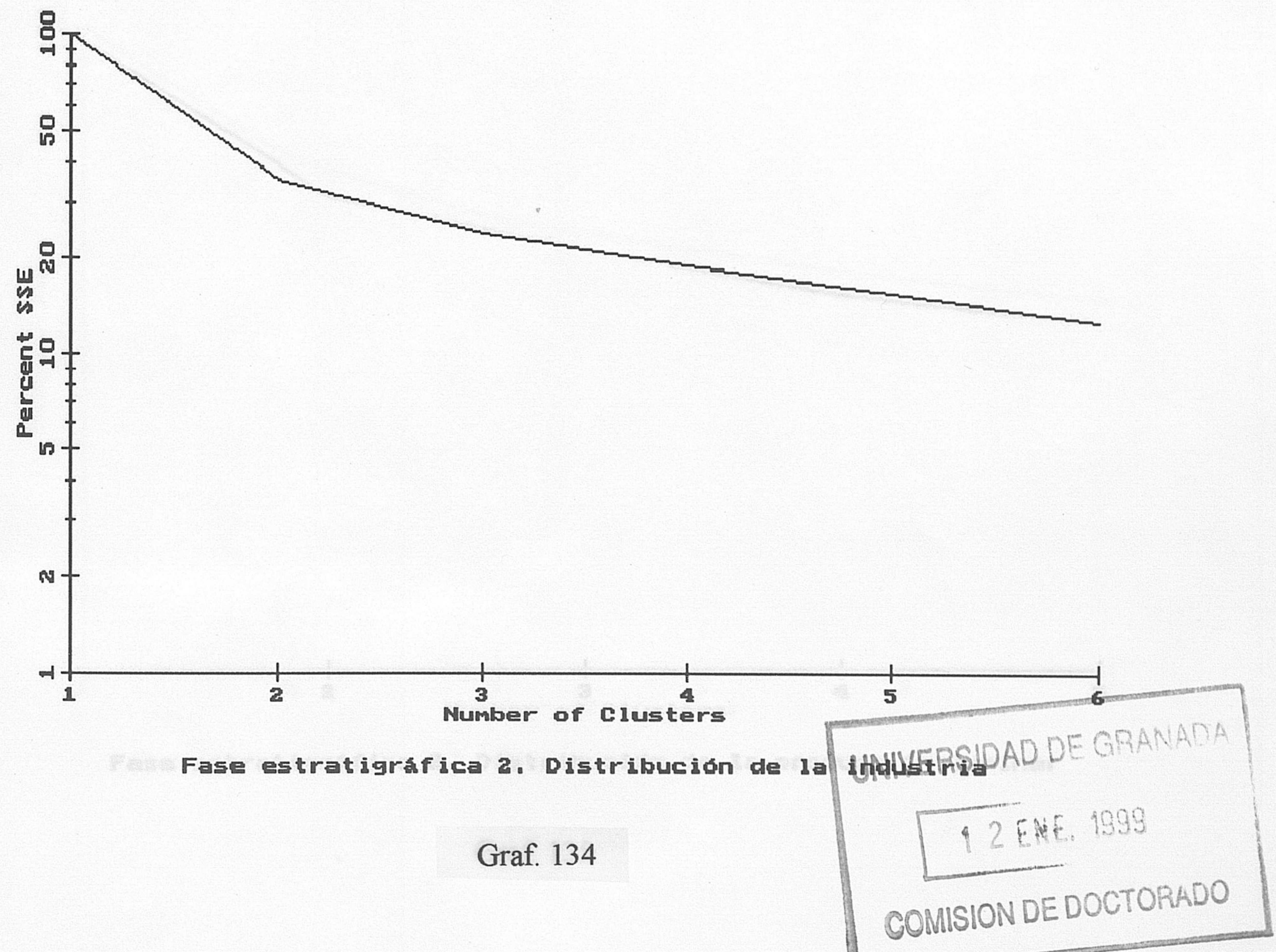




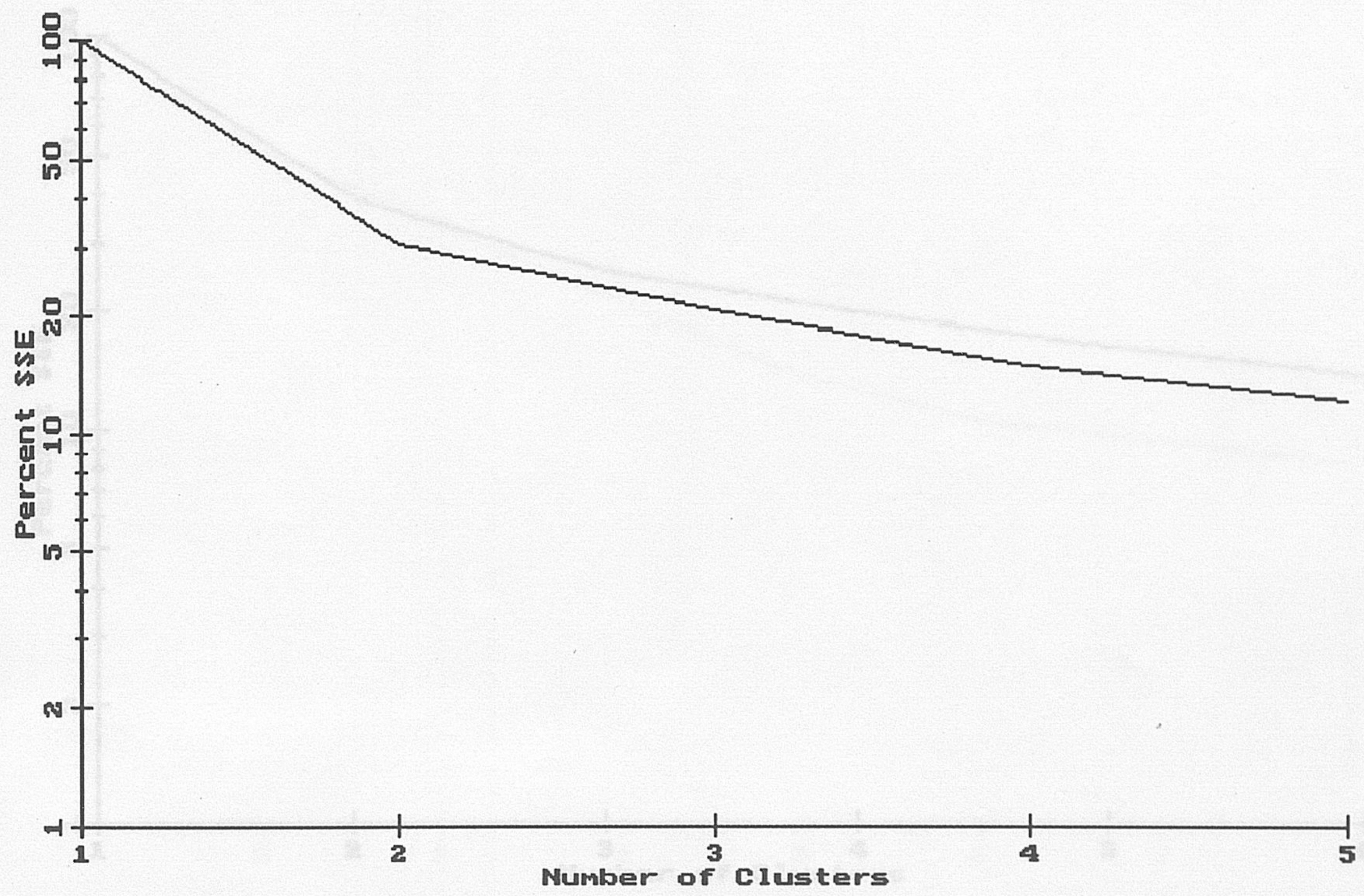

Fase estratigrafica 2. Distribución de la producción laminar

Graf. 135 


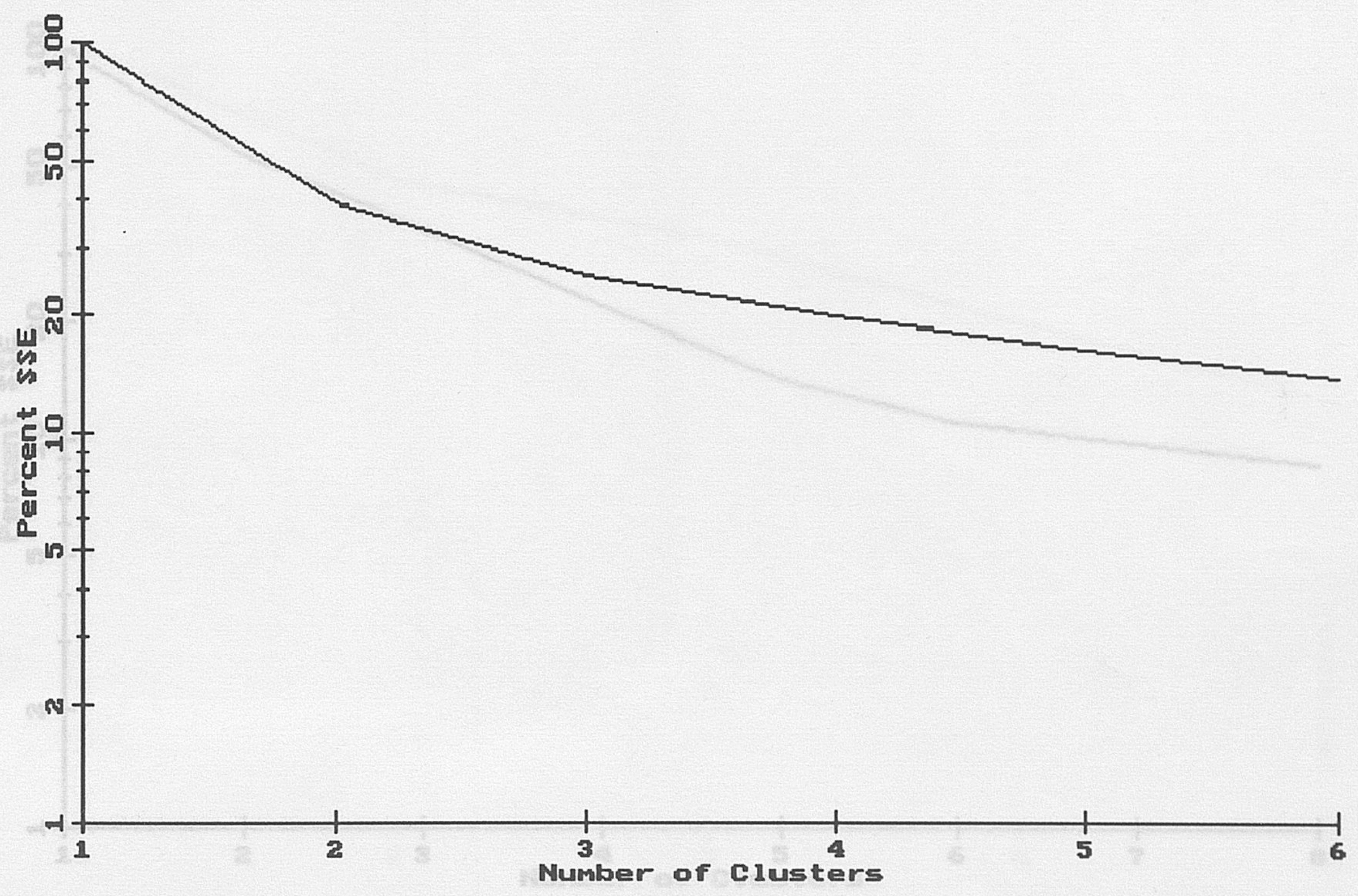

Fase estratigrafica 2. Distribución de la producción lascar

Graf. 136 


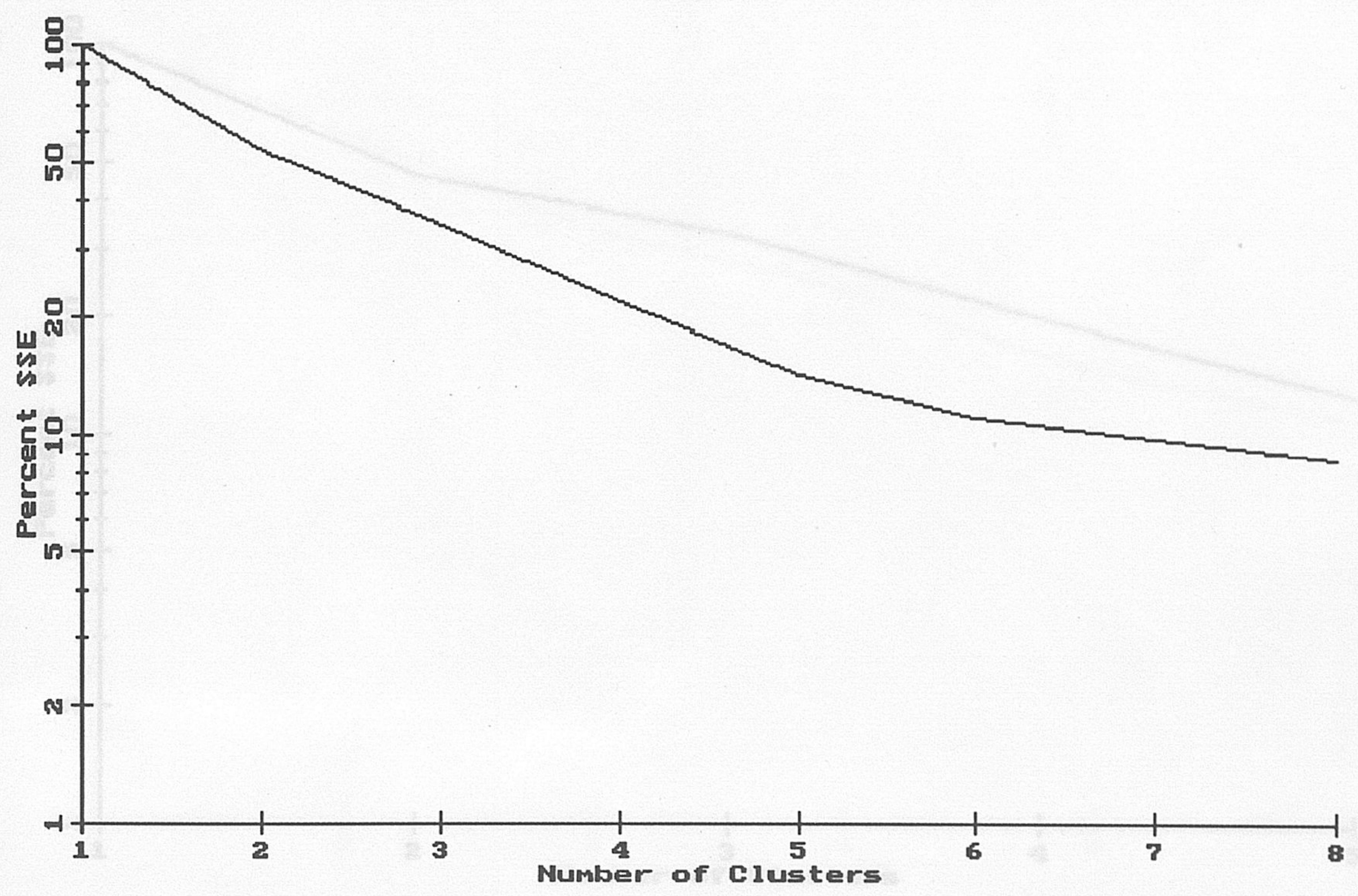

Fase estratigrafica 3. Distribución de la industria

Graf. 137 


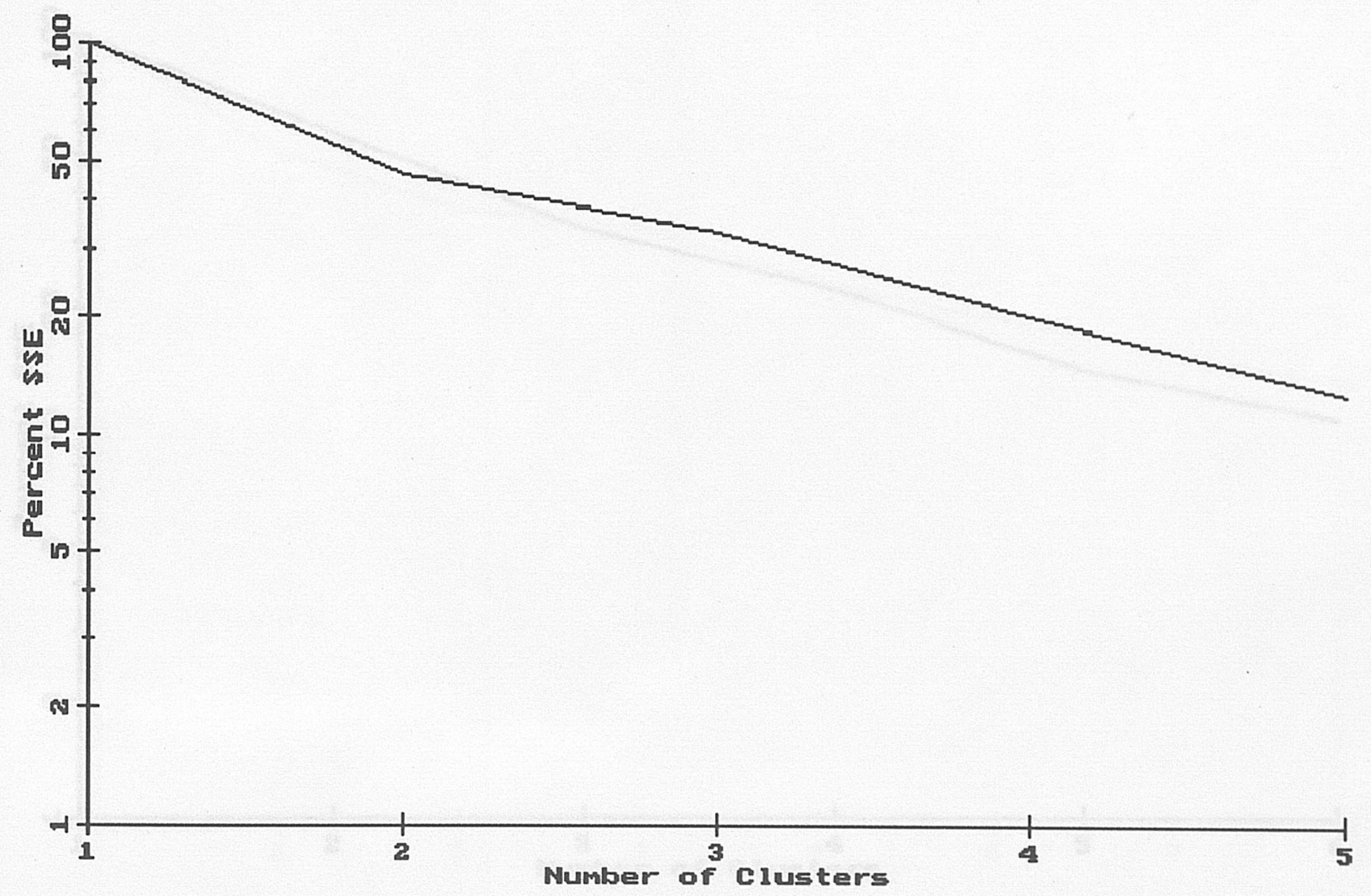

Fase estratigrafica 3. Distribucion de la producción laminar

Graf. 138 


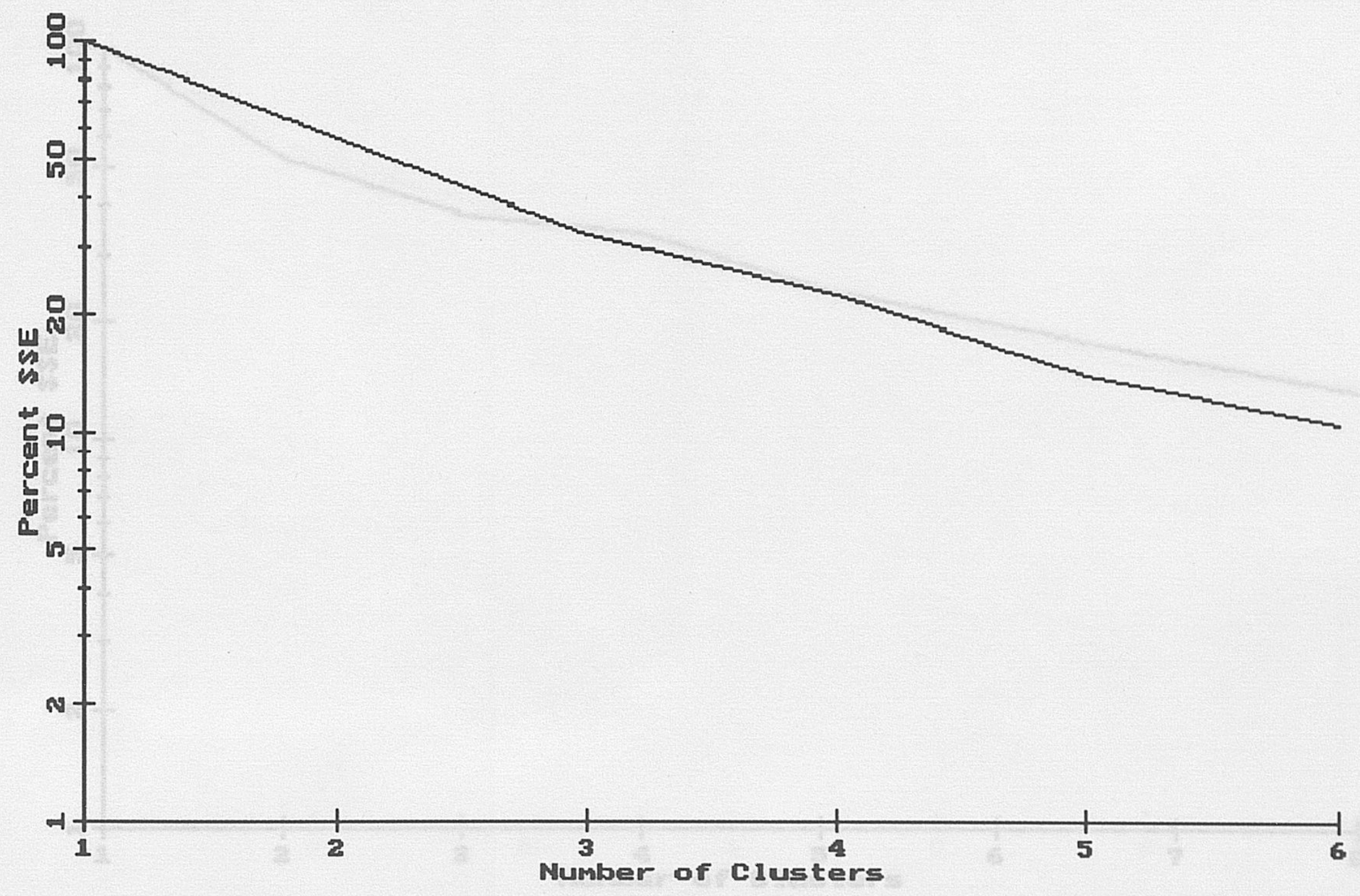

Fase estratigrafica 3. Distribución de la producción lascar

Graf. 139 


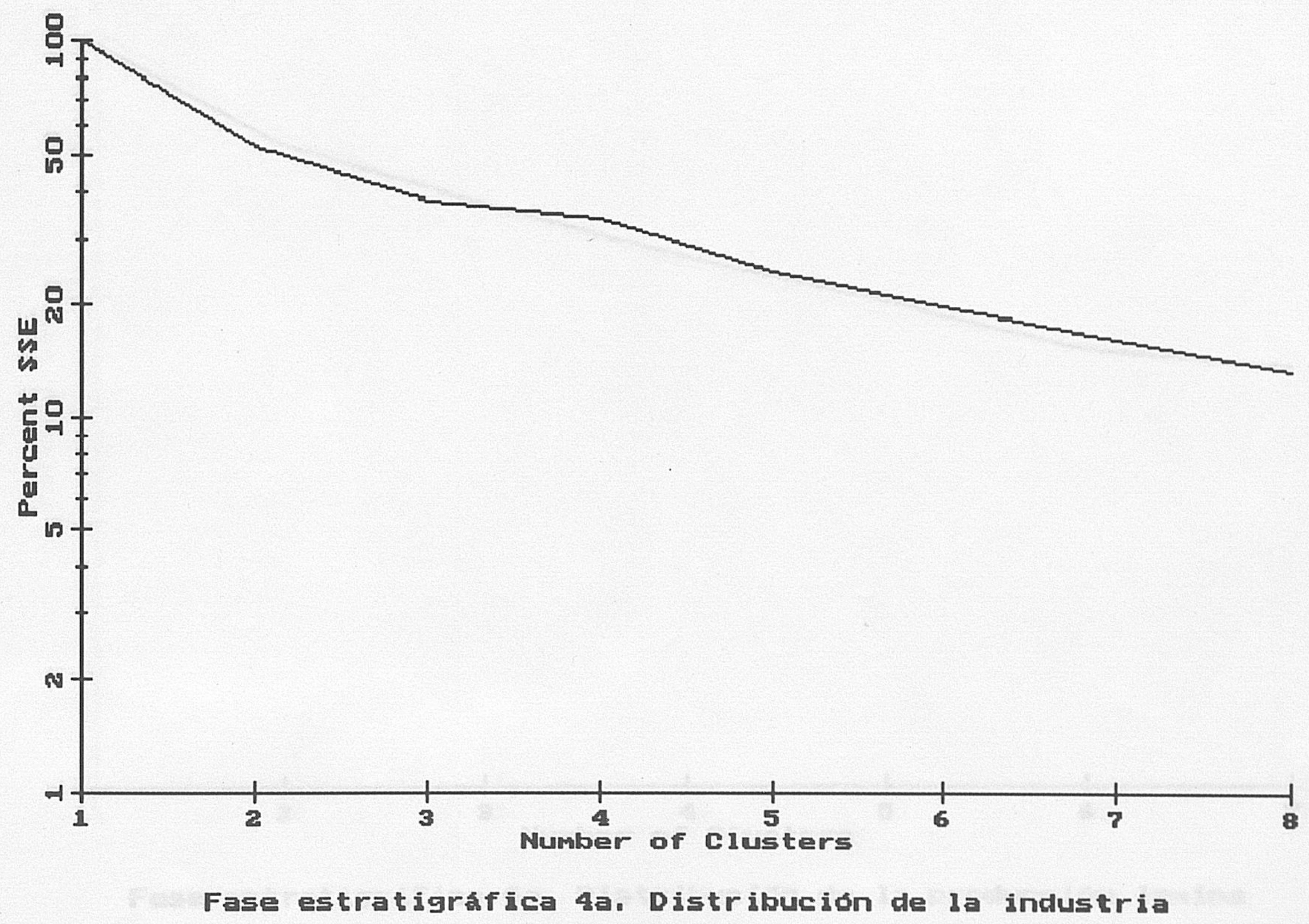

Graf. 140 


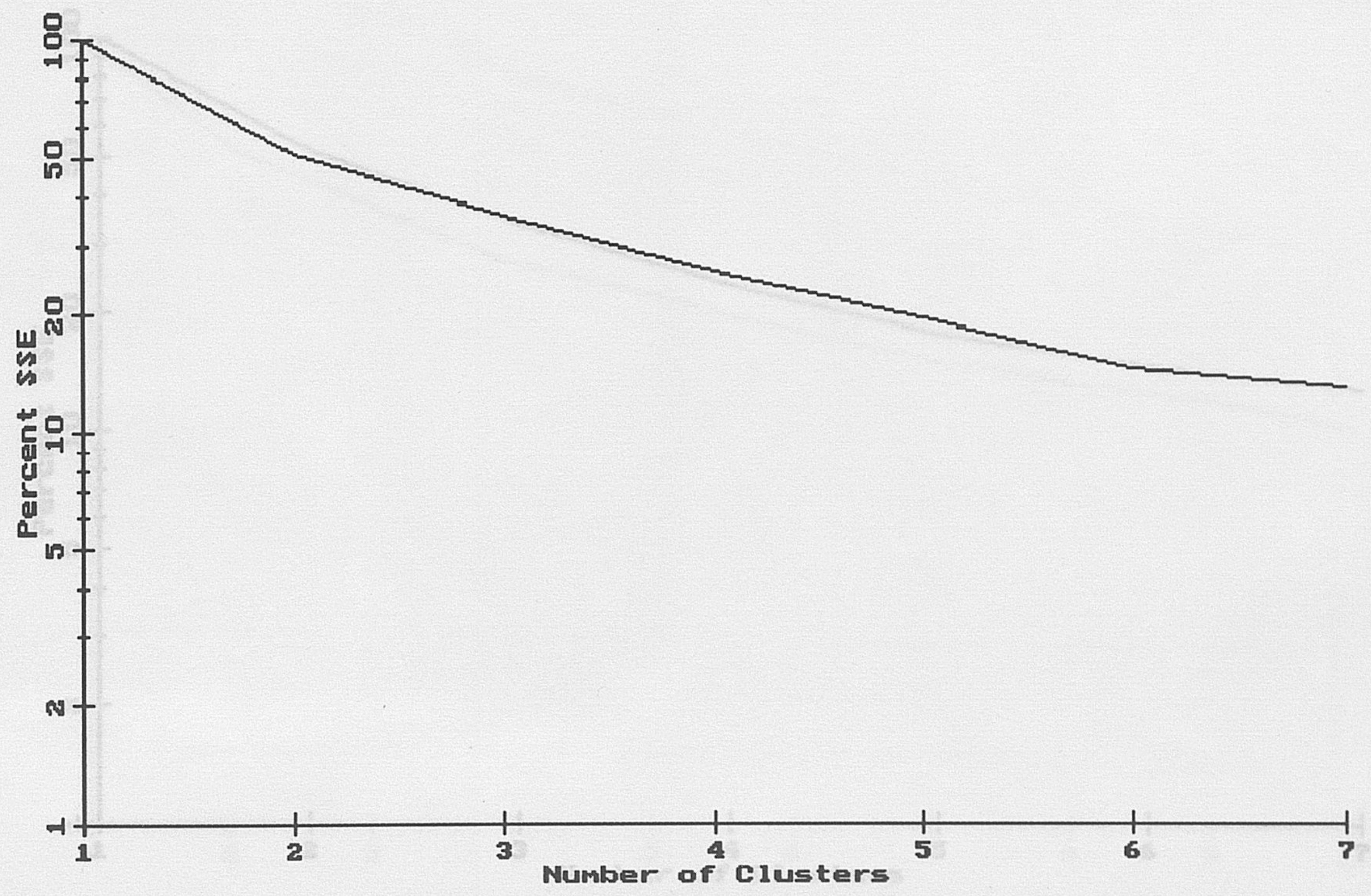

Fase estratigrafica 4a. Distribucion de la produccion lamina

Graf. 141 


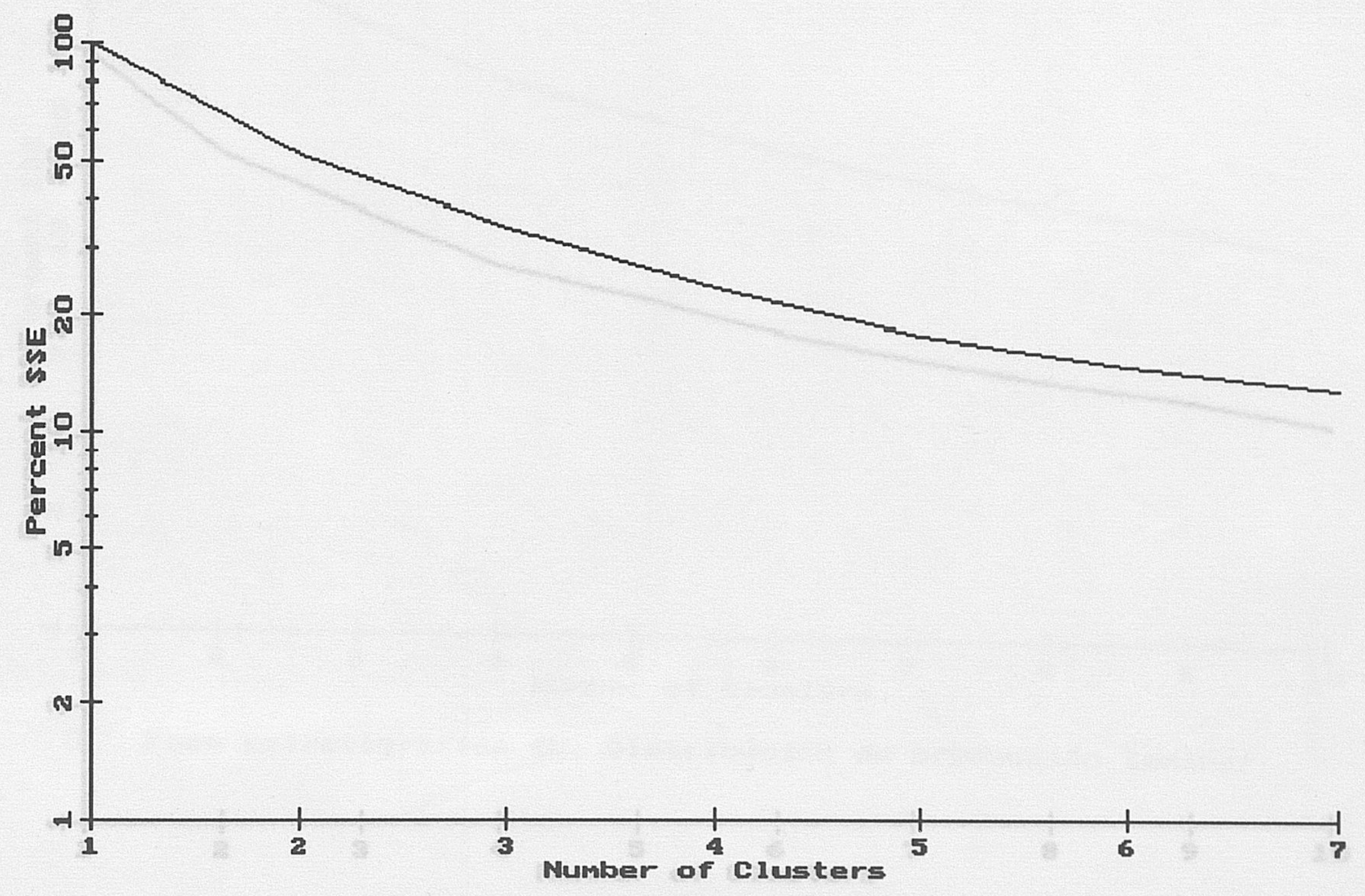

Fase estratigrafica 4a. Distribucion de la produccion lascar

Graf. 142 


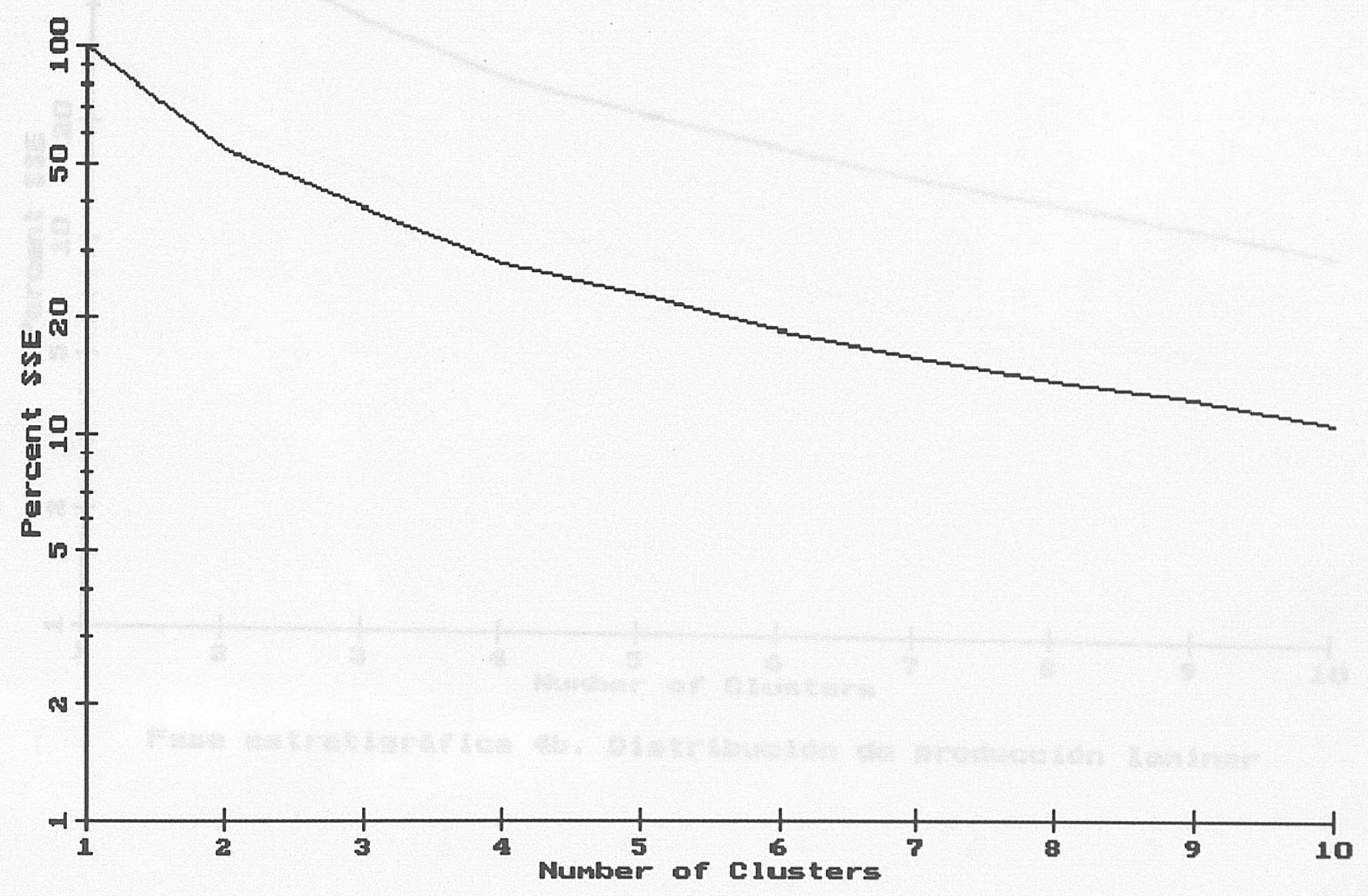

Fase estratigrafica $4 b$. Distribución de la industria

Graf. 143 


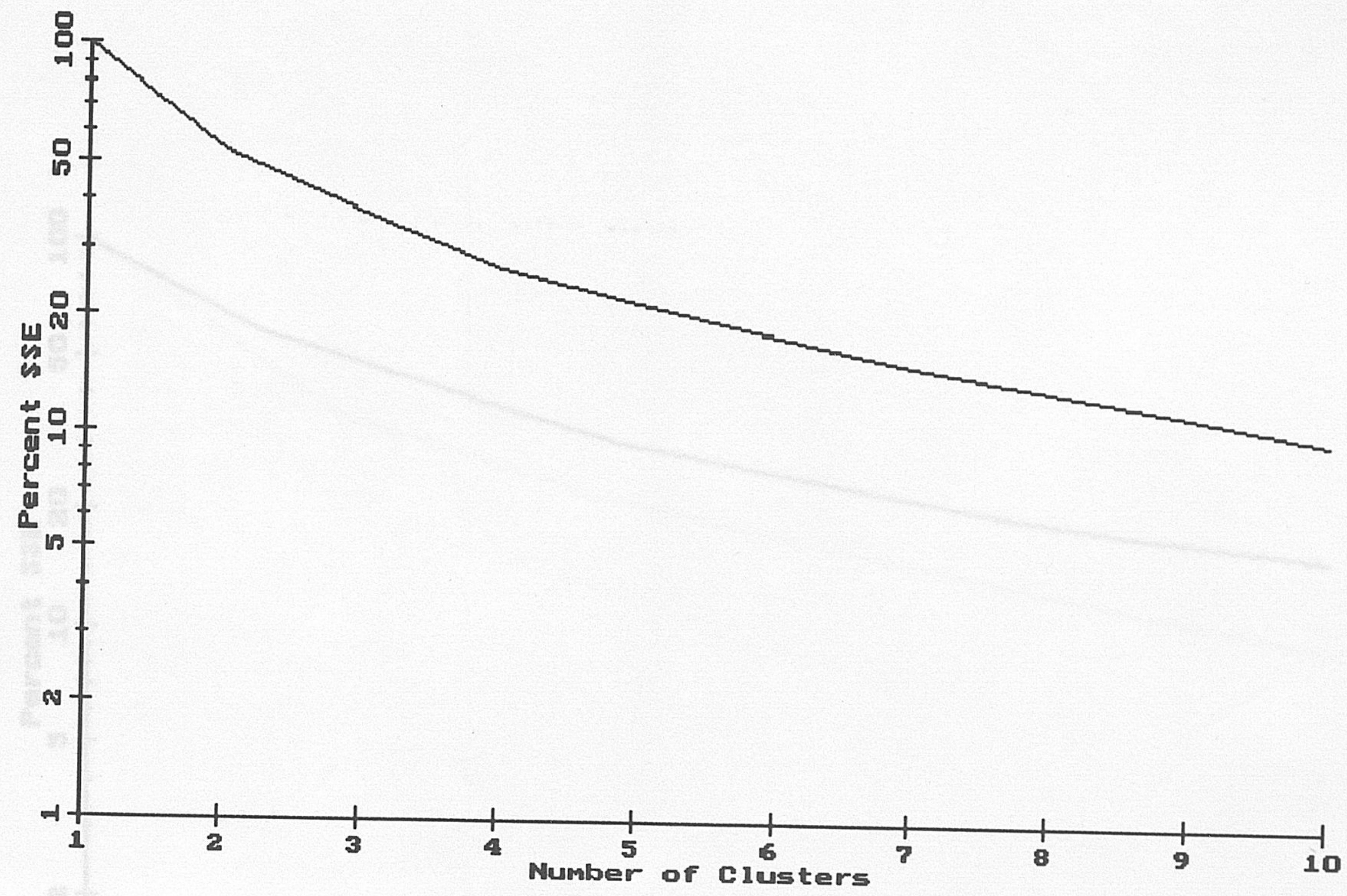

Fase estratigrafica 4b. Distribución de producción laminar 


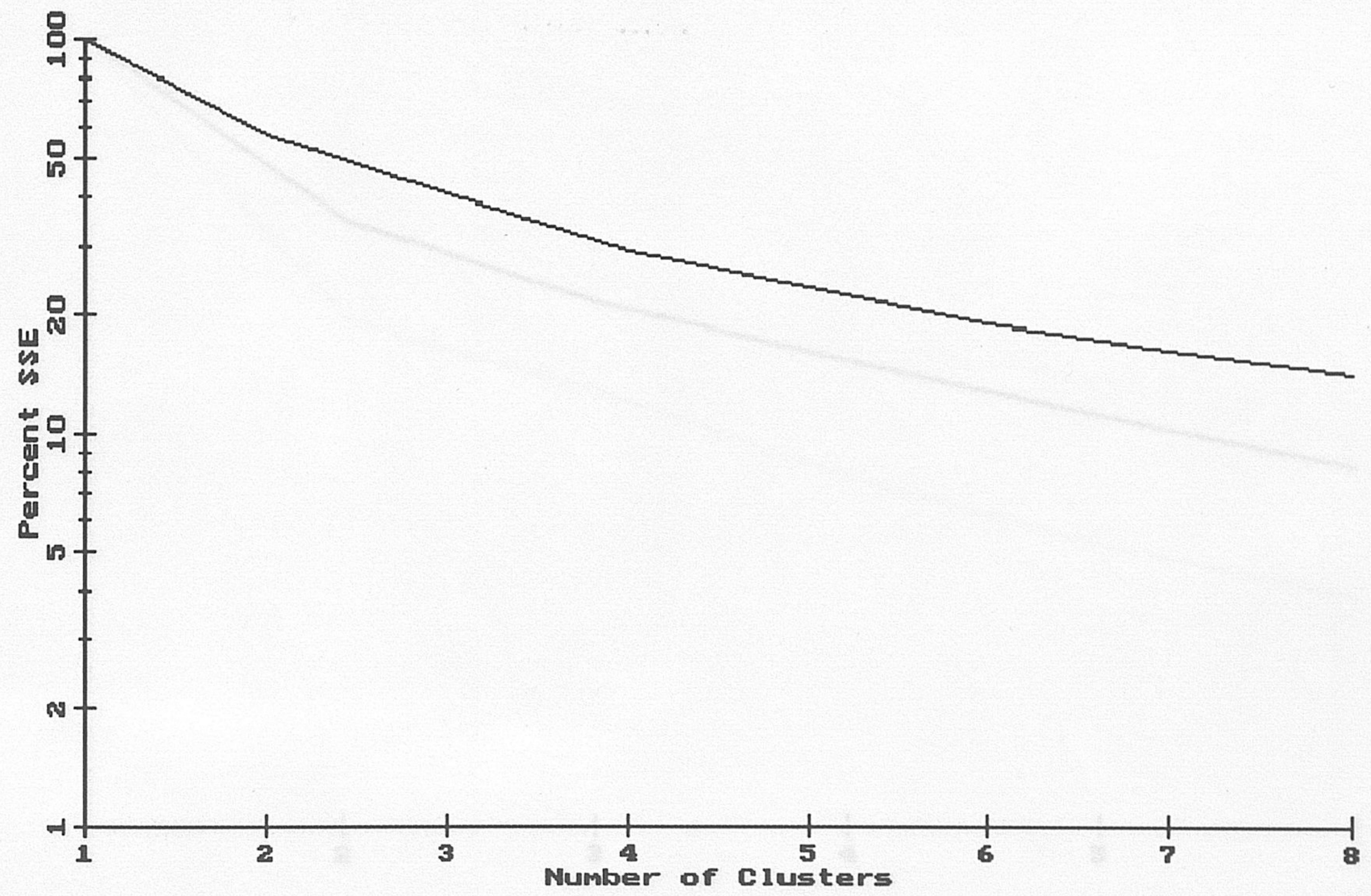

Fase estratigrafica 4b. Distribucion de la producción lascar 


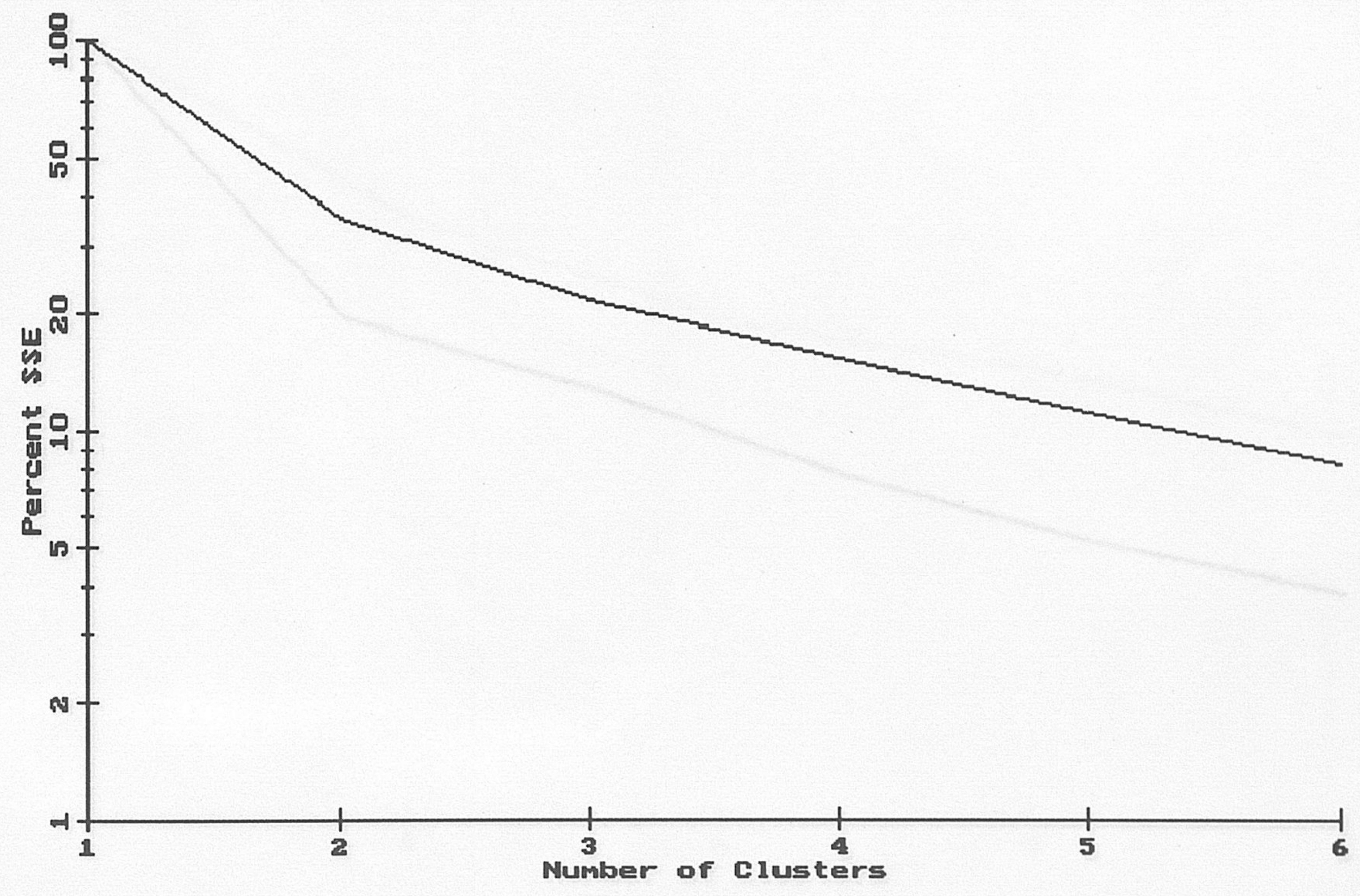

Fase estratigrafica 5. Distribución de la industria

Graf. 144 


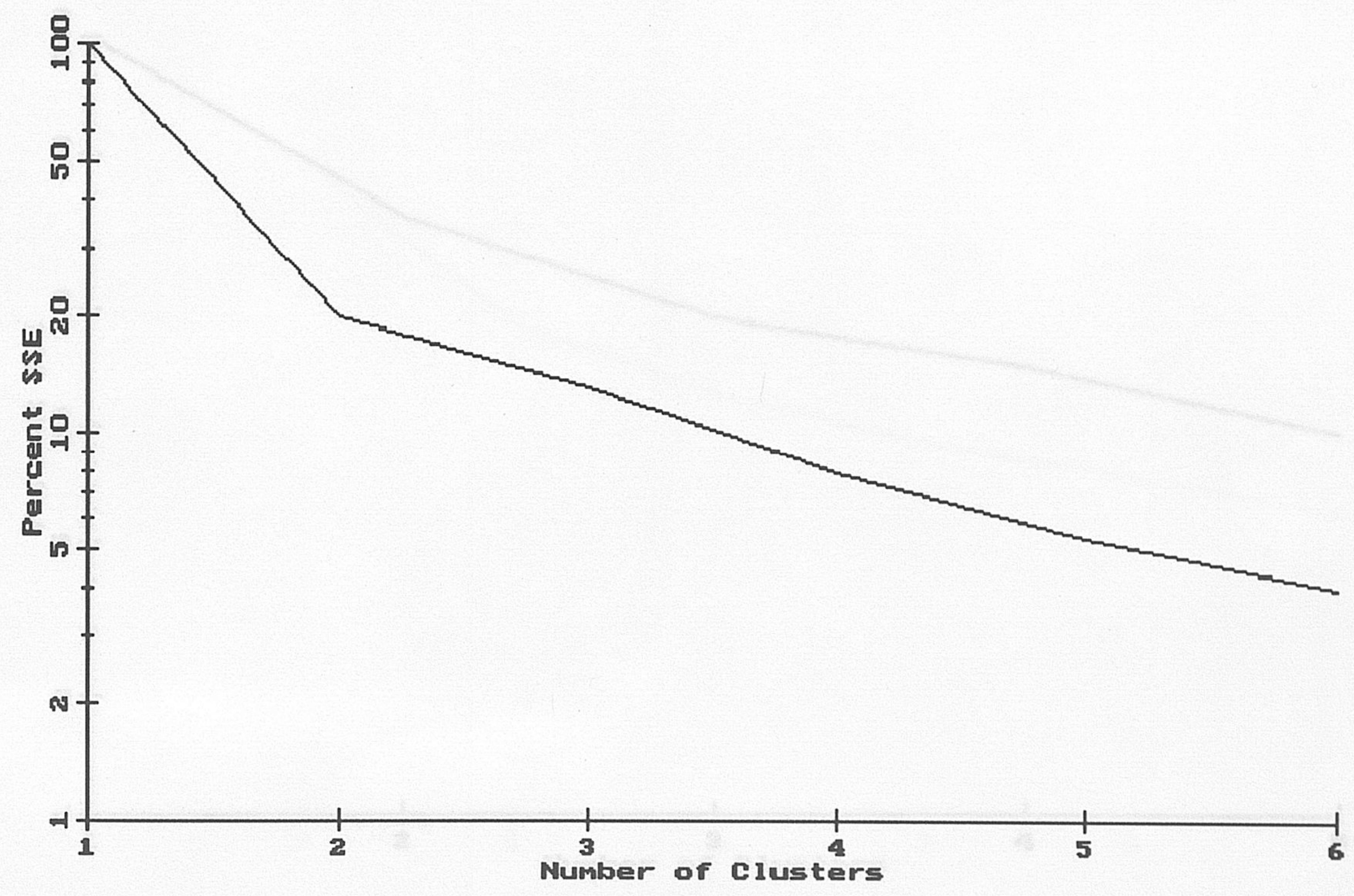

Fase estratigrafica 5. Distribución de la producción laminar

Graf. 145 


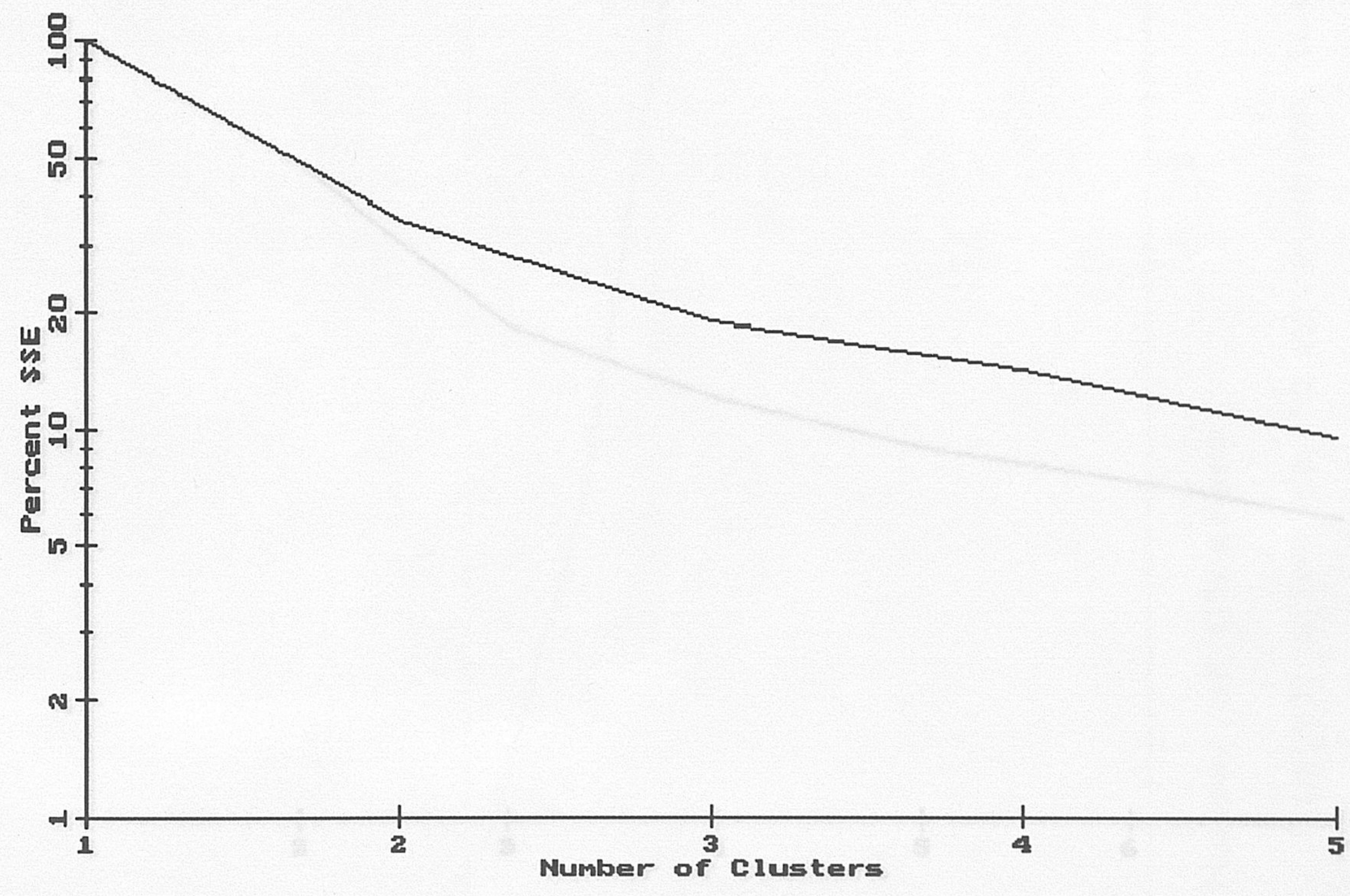

Fase estratigrafica 5. Distribución de la producción lascar

Graf. 146 


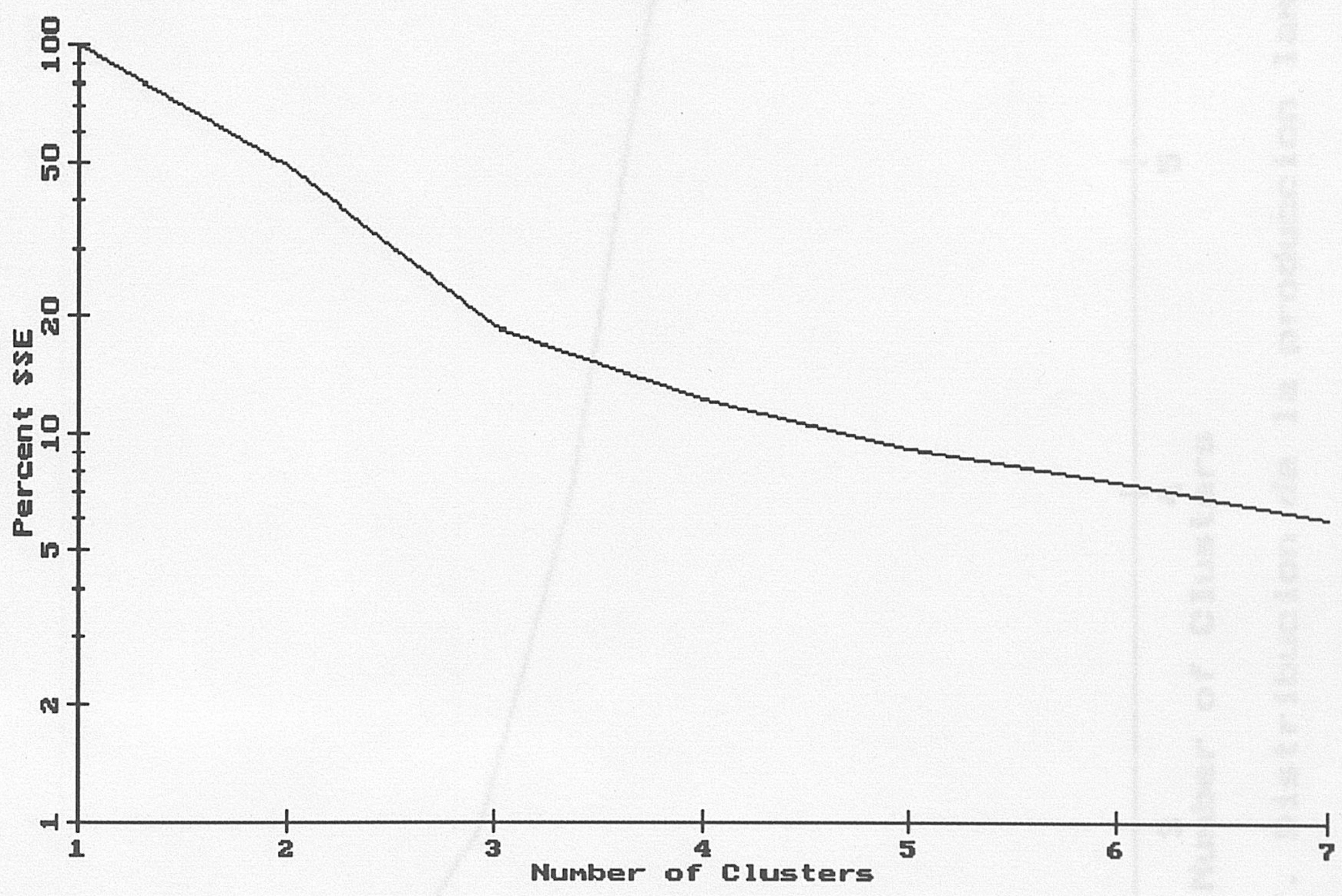

Fase estratigrafica 7. Distribución de la industria

Graf. 147 


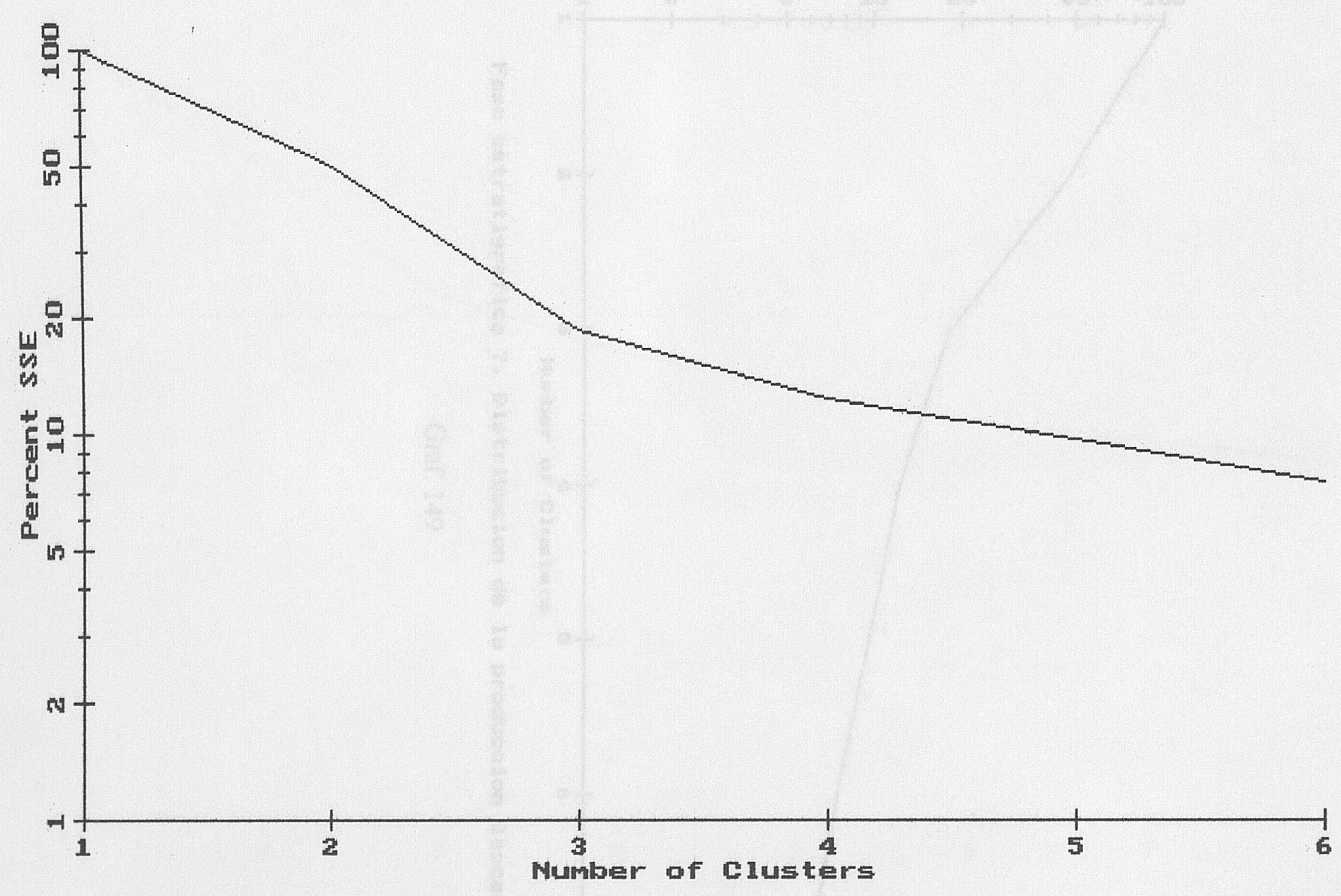

Fase estratigrafica 7 . Distribucian de la produccion laminar

Graf. 148 


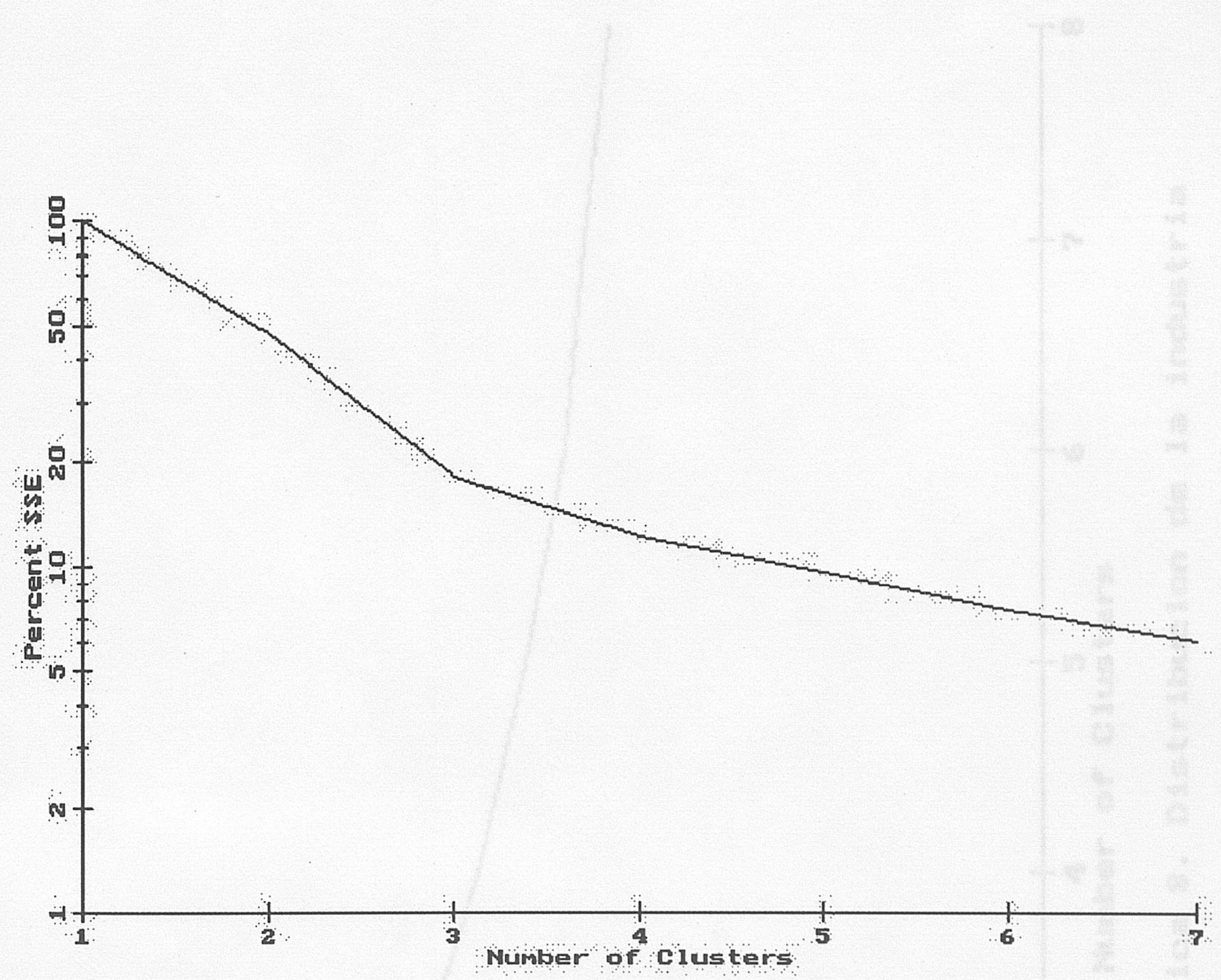

Fase estratigrafica 7. Distribucion de la produccion lascar

Graf. 149 


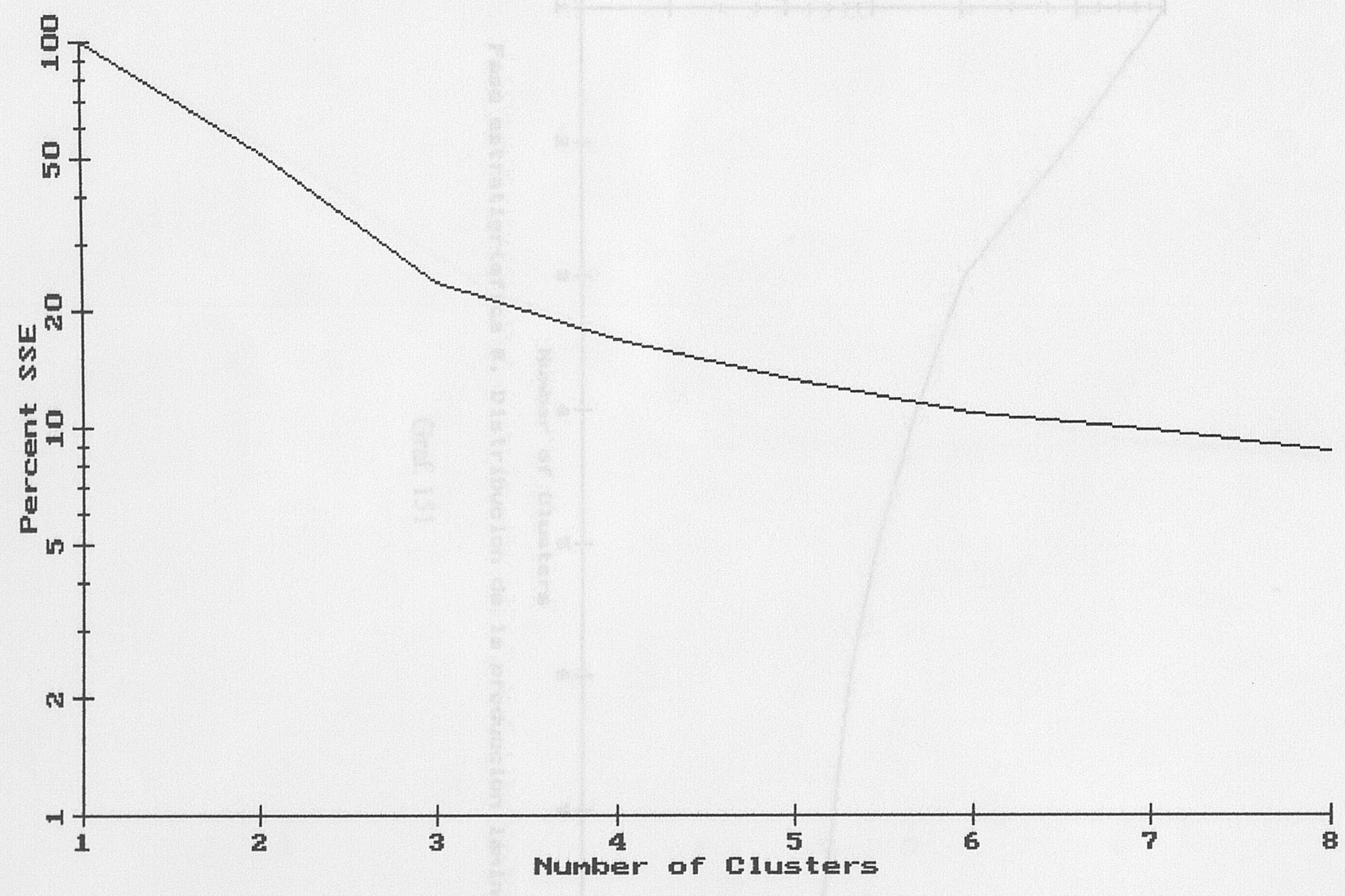

Fase estratigrafica 8 . Distribucion de 1 a industria 


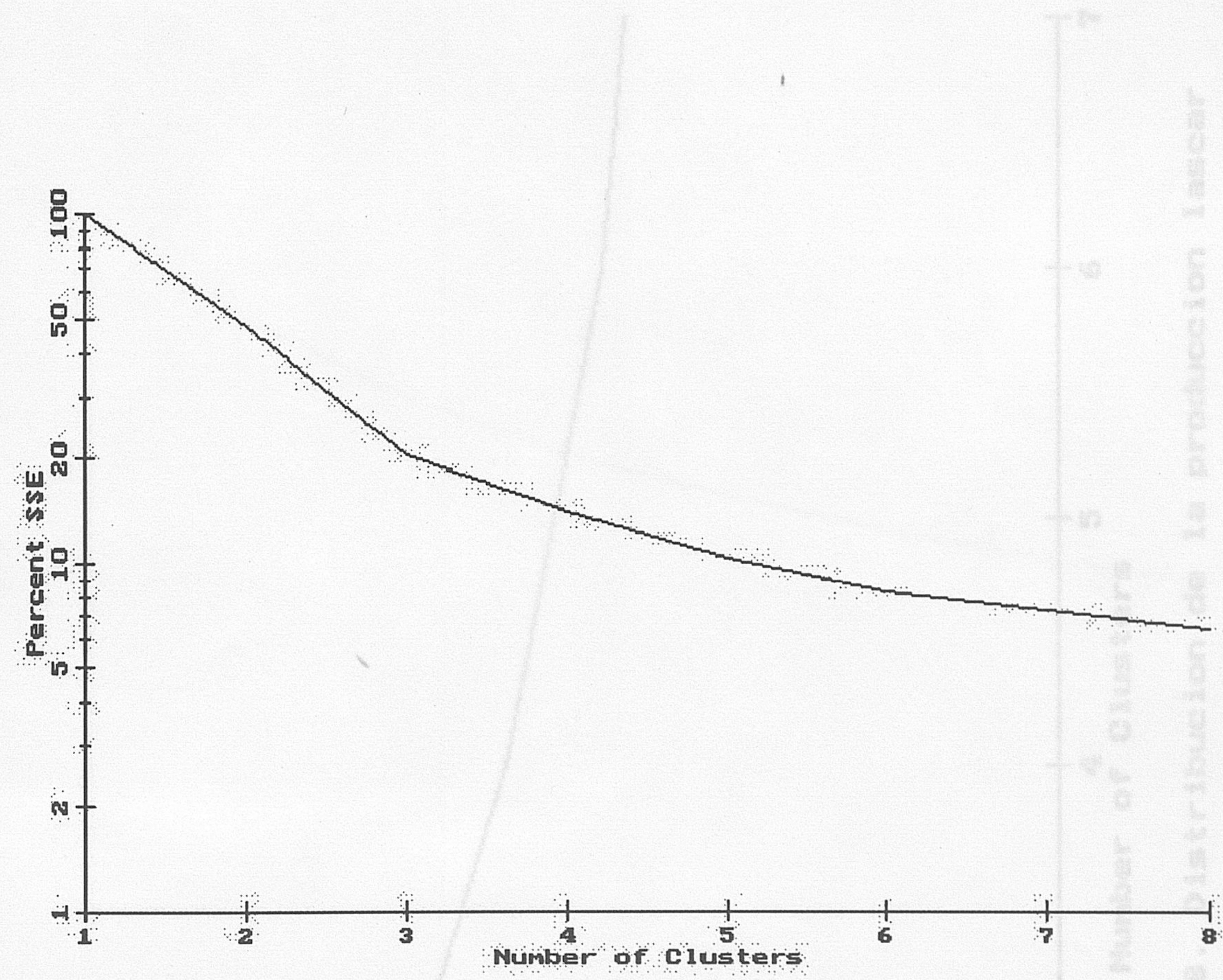

Fase estratigrefica 8. Distrabucan de la produccion lamina

Graf. 151 


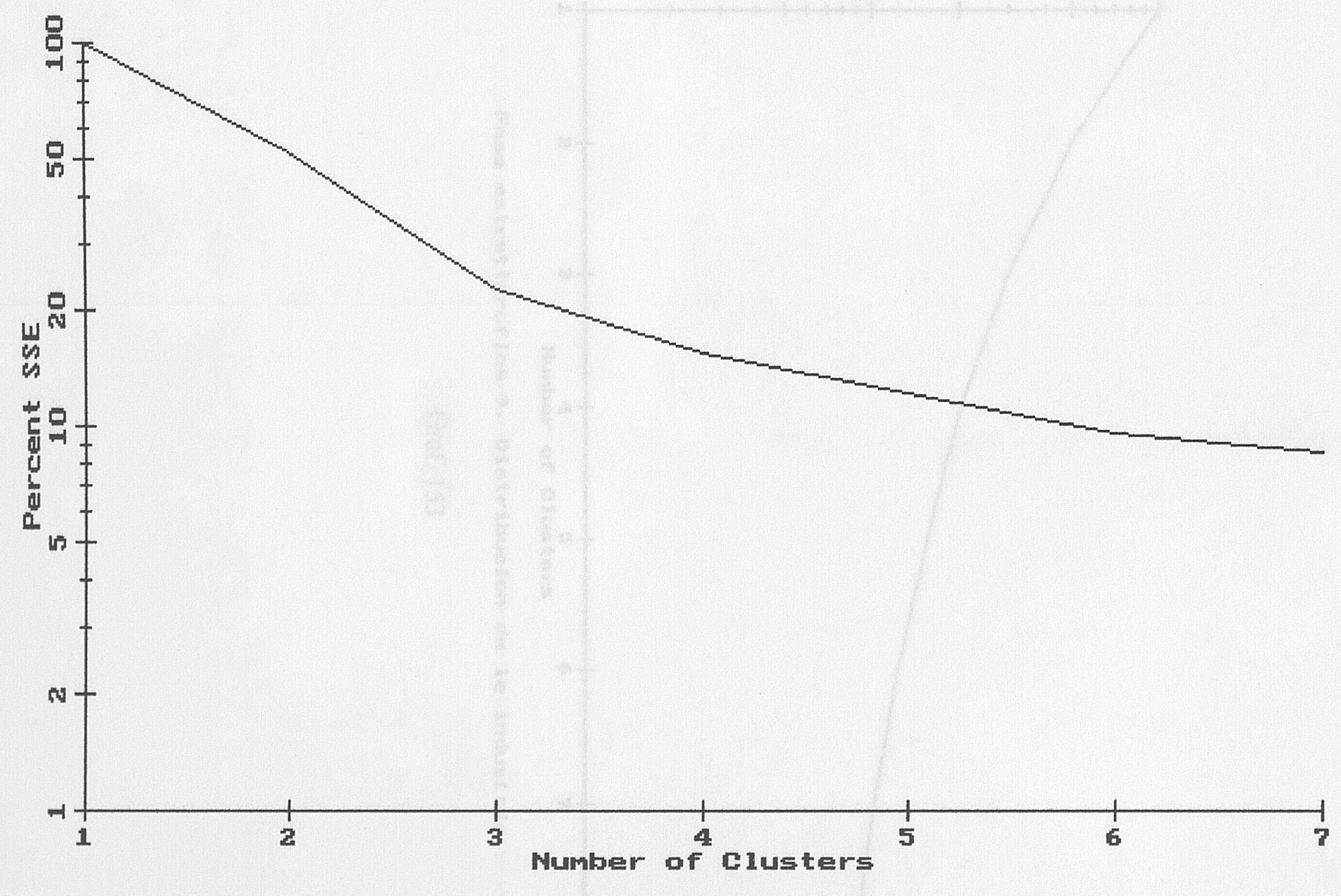

Fase estratigrafica 8. Distribucion de 1 a procluccion lascar 


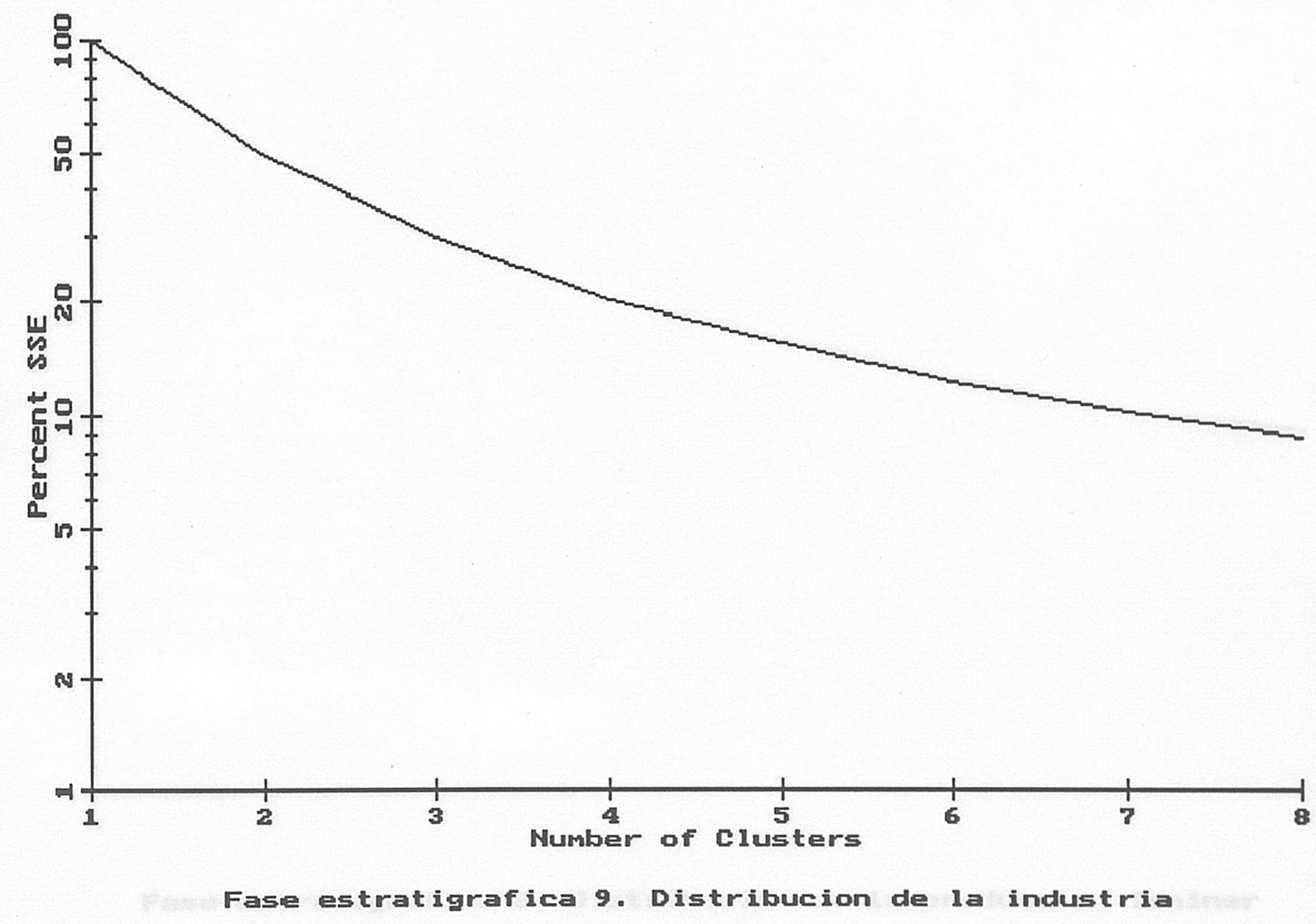

Graf. 153 


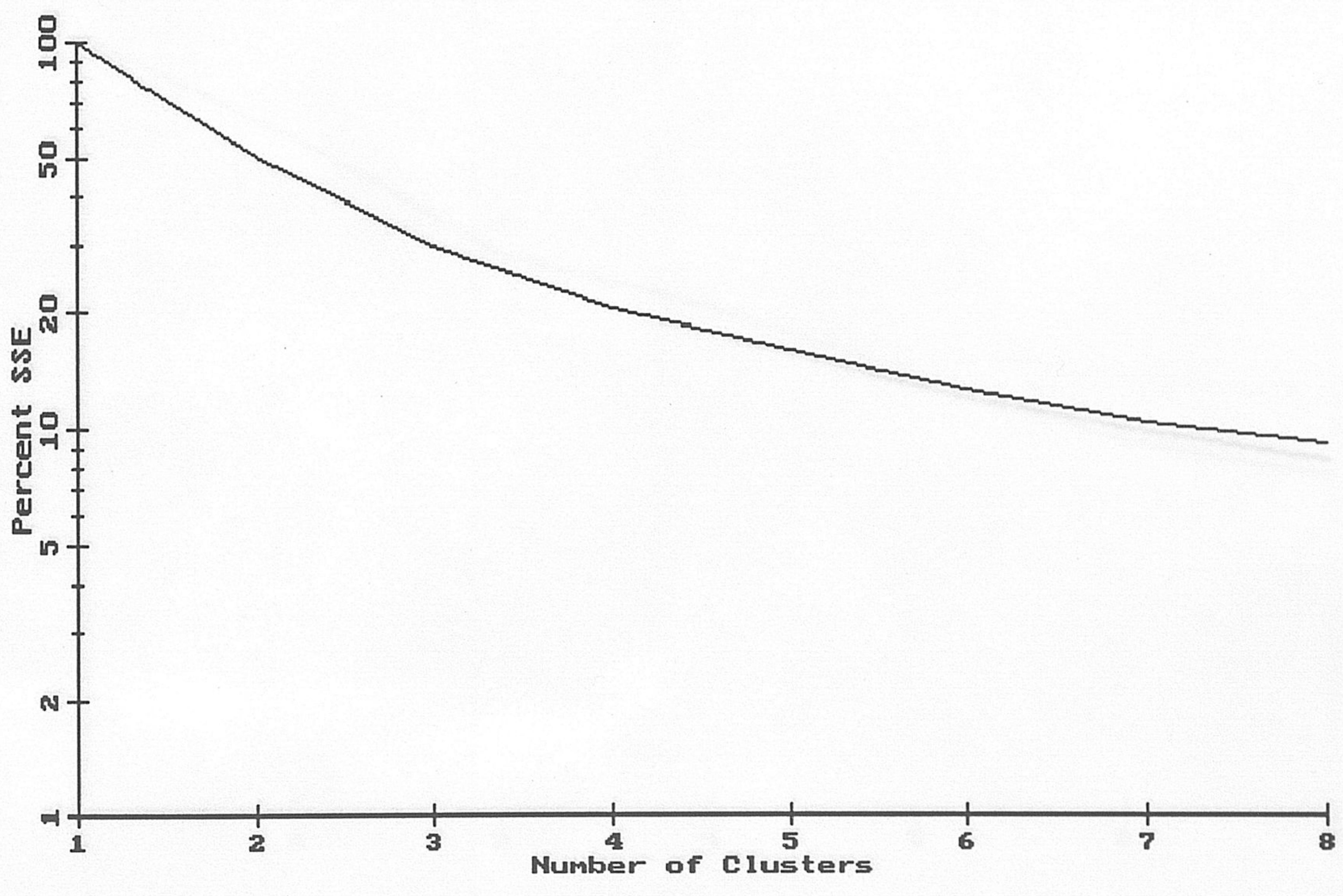

Fase estratigrafica 9. Distribucion de la produccion laminar

Graf. 154 


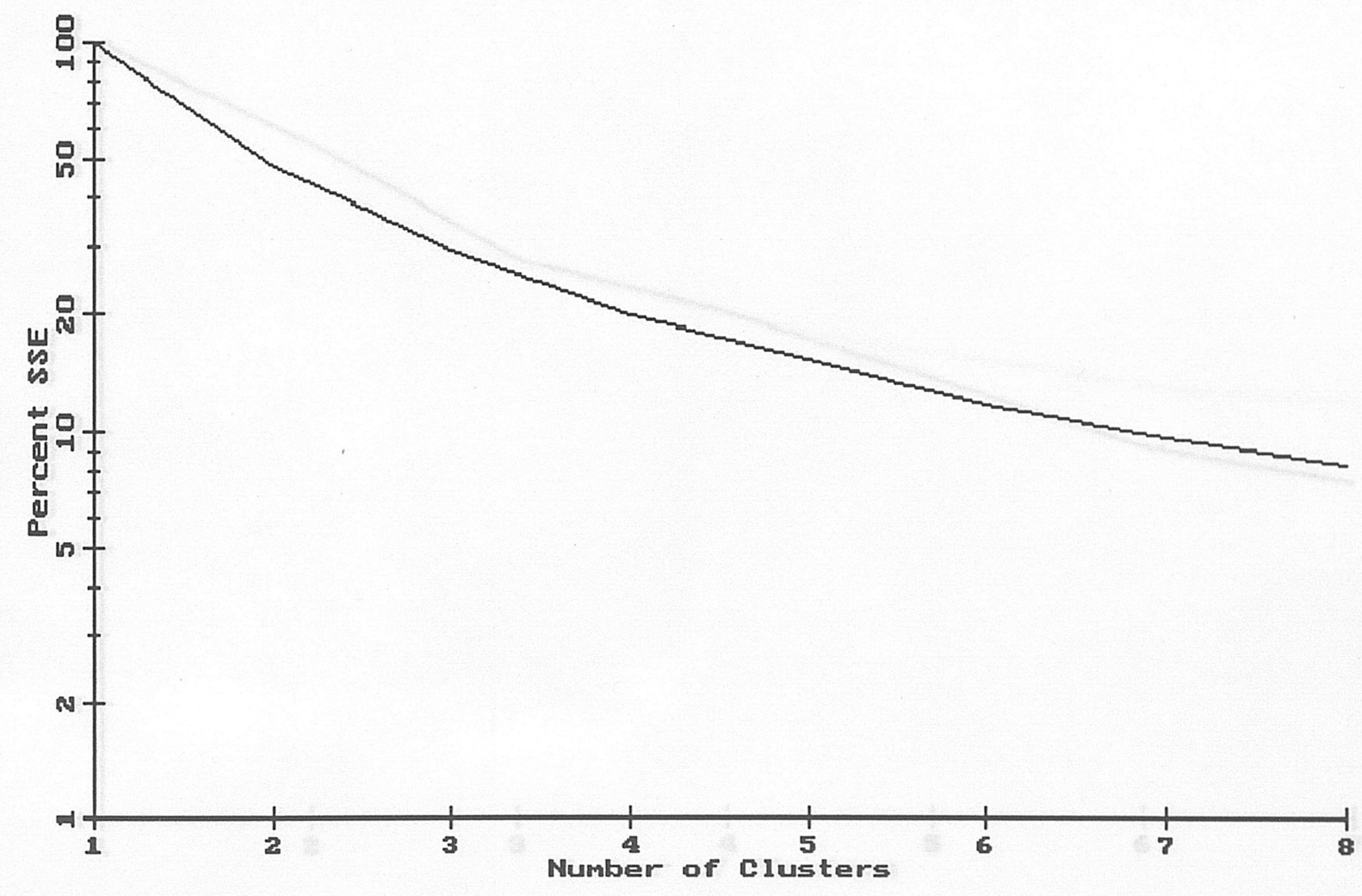

Fase estratigrafica 9. Distribucion de la procluccion lascar

Graf. 155 


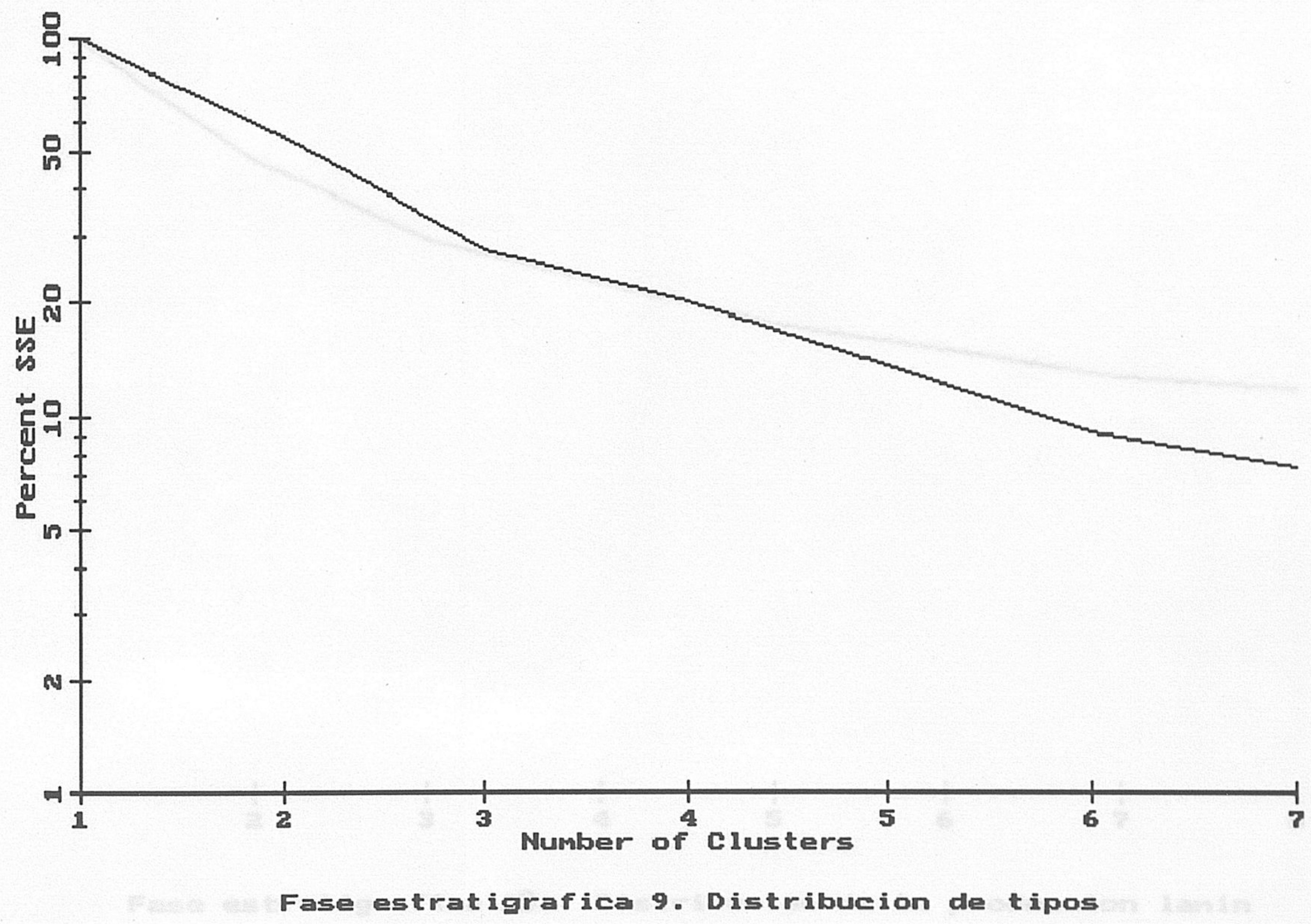

Graf. 156 


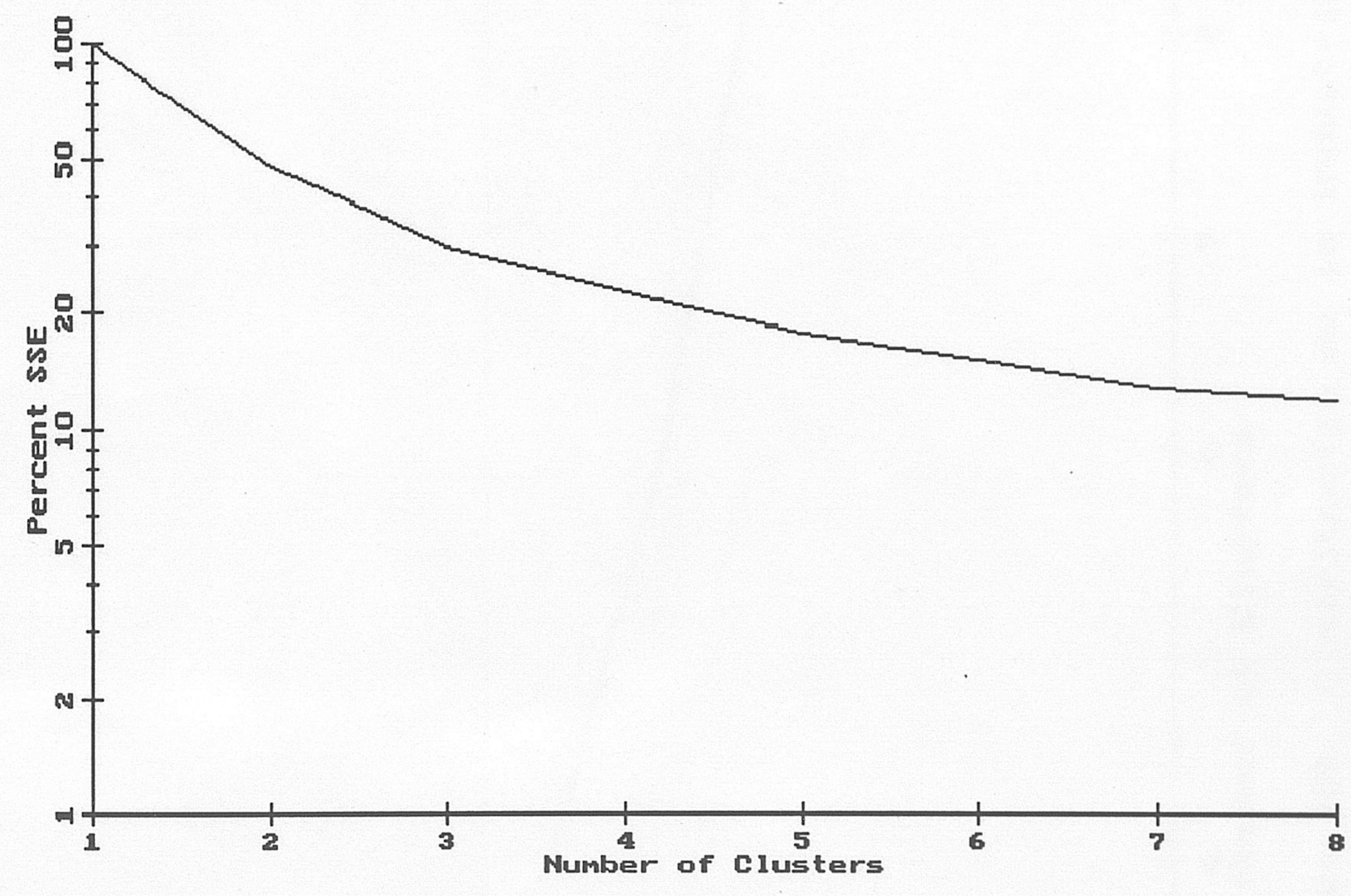

Fase estratigrafica 10a. Distribucion de la produccion lamin

Graf. 157 


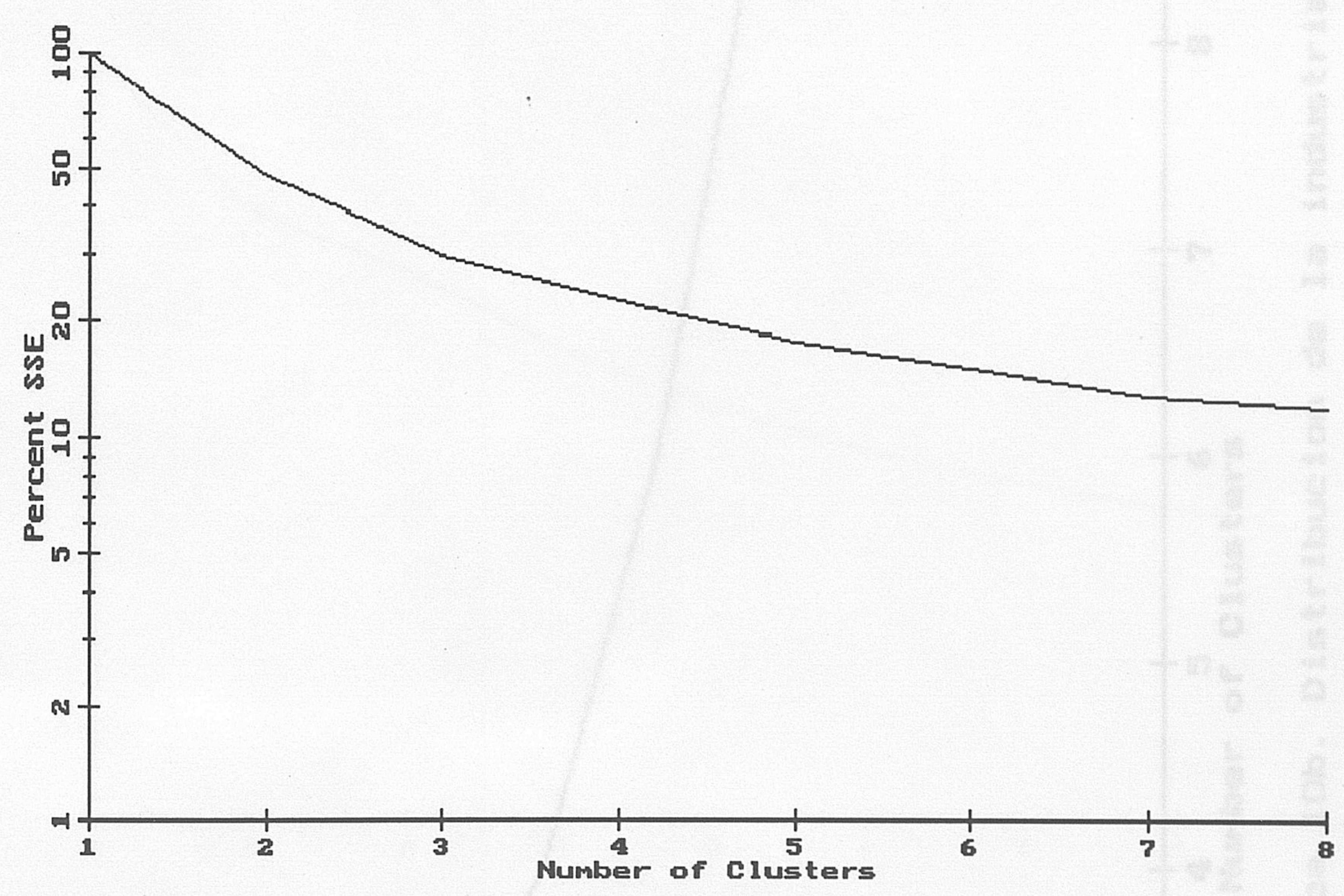

Fase estratigrafica 10a. Distribucion de la produccion lamin

Graf. 158 


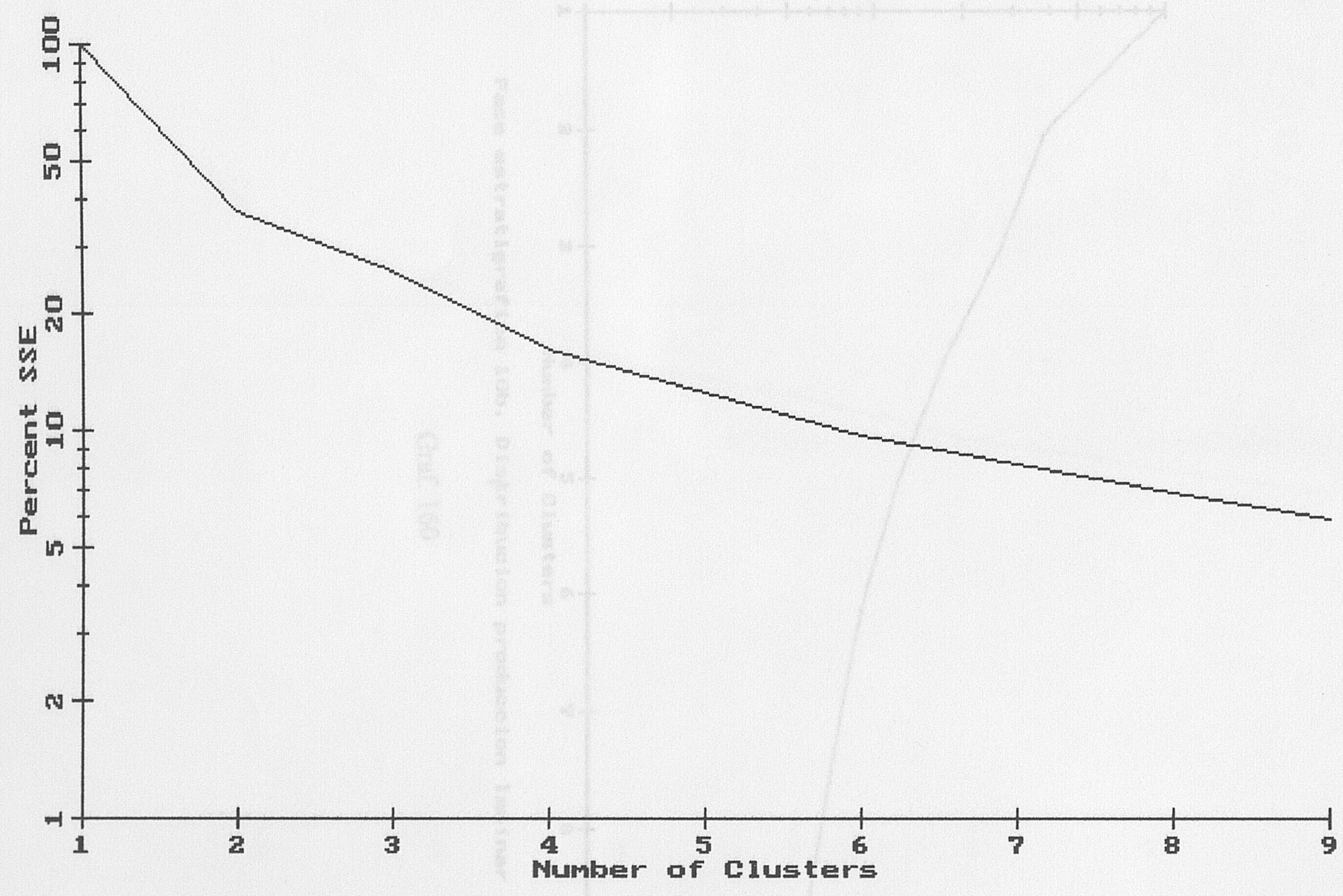

Fase estratigrafica 10b. Distribucion de la industria

Graf. 159 


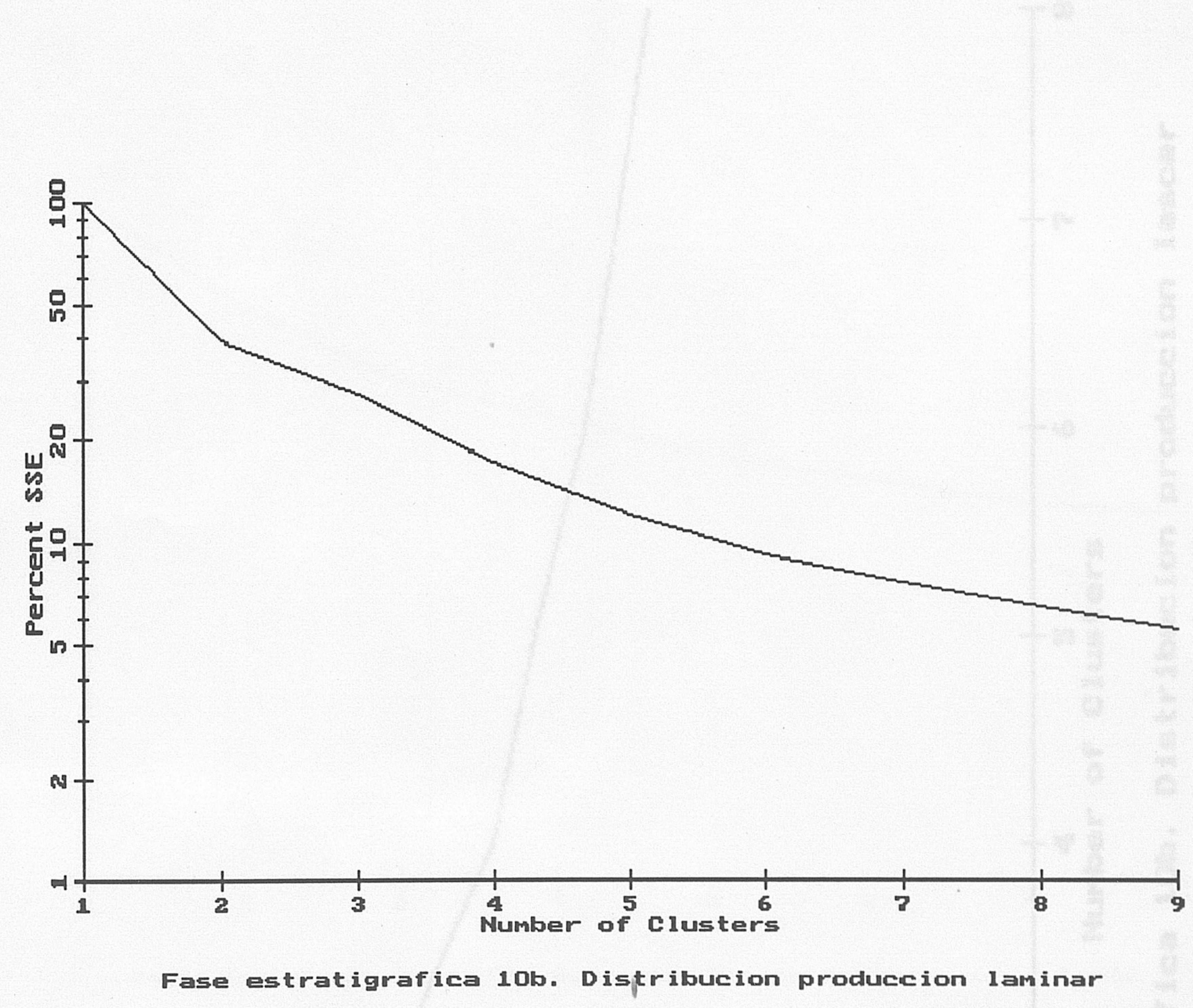

Graf. 160 


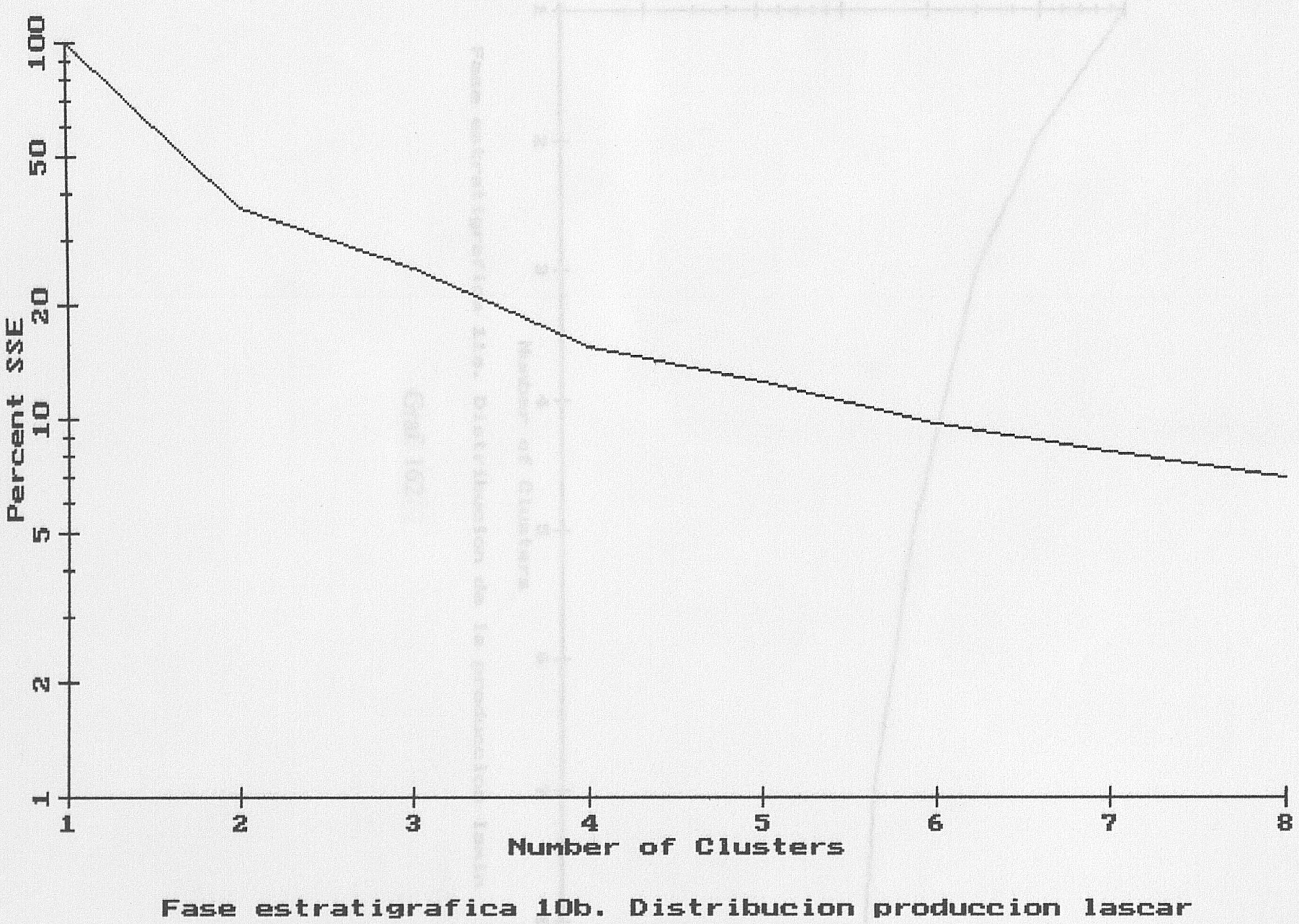

Graf. 161 


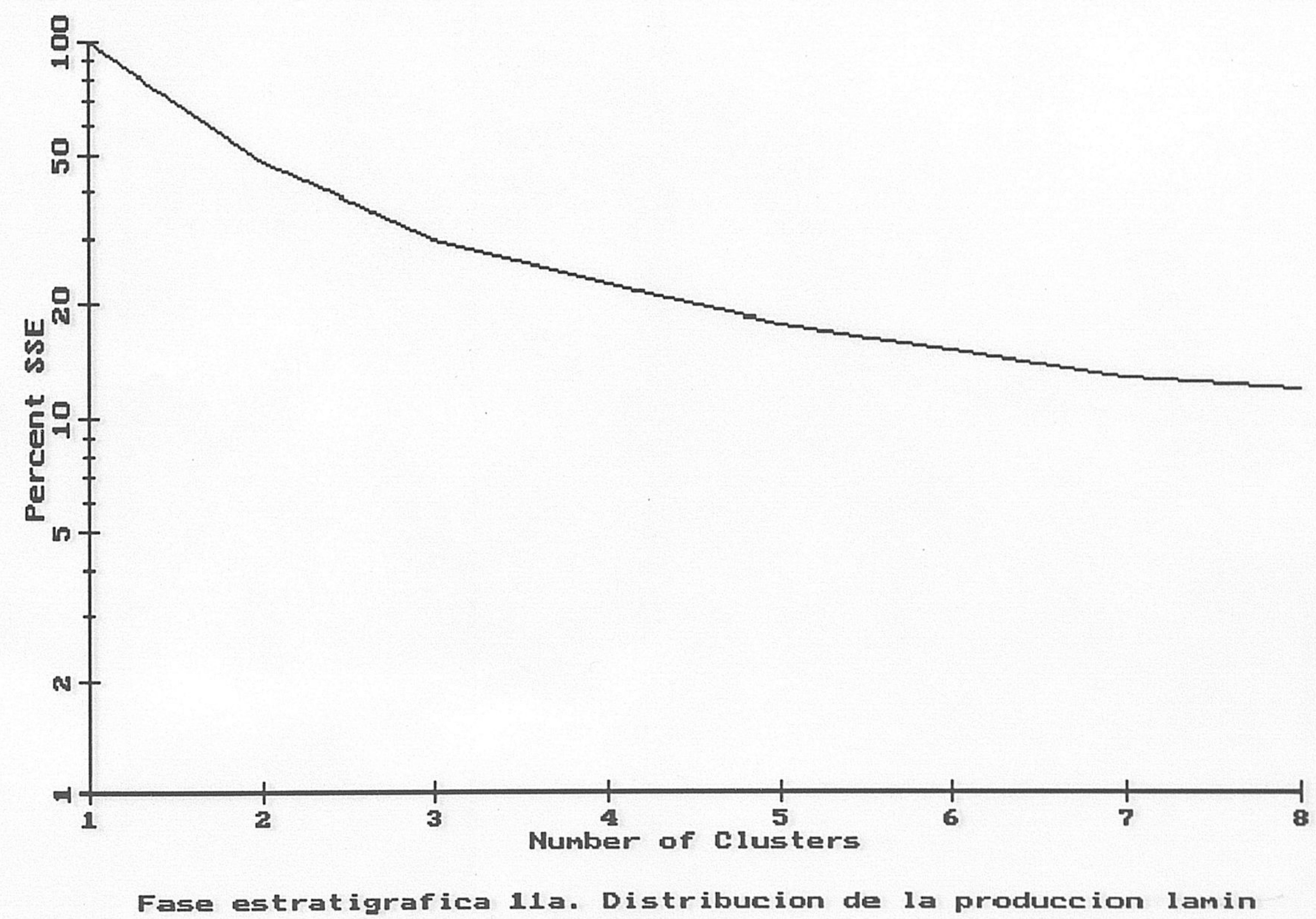

Graf. 162 


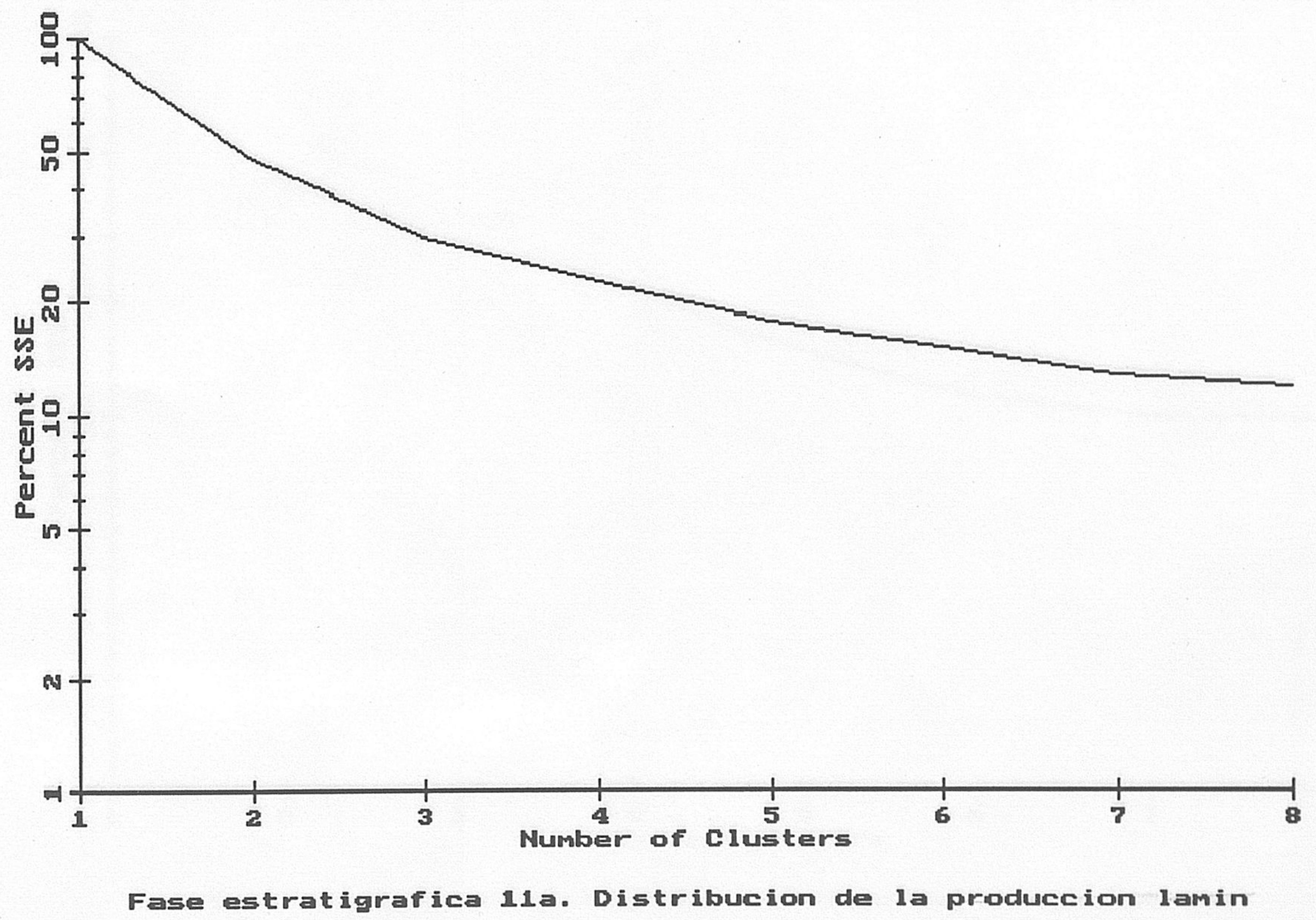

Graf. 163 


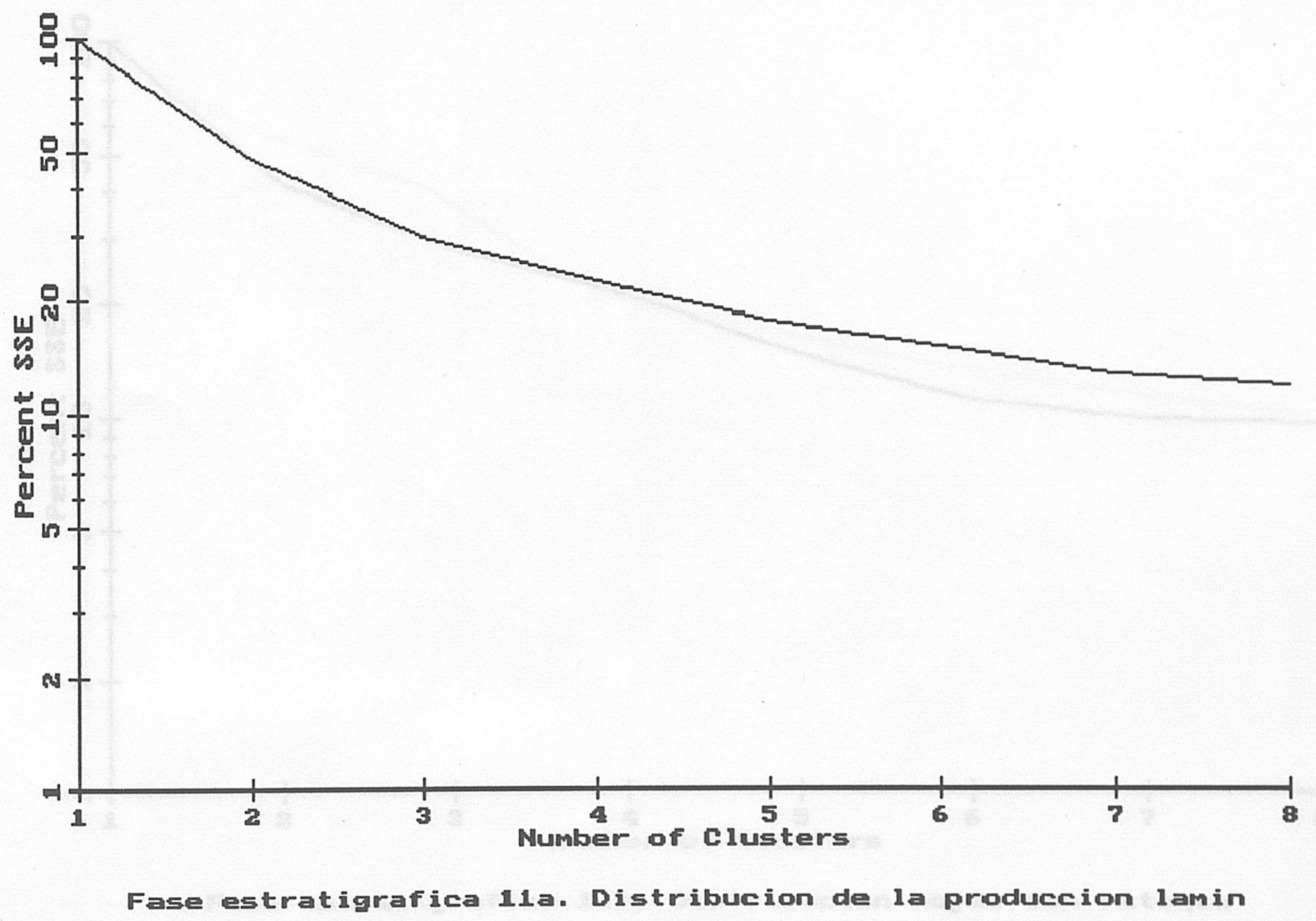

Graf. 164 


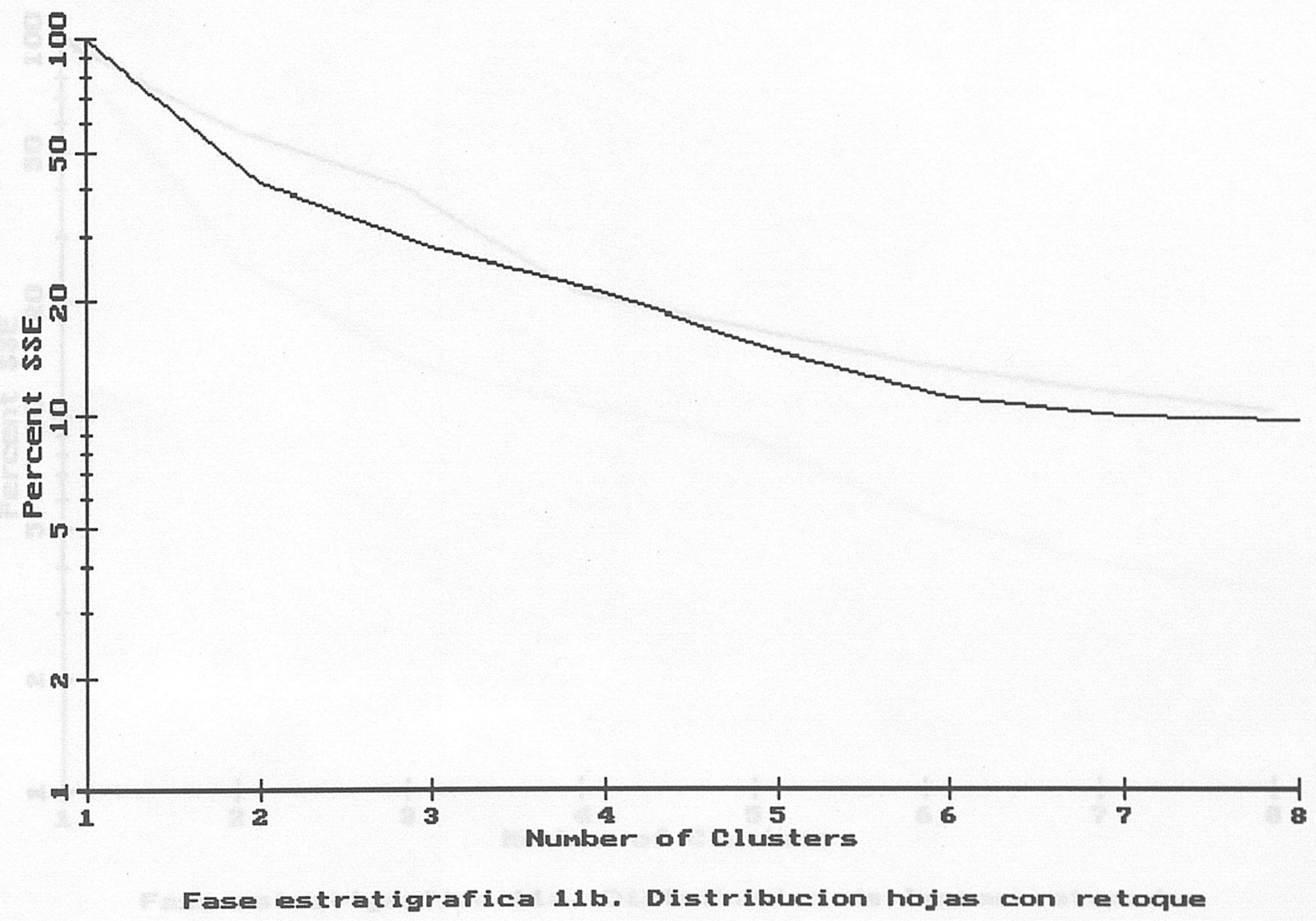

Graf. 165 


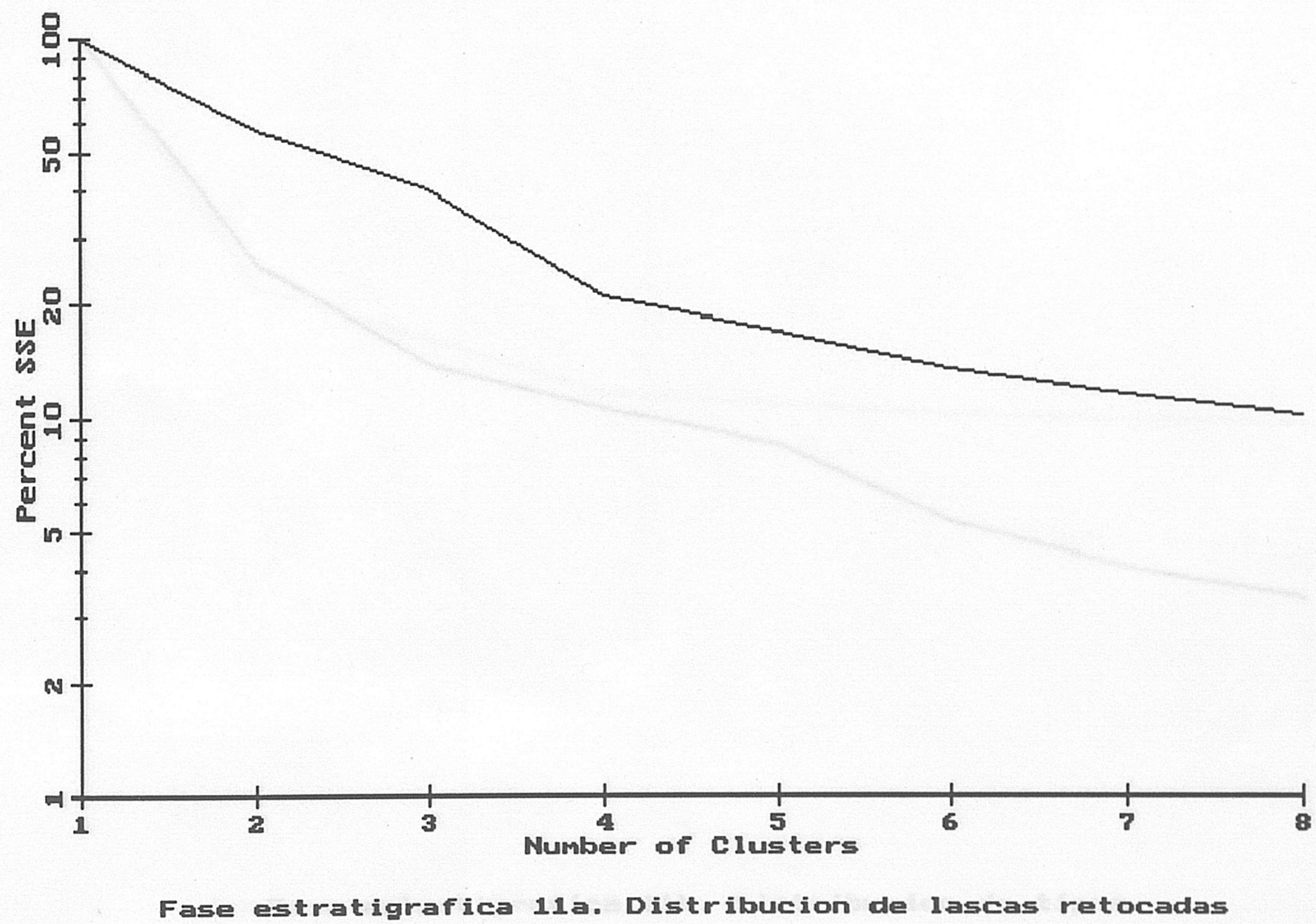

Graf. 166 


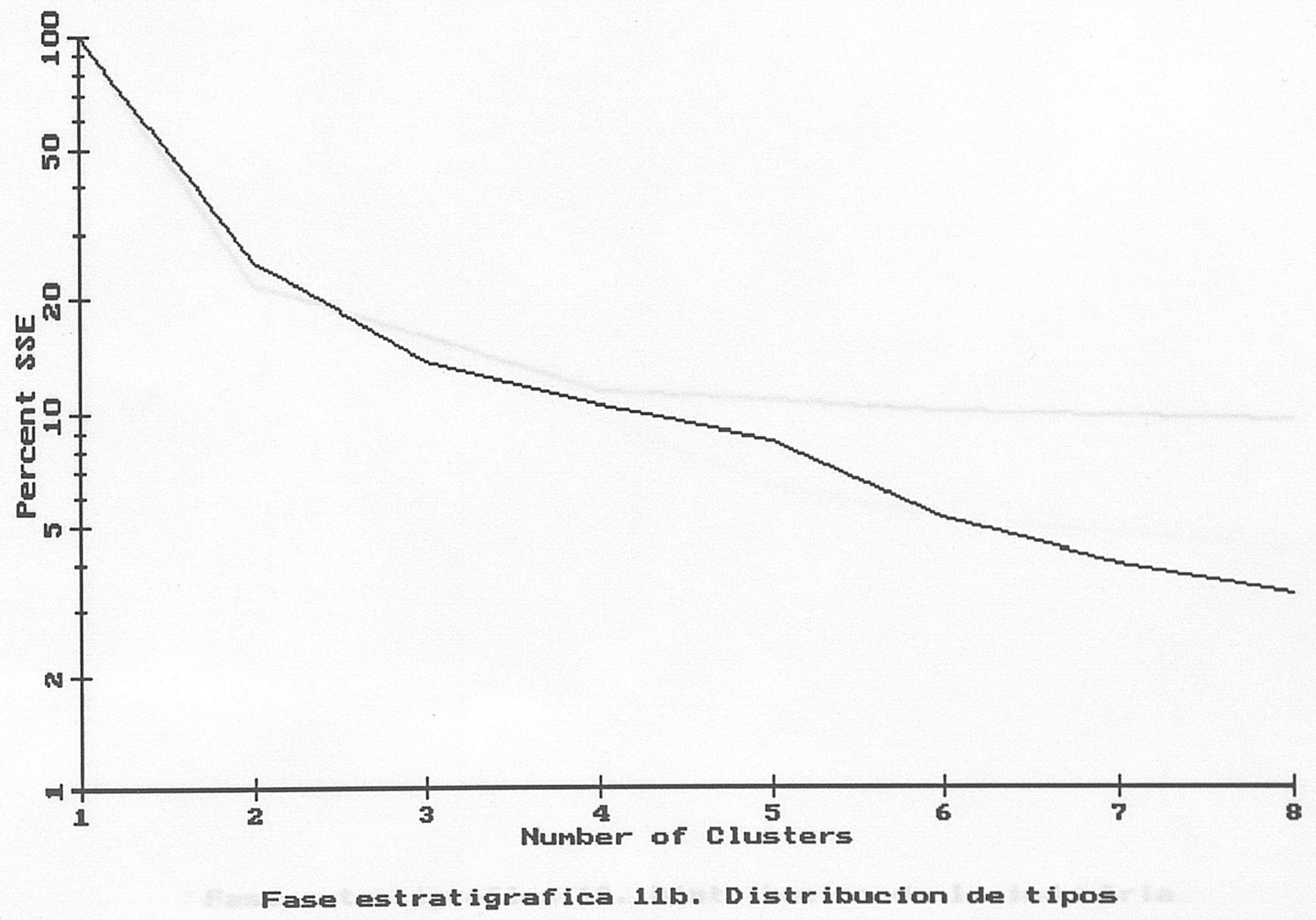

Graf. 167 


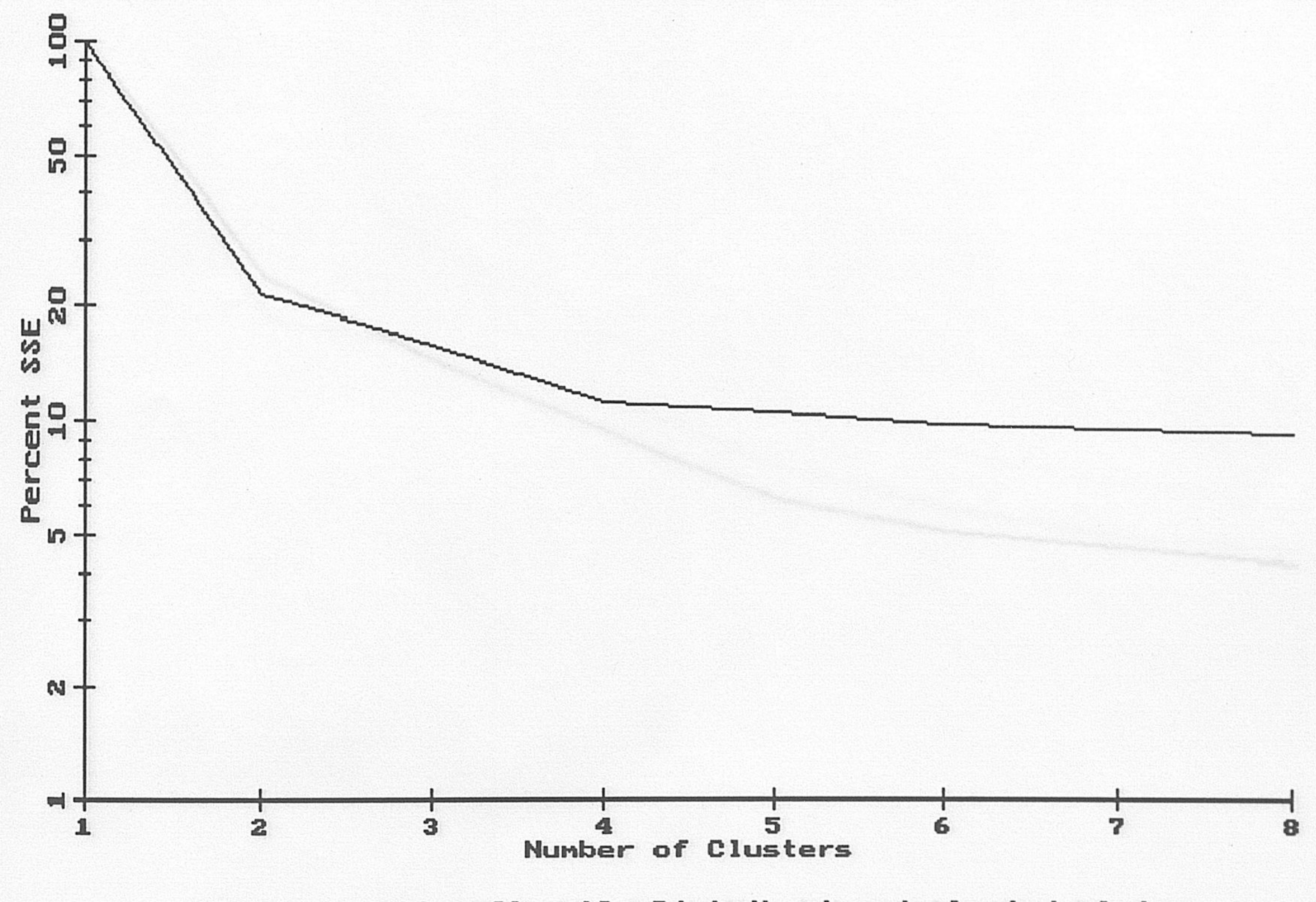

Fase estratigrafica 12. Distribucion de la industria

Graf. 168 


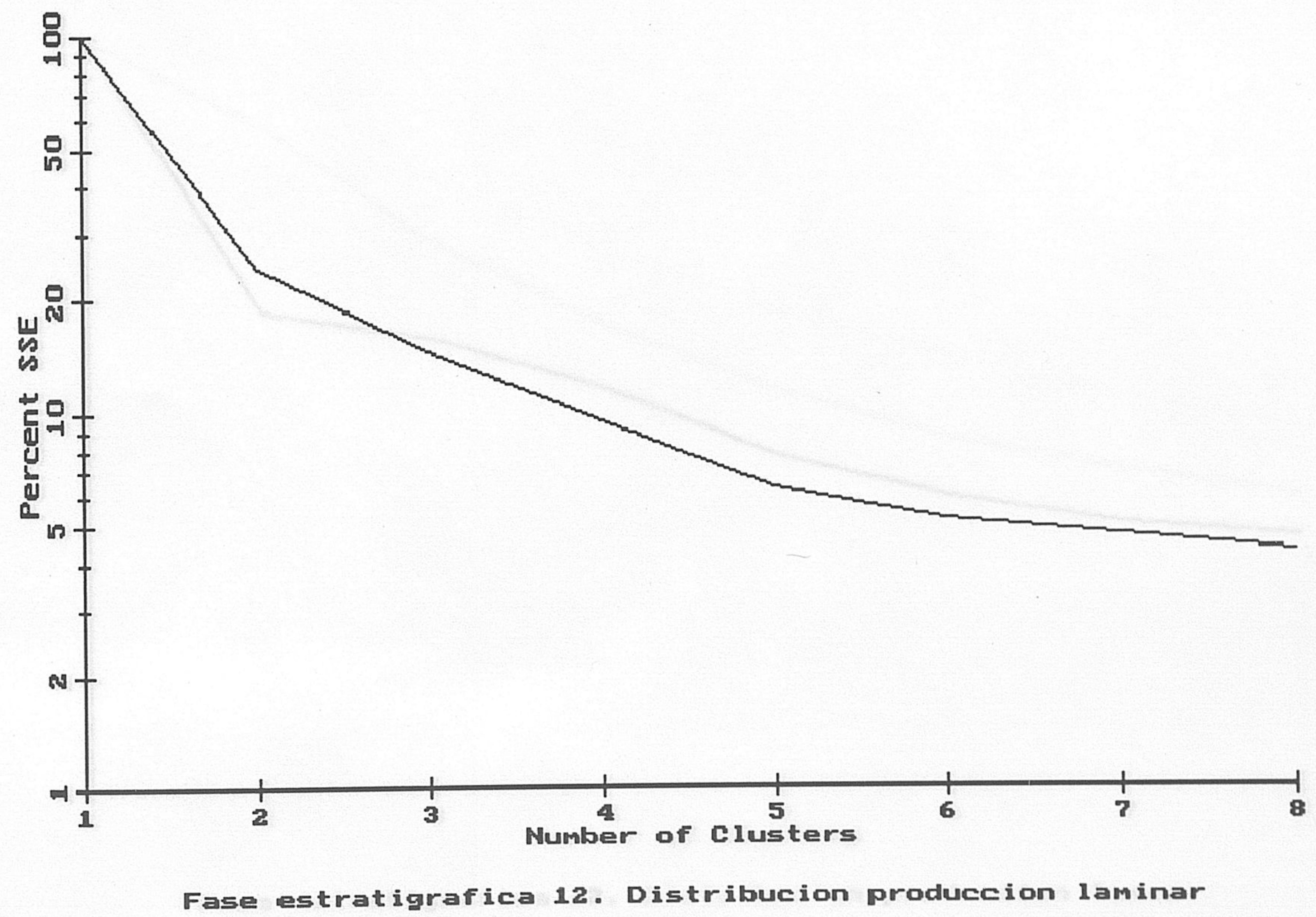

Graf. 169 


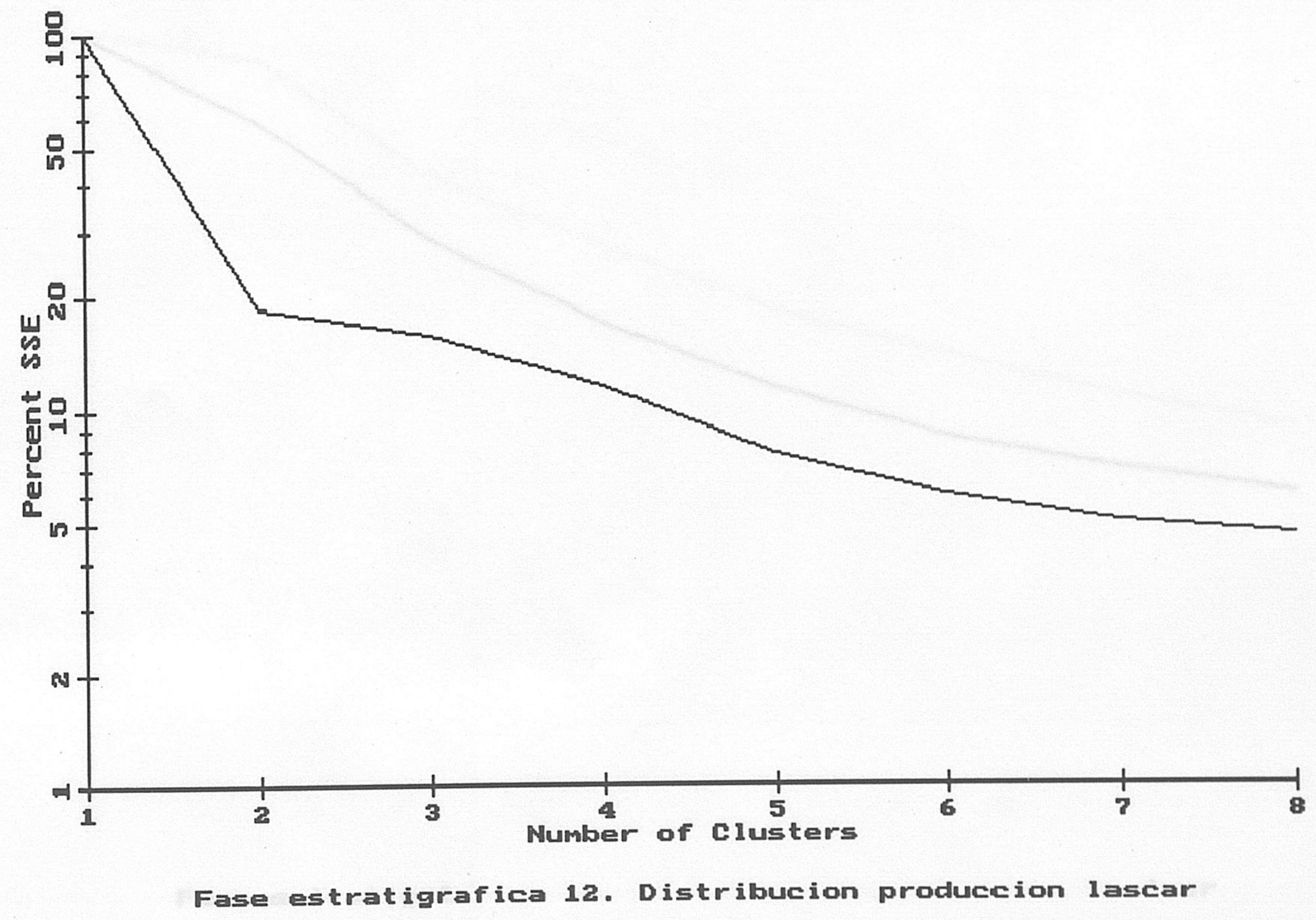

Graf. 170 


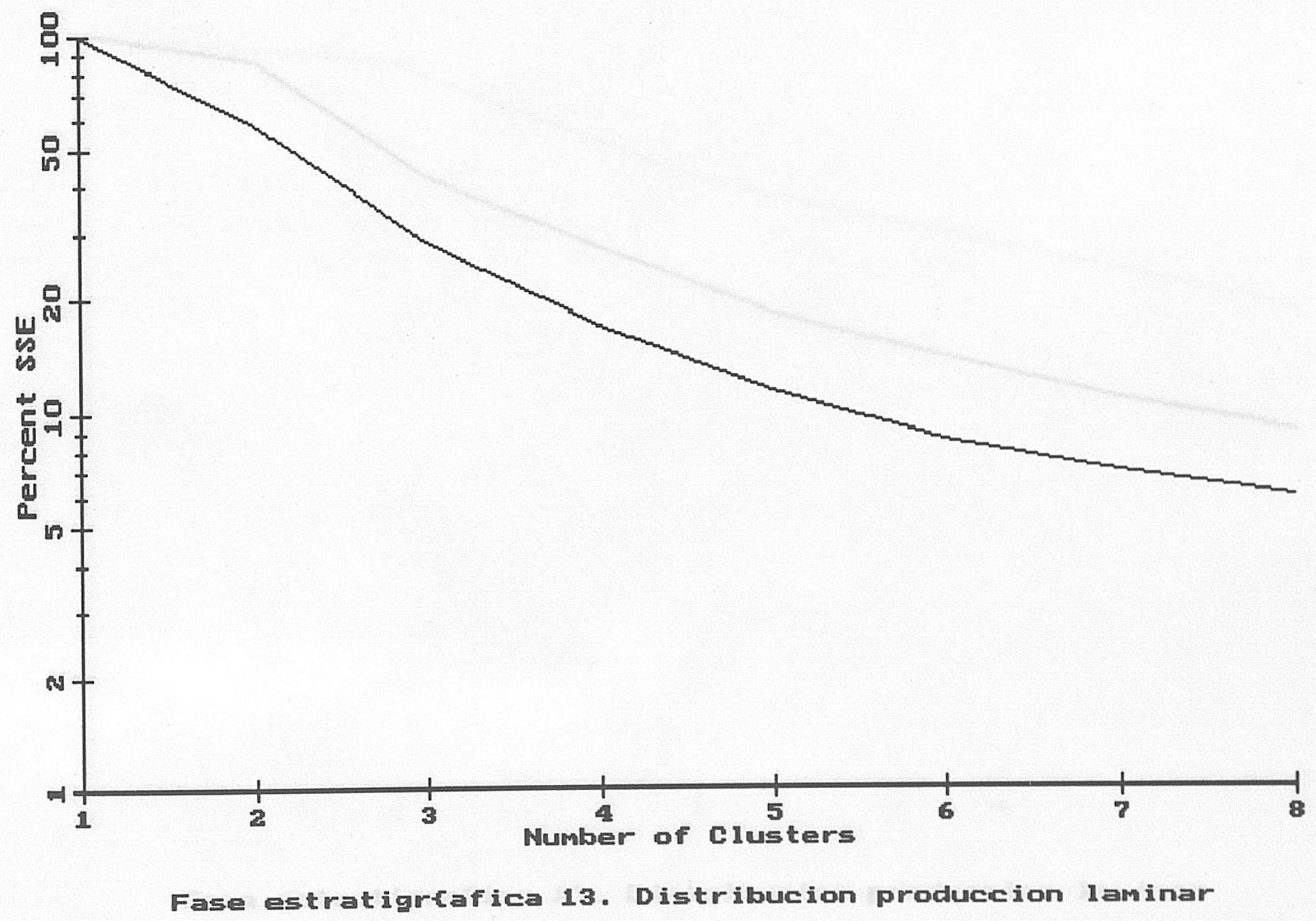

Graf. 171 


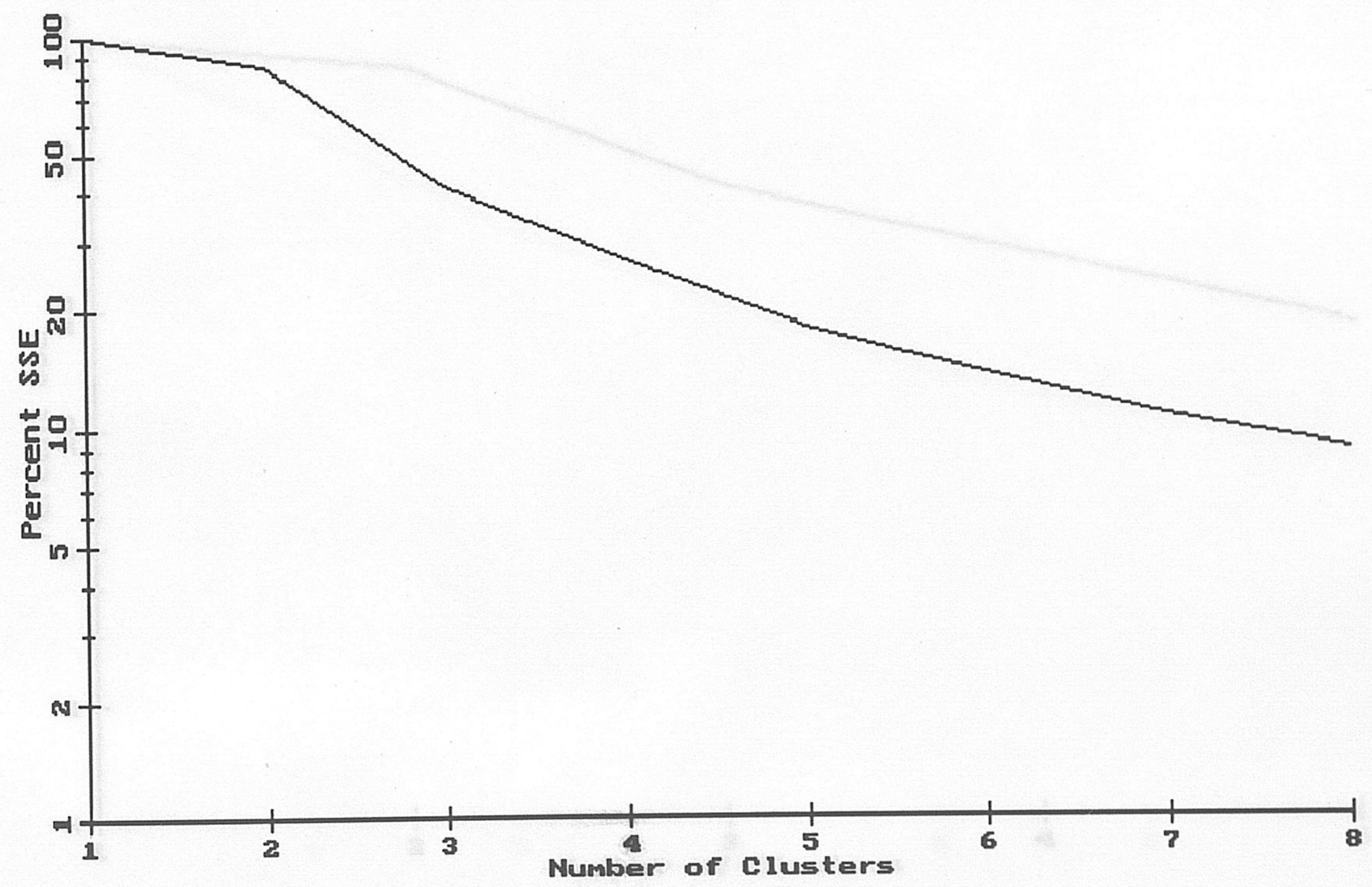

Fase estratigrafica 13. Distribucion produccion laminar

Graf. 172 


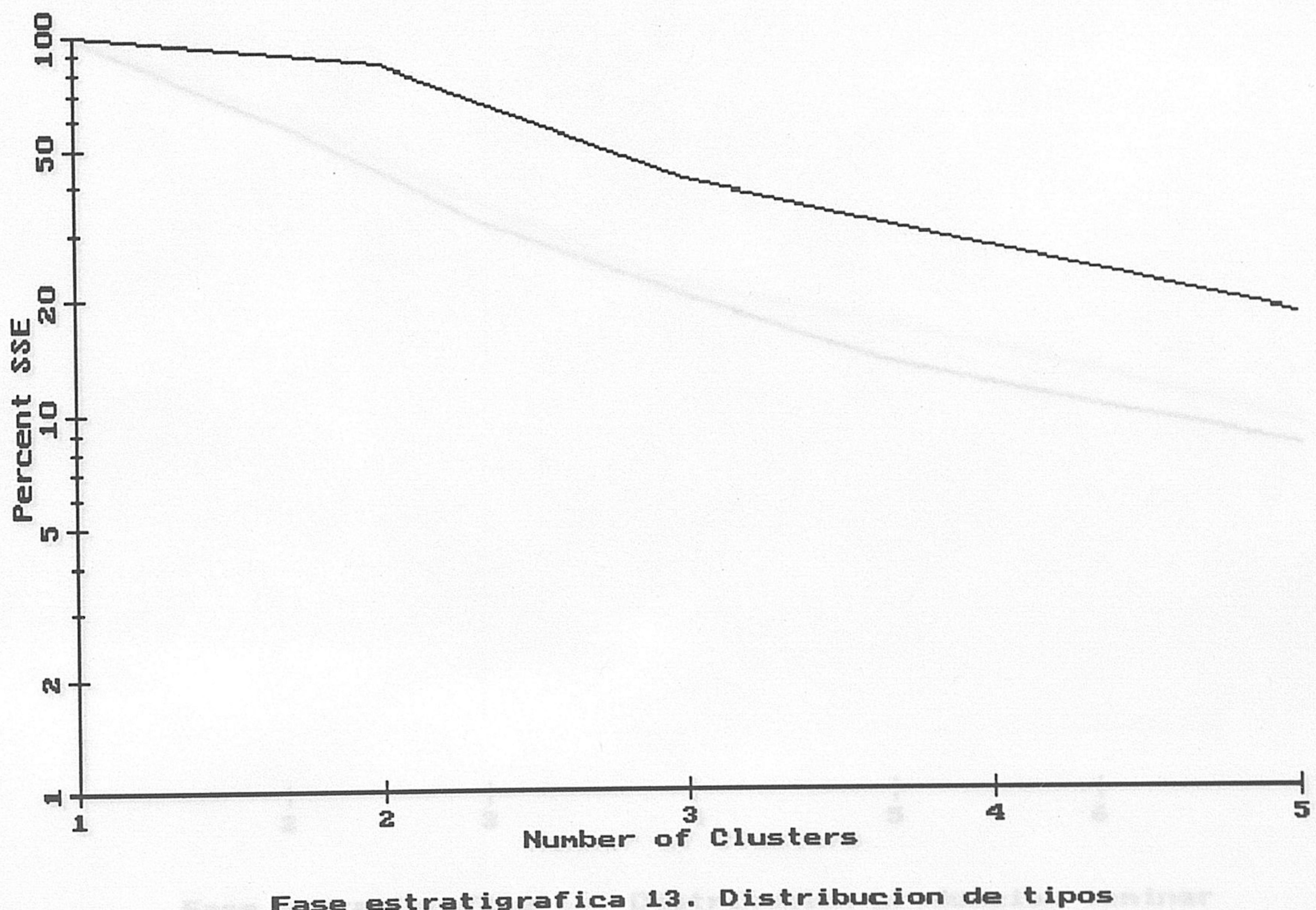

Graf. 173 


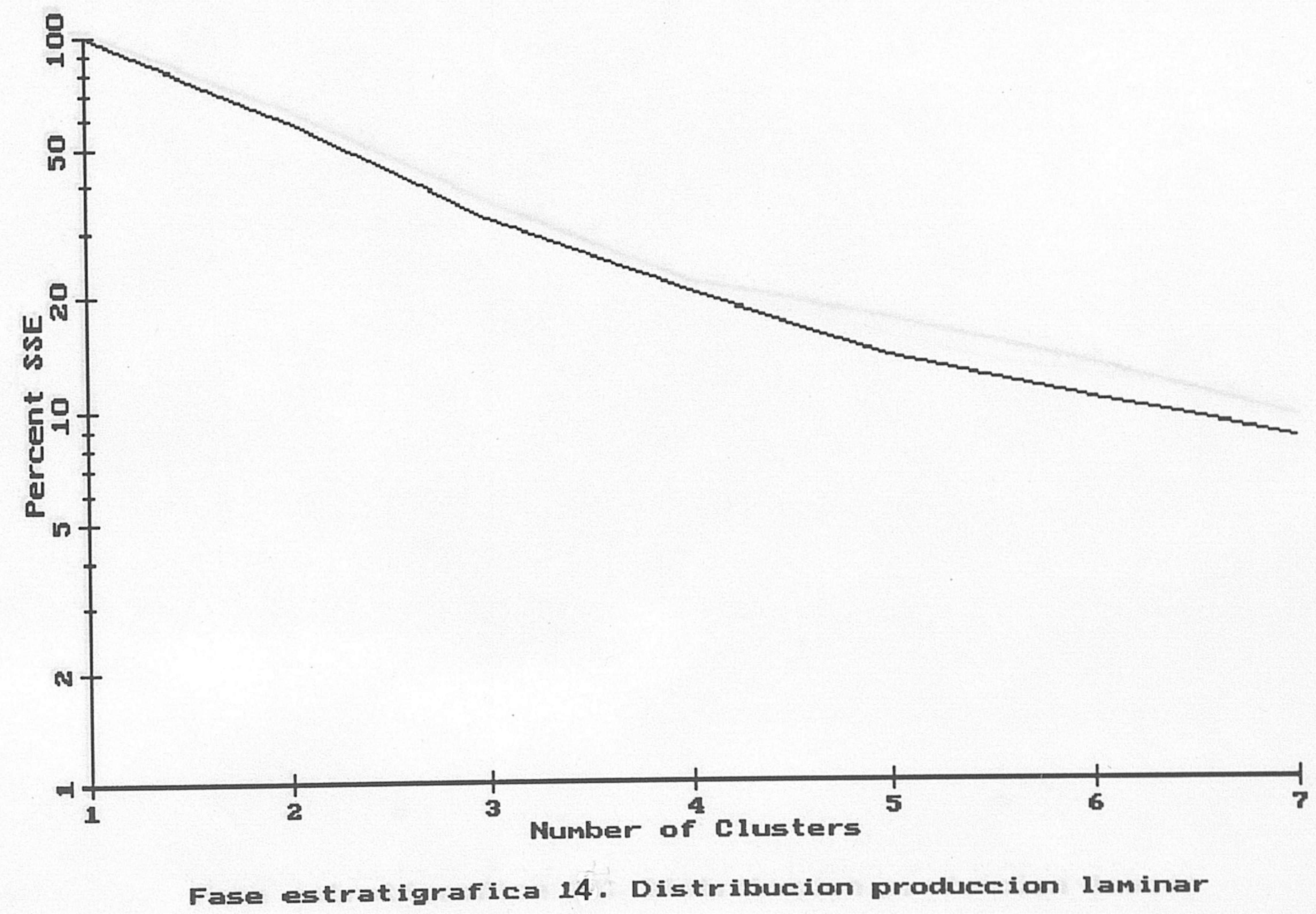

Graf. 174 


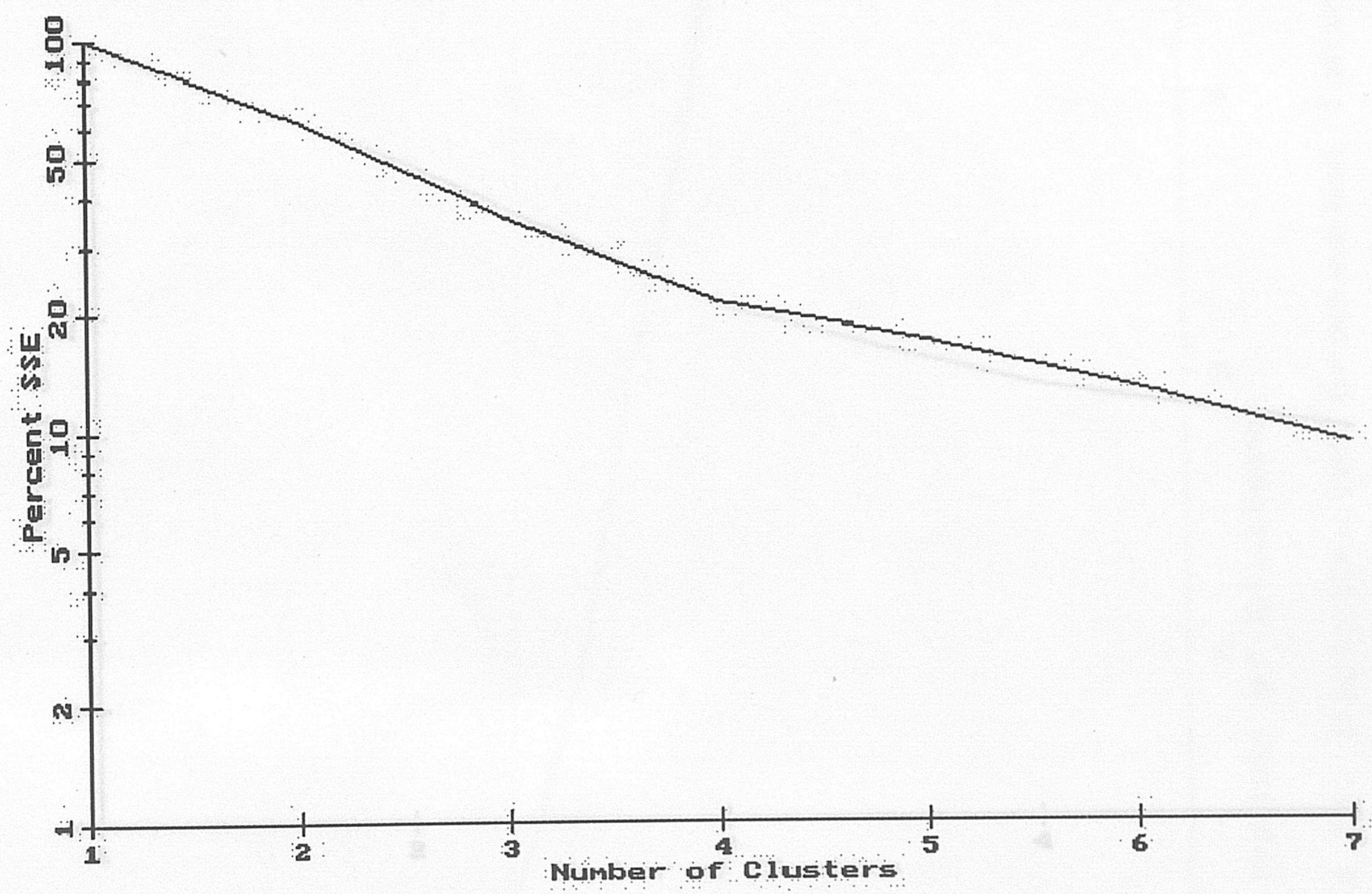

Fase estrat igrafica 14, Distribucion produceion lascar

Graf. 175 


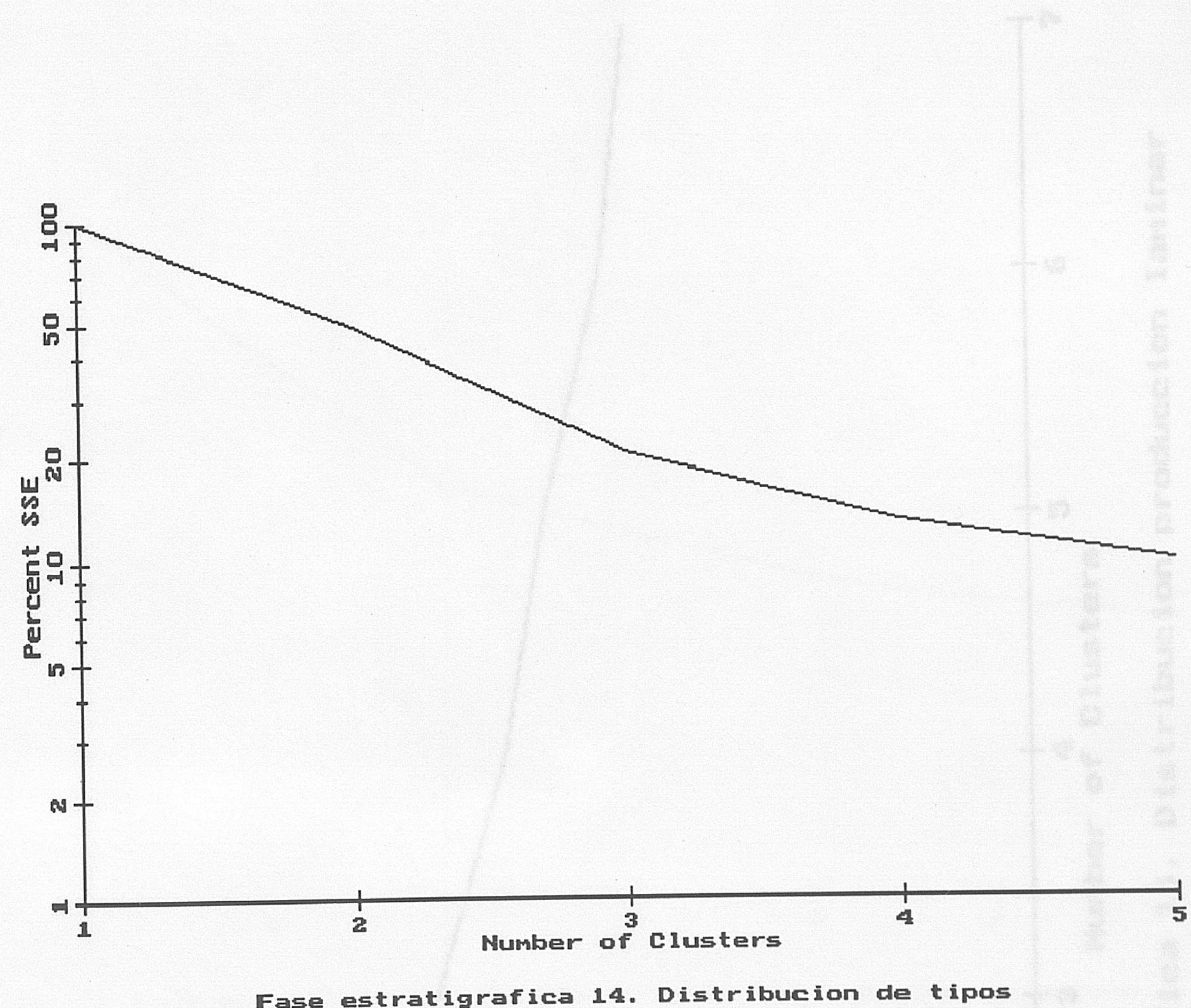

Graf. 176 


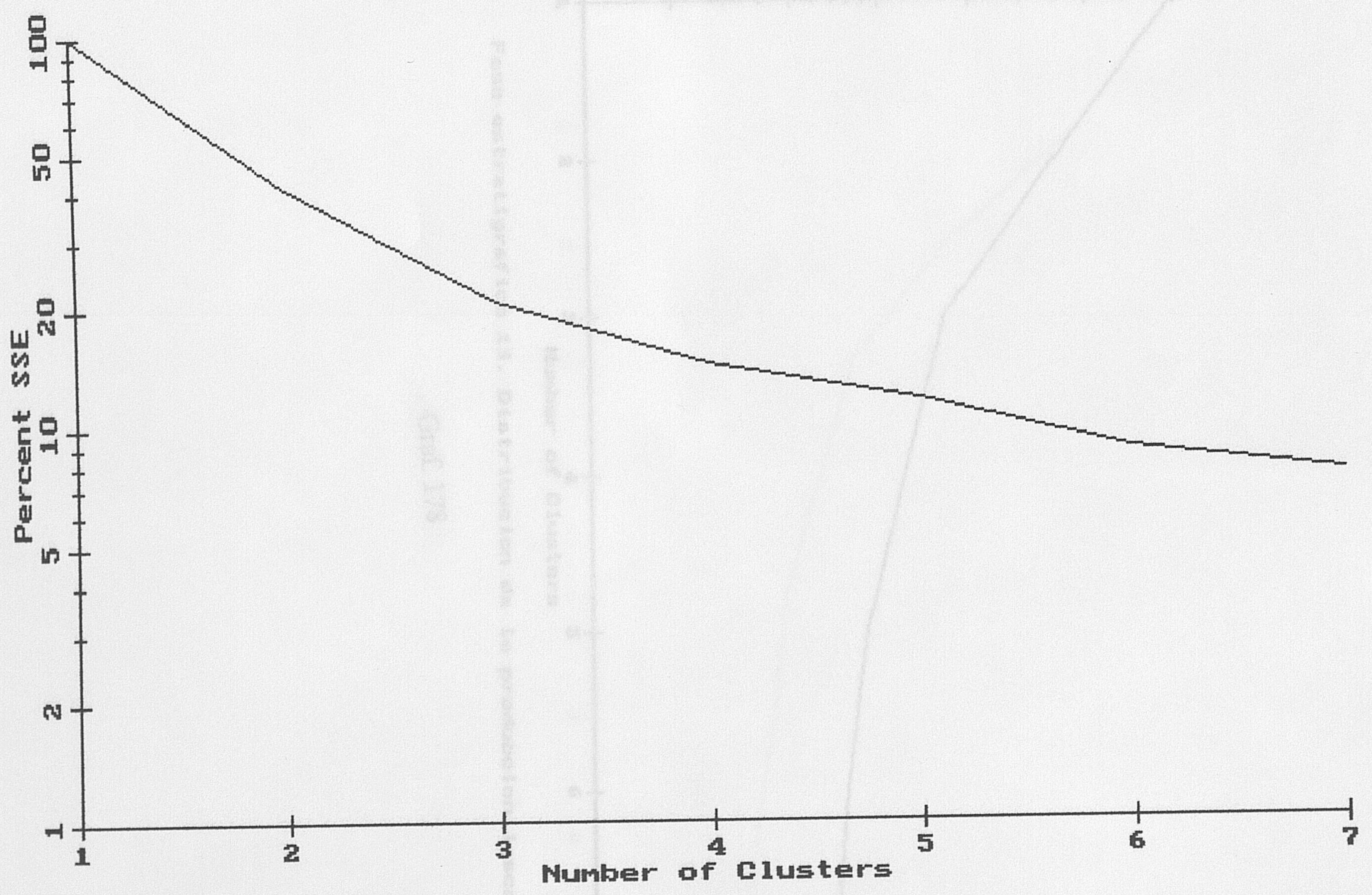

Fase estratigrafica 15. Distribucion produceion laminar

Graf. 177 


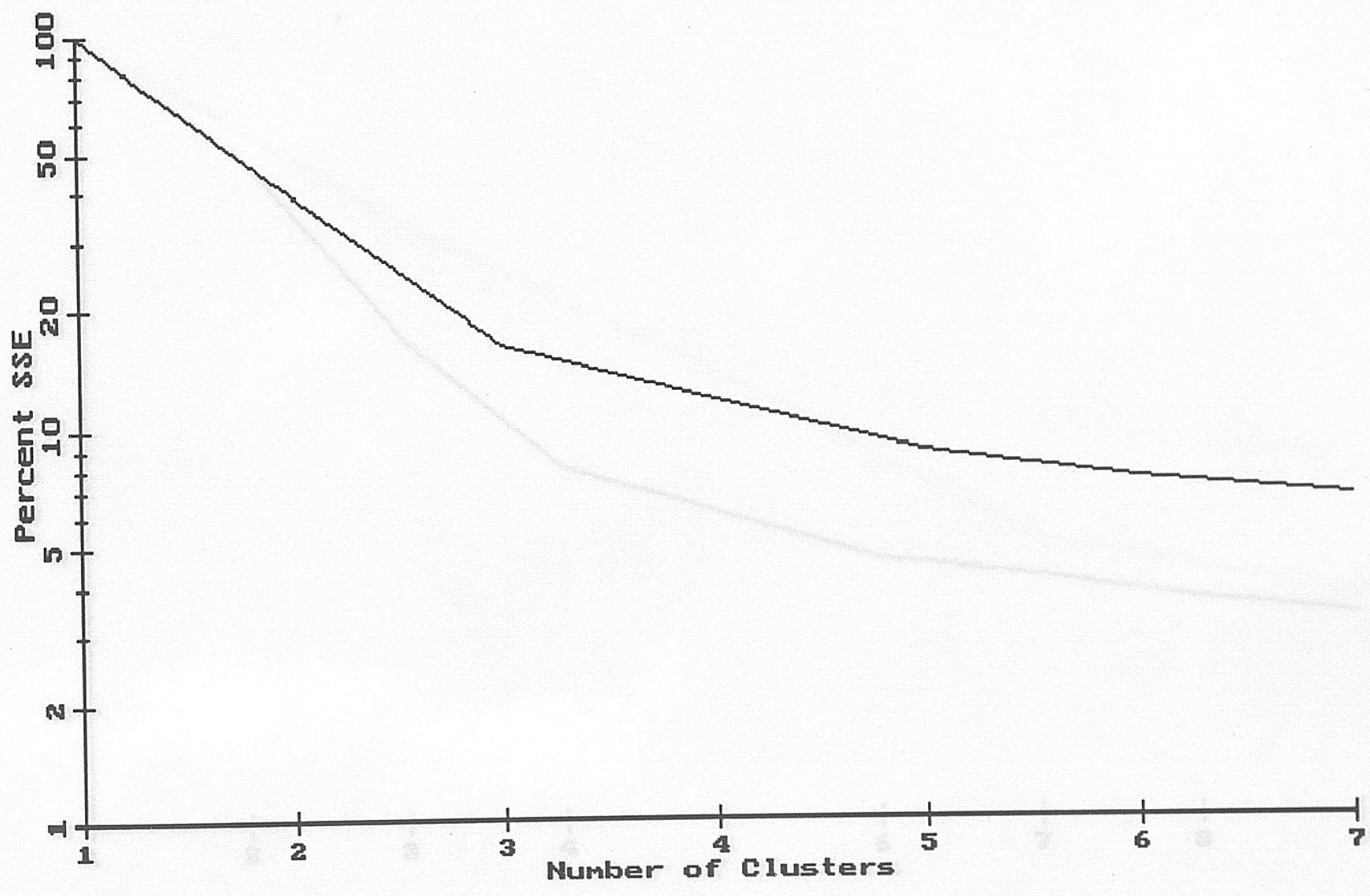

Fase estratigrafica 15. Distribucion de la produccion lascar

Graf. 178 


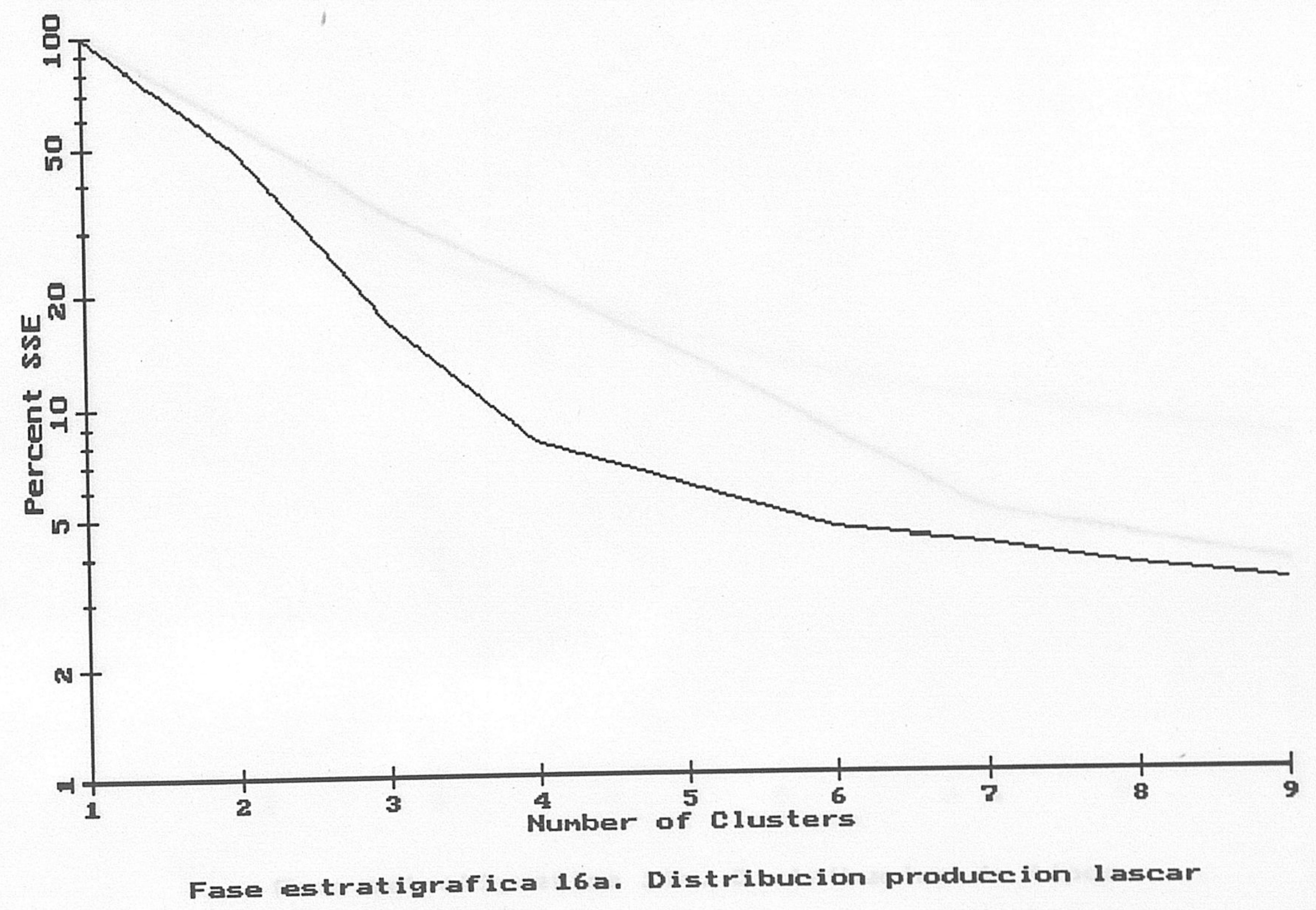

Graf. 179 


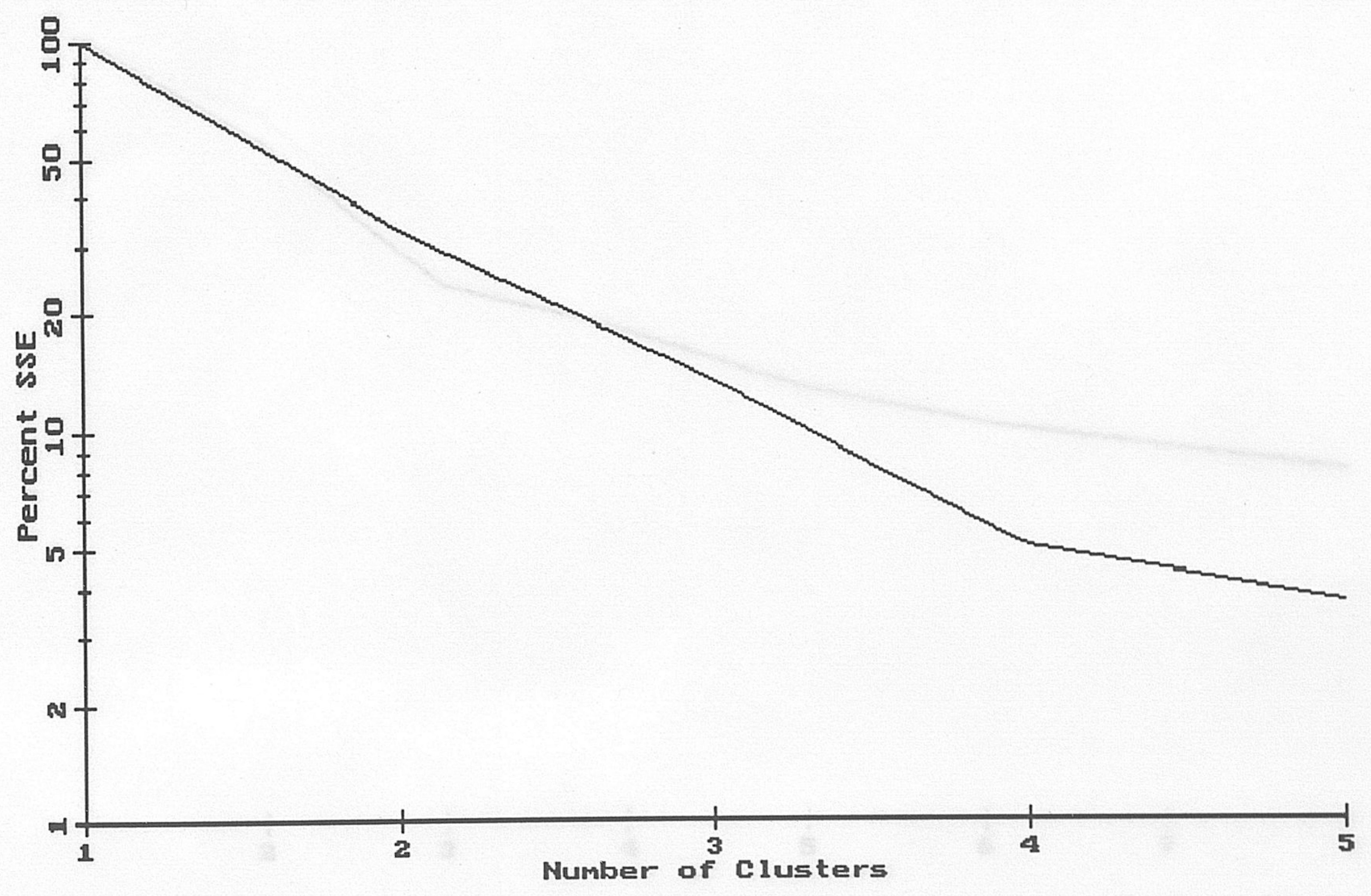

Fase estratigrafica 16a. Distribucion dre tipos

Graf. 180 


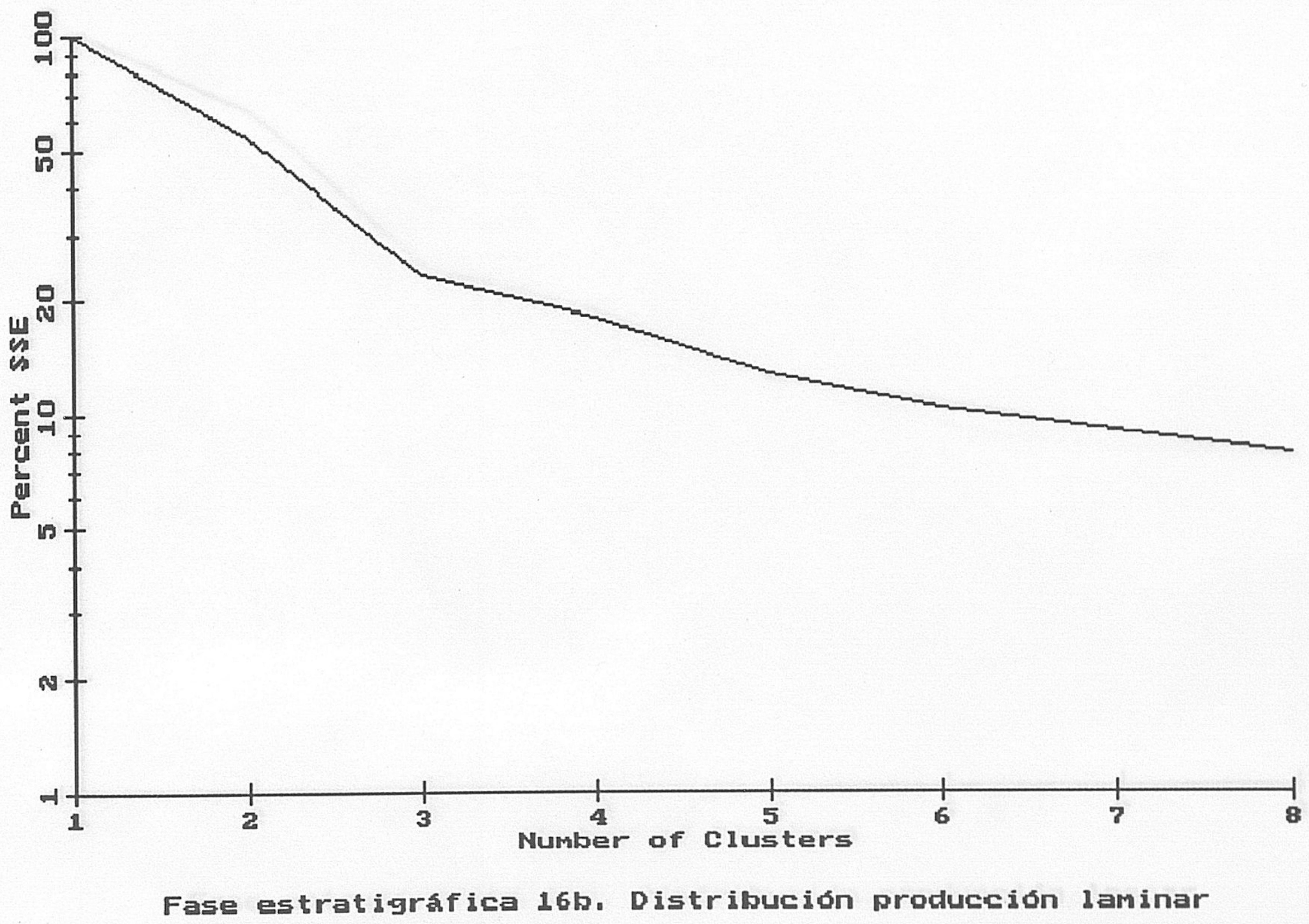

Graf. 181 


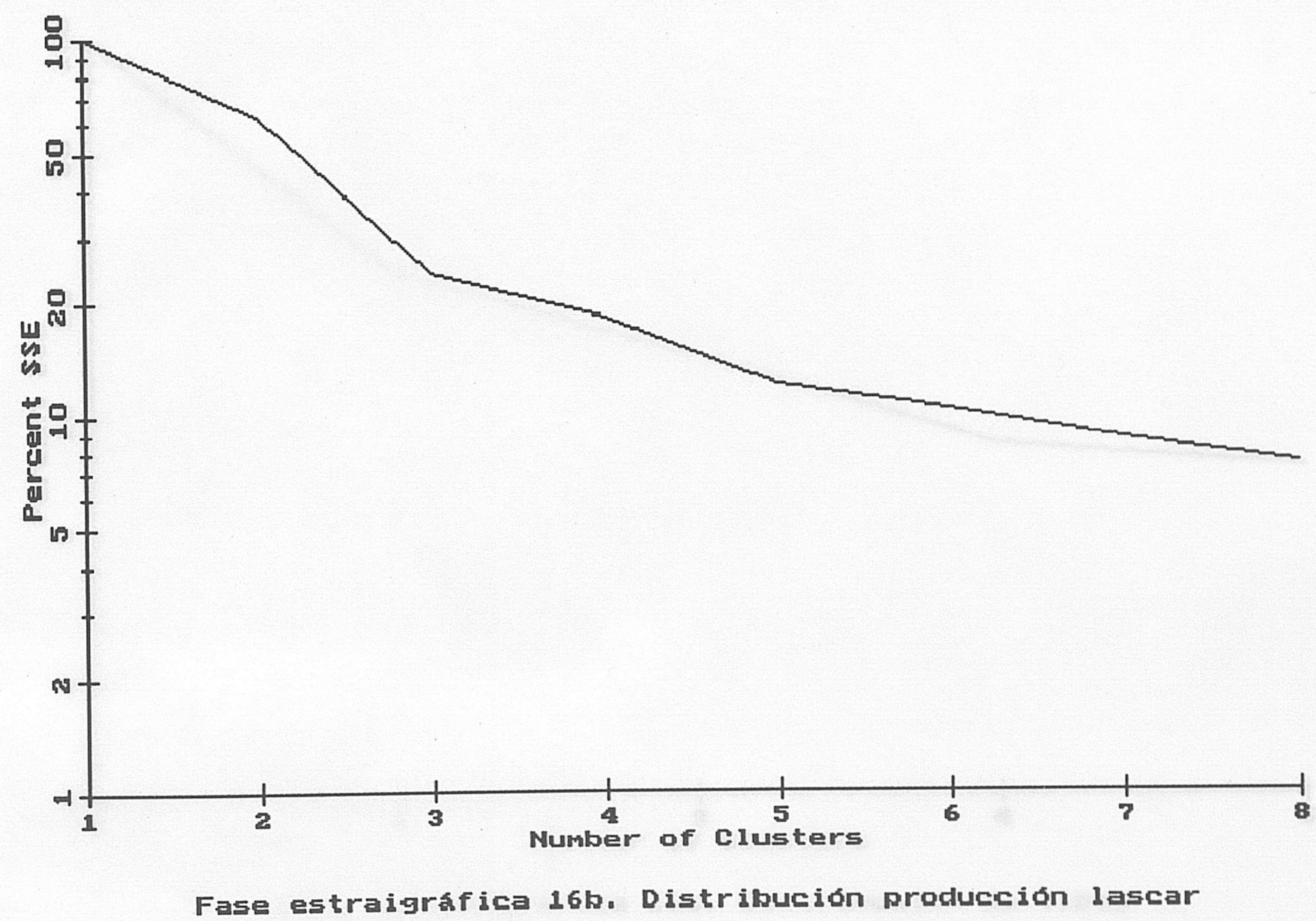

Graf. 182 


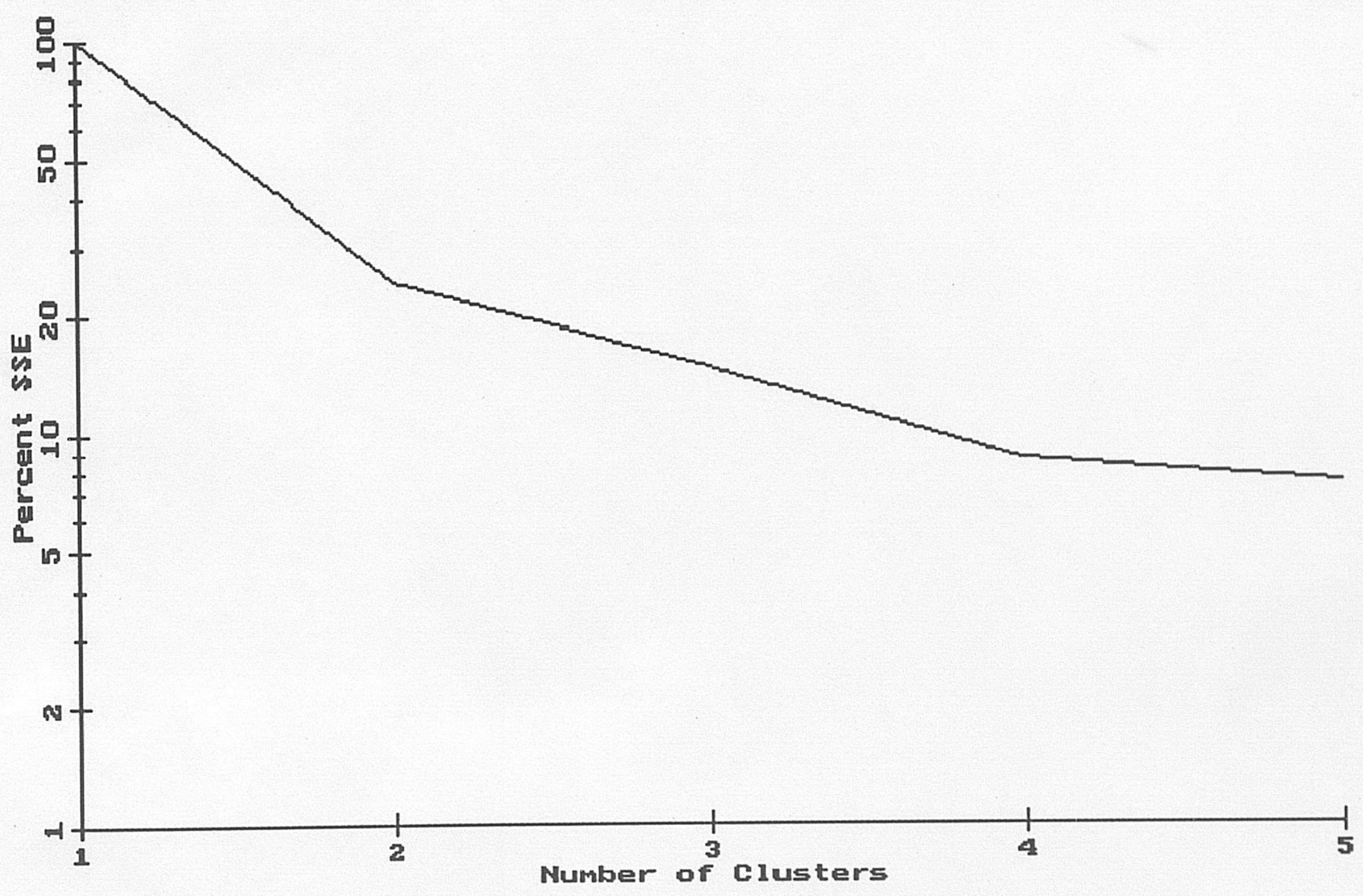

Fase estratigrafica 16h. Distribucion de tipos

Graf. 184 
